\title{
sustainability
}

\section{Sustainable Human Resource Management}




\section{Sustainable Human Resource Management}





\section{Sustainable Human Resource Management}

Special Issue Editor

Tamás Bányai

MDPI • Basel • Beijing • Wuhan • Barcelona • Belgrade

\section{MDPI}


Special Issue Editor

Tamás Bányai

University of Miskolc

Hungary

\section{Editorial Office}

MDPI

St. Alban-Anlage 66

4052 Basel, Switzerland

This is a reprint of articles from the Special Issue published online in the open access journal Sustainability (ISSN 2071-1050) from 2018 to 2019 (available at: https://www.mdpi.com/journal/ sustainability/special_issues/Human_Resource_Management).

For citation purposes, cite each article independently as indicated on the article page online and as indicated below:

LastName, A.A.; LastName, B.B.; LastName, C.C. Article Title. Journal Name Year, Article Number, Page Range.

ISBN 978-3-03921-682-6 (Pbk)

ISBN 978-3-03921-683-3 (PDF)

(C) 2019 by the authors. Articles in this book are Open Access and distributed under the Creative Commons Attribution (CC BY) license, which allows users to download, copy and build upon published articles, as long as the author and publisher are properly credited, which ensures maximum dissemination and a wider impact of our publications.

The book as a whole is distributed by MDPI under the terms and conditions of the Creative Commons license CC BY-NC-ND. 


\section{Contents}

About the Special Issue Editor $\ldots \ldots \ldots \ldots \ldots \ldots \ldots \ldots$ vii

Preface to "Sustainable Human Resource Management" . . . . . . . . . . . ix

Živilè Stankevičiūtė and Asta Savanevičienė

Designing Sustainable HRM: The Core Characteristics of Emerging Field

Reprinted from: Sustainability 2018, 10, 4798, doi:10.3390/su10124798 . . . . . . . . . . . . 1

Jihye Park, Dawoon Jung and Pyoungsoo Lee

How to Make a Sustainable Manufacturing Process: A High-Commitment HRM System

Reprinted from: Sustainability 2019, 11, 2309, doi:10.3390/su11082309 . . . . . . . . . . . . . . 24

Hyejin Cho, Pyoungsoo Lee and Choong Ho Shin

Becoming a Sustainable Organization: Focusing on Process, Administrative Innovation and Human Resource Practices

Reprinted from: Sustainability 2019, 11, 3554, doi:10.3390/su11133554 . . . . . . . . . . . . 44

Mariana Strenitzerová and Karol Achimský

Employee Satisfaction and Loyalty as a Part of Sustainable Human Resource Management in

Postal Sector

Reprinted from: Sustainability 2019, 11, 4591, doi:10.3390/su11174591 _ . . . . . . . . . . . 61

Silvia Lorincová, Peter Štarchoň, Dagmar Weberová, Miloš Hitka and Martina Lipoldová

Employee Motivation as a Tool to Achieve Sustainability of Business Processes

Reprinted from: Sustainability 2019, 11, 3509, doi:10.3390/su11133509 . . . . . . . . . . . . 91

Tamás Bányai, Christian Landschützer and Ágota Bányai

Markov-Chain Simulation-Based Analysis of Human Resource Structure: How Staff

Deployment and Staffing Affect Sustainable Human Resource Strategy

Reprinted from: Sustainability 2018, 10, 3692, doi:10.3390/su10103692 ‥ . . . . . . . . . . 106

Khwaja Abdul Naim Latifi and Seunghoo Lim

Strategic Human Resource Management in the Afghanistan Ministry of Mines and Petroleum:

A Network Perspective

Reprinted from: Sustainability 2019, 11, 3830, doi:10.3390/su11143830 . . . . . . . . . . . . 127

Annibal Scavarda, Gláucya Daú, Luiz Felipe Scavarda and

Rodrigo Goyannes Gusmão Caiado

An Analysis of the Corporate Social Responsibility and the Industry 4.0 with Focus on the Youth

Generation: A Sustainable Human Resource Management Framework

Reprinted from: Sustainability 2019, 11, 5130, doi:10.3390/su11185130 . . . . . . . . . . . . 146

Alexandra Marcos, María del Carmen Pérez-Llantada and Gabriela Topa

Integration in the Organizational Environment of the Spanish National Police

Reprinted from: Sustainability 2019, 11, 4706, doi:10.3390/su11174706 . . . . . . . . . . . . 166

Sabina-Cristiana Necula and Cătălin Strîmbei

People Analytics of Semantic Web Human Resource Résumés for Sustainable Talent Acquisition

Reprinted from: Sustainability 2019, 11, 3520, doi:10.3390/su11133520 . . . . . . . . . . . . 179 
Alina-Mihaela Dima, Claudia-Elena T, Tuclea, Diana-Maria Vrânceanu and Gabriela Tigu Sustainable Social and Individual Implications of Telework: A New Insight into the Romanian Labor Market

Reprinted from: Sustainability 2019, 11,3506, doi:10.3390/su11133506 . . . . . . . . . . . . . . 197

\section{Xingshan Zheng, Lan Li, Fangyu Zhang and Mengyuan Zhu}

The Roles of Power Distance Orientation and Perceived Insider Status in the Subordinates' Moqi with Supervisors and Sustainable Knowledge-Sharing

Reprinted from: Sustainability 2019, 11, 1421, doi:10.3390/su11051421 . . . . . . . . . . . . . . . 209

Qi Zhang, Siwei Sun, Xingshan Zheng and Wei Liu

The Role of Cynicism and Personal Traits in the Organizational Political Climate and Sustainable Creativity

Reprinted from: Sustainability 2019, 11, 257, doi:10.3390/su11010257 . . . . . . . . . . . . . . . . 226

Shuo Han, Weijun Cui, Jin Chen and Yu Fu

Why Do Companies Choose Female CEOs?

Reprinted from: Sustainability 2019, 11,4070, doi:10.3390/su11154070 . . . . . . . . . . . . . . . 243

Faiza Manzoor, Longbao Wei, Tamás Bányai, Mohammad Nurunnabi and Qazi Abdul Subhan

An Examination of Sustainable HRM Practices on Job Performance: An Application of Training as a Moderator

Reprinted from: Sustainability 2019, 11, 2263, doi:10.3390/su11082263. 


\section{About the Special Issue Editor}

Tamás Bányai received his master's degree in 1993 and Ph.D. degree in 1999 from the University of Miskolc, where he is currently Associate Professor. He has more than 25 years of teaching and research experience in the design and control of material-handling systems and supply chain management, with special emphasis in the heuristic optimization of large-scale systems. He has published over 150 research papers, book chapters, and conference proceedings. He has been a member and manager of more than 50 national and international R\&D projects. Away from academia, his other interests include playing the piano and photography. 



\section{Preface to "Sustainable Human Resource Management"}

The concept of sustainability is important for companies both in the case of SMEs and worldwide multinational companies. Some key factors to help a company achieve its sustainability objectives are based on human resource management. Sustainable human resource management is a typical cross-functional task that becomes increasingly important at the strategic level of a company. Industry 4.0 technologies, Internet of Things, and competitive demands, as signs of globalization, have led to significant changes across the organizational structures and human resource strategies of companies. The increasing importance of sophisticated human resource strategies in the life of companies and the intention to find optimal design and operation strategies for sustainable human resource management were a motivation for launching this book. This book offers a selection of papers which explain the impact of smart human resource management on economy. Authors from 14 countries published working examples and case studies resulting from their research in this field. The aim of this book is to help students at the level of BSc, MSc, and PhD level, as well as managers and researchers, to understand and appreciate the concept, design, and implementation of sustainable human resource management solutions.

Tamás Bányai

Special Issue Editor 

Article

\title{
Designing Sustainable HRM: The Core Characteristics of Emerging Field
}

\author{
Živilè Stankevičiūtè * and Asta Savanevičienè \\ School of Economics and Business, Kaunas University of Technology, Gedimino g. 50, LT-44249 Kaunas, \\ Lithuania; asta.savaneviciene@ktu.lt \\ * Correspondence: zivile.stankeviciute@ktu.lt; Tel.: +370-650-11-505
}

Received: 29 November 2018; Accepted: 13 December 2018; Published: 16 December 2018

\begin{abstract}
The common agreement in human resource management (HRM) literature suggests that organizations willing to attract and retain human resources for running business in the future must change the prevailing situation where human resources are rather consumed than developed. In doing this, sustainable HRM has been introduced recently as a response to changes on societal level, labor market, and employment relations. Sustainable HRM is seen as an extension of strategic HRM and presents a new approach to people management with the focus on long-term human resource development, regeneration, and renewal. However, the attributes of sustainable HRM, as compared to mainstream HRM, are not clear. The paper aims at closing this gap by proposing and revealing the characteristics of sustainable HRM, namely: Long-term orientation, care of employees, care of environment, profitability, employee participation and social dialogue, employee development, external partnership, flexibility, compliance beyond labour regulations, employee cooperation, fairness, and equality. This is a theoretical paper.
\end{abstract}

Keywords: sustainable human resource management; characteristics of sustainable human resource management; sustainability

\section{Introduction}

Beginning in the 1980s, theory and research on HRM has started developing rapidly [1-4]. Typically, the impact of HRM on performance has become the prevailing research issue in the field $[5,6]$. The mainstream literature has generally focused on the plea of Guest [7] trying to provide answers to the following three questions: What is HRM? What is performance? How are they are linked? The findings have sounded optimistic and encouraging, while at that date, the empirical research has largely supported the idea and provided evidence that HRM is positively related to performance $[6,8]$. Thus, the leading message was that HRM contributes to business success and has the ability to translate strategic rhetoric into workplace reality [1]. However, several issues need to be taken into consideration for further fruitful discussion of that paper. First, despite the multidimensional nature of organizational outcomes [9], a huge number of studies have mainly defined the organizational performance outcomes in terms of economic measures, neglecting employee well-being [3,4]. Second, analyzing the pathways through which HRM affect organizational performance, employee well-being is mainly treated as a mediator between HRM and performance [10]. Thus, generally speaking, the common feature of mainstreaming writing in HRM was the fact that employees are viewed as a means rather than an end [4].

The mentioned two aspects allow concluding that, to date, employee concerns were very much of secondary consideration in the HRM field [4]. Meanwhile the neglect of employee well-being is particularly troubling because the statistical data and findings of a number of recent studies have indicated non-gratifying challenges in the labor market as well in employment relationships. 
For instance, according to the sixth European Working Conditions Survey (EWCS), 21\% of workers are too exhausted after work to carry out the necessary home tasks, whereas $12 \%$ of workers think that their job prevents them from giving the desired amount of time to their family. Moreover, about $15 \%$ of workers in EU28 usually work long hours and 26\% agree that their health is negatively affected by the work in Reference [11].

Thus, nowadays, employee burnout, stress at work, health problems, or difficulties in balancing work duties and private life are extremely relevant challenges. Such situation leads to rethinking HRM if companies are willing to have the employees for running the business in future. Among various propositions, some scholars argue that sustainable HRM could serve as a possible solution bringing humanity back into HRM [12], while sustainability refers to resource regeneration, development, and renewal [13]. From the sustainability point of view, it is a survival strategy for organizations to deal with people in such way that the current and potential employees would have (a) the wish to work for a particular organization; (b) the ability to perform duties in a manner appropriate for business; and (c) the possibilities to work in terms of health, stress, or work-life balance [13].

The idea of sustainability has been known for a long time and it goes back to the time of Aristotle [14]. However, the concept gained its popularity since Brundtland Commission (1987) defined sustainable development as "development that meets the needs of the present without compromising the ability of future generations to meet their own needs" [15] (p. 43). From societal level sustainability, it was transposed to business level arguing that corporate sustainability requires organizations to address interconnected and interdependent economic, environmental, and social concerns at different levels $[16,17]$. Corporate sustainability places the emphasis on "broader concept of outcome", addressing multiple bottom lines by including more outcomes than just financial, and thus changes the understanding of business success [18].

Not denying other antecedents of growing business commitment to sustainability, it seems that in the past, sustainability was a choice mainly in the situations of a serious crisis or resource shortage $[19,20]$. While mainstream HRM literature is crowded with proclamations that human resources are an asset of critical importance to the organization [21], businesses seem being wasteful with human resources [20]. Referring to the abovementioned convincing examples of negative effect on employees, sustainability is increasingly considered as a design option for employment relationships and people management [13].

The research on sustainability in HRM covers numerous related topics such as Sustainable HRM [19,22-26], green HRM [27-29], socially responsible HRM [30-34], and ethical HRM [35-37] depending on the key focus of the approach. The presented paper focuses on sustainable HRM following a definition recently provided by Ehnert et al. [38] considering sustainable HRM

"as the adoption of HRM strategies and practices that enable the achievement of financial, social and ecological goals, with an impact inside and outside of the organisation and over a long-term time horizon while controlling for unintended side effects and negative feedback."

(p. 90)

Referring to the short history of sustainable HRM, the construct is still at the pioneering if not emerging phase [20]. While the number of publications in the field of sustainable HRM has recently been growing $[12,39,40]$, scholars still struggle with the attempt at answering what characterizes sustainable HRM. Despite significant contribution to the field of sustainable HRM per se, the area of characteristics of sustainable HRM remains underdeveloped, relatively diverse, and piecemeal. The paper seeks to close this gap by revealing the main characteristics of sustainable HRM.

The purpose of this paper is to deepen current analysis in the field of sustainable HRM by identifying the main characteristics of the construct. Specifically, it seeks to answer the following: Why is linking sustainability and HRM so relevant for contemporary business? How could sustainable HRM be described and defined? What approaches dominate as a theoretical background for justifying 
sustainable HRM? What are the main characteristics of sustainable HRM? How do these characteristics manifest in terms of their content?

The paper contributes to the sustainable HRM literature in several ways. Firstly, the paper introduces the characteristics of sustainable HRM and contributes to the answer what HRM should look like in order to deserve the sustainability attribute. Drawing on the models of sustainable HRM, provided by Ehnert [19], Zaugg [41], Kramar [22], and from the overall literature on sustainable HRM, the characteristics of sustainable HRM are formulated. They reflect Principle 1 of the Rio Declaration on Environment and Development stating that "Human beings are at the centre of concerns for sustainable development. They are entitled to a healthy and productive life in harmony with nature" [42] (p. 1), and are in line with the concept of corporate sustainability. Secondly, it is well established in the current literature that sustainable HRM has a double role: (a) To contribute to implementing sustainability in organizations; and (b) to make HRM systems themselves sustainable [43]. The paper contributes to the last research stream addressing the key features of sustainable HRM. Thirdly, the paper responds to Pfeffer's [44] call to treat the social dimension of corporate sustainability seriously, instead of overlooking, and in particular from the HRM perspective, as sustainability has received comparatively little attention from HR researchers [45]. In doing this, the paper contributes to theory enrichment, not only in the field of sustainable HRM, but also in the field of corporate sustainability.

The paper commences with a brief outline of the rationale for linking sustainability and HRM and then presents the construct of sustainable HRM. Next, the paper proceeds by identifying the main characteristics of HRM and revealing their contents. Last, the paper offers some general conclusions before indicating some future research avenues.

\section{Rationale for Linking Sustainability to HRM}

This section focuses briefly on the repetitive call in the scientific literature to revise HRM as it seems that HRM is moving in the opposite direction from its roots having the primary goal to promote employee well-being [3,4]. Certainly, from the perspective of developments, significant progress has been made in the HRM field [2]. Over the last 30 years, the research presented more than adequate empirical evidence that human resources and their management add value to organizational performance [6]. However here, the question arises as regards the understanding of performance in terms of outcomes. While Dyer and Reeve [9] introduced several types of outcomes (human resource-related outcomes represent one of the types), outcomes in empirical research were mainly defined in terms of financial outcomes, neglecting those related to employees. Naturally, human resource-related outcomes were a part of a number of researches; however, mainly they served as a key mediator between HRM and financial results of an organization [8]. Thus, human resources were viewed as means rather than an end and the search for the link between HRM and performance has been pursued at the expense of employee well-being [4]. Ironically, such neglect of employee concerns made the discipline of HRM successful [3].

Recently, the changes in society and labor market have promoted the organizations to search for new ways to manage human resources in order to have these resources in the future $[13,46]$. Traditionally employment relations, defined as the connection between employer and employee through which people sell their labor, followed the economic imperative [13]. In this sense, human resources can be exploited as much as possible for gaining better financial results. However, treating people as resources means that the rules of resource scarcity, shortage, damage, or extinction apply for people too. While mainstream HRM treats employees as a critically important asset to the organization, HRM nonetheless does not give priority to employee concerns [4]. On the contrary, following the conflicting outcomes perspective, HRM is not beneficial or could even be harmful for employees [47]. Thus, people can feel a negative effect caused by HRM. Meanwhile, even nowadays, HRM exists not for the purpose of serving employees per se [21].

However, the situation is changing as scholars and practitioners are trying to respond to the call of Pfeffer [44]: “Why are < . > milk jugs more important than people?" (p. 2010). 
Dealing with the external pressure of society and issues in the labor market as well as tackling internal issues in employment relations, businesses need to rethink their responsibility and business models. Aging society, shortage of skilled labor force, and employee health issues are convincing examples impelling the organizations to revise HRM. As sustainability refers to maintaining, reviewing, or restoring a resource [48], some scholars advice using the potential of sustainability for HRM [19].

In general, corporate sustainability refers to organizational activities "demonstrating the inclusion of social and environmental concerns in business operations and in interactions with stakeholders" [49]. Corporate sustainability debates shift the attention to success factors going beyond financial outcomes, applying a multiple bottom line approach. In this vein, the "value of human resources is recognised as being more than immediate financial usefulness" [50] (p. 423). The previous literature confirms that more organizations commit to sustainability [51]. Turning to rationale why business should want (or need) to apply sustainability for HRM, there is both the economic and ethical argument of sustainability linkage with HRM [13]. Harry [52] argues that to ignore sustainability means to ignore opportunities and concludes that "there is certainly profit to be made from sustainability and losses may occur if sustainability is overlooked" (p. 405).

As it was mentioned before, the research linking sustainability and HRM emerged under different labels. The paper focuses on sustainable HRM, following the attitude that sustainable HRM is an umbrella term covering multiple levels of analysis and multiple dimensions [20]. Sustainable HRM is seen as a design option for employment relations [13]. Wikhamn [40] argues that:

"Sustainable HRM evolves around soft issues such as demonstrating sincerity towards the employees, including providing a decent work environment and conditions, providing development opportunities and being attentive to employees' physical and psychosocial well-being at work"

(p. 103)

In general, sustainable HRM forms the next stage in the tradition of HRM thinking.

\section{The Emergence and Scope of Sustainable HRM}

This section focuses on sustainable HRM as the emerging research area addressing the genesis of construct, different streams under the label of sustainable HRM, and what different scholars mean by sustainable HRM.

The term 'sustainable HRM' is relatively new. While recently the field has rapidly evolved [39,53-59], it is nonetheless recognized that there is no "consistent" literature on sustainable HRM [20] and sustainable HRM can be understood in terms of a number of complimentary frameworks [22]. Despite the plurality of approaches, Ehnert and Harry [20] managed to assign all publications in the field of sustainable HRM to the first, second or third "waves" of research. The main criteria is the added value to sustainable HRM. More recently, Kramar [22] categorized the literature on sustainable HRM based on the writings' outcomes into three groups: Capacity reproduction, promoting social and environmental health, and connections. As the comprehensive analysis of all publications in the field of sustainable HRM is beyond the scope this paper, only aspects that are relevant for the main purpose of the paper, namely the disclosure of the characteristics of sustainable HRM, are further underlined.

The initial writings on sustainable HRM appeared at the end of 1990s in Germany [60], Switzerland [41,61], and Australia [62]. The German approach was developed in the context of sustainable resource management referring to organizations as open systems, resource-dependent systems that "depend on a constant stream of resources to stay alive, fulfil their ends, and reach their goals" [14] (p. 54). This approach relies on an economically rational interpretation of sustainability arguing that it is economically rational for business to balance the consumption and reproduction of human resources by investing in the relations with business environments, as environments are "sources of resources". Not surprisingly, based on this understanding, Müller-Christ and Remer [60] 
defined sustainable HRM as "what companies themselves have to do in their environments to have durable access to skilled human resources" (p. 76).

In the meantime, the Swiss approach relies more on normative understanding of sustainability as a moral, ethical value building in line with Brundtland Commisssion's definition. Considering that human resources are more "consumed" than "developed" as a starting point, sustainability in HRM is characterized by increasing employability, promoting individual responsibility, and ensuring a harmonious work-life balance. The Swiss approach conceptualizes sustainability as a mutual benefit referring to employers and employees as equal partners: Satisfaction of individual needs and maintaining of competitiveness of an organization is supported by sustainable HRM. Accordingly, sustainable HRM is defined as "the long-term socially and economically efficient recruitment, development, retainment, and disemployment of employees" [61] (p. II). It is important to underline, that the Swiss approach was developed as a synthesis of theoretical and empirical insights, revealing the heterogeneous understanding of sustainable HRM in organizations.

By linking sustainability and HRM more systematically and conceptualizing sustainable HRM, works by Ehnert [19,63], Mariappanadar [64-66], Kramar [22], De Prins et al. [12], Guerci, Shani, and Solari [67] can be mentioned.

The colossal contribution in fostering and making the field of sustainable HRM more mature was brought by Ehnert $[19,50,63,68-70]$. Referring to previous works in literature linking sustainability and HRM, Ehnert [19] provided a broader understanding of sustainable HRM at the same time rooting it in the strategic HRM literature and extending the Wright and McMahan's [71] strategic HRM framework. More recently, sustainable HRM definition provided by Ehnert et al. [38] (see Section 1) underlined two components. Firstly, multiple, potentially contradictory, economic, ecological, and social goals are recognized [19,70]. Certainly, the multiple bottom line orientation allows expanding the success of the organization and serves as a basis for long-term organizational viability in terms of skilled workforce attraction and maintaining of healthy employees. However, at the same time implication of sustainability in daily HRM practices raises the issues of dilemmas and tensions [19], as organizations may find themselves faces with conflicting needs, for instance of employee being available $24 \mathrm{~h}$ and employee work-life balance. Secondly, complex interrelations between the HRM systems and their environments (internal and external) with particular emphasis on relationships, which control externalities [23] and allow the long-term reproduction of resources [19], are recognized. Through the lenses of sustainable HRM, organization is viewed as an open system that "needs to develop and regenerate its HRs at least as fast as it 'consumes' them" [22] (p. 1777). Hence, the relevance of HRM impact in terms of externalities for different stakeholders within and outside the organization is well established (externality theory is well explained in works by Mariappanadar [23,72]; therefore; externalities are described later in analyzing his approach).

Ehnert $[19,70]$ contributed significantly to the field of sustainable HRM by applying the paradox theory as an underlying approach for sustainable HRM. Hahn, Preuss, Pinkse, and Figge [73] emphasize that sustainability creates situations when organizations need to simultaneously address multiple desirable, but conflicting economic, environmental, and social outcomes at company, and societal levels. Transferred to the HRM context, this means that sustainable HRM also produces some tensions and paradoxes. Consequently, Ehnert $[19,70]$ used paradox as a lens for theorizing upon sustainable HRM. Following the understanding that paradoxes can be understood as two or more contradictions, which operate simultaneously, Ehnert [19] identified three key paradoxes of sustainable HRM: Tensions between deploying human resources efficiently and maintaining their capabilities; tensions between economic rationality and relational rationality (here, the main aim is to maintain social legitimacy by acting in a responsible way); and tensions between short and long-term effects.

Going further, Mariappanadar's $[23,64-66,72,74]$ writings on sustainable HRM could be categorized under the label "promoting social and environmental health" [22]. Mariappanadar [23,72] applies negative externality and stakeholder harm theory as an underlying approach for sustainable HRM. Negative externality refers to "something that costs the organisation less for their actions or 
business practices than they save" [23] (p. 184). However, someone has to absorb and cover these costs and, it is not surprising; however, following the social cost theory, the costs are imposed on the weaker members of society, such as employees and their family members [72]. This implies that organizations harm the employees by extracting maximum skills, abilities, and motivations, and preventing them from achieving positive work-related well-being outcomes [75]. Commonly, negative externalities harm the employee families and the living standard of society as a whole. As a solution, at the institutional level, sustainable HRM has been suggested for reducing harm on employees, highlighting the synthesis effect [74]. That is, organizations can apply "both/and" approach and use the HRM practices to maximize their profits, and in addition to reduce the harm of HRM practices on the stakeholders because "these two polarities are not mutually exclusive but are rather mutually reinforcing" [72] (p. 314). It ensues that sustainable HRM is defined as "those HR systems or bundles that enhance both profit maximisation for the organisation and also 'reduce the harm' on employees, their families and communities" [72] (p. 313). Following negative externality and stakeholder harm theory, more recently, the health harm of work scale was developed [74] and the harm side of overwork is revealed [76].

The revision of mainstream HRM literature by focusing on stakeholder, institutional, ethical HRM, and critical HRM theories allowed De Prins et al. [12] to introduce the ROC model. The model encompasses three blocks, namely: Respect, Openness, and Continuity. Respect is expressed by a renewed focus on respect for employees as internal stakeholders in the organizations; Openness refers to environmental awareness and outside-in perspective on HRM; meanwhile, continuity reflects a long-term approach both in terms of economic and societal sustainability [12].

Guerci et al. [67] supplemented the field of sustainable HRM by exploring sustainable HRM from the stakeholder perspective. A stakeholder is "any individual or group who can affect or is affected by actions, decisions, policies, practices or goals of an organisation" [77] (p. 25). The present definition supposes that an organization has the duty to take care of all stakeholders and this discords with the classic approach (sometimes called the shareholder value theory) where an organization takes care exclusively of its owners [36].

Limited resources and rationality lead organizations not only to identify the stakeholders, but also to prioritize them [78]. Based on the stakeholders' attributes, such as power, legitimacy, and urgency [79], diverse matrixes of key stakeholders are proposed. In the stakeholder matrix of Zaugg [41], employees are identified as the stakeholders of the utmost importance according to two dimensions: Importance for sustainable human resource management (high, medium, low) and affinity to an organization (internal, internal and external, external). Not going in deep, the mega-message given by HRM literature is that employees are crucial stakeholders [80]. However, sustainable HRM is aimed at satisfying the expectations of all key stakeholders [81]. According to Guerci et al. [67], the success of an organization depends on its capability to integrate the interests of different stakeholders, and given the fact that integration is realized through the human resource management function, the sustainability dimension analysis in human resource management while focusing on the stakeholders is an important component of organizational activities.

Kramar [22] further developed the model of sustainable HRM proposed by Ehnert [19] taking into account the literature on sustainable work systems [82] and negative externalities [23]. In doing this, the recognition of positive and negative impact of HRM on various stakeholders is explicitly expressed. On the contrary to Ehnert's [19] model, ecological outcomes are explicitly treated as kinds of HRM outcomes. Moreover, Kramar [22] acknowledges the critical role of a manager for the strength of sustainable HRM system [83].

More recently, the topic of sustainable HRM has been gaining increased importance and getting more attention from researchers and practitioners. Such conclusion is based on two facts. First, the number of publications in sustainable HRM is growing by tackling various aspects: Wikhamn [40] explores the ways sustainable HRM impacts the innovation-customer satisfaction relationship; Baum [39] focuses on sustainable HRM in tourism industry; Vihari and Rao [84] analyse antecedents and consequences of sustainable HRM; Järlström, Saru and Vanhala [85] explore the ways 
top managers construct sustainable HRM, etc. Second, several special issues in sustainable HRM were prepared, such as Special issues in International Journal of Manpower (2016) or Asia-Pacific Journal of Business Administration (2014) or Management Review (2012).

In summary, the scholars understand sustainable HRM in slightly different ways. The paper shares the attitude that sustainable HRM forms the next, complementary, stage in the tradition of HRM thinking $[12,19,22]$. It reframes and revises the mainstream principles of strategic HRM; however, sustainable HRM does not refute the aspects of strategic HRM. Just as strategic HRM includes the operational activities of personnel management, sustainable HRM can likewise include aspects of strategic HRM [22]. Sustainable HRM is seen as an extension of strategic HRM, because it includes multiple bottom line outcomes and moves from short-term to long-term perspective [67]. Thus, the main difference between strategic and sustainable HRM concerns broader purposes of HRM. In case of strategic HRM, focus is clearly placed on organizational performance, primarily in terms of economic outcomes. Meanwhile, sustainable HRM acknowledges a variety of outcomes, including social, human, environmental, and financial ones [22]. Moreover, sustainable HRM explicitly identifies the negative effect of HRM not only on employees, but also on other stakeholders [23]. However, as it was mentioned before, the aspects of strategic HRM are an integral part of sustainable HRM, just the emphasis is on resource regeneration, development, and renewal when managing people.

As it was mentioned before, there is a plurality of competing approaches linking sustainability and HRM. Gladwin, Kennelly, and Krause [86] treat such definitional diversity as a matter-of-course thing. The paper shares the attitude of Gladwin et al. [86], inviting scholars to define clear lines around each construct and to be able to distinguish one construct from another. In keeping with this goal, this explicitly indicated characteristics of sustainable HRM that become of high importance.

\section{Characteristics of Sustainable HRM}

This section focuses on characteristics of sustainable HRM revealing their contents. One of the central questions when presenting a new approach is how to distinguish it from other similar ones. The same concern applies for sustainable HRM not leaving out of consideration that "many of HR colleagues seem to remain critical of the concept" [20] (p. 223) and that there is a danger of "old wine in new bottles" [87]. Generally, despite progress towards the features of sustainable HRM [70,85], the issue of the characteristics still remains underdeveloped.

The characteristics of sustainable HRM explain how sustainability can be used for HRM. The characteristics describe what HRM should look like in order to deserve the attribute 'sustainable'. Literature review allows stating that researchers choose different ways and forms to present the characteristics of the construct. Some of them appear to provide characteristics by describing the construct per se. For instance, Zaugg et al. [61] argue that employees' self-responsibility and participation in decisions, while HRM operates as a "guardian" of human resources with the objective to support the employees, are the underlying aspects of construct. Thus, these aspects serve as characteristics of sustainable HRM. Further, Cohen, et al. [43] argue that in designing sustainable HRM, three dimensions, namely, equity, well-being, and employee development should be included. Again, the mentioned dimensions can play the role of characteristics.

Other writers focus on the features that differentiate sustainable HRM from mainstream HRM, including strategic HRM, and in that vein, disclose the characteristics. Therefore, treating organizational outcomes in a broader sense rather than just financial outcomes [22] and acknowledging the negative effects of HRM on different stakeholders [23,72] are the characteristics of sustainable HRM. Finally, besides the implicitly expressed characteristics of the construct, some researchers do it explicitly. Zaugg [41] even incorporates the following characteristics in his sustainable HRM: Flexibility, employee participation, value orientation, strategy orientation, competency and knowledge orientation, stakeholder orientation, and building mutually trustful employee-employer relationships. Ehnert [68] introduced some other characteristics: Exploring short-term as well as long-term effects as well as side and feedback effects; extending the notion of success by considering economic, social, and ecological 
objectives; considering moral, ethical positions, as well as economic arguments; fostering the ability of HRM to develop and sustain the HR base and environments from within; and balancing paradoxes, dualities, dilemmas, and tensions. Several years later, Ehnert [70] compiled a short list of characteristics in terms of their titles including: Long-term oriented; impact-control oriented; substance and self-sustaining oriented; partnership-oriented; multiple-bottom lines-oriented; and paradox-oriented. More recently, based on qualitative study Järlström et al. [85] introduced four dimensions as sustainable HRM characteristics, namely justice and equality, transparent human resource practices, profitability, and employee well-being.

In summary, characteristics of sustainable HRM have been proposed for addressing the scarcity of knowledge about how to make the construct more explicit and distinguish it from others. Drawing on the previous literature, the paper proposes separating two things: underlying approaches and characteristics of sustainable HRM. In that vein, underlying approaches serve as keynotes, as a "roof" for characteristics arguing that the characteristics should be aligned with approaches. The paper takes the three approaches that are already well established in the literature and applied for sustainable HRM: Paradox theory $[19,70]$, theory of negative externality and stakeholder harm [23], and stakeholder theory [67]. Drawing on literature from a range of works linking sustainability and HRM and following the essence of corporate sustainability, the paper proposes 11 characteristics of sustainable HRM, namely: Long-term orientation, care of employees, care of environmental, profitability, employee participation and social dialogue, employee development, external partnership, flexibility, compliance beyond labor regulations, employee cooperation, fairness, and equality.

As the description of the approaches was provided previously, here, only the necessity to interconnect the approaches with characteristics is highlighted, treating the approaches as a "red line" for characteristics. Further, a review of these characteristics and how they contribute to the understanding of sustainable HRM are addressed. In Table 1, the summary of characteristics and some of their core aspects are provided.

Table 1. Characteristics of sustainable human resource management and their core aspects.

\begin{tabular}{|c|c|}
\hline Characteristic of Sustainable HRM & The Core Aspects \\
\hline long-term orientation & $\begin{array}{l}\text { Identification of the availability of human resources in the } \\
\text { future; identification of the needs of the future employees; } \\
\text { elimination of the "hire and fire" approach }\end{array}$ \\
\hline care of employees & Health and safety management; work-life balance \\
\hline care of environment & $\begin{array}{l}\text { Evaluating the employee performance according to } \\
\text { environment-related criteria; fostering "eco-career"; } \\
\text { employee rewarding according to environment-related } \\
\text { criteria }\end{array}$ \\
\hline profitability & Share programmes \\
\hline employee participation and social dialogue & Different types and forms of participation \\
\hline employee development & $\begin{array}{l}\text { Job rotation; different training forms and methods; the } \\
\text { transfer of experience; focus on future skills and } \\
\text { employability }\end{array}$ \\
\hline external partnership & $\begin{array}{l}\text { Cooperation with education system; partnership with all } \\
\text { external stakeholders }\end{array}$ \\
\hline flexibility & Flexible working arrangements; job rotation \\
\hline compliance beyond labour regulations & $\begin{array}{l}\text { involves employee representatives in many decision-making } \\
\text { processes beyond those for which worker participation is a } \\
\text { statutory requirement; financial and non-financial support }\end{array}$ \\
\hline employee cooperation & Teamwork; good relationships of managers and employees \\
\hline fairness and equality & $\begin{array}{l}\text { Fostering diversity; respectful relationships; fairness as } \\
\text { regards as remuneration, career }\end{array}$ \\
\hline
\end{tabular}


Long-term orientation. As noted by Lumpkin and Brigham [88], time considerations enter into many of the decisions organizations make, while short-term and long-term orientations are used as opposite dimensions of time. The discourse about sustainability is based on long-term orientation defining it as "the tendency to prioritise the long-range implications and impact of decisions and actions that come to fruition after an extended time period" [89] (p. 241). Three dimensions of long-term orientation are identified: futurity (it reflects a concern for the future); continuity (it highlights bridging from the past to the future), and perseverance (it underlines how decisions and actions in the present affect the future) [88]. Ironically, but "in many crucial decisions, the course of action that is most desirable over the long run is not the best course of action in the short term" [90]. Thus, the issue of balancing long-term and short-term decisions becomes of high importance.

The relevance of long-term orientation as a characteristic of sustainable HRM is well recognized. For instance, Zaugg et al. [61] argue that future orientation is a keystone of sustainable HRM. In a similar manner, Ehnert $[19,70]$ calls to "integrate future in the present" while nowadays the requirement to use human resources efficiently and effectively are balanced with the tomorrow's requirements to maintain, nourish and develop people. De Prins et al. [12] approach long-term orientation through the lens of continuity by offering insights on sustainable career.

Generally speaking, long-term orientation is relevant for people management considering various HRM practices, from employee planning till dismissal. The challenges organizations are facing, like demographical changes, free movement of people or the mismatch between the current skills of employees and those needed for future, serve as drivers for long-term orientation, addressing employee attraction, and retention. Typically, the assessment of past, present and future allows organizations to identify the availability of human resources in the future. Forecasting and labor market research could enhance sustainability in HRM, as the more specific labor market information is available, the easier is to recruit the "best" ones [61]. From sustainability perspective, being the "best" candidate means matching the organization's needs throughout a long period at a cost, which the organization can afford [52]. Moreover, "hire and fire" or "fire and forget" are approaches, which contradict the sustainable HRM, as being sustainable requires more efforts in "selecting the candidates who will contribute over the long term and during changing circumstances" [52] (p. 412).

Long-term orientation should be included by attracting employees who are committed to a sustainability culture and share the same sustainability values. Anticipation of preferences of future employees is of equal importance. Studies carried out in the UK and USA revealed that graduates and other individuals searching for a job that pays are mindful of the environmental sustainability dimension of an organization and use this information when making the decisions concerning employment [91].

Care of employees. As it was mentioned before, human beings are in center of concerns of sustainable development [92]. Accordingly, from sustainability perspective, each organization is in charge of ensuring that it "retains a healthy and productive workforce over time" [19]. Certainly, it is challenging to define what is meant by "care of employees", while the majority of practices treating employee as "an end in itself" could be classed under the label "care of employees". However, drawing mainly on the work of Guest and Pedrini [93], in the present paper care of employees is perceived in terms of health and safety, work-life balance, remuneration, and workload.

Care of employees is clearly reflected in health and safety management. It seems that employee health covering various topics like diseases, mortality, ergonomic work conditions, or stress, is a relevant research field addressing the necessity to rethink people management $[44,82,92]$. Based on the website content analysis, Ehnert [19] concluded that among internal drivers, organizations link sustainability to HRM and there is also the maintaining of a healthy and productive workforce. In doing this, one of banks implemented a "new" health management system, aimed at designing work in a way that preserves the health of employees and fostering health promoting behavior [94]. Obviously, that system, which covers, inter alia, occupational safety, occupational medicine, and social counselling, reflects the proposition of Hirsig, Rogovsky, and Elkin [95] that safe work environment 
"not only meets a basic human requirement, but is also conducive to productive and quality work" (p. 144). Huge achievements in the field of employee health are demonstrated by well-known company Nissan Motor Corporation [96], as employee health is a top priority for that company. For instance, workplaces are designed with employee safety and health in mind; proprietary safety management diagnostic methods are employed; the company has put together a specialized team led by a mental health professional to care for the mental well-being of employees.

Work-life balance represents another example of care of employees, as dual-career families, high work demands and long working hours have become the norm [97]. Zaugg et al. [61] treat a harmonious work-life balance as one of the underlying objectives of sustainable HRM. Accordingly, Rowan [35] argues that there is no reason for thinking that work life must be opposed to personal life. This is based on the idea of personal autonomy importance and the general idea that organizations should take care of the people they affect.

Definitely, it is not easy to combine work and private life, while challenges relate to a variety of aspects, such as disabilities, care of children, or employee age. However, experience of Germany suggests that organizations that handle the challenges successfully may achieve a certificate of a family-friendly company, yielding dual benefits to them: It helps retaining the employees and is a component of employer value proposition [94]. Time-related, informational, financial, and direct support for employees enable people to achieve work-life balance [94]. The key is that these family-friendly practices should meet the needs of staff while meeting the needs of organizations [95].

Nissan Motor Corporation [96] creates an environment conducive to work-life balance by supporting employee performance (for instance, internal social networking site "Work-Life Balance Park"); by supporting managers who have employees in the nurturing stage (for instance, management seminars); by creating company infrastructure-systems (for instance, work at home programme or super-flextime without core time) and creating company infrastructure-facilities and equipment (for instance, in-house childcare center).

Care of employees is also related to workload [44,65,66,82], which should be taken into account if healthy and productive workforce is to be had. Not less important is fair pay as an outcome of care of employees, arguing that justification for the minimum wage should be clear [35]. Work activities are supposed to ensure a certain minimum standard of living and to protect employees from stress, arising when considering the possibilities for "survival". Consequently, maximization of shareholder profit is insufficient justification for using employees as a mere tool for profit and for paying minimum wages [35]. Moreover, the double game offering low wages and overtime payments is in contradiction with sustainable HRM. In general, organizations mapping tensions should provide to employees such remuneration, which is sufficient for them to satisfy their needs, but also does not put financial viability of the organization in danger [95].

Care of environment. Although care of environment is a major concern of green HRM [27], ecological outcomes of sustainable HRM have been already recognized in theory [22]. Unfortunately, empirical data contradict the theoretical insights, as Järlström et al. [85] found out that environmental HRM did not relate to people management in the minds of top managers from Finland and that managers viewed care of environment as being separate from the other two dimensions-people and profit—of sustainability. Such findings encourage focusing more precisely on environmental issues from the people management perspective, if sustainable HRM fully represents the idea of sustainability.

Care of environment is strongly reflected in employee recruitment and selection, particularly targeting an increasingly environmentally aware younger generation or highly skilled employees (for a detailed review see Reference [27]). Competing for these employees, an environmentally responsible employer branding serves as a feature of employer attractiveness. Following the signaling theory, candidates use the environmental image and reputation of the organization to make inferences about its future intentions [27]. Alongside branding, there is a wide range of other actions to care of environment in terms of recruiting and selecting people, namely, use of technology, including 
environmental criteria in the recruitment messages, and selecting applicants who are sufficiently aware of environmental issues to fill the job vacancies $[51,98,99]$.

Care of environment could be embodied in employee training and development. This is mostly related to the increase of the level of "eco-literacy" [100], emphasizing the dual nature of the organization's actions: From one side, to impart the right knowledge and skills about environmental issues to each employee, and from another side, to analyze the training needs to identify the real training needs of employees [99]. Actually, Renwick et al. [27] raise the issues of employee cynicism regarding the relevance of such training, as sometimes training is delivered in a "politically correct way".

Care of environment is expressed in employee performance management and appraisal by evaluating the employee job performance according to environment-related criteria and providing a feedback on progress [99]. It is interesting that in practice some negative reinforcements are implemented to get the employees to make environmental improvements. For instance, Chan and Hawkins [101] found out that hotel workers were "repeatedly reminded" in cases where they did not fully implement the hotel's environmental practices.

Rewarding can also include care of environment applying financial and non-financial measures for environmentally correct behavior. Moreover, the link between the environmental performance and executive compensation is well established in literature [102].

More generally, sustainable care for the environment in everyday activities could manifest in justified consumption of electricity; reasonable printing of documents; moving of paper processes to the electronic space; and sorting of waste and options for arriving to work [22,103].

Profitability. Profit-seeking has dominated organizational activities for a long time. However, as organizations increasingly commit themselves to sustainability [104], financial indicators such as profits or return on investments are no longer the only criteria to measure success. This in no way negates the nature of a business organization, seeing that the economic component of sustainability preserves its importance; rather, a logical partnership of three components is emphasized. A long-term survival of an organization depends on its financial strength and competitiveness in the environment. Economic effectiveness is linked with the majority of business decisions, if not all [48]. This implies that the capacities of the economic component of sustainability generate the financial funds necessary for the realization of each classic human resource management function.

In summary, it could be stated that striving for economic effectiveness is a natural goal of every business organisation and it is not negated by the sustainability dimension. When recognising the necessity for the funds for human resource management, it is important not to justify the consumption of human resources and negative impact on employees, society as a whole, and environment by the striving for economic effectiveness.

From sustainability perspective, share programmes are worth mentioning. Since 2001, well-known company Henkel [105] has offered an employee share programme assuming that it is important for employees to share in the financial success of business. For each euro invested in 2017 by an employee (limited to 4 percent of salary up to a maximum of 4992 euros per year), Henkel added 33 eurocents. The added value of such programme lies in improved employee motivation and identification with the organization.

Employee participation and social dialogue. The added value of employee participation in terms of win-win for both sides, employer and employee, is well established in literature. The management approach views participation as an instrument to enhance the employees' attachment and loyalty to a particular organization, meanwhile the humanistic approach treats participation as beneficial to human growth and satisfaction of social needs [106]. While participation is not a new construct in management, debates about it are still continuing [106]. Glew, O'Leary-Kelly, Griffin and Van Fleet [107] define participation as conscious and intentional effort of individuals on the higher level in organization to provide an obvious role or expansion of opportunities for individuals or groups on the lower level in organization to provide larger voice in one or more areas of fulfilment of organizational 
goals. Meantime, Wilpert [108] perceives participation as a multidimensional construct, arguing that participations encompass various forms by which individuals or groups secure their interests or contribute to the choice process. Multidimensional nature implies that intensity of participation, form of participation, and issues to be solved are highly important [108]. Intensity of participation refers to the varying degree of influence, expressing the extent to which the appropriate interests can be safeguarded. The form of participation refers to whether the employees act as individuals or groups. Further, employee participation may apply to decisions about very different issues acknowledging two types of issues: work-related (or "proximal issues") and organizational issues ("distal issues"). "Proximal issues" are related to employees' immediate conditions for performing the job. Organizing work tasks or working time are examples of such issues. In the meantime, "distal issues" are related to employees' distal organizational environment, such as decisions on organizational strategy or financial decisions [106].

Employee participation creates the conditions for a fruitful social dialogue between employer, employees, and trade unions or other collective bodies.

It seems that employee participation has been already implicitly or explicitly mentioned when describing sustainable HRM [41,68,70,85]. Zaugg [41]) treats participation as an underlying objective of sustainable HRM, seeing that participation makes the transformation in treating employees not as object but as subject possible. This notwithstanding, participation is conditional on the existence of decision-making freedom that is tied to responsibility. Furthermore, Zaugg [41] emphasizes that participation is not merely a bipartite relationship between the employees and those in charge of the human resource management: In the narrow sense, a tripartite relationship is analyzed (employees, management, and human resource experts), whereas in the broad sense, a multipartite relationship should be examined (peers, external advisors, relatives, budget organizations, etc.).

Järlström et al. [85] conclude, based on empirical study results, that employee participation refers to a sustainable HRM in the minds of top managers. Research revealed that open, two-way communication is seen as an integral part of sustainable HRM. Moreover, employee participation in work-related decision-making is another element fostering sustainability in HRM.

Summing up, intensity, form and type of participation, as well as issues to be solved in the context of sustainable human resource management are all important objects of analysis. Enabling the employees to participate is a prerequisite in an organization that alone is nonetheless not sufficient; it is essential that the participation of employees in human resource management be intense, that the forms of participation are aligned with the types of participation, whereas the participation itself is realized in solving both "distant" and "immediate" problems.

Employee development. Development of employees in the light of sustainability means that the focus should be placed not only on the development of any current skills and capacities, but rather on skill-sets and capacities the employees will need in the future. Thus, development of employees is related to long-term orientation, considering employees both as main assets and agents of change [95]. Moreover, investment in future skills adds a challenge to the overall corporate sustainability debate as business environment is constantly changing and requires an urgent and concerted effort for adjustment also in terms of employee skills. This is supported by the World Economic Forum [109] announcing in The Future of Jobs report that on average, by 2020, more than a third of the desired core skill-sets of most occupations will be comprised of skills that are not yet considered crucial to the job today. Such foresight calls for the need to integrate employee development in the overall business strategy. Before starting, each organization should address the question of how it treats employees, as "zero inventory" or "time-phased investment" [30]. While "just in time" concept has been proposed for HRM, treating employees as "change agents" rather than "repositories of knowledge" determines that employees should be approached as investment, not as costs [30]. In supporting this, Hirsig et al. [95] argue that "if resources allow it, it is equally or more important for the enterprise to invest in continuous training and education for the workforce than in infrastructure and equipment" (p. 144). In general, development of employee skills is beneficial 
for employees (future employability and career opportunities) or employer (profitability and success) creating a win-win effect. Accordingly, the experience of business indicates that cutting on training and development even during economic crises creates longer-term problems for both parties [52]. Actually, employee development as a characteristic of sustainable HRM can be analyzed from various angles and several of them are described below.

Following the paradox theory, organizations surely focus on the tensions in the field of employee attraction. Mainly two options are available-either to buy talents on the market or to create flexibility through postponement [30]. Buying seems attractive because organizations can target specific skills they currently need. However, buying has been criticized for being expensive and exceeding the financial limits organizations can afford. Moreover, employees taken from the outside might give rise to disappointment in internal career mechanism and contribute to frustration of the existing employees. Flexibility through postponement relies on the idea that employees are given the chance to develop their full potential over the long term and across different positions, for instance in the form of job rotation [30]. Essentially, the above options seem appropriate from the HRM perspective. Mainstream HRM would prefer buying, seeing that experienced people rapidly generate economic value for the business. Meanwhile, sustainability in HRM is expressed through employee development appreciating on-the job training and performing diverse tasks. According to Hirsig et al. [95], on-the-job training represents a cost-saving approach within the organization, whereas performing diverse tasks allows the employees to understand the processes, operations, and goals of organizations better, which in turn can lead to higher job motivation and innovations. Taking examples from business, well-known company Honda [110] can serve as a perfect one. Honda's approach to personnel education is built around on-the-job training as the company aims at building specialized skills and professional capabilities through direct experience. However, supplementary off-the-job training is also offered and is designed to provide the associates with an opportunity to enhance their careers by developing new specialized skills or management capabilities.

It seems that in the literature the debate regarding training intensity and cost covering is still going, given the importance of economic usefulness of employee development. The fear of employee turnover might result in the organization's minimization of employee training and development. However, an empirical research by Hansson [111] reveals that intensity of the investment in trainings is one of the key factors affecting profits. Economic outcome of operations-economic benefit of trainings outweighs the costs of employee turnover. Suggesting that employees should cover the costs of their trainings presumes that employees are the sole recipients of training benefits [112], and this is out of line with the idea of sustainability. This also contradicts the empirical findings of Järlström et al. [85] where managers acknowledged the meaning of development both for the individuals and the organization. Such recognition strongly supports the idea of life-long learning. Henkel supports the life-long learning idea seeing it as a central factor in further employee development. The idea is implemented through learning as part of everyday work and through handling a varied range of tasks. The company encourages this, especially by taking advantage of new roles both locally and in other countries.

In the light of sustainability, training forms and methods are relevant. Saving the costs, seeking to standardise the training materials as well as dealing with the geographical distance issues, some of the organisations have replaced direct contact training by online training. However, a negative consequence of technological advance becomes obvious: Employees are deprived of the interaction with experienced colleagues and of the possibility to get to know the organisational culture. Sustainability comes to the fore when an aligned approach is applied, encompassing both online and direct interaction sessions [31]. The case of Henkel [105] seems to be following the mentioned advice. By greater use of digital communication channels, Henkel supports internal knowledge transfer. However, knowledge transfer is also encouraged by face-to-face learning from supervisors, team members, and other colleagues.

When examining the transfer of experience in an organisation, mentoring and creation of the conditions for enabling it are to be emphasised. Moreover, it is expedient to reward the employees 
for their efforts to transfer the experience and it is, therefore, likely that they will be more open about sharing the specialist knowledge with the new employees [31].

It is important not to forget the indirect value of employee development, seeing as it is the key element in attracting new employees and also offers more opportunities for the employees who wish to terminate the employment to search for jobs successfully [113]. Thus, the employability of the people is enhanced; however, it should be pointed out that trainings and development send to the employees a message that the organisation is interested in retaining them in the long term.

Incidentally, it is important for the organizations to also develop such abilities of employees that are aimed at enhancing corporate sustainability. In 2012, Henkel [105] launched the Sustainability Ambassador Programme to anchor sustainability in all employees. The aim of the programme is to communicate the company's motivation, strategy, and commitment to sustainability to its employees. By the end of 2017, more than 50,000 employees were already trained to become Sustainability Ambassadors.

External partnership. This characteristic mainly relies on the stakeholder theory [67] and sustainable resource management [14] considering the opportunities of the organization to provide the resources needed for doing business in the long run. From the sustainability perspective, an organization does not only have to ensure that it attracts and retains workforce today, but also that it sustains access to the desired groups of people, the so-called "source of resources" [19]. External partnership is strongly reflected in Ehnert's [19] sustainable HRM model, which lies on the "substance-oriented" meaning of sustainability arguing for the balance between the "consumption" and "reproduction" of human resources by fostering their regeneration and investing into the environments the human resources come from [19]. Emphasizing close cooperation with the "sources of resources", the relations with labor market, educational institutions, non-governmental institutions, and even employee families are seen as adding value on the road to sustainable HRM [70]. The examples of relationships mutually beneficial for employers and employees are the following: Coverage of training expenses, grants, support for lifelong learning, cooperation with universities, and other educational bodies by attending courses or getting possible solutions to business problems.

External partnership contributes to becoming an employer of choice, as job fairs or other forms of cooperation with educational institutions can be used to attract the right employees to the organization. Business has the right to hire globally or to use the local labor force, however, if skills of candidates are on the same level, sustainability always stands for local employees, and as such, decisions that also foster local communities [31].

Going further, inter-organisational relationships are also important in the context of partnership with the external environment. As seen from the sustainability perspective, organisations have to support each other in developing the human resources. Nonetheless, an opposite trend is observed that could be illustrated by a rhetorical question- "Why should we develop people when our competitors are willing to do it for us" [112] (p. 76). Thus, non-sharing of training expenses between organisations should be approached as anti-sustainability.

Recently, Ulrich and Dulebohn [2] proposed that future HRM will need to adopt an outside/inside approach where stakeholders and external environment influence what HRM does inside the organization. External partnership partly corresponds to the idea of outside/inside approach stating that HRM creates value by making sure "that services HR offers inside the company align to expectations outside the company" [2] (p. 191).

Flexibility. The concept of flexibility is well recognized and established in strategic HRM literature [114-116]. Functional and numerical flexibility tend to be viewed as alternative types of flexibility, both underlying distinct approaches to people management. Functional flexibility relies on long-term mutual investment in employment relationships and is usually seen as the ability to respond to changes in business "needs by having multi-skilled, adaptable and internally mobile employees" [113]. In other words, functional flexibility "concerns the ability to perform various and heterogeneous tasks as well as the practice of moving workers from one task to another to maintain 
their efficiency" [117]. Numerical flexibility, on the other hand, refers to cost minimization and is, on the other hand, the ability of the organization to vary the quantity of workers employed to match the changes in the business needs [113].

Considering that numeral flexibility presents a cost-cutting approach and is associated with the short-term perspective, it is supposed that the numeral flexibility is hardly in line with the sustainability idea. Certainly, in same situations as temporary employment of students or people with disabilities or other persons helping them to integrate into labor market and to increase the chances of future employability, numeral flexibility is justified from the sustainability point of view. On the contrary, the added value of functional flexibility is much higher. Generally, functional flexibility becomes possible as a result of work rotation and employee substitution. In rotation, flexibility is beneficial to both parties-employer and employee, seeing that the determination of the match between the individual and job is postponed. Furthermore, job rotation allows the managers to understand the essential value-creating processes of other units, and makes it possible for the employees to enhance their employability. Furthermore, it should be emphasised that functional flexibility requires committed and skilled employees, whereas this could be achieved by investing in trainings and long-term employment relationships.

Flexibility, as a characteristic of sustainable HRM, is mainly reflected in terms of employee needs. The need for flexibility in such issues like work hours, leave, remote work, vacations, rewards, and retirements was recognized by managers in Finnish companies [85]. In 2012, Henkel [105] signed the global Work-Life Flexibility Charter. Nowadays, based on a culture of trust, flexible working hours, part-time work, new workplace concepts and mobile working represent a natural part of work at Henkel. It is relevant from the sustainability point of view that managers are instructed on how to put flexible working arrangements into practice and to support them actively. In general, Henkel acknowledges the added value of flexible working due to the improved work-life balance and employee motivation.

However, flexibility should be treated carefully with caution due to several reasons. First, flexibility requires taking into consideration the special needs of employees emerging due to individual or family concerns, while at the same time meeting the needs of the organization [95]. Usually, reality is undoubtedly challenging as it is not easy to reconcile the need for flexibility and human resource planning, although they should ideally be integrated [85]. Secondly, empirical findings are not homogenous and some of them do not support theoretical insights and empirical conclusions that flexibility has a positive effect on employee well-being. For instance, Mariappanadar and Kramar [75] found out that tele-working and compressed working week both increased employee harm (increased absenteeism and sick leaves). However, in the same research flexi-time and home-based work did not have the mentioned effect.

Compliance beyond labor regulations. Running business according to law is a compulsory precondition for each organization. Cohen et al. [43] argue that compliance with labor regulations is an essential starting-point for sustainable HRM. The existing well known and mostly prevailing sustainability frameworks, such as Global Reporting Initiative (GRI) framework or the United Nations Global Compact, also include information if the organizations' actions, namely labor practices and practices in the field of human rights, are in accordance with the legal requirements.

However, for being sustainable in people management, it is not enough just to obey the laws and regulations. In order to employ sustainability in HRM and to reap the benefits, a broader approach that reaches beyond the labor regulations is needed, as "obeying institutional requirements does not necessarily signal that a particular organization is sustainable" [85] (p. 7). In Germany, Henkel involves employee representatives in many decision-making processes beyond those for which worker participation is a statutory requirement. The company sees the value of such choice in several areas, for instance, improved work-life balance or accident prevention.

Employee cooperation. Brown and Shields [118] argue that according to tournament theory competing employees have strong intentions to undermine their co-workers' activities. In doing 
this, the employees can improve their own performance and be rewarded. However, workplace cooperation is much more beneficial than competition in terms of economic and social outcomes. For instance, Hirsig et al. [95] underline that cooperation fosters improved quality and productivity, reduces absenteeism, lowers the risk of labor disputes, and increases overall job satisfaction. Information sharing, trust and respect within an organization or open and proactive communication can be applied for creating and enhancing employee cooperation.

Fairness and equality. This characteristic corresponds to Greenwood's [36] conclusion that question "is this right or wrong" appears to be long overlooked in HRM. Järlström et al. [85] underline that fair treatment of employees means that "rules, responsibilities, and rights are intended to be the same for everyone throughout an organization" (p. 7).

Diversity literature mostly defines diversity by referring to employee socio-demographic traits, such as age, gender, ethnicity, etc. [119]. Harrison, Price and Bell [120] proposed two distinct dimensions of diversity, i.e., surface-level diversity and deep-level diversity. Surface-level diversity refers to differences among people in overt, biological characteristics that are typically reflected in physical features, which are visible and easily perceived by individuals (examples: Age or gender). Deep-level diversity, on the contrary, relies on more subtle attributes that cannot necessarily be immediately and directly observed. Such attributes refer to employees' attitudes, beliefs and values [121]. Incidentally, diversity management and non-discrimination do not mean the same in terms of pursuing sustainability. Sustainable HRM requires not only ensuring non-discrimination, but also going one step forward and encouraging diversity within workforce [95]. In general, fairness and equality could be reflected throughout the entire HRM addressing selection, performance evaluation, rewarding, etc.

Turning to business practice, Starbucks [122] can serve as an excellent example. On its website, Starbucks declares it strives to create a culture that values and respects diversity and inclusion and this not a mere declaration. When the police were called to arrest two black men waiting for a colleague at a Philadelphia Starbucks in April, 2018, Starbucks' CEO Kenneth Johnson responded swiftly to the event, and among other measures, a day of anti-bias training for employees in over 8000 Starbucks stores was scheduled. Starbucks stores and corporate offices were closed for trainings of 175,000 employees, this being just a part of a longer, comprehensive effort to make Starbucks even more diverse and equitable.

\section{Discussion and Conclusions}

Over the last 30 years, people and performance linkage have been approached in HRM literature more as a means rather than an end in itself. Moreover, no effect or negative effect of HRM on human resources has been also largely neglected. To be honest, the situation when human resources were more consumed than developed became more or less prevailing. Such treatment has resulted in employee health issues, difficulties to reconcile work and private life or other forms of harm on employees, their family members and society as a whole making it more difficult for business to have skilled and healthy labor force. Alongside internal issues in employment relationships, external factors, such as demographical changes or increased external pressure of various stakeholders also require a paradigm shift in HRM if organizations are to attract and retain human resources for running business in the future. The paper fully shares the idea of Ehnert and Harry [20] that there is no time to postpone choices and actions to sometime in "the future" and supports the idea for choosing sustainable HRM as a new approach for people management. Taking into consideration the young age of the construct, different understandings of sustainable HRM are presented. Drawing on insights by Ehnert [70], Kramar [22], and Mariappanadar [23,72], the paper underlines several components of sustainable HRM, for example: Sustainable HRM acknowledges organizational performance outcomes, which are broader than financial outcomes, thus including environmental and social outcomes; sustainable HRM assumes that multiple goals can be contradictory; the temporal perspective of evaluating the mentioned outcomes moves from short-term to long-term perspectives; sustainable HRM recognizes complex 
interrelations between HRM and internal and external environments with the purpose to have access to resources and to control negative externalities. Thus, sustainable HRM is dedicated to human resource development, regeneration, and renewal.

Further, the paper argues that the first premise how to translate sustainable HRM into practice [38] is being aware what it means to manage people in a sustainable way. Trying the fill the gap in the literature for answers to Ehnert's [70] question: "What would an HRM system look like which deserves the attribute 'sustainable'?" (p. 257), the characteristics of sustainable HRM are introduced. Drawing from the previous writings in the field of sustainable HRM and being in line with the concept of corporate sustainability, the 11 characteristics of sustainable HRM are the following: long-term orientation, care of employees, care of environmental, profitability, employee participation and social dialogue, employee development, external partnership, flexibility, compliance beyond labor regulations, employee cooperation, fairness, and equality. In fact, the paper proposes separating two things: Underlying approaches and characteristics of sustainable HRM. In this sense, underlying approaches serve as keynotes, as a "roof" for characteristics arguing that the characteristics should correspond to the approaches. The paradox theory $[19,70]$, theory of negative externality and stakeholder harm [23], and stakeholder theory [67] were suggested as approaches described coherently in sustainable HRM literature.

The paper elaborated on each characteristic of sustainable HRM by presenting the theoretical explanations and some examples from world-leading companies on how these characteristics could be translated "into shared meanings or into measureable processes and outcomes" [13] (p. 17). Overall, by revealing the features of sustainable HRM, the paper supports the idea of Cleveland et al. [21] that HRM must be strong advocates of employees. Surely, profitability goals of businesses cannot be denied, and having this in mind, it becomes essential to align and adjust the employer and employee needs. The dialogue between two parties could rely on the harmonious co-existence of employees, corporations, and society or pursuing the "win-win" situation.

As it was mentioned before, the paper introduces some examples from business on the expression of characteristics. Thus, it is shown that characteristics can acquire different forms across different organizations. Such attitude corresponds to the insights suggested 20 years ago by Porter and Kramer [123]. They argued that the pressure for organizations to think of corporate social responsibility in generic ways instead of in the way most appropriate to each company's strategy serves as an obstacle to higher achievements improving social and environmental outcomes of their activities. Hence, presuming diversity in the expression of characteristics, the paper supports the view of Mariappanadar [23] that sustainable HRM is a self-regulation system at the institutional level. However, having this in mind, it is no less important that sustainable HRM should have clear daily practices rather than reflect a "good catalog of intention". For instance, talking about the care of employee practices that are related to healthy employees, employee-friendly physical workspace, work-life balance, constructive stress management, attention to employees, or adequate workload could be implemented [25]. Moreover, challenges related to digital age and new emerging technologies need to be included when talking about sustainability in HRM.

The paper has several limitations, namely in terms of not including aspects of cultures or religions when analysing sustainable HRM or not proposing how to measure the level of sustainability in HRM. However, these limitations could be overcome by further research.

With regard to future research opportunities, different cultures and even religions could be included while analyzing the meaning of sustainability for societies and business worldwide. Sustainability debates address the values and these values are not shared universally. Moreover, sustainability and characteristics of sustainable HRM can be interpreted differently across different cultures [20]. This leads to the proposition that characteristics of sustainable HRM cannot be generalized worldwide and there is a need to expand research in mentioned field. Actually, some efforts have already been made and the paper on implications of Confucian thinking for sustainable HRM serves as an excellent starting example [56]. Further, for sustainable HRM to be useful and fruitful for practitioners, it is 
necessary to propose how to measure that construct in terms of characteristics. Several attempts at providing validated scales for measuring have already been made, for instance by Wikhamn [40]; however, sustainable HRM measuring still remains a challenging field. Next, as Industry 4.0 with the emerging technologies affects the work design and job processes, the impact of these technologies on people management by taking sustainability perspective could also be addressed in further research. Finally, sustainability does not meant stability; it is a dynamic process [124]. Referring to people management, this means that sustainability in HRM is constantly changing and further research is needed to discover the characteristics of sustainable HRM emerging during that journey.

Author Contributions: conceptualization, Ž.S. and A.S.; formal analysis, Ž.S. and A.S.; resources, Ž.S. and A.S.; writing—original draft preparation, Ž.S. and A.S.; writing—review and editing, Ž.S. and A.S.

Funding: This research received no external funding.

Conflicts of Interest: The authors declare no conflict of interest.

\section{References}

1. Marchington, M. Human resource management (HRM): Too busy looking up to see where it is going longer term? Hum. Resour. Manag. Rev. 2015, 25, 176-187. [CrossRef]

2. Ulrich, D.; Dulebohn, J.H. Are we there yet? What's next for HR? Hum. Resour. Manag. Rev. 2015, 25, 188-204. [CrossRef]

3. Beer, M.; Boselie, P.; Brewster, C. Back to the future: Implications for the field of HRM of the multistakeholder perspective proposed 30 years ago. Hum. Resour. Manag. 2015, 54, 427-438. [CrossRef]

4. Guest, D.E. Human resource management and employee well-being: Towards a new analytic framework. Hum. Resour. Manag. J. 2017, 27, 22-38. [CrossRef]

5. Becker, B.E.; Huselid, M.A. Strategic human resources management: Where do we go from here? J. Manag. 2006, 32, 898-925. [CrossRef]

6. Combs, J.; Liu, Y.; Hall, A.; Ketchen, D. How much do high-performance work practices matter? A meta-analysis of their effects on organizational performance. Pers. Psychol. 2006, 59, 501-528. [CrossRef]

7. Guest, D.E. Human resource management and performance: A review and research agenda. Int. J. Hum. Resour. Manag. 1997, 8, 263-276. [CrossRef]

8. Jiang, K.; Lepak, D.P.; Hu, J.; Baer, J.C. How does human resource management influence organizational outcomes? A meta-analytic investigation of mediating mechanisms. Acad. Manag. J. 2012, 55, 1264-1294. [CrossRef]

9. Dyer, L.; Reeves, T. Human resource strategies and firm performance: What do we know and where do we need to go? Int. J. Hum. Resour. Manag. 1995, 6, 656-670. [CrossRef]

10. Boxall, P.; Guthrie, J.P.; Paauwe, J. Editorial introduction: Progressing our understanding of the mediating variables linking HRM, employee well-being and organisational performance. Hum. Resour. Manag. J. 2016, 26, 103-111. [CrossRef]

11. Eurofound. Sixth European Working Conditions Survey-Overview Report; Publications office of the European Union: Luxembourg, 2016.

12. De Prins, P.; Van Beirendonck, L.; De Vos, A.; Segers, J. Sustainable HRM: Bridging theory and practice through the 'Respect Openness Continuity (ROC)'-model. Manag. Rev. 2014, 25, 263-284. [CrossRef]

13. Ehnert, I.; Harry, W.; Zink, K.J. Sustainability and HRM. An introduction to the field. In Sustainability and Human Resource Management: Developing Sustainable Business Organizations; Ehnert, I., Harry, W., Zink, K.J., Eds.; Springer: Berlin/Heidelberg, Germany, 2014; pp. 3-32, ISBN 978-3-642-37524-8.

14. Müller-Christ, G. Sustainable Management: Coping with the Dilemmas of Resource-Oriented Management; Springer: Berlin/Heidelberg, Germany, 2011; ISBN 978-3-642-19164-0.

15. World Commission on Environment and Development. Our Common Future. 1987. Available online: http:/ / www.un-documents.net/our-common-future.pdf (accessed on 11 August 2018).

16. Bansal, P. Evolving sustainably: A longitudinal study of corporate sustainable development. Straegt. Manag. J. 2005, 26, 197-218. [CrossRef] 
17. Hahn, T.; Pinkse, J.; Preuss, L.; Figge, F. Tensions in corporate sustainability: Towards an integrative framework. J. Bus. Eth. 2015, 127, 297-316. [CrossRef]

18. Hahn, T.; Figge, F. Beyond the bounded instrumentality in current corporate sustainability research: Toward an inclusive notion of profitability. J. Bus. Eth. 2011, 104, 325-345. [CrossRef]

19. Ehnert, I. Sustainable Human Resource Management. A Conceptual and Exploratory Analysis from a Paradox Perspective; Physica-Verlag: Berlin/Heidelberg, Germany, 2009; ISBN 978-3-7908-2188-8.

20. Ehnert, I.; Harry, W. Recent developments and future prospects on sustainable human resource management: Introduction to the special issue. Manag. Rev. 2012, 23, 221-238. [CrossRef]

21. Cleveland, J.N.; Byrne, Z.S.; Cavanagh. The future of HR is RH: Respect for humanity at work. Hum. Resour. Manag. Rev. 2015, 25, 146-161. [CrossRef]

22. Kramar, R. Beyond strategic human resource management: Is sustainable human resource management the next approach? Int. J. Hum. Resour. Manag. 2014, 25, 1069-1089. [CrossRef]

23. Mariappanadar, S. The model of negative externality for sustainable HRM. In Sustainability and Human Resource Management: Developing Sustainable Business Organizations; Ehnert, I., Harry, W., Zink, K.J., Eds.; Springer: Berlin/Heidelberg, Germany, 2014; pp. 181-203, ISBN 978-3-642-37524-8.

24. Diaz-Carrion, R.; López-Fernández, M.; Romero-Fernandez, P.M. Developing a sustainable HRM system from a contextual perspective. Corp. Soc. Responsib. Environ. Manag. 2018, 25, 1143-1153. [CrossRef]

25. Stankevičiūtè, Ž.; Savanevičienè, A. Raising the Curtain in People Management by Exploring How Sustainable HRM Translates to Practice: The Case of Lithuanian Organizations. Sustainability 2018, 10, 4356. [CrossRef]

26. Savaneviciene, A.; Stankeviciute, Z. The disclosure of sustainability and human resource management linkage. Hum. Resour. Manag. Ergon. 2014, 8, 88-104.

27. Renwick, D.W.; Redman, T.; Maguire, S. Green human resource management: A review and research agenda. Int. J. Manag. Rev. 2013, 15, 1-14. [CrossRef]

28. Jackson, S.E.; Seo, J. The greening of strategic HRM scholarship. Organ. Manag. J. 2010, 7, 278-290. [CrossRef]

29. Bombiak, E.; Marciniuk-Kluska, A. Green Human Resource Management as a Tool for the Sustainable Development of Enterprises: Polish Young Company Experience. Sustainability 2018, 10, 1739. [CrossRef]

30. Becker, W. Are you leading a socially responsible and sustainable human resource function? People Strateg. 2011, 34, 18-23.

31. Becker, W.; Smith, R. Social and Environmental Responsibility, Sustainability, and Human Resource Practices (30 July 2012). In Sustainable Value Chain Management: Analyzing, Designing, Implementing, and Monitoring for Social and Environmental Responsibility; Lindgreen, A., Sen, S., Maon, F., Vanhamme, J., Eds.; Gower Publications: Aldershot, UK, 2012; Available online: https://ssrn.com/abstract=2120195 (accessed on 4 September 2018).

32. Shen, J.; Jiuhua Zhu, C. Effects of socially responsible human resource management on employee organizational commitment. Int. J. Hum. Resour. Manag. 2011, 22, 3020-3035. [CrossRef]

33. Barrena-Martinez, J.; López-Fernández, M.; Romero-Fernandez, P.M. Drivers and Barriers in Socially Responsible Human Resource Management. Sustainability 2018, 10, 1532. [CrossRef]

34. Diaz-Carrion, R.; López-Fernández, M.; Romero-Fernandez, P.M. Evidence of different models of socially responsible HRM in Europe. Bus. Eth. Eur. Rev. 2018. [CrossRef]

35. Rowan, J.R. The moral foundation of employee rights. J. Bus. Eth. 2000, 24, 355-361. [CrossRef]

36. Greenwood, M.R. Ethics and HRM: A review and conceptual analysis. J. Bus. Eth. 2002, 36, 261-278. [CrossRef]

37. Greenwood, M. Ethical analyses of HRM: A review and research agenda. J. Bus. Eth. 2013, 114, 355-366. [CrossRef]

38. Ehnert, I.; Parsa, S.; Roper, I.; Wagner, M.; Muller-Camen, M. Reporting on sustainability and HRM: A comparative study of sustainability reporting practices by the world's largest companies. Int. J. Hum. Resour. Manag. 2016, 27, 88-108. [CrossRef]

39. Baum, T. Sustainable human resource management as a driver in tourism policy and planning: A serious sin of omission? J. Sustain. Tour. 2018, 26, 873-889. [CrossRef]

40. Wikhamn, W. Innovation, sustainable HRM and customer satisfaction. Int. J. Hosp. Manag. 2019, 76, $102-110$. [CrossRef]

41. Zaugg, R.J. Sustainable HR Management: New Perspectives and Empirical Explanations; Gabler: Wiesbaden, Germany, 2009; ISBN 978-3-8349-2103-1. 
42. Rio Declaration on Environment and Development, 1992. United Nations Department of Economic and Social Affairs. Available online: http://www.unesco.org/education/pdf/RIO_E.PDF (accessed on 1 September 2018).

43. Cohen, E.; Taylor, S.; Muller-Camen, M. HRM's Role in Corporate Social and Environmental Sustainability; SHRM Report: Alexandria, VA, USA, 2012.

44. Pfeffer, J. Building sustainable organizations: The human factor. Acad. Manag. Perspect. 2010, 24, $34-45$.

45. Boudreau, J.W.; Ramstad, P.M. Talentship and the new paradigm for human resource management: From professional practices to strategic talent decision science. People Strateg. 2005, 28, 17.

46. Zink, K.J. Social sustainability and quality of working life. In Sustainability and Human Resource Management: Developing Sustainable Business Organizations; Ehnert, I., Harry, W., Zink, K.J., Eds.; Springer: Berlin/Heidelberg, Germany, 2014; pp. 35-55, ISBN 978-3-642-37524-8.

47. Van De Voorde, K.; Paauwe, J.; Van Veldhoven, M. Employee well-being and the HRM-Organizational performance relationship: A review of quantitative studies. Int. J. Manag. Rev. 2012, 14, 391-407. [CrossRef]

48. Clarke, M. Sustainable HRM: A New Approach to People Management; Tilde University Press: Prahran, Australia, 2011; ISBN 978-0-7346-1101-7.

49. Van Marrewijk, M. Concepts and definitions of CSR and corporate sustainability: Between agency and communion. J. Bu. Eth. 2003, 44, 95-105. [CrossRef]

50. Ehnert, I. Sustainability and human resource management: Reasoning and applications on corporate websites. Eur. J. Int. Manag. 2009, 3, 419-438. [CrossRef]

51. DuBois, C.L.; Dubois, D.A. Strategic HRM as social design for environmental sustainability in organization. Hum. Resour. Manag. 2012, 51, 799-826. [CrossRef]

52. Harry, W. The relevance of the vision of sustainability to HRM practice. In Sustainability and Human Resource Management: Developing Sustainable Business Organizations; Ehnert, I., Harry, W., Zink, K.J., Eds.; Springer: Berlin/Heidelberg, Germany, 2014; pp. 401-419, ISBN 978-3-642-37524-8.

53. Tabatabaei, S.A.N.; Omran, E.S.; Hashemi, S.; Sedaghat, M. Presenting Sustainable HRM Model Based on Balanced Scorecard in Knowledge-based ICT Companies (The Case of Iran). Econ. Sociol. 2017, 10, 107. [CrossRef]

54. Au, W.C.; Ahmed, P.K. Sustainable people management through work-life balance: A study of the Malaysian Chinese context. Asia Pac. J. Bus. Adm. 2014, 6, 262-280. [CrossRef]

55. Sotome, R.; Takahashi, M. Does the Japanese employment system harm productivity performance? A perspective from DEA-based productivity and sustainable HRM. Asia Pac. J. Bus. Adm. 2014, 6, 225-246. [CrossRef]

56. Mak, A.; Cheung, L.; Mak, A.; Leung, L. Confucian thinking and the implications for sustainability in HRM. Asia Pac. J. Bus. Adm. 2014, 6, 173-189. [CrossRef]

57. Kozica, A.; Kaiser, S. A sustainability perspective on flexible HRM: How to cope with paradoxes of contingent work. Manag. Rev. 2012, 23, 239-261. [CrossRef]

58. Lis, B. The relevance of corporate social responsibility for a sustainable human resource management: An analysis of organizational attractiveness as a determinant in employees' selection of a (potential) employer. Manag. Rev. 2012, 279-295. [CrossRef]

59. App, S.; Merk, J.; Büttgen, M. Employer branding: Sustainable HRM as a competitive advantage in the market for high-quality employees. Manag. Rev. 2012, 23, 262-278. [CrossRef]

60. Müller-Christ, G.; Remer, A. Umweltwirtschaft oder Wirtschaftsökologie? Vorüberlegungen zu einer Theorie des Ressourcenmanagements. In Betriebliches Umweltmanagement im 21. Jahrhundert; Seidel, E., Ed.; Springer: Berlin/Heidelberg, Germany, 1999; pp. 69-87, ISBN 978-3-642-64320-0.

61. Zaugg, R.J.; Blum, A.; Thom, N. Sustainability in Human Resource Management. Evaluation Report. Survey in European Companies and Institutions. Arbeitsbericht des Instituts für Organisation und Personal der Universität Bern und des eidgenössischen Personalamtes; IOP Press: Berne, Switzerland, 2001; ISBN 3-906471-48-9.

62. Gollan, P.J. Human resources, capabilities and sustainability. In Sustainability: Corporate Challenge for the 21st Century; Dunphy, D., Benveniste, J., Griffiths, A., Sutton, P., Eds.; Allen and Unwin: St. Leonards, NSW, Austalia, 2000; pp. 55-77, ISBN 9781865082288.

63. Ehnert, I. Sustainability Issues in Human Resource Management: Linkages, theoretical approaches, and outlines for an emerging field. In Proceedings of the 21st EIASM Workshop on SHRM, Birmingham, UK, 30-31 March 2006; pp. 30-31. 
64. Mariappanadar, S. Sustainable human resource strategy: The sustainable and unsustainable dilemmas of retrenchment. Int. J. Soc. Econ. 2003, 30, 906-923. [CrossRef]

65. Mariappanadar, S. The harm indicators of negative externality of efficiency focused organizational practices. Int. J. Soc. Econ. 2012, 39, 209-220. [CrossRef]

66. Mariappanadar, S. Harm of efficiency oriented HRM practices on stakeholders: An ethical issue for sustainability. Soc. Bus. Rev. 2012, 7, 168-184. [CrossRef]

67. Guerci, M.; Shani, A.B.R.; Solari, L. A stakeholder perspective for sustainable HRM. In Sustainability and Human Resource Management: Developing Sustainable Business Organizations; Ehnert, I., Harry, W., Zink, K.J., Eds.; Springer: Berlin/Heidelberg, Germany, 2014; pp. 205-223, ISBN 978-3-642-37524-8.

68. Ehnert, I. Sustainability and HRM: A model and suggestions for future research. In The Future of Employment Relations. New Paradigms, New Developments; Wilkinson, A., Townsend, K., Eds.; Palgrave Macmillan: London, UK, 2011; pp. 215-237, ISBN 978-0-230-24094-0.

69. Ehnert, I. Nachhaltiges Personalmanagement: Konzeptionalisierung und Implementierungsansätze. In Ethik im Personalmanagement: Zentrale Konzepte, Ansätze und Fragestellungen; Kozica, A., Kaiser, S., Eds.; Rainer Hampp Verlag: Bavaria, Germany, 2012; pp. 131-157, ISBN 978-3-86618-773-3.

70. Ehnert, I. Paradox as a lens for theorizing sustainable HRM. In Sustainability and Human Resource Management:Developing Sustainable Business Organizations; Ehnert, I., Harry, W., Zink, K.J., Eds.; Springer: Berlin/Heidelberg, Germany, 2014; pp. 247-271, ISBN 978-3-642-37524-8.

71. Wright, P.M.; McMahan, G.C. Theoretical perspectives for strategic human resource management. J. Manag. 1992, 18, 295-320. [CrossRef]

72. Mariappanadar, S. Stakeholder harm index: A framework to review work intensification from the critical HRM perspective. Hum. Resour. Manag. Rev. 2014, 24, 313-329. [CrossRef]

73. Hahn, T.; Preuss, L.; Pinkse, J.; Figge, F. Cognitive frames in corporate sustainability: Managerial sensemaking with paradoxical and business case frames. Acad. Manag. Rev. 2014, 39, 463-487. [CrossRef]

74. Mariappanadar, S. Health harm of work from the sustainable HRM perspective: Scale development and validation. Int. J. Manpower 2016, 37, 924-944. [CrossRef]

75. Mariappanadar, S.; Kramar, R. Sustainable HRM: The synthesis effect of high performance work systems on organisational performance and employee harm. Asia Pac. J. Bus. Adm. 2014, 6, 206-224. [CrossRef]

76. Mariappanadar, S.; Aust, I. The Dark Side of Overwork: An Empirical Evidence of Social Harm of Work from a Sustainable HRM Perspective. Int. Stud. Manag. Organ. 2017, 47, 372-387. [CrossRef]

77. Freeman, R.E. Stakeholder Management: A Strategic Approach; Pitman: New York, NY, USA, 1984.

78. Wereda, W.; Paliszkiewicz, J.O.; Lopes, I.T.; Woźniak, J.; Szwarc, K. Intelligent Organization (IO): Towards Contemporary Trends in the Process of Management-Selected Aspects; Military University of Technology: Warszawa, Poland, 2016; ISBN 978-83-7938-134-0.

79. Mitchell, R.K.; Agle, B.R.; Wood, D.J. Toward a theory of stakeholder identification and salience: Defining the principle of who and what really counts. Acad. Manag. Rev. 1997, 22, 853-886. [CrossRef]

80. Osranek, R.; Zink, K.J. Corporate human capital and social sustainability of human resources. In Sustainability and Human Resource Management: Developing Sustainable Business Organizations; Ehnert, I., Harry, W., Zink, K.J., Eds.; Springer: Berlin/Heidelberg, Germany, 2014; pp. 105-126, ISBN 978-3-642-37524-8.

81. Jamali, D. A stakeholder approach to corporate social responsibility: A fresh perspective into theory and practice. J. Bus. Eth. 2008, 82, 213-231. [CrossRef]

82. Docherty, P.; Kira, M.; Shani, A.B. What the world needs now is sustainable work systems. In Creating Sustainable Work Systems. Developing Social Sustainability, 2nd ed.; Docherty, P., Kira, M., Shani, A.B., Eds.; Routledge: London, UK, 2009; pp. 1-21, ISBN 978-0-415-77271-6.

83. Bowen, D.E.; Ostroff, C. Understanding HRM-firm performance linkages: The role of the "strength" of the HRM system. Acad. Manag. Rev. 2004, 29, 203-221.

84. Vihari, N.S.; Rao, M.K. Antecedents and Consequences of Sustainable Human Resource Management: Empirical Evidence from India. Jindal J. Bus. Res. 2018, 7, 61-85. [CrossRef]

85. Järlström, M.; Saru, E.; Vanhala, S. Sustainable human resource management with salience of stakeholders: A top management perspective. J. Bus. Eth. 2016, 152, 703-724. [CrossRef]

86. Gladwin, T.N.; Kennelly, J.J.; Krause, T.S. Shifting paradigms for sustainable development: Implications for management theory and research. Acad. Manag. Rev. 1995, 20, 874-907. [CrossRef]

87. Armstrong, M. Human Resource Management: A Case of Emperor's New Clothes? Pers. Manag. 1987, 19, 30-35. 
88. Lumpkin, G.T.; Brigham, K.H. Long-Term Orientation and Intertemporal Choice in Family Firms. Entrep. Theory Pract. 2011, 35, 1149-1169. [CrossRef]

89. Lumpkin, G.T.; Brigham, K.H.; Moss, T.W. Long-term orientation: Implications for the entrepreneurial orientation and performance of family businesses. Entrep. Reg. Dev. 2010, 22, 241-264. [CrossRef]

90. Laverty, K.J. Economic "short-termism": The debate, the unresolved issues, and the implications for management practice and research. Acad. Manag. Rev. 1996, 21, 825-860.

91. Jackson, S.E.; Renwick, D.W.; Jabbour, C.J.; Muller-Camen, M. State-of-the-art and future directions for green human resource management: Introduction to the special issue. German J. Hum. Resour. Manag. 2011, 25, 99-116. [CrossRef]

92. Zink, K.J. Designing sustainable work systems: The need for a systems approach. Appl. Ergon. 2014, 45, 126-132. [CrossRef]

93. Guerci, M.; Pedrini, M. The consensus between Italian HR and sustainability managers on HR management for sustainability-driven change-towards a 'strong'HR management system. Int. J. Hum. Resour. Manag. 2014, 25, 1787-1814. [CrossRef]

94. Hoeppe, J.C. Practitioner's View on Sustainability and HRM. In Sustainability and Human Resource Management: Developing Sustainable Business Organizations; Ehnert, I., Harry, W., Zink, K.J., Eds.; Springer: Berlin/Heidelberg, Germany, 2014; pp. 273-294, ISBN 978-3-642-37524-8.

95. Hirsig, N.; Rogovsky, N.; Elkin, M. Enterprise Sustainability and HRM in Small and Medium-Sized Enterprises. In Sustainability and Human Resource Management: Developing Sustainable Business Organizations; Ehnert, I., Harry, W., Zink, K.J., Eds.; Springer: Berlin/Heidelberg, Germany, 2014; pp. 127-152, ISBN 978-3-642-37524-8.

96. Nissan Motor Corporation. Nissan Motor Corporation Sustainability Report. 2017. Available online: https: //www.nissan-global.com/EN/DOCUMENT/PDF/SR/2017/SR17_E_All.pdf (accessed on 14 September 2018).

97. Kinman, G.; McDowall, A. Does work/life balance depend on where and how you work? EAWOPinPractice 2009, 3, 3-10.

98. Bauer, T.N.; Erdogan, B.; Taylor, S. Creating and Maintaining Environmentally Sustainable Organizations: Recruitment and Onboarding. Bus. Fac. Publ. Present. 2012, 28. Available online: https:/ /pdxscholar.library. pdx.edu/busadmin_fac/28 (accessed on 14 November 2018).

99. Opatha, H.H.D.N.P.; Arulrajah, A.A. Green human resource management: Simplified general reflections. Int. Bus. Res. 2014, 7, 101. [CrossRef]

100. Roy, M.J.; Thérin, F. Knowledge acquisition and environmental commitment in SMEs. Corp. Soc. Respons. Environ. Manag. 2008, 15, 249-259. [CrossRef]

101. Chan, E.S.; Hawkins, R. Application of EMSs in a hotel context: A case study. Int. J. Hosp. Manag. 2012, 31, 405-418. [CrossRef]

102. Berrone, P.; Gomez-Mejia, L.R. Environmental performance and executive compensation: An integrated agency-institutional perspective. Acad. Manag. J. 2009, 52, 103-126. [CrossRef]

103. Inkson, K.; Parker, P. Eco-careers: Expressing green values in working lives. In Readings in HRM and Sustainability; Clarke, M., Ed.; Tilde University Press: Prahran, Australia, 2011; pp. 22-35, ISBN 978-0-7346-1101-7.

104. Kiron, D.; Kruschwitz, N.; Haanaes, K.; von Streng Velken, I. Sustainability nears a tipping point. MIT Sloan Manag. Rev. 2012, 53, 69-74. [CrossRef]

105. Henkel Sustainability Report. 2017. Available online: https://www.henkel.com/sustainabilityreport-2017. pdf (accessed on 12 September 2018).

106. Joensson, T. A multidimensional approach to employee participation and the association with social identification in organizations. Empl. Relat. 2008, 30, 594-607. [CrossRef]

107. Glew, D.J.; O'Leary-Kelly, A.M.; Griffin, R.W.; Van Fleet, D.D. Participation in organizations: A preview of the issues and proposed framework for future analysis. J. Manag. 1995, 21, 395-421. [CrossRef]

108. Wilpert, B. A view from psychology. In Organizational Participation: Myth and Reality; Heller, F., Pusic, E., Strauss, G., Wilpert, B., Eds.; Oxford University Press: Oxford, UK, 1998; pp. 40-64.

109. World Economic Forum. Available online: https://www.weforum.org/ (accessed on 10 October 2018).

110. Honda Sustainability Report. Available online: https://world.honda.com/sustainability/report/pdf/2017/ Honda-SR-2017-en-all.pdf (accessed on 11 June 2018). 
111. Hansson, B. Company-based determinants of training and the impact of training on company performance: Results from an international HRM survey. Pers. Rev. 2007, 36, 311-331. [CrossRef]

112. Cappelli, P. Talent management for the twenty-first century. Harv. Bus. Rev. 2008, 86, 74-81.

113. Carvalho, A.; Cabral-Cardoso, C. Flexibility through HRM in management consulting firms. Pers. Rev. 2008, 37, 332-349. [CrossRef]

114. Wright, P.M.; Snell, S.A. Toward a unifying framework for exploring fit and flexibility in strategic human resource management. Acad. Manag. Rev. 1998, 23, 756-772. [CrossRef]

115. Mayne, L.; Tregaskis, O.; Brewster, C.A. comparative analysis of the link between flexibility and HRM strategy. Empl. Relat. 1996, 18, 5-24. [CrossRef]

116. Akingbola, K. Contingency, fit and flexibility of HRM in nonprofit organizations. Empl. Relat. 2013, 35, 479-494. [CrossRef]

117. López-Cabrales, A.; Valle, R.; Galan, J.L. Employment relationships as drivers of firm flexibility and learning. Pers. Rev. 2011, 40, 625-642. [CrossRef]

118. Brown, M.; Shields, J. Reward management: Rethinking individual performance pay. In Readings in HRM and Sustainability; Clarke, M., Ed.; Tilde University Press: Prahran, Australia, 2011; pp. 64-81, ISBN 978-0-7346-1101-7.

119. Janssens, M.; Zanoni, P. Many diversities for many services: Theorizing diversity (management) in service companies. Hum. Relat. 2005, 58, 311-340. [CrossRef]

120. Harrison, D.A.; Price, K.H.; Bell, M.P. Beyond relational demography: Time and the effects of surface-and deep-level diversity on work group cohesion. Acad. Manag. J. 1998, 41, 96-107.

121. Roberge, M.É.; Van Dick, R. Recognizing the benefits of diversity: When and how does diversity increase group performance? Hum. Resour. Manag. Rev. 2010, 20, 295-308. [CrossRef]

122. Starbucks. Available online: https://www.starbucks.com (accessed on 10 September 2018).

123. Porter, M.E.; Kramer, M.R. The link between competitive advantage and corporate social responsibility. Harv. Bus. Rev. 2006, 84, 78-92.

124. Kira, M.; Lifvergren, S. Sowing seeds for sustainability in work systems. In Sustainability and Human Resource Management: Developing Sustainable Business Organizations; Ehnert, I., Harry, W., Zink, K.J., Eds.; Springer: Berlin/Heidelberg, Germany, 2014; pp. 57-81, ISBN 978-3-642-37524-8.

(C) 2018 by the authors. Licensee MDPI, Basel, Switzerland. This article is an open access article distributed under the terms and conditions of the Creative Commons Attribution (CC BY) license (http:/ / creativecommons.org/licenses/by/4.0/). 


\title{
How to Make a Sustainable Manufacturing Process: A High-Commitment HRM System
}

\author{
Jihye Park ${ }^{1}$, Dawoon Jung ${ }^{2, *}$ and Pyoungsoo Lee ${ }^{3, *}$ \\ 1 Korea University Business School, Korea University, Seoul 02841, Korea; ahjilove@korea.ac.kr \\ 2 Dongwu Business School, Soochow University, Suzhou 21500, China \\ 3 Department of Business Administration, Kyonggi University, Gwanggyosan-ro, Yeongtong-gu, \\ Suwon 16227, Korea \\ * Correspondence: dwjung@suda.edu.cn (D.J.); pyoungsoo@kyonggi.ac.kr (P.L.); Tel.: +82-31-249-9457 (P.L.)
}

Received: 6 March 2019; Accepted: 9 April 2019; Published: 17 April 2019

\begin{abstract}
The primary purpose of this study is to investigate the relationship between highcommitment human resource management (HCHRM) practices and process improvement activities (i.e., manufacturing flexibility) by utilizing the theory of social exchange. We conducted an empirical study to discover the links between social exchange theory and process management from an HRM perspective. For the empirical investigation, we used data from 601 manufacturing enterprises provided by the Ministry of Trade, Industry, and Energy in South Korea. The research is conducted based on employees' capabilities for process management as a mediator in the analysis of the impact of the HCHRM system on manufacturing flexibility (i.e., internally-driven and externally-driven flexibility). The results of the study show that the HCHRM system ultimately explains manufacturing flexibility through enhancement of employees' capabilities.
\end{abstract}

Keywords: manufacturing flexibility; high-commitment HRM system; social exchange theory

\section{Introduction}

The fourth industrial revolution, generally referred to as Industry 4.0, is expected to have a significant impact on manufacturing industries, as it creates faster changes in technology and market conditions. Manufacturers are facing a moment of change that this paradigm shift will generate. However, industry 4.0 is not only an obstacle but a formidable opportunity for manufacturers that are capable of keeping up with the new environment, while threatening those preserving the status quo [1]. Thus, appropriate responses to existing or upcoming changes are essential to achieving sustainable, competitive advantages for manufacturers. Since these changes usually accompany an increase in uncertainty due to changing customer needs, taking flexible actions in the face of changes, and ultimately creating sustainable business value, become more crucial in this era [2].

In today's business environment, represented by rapid market change and technological acceleration, researchers and practitioners recognize that manufacturing flexibility is critical for building sustainable manufacturing because the flexibility of manufacturing process enables firms to achieve customization, even in large-scale production, without sacrificing cost efficiency. Since manufacturing flexibility is defined as the ability that enables firms to cope with market uncertainty effectively $[3,4]$, prior research has focused on the technological aspects of manufacturing flexibility, or on the corresponding strategic fit. For instance, Gupta and Somers [5] found that proper business strategy helps increase manufacturing flexibility and achieve better organizational performance. Gerwin [6] also suggested links between manufacturing strategy, manufacturing flexibility, and performance in response to environmental uncertainties. Cousens et al. [7] suggested a framework to enable manufacturers to establish a competitive capability for flexible manufacturing. A recent study has shown the influence of manufacturing flexibility on business models and firm performances, 
considering their contextual fit with the market environment [8]. Besides, Chen et al. [9] considered the impact of manufacturing flexibility on the product-process relationship that resulted from technological evolution and cyclical development. Kotha and Swamidass [10] investigated the interaction effect of strategy and advanced manufacturing technology on growth and profitability. In sum, we can find a positive relationship between manufacturing flexibility and sustainable competitive advantage, in terms of increasing efficiency internally and satisfying customers externally. To put it concretely, if a firm has a high level of manufacturing flexibility, the firm can make good performance (i.e., profits or growth) which is known as the source of firm's sustainability. It is important to consider that manufacturing flexibility makes a firm likely to achieve both generic goals (i.e., cost efficiency and customer satisfaction) without compromise. Based on this good performance, the firm with a high level of manufacturing flexibility finds a way of sustainable improvement. Thus, manufacturing flexibility contributes to maturing sustainable manufacturing processes because sustainable manufacturing processes connote an integrative view for economic (i.e., profitability and productivity), social, and environmental stewardship to generate the firm's sustainable competitive advantage [11].

However, the implementation of a new technology or particular strategy should be applied to firms with a reasonable amount of resources (e.g., time, money, or effort), and their success will depend on the human resources that are responsible for performing the task. In other words, it is people who do the real work, even though highly advanced technologies or particular business strategies are involved in the manufacturing system. Therefore, appropriately trained and well-managed employees are a vital factor in fueling an improvement in manufacturing flexibility.

Without a doubt, one of the most critical resources in a business unit is human resources. Our topic begins with the following question, which is old and perhaps somewhat banal. Are human resources consumed or developed? Some researchers in the strategic human resource management (HRM) field which is mainly interested in a firm's financial outcomes have assumed that human resources can be consumed or even exploited like other substitutive resources [12]. In reality, some people also believe that human resources, like other resources, have to be reduced to improve productivity or efficiency in the economic sense. For example, many manufacturers predict that technological advances in the fourth industrial revolution will undermine the importance of human resources because technology will replace most human workers. This shows that human resources are still perceived in a quantitative, not qualitative, way. However, other researchers in strategic HRM that emphasizes the human factor or sustainability of HRM have argued that human resources are not cost rather investment objects to be developed for a firm's sustainability $[13,14]$. As Ehnert and Harry [15] pointed out, the view that human resources are consumed is too short-term oriented and not enough to see the human resources' distinct features whereas a developmental view is based on a long-term oriented and considering people in organizations as a source of competitive advantage to make the firm sustainable. In the developmental view of human resources, technology will not simply replace human workers rather human takes other roles that only people can conduct in this era. Therefore, in this research, we follow the literature that assumes human resources can be developed and reproduced.

As noted by Bányai et al. [16], the human factor cannot be neglected in manufacturing. Thus, we can presume that the manufacturing flexibility, the measure of operational performance, will vary depending on how firms leverage the human resources. Barney [17] showed that corporate human resources are one of the most important sources of sustained competitive advantage, and Youndt et al. [18] also demonstrated that human resource management (HRM) has a crucial role in developing employees' capabilities to achieve organization-level goals. Accumulated research focusing on HRM configurations fitted with the firm's environment, and their systematic effect on organizational-level outcomes, is defined as strategic HRM [19]. In particular, the high-commitment HRM system (HCHRM), a type of strategic HRM system, refers to a set of HRM policies and procedures that influence employee attitude (i.e., commitment) and motivation toward their work and organization [20]. In the literature, HCHRM is known as practices that contribute to greater achievements in manufacturing (e.g., higher productivity) [21-23], successful implementation of 
integrated management in manufacturing [24], and lower scrap rates [19]. However, while there are many studies on the relationship between HRM practices, specific business competitive strategies, and their outcomes [25-27], there are few studies on the relationship between HCHRM and manufacturing flexibility. Moreover, it is hard to find literature investigating the mediating role of employees in the HCHRM-manufacturing flexibility relationship. To fill this gap, we empirically examine the link between two business functions, HRM and manufacturing (i.e., production), while considering HCHRM and manufacturing flexibility. Thus, the main purpose of this study is to investigate the detailed mechanism through which HCHRM systems influence manufacturing flexibility. In addition, we present additional implications for the analysis of this relationship by incorporating the mediating effect of employees' capabilities. We draw the theoretical framework as shown in Figure 1.

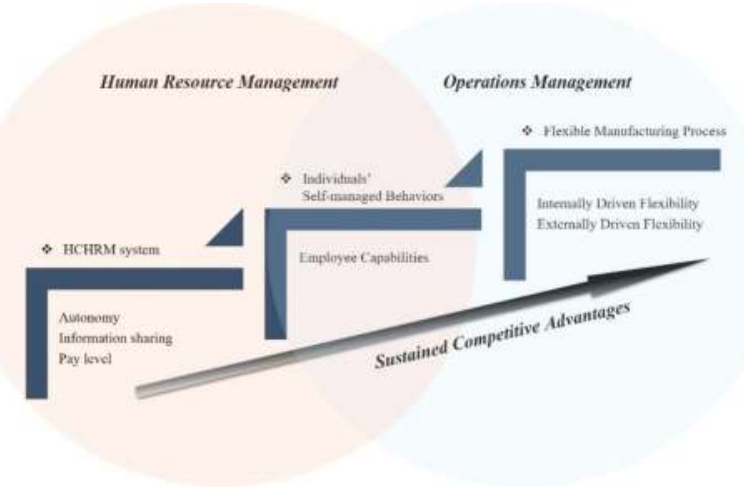

Figure 1. Theoretical framework.

We expect this study to make theoretical and empirical contributions in three ways. First, we advance the strategic HRM literature by focusing on the HCHRM system. The HCHRM system integrates several HR practices (e.g., autonomy, information sharing, pay level, etc.) that enhance manufacturing outcomes and organizational performance, by fostering employees' capabilities resulted in treating employees as investment objects. Thus, it is important for firms to motivate employees to work appropriately, since manufacturing employees may create manufacturing effectiveness. The HCHRM system can enhance employees' efforts and ability, especially by motivating them internally. According to social exchange theory [28], employees respond to employers' favor not because of economic transactions, but due to long-term trust relationships. That is, people in organizations try to work more and harder if the organizations are sufficiently supportive of them, implicitly or explicitly, by instituting practices that satisfy employees' internal needs [29]. Therefore, managing employees becomes an important issue for the firm's sustainable operations. With regard to the previous research, we suggest that the HCHRM system can be an essential component of firm sustainability.

Second, we advance the understanding of the literature on manufacturing flexibility by investigating its relationship with the HCHRM system. Organization-wide practices (e.g., discretionary level, information sharing by the top management team (TMT), HR practice consistency, etc.) directly or indirectly influence manufacturing processes including enhancing manufacturing flexibility. Following D'Souza and Williams' typology [30], we examine the HRM system's effect, not only on manufacturing flexibility during the firm's manufacturing processes (internally-driven flexibility), but also on manufacturing flexibility to satisfy customer needs (externally-driven flexibility). This typology will help us to understand the HCHRM-manufacturing flexibility relationship in terms of competitive strategy (i.e., the generic strategy of the firm); that is, HCHRM makes firms increase the sustainable competitive advantage by making their manufacturing processes flexible in response to 
internally or externally generated needs. Thus, we can suggest a novel approach to manufacturing flexibility literature.

Finally, we offer a new mechanism to explain how HCHRM practices impact on manufacturing flexibility. Employees' capabilities take a key role in the mediated relationship between HCHRM and manufacturing flexibility. As mentioned, people take a pivotal role in strategic or policy implementation during the manufacturing process. Employees' capabilities can be regarded as a proximal outcome developed by HCHRM practices, and in the end, they allow the manufacturing system more flexibility. However, empirical research examining this relationship is lacking. We suggest that employees' capabilities are a mediator that helps to understand the positive relationship between HCHRM practices and manufacturing flexibility.

The rest of this article proceeds as follows: The next section presents the theoretical background, reviewing the relevant literature, and articulates our research hypotheses. Section 3 describes the measures, sample, and data. Section 4 presents the statistical results. In Section 5, we conclude the paper by highlighting our contributions and limitations.

\section{Theoretical Backgrounds}

\subsection{HCHRM: A Source of Firm Sustainability}

A great deal of research is conducted in the field of strategic HRM, which focuses on how the role of HRM aligns with a firm strategy in continually changing environments [19]. According to Boselie et al. [31], HRM refers to attentively designed combinations of practices for managing employees, coordinated to enhance organizational effectiveness and boost performances. Researchers in the field of strategic HRM have concentrated on the effect of a particular bundle of HRM practices aligned with the firm's goal or its context, not on the effect of each HRM practice. According to Arthur [19], there are two distinct HRM systems: control and commitment. A control HRM system monitors or enforces employees with strict rules and steps they should follow, and rewards employees based on quantitative performance appraisals. In addition, the control HRM system enhances organizational or individual outcomes only when the manager has complete knowledge of the field or perfect monitoring-reward policies [19]. On the other hand, a commitment HRM system (i.e., the HCHRM system) draws on desired employee behaviors and attitudes by reconciling individual goals with organizational goals [19]. Moreover, the HR practices that represent the HCHRM system are combined with organizational-level policies that encourage employees to be intrinsically motivated and committed to their work [20]. Specifically, practices based on the HCHRM system include employment security, selective hiring, incentive compensation, comparatively higher than industry-average pay levels, developmental appraisals, extensive training and development activities, employee participation, pervasive information sharing, discretion and decentralization, and flexible work arrangements $[18,24,32,33]$. The HCHRM system has been known to lead to improvements in various outcomes such as financial performance [21,23,34,35], productivity [21-23], integrated manufacturing management (advanced manufacturing technology, total quality, just-in-time) [24], scrap rate [19], turnover or retention [21-23], employee commitment [20,36], job satisfaction [36], and employees' AMO (ability, motivation, and opportunity) [23].

According to Ehnert and Harry [15], there is no 'consistent' research in sustainable HRM. Moreover, the research on sustainable HRM is not integrative yet, and there are various related concepts, such as sustainable HRM, green HRM, socially responsible HRM, or ethical HRM [14]. Regardless of how it is called, these concepts share perceptions about sustainable HRM, and researchers in this field have been attempted to clarify what the socially responsible corporate behaviors are. According to the literature, there are two different foci in the socially responsible corporate behaviors: a focus on internal employees and a focus on external stakeholders. Diaz-Carrion et al. [37] argued that the employee focused firm's behaviors (i.e., a firm's activities for increasing employee satisfaction) make a firm get sustained competitive advantages whereas the contextual focused firm's behaviors (i.e., a firm's 
activities for following market or institutional pressures) help a firm to adopt sustainable HRM as a response of national pressures. Similarly, Jamali et al. [38] pointed out that internal level corporate social responsibility (CSR) includes organization-wide behaviors related to "employees' skill and education, workplace safety, working conditions, human rights, equity considerations, equal opportunity, health and safety, and labor rights" (p. 446) while external level CSR considers responsibility for social and environmental citizenship. The research on sustainable HRM, ultimately, stresses not only to fulfill social or environmental standards but also to satisfy employees in organizations as an end (e.g., considering employees' well-being), not as a mean [14,39]. In other words, we can understand that HCHRM follows the principle of CSR (e.g., transparency, empowerment, non-discrimination, objectivity, etc.) as sustainable HRM does [37]. Thus, HCHRM system grounded in the high-performance HRM can be a conventional, but more intensive approach, going along with sustainable HRM, to explain how HRM works for long-term sustainability.

The HCHRM system works based on social exchange theory [28]. Social exchange refers to "favors that create diffuse future obligations, not precisely specified ones, and the nature of the return cannot be bargained about but must be left to the discretion of the one who makes it" [28] (p. 93). It is different from an economic exchange, which is a relatively quick, small, and monetary-based transaction [40]. Moreover, social exchange assumes the norm of reciprocity, meaning "people should help those who have helped them" [41] (p. 171). In other words, people in social exchange relationships consider some exchanges to be based on long-term reciprocal transactions, not on short-term simple mercantile deals, so they behave reciprocally towards others in the social exchange relationship [40,42,43]. Putting this theory into our argument, the HCHRM system builds the social exchange relationship between the organization and its employees, because the system consists of practices that let employees feel autonomous, fairly treated, and well-regarded. Employees who perceive the organization's good faith think that they have received something from the organization and ought to do something favorable for the organization to pay back its kindness. Thus, they are more likely to develop into well-trained, skillful workers, and to make great achievements in their jobs.

There is a growing literature on corporate sustainability that connects issues on the sustainability to economic motivations. These studies commonly explain that a firm's consideration for society and the environment is rooted in the desire for higher economic efficiency, and thus corporate social and/or environmental strategies are perceived as a means to enhance financial outcomes. However, this line of research is challenged and questioned by scholars who consider corporate sustainability performance from a more integrated perspective. Hahn and Figge [44] claimed that the aforementioned approach impairs precise decision making based on a comprehensive assessment, as it results in a priori predominance of just one facet of sustainability. While we adopt this newly emerging view, we consider human resources as one source of corporate sustainability that contributes to enhancing the value of firms in the long run. In other words, we argue that employees' capabilities to perform in their positions fuels corporate sustainability by building and maintaining competitive advantages.

Although it is not an easy task, requiring a long wait and massive effort, having quality human resources is critical for a firm's sustained competitiveness. It is required to have HRM practices that motivate employees internally, to develop long-lasting and trustworthy capabilities. Besides, it is also critical to be consistent in those practices to achieve the desired outcome; that is, implemented practices should fit together to reach organizational goals [45]. Thus, it is worth it to contemplate implementing an HCHRM system in the workplace, because it is a well-aligned practice that emphasizes personal responsibility, independence, and employee empowerment. Given this discussion, we consider a HCHRM system as a set of intrinsic motivation-enhancing practices, coupled with fair assessment and compensation, for cultivating human resources in pursuit of corporate sustainability.

\subsection{Manufacturing Flexibility and HCHRM}

Demand uncertainty is one of the most significant challenges in manufacturing. The ability of a manufacturing system to respond appropriately to demand variability determines the stability 
and profitability of a business unit [2]. Such an ability is defined as manufacturing flexibility in the literature; that is, manufacturing flexibility enables firms to cope effectively with uncertainties coming from changes in customer requests and varying market conditions [3,4]. Thus, there is a consensus that honing flexibility is a sterling, strategic weapon for modern manufacturing, in that it contributes to the stability and profitability of a business unit, especially given a complex, competitive, and fast-changing market. In other words, manufacturing flexibility is closely associated with the firm's sustainability because a firm that has a flexible manufacturing process can earn more profits pursuing both cost-efficiency and customer satisfaction without compromise. Based on this economic sustainability, firms can expand their contributions to other stakeholders.

From early research in the eighties, a considerable literature has accumulated on the multi-dimensionality of manufacturing flexibility. While Sethi and Sethi [45] identified 11 dimensions of flexibility, Gerwin [6] suggested taxonomy of seven dimensions. These are the ability to: produce a variety of products with fast set-ups (mix flexibility), change the products currently being offered into new ones in a short time (changeover flexibility), rapidly implement minor design changes (modification flexibility), change production volume at an aggregate level (volume flexibility), alter the sequence of jobs (rerouting flexibility), adapt to unexpected variations in input materials (material flexibility), and the ability to incorporate the other six flexibilities (flexibility responsiveness). Contrary to early studies that provide sophisticated classifications, D'Souza and Williams [30] proffered four dimensions of manufacturing flexibility that fall into two generalized dimensions: externally and internally driven. Externally driven dimensions include volume and mix flexibilities that are closely related to the ability to adjust the outputs of a process (e.g., quality or product mix). Internally driven dimensions, including process and materials handling flexibilities, are associated with the ability to accommodate a manufacturing process even during unpredictable events such as machine breakdowns. Similarly, Zhang et al. [46] classified the various dimensions of manufacturing flexibility into flexible competence and capability. Zhang et al. [46] also empirically found that flexible competence antecedes flexible capability, where flexible competence consists of the flexibilities that accommodate the flow of jobs in the manufacturing process, and flexible capability includes the volume and mix flexibilities that heavily associate with customer satisfaction. Given this line of research, we consider these two dimensions of flexibility (externally and internally driven) as the measures of performance in manufacturing.

To establish either internally or externally flexible practices in manufacturing processes, managing employees is a critical success factor. The people in firms have been strongly emphasized as a source of the firms' sustained competitive advantage [17]. Since a pivotal role in HRM is to develop the relationship between employees' capabilities and the performance of the firm [18], internal or external manufacturing flexibility is achieved by well-managed employees suited to the manufacturing processes of the firm.

Therefore, we expect that the HCHRM system will positively impact a firm's process management, in particular with regard to manufacturing flexibility. As mentioned above, internally driven flexibility requires improved process management practices, such as eliminating bottlenecks, rapid changes in resource allocation, and quick adjustments of operations [2]. These practices are attributed to employees' quick judgments and responses derived from discretionary work decisions, explicit or implicit work knowledge, intrinsic motivation, and experience levels. In addition, autonomous decision making and work-related knowledge also contribute to a firm's externally driven flexibility, which requires rapid responses to satisfy customer needs. Consequently, the HCHRM system helps firms increase their manufacturing flexibility level since the HCHRM system encourages employees to perform autonomous decision-making, intensive training, incentive compensation related to performance, and sharing core information.

However, there is one thing we should ponder. Although the HCHRM system finally makes manufacturing flexible, the implementation of HRM practices in the workplace must entail a medium, namely people. As pointed out in Section 2.1, the HCHRM system develops capable employees. Thus, 
employees' capabilities, fostered by the HRM system, become a link between the HCHRM system and internally or externally driven manufacturing flexibility.

\subsection{Employees' Capabilities}

Human capital is pivotal in a high-commitment organization, composing a source of businesses' competitive advantage [47-49]. It is more and more apparent that value creation depends on employee competence, especially in new firms that have invested in advanced manufacturing processes and technologies [18,50]. Accordingly, employees' capabilities can be defined as their abilities to solve problems, make decisions, and handle overall processes in manufacturing management. Considering the HCHRM system, the commitment perspective has focused on people's intrinsic motivations, endogenous commitments, or enhanced satisfaction. It implies that the HCHRM system treats employees not as instruments, but as goals. Therefore, the term "capability," which refers to "the ability of human beings to lead lives they have reason to value and to enhance the substantive choices they have" [51] (p. 1959), is more appropriate to comprehend the HCHRM system. As Sen [51] has clarified, capability includes the meaning, not only of economic production (which the "human capital" view usually highlights) but also of social development. This argumentation can be applied to sustainability; that is, employees' capabilities enhance a firm's economic sustainability based on increasing the firm's efficiency. Moreover, developing employees' capabilities can be regarded as one activity of increasing a firm's social sustainability. Thus, developing employees' capabilities directly or indirectly contributes to the firm's sustainability. In line with this perspective, high-commitment firms utilize HR practices that develop and support employees who are self-managing or self-regulating [22]. In other words, as we have discussed, the HCHRM system develops employees in terms of self-management (e.g., autonomous decision making, self-regulated work scheduling, or discretionary participation) because the system promotes individuals' self-managed behaviors, based on practices like secure employment, selectivity, competitive compensation, developmental appraisal, structured training, participatory activities, bilateral information sharing, autonomy, and flexible work arrangements [18,24,32,33]. Finally, the HCHRM system fosters the employee capabilities required in organizations. This leads to our first hypothesis.

Hypothesis 1 (H1). The HCHRM system is positively related to employees' capabilities.

The employee capabilities cultivated by the HCHRM system are likely to be remarkable in the field of process management, especially manufacturing flexibility. Manufacturing flexibility, by definition, requires autonomous decision-making, abundant skills and work knowledge, and executive ability, even though the types of manufacturing flexibility are distinct (internally versus externally driven). These requirements are more likely to be satisfied when the firm implements a higher level of commitment-centered HR practices that advance the employees' capabilities. Not surprisingly, reinforcing employees' capabilities increases the level of both internally driven and externally driven manufacturing flexibility in the firm. Therefore, we develop the following hypotheses:

Hypothesis 2a (H2a). Employee capabilities are positively related to the level of internally driven manufacturing flexibility in the firm.

Hypothesis $\mathbf{2 b} \mathbf{b} \mathbf{H} \mathbf{2 b})$. Employee capabilities are positively related to the level of externally driven manufacturing flexibility in the firm.

With Hypotheses 1 and 2, we propose that employee capability improvement is the mechanism through which the HCHRM system enhances the firm's level of manufacturing flexibility. That is, if a firm implements HCHRM practices, the employees of the firm improve in terms of their abilities, motivations, and opportunities. In turn, they perform better work with their enhanced capabilities. Virtuous cycles between the firm and the employees, so-called reciprocity, are more likely to be planted 
in a firm utilizing the HCHRM system $[40,42,43]$. This mechanism reflects the central argument of social exchange theory. From a social exchange perspective, when people think that their company is furnishing them with a system of interconnected and well-designed HR practices, they are more likely to be committed to the organization and more willing to perform, not only in-role behaviors but also extra-role ones, well [52]. Through this mechanism, individuals' abilities for work enhance reciprocal relationships [53].

In conclusion, well-developed employees contribute to organizational performance, especially organizations facing abrupt changes in internal or external circumstances. This means that reinforcing employees' capabilities with an HCHRM system is more likely to lead to improvements in a firm's level of manufacturing flexibility. Therefore, instituting HCHRM practices is not a costly practice, but rather a long-term investment for the firm. Based on social exchange theory, we predict the following:

Hypothesis 3a (H3a). Employee capabilities partially mediate the relationship between HCHRM and internally driven manufacturing flexibility.

Hypothesis $3 \mathbf{b}(\mathbf{H} 3 \mathbf{b})$. Employee capabilities partially mediate the relationship between HCHRM and externally driven manufacturing flexibility.

To sum up, this paper proposes to investigate a research model (see Figure 2) in which HCHRM systems and employees' capabilities are identified as critical antecedents for managing processes in the production line more flexibly.

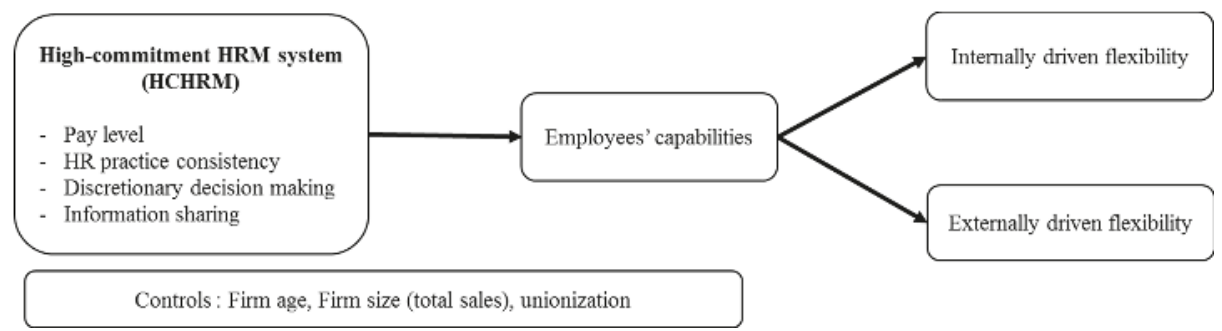

Figure 2. Research model of this study.

\section{Methods}

\subsection{Measurements}

\subsubsection{Dependent Variables: Manufacturing Flexibility}

We followed the manufacturing flexibility taxonomy of D'Souza and Williams [30]: internally driven flexibility and externally driven flexibility. Internally driven flexibility is operationalized by process flexibility, focusing on efficiency improvement during manufacturing processes, such as the effort that firms use to try to save preparation time or the duration of fixed product plans, to employ a small lot system, or to coordinate work processes flexibly. Externally driven flexibility is specified by product flexibility, concentrating on firms' competences in modifying their product lines when the environment (e.g., customers' needs, industrial forces, economic boom, and bust, etc.) changes.

We measured the two distinct concepts of internally driven flexibility and externally driven flexibility, employing several items that were developed and validated in previous studies. Specifically, we asked four questions to measure internally driven flexibility. Modifying items from D'Souza and Williams [30], they were: "our firm tries to reduce lot sizes," "our firm tries to shorten the preparing time for molds or tools," "our firm tries to shorten the fixed cycle time of production planning," and "continuing production is possible, based on coordinating the work processes when production 
facilities are broken." Externally driven flexibility can be captured by four different items, such as "our firm can produce a variety of products," "our firm smoothly deals with the customers' modification of orders," "our firm rapidly responds the radical change of production," and "our firm can properly react to the product changes." These items are derived from Avittathur and Swamidass [54], with contextual modifications.

Each manager in the manufacturing department evaluated their firm's manufacturing flexibility level compared to the industry average using a seven-point Likert scale (1: relatively very low, $\sim 4$ : average, $\sim$ : relatively very high).

\subsubsection{Independent Variable: HCHRM System}

According to Whitener [20], the HCHRM system can be defined as configurations of HR practices that enhance organizational effectiveness by making employees highly involved in their work. Following prior studies, we chose four sub-dimensions of HCHRM: pay level compared to industry average, HR practice consistency, employees' work autonomy level, and information sharing by the TMT. An HR manager in each firm appraised its pay levels and HR practice consistency, while a manufacturing manager evaluated the autonomy level of the manufacturing workers and the level of information sharing from the TMT. Specifically, the item for pay level was "the pay level for the production workers of our company is competitive relative to its market competitors (1: relatively very low, 7: relatively very high)," adapted from Chiang et al. [55]. For HR practice consistency the items were "how does the skillfulness/training and development/multi-functional/participation level of the production workers in your company influence their performance appraisal, promotion, or compensation? (1: no influence at all, 7: very highly influenced)," four items developed for this study. For autonomous decision making, the items were "this organization provides manufacturing workers with a role and responsibilities for their process," "this organization allows manufacturing workers to make their own decisions," and "manufacturing workers solve normal problems of their own accord (1: relatively very low, 7: relatively very high)," three items from Kwon et al. [42] with contextual modifications. The items for TMT information sharing were "my company provides employees with timely business information," "my company communicates the company's key decisions to the employees without delay," and "my company shares the firm's strategies and goals with employees, and the employees understand them well (1: strongly disagree, 7: strongly agree)," three items modified from $\mathrm{Wu}[56]$.

\subsubsection{Mediating Variable: Employees' Capabilities}

We used the level of employee capabilities as a proximal outcome of the HCHRM system. Improvements in the manufacturing flexibility level are derived from the company's HRM system by enhancing the production workers' abilities. An HR manager from each company evaluated the capability level of their manufacturing workers, based on four criteria: knowledge or skill level, work proficiency, work-related problem-solving ability, and overall ability. A Likert seven-point scale was used, in a way similar to the flexibility measures (1: relatively very low, $\sim 4$ : average, $\sim 7$ : relatively very high).

\subsubsection{Control Variables}

\section{- Firm age}

Firm age is a determinant of firm growth and the possibility of firm dissolution [57]. Young firms are more likely to face risks resulting from deficiencies in resources and capabilities than are older firms [58]. A lack of resources and capabilities can lead to a firm's early failure, known as the "liability of newness," which refers to the drastically increased mortality rate in the early years of a firm [58]. This phenomenon implies that firm age matters to firm performance, not only financially, but also on the manufacturing side. That is, firms are likely to have different levels of process management, 
depending on the age of the firms. Thus, we considered each firm's age in our analysis, to control for this effect. However, since the age ranges given for firm age vary widely in the data, we took the natural log of the firm age in the regression function. If the firm's age was less than one year, we entered it as zero.

\section{- Firm size}

Firm size plays a role in firm resource deficiencies that is similar to firm age [57]. A larger firm with good financial performance (i.e., high sales or profit), is more likely to have abundant resources and capabilities from inside and outside the company [59]. Employing abundant resources and capabilities represents the firm's ability to invest in products or process improvements. It is a reasonable assumption that large firms can afford the expense of instituting novel technologies, implementing new HR practices, or fostering a desirable organizational culture [60]. As Dang et al. [61] pointed out, choosing a proper firm size measure as a control variable is important because each firm size measure reflects different aspects of the firm size. In the literature, various proxies represent firm size such as total assets, market capitalization, total sales, or a total number of employees [61]. Among these proxies, total sales is a proper measure of this study since total sales reflects product market competition [61] and manufacturing flexibility can be influenced by product market characteristics. Manufacturing flexibility, by definition, is sensitive to the internal (e.g., process defects in the company) or external changes (e.g., customer preferences transition). Total sales can represent to overcome these internal or external changes as the firm in the turbulent circumstances survives recording the higher level of total sales. Thus, we used the log form of total sales in 2012 as a firm size measure [59-61].

- Union representation

Unions can affect employees' competencies and attitudes, as well as firms' decision-making processes and their organizational culture. This is because employees in unionized settings are more likely to remain at the same workplace, to have secure employment, and to accumulate explicit or implicit work knowledge [22,32]. Therefore, we controlled for the union effect (if the firm had a union, then we coded it as one).

\subsection{Data Collection and Sample}

We used the manufacturing productivity survey (MPS) data collected by the Korean Productivity Center in 2012, entrusted by the Ministry of Trade, Industry, and Energy in South Korea. The sample was composed of 2218 firms in the first stage, based on the KIS-LINE database, which provides Korean enterprises' financial and credibility information, of the NICE Information Service. 601 enterprises $(27 \%)$ responded to the survey. The original MPS survey questionnaire was divided into seven categories: financial management, human resources management, planning management, sales planning, production management, purchasing management, and research and development. Divisional managers responded to the questionnaire. Responses from different departments were helpful for reducing the risks of falling into a single source variance. For this study, the responses of HR management and production teams were used for statistical analysis. Table 1 gives the sample breakdown. In terms of firm age, firms established for 10 to 15 years were the plurality at $24.13 \%$, and 15- to 20-year-old firms were next at $18.30 \%$. By total sales in $2012,39.43 \%$ of the firms recorded sales between KRW 10 billion to KRW 30 billion, and firms with KRW 30 billion to KRW 50 billion in sales were the next largest group (15.81\%). The majority of firms (83\%) had no union. 
Table 1. Profile of companies.

\begin{tabular}{cccc}
\hline Characteristics & Item & Number & $\begin{array}{c}\text { Percentage of the } \\
\text { Sample (\%) }\end{array}$ \\
\hline \multirow{3}{*}{ Firm age (years) } & $0 \sim 5$ & 56 & 9.32 \\
& $5 \sim 10$ & 90 & 14.98 \\
& $10 \sim 15$ & 145 & 24.13 \\
& $15 \sim 20$ & 110 & 18.30 \\
& $20 \sim 25$ & 62 & 10.32 \\
& $25 \sim 30$ & 54 & 8.98 \\
& 30 or longer & 84 & 13.97 \\
\hline \multirow{2}{*}{ Sales in 2012 (\$) } & $0 \sim 5$ billion & 33 & 5.49 \\
& 5 billion 10 billion & 66 & 10.98 \\
& 10 billion 30 billion & 237 & 39.43 \\
& 30 billion 50 billion & 95 & 15.81 \\
& 50 billion 100 billion & 81 & 13.48 \\
& 100 billion 300 billion & 58 & 9.65 \\
& 300 billion or more & 31 & 5.16 \\
\hline \multirow{2}{*}{ Unionization } & Yes (1) & 102 & 17.00 \\
& No (0) & 499 & 83.00 \\
\hline
\end{tabular}

\subsection{Reliability and Validity}

Before testing our hypothesized model, we assessed three types of validity: content validity, convergent validity, and discriminant validity. Content validity is established by confirming consistency between the measurement items and the extant literature. Threats regarding content validity are minimized by using established questionnaires from the literature. We assessed convergent validity by examining composite reliability (CR) and average variance extracted (AVE) from the measures [62]. Although many studies have used 0.5 as the reliability threshold for their measures, 0.7 is the recommended value for a reliable construct. As shown in Table 2, our CR values range from 0.864 to 0.925 . For the AVE by item, a score of 0.5 indicates acceptability [62]. Table 2 also shows that the AVEs for our measures range from 0.615 to 0.760 , which are above the acceptable value. All of our Cronbach's $\alpha$ values, a traditional reliability indicator, are also acceptable (above 0.70 ) since the reliability coefficients indicated that all scales have an acceptable level of internal consistency. In addition, Table 2 exhibits the measurement loadings of our research model, resulted from confirmatory factor analysis (CFA). The standardized loadings ( $\lambda$ ) in Table 2 can be interpreted in a way similar to exploratory factor analysis. The squared multiple correlations (SMCs) in Table 2 are the commonalities of the variables. All signs show that it is proper to use these measurements (factor loadings are over 0.6 and SMCs are over 0.5 [63]), and model fit indicators such as the $\chi^{2}$ test, comparative fit index (CFI), Tucker-Lewis index (TLI), and the root mean square error of approximation (RMSEA) present good fits for the research model. Second-order factor analysis was used to verify whether the data structure was proper for the construct, as we assumed (see Figure 3). In this sample, an excellent fit was obtained $(\mathrm{CFI}=0.981$, TLI $=0.975$, RMSEA $=0.051)$, and each of the items loads strongly on the appropriate factor. In addition, we tested a measurement model analysis with HCHRM as a second-order construct. The results in Figure 4 suggest that our measurement model shows a good fit to the data (CFI $=0.960$, TLI $=0.955$, and RMSEA $=0.052$ ). 
Table 2. Confirmatory factor analysis (CFA).

\begin{tabular}{|c|c|c|c|c|c|c|c|}
\hline \multicolumn{2}{|c|}{ Construct } & Measurements & $\begin{array}{c}\text { Factor } \\
\text { Loadings }(\lambda)\end{array}$ & SMC & CR & AVE & Cronbach's $\alpha$ \\
\hline \multirow{4}{*}{ HC HRM } & Pay level & payment & - & - & - & - & - \\
\hline & $\begin{array}{l}\text { HR practice } \\
\text { consistency }\end{array}$ & $\begin{array}{c}\text { HS1_skill } \\
\text { HS2_training } \\
\text { HS3_multifunction } \\
\text { HS4_participatory }\end{array}$ & $\begin{array}{l}0.781 \\
0.730 \\
0.866 \\
0.752 \\
\end{array}$ & $\begin{array}{l}0.610 \\
0.533 \\
0.750 \\
0.565\end{array}$ & 0.864 & 0.615 & 0.862 \\
\hline & $\begin{array}{c}\text { Discretionary } \\
\text { decision } \\
\text { making }\end{array}$ & $\begin{array}{l}\text { DM1 } \\
\text { DM2 } \\
\text { DM3 }\end{array}$ & $\begin{array}{l}0.764 \\
0.894 \\
0.852 \\
\end{array}$ & $\begin{array}{l}0.584 \\
0.799 \\
0.725 \\
\end{array}$ & 0.876 & 0.703 & 0.872 \\
\hline & $\begin{array}{l}\text { Information } \\
\text { sharing }\end{array}$ & $\begin{array}{l}\text { IS1 } \\
\text { IS2 } \\
\text { IS3 }\end{array}$ & $\begin{array}{l}0.831 \\
0.926 \\
0.855\end{array}$ & $\begin{array}{l}0.691 \\
0.857 \\
0.732 \\
\end{array}$ & 0.904 & 0.760 & 0.902 \\
\hline \multicolumn{2}{|c|}{ Employees' capabilities } & $\begin{array}{l}\text { PMC1 } \\
\text { PMC2 } \\
\text { PMC3 } \\
\text { PMC4 }\end{array}$ & $\begin{array}{l}0.801 \\
0.822 \\
0.891 \\
0.957\end{array}$ & $\begin{array}{l}0.641 \\
0.675 \\
0.794 \\
0.916\end{array}$ & 0.925 & 0.757 & 0.924 \\
\hline \multicolumn{2}{|c|}{ Internally-driven flexibility } & $\begin{array}{l}\text { IDF1 } \\
\text { IDF2 } \\
\text { IDF3 } \\
\text { IDF4 }\end{array}$ & $\begin{array}{l}0.730 \\
0.871 \\
0.911 \\
0.759\end{array}$ & $\begin{array}{l}0.532 \\
0.758 \\
0.830 \\
0.576\end{array}$ & 0.891 & 0.674 & 0.886 \\
\hline \multicolumn{2}{|c|}{ Externally-driven flexibility } & $\begin{array}{l}\text { EDF1 } \\
\text { EDF2 } \\
\text { EDF3 } \\
\text { EDF4 }\end{array}$ & $\begin{array}{l}0.763 \\
0.872 \\
0.877 \\
0.899\end{array}$ & $\begin{array}{l}0.582 \\
0.760 \\
0.768 \\
0.807\end{array}$ & 0.915 & 0.730 & 0.913 \\
\hline
\end{tabular}

Six factor CFA: $\chi^{2}(\mathrm{df}=210)=446.783, p<0.01, \mathrm{CFI}=0.974, \mathrm{TLI}=0.969, \mathrm{RMSEA}=0.043(90 \%$ CI 0.038-0.049). Four factor CFA (with second-ordered high-commitment human resource management (HCHRM), excluding control variables): $\chi^{2}(\mathrm{df}=221)=580.611, p<0.01, \mathrm{CFI}=0.960, \mathrm{TLI}=0.955, \mathrm{RMSEA}=0.052(90 \%$ CI $0.047-0.057)$. NOTE: $\mathrm{CFA}=$ confirmatory factor analysis, $\mathrm{CFI}=$ comparative fit index, TLI $=$ Tucker-Lewis index, RMSEA $=$ the root mean square error of approximation.

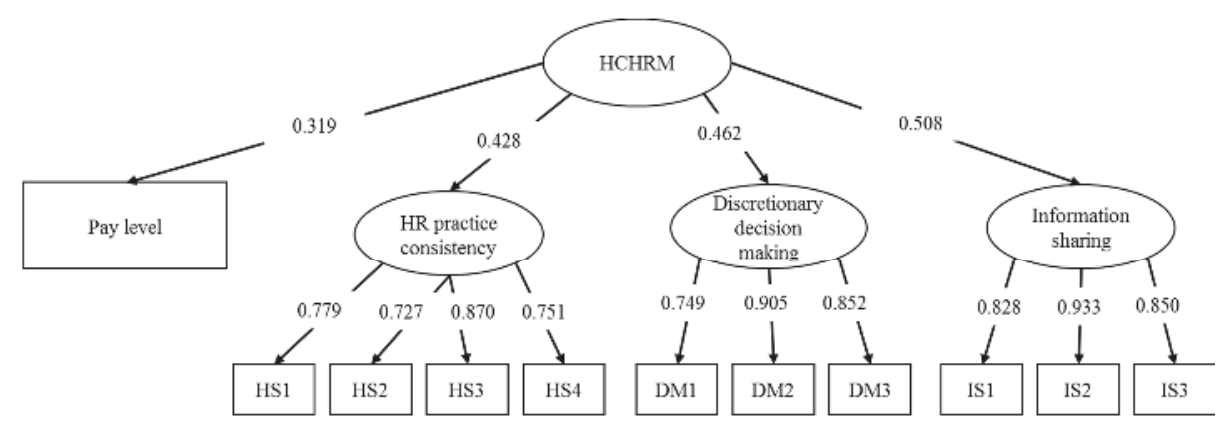

[Goodness-of-fit Statistics] $\mathrm{n}=601, \chi^{2}(\mathrm{df}=41)=104.107, \mathrm{p}<0.01, \mathrm{CFI}=0.981, \mathrm{TLI}=0.975, \mathrm{RMSEA}=0.051(90 \% \mathrm{CI} 0.039-0.063)$;

* NOTE: CFI = comparative fit index, TLI $=$ Tucker-Lewis index, RMSEA = the root mean square error of approximation.

Figure 3. Second-order confirmatory factor analysis (CFA) of high commitment human resource management (HRM) system. 


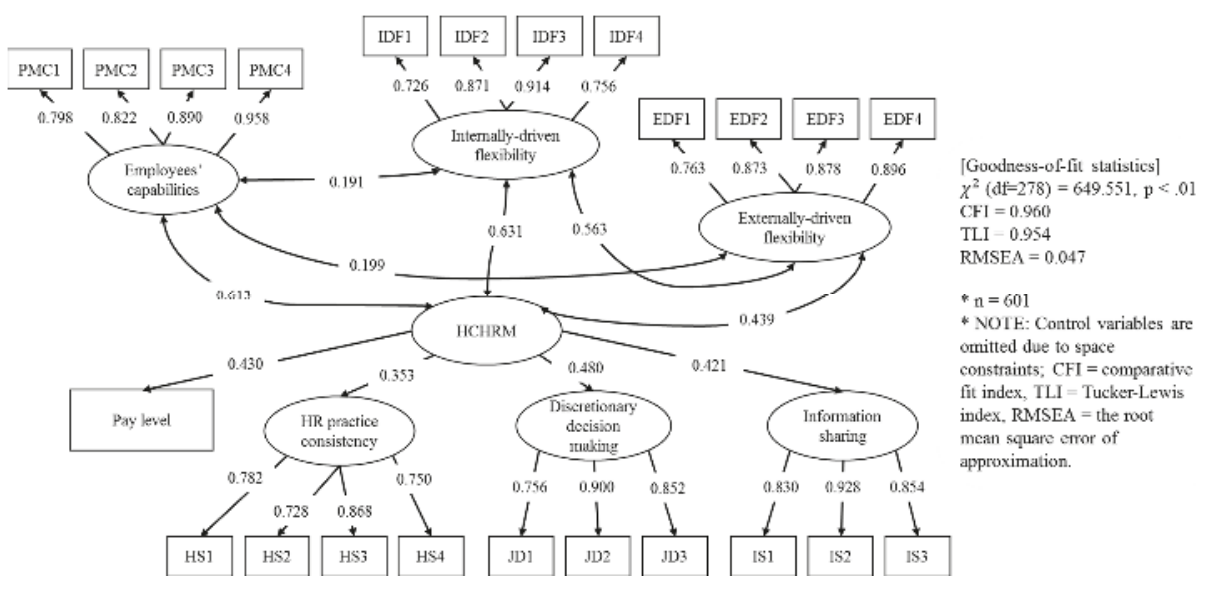

Figure 4. The measurement model.

Finally, we verified the discriminant validity of our instruments by looking at the square root of the AVE, as recommended by Fornell and Larcker [62]. Figure 4 shows the correlation coefficients of the latent variables examined in this study, which confirms the discriminant validity. The square root of the AVE (calculated in Table 2) for each construct is greater than the levels of correlations involved with each construct. The results of the inter-construct correlations also indicate that each construct shares more parts of variances with its measures than with other measures. Therefore, we concluded that this data was appropriate for testing our research model.

\section{Results}

We used the structural equation modeling of Amos 21.0 to test the hypotheses. Figure 5 shows the results of our structural equation modeling after controlling for the effects of firm age, total sales, and unionization. The hypothesized model showed a good fit with the data $\left(\chi^{2}(\mathrm{df}=284)=883.706\right.$, $p<0.01, \mathrm{CFI}=0.936$, TLI $=0.927, \mathrm{RMSEA}=0.059,90 \% \mathrm{CI}[0.055-0.064]$ ). As shown Figure 5 , the level of the HCHRM system is positively associated with the employees' capabilities $(b=1.739$, s.e. $=0.346, p<0.01$, standardized $B=0.710$ ), supporting Hypothesis 1 . The level of employees' capabilities is likely to increase the level of internally driven manufacturing flexibility in the firm $(b=0.208$, s.e. $=0.046, p<0.01$, standardized $B=0.200)$, consistent with Hypothesis $2 a$. In addition, the relationship between employees' capabilities and externally driven manufacturing flexibility in the firm is positive, supporting Hypothesis $2 b(b=0.249$, s.e. $=0.053, p<0.01$, standardized $B=0.207)$. 


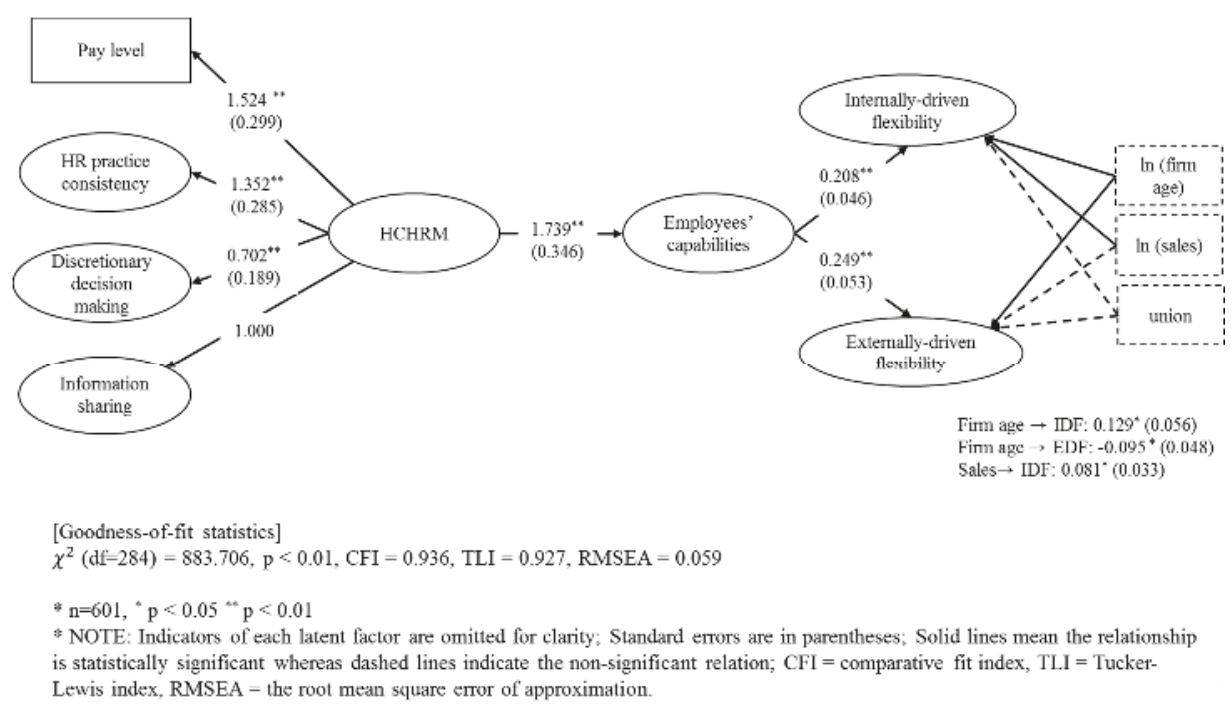

Figure 5. Results of the structural equation modeling.

Hypothesis 3a and 3b predicted that employees' capabilities mediate the relationship between the level of HCHRM and manufacturing flexibility in the firm (H3a: internally driven flexibility, H3b: externally driven flexibility). To test these mediation effects, we used bootstrap procedures to construct $95 \%$ bias-corrected confidence intervals based on 5000 random samples with replacement from the full sample [64]. In support of Hypothesis 3a, we found that employees' capabilities mediated the relationship between the HCHRM system and internally driven manufacturing flexibility $(b=0.362$, Bootstrapped s.e. $=0.150,95 \%$ CI $[0.167-0.746])$. The other mediated relationship was also statistically significant ( $b=0.434$, Bootstrapped s.e. $=0.178,95 \%$ CI [0.206-0.882]), as we expected in Hypothesis $3 \mathrm{~b}$. Hence, we conclude that the HCHRM system helps to increase the manufacturing flexibility level by enhancing employees' capabilities.

\section{Discussion}

The primary purpose of this study is to investigate the relationship between HRM practices and manufacturing flexibility in Korean enterprises. We find that the HCHRM system, which refers to a configuration of HR practices that enhance employee commitment and motivation $[19,20]$, has a strong positive relationship with employees' capabilities for process management. In addition, employees' capabilities mediate the relationship between the HCHRM system and manufacturing flexibility (both internally and externally driven). These findings suggest that the pervasive execution of HCHRM in a company improves its manufacturing flexibility level by fostering the employees' capabilities in manufacturing parts. In line with social exchange theory, HCHRM encourages reciprocal relations between a firm and its employees. That is, HCHRM promotes individual autonomy, skill or knowledge development, and active participation; benefits that employees then pay back to the firm by performing desired behaviors for work-related performance. For example, workers who have opportunities to make discretionary decisions in their jobs are likely to be more capable (with better problem-solving or decision-making abilities). In turn, employees who are well trained and capable achieve good performances at their work. That is, good workers developed through executing HCHRM practices repay their companies with the desired behaviors on their performances. Our research investigates this reciprocal mechanism, not only in theoretical elaborations but also through an empirical test, by concentrating on the manufacturing process. In addition, our findings show that manufacturing flexibility is achieved by developing employees' capabilities by instituting an HCHRM 
system. Managing manufacturing processes flexibly to meet changes in customers' needs promptly is an important skill for surviving under rapidly changing circumstances. From our results, employees' capabilities are the requisite antecedent of manufacturing flexibility, because not just internally driven flexibility, but also externally driven flexibility, needs quick decisions and handling competences, depending on the changing needs. In addition, HCHRM plays a role in improving internally driven and externally driven manufacturing flexibility as well.

The results of this study contribute to the strategic HRM literature by finding the link between the HCHRM system and departmental outcomes (e.g., manufacturing flexibility). Considering that flexibility is an emerging issue in HRM disciplines (employment flexibility, workplace flexibility), investigating the relationship between HCHRM and manufacturing flexibility is newly explained and empirically tested in our study. This is important because manufacturing flexibility improves manufacturing firm's sustained competitive advantages that the strategic HRM researchers are also interested in. The reason why we choose HCHRM, and not sustainable HRM practices, is because we think the HCHRM system has the explicitly or implicitly overlapped region between the existing strategic HRM studies (as mainstream as Ehnert and Harry [15] mentioned) and the newly arising sustainable HRM research. To be specific, the HCHRM system and the sustainable HRM has a similar assumption to employees, which is employees in organizations are important in themselves because they are not a means to achieve goals but an end to have values, despite different research foundations. With this assumption, we are inevitable to focus on the role of employee capabilities that allow HCHRM to ultimately influence manufacturing flexibility that can be crucial for a firm's long-term sustainability. Unlike the existing literature on strategic HRM (e.g., see Beltrán-Martín et al. [65]), we believe that our work can make a distinctive contribution to HRM research, in that we try to articulate the impact of HCHRM on the operational outcomes (i.e., manufacturing flexibility) on the basis of the internal level CSR view (i.e., employee focus) developed in sustainability research. In sum, our findings have a theoretical and empirical contribution to the strategic HRM literature and sustainability literature, finding the related point_employees' capabilities—between two different research backgrounds.

The implications for the sustainability literature are not limited to the HCHRM viewpoint. As we mentioned, manufacturing flexibility is another key to make manufacturing processes sustainable. Since the meaning of sustainable manufacturing processes is related to the possibility of simultaneously achieving organizational goals (i.e., cost efficiency and customer satisfaction) without compromise, manufacturing flexibility is an appropriate concept to discuss the firm's sustainability. We suggest the mechanism of the HCHRM-manufacturing flexibility relationship based on the competitive strategy (i.e., generic strategy of the firm). In other words, HCHRM makes firms increase the sustainable competitive advantage by making their manufacturing processes flexible in response to internally or externally generated needs. After all, based on the results, we can conclude that for increasing firm's sustainability, implementing HCHRM is helpful because it develops the employees' capabilities and finally enhances manufacturing flexibility, which can be a direct source of firm's sustainability.

In addition, our study helps theoretically explain reciprocities in the workplace based on social exchange theory. Although the effects of implementing HR practices can be interpreted through various points of view, social exchange theory is suitable to interpret our findings. Employing this theory, we can comprehensively explain the phenomenon of how HRM practices (i.e., HCHRM) create manufacturing flexibility in organizations through employees' capabilities. This is a sound rationale to explain our findings in the field of HRM and manufacturing flexibility.

Finally, our findings have practical implications for organizational leaders or HR professionals. Implementation of HCHRM such as providing opportunities to make decisions autonomously to employees, sharing managerial information, and designing highly consistent HR practices in an organization is vital to nurture employees' capabilities and improve the firm's manufacturing flexibility. Therefore, organizations that want to make the firm sustainable need to be actively considering introducing the HCHRM practices in their organization. 
Although it looks expensive in the beginning because the definite effect of the HCHRM implementation will appear when the HCHRM is applied as a system (i.e., a bundle of the related HR practices), the HCHRM system helps the firm manage manufacturing employees by internally motivating and training them, and thus ultimately increases the firm's sustained profitability. Furthermore, organizational leaders or HR professionals need to focus on the development of employees' capabilities. Employees' capability enhancement itself is critical for the firm's sustainability because it is not only a means to increase manufacturing flexibility that is another base of firm's sustained competitive advantage but also an end to make employees satisfy or feel developed. Thus, further efforts to develop and reproduce employees' capabilities are needed in practice because our findings demonstrate it works.

Several limitations should be carefully considered when interpreting our results. First, performance evaluation practices were not included in our study. Some researchers have suggested three dimensions of HR systems, such as skill-enhancing, motivation-enhancing, and opportunity-enhancing [23], or people flow, appraisals and rewards, and employment relations [66]. Motivation-enhancing [23] or appraisals and rewards [66] practices are associated with performance appraisals and incentive programs. Since we follow the control and commitment approach [19], we focused less on performance evaluation and compensation practices in our analysis. Three-dimensional approaches need to be considered in future research. In line with considering three-dimensional approaches, future researchers are invited to discuss sustainable HRM system as an extension of our study. We believe our work regarding the internal level CSR can be a starting point to expand the discussion on the relationship between sustainable HRM and Strategic HRM in the workplace. Although the empirical test of the effect of firm's HRM system is not easy work, in future research, it will be necessary to show what specific HR practices consist of a sustainable HRM system and how to observe and test the effect of a sustainable HRM system on various organizational outcomes considering firm's sustainability.

Second, we collected our data from seven department managers, which this way might benefit to lower common method variance. However, it is less likely to reflect the actual perceptions of manufacturing employees. Future research needs the employees' evaluations of HRM practices, their attitudinal variables, and their cognitive or affective states. This may improve our understandings of the issue with more realistic interpretation. In addition, when the data is collected from each employee, multilevel modeling will be applied to test the relationships.

Third, a potential endogeneity problem should be considered. The endogeneity problem happens "when the explanatory variables and the error term are correlated in a regression model" [67] (p. 149). According to Li [67], there are several remedies of the endogeneity problem in the cross-sectional annual data regressions: control variables, lagged independent variable, firm or industry fixed effects, instrumental variable, lagged dependent variable, or GMM/dynamic model. There is a generic limitation from a simple cross-sectional data, which is employed in this study. Although we input three control variables (e.g., firm age, firm size, and union) that simultaneously influence the explanatory and explained variables, assume and clearly test the second-order factor structure [68], and elaborate the theoretical rationale of how HCHRM (practices) impacts employees' capabilities (ability) and manufacturing flexibility (behaviors) to remedy our data's shortcoming (i.e., a simple cross-sectional data), it remains to worry about the endogeneity problem. In future research, a longitudinal study would be useful to understand the relationship between the HCHRM system and employees' performances. If we can collect a panel data of our model, the causality of HCHRM and manufacturing flexibility will become more apparent, being able to use lagged independent variables or lagged dependent variables. Or quasi-experiment or experimental study will be helpful for improving our understanding in this field. For example, if we know a firm will institute a new HCHRM practice, then we can measure the perceptions, abilities, or behaviors from employees before and after introducing the new practice. Based on a social exchange view, social exchange relationships are based on long-term relationships; that is, they are built on reciprocal experiences of trust. Thus, future research should include investigating perceptional or behavioral changes over time in order to test a dynamic model. 
Lowering the endogeneity concerns is very critical to conduct social science research, future research should consider these aspects and encourage not only to make a new methodological process (i.e., data collection, statistical tests) but also to make new logical argumentations based on developed theories.

Finally, we should consider the issue of generalizability. We tested our model with 601 manufacturing firms in South Korea. The reason why we chose this context is that we expect the effect of implementing the HCHRM system might vary in Korea manufacturing firms. South Korea is known to have strengths and dynamics in the manufacturing industry with well-trained employees and highly developed technology. However, in Korea, a lot of manufacturing firms are small or medium-sized and this implies majority of manufacturing firms in Korea are less likely to actively implement HCHRM so that the implementation level of HCHRM, or the considering level of employees by HR policies, varies from firms to firms, so we think the Korea manufacturing context is suitable to observe the effect of HCHRM system on manufacturing sustainability (i.e., manufacturing flexibility). Although we expect that our findings can be applied to other industries and other countries, our focus has fundamental cautions to interpret the results. Our study may not be able to draw a consistent conclusion from other countries (e.g., different cultures or different levels of economic development) and neither does different industries. For example, in some industries in which managing people is critical for the firm's survival, our findings may be working with a strong effect, whereas in other industry in which the firms consider employees as costs, our results are useless to give implications. Therefore, future research should examine other industries (e.g., service or high-tech) to cross-validate our model in different settings.

Despite the limitations of this study, our findings extend the work in the HCHRM literature by examining the relationship between HCHRM practices and manufacturing flexibility via employees' capabilities. On that basis, further research should be able to extend our understanding of the mediation mechanism or find boundary conditions that strongly influence that mechanism. In this way, we can expand our understanding of strategic HRM practices and their outcomes.

Author Contributions: Conceptualization, J.P. and D.J.; formal analysis, methodology, and validation, J.P.; writing—original draft, J.P., P.L., and D.J.; writing—review and editing, P.L. and D.J.; funding acquisition, D.J.; project administration, D.J. and P.L.

Funding: This research received no external funding.

Conflicts of Interest: The authors declare no conflict of interest.

\section{References}

1. Becker, M.C. Organizational routines: A review of the literature. Ind. Corp. Chang. 2004, 13, 643-678. [CrossRef]

2. Gupta, Y.P.; Goyal, S.J. Flexibility of manufacturing systems: Concepts and measurements. Eur. J. Oper. Res. 1989, 43, 119-135. [CrossRef]

3. Jordan, W.C.; Graves, S.C. Principles on the benefits of manufacturing process flexibility. Manag. Sci. 1995, 41, 577-594. [CrossRef]

4. Vokurka, R.J.; O'Leary-Kelly, S.W. A review of empirical research on manufacturing flexibility. J. Oper. Manag. 2000, 18, 485-501. [CrossRef]

5. Gupta, Y.P.; Somers, T.M. Business strategy, manufacturing flexibility, and organizational performance relationships: A path analysis approach. Prod. Oper. Manag. 1996, 5, 204-233. [CrossRef]

6. Gerwin, D. Manufacturing flexibility: A strategic perspective. Manag. Sci. 1993, 39, 395-410. [CrossRef]

7. Cousens, A.; Szwejczewski, M.; Sweeney, M. A process for managing manufacturing flexibility. Int. J. Oper. Prod. Manag. 2009, 29, 357-385. [CrossRef]

8. Wei, Z.; Song, X.; Wang, D. Manufacturing flexibility, business model design, and firm performance. Int. J. Prod. Econ. 2017, 193, 87-97. [CrossRef]

9. Chen, I.J.; Calantone, R.J.; Chung, C.H. The marketing-manufacturing interface and manufacturing flexibility. Omega 1992, 20, 431-443. [CrossRef] 
10. Kotha, S.; Swamidass, P.M. Strategy, advanced manufacturing technology and performance: Empirical evidence from US manufacturing firms. J. Oper. Manag. 2000, 18, 257-277.

11. Rosen, M.A.; Kishawy, H.A. Sustainable manufacturing and design: Concepts, practices, and needs. Sustainability 2012, 4, 154-174. [CrossRef]

12. Ehnert, I. Sustainable Human Resource Management. A Conceptual and Exploratory Analysis from a Paradox Perspective; Physica-Verlag: Berlin/Heidelberg, Germany, 2009.

13. Stankeviciute, Z.; Savaneviciene, A. Sustainability as a concept for human resource management. Econ. Manag. 2013, 18, 837-846. [CrossRef]

14. Stankeviciute, Z.; Savaneviciene, A. Designing sustainable HRM: The core characteristics of emerging field. Sustainability 2018, 10, 4798. [CrossRef]

15. Ehnert, I.; Harry, W. Recent developments and future prospects on sustainable human resource management: Introduction to the special issue. Manag. Rev. 2012, 23, 221-238. [CrossRef]

16. Bányai, T.; Landschützer, C.; Bányai, Á. Markov-chain simulation-based analysis of human resource structure: How staff deployment and staffing affect sustainable human resource strategy. Sustainability 2018, 10, 3692. [CrossRef]

17. Barney, J. Firm resources and sustained competitive advantage. J. Manag. 1991, 17, 99-120. [CrossRef]

18. Youndt, M.A.; Snell, S.A.; Dean, J.W., Jr.; Lepak, D.P. Human resource management, manufacturing strategy, and firm performance. Acad. Manag. J. 1996, 39, 836-866. [CrossRef]

19. Arthur, J.B. Effects of human resource systems on manufacturing performance and turnover. Acad. Manag. J. 1994, 37, 670-687. [CrossRef]

20. Whitener, E.M. Do "high commitment" human resource practices affect employee commitment? A cross-level analysis using hierarchical linear modeling. J. Manag. 2001, 27, 515-535. [CrossRef]

21. Combs, J.; Liu, Y.; Hall, A.; Ketchen, D. How much do high-performance work practices matter? A meta-analysis of their effects on organizational performance. Pers. Psychol. 2006, 59, 501-528. [CrossRef]

22. Guthrie, J.P. High-involvement work practices, turnover, and productivity: Evidence from New Zealand. Acad. Manag. J. 2001, 44, 180-190. [CrossRef]

23. Jiang, K.; Lepak, D.P.; Hu, J.; Baer, J.C. How does human resource management influence organizational outcomes? A meta-analytic investigation of mediating mechanisms. Acad. Manag. J. 2012, 55, 1264-1294. [CrossRef]

24. Snell, S.A.; Dean, J.W., Jr. Integrated manufacturing and human resource management: A human capital perspective. Acad. Manag. J. 1992, 35, 467-504. [CrossRef]

25. Miles, R.E.; Snow, C.C. Designing strategic human resources systems. Organ. Dyn. 1984, 13, 36-52. [CrossRef]

26. Porter, M.E. The Competitive Advantage: Creating and Sustaining Superior Performance; Free Press: New York, NY, USA, 1985.

27. Schuler, R.S.; Jackson, S.E. Organizational strategy and organization level as determinants of human resource management practices. Hum. Resour. Plan. 1987, 10, 125-141.

28. Blau, P. Exchange and Power in Social Life; John Wiley: New York, NY, USA, 1964.

29. Lee, J.; Miller, D. People matter: Commitment to employees, strategy and performance in Korean firms. Strateg. Manag. J. 1999, 20, 579-593. [CrossRef]

30. D'Souza, D.E.; Williams, F.P. Toward a taxonomy of manufacturing flexibility dimensions. J. Oper. Manag. 2000, 18, 577-593. [CrossRef]

31. Boselie, P.; Dietz, G.; Boon, C. Commonalities and contradictions in HRM and performance research. Hum. Resour. Manag. J. 2005, 15, 67-94. [CrossRef]

32. Huselid, M.A. The impact of human resource management practices on turnover, productivity, and corporate financial performance. Acad. Manag. J. 1995, 38, 635-672. [CrossRef]

33. Pfeiffer, J. Seven practices of successful organizations. Calif. Manag. Rev. 1998, 40, 96-124. [CrossRef]

34. Bae, J.; Lawler, J. Organizational and HRM strategies in Korea: Impact on firm performance in an emerging economy. Acad. Manag. J. 2000, 43, 502-517. [CrossRef]

35. Delery, J.E.; Doty, D.H. Modes of theorizing in strategic human resource management: Tests of universalistic, contingency, and configurational performance predictions. Acad. Manag. J. 1996, 39, 802-835. [CrossRef]

36. Kooij, D.T.; Jansen, P.G.; Dikkers, J.S.; De Lange, A.H. The influence of age on the associations between HR practices and both affective commitment and job satisfaction: A meta-analysis. J. Organ. Behav. 2010, 31, 1111-1136. [CrossRef] 
37. Diaz-Carrion, R.; López-Fernández, M.; Romero-Fernandez, P.M. Evidence of different models of socially responsible HRM in Europe. Bus. Ethics Eur. Rev. 2019, 28, 1-18. [CrossRef]

38. Jamali, D.; Safieddine, A.M.; Rabbath, M. Corporate governance and corporate social responsibility synergies and interrelationships. Corp. Gov. 2008, 16, 443-459. [CrossRef]

39. Mariappanadar, S.; Kramar, R. Sustainable HRM: The synthesis effect of high performance work systems on organisational performance and employee harm. Asia-Pac. J. Bus. Adm. 2014, 6, 206-224. [CrossRef]

40. Shaw, J.D.; Dineen, B.R.; Fang, R.; Vellella, R.F. Employee-organization exchange relationships, HRM practices, and quit rates of good and poor performers. Acad. Manag. J. 2009, 52, 1016-1033. [CrossRef]

41. Gouldner, A.W. The norm of reciprocity: A preliminary statement. Am. Sociol. Rev. 1960, 25, 161-178. [CrossRef]

42. Kwon, K.; Bae, J.; Lawler, J.J. High commitment HR practices and top performers. Manag. Int. Rev. 2010, 50, 57-80. [CrossRef]

43. Takeuchi, R.; Lepak, D.P.; Wang, H.; Takeuchi, K. An empirical examination of the mechanisms mediating between high-performance work systems and the performance of Japanese organizations. J. Appl. Psychol. 2007, 92, 1069. [CrossRef]

44. Hahn, T.; Figge, F. Beyond the bounded instrumentality in current corporate sustainability research: Toward an inclusive notion of profitability. J. Bus. Ethics 2011, 104, 325-345. [CrossRef]

45. Sethi, A.K.; Sethi, S.P. Flexibility in manufacturing: A survey. Int. J. Flex. Manuf. Syst. 1990, 2, $289-328$. [CrossRef]

46. Zhang, Q.; Vonderembse, M.A.; Lim, J.S. Manufacturing flexibility: Defining and analyzing relationships among competence, capability, and customer satisfaction. J. Oper. Manag. 2003, 21, 173-191. [CrossRef]

47. Schroeder, R.G.; Bates, K.A.; Junttila, M.A. A resource-based view of manufacturing strategy and the relationship to manufacturing performance. Strateg. Manag. J. 2002, 23, 105-117. [CrossRef]

48. Wright, P.M.; Dunford, B.B.; Snell, S.A. Human resources and the resource based view of the firm. J. Manag. 2001, 27, 701-721. [CrossRef]

49. Wright, P.M.; McMahan, G.C.; McWilliams, A. Human resources and sustained competitive advantage: A resource-based perspective. Int. J. Hum. Resour. Manag. 1994, 5, 301-326. [CrossRef]

50. Li, S.; Rao, S.S.; Ragu-Nathan, T.; Ragu-Nathan, B. Development and validation of a measurement instrument for studying supply chain management practices. J. Oper. Manag. 2005, 23, 618-641. [CrossRef]

51. Sen, A. Human capital and human capability. World Dev. 1997, 25, 1959-1961. [CrossRef]

52. Messersmith, J.G.; Patel, P.C.; Lepak, D.P.; Gould-Williams, J.S. Unlocking the black box: Exploring the link between high-performance work systems and performance. J. Appl. Psychol. 2011, 96, 1105. [CrossRef]

53. Zatzick, C.D.; Iverson, R.D. High-involvement management and workforce reduction: Competitive advantage or disadvantage? Acad. Manag. J. 2006, 49, 999-1015. [CrossRef]

54. Avittathur, B.; Swamidass, P. Matching plant flexibility and supplier flexibility: Lessons from small suppliers of US manufacturing plants in India. J. Oper. Manag. 2007, 25, 717-735. [CrossRef]

55. Chiang, H.-H.; Han, T.-S.; Chuang, J.-S. The relationship between high-commitment HRM and knowledge-sharing behavior and its mediators. Int. J. Manpow. 2011, 32, 604-622. [CrossRef]

56. $\mathrm{Wu}, \mathrm{W}$. Dimensions of social capital and firm competitiveness improvement: The mediating role of information sharing. J. Manag. Stud. 2008, 45, 122-146. [CrossRef]

57. Evans, D.S. The relationship between firm growth, size, and age: Estimates for 100 manufacturing industries. J. Ind. Econ. 1987, 35, 567-581. [CrossRef]

58. Thornhill, S.; Amit, R. Learning about failure: Bankruptcy, firm age, and the resource-based view. Organ. Sci. 2003, 14, 497-509. [CrossRef]

59. Ebben, J.J.; Johnson, A.C. Efficiency, flexibility, or both? Evidence linking strategy to performance in small firms. Strateg. Manag. J. 2005, 26, 1249-1259. [CrossRef]

60. Swamidass, P.M.; Kotha, S. Explaining manufacturing technology use, firm size and performance using a multidimensional view of technology. J. Oper. Manag. 1998, 17, 23-37. [CrossRef]

61. Dang, C.; Li, Z.; Yang, C. Measuring firm size in empirical corporate finance. J. Bank. Financ. 2018, 86, 159-176.

62. Fornell, C.; Larcker, D.F. Evaluating structural equation models with unobservable variables and measurement error. J. Mark. Res. 1981, 18, 39-50. [CrossRef]

63. Hox, J.J.; Bechger, T.M. An introduction to structural equation modeling. Fam. Sci. Rev. 1998, 11, $354-373$. 
64. Shrout, P.E.; Bolger, N. Mediation in experimental and nonexperimental studies: New procedures and recommendations. Psychol. Methods 2002, 7, 422-445. [CrossRef]

65. Beltrán-Martín, I.; Bou-Llusar, J.C.; Roca-Puig, V.; Escrig-Tena, A.B. The relationship between high performance work systems and employee proactive behaviour: Role breadth self-efficacy and flexible role orientation as mediating mechanisms. Hum. Resour. Manag. J. 2017, 27, 403-422. [CrossRef]

66. Zhang, Z.; Jia, M. Using social exchange theory to predict the effects of high-performance human resource practices on corporate entrepreneurship: Evidence from China. Hum. Resour. Manag. 2010, 49, 743-765. [CrossRef]

67. Li, F. Endogeneity in CEO power: A survey and experiment. Invest. Anal. J. 2016, 45, 149-162. [CrossRef]

68. Koufteros, X.; Babbar, S.; Kaighobadi, M. A paradigm for examining second-order factor models employing structural equation modeling. Int. J. Prod. Econ. 2019, 120, 633-652. [CrossRef]

(C) 2019 by the authors. Licensee MDPI, Basel, Switzerland. This article is an open access article distributed under the terms and conditions of the Creative Commons Attribution (CC BY) license (http://creativecommons.org/licenses/by/4.0/). 


\title{
Becoming a Sustainable Organization: Focusing on Process, Administrative Innovation and Human Resource Practices
}

\author{
Hyejin Cho ${ }^{1}$, Pyoungsoo Lee ${ }^{2, *}$ and Choong Ho Shin ${ }^{3, *}$ \\ 1 Department of Business Administration, Korea University, Anam-ro 145, Seoul 02841, Korea \\ 2 Department of Business Administration, Kyonggi University, Gwanggyosan-ro 154-42, Suwon 16227, \\ Gyeonggi, Korea \\ 3 Department of IT Management, Kyungmin University, Seobu-ro 545, Euijeongbu 11618, Gyeonggi, Korea \\ * Correspondence: pyoungsoo@kgu.ac.kr (P.L.); cshin24@kyungmin.ac.kr (C.H.S.); \\ Tel.: +82-31-249-9457 (P.L.); +82-31-828-7170 (C.H.S.)
}

Received: 29 May 2019; Accepted: 17 June 2019; Published: 28 June 2019

\begin{abstract}
Despite the importance of constant product improvement to becoming a sustainable organization, the relationship between different types of innovation and new product development has received little attention. This article contributes to prior research by proposing a necessary condition for successful product development, which increases organizational sustainability. While it has been widely argued that technological innovation is an important factor for new product development, we contribute by illustrating the importance of process and administrative innovation, which changes an organization's way of doing business. By analyzing survey responses from 2127 Korean firms, we empirically demonstrate that process and administrative innovation increase the likelihood of achieving new product development goals. Our findings also show that innovation-supporting human resource practices such as talent development programs and work autonomy increase the effectiveness of process and administrative innovations. Overall, we suggest that organizations are able to achieve a sustainable presence in the product market when they constantly innovate the way they run themselves. Additionally, in order to manage such innovation, organizations should nurture a creative environment by devising effective, innovation-supporting human resource practices.
\end{abstract}

Keywords: process innovation; administrative innovation; product development; human resource policies; organizational sustainability

\section{Introduction}

Over the past twenty years, the topic of organizational sustainability has received considerable attention from management researchers as it focuses on an organization's long-term success instead of short-term financial performance [1]. It has long been argued that the sustainability of a firm is supported by innovation, or the potentially transformational force that challenges existing practices and generates new processes [2]. By definition, innovation is "the international introduction and application within a role, group or organization of ideas, processes, products or procedures, new to the relevant unit of adoption, designed to significantly benefit the individual, the group, the organization and wider society" [3] (p. 9). Both academics and practitioners continue to argue that innovation is one of the key elements through which organizations, institutions, communities, and countries can implement change and become more sustainable [4], and sustainable product development is one of the most important elements in achieving long-term prosperity and growth [5]. New product development is generally considered to be a necessary factor for surviving today's fast-paced market environment [6]. Improving product performance also benefits consumers and society, which, ultimately, leads to sustained market competitiveness for firms. 
The concept that always appears when discussing the performance of new product development is technological innovation, and prior research has primarily emphasized the role of technological innovation [7-10]. Technology drives innovation, in general, and the performance of innovation is often interpreted as the performance of new product development. In the academic field, technology is also recognized as an important factor in the development of new products because it enables the creation of new products $[10,11]$. While it is clear that technical ability is important in new product development, not all companies with such advanced technology develop new products successfully. Therefore, it is necessary to pay attention to factors other than technology in terms of organizational internal aspects. We focus on product innovation from the perspective of the processes and organizational structures that an organization has, rather than directly linking the technology to the performance of new product development.

In this study, we propose that organizational innovation, that is, process and administrative innovation, can also be viewed as a means of developing valuable resources, as organizational processes/systems may also be important to achieving sustainable competitive advantage. Based on prior research that highlights the relationship between an organization's innovative capability and new product development [12-16], we first propose that process innovation aimed at creating production efficiency will promote the development of new products. A more efficiently managed process can support the emergence of new products as this environment is better suited to the creation and production of advanced goods. Secondly, administrative innovation such as improvements in information management and work efficiency is likely to support employees by providing a more efficient management system. We expect that such innovation within organizational systems will promote the development of new products.

Lastly, we test the role of innovation related to human resource (HR) practices, as human resources are a key factor of innovative performance [17]. Attempts by firms to innovate their current environments are likely to be successful when employees responsible for running innovative processes are motivated; hence, we predict that proper HR practices improve the outcomes of innovation attempts. Given the important role of talent, that is, key personnel, in leading and completing innovation activities, we first test whether HR programs that support talent boost the effectiveness of innovation in organizational processes and administration. We also analyze whether the effectiveness of innovation increases when employees are given increased work autonomy. As innovation leads to the enhancement of current activities or processes by allowing and absorbing new approaches and standards, we expect that increased work autonomy will help organizations achieve higher levels of innovation.

Using survey responses from 2127 Korean manufacturing firms, we test the effect of administrative and process innovation on the probability of new product development. We also analyze whether HR practices positively moderate the effect of innovation on new product development. Our empirical findings suggest that both process and administrative innovation enhance the likelihood of new product development. This relationship is also strengthened in the presence of HR practices related to talent management and work autonomy. However, work autonomy has an insignificant moderating effect on the relationship between administrative innovation and new product development.

This study contributes to the literature on innovation by examining how a firm's attempt to innovate its current organizational system or processes matters in terms of new product development. First, while prior research has extensively explored the role of technological innovation, in business practices or processes, in creating sustainable growth in the industry [18,19], we shed light on the relationship between other types of innovation and firm performance, which we understand less [20]. Our findings suggest that the sustainable competitiveness of firms in the market is ultimately dependent upon the innovation of status quo internal systems, that is, business structures and processes. Such innovation can shape a supportive environment for the sustainable development of new products. Thus, our findings extend the existing literature by showing that the effect of innovation in organizational management in general, i.e., process and administrative innovation also has a significant impact on 
new product development. Second, this study examines the joint effects of innovation and HR practices on new product development. Our findings imply that a firm's innovation strategy for pursuing sustainable growth should be employed in tandem with practices that support the people who are actually implementing and operating these innovation processes.

The remainder of this paper is organized as follows. First, the second section provides a review of the literature related to new product development and the research questions we want to address. In the third section, the data and method used for the empirical analysis are explained. The third section will also present results, and in the final section, the main conclusions are presented, and implications are suggested.

\section{Literature Review and Hypothesis Development}

\subsection{Literature Review}

Over the past three decades, new product development issues have received considerable attention in various business fields, and they have become an important research topic. In the field of operations and supply chain management, as business organizations continue to make efforts to develop new products, with a low success rate, most of the product development literature has focused on the overall process of product development or key success factors affecting product outcomes (e.g., [12,21-28]). The suggestion that project-specific factors affect the outcomes of new product development activities has been widely analyzed $[10,11,29,30]$. Also, a firm's performance in terms of new product development is believed to be positively related to third-party suppliers [31-34], or collaboration with customers [35-39]. As Joshi and Sharma [40] mentioned, researchers argue that developing new products using only internal knowledge is no longer sufficient to maintain or enhance competitive status. It is clear that innovation within an organization is a prerequisite for a strong performance in terms of new product development. Hence, we expand the discussion by attempting to identify the role of innovation within an organization in achieving better product development performance. This, in turn, will provide a more integrated view of new product development. In a recent study by Cooper [10], three key success factors are identified from prior studies that explain new product development performance. These success factors can be found at three different levels: (1) the individual project level, (2) business level, and (3) systems and methods level. As we are primarily concerned with research related to the overall management of an organization, rather than individual product development projects, we focused on the second and third categories identified by Cooper [10]. While prior research has analyzed "methods and systems" that are directly relevant to the product development process itself, we extend this view by investigating the effect of organizational-level methods and systems rather than focusing solely on the product development process level.

Also, organizational studies have shown how appropriate organizational management or HR practices can nurture the innovative environment (e.g., [8,41,42]). For instance, Haneda and Ito [42] connect the organizational and HR practices to product/process innovation and Mokhber et al. [43] show effect of leadership style on new product development. However, how an organization can achieve its new product development goals through innovations in organizational management has been under-researched. While prior organizations literature view that organization management practices are static and innovation take place only in the product development, we focus on whether attempts by firms to innovate organizational management itself influence new product development. Organization studies have suggested that an organization's sustained performance and growth is determined by the organization's ability to employ new practices to rejuvenate its strategy, structure, and processes [44-47]. Hence, we attempt to propose a model that increases our understanding of how innovations in organizational management, that is, processes or administrative practices, change the likelihood of successfully introducing a new product.

In proposing the relationship between organizational innovation and new product development, we extend the argument by integrating the role of HR practices. The effectiveness of innovation attempts 
can differ depending on whether an organization's HR practices motivate employees and nurture an innovative environment. Human resource management (HRM) research emphasizes the relationship between HR practices and organizational performance; a firm must possess a good system for ensuring the effective utilization of human resources in order to develop and maintain competitiveness [48]. Especially in today's knowledge-based economy, one of the most important antecedents of sustainable competitive advantage is acquiring and retaining talented personnel [49]. HR practices are the primary means by which firms achieve organizational goals as these practices shape the skills, attitudes, and behavior of employees [50,51]. HR practices that emphasize extensive training and development are regarded as a necessary step in product innovation [52]. While prior research has highlighted the role of HR practices in achieving innovation, this research attempts to analyze how HR practices strengthen the impact of introduced innovation on new product development. While a firm may attempt to change existing processes and norms, such innovation attempts will lead to actual new product development only when employees are supported by strong HR practices that allow them to utilize introduced innovation in the organization. Hence, our study aims to contribute to the HR literature by demonstrating the important role of HR practices in intensifying the effectiveness of innovation on new product development.

\subsection{Hypothesis Development}

\subsubsection{Relationship between Process Innovation and New Product Development}

Process innovation is defined as the introduction of new elements into an organization's production or service operations to produce a product or render a service [53-55]. More specifically, it refers to alterations to processes, through significant changes in technology, equipment, and/or software, that are intended to reduce costs or improve quality [56]. Since process innovation is primarily efficiency driven, it requires a firm to apply technology to improve the performance of new product development [57]. In other words, process innovation is crucial for product innovation, which translates into the successful introduction of new products [58].

While it is unquestionable that new product development and process innovation affect one another, their pattern of interaction is unclear [59]. We argue that by improving their processes, organizations can strengthen their product development capabilities. A more efficient process better supports the emergence of new products as employees can enjoy an efficient usage of resources.

Therefore, we suggest the following hypothesis under the premise that success in new product development depends on a firm's attempts to improve the efficiency of its current processes.

H1. Process innovation increases the likelihood of new product development.

\subsubsection{Relationship between Administrative Innovation and New Product Development}

Administrative innovation aims to improve an organization's capability by changing its organizational structure, and administrative or work processes $[54,58]$. Cummings and Srivastava [60] explain that it is the innovation of communication and exchange among people with the same goal or task, or between the environment and people. For instance, improving online connectivity and knowledge sharing among different departments may allow employees to easily utilize highly accumulated knowledge without hassle. Another example of this type of innovation is when a firm attempts to innovate its current operational flow by partnering with external parties. Such utilization of external resources takes place when a firm perceives that certain processes can be more efficiently handled by others. In this way, an organization can improve the efficiency of resource allocation by focusing its limited resources on its core strength. Administrative innovation is closely related to the improvement of the management of an organization, which in turn leads to a higher quality and more efficient workflow. 
We expect that administrative innovation supports firms in achieving new product development goals for several reasons. First, administrative innovation is needed to adapt to the changing marketplace and to create a new environment, such as by introducing new products or services. Damanpour and Evan [61] emphasize the importance of increasing system effectiveness to match new market requirements by providing the following example. For instance, a library that replaces a card catalog system with a computer-based cataloging system must establish a new administrative structure that is able to serve this new type of data management, and it must create new work procedures with new roles for employees. Without such a change in the organization, the library cannot offer timely and advanced services. Likewise, in order for firms to achieve new product development, administrative innovation is needed to support the emergence of new products.

Second, administrative innovation improves organizational learning capability and provides employees with a better environment that enables them to focus their time and effort on the core issues related to new product development. The development of a new product is a complicated process that requires searching for market information and preparing to meet new market trends [62]. Hence, increasing firm efficiency through administrative innovation will lead to better knowledge management, for example, efficient information transfer increases learning opportunities and the level of knowledge sharing among employees [63]. Such an improved ability to adapt and reconfigure resources and capabilities can be regarded as a sustainable competitive advantage $[64,65]$.

Based on the above arguments, we propose the following hypothesis:

H2. Administrative innovation increases the likelihood of new product development.

\subsubsection{Moderating Effect of HR Practices}

HRM research emphasizes the relationship between HR practices and organizational performance. A firm must possess a good system that ensures the effective utilization of human resources in order to develop and maintain competitiveness [48]. In particular, it has been largely suggested that the effectiveness of innovation is determined by a supportive, innovative climate, and related capabilities are needed [66]. Hence, an innovation-enhancing HR practice is critical. As an appropriate HR system suited to the organizational context contributes to competitive success [52], an exploration of which HR practices increase the effectiveness of innovation within an organization is needed. Prior research has highlighted the importance of (1) functions and (2) motivators in higher innovative performance (e.g., [67]). First, functions that support innovative attempts is majorly handled by talents within the organization. Roberts and Fusfeld [68] described that critical functions, e.g., idea generating, entrepreneuring, or project leading are essential, and the employees who provide such critical functions account for a fairly small part of the total employees [69]. There has been a growing popularity of talent management as it has been suggested as a contributor to an organization's sustainable competitive advantage [70]. Second, employees are often motivated by the work environment factors which can increase the personal satisfaction, and one of the most important factors is the ability and freedom to pursue ideas of greatest interests of the workers [69]. A controlling management style is likely to reduce employee's motivation and lower creative performance, which in turn reduce creativity and innovation [71]. Contrarily, work autonomy which nurtures the environment in that employees can address problems and opportunities that arise contemporaneously [72,73]. These advantages of task autonomy and employee empowerment are most beneficial for organizations that are attempting innovate, as task autonomy foster creativity and innovation and provide ground for exploratory learning [74]. Furthermore, the innovation process involves intrinsic uncertainty, which is most effectively dealt with by allowing employees to have the greater flexibility in making decisions $[75,76]$. In this regard, we suggest that two types of HR practices, related to talent management and work autonomy, contribute to new product development by supporting innovative activities within an organization. 
First, given the importance of talent in innovative activities and new product development, an HR program that supports talent is expected to strengthen innovation-related pursuits. Firms are increasingly facing a War for Talent, as attracting and retaining talent provides firms with sustainable competitiveness [77]. Huselid at al. [78] argue that there is disproportionate importance placed on a firm's ability to execute some parts of its strategy and wide variability in the quality of work displayed among employees in different positions. While the term talent does not have a widely accepted definition, it is often reported that firms, in practice, define talent as executives, directors, or A-player managers in all functions, or future business leaders with more strategic capabilities than just skills related to operational excellence [79]. One of the most adopted definitions for talent management is "activities and processes that involve the systematic identification of key positions that differentially contribute to the organization's sustainable competitive advantage, the development of a talent pool of high-potential and high-performing incumbents to fill these roles, and the development of a differentiated human resource architecture to facilitate filling these positions with competent incumbents, and to ensure their continued commitment to the organization," by Collings and Mellahi [70] (p. 305). Talent management is closely related to the improvement of operational excellence since a firm's talent is comprised of key decision makers who can handle complex decision processes [80]. Talent provides creative ideas and knowledge creation and enables organizations to improve competitiveness [81-83]. Managing critical talent within the organization is especially important for firms that face uncertainties as talent is most needed when firms have important strategic decisions to make. Joyce and Slocum [84] find that an organization's particular strategic situation increases the need for talent management as it allows the organization to achieve its highest levels of performance. Hence, we expect that the innovation process will be handled more efficiently by firms that have practices that support talent.

Second, it is necessary for firms to respond and adapt to the rapidly changing environment in a timely manner, and this requires flexibility within the organization [71]. It is often argued that the level of exploration is closely related to the level of autonomy given to employees as employees that have new ways of thinking are likely to show autonomous characteristics [85]. Mumford and Gustafson [86] and Zhu [87] highlights the role of autonomy within an organization in facilitating creativity. Higher levels of autonomy allow employees to utilize the best methods and procedures to achieve innovative goals. Prior studies provide empirical evidence of the effects of autonomy on creative performance (e.g., [88-90]). As creativity is affected by autonomy, allowing employees to decide for themselves how best to explore and achieve a goal, we expect that HR practices that support work autonomy will support employees in fully utilizing the new environment that process and organization innovation provides.

Based on the above argument, we propose that talent development and work autonomy will positively moderate the influence of innovation on new product development, leading to the following hypotheses:

H3. Existence of a talent development program strengthens the positive relationship between process/administrative innovation and new product development.

H4. Higher work autonomy strengthens the positive relationship between process/administrative innovation and new product development.

\section{Research Design}

\subsection{Sample}

In order to test the suggested theoretical model (as shown in Figure 1), we utilize the Workplace Panel Survey 2015 [91], a statistical survey approved by the national government and conducted by the Korean Labor Institute, a government-funded policy research body. The sample represents workplaces 
in Korea using stratified sampling and surveys of HR personnel and employee representatives. We only include data obtained from private sector firms, so the final sample consists of 2127 firms.

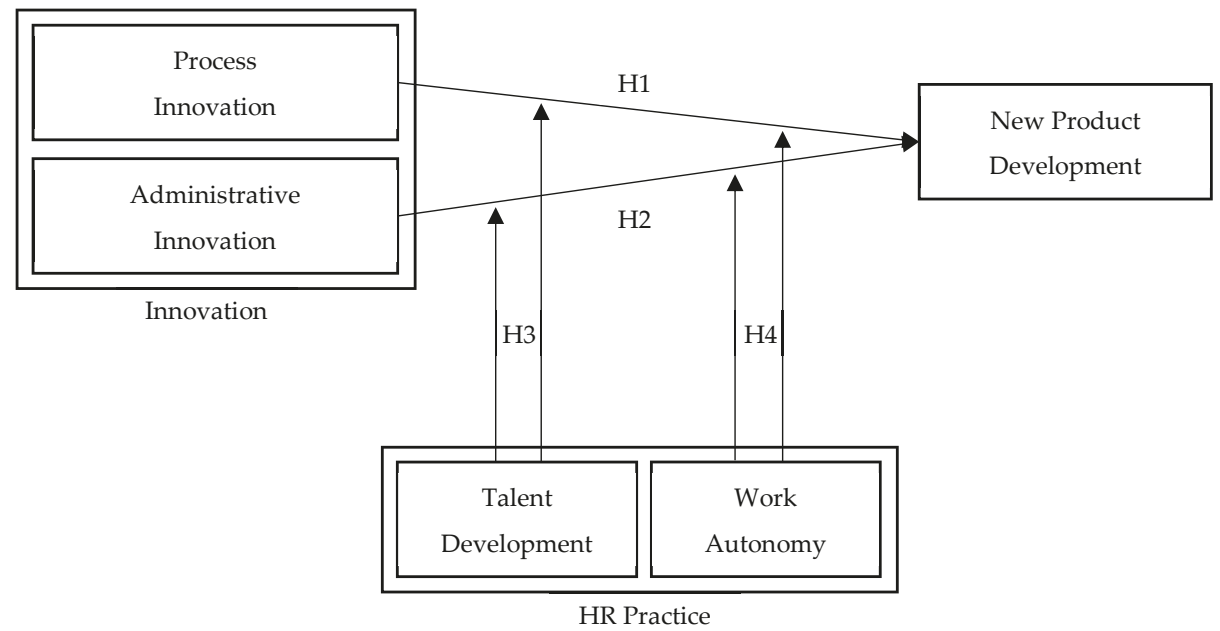

Figure 1. Theoretical research model.

\subsection{Measures}

The dependent variable is New Product Development, which reflects the development of an entirely new, or newly enhanced, product by utilizing the response to the following question: "Did your workplace or company, via innovations of \{product/service\}, launch a new \{product/service\} or a newly improved \{product/service\} in the market?" [91]. An example of a new product innovation is developing a digital camera from a film camera or introducing real-time mobile information delivery, from internet information delivery. The innovations mentioned in the survey responses are innovations in products/services that have been commercialized within the past year, based on the point of view of the organization in question.

Process Innovation is an independent variable that captures significant enhancements in manufacturing logistics or retailing delivery that achieved cost reductions or quality enhancement. We utilize the response to the following question: "Did your workplace implement process innovation last year?" [91]. In this definition of process innovation, only the adoption of manufacturing processes is applicable here. For example, new manufacturing methods (Enterprise Resource Planning, Just-In-Time, etc.); production automation; radio-frequency identification (RFID) on logistics; and IT technology for procurement, accounting, and maintenance are types of process innovation that may have been adopted.

Administrative Innovation is another independent variable that reflects improvements in organizational capability, such as new work processes that improve the quality or efficiency of workflow, new methods of knowledge management, and external relationship improvements. To measure this, we utilize the following question: "Did your workplace implement administrative innovation last year?" This may include, for example, a significant improvement in information collection and sharing within a company, trial administrative changes to improve work flexibility and efficiency, partnering with other companies, and outsourcing. Such innovation should be the result of a management decision and have been executed in a manner that is in line with administrative innovation.

Talent Program is a moderating variable that shows the existence of an HR program that supports talent. Talent can be defined as employees who are professional experts in each job function (research and development, marketing, finance, etc.) or high performers. It is a dummy variable that shows the value of 1 when a firm has a separate personnel management policy to secure, develop, and retain talent, and 0 otherwise. Such a firm will have clearly distinguished talent from workers in general. 
Work Autonomy is a moderating variable that captures the level of autonomy given to the major teams or work groups in making decisions (e.g., working method, the pace of work, recruitment, or training). The value of Work Autonomy varies from 1 to 4, with 4 indicating the highest level of autonomy.

While analysis based on survey allows researchers to construct variables reflecting the theoretical domain, our variable is reflecting the response to a single questionnaire. It is because our sample was extracted from a survey executed by a government-funded policy research body with the aim to understand a firm's behaviors and relevant outcomes. Hence, the questionnaire itself had not been formulated with the academic perspective, and the multiple items are not included to understand a higher theoretical domain. However due to the nature of the research institution, this survey provides a higher response rate and allows us to find the more generalized relationship between organizational innovation, HR practices, and product innovation.

To control for other firm effects, we utilized various firm-specific variables. As a firm size implies the degree of resources availability has been suggested to have an influence on the level of innovation [92] or new product introduction [93], we included Firm Size defined as the natural logarithm value of total assets following Hoskisson et al. [94]. As innovation opportunity can be utilized with financial resources [95], we included two variables related to a firm's financial status. Return on assets (ROA) is defined as net income divided by total assets following Santos et al. [96] and Hoskisson et al. [94]. Debt Ratio is defined as total debts divided by total assets following Aghion et al. [97]. Sales Growth is defined as the percentage change in total sales compared to the prior year's total sales figure following Uhlaner et al. [98]. It is to control the relationship between sales growth and new product development [98]. All control variables were lagged at $\mathrm{t}-1$ following prior studies (e.g., $[99,100])$.

Table 1 summarizes the variables included in the empirical models, and Table 2 displays the correlation relationship between variables.

Table 1. Summary statistics.

\begin{tabular}{lccccc}
\hline \multicolumn{1}{c}{ Variable } & Obs. & Mean & Std. Dev. & Min & Max \\
\hline New Product Development & 2125 & 0.22 & 0.41 & 0 & 1 \\
Process Innovation & 2125 & 0.21 & 0.41 & 0 & 1 \\
Administrative Innovation & 2125 & 0.21 & 0.41 & 0 & 1 \\
Talent Program & 2125 & 0.15 & 0.35 & 0 & 1 \\
Work Autonomy & 2125 & 2.59 & 0.63 & 1 & 4 \\
Firm Size & 2125 & 10.30 & 2.16 & 2.83 & 17.93 \\
ROA & 2125 & 0.06 & 0.28 & -0.59 & 11.94 \\
Debt Ratio & 2125 & 0.57 & 0.37 & 0.00 & 5.34 \\
Sales Growth & 2125 & 0.14 & 2.08 & -0.94 & 66.69 \\
\hline
\end{tabular}

Table 2. Correlation matrix.

\begin{tabular}{|c|c|c|c|c|c|c|c|c|c|}
\hline & & 1 & 2 & 3 & 4 & 5 & 4 & 5 & 6 \\
\hline 1 & New Product Development & 1 & & & & & & & \\
\hline 2 & Process Innovation & $0.48^{*}$ & 1 & & & & & & \\
\hline 3 & Administrative Innovation & 0.35 * & $0.62 *$ & 1 & & & & & \\
\hline 4 & Talent Development & 0.17 * & 0.27 * & $0.26 *$ & 1 & & & & \\
\hline 5 & Work Autonomy & 0.01 & 0.00 & $0.04 *$ & 0.08 * & 1 & & & \\
\hline 6 & Firm Size & $0.22 *$ & $0.27 *$ & $0.26 *$ & 0.28 * & -0.03 & 1 & & \\
\hline 7 & $\mathrm{ROA}$ & 0.03 & 0.02 & 0.02 & -0.02 & 0.01 & $-0.15^{*}$ & 1 & \\
\hline 8 & Debt Ratio & -0.00 & 0.02 & 0.02 & -0.02 & -0.01 & $-0.09 *$ & $-0.06^{*}$ & 1 \\
\hline 9 & Sales Growth & 0.07 * & 0.03 & 0.03 & 0.00 & 0.00 & 0.00 & 0.01 & -0.01 \\
\hline
\end{tabular}




\section{Empirical Analysis and Results}

We employed an ordinary least squares regression model with the fixed effect estimators to test our prediction, and STATA13 was utilized to run the statistical model. Table 3 displays the empirical results for the effect of innovation on product development. Models (1) and (2) show the significant positive effect of Process Innovation and Administrative Innovation on New Product Development, respectively. Model (3) also shows similar results, which supports Hypotheses 1 and 2. Our empirical analysis implied that firms' attempts to innovate their business processes or structures support sustainable product development.

Table 3. Regression analysis: The effect of innovation on product development.

\begin{tabular}{lccc}
\hline \multirow{2}{*}{ Variable } & \multicolumn{2}{c}{ Dependent Variable: New Product Development } \\
\cline { 2 - 4 } & Model (1) & Model (2) & Model (3) \\
\hline Process Innovation & $0.434^{* * *}$ & & $0.388^{* * *}$ \\
& $(21.729)$ & & $(15.833)$ \\
Administrative Innovation & & $0.303^{* * *}$ & $0.078^{* * *}$ \\
& & $(14.456)$ & $(3.193)$ \\
Firm Size & $0.013^{* * *}$ & $0.019^{* * *}$ & $0.012^{* * *}$ \\
& $(3.172)$ & $(4.318)$ & $(2.755)$ \\
Financial Performance & $0.064^{* *}$ & $0.076^{* * *}$ & $0.061^{* *}$ \\
& $(2.298)$ & $(2.579)$ & $(2.173)$ \\
Debt Ratio & -0.003 & 0.000 & -0.006 \\
& $(-0.137)$ & $(0.008)$ & $(-0.270)$ \\
Sales Growth & $0.010^{* * *}$ & $0.011^{* * *}$ & $0.010^{* * *}$ \\
& $(2.793)$ & $(2.774)$ & $(2.744)$ \\
Industry Effect & Controlled & Controlled & Controlled \\
Constant & 0.021 & 0.006 & 0.034 \\
& $(0.432)$ & $(0.107)$ & $(0.698)$ \\
Observations & 2125 & 2125 & 2125 \\
R-squared & 0.267 & 0.177 & 0.264 \\
\hline
\end{tabular}

Note: t-statistics in parentheses. ${ }^{* *} p<0.01,{ }^{* *} p<0.05,{ }^{*} p<0.1$.

Table 4 presents the empirical results for the moderating effect of HR practices in promoting the effect of innovation on new product development. Models (1) and (2) showed that the effect of process innovation on new product development was strengthened when firms have a talent-focused development program and higher work autonomy in the workplace. Similarly, Models (3) and (4) showed that administrative innovation was more effective in terms of new product development when firms had a talent development program and higher work autonomy. The results support hypotheses 3 and 4 .

We utilized STATA13's postestimation command, lincom (linear combinations of estimators), which provides the odds ratio of two variables in question. An odds ratio is a relative measure of the effect size of two variables. Followings are the results. Process innovation had a higher influence on new product development than talent development as the odds ratio was $1.715(p<0.00)$. Process innovation had a higher influence on new product development than work autonomy as the odds ratio was $1.325(p<0.00)$. Administrative innovation had a higher influence on new product development than talent development as the odds ratio was $1.456(p<0.00)$. Administrative innovation had a higher influence on new product development than work autonomy as the odds ratio was $1.329(p<0.00)$. The size above $1 \mathrm{implies}$ the higher \% of odds of new product development in the process/administrative innovation than HR practices. 
Table 4. Regression analysis: The moderating effect of HR practices.

\begin{tabular}{|c|c|c|c|c|}
\hline \multirow{2}{*}{ Variable } & \multicolumn{4}{|c|}{ Dependent Variable: Product Innovation } \\
\hline & Model (1) & Model (2) & Model (3) & Model (4) \\
\hline Process Innovation & $\begin{array}{l}0.394^{* * *} \\
(16.972)\end{array}$ & $\begin{array}{c}0.180^{* *} \\
(2.196)\end{array}$ & & \\
\hline Process Innovation * Talent Development & $\begin{array}{c}0.146^{* * *} \\
(3.154)\end{array}$ & & & \\
\hline Process Innovation * Work Autonomy & & $\begin{array}{c}0.096^{* * *} \\
(3.133)\end{array}$ & & \\
\hline Administrative Innovation & & & $\begin{array}{l}0.267^{* * *} \\
(10.917)\end{array}$ & $\begin{array}{c}0.252 * * * \\
(2.884)\end{array}$ \\
\hline Administrative Innovation * Talent Development & & & $\begin{array}{c}0.110^{* *} \\
(2.235)\end{array}$ & \\
\hline Administrative Innovation * Work Autonomy & & & & $\begin{array}{c}0.016 \\
(0.484)\end{array}$ \\
\hline Talent Development & $\begin{array}{c}-0.037 \\
(-1.239)\end{array}$ & $\begin{array}{c}0.025 \\
(1.050)\end{array}$ & $\begin{array}{c}0.017 \\
(0.535)\end{array}$ & $\begin{array}{l}0.061^{* *} \\
(2.478)\end{array}$ \\
\hline Work Autonomy & $\begin{array}{c}0.007 \\
(0.528)\end{array}$ & $\begin{array}{c}-0.015 \\
(-1.074)\end{array}$ & $\begin{array}{c}0.002 \\
(0.180)\end{array}$ & $\begin{array}{c}-0.003 \\
(-0.204)\end{array}$ \\
\hline Firm Size & $\begin{array}{c}0.012 * * * \\
(2.886)\end{array}$ & $\begin{array}{c}0.013^{* * *} \\
(2.949)\end{array}$ & $\begin{array}{c}0.017^{* * *} \\
(3.702)\end{array}$ & $\begin{array}{c}0.017^{* * * *} \\
(3.710)\end{array}$ \\
\hline Financial Performance & $\begin{array}{l}0.067^{* *} \\
(2.384)\end{array}$ & $\begin{array}{l}0.061^{* *} \\
(2.191)\end{array}$ & $\begin{array}{c}0.078^{* * *} \\
(2.626)\end{array}$ & $\begin{array}{l}0.075^{* *} \\
(2.547)\end{array}$ \\
\hline Debt Ratio & $\begin{array}{c}-0.002 \\
(-0.071)\end{array}$ & $\begin{array}{c}-0.003 \\
(-0.151)\end{array}$ & $\begin{array}{c}0.001 \\
(0.032)\end{array}$ & $\begin{array}{c}-0.000 \\
(-0.016)\end{array}$ \\
\hline Sales Growth & $\begin{array}{c}0.010^{* * *} \\
(2.805)\end{array}$ & $\begin{array}{c}0.011^{* * *} \\
(2.877)\end{array}$ & $\begin{array}{c}0.011^{* * *} \\
(2.791)\end{array}$ & $\begin{array}{c}0.011^{* * *} \\
(2.805)\end{array}$ \\
\hline Industry Effect & Controlled & Controlled & Controlled & Controlled \\
\hline Constant & $\begin{array}{c}0.018 \\
(0.295)\end{array}$ & $\begin{array}{l}0.066 \\
(1.074)\end{array}$ & $\begin{array}{c}0.022 \\
(0.341)\end{array}$ & $\begin{array}{c}0.031 \\
(0.472)\end{array}$ \\
\hline Observations & 2125 & 2125 & 2125 & 2125 \\
\hline R-squared & 0.264 & 0.264 & 0.188 & 0.186 \\
\hline
\end{tabular}

Note: t-statistics in parentheses. ${ }^{* *} p<0.01,{ }^{* *} p<0.05,{ }^{*} p<0.1$.

\section{Discussion and Conclusions}

Organizational sustainability has received considerable management research attention for the past 20 years, and it emphasizes an organization's longer-term success rather than short-term performance. New product development is generally considered as one of the important goals since it benefits society with the innovative products, which in turn allows the firm to have a more durable market presence. Understanding the relationship between organizational innovation and new product development is important as it is not about how to earn more financial gains, rather it is about how to achieve sustainable market participation. Although a firm's attempt to introduce a new offering to the market is important, scholars have paid little attention to the role of innovation in business processes, and organizational structure in creating a new product.

The two main research goals of the present study are: (1) to explore and (2) examine the effect of process and administrative innovation on new product development and the supporting role of HR practices that support innovation. Our empirical findings reveal that organizational innovation increased the likelihood of achieving new product development goals. Existing literature has been mainly focused on the effect of technological innovation or product development specific process innovation on product development (e.g., [7-10]). This is majorly due to the fact that prior research has put most of the emphasis on the role of technological innovation in strengthening the competitiveness, based on a resource-based view which majorly asserts the importance of having resources that are rare, valuable, durable, non-substitutable, inimitable, and appropriable [101-103]. Our findings extend the current literature by showing the importance of organizational innovation on new product development. In this study, we propose that the introduction of process and administrative innovation also serves the resource-based view perspective, as management, and organizational process/system 
may also be firms' important sustainable competitive advantage. Thus, we can conclude that increasing organizational efficiency allows the firm to increase its sustainable presence in the product market.

\subsection{Theoretical Contribution and Implications}

First, our results enhance the understanding of the effect of process and administrative innovations on new product development. In innovation research on product development, we have less understanding of organizational innovation. Damanpour [41] suggested that organization innovation is a non-technological innovation, while innovation has been primarily conceptualized as a technology-based phenomenon. While advancement in technological resources has been argued to be important for the type of competitiveness that leads to new product development, we propose, and show, the value of innovating an organization's way of doing business. This suggests that organizational sustainability is largely determined by how the organization innovates its internal systems and processes to strengthen the efficiency and effectiveness of an organization's daily operations. Our empirical findings are in line with the Edquist et al. [104] and Sanidas [105], in that organizational change is often a cue for technological innovation. Second, our findings on the moderating effects of HR practices imply that the combined effect of process and administrative innovation and constructive HR practices are the most effective way to develop a new product. The external change, that is, process change or administrative structural change, may act as a basic mechanism that allows for a favorable outcome; how employees utilize such a system significantly changes the effectiveness of the innovation attempts. Our results suggest that considering HR practices in examining the effectiveness of innovation may help to better understand the overall effect of an innovation-related attempt in an organization. Third, while prior operations management and supply chain management studies have suggested that external relationships, for example, with supply chain partners [106-109] or customers [110-113], play an important role in achieving new product development, we explore how an organization's internal attempts to increase efficiency and improve human resource utilization matter for the development of new products. Complementary resources or new insights from the external environment may guide organizations in improving sustainability. However, efforts devoted to improving the internal environment are important antecedents of organizational sustainability.

\subsection{Practical Contribution and Implications}

First, our findings suggest that managers should be aware of the importance of increasing efficiency in daily organizational operations. Focusing only on improving technological resources may be an inefficient way to increase organizational sustainability as improvement in an organization's processes and systems nurtures an environment in which employees can utilize resources efficiently. While having a technical ability is an obvious pre-condition for new product development, not all firms with such advanced technical ability successfully develop new products. Our results imply that organizational efficiency achieved through the process and administrative innovation is an important factor for organizational sustainability. However, it is easier for managers to understand the importance of technological innovation on product development, as technology capabilities have been suggested as a core competency of organizations. That is one of the reasons why prior literature also has been mostly focusing on technological innovation [10,11]. To attempt organizational innovation, organizations should expect tangible results, but merely having a goal of developing a new product may not be sufficient enough to convince. Firms are in need of changing their structures or processes may execute organizational innovation, and it may benefit the firm to have ability related to a new product development. Second, our results on the joint effectiveness of the process and administrative innovation and high-quality HR practices in achieving new product development suggest that innovation-supportive HR practices will maximize the benefits of such innovation. Even though innovation attempts are meaningful by themselves, adequately supporting employees who are working toward business projects can change the outcome. Managers should be aware that changes to processes and organizational systems are the external system changes that employees are 
responsible for implementing. In addition, the implication of our findings is that the role of talent is specifically important for new product development, or innovation. In devising HR practices that promote innovation activities in organizations, it is more efficient to prioritize talent in resource allocation. Furthermore, our empirical results show that a creative work environment can be nurtured when employees are given higher levels of work autonomy. Our findings do not suggest that higher work autonomy is beneficial for all organizational activities, but rather highlights its importance in innovative activity.

\subsection{Limitation of the Study and Agenda for Future Research}

Our study is not without limitations. First, we utilized cross-sectional data, which provides a limited time scope. Follow up studies may test the proposed theoretical model using longitudinal data. The accumulation of innovative activities may provide larger benefits in developing new products. Second, while the intensity of innovation may differ among firms, we utilized a binary variable that does not address such differences. Further study may consider other factors that influence the intensity of innovation, such as different characteristics of industry or business cycle. However, our approach also offers value as it is difficult to find organizations that develop the same process or administrative innovations, as all organizations have different structures and systems. Our approach is an efficient way to measure an organization's successful attempt to change its current processes and administrative structure/system. Third, new product development is a variable that captures the introduction of a new product to the market, but it does not reflect the actual market performance of that new product. While we focus on new product development itself, the success of that new product may provide an additional view on the effect of process and administrative innovation. Fourth, while we show the influence of process and administrative innovations on new product development, the next step of this study should test the joint effect of technological and process/administrative innovations.

Author Contributions: Conceptualization, H.C.; formal analysis, methodology, and validation, H.C.; writing-original draft preparation, H.C., P.L., and C.H.S.; writing-review and editing, P.L. and C.H.S.; funding acquisition, H.C.; project administration, P.L. and C.H.S.

Funding: This research received no external funding.

Acknowledgments: This research was supported by the Korea University Research Grant.

Conflicts of Interest: The authors declare no conflict of interest.

\section{References}

1. Kim, W.; Park, J. Examining structural relationships between work engagement, organizational procedural justice, knowledge sharing, and innovative work behavior for sustainable organizations. Sustainability 2017, 9, 205. [CrossRef]

2. Blum-Kusterer, M.; Hussain, S.S. Innovation and corporate sustainability: An investigation into the process of change in the pharmaceuticals industry. Bus. Strategy Environ. 2001, 10, 300-316. [CrossRef]

3. Farr, J.L.; West, M.A. (Eds.) Innovation and Creativity at Work: Psychological and Organizational Strategies; Wiley: Chichester, UK, 1990.

4. Silvestre, B.S. A hard nut to crack! Implementing supply chain sustainability in an emerging economy. J. Clean. Prod. 2015, 96, 171-181. [CrossRef]

5. Ahlstrom, D. Innovation and growth: How business contributes to society. Acad. Manag. Perspect. 2010, 24, 11-24.

6. Baumol, W. Red-queen games: Arms races, rule of law and market economies. J. Evol. Econ. 2004, 14, 237-247. [CrossRef]

7. Guan, J.C.; Yam, R.C.; Mok, C.K.; Ma, N. A study of the relationship between competitiveness and technological innovation capability based on DEA models. Eur. J. Oper. Res. 2006, 170, 971-986. [CrossRef]

8. Camisón, C.; Villar-López, A. Organizational innovation as an enabler of technological innovation capabilities and firm performance. J. Bus. Res. 2014, 67, 2891-2902. [CrossRef] 
9. Evangelista, R.; Vezzani, A. The economic impact of technological and organizational innovations. A firm-level analysis. Res. Policy 2010, 39, 1253-1263. [CrossRef]

10. Cooper, R.G. The drivers of success in new-product development. Ind. Mark. Manag. 2019, 76, 36-47. [CrossRef]

11. Noke, H.; Hughes, M. Climbing the value chain: Strategies to create a new product development capability in mature SMEs. Int. J. Oper. Prod. Manag. 2010, 30, 132-154. [CrossRef]

12. Laosirihongthong, T.; Prajogo, D.I.; Adebanjo, D. The relationships between firm's strategy, resources and innovation performance: Resources-based view perspective. Prod. Plan. Control 2014, 25, 1231-1246. [CrossRef]

13. Perdomo-Ortiz, J.; Gonzalez-Benito, J.; Galende, J. The intervening effect of business innovation capability on the relationship between Total Quality Management and technological innovation. Int. J. Prod. Res. 2009, 47, 5087-5107. [CrossRef]

14. Zhou, K.Z.; Wu, F. Technological capability, strategic flexibility, and product innovation. Strateg. Manag. J. 2010, 31, 547-561. [CrossRef]

15. Terziovski, M. Innovation practice and its performance implications in small and medium enterprises (SMEs) in the manufacturing sector: A resource-based view. Strateg. Manag. J. 2010, 31, 892-902. [CrossRef]

16. Liao, J.; Kickul, J.R.; Ma, H. Organizational dynamic capability and innovation: An empirical examination of internet firms. J. Small Bus. Manag. 2009, 47, 263-286. [CrossRef]

17. Sanz-Valle, R.; Jiménez-Jiménez, D. HRM and product innovation: Does innovative work behaviour mediate that relationship? Manag. Decis. 2018, 56, 1417-1429. [CrossRef]

18. Moorman, C. Organizational market information processes: Cultural antecedents and new product outcomes. J. Mark. Res. 1995, 32, 318-335. [CrossRef]

19. Andersson, M.; Karlsson, C. Knowledge in regional economic growth-The role of knowledge accessibility. Ind. Innov. 2007, 14, 129-149. [CrossRef]

20. Kyläheiko, K.; Jantunen, A.; Puumalainen, K.; Saarenketo, S.; Tuppura, A. Innovation and internationalization as growth strategies: The role of technological capabilities and appropriability. Int. Bus. Rev. 2011, 20, 508-520. [CrossRef]

21. Fu, X.; Pietrobelli, C.; Soete, L. The role of foreign technology and indigenous innovation in the emerging economies: Technological change and catching-up. World Dev. 2011, 39, 1204-1212. [CrossRef]

22. Maidique, M.A.; Zirger, B.J. A study of success and failure in product innovation: The case of the US electronics industry. IEEE Trans. Eng. Manag 1984, EM-31, 192-203. [CrossRef]

23. Athaide, G.A.; Klink, R.R. Managing seller-buyer relationships during new product development. J. Prod. Innov. Manag. 2009, 26, 566-577. [CrossRef]

24. Patanakul, P.; Chen, J.; Lynn, G.S. Autonomous teams and new product development. J. Prod. Innov. Manag. 2012, 29, 734-750. [CrossRef]

25. Yan, T.; Dooley, K. Buyer-supplier collaboration quality in new product development projects. J. Supply Chain Manag. 2014, 50, 59-83. [CrossRef]

26. Brockman, B.K.; Rawlston, M.E.; Jones, M.A.; Halstead, D. An exploratory model of interpersonal cohesiveness in new product development teams. J. Prod. Innov. Manag. 2010, 27, 201-219. [CrossRef]

27. Chien, S.H.; Chen, J.J. Supplier involvement and customer involvement effect on new product development success in the financial service industry. Serv. Ind. J. 2010, 30, 185-201. [CrossRef]

28. Schimmoeller, L.J. Success factors of new product development processes. Adv. Prod. Eng. Manag. 2010, 5, $25-32$.

29. Jaworski, B.J.; Kohli, A.K. Market orientation: Antecedents and consequences. J. Mark. 1993, 57, 53-70. [CrossRef]

30. Lynn, G.S.; Akgün, A.E. Innovation strategies under uncertainty: A contingency approach for new product development. Eng. Manag. J. 1998, 10, 11-18. [CrossRef]

31. Tatikonda, M.V.; Rosenthal, S.R. Successful execution of product development projects: Balancing firmness and flexibility in the innovation process. J. Oper. Manag. 2000, 18, 401-425. [CrossRef]

32. Chen, K.H.; Wang, C.H.; Huang, S.Z.; Shen, G.C. Service innovation and new product performance: The influence of market-linking capabilities and market turbulence. Int. J. Prod. Econ. 2016, 172, 54-64. [CrossRef]

33. Takeishi, A. Bridging inter-and intra-firm boundaries: Management of supplier involvement in automobile product development. Strateg. Manag. J. 2001, 22, 403-433. [CrossRef] 
34. Carr, A.S.; Kaynak, H. Communication methods, information sharing, supplier development and performance: An empirical study of their relationships. Int. J. Oper. Prod. Manag. 2007, 27, 346-370. [CrossRef]

35. Cousins, P.D.; Lawson, B.; Petersen, K.J.; Handfield, R.B. Breakthrough scanning, supplier knowledge exchange, and new product development performance. J. Prod. Innov. Manag. 2011, 28, 930-942. [CrossRef]

36. Hsu, C.C.; Tan, K.C.; Kannan, V.R.; Keong Leong, G. Supply chain management practices as a mediator of the relationship between operations capability and firm performance. Int. J. Prod. Res. 2009, 47, 835-855. [CrossRef]

37. Chesbrough, H. The logic of open innovation: Managing intellectual property. Calif. Manag. Rev. 2003, 45, 33-58. [CrossRef]

38. Coviello, N.E.; Joseph, R.M. Creating major innovations with customers: Insights from small and young technology firms. J. Mark. 2012, 76, 87-104. [CrossRef]

39. Gruner, K.E.; Homburg, C. Does customer interaction enhance new product success? J. Bus. Res. 2000, 49, 1-14. [CrossRef]

40. Joshi, A.W.; Sharma, S. Customer knowledge development: Antecedents and impact on new product performance. J. Mark. 2004, 68, 47-59. [CrossRef]

41. Damanpour, F. Footnotes to research on management innovation. Organ. Stud. 2014, 35, 1265-1285. [CrossRef]

42. Haneda, S.; Ito, K. Organizational and human resource management and innovation: Which management practices are linked to product and/or process innovation? Res. Policy 2018, 47, 194-208. [CrossRef]

43. Mokhber, M.; Khairuzzaman, W.; Vakilbashi, A. Leadership and innovation: The moderator role of organization support for innovative behaviors. J. Manag. Organ. 2018, 24, 108-128. [CrossRef]

44. Armbruster, H.; Bikfalvi, A.; Kinkel, S.; Lay, G. Organizational innovation: The challenge of measuring non-technical innovation in large-scale surveys. Technovation 2018, 28, 644-657. [CrossRef]

45. Birkinshaw, J.; Hamel, G.; Mol, M.J. Management innovation. Acad. Manag. Rev. 2008, 33, 825-845. [CrossRef]

46. Damanpour, F.; Aravind, D. Managerial innovation: Conceptions, processes and antecedents. Manag. Organ. Rev. 2012, 8, 423-454. [CrossRef]

47. Volberda, H.W.; Van Den Bosch, F.A.; Heij, C.V. Management innovation: Management as fertile ground for innovation. Eur. Manag. Rev. 2013, 10, 1-15. [CrossRef]

48. Chen, C.J.; Huang, J.W. Strategic human resource practices and innovation performance-The mediating role of knowledge management capacity. J. Bus. Res. 2009, 62, 104-114. [CrossRef]

49. O'Reilly, C.A.; Pfeffer, J. Cisco Systems: Acquiring and retaining talent in hypercompetitive markets. People Strategy 2000, 23, 38-52.

50. Grant, J.L. Seeking Talent for Creative Cities: The Social Dynamics of Innovation; University of Toronto Press: Toronto, ON, Canada, 2014.

51. Van Esch, E.; Wei, L.Q.; Chiang, F.F. High-performance human resource practices and firm performance: The mediating role of employees' competencies and the moderating role of climate for creativity. Int. J. Hum. Resour. Manag. 2018, 29, 1683-1708. [CrossRef]

52. Lau, C.M.; Ngo, H. The HR system, organizational culture, and product innovation. Int. Bus. Rev. 2004, 13, 685-703. [CrossRef]

53. Ettlie, J.E.; Reza, E.M. Organizational integration and process innovation. Acad. Manag. J. 1992, 35, $795-827$. [CrossRef]

54. Knight, K.E. A descriptive model of the intra-firm innovation process. J. Bus. 1967, 40, 478-496. [CrossRef]

55. Utterback, J.M.; Abernathy, W.J. A dynamic model of process and product innovation. Omega 1975, 3, 639-656. [CrossRef]

56. OECD; Eurostat. Oslo Manual: Guidelines for Collecting and Interpreting Innovation Data, 3rd ed.; OECD Publishing: Paris, France, 2005.

57. Chang, J.; Bai, X.; Li, J.J. The influence of leadership on product and process innovations in China: The contingent role of knowledge acquisition capability. Ind. Mark. Manag. 2015, 50, 18-29. [CrossRef]

58. Najafi-Tavani, S.; Najafi-Tavani, Z.; Naudé, P.; Oghazi, P.; Zeynaloo, E. How collaborative innovation networks affect new product performance: Product innovation capability, process innovation capability, and absorptive capacity. Ind. Mark. Manag. 2018, 73, 193-205. [CrossRef]

59. Damanpour, F.; Gopalakrishnan, S. The dynamics of the adoption of product and process innovations in organizations. J. Manag. Stud. 2001, 38, 45-65. [CrossRef] 
60. Cummings, T.G.; Srivastva, S. Management of Work: A Socio-Technical Systems Approach; Comparative Administration Research Institute, Kent State University Press: Kent, OH, USA, 1997.

61. Damanpour, F.; Evan, W.M. Organizational innovation and performance: The problem of "organizational lag". Adm. Sci. Q. 1984, 29, 392-409. [CrossRef]

62. Roberts, E.B. Managing invention and innovation. Res. Technol. Manag. 1988, 31, 11-29. [CrossRef]

63. Tyre, M.; von Hippel, E. Locating Adaptive Learning: The Situated Nature of Adaptive Learning in Organizations; Working Paper 90-93; International Center for Research on the Management of Technology, MIT: Cambridge, MA, USA, 1993.

64. Eisenhardt, K.M.; Martin, J.A. Dynamic capabilities: What are they? Strateg. Manag. J. 2000, 21, 1105-1121. [CrossRef]

65. Huang, K.F.; Dyerson, R.; Wu, L.Y.; Harindranath, G. From temporary competitive advantage to sustainable competitive advantage. Br. J. Manag. 2015, 26, 617-636. [CrossRef]

66. Abdi, K.; Senin, A.A. Investigation on the impact of organizational culture on organization innovation. J. Manag. Policies Pract. 2014, 2, 1-10.

67. Amabile, T.M. A model of creativity and innovation in organizations. Res. Organ. Behav. 1988, 10, $123-167$.

68. Roberts, E.B.; Fusfeld, A.R. Staffing the innovative technology-based organization. Sloan Manag. Rev. 1981, 22, 19.

69. James, W.M. Best HR practices for today's innovation management. Res. Technol. Manag. 2002, 45, 57-60. [CrossRef]

70. Collings, D.G.; Mellahi, K. Strategic talent management: A review and research agenda. Hum. Resour. Manag. Rev. 2009, 19, 304-313. [CrossRef]

71. Beugelsdijk, S. Strategic human resource practices and product innovation. Organ. Stud. 2008, 29, 821-847. [CrossRef]

72. Lepak, D.P.; Snell, S.A. The human resource architecture: Toward a theory of human capital allocation and development. Acad. Manag. Rev. 1999, 24, 31-48. [CrossRef]

73. Kang, S.-C.; Morris, S.S.; Snell, S.A. Relational archetypes, organizational learning, and value creation: Extending the human resource architecture. Acad. Manag. Rev. 2007, 32, 236-256. [CrossRef]

74. Drucker, P. Management Challenges for the 21st Century; HarperCollins: New York, NY, USA, 1999.

75. Sanchez, R. Strategic flexibility in product competition. Strateg. Manag. J. 1995, 16, 135-159. [CrossRef]

76. Griffin, M.A.; Neal, A.; Parker, S.K. A new model of work role performance positive behavior in uncertain and interdependent contexts. Acad. Manag. J. 2007, 50,327-347. [CrossRef]

77. Bhatnagar, J. Talent management strategy of employee engagement in Indian ITES employees: Key to retention. Empl. Relat. 2007, 29, 640-663. [CrossRef]

78. Huselid, M.A.; Beatty, R.W.; Becker, B.E. 'A players' or 'A positions'? The strategic logic of workforce management. Harv. Bus. Rev. 2005, 83, 110-117. [PubMed]

79. Ashton, C.; Morton, L. Managing talent for competitive advantage: Taking a systemic approach to talent management. Strategic HR Rev. 2005, 4, 28-31. [CrossRef]

80. Boudreau, J.W.; Ramstad, P.M. Beyond HR: The New Science of Human Capital; Harvard Business Press: Boston, MA, USA, 2007.

81. Cappelli, P. Talent management for the twenty-first century. Harv. Bus. Rev. 2008, 86, 74. [PubMed]

82. Makarova, I.; Shubenkova, K.; Pashkevich, A. Development of an Intelligent Human Resource Management System in the Era of Digitalization and Talentism. In Proceedings of the 2018 18th International Conference on Mechatronics-Mechatronika (ME), Brno, Czech Republic, 5-7 December 2018; pp. 1-6.

83. Michaels, E.; Handfield-Jones, H.; Axelrod, B. The War for Talent; Harvard Business Press: Boston, MA, USA, 2001.

84. Joyce, W.F.; Slocum, J.W. Top management talent, strategic capabilities, and firm performance. Organ. Dyn. 2012, 41, 183-193. [CrossRef]

85. Peng, S.L.; Cherng, B.L.; Chen, H.C.; Lin, Y.Y. A model of contextual and personal motivations in creativity: How do the classroom goal structures influence creativity via self-determination motivations? Think. Skills Creat. 2013, 10, 50-67. [CrossRef]

86. Mumford, M.D.; Gustafson, S.B. Creativity syndrome: Integration, application, and innovation. Psychol. Bull. 1988, 103, 27-43. [CrossRef] 
87. Zhu, W.; Avolio, B.J.; Walumbwa, F.O. Moderating role of follower characteristics with transformational leadership and follower work engagement. Group Organ. Manag. 2009, 34, 590-619. [CrossRef]

88. Lumpkin, G.T.; Cogliser, C.C.; Schneider, D.R. Understanding and measuring autonomy: An entrepreneurial orientation perspective. Entrep. Theory Pract. 2009, 33, 47-69. [CrossRef]

89. Volmer, J.; Spurk, D.; Niessen, C. Leader-member exchange (LMX), job autonomy, and creative work involvement. Leadersh. Q. 2012, 23, 456-465. [CrossRef]

90. Liu, D.; Chen, X.P.; Yao, X. From autonomy to creativity: A multilevel investigation of the mediating role of harmonious passion. J. Appl. Psychol. 2011, 96, 294-309. [CrossRef]

91. Korean Labor Institute. The Workplace Panel Survey 2015; Korea Labor Institute: Seoul, Korea, 2015.

92. Forés, B.; Camisón, C. Does incremental and radical innovation performance depend on different types of knowledge accumulation capabilities and organizational size? J. Bus. Res. 2016, 69, 831-848. [CrossRef]

93. Chaney, P.K.; Devinney, T.M. New product innovations and stock price performance. J. Bus. Financ. Account 1992, 19, 677-695. [CrossRef]

94. Hoskisson, R.E.; Hitt, M.A.; Johnson, R.A.; Grossman, W. Conflicting voices: The effects of institutional ownership heterogeneity and internal governance on corporate innovation strategies. Acad. Manag. J. 2002, $45,697-716$.

95. Acharya, V.; Xu, Z. "Financial dependence and innovation: The case of public versus private firms". J. Financ. Econ. 2017, 124, 223-243. [CrossRef]

96. Santos, D.F.L.; Basso, L.F.C.; Kimura, H.; Kayo, E.K. Innovation efforts and performances of Brazilian firms. J. Bus. Res. 2014, 67, 527-535. [CrossRef]

97. Aghion, P.; Bond, S.; Klemm, A.; Marinescu, I. Technology and financial structure: Are innovative firms different? J. Eur. Econ. Assoc. 2004, 2, 277-288. [CrossRef]

98. Uhlaner, L.M.; van Stel, A.; Duplat, V.; Zhou, H. Disentangling the effects of organizational capabilities, innovation and firm size on SME sales growth. Small Bus. Econ. 2013, 41, 581-607. [CrossRef]

99. Chen, H.L.; Hsu, W.T. Family ownership, board independence, and R\&D investment. Fam. Bus. Rev. 2009, $22,347-362$.

100. Chrisman, J.J.; Patel, P.J. Variations in R\&D investments of family and non-family firms: Behavioral agency and myopic loss aversion perspectives. Acad. Manag. J. 2012, 55, 976-997.

101. Amit, R.; Schoemaker, P.J. Strategic assets and organizational rent. Strateg. Manag. J. 1993, 14, 33-46. [CrossRef]

102. Barney, J.B. Resource-based theories of competitive advantage: A ten-year retrospective on the resource-based view. J. Manag. 2001, 27, 643-650. [CrossRef]

103. Peteraf, M.A. The cornerstones of competitive advantage: A resource-based view. Strateg. Manag. J. 1993, 14, 179-191. [CrossRef]

104. Edquist, C.; Hommen, L.; McKelvey, M.D. Innovation and Employment: Process versus Product Innovation; Edward Elgar Publishing: Cheltenham, UK, 2001.

105. Sanidas, E. Organizational Innovations and Economic Growth: Organosis and Growth of Firms, Sectors, and Countries; Edward Elgar Publishing: Cheltenham, UK, 2005.

106. Swink, M. Threats to new product manufacturability and the effects of development team integration processes. J. Oper. Manag. 1999, 17, 691-709. [CrossRef]

107. Petersen, K.J.; Handfield, R.B.; Ragatz, G.L. Supplier integration into new product development: Coordinating product, process and supply chain design. J. Oper. Manag. 2005, 23, 371-388. [CrossRef]

108. Yoo, S.H.; Shin, H.; Park, M.S. New product development and the effect of supplier involvement. Omega 2015, 51, 107-120. [CrossRef]

109. Yan, T.; Kull, T.J. Supplier opportunism in buyer-supplier new product development: A China-US study of antecedents, consequences, and cultural/institutional contexts. Decis. Sci. 2015, 46, 403-445. [CrossRef]

110. Chang, W.; Taylor, S.A. The effectiveness of customer participation in new product development: A meta-analysis. J. Mark. 2016, 80, 47-64. [CrossRef]

111. Brockhoff, K. Customers' perspectives of involvement in new product development. Int. J. Technol. Manag. 2003, 26, 464-481. [CrossRef] 
112. Cooper, R.G.; Kleinschmidt, E.J. New Products: The Key Factors in Success; Marketing Classics Press: Chicago, IL, USA, 2011.

113. Cui, A.S.; Wu, F. The impact of customer involvement on new product development: Contingent and substitutive effects. J. Prod. Innov. Manag. 2017, 34, 60-80. [CrossRef]

(c) (1)

(C) 2019 by the authors. Licensee MDPI, Basel, Switzerland. This article is an open access article distributed under the terms and conditions of the Creative Commons Attribution (CC BY) license (http://creativecommons.org/licenses/by/4.0/). 
Article

\title{
Employee Satisfaction and Loyalty as a Part of Sustainable Human Resource Management in Postal Sector
}

\author{
Mariana Strenitzerová * and Karol Achimský \\ Faculty of Operation and Economics of Transport and Communications, University of Žilina, Univerzitná 8215/1, \\ 01026 Žilina, Slovakia \\ * Correspondence: mariana.strenitzerova@fpedas.uniza.sk; Tel.: +421-41-513-3131
}

Received: 30 May 2019; Accepted: 20 August 2019; Published: 23 August 2019

\begin{abstract}
The labor market situation in the postal and logistics sector has led to sustainable human resource management becoming increasingly important at the strategic level of each postal operator. This study proposes a new perspective of employee satisfaction assessment that not only quantifies total satisfaction but identifies job attributes and socio-demographic characteristics affecting employee satisfaction and loyalty as a key concern for sustainable human resource management. Findings of 1775 survey questionnaires of employees in Slovak Postal enterprise revealed that employee satisfaction is on average. The greatest dissatisfaction was related to the financial reward of employees and the employer's lack of interest in the views and attitudes of employees. The use of regression and correlation analysis pointed to the fact that not only their satisfaction, but also the situation on the labor market in the region, the age of the employee, the job position and the length of employment have a strong influence on employee loyalty.
\end{abstract}

Keywords: sustainability; sustainable human resource management; labor market in postal sector; employee satisfaction; employee loyalty

\section{Introduction}

The concept of sustainability is important for companies in the sector of postal services. Globalization, liberalization of postal market, the entry of competition into the postal market, and Internet of Things have led to significant changes across the functioning of postal companies. The changes also concerned human resource management. Sustainable human resource management is a typical cross-functional task that becomes more and more important at the strategies of postal companies.

Sustainable human resource management (HRM) can help postal companies to establish an attractive employer brand that can address the different needs and expectations of potential and existing employees, without compromising a consistent employer image, which can result in a sustained competitive advantage of the postal company. Sustainable HRM can help postal companies attract and retain high-quality employees, because by integrating sustainable HRM practices into the employee value proposition, they establish a unique, attractive employer brand. An interesting study in this area was carried out by App et al. [1] whose conclusions can also be applied to postal employers.

Postal companies become aware of their responsibilities towards employees and engage in sustainable HRM. In particular, they consider the creation of the best working conditions for safety, health, social background and continuous training of employees as their role. All these activities aim at the main goal of postal companies in the area of HRM-to increase the satisfaction and loyalty of their employees. However, are these activities effective and efficient? How do employees perceive them? Are they satisfied with this care by the employer? The aim of this study is to assess the sustainable HRM practices from the perspective of postal company employees and its impact on their 
satisfaction and loyalty. We tried to include in our research the comprehensive activity of the Human Resource Division and the activities related to sustainable HRM. The postal sector suffers from a lack of workforce and therefore postal companies pay great attention to the satisfaction and loyalty of employees. Employer image, employee expectations, perceived quality of services of Human Resource Division, value perceived by employees are factors that significantly affect the employee satisfaction and employee loyalty to postal companies. The purpose of this study is to evaluate the impact of these factors (latent variables) on employee satisfaction and consequently evaluate the impact of employee satisfaction on their loyalty to the employer. Our research has drawn attention to the importance of relationships between employee expectations, perceived HR service quality, value perceived by employees and employee satisfaction. Our research has pointed out how demographic factors (age, length of employment for the postal provider, job classification, place of work-region, labor market in a region) influence satisfaction and loyalty of Slovak Post employees.

\section{Theoretical Framework and Hypotheses Development}

\subsection{Sustainable Human Resource Management Literature}

Companies willing to attract and retain human resources for running businesses in the future must change the prevailing situation where human resources are rather consumed than developed. In doing this, sustainable HRM has been introduced recently as a response to changes on societal levels, labor market, and employment relations. Sustainable HRM is seen as an extension of strategic HRM and presents a new approach to people management with the focus on long-term human resource development, regeneration, and renewal [2].

Researchers and other professionals unanimously agree that companies should become more sustainable, but this will not happen without the support of HRM [3]. Labbour and Santos [4], in their work, present the main contributions of HRM to develop sustainable organizations. The relationship between human resources and organizational sustainability involves some important aspects concerning management such as innovation, cultural diversity and the environment.

Kramar [5] examines the major features of sustainable HRM, some of the meanings given to sustainability and the relationship between sustainability and HRM. He emphasizes the need focus on the sustainable HRM contributing not only to financial outcomes, but also to the importance of human, social and ecological outcomes in terms of their contribution to business outcomes.

Esfahani et al. [6] investigate the main characteristics of a sustainable HRM in innovative organizations. The aim of their research was to find the relationship between psychological capital, HR flexibility and sustainable HRM in innovative organizations. They examined HRM in innovative organizations may benefit from psychological capital and the flexibility of human resources. They found that functional HR flexibility and optimism have maximum effect on HR sustainability.

Even family businesses, and small and medium enterprises (SME) need to think about their sustainability. Ping [7], in his research, presents some strategies and proposals for the innovation of HRM of a family business under the background of sustainable development. Liu and Yu [8] analyze HRM based on sustainable development in SMEs and bring forward some strategies and recommendations to improving HRM in SMEs.

Jarlstrom, Saru, Vanhala, illustrate the dimensions and broader responsibilities of sustainable HRM. Their research analyses how top managers construct sustainable HRM, its responsibility areas and how top managers identify and prioritize stakeholders in sustainable HRM [9].

Enterprise culture is one of the key factors of HRM. Wu et al. [10] confirmed that Harmony-Oriented Culture forms the basis for the sustainable development of enterprise management.

Kazlauskaite and Buciuniene [11] attach great importance to human resources and their management in the establishment of sustainable competitive advantage. They are convinced that human resources make the strategic value for an organization. Acquiring and sustaining of competitive advantage necessitates unique, valuable, and inimitable employees and effective people management 
practices. According to Kucharcikova et al. [12] human capital management represents a modern concept of people management which also leads to the increase of performance and competitiveness of the enterprise within the context of sustainability. It is necessary measurement and assessment of the effectiveness of the utilization of human capital and effectiveness of investment in its development.

Realizing the sustainable development of economy is the most important strategic target of regional economic development. It is also decided by the human resource reasonable development and optimization. Wang and Wang [13] elaborated the relations between the HRM and the regional economic sustainable development. Sustainable employability policy can positively influence regional economic development. Van der Heijden [14] pays directed attention to sustainable employability policy as being part of strategic HRM.

Lis [15] focuses the relevance of corporate social responsibility for a sustainable HRM. Each aspect of Corporate Social Responsibility (CSR) has a specific effect on company's attraction and can be an effective tool to attract potential employees.

Macke and Genari [16], in their study, aim to analyze the state-of-the-art advancements of sustainable HRM and to identify key elements, trends and research gaps. They define four categories of studies. The first category comprises studies on sustainable leadership, based on individual and group power and is embedded in its principles, processes, practices and organizational values. The second category demonstrates the relationship among HRM, environmental sustainability and organizational performance. The third category considers the tensions and paradoxes between HRM practices and sustainability: on the one hand, HRM should focus on cost reduction and corporate profitability (in the short-term); on the other, their actions should provide long-term sustainability of organizational performance. The last category deals with the link between HRM and the social dimension of sustainability, especially with regard to organizational social responsibility and the company's relationship with its stakeholders.

Drawing on literature from a range of works linking sustainability and HRM and following the essence of corporate sustainability, Stankeviciute and Savaneviciene [2] propose 11 characteristics of sustainable HRM, namely: Long-term orientation, care of employees, care of environmental, profitability, employee participation and social dialogue, employee development, external partnership, flexibility, compliance beyond labor regulations, employee cooperation, fairness, and equality. All these characteristics affect the employee satisfaction and loyalty ratings, which are the subject matter of our research. The objective to succeed, ensure sustainability, remain competitive, and to increase business efficiency can only be ensured by satisfying the needs of employees by providing them with good working conditions [17-19]. The quality of work life positively and significantly influences employee job satisfaction, and employee loyalty [20]. Additionally, Al Mamun et al. [21], Cantele, and Zardini [22], Delmas, and Pekovic [23], Pintão et al. [24], and Dongho [25] referred to employee satisfaction as one of many challenges, since the productivity of employees was crucial to the company's success or failure.

Employees satisfied with their rewards and work environment do not have a need to leave the company; they are loyal. It is optimum when employees are satisfied with their conditions and work environment [26-28]. The same view was presented by Chang et al. [29], Chatterjee et al. [30], Gianni et al. [31], Roxas et al. [32], and Chandrasekar [33], who argued that the company needs to pay attention to creating a work environment that enhanced the satisfaction and motivation of employees in order to increase corporate sustainability performance.

Giovanis [34], explored the relationship between job satisfaction, employee loyalty and two types of flexible employment arrangements; teleworking and flexible timing. The author applied the Bayesian networks (BN) and directed acyclic graphs (DAGs) to confirm the causality between employment types explored and the outcomes of interest. Additionally, he proposed an instrumental variables (IV) approach based on the BN framework. The results support that a positive causal effect from these employment arrangements on job satisfaction and employee loyalty is present. The subject 
of our research is also the relationship between job satisfaction, employee loyalty and job classification in condition of postal companies.

Kot-Radojewska and Timenko [35], examined the relationship between employee loyalty to the employer and the form of employment. The research results indicated that the employees who have an indefinite duration employment contract rated the degree of their own loyalty to the employer higher than people that have a fixed-term employment contract. This is an interesting finding that will be the subject of our research of dependence of employee loyalty on length of employment for Slovak Post.

Recently there has been a resurgence of interest in the analysis of job satisfaction variables. Job satisfaction is correlated with labor market behavior such as productivity, resignations and absenteeism. Gazioglu and Tansel [36], provide an empirical analysis of the determinants of job satisfaction in Britain. Four different measures of job satisfaction are used: satisfaction with influence over job; satisfaction with amount of pay; satisfaction with sense of achievement; and satisfaction with respect from supervisors. These four different measures of job satisfaction are related to a variety of personal and job characteristics. The main results can be summarized as follows: job satisfaction is U-shaped in relation to age; the better-educated are less satisfied relative to those with no or few qualifications; higher income produces higher levels of satisfaction; long working hours reduce satisfaction; satisfaction is lower in larger establishments; those who are in managerial, professional and clerical occupations are more satisfied than sales employees; those employees who had job training were more satisfied than those who had no training opportunities. These are interesting results that have led us to research how some of these characteristics affect employee satisfaction and loyalty in the postal sector. Baumgardt et al. [37] are also convinced that aspects to be considered to reinforce job satisfaction are age, years of practice, quality and quantity of cooperation.

It is generally believed that job satisfaction increases linearly with age. However, there are persuasive arguments, and some empirical evidence, that the relationship is U-shaped, declining from a moderate level in the early years of employment and then increasing steadily up to retirement. For overall job satisfaction, satisfaction with pay, and satisfaction with the work itself a strongly significant U-shape is observed. Clark et al. [38] thus provide strong evidence for a U-shaped relationship between age and job satisfaction. This is an interesting finding that has also been the subject of our research.

Sustainable HRM has a broad scope and all areas of its research can be applied to the postal sector and postal companies; these are among the major employers and attribute HRM great importance.

\subsection{Sustainable Human Resource Management in Postal Sector}

The postal sector demonstrates leadership and innovation in the field of global corporate sustainability. Significant international developments such as the adoption of the Paris Agreement and the rising prominence of the UN Sustainable Development Goals (SDGs) have signaled the need for more urgent sustainability action from the global business community. Accordingly, in 2019 International Post Corporation's (IPC) Environmental Measurement and Monitoring System (EMMS) program will be expanded beyond carbon management to encompass broader sustainability goals. IPC will set ambitious targets across a range of sustainability issues, designed to drive significant improvements and ultimately help the postal sector maintain its position as a sustainability leader [39].

Last year, the program's participants identified the five UN SDGs most material to the postal sector, which take action to mitigate climate change and cover issues such as ensuring decent working conditions, promoting innovation, building sustainable cities and communities, ensuring responsible production and consumption. The postal operators involved in the program have implemented many activities related to sustainable HRM. They mainly concerned decent working conditions and employee training.

The bpost, Belgium's largest postal service, has defined its wider Corporate Social Responsibility (CSR) strategy and its potential impact on the sustainability score, around three main pillars:

- People: care about employees and engage them with sustainably (employee health and safety, employee training and talent development, ethics and diversity, social dialogue); 
- Planet: to strive to reduce its impact on the environment (green fleet, green buildings, waste management);

- Proximity: to engage with the community it serves (be close to the society: to community, to suppliers, to customers through its services).

The goal is the shared value creation: continuity of business, employee satisfaction and engagement, customer satisfaction.

The bpost plays a major role in society, and it strives to be an organization that its customers can trust. Embedding its CSR strategy and introducing innovative programs into its corporate operations and culture will help it reach its ambition of sustainable growth and demonstrating sustainability leadership.

In order to address the environmental impact of last-mile deliveries, Spanish operator Correos and Correos Express have joined forces to implement a sustainable delivery program. The Correos and Correos Express programs integrating efficiencies and new technologies underpin its commitment to the environment and capacity for innovation. Correos implemented route optimization systems and developed new delivery methods such as the CityPaq service, an automated collection point. These initiatives have engaged and brought satisfaction to employees, introduced more sustainable and cost-effective transport and reduced the environmental impact on local communities.

For Le Groupe La Poste, sustainability and innovation go hand in hand. France's postal operator has developed creative technological delivery solutions including a remote-controlled drone and an automated mail cart named Effibot. This autonomous cart accompanies the postman/postwoman during his/her delivery round and facilitates the work, stopping when they stop, circumventing obstacles and carefully avoiding pedestrians. The DPD group drone simplifies deliveries in secluded or difficult to access areas, and can facilitate deliveries in emergency situations, such as delivering medicine. These sustainable solutions are not only safer for employees and more efficient for customers. They are part of the new and innovative technologies that can help deliver environmental benefits and improve employees' working conditions.

Poste Italiane is empowering people through sustainability insights. Managing the impact of the mobility of people and goods is an ever increasing environmental and social challenge. Knowledge sharing, particularly around transportation and behavior, is a key element to empowering people to make choices that will have positive impacts for the community now and for generations to come. In 2017, Poste Italiane's corporate Mobility Management unit produced an e-book entitled Perché muoversi in modo sostenibile? (i.e., Why should we opt for a sustainable mobility?). This e-book illustrates a series of best practices and economic advantages linked to more environmentally sustainable lifestyles, aimed at promoting greater awareness and sustainable mobility amongst Poste Italiane's employees. The e-book is free and employees are encouraged to share these insights with their communities, thereby empowering a greater number of people to make more sustainable mobility choices. This knowledge sharing builds on Poste Italiane's 150-year history and aligns its reputation with progress, innovation and care for the community.

Driver training is another key way in which program's participants can achieve emissions reductions from own transport. Many of our participants have already introduced eco-driving initiatives and communications campaigns for their drivers and are already making progress in this area. Moreover, the participation of nine postal companies in IPC's fifth International Drivers' Challenge in April 2018 illustrates participants' ongoing commitment to reducing emissions from transport. Their participation also demonstrates their commitment to engaging employees in sustainability issues, a key part of effective carbon management. Through this event, which was hosted at the Estoril Racing track in Portugal, IPC emphasized the importance of economic and fuel-efficient driving behavior and demonstrated the benefits of investment in eco-driving initiatives.

Postal companies become aware of their responsibilities towards employees and engage in sustainable HRM. In particular, they consider the creation of the best working conditions for safety, health, social background and continuous training of employees as their role. Postal companies are 
making considerable efforts towards continuous improvement in the area of occupational safety and health protection. Equally, in the implementation of education and in the consistent application of the principles of diversity and equal opportunities. An open communication culture, supporting employee engagement in these processes and activities, is a matter, of course, for postal companies. In this context, they realize that a motivating work environment is also important. All these activities aim at the main goal of postal companies in the area of HRM — to increase the satisfaction and loyalty of their employees. The postal sector suffers from a lack of workforce and therefore postal companies pay great attention to the satisfaction and loyalty of employees as a part of sustainable HRM. That is why Slovak Post, as a universal postal service provider and the second largest employer in Slovakia, welcomed cooperation in solving our research.

\subsection{Labor Market Situation in the EU and Slovak Republic Postal Sector}

The provision of postal services is of fundamental importance in terms of regional development, social inclusion and the economic and territorial cohesion of the EU. The postal sector has undergone significant changes in recent years as a result of technological advances and digitalization, and the modernization and diversification of postal services also has a strong impact on working conditions and employment in this sector. The liberalization of postal services as a process of removing obstacles to free enterprise in the postal market has had an impact on the development of the postal market in the Slovak Republic. However, its impact can be assessed from a variety of aspects. It influenced the activity of the universal service provider, contributed to the development of competition in the postal market, influenced the behavior and satisfaction of the customers of the postal market and also contributed to the development of the postal market. However, the liberalization of the postal market has also significantly affected the labor market situation in the postal sector and employment in the sector.

HR managers of postal operators find that getting and keeping quality staff is not as easy as it used to be in the past. Qualified staff in the area of postal services have the opportunity to use a much wider offer of work by postal operators. The need for sustainable, high-quality employment in this sector leads the postal operators to spend considerable investment to sustainable HRM, creating the HRM strategy and HR marketing activities.

Until the mid-1980s, post was considered to be part of the public service in all EU countries. In the 1990s, several state-owned postal organizations were privatized and became private by the organizations that provide postal services. The terminology also includes the term of a national operator or postal operator or "incumbent" to designate entities that "hold power" and "have a duty" resulting from their market position. At the same time, their position is historically conditioned, when in the past these entities represented monopolistic institutions in their countries most often in state ownership. The development of technologies and market also leads to their changes-the loss of monopoly and privatization, respectively change of ownership structure [40].

Competition is a healthy and desirable phenomenon in the whole economy, and the post is no exception, stimulating innovation-exploring new and existing customer service methods, including identifying potential customers and their needs. Success in a competitive environment is generally expressed not only by the benefits, but also by the quality of the HR activities and by the quality of staff (the level of management work, increasing moral awareness among employees, etc.).

Postal operators play an important role in the social policy of the state by creating employment opportunities. In many countries, operators operating in the postal markets are one of the largest employers, and secondarily, they create a high number of jobs in the electronics and downstream industries [40].

The European Commission collects data on postal services in cooperation with the National Regulatory Authorities of the Post (NRAs) of participating countries through the EU Postal Survey. Data are collected annually from the 33 countries that participate voluntarily in data collection, including the 28 EU Member States. The indicator for the number of employees of individual universal service 
providers (Table 1) captures staff working exclusively in the field of postal services in the economic territory of the reference country [41]. The above statistics show that the number of employees of the universal service provider in Slovakia is decreasing. According to data of the Office for Regulation of Electronic Communications and Postal Services, currently 25 postal enterprises are registered in Slovakia. The statistics show that the average number of employees in postal services and courier services is up to $89.2 \%$ employees of universal service providers [42]. Employment with other postal operators (outside universal service providers) is the driving force behind overall employment growth in the postal sector. Employment rates for other postal service providers increased significantly between 2013 and 2015. Based on the results of the ERGP37 study, an increase of 29.8\% for the number of persons employed by other postal service providers was recorded between 2008 and 2015 [43].

Table 1. The number of persons employed in the provision of postal services domestically (persons employed by universal service providers).

\begin{tabular}{|c|c|c|c|c|c|}
\hline Geo/Time & 2012 & 2013 & 2014 & 2015 & 2016 \\
\hline Belgium & 29,922 & 28,747 & 27,479 & 24,703 & 24,850 \\
\hline Bulgaria & 11,384 & 11,126 & 10,794 & 10,572 & 10,508 \\
\hline Czechia & : & 62,678 & 59,610 & 58,890 & 58,345 \\
\hline Denmark & 13,386 & 12,727 & 11,772 & 10,399 & 9314 \\
\hline Germany & : & : & 148,518 & 148,669 & 146,826 \\
\hline Estonia & 2049 & 2059 & 1640 & 1768 & 1804 \\
\hline Ireland & 8729 & 8251 & 8006 & 7890 & 7803 \\
\hline Greece & 8837 & 7977 & 7185 & 6859 & 8039 \\
\hline Spain & $:$ & : & 51,275 & 50,153 & 54,764 \\
\hline France & : & : & : & 207,890 & 205,053 \\
\hline Croatia & 8137 & 7394 & 7082 & 7912 & 8078 \\
\hline Cyprus & 1224 & 1210 & 1690 & 1702 & 650 \\
\hline Latvia & 4215 & 4095 & 4189 & 4236 & 4239 \\
\hline Lithuania & 6482 & 6272 & 6019 & 5924 & 5783 \\
\hline Luxembourg & 1402 & 1376 & 1415 & 1385 & 1385 \\
\hline Hungary & 31,610 & 25,787 & 23,779 & 28,427 & 27,967 \\
\hline Malta & : & : & : & : & $:$ \\
\hline Netherlands & : & 59,280 & 52,364 & 49,174 & 46,456 \\
\hline Austria & : & 20,145 & : & : & : \\
\hline Poland & 91,373 & 83,468 & 79,741 & : & : \\
\hline Portugal & 11,715 & 11,043 & 10,765 & 10,812 & 10,881 \\
\hline Romania & 32,887 & 27,451 & 26,784 & 24,518 & 24,139 \\
\hline Slovenia & 5598 & 5352 & 5968 & 5831 & 5510 \\
\hline Slovakia & 14,470 & 14,363 & 14,329 & 14,214 & 14,049 \\
\hline Finland & 18,610 & 18,610 & 16,558 & 16,669 & 16,220 \\
\hline Sweden & 23,912 & 23,721 & 21,853 & 21,462 & 20,272 \\
\hline United Kingdom & 149,710 & 149,172 & 145,205 & 139,000 & 142,000 \\
\hline Iceland & 1078 & 1053 & 1001 & 1093 & 1115 \\
\hline Norway & 19,388 & 19,022 & 19,114 & 18,590 & 16,992 \\
\hline Switzerland & 52,378 & 51,779 & 52,831 & 51,619 & : \\
\hline Former Yugoslav Republic of Macedonia & 2288 & 2217 & 2306 & 2265 & 2343 \\
\hline Serbia & 15,068 & 15,155 & 15,015 & 14,965 & 14,868 \\
\hline
\end{tabular}

Source: https://ec.europa.eu/growth/sectors/postal-services/statistics_en. 
The Committee on Employment and Social Affairs of the European Parliament notes that employment in universal service providers is declining as a result of declining volumes of letter shipments and current modernization and increasing automation. Replacing paper mail with digital tools, technological advances to enable citizens to access services and communications from home also led to a decline in the number of post offices and a decline in the number of postal service staff.

Even though the number of employees in the postal service sector is decreasing, the number of short-time employees, agency workers and the self-employed in this sector has risen. The trend is towards more flexible employment contracts, which in some cases can lead to precarious jobs without adequate protection for employees [44].

The average wage in the EU postal sector is about 13 euros per hour and increased by six percent in the period 2013-2016. Wages in the postal sector vary considerably across European regions, with Eastern Europe having the lowest average wage, around 3.5 euros per hour, and Western Europe the highest, around 23 euros per hour. North and South Europe show similar average wages ranging between $€ 12$ and $€ 14$ per hour.

Payroll mechanisms are influenced by various factors, from the general macroeconomic situation of the country to the financial position of the postal operator. Political factors also play a role, particularly in situations of conflicting policy objectives, maximizing financial returns from state-owned enterprises and maintaining a stable level of employment [43].

The liberalization of postal services has led to significant differences in some Member States as regards working conditions and wages offered by universal service providers and competing companies providing specific postal services. The evolution of the average nominal monthly salary of an employee in postal and courier services in the Slovak republic (SR) is below the average nominal wage throughout the economy (Figure 1) [45].

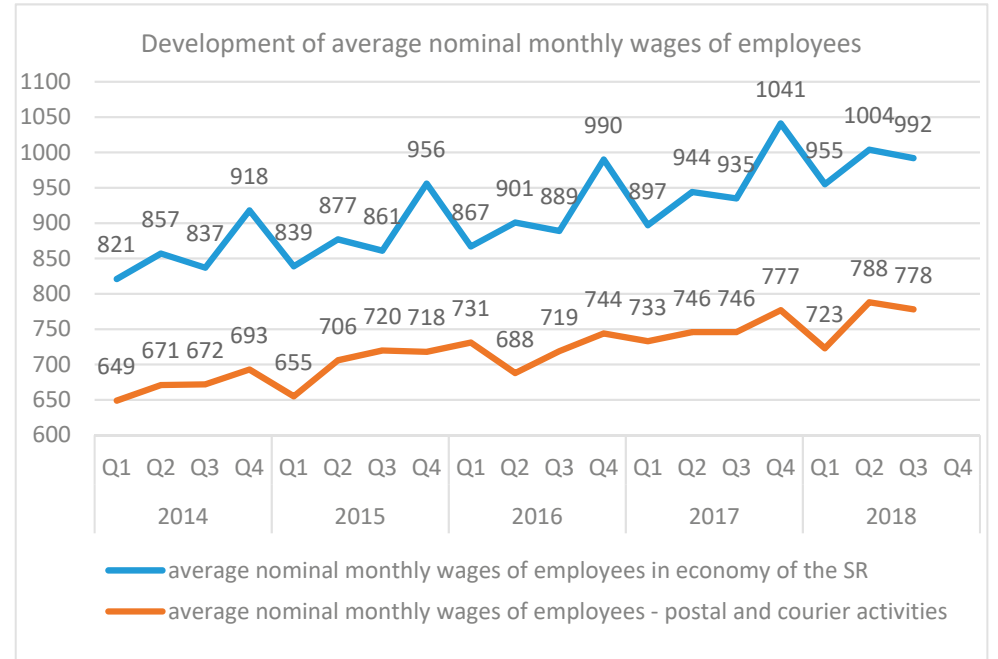

Figure 1. Development of average nominal monthly wages in sector of postal and courier activities. (Source: Statistical Office of the Slovak Republic. DATAcube. Created by author).

Average hourly wages at a universal service provider are often lower than average wages at national level. In most regions, wages in the transport and storage sector as a whole (including postal and courier services) are lower than average wages at national level.

The average monthly wage in postal and courier services of EUR 720 in the year 2016 was $86.4 \%$ of the average monthly wage in the transport, storage and postal services sector and was also the lowest average monthly wage within the sector [42]. 
Market opening and increased competition have forced national postal operators to modernize their wage structure. Such changes would, however, be more pronounced if collective labor contracts could be predefined and more flexible. Changes in minimum wages are an important driving force for salary development in the postal sector. However, minimum wage regimes differ in some major European economies. In France they are indexed by the consumer price index, while in Sweden there is no minimum wage regime. In many countries, the minimum wage is set by the state, which can be based on wages agreed on the market or negotiated with stakeholders.

Working condition rules and the role of the social partners also influenced the development of employment conditions in some postal markets. Social dialogue in the postal sector has played an important role in minimizing the negative impact of market changes on employment, for example through collective labor agreements. Employers and trade unions constructively work together to manage change in a socially responsible way. Coverage of trade unions and collective bargaining, however, shows the different levels of competence of trade unions in wage negotiations in individual countries.

Slovak Post (SP), as a universal service provider, is the second largest employer in Slovakia. In 2016, SP provided services by 13,446 employees in an average recalculated number. Of the total, women accounted for $82.50 \%$. Compared to 2015 , employment declined by $0.92 \%$. Employees of SP were paid wages in the amount of 114,862 thousand $€$. The year-on-year growth rate of the average monthly wage of SP employees affected by the development of employment and wage earners reached $103.31 \%$ in 2016, it means the average monthly wage reached $€ 711.85$ [46]. However, the average monthly wage is below the average in the national economy as well as in the sector of postal and courier services. The analysis of the labor market situation in the postal sector, the development of the number of employees and the development of the average wage in the postal sector have served as a basis for the assessment of employee satisfaction with the remuneration system and for the survey of employee loyalty.

\section{Materials and Methods}

Our research pointed out that the designed HRSI model can provide a better understanding of the complex relationships of the variables of employees' loyalty and employee satisfaction and their impact on sustainability of the postal provider. Factor analysis was used to summarize indicators (measurable variables) which identify the crucial factors. The regression and correlation analysis was used to examine the relationships between latent variables and measurable variables (indicators) which affect the satisfaction of employees and their loyalty to the employer. The regression and correlation analysis and association analysis was used to address the impact of demographic factors on employee satisfaction and loyalty.

\subsection{Employee Job Satisfaction-Methodology}

The academic literature has a long history of investigating employee job satisfaction. According to Spector, employee satisfaction is now a common concern among companies. Job satisfaction is a key factor in an employee's life, and thus job satisfaction is a stimulating topic to study [47]. Most academic research on this topic focuses on measuring and assessing job satisfaction [48-55]. When using the job elements comprehensive scoring method, scholars hold different views of the structure of job satisfaction. An often-used method is the Minnesota Satisfaction Questionnaire (MSQ), which classifies job satisfaction into four main aspects: work itself, interpersonal relationships on the job, reward and development [56]. Psychologist Smith advances Job Descriptive Index (JDI), which is comprised of five key dimensions, including satisfaction with: work itself, pay, supervision, opportunities for promotion, and co-workers. The JDI is designed to measure employees' satisfaction with their jobs. The JDI is a "facet" measure of job satisfaction, meaning that participants are asked to think about specific facets of their job and rate their satisfaction with those specific facets. The Job In General (JIG) is also designed 
to measure employees' satisfaction with their jobs. The JIG is a measure of global satisfaction, meaning that participants are asked to think about how satisfied they are with their job in a broad, overall sense.

Many studies, however, provide a partial view of job satisfaction since they usually focus on the one-to-one relationship between an antecedent condition and job satisfaction, without taking a global view, to show how different factors simultaneously affect job satisfaction. This research posits that a combination of factors (e.g., employer image, employee expectations, perceived HR service quality, value perceived by employees) affects employee job satisfaction and loyalty. This study used a qualitative comparative analysis to explore the association between employee satisfaction, loyalty and the different socio-demographic factors and work attributes developed by postal employers.

As a suitable tool for this purpose, we created the HRSI (Human Resource Satisfaction Index) model (Figure 2), which can provide diagnostic of the complex relationships of the variables of employee satisfaction and their impact to loyalty of employee and sustainability of Slovak Postal provider. When creating the HRSI model, we based it on the general ECSI (European Customer Satisfaction Index) model, in which we considered Slovak Post employees as an internal customer of the Human Resource Division of the Slovak Post. The ECSI model monitors seven areas (latent variables) that have a determining impact on customer satisfaction, namely product/service/company image, customer expectations, customer perception, customer perceived value, customer satisfaction, customer complaints and customer loyalty. Measurable variables (indicators) within the monitored areas were determined after consultation with the management of Human Resource Division.

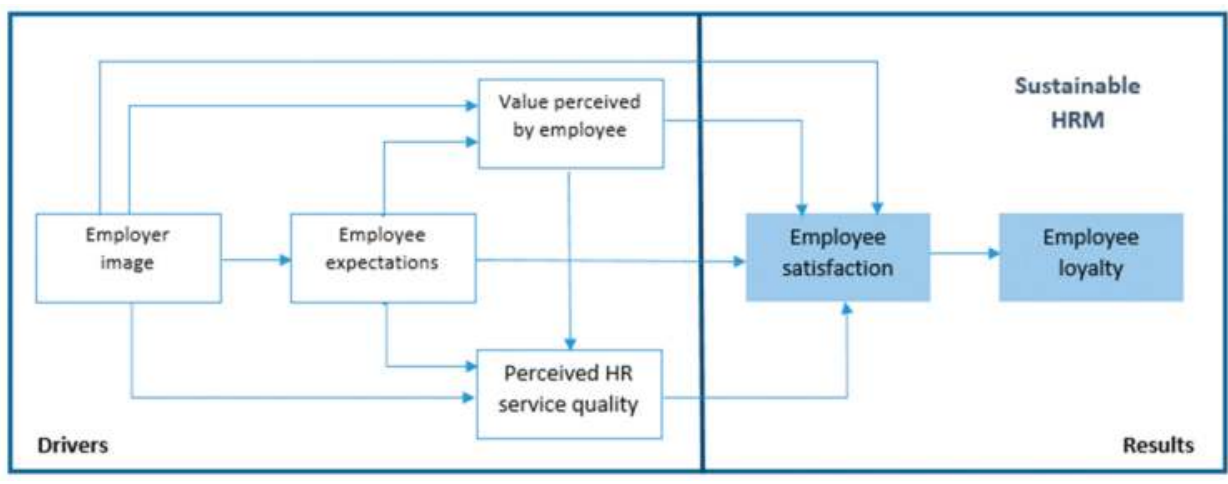

Figure 2. Human Resource Satisfaction Index (HRSI) model (created by author).

We designed the HRSI model to evaluate employee satisfaction and loyalty. The HRSI model represents one of the possible models to quantify employee satisfaction and loyalty. HRSI introduces six latent variables (employer image, employee expectations, perceived HR service quality, value perceived by employee, employee satisfaction, employee loyalty) corresponding to the areas of interest examined. Each of these latent variables is determined by measurable variables (22). This model is based on the use of a questionnaire survey among the employees of the postal company, which gives the primary input data [57].

Application of HRSI model within the research itself consisted of the following steps:

- $\quad$ Specification of measurable variables for HRSI model;

- Determining the importance of individual measurable variables;

- Converting measurable variables into questionnaire scale questions;

- Calculation of Human Resource Satisfaction index (HRSI).

The questionnaire consists of three parts. The first part deals with the socio-demographic characteristics of the participants in the research. The evaluation of variables: employer image (confidence, stability, flexibility and innovation, employer branding), meeting employee expectations 
(in terms of workload, responsibility, rewarding, professional and career growth, organizational and personal provision, working environment, atmosphere and equipment at the workplace), perceived HR service quality (employee awareness, access to information, quality of communication, quality of superior-subordinate relationships, quality of teamwork, quality of education system), value perceived by employee (employee performance in relation to their workload, evaluation of social services), employee satisfaction (with job description, remuneration, professional and career growth), employee loyalty (fidelity, staff turnover) by respondents are in the second part of questionnaire. The level of satisfaction was expressed by one of the five levels based on the Likert scale ( 5 = very satisfied; $4=$ satisfied; 3 = neutral; 2 = dissatisfied; 1 = very dissatisfied). The third part of questionnaire contains closed and open questions in order to better diagnostic the respondents' personal views concerning the monitored variables.

The application of the HRSI model, which includes the implementation of the employee satisfaction survey with the services of HR department of postal provider, has enabled us to find out what is the real satisfaction of Slovak Post's employees.

\subsection{Calculation of HRSI Index}

On the basis of the values obtained from employees through a questionnaire survey, satisfaction index according to relation 1 was calculated for each latent variable. We calculated the satisfaction index based on the general weighted arithmetic mean. Total satisfaction index values, calculated as the average of all indices, are expressed as a percentage. From these values, the overall value of the HRSI index was averaged [57].

$$
I_{i}=\frac{\sum_{j=1}^{n} M V_{i j} \times w_{j}}{\frac{\sum_{j=1}^{n} w_{j}}{X}}
$$

where:

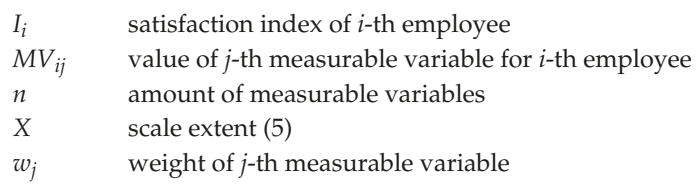

The weights of measurable variables $w_{j}$ can be entered by the user or they are calculated as a covariance between the value of $x_{j i}$ and $y_{i}$, where $y_{i}$ is the sum of all measurable variables for the $j$-th latent variable that is divided by the number of these measurable variables [58].

$$
w_{j}=\sum_{j=1}^{n}\left(M V_{i j}-P_{j}\right) \times\left(R_{i}-R_{t}\right)
$$

where:

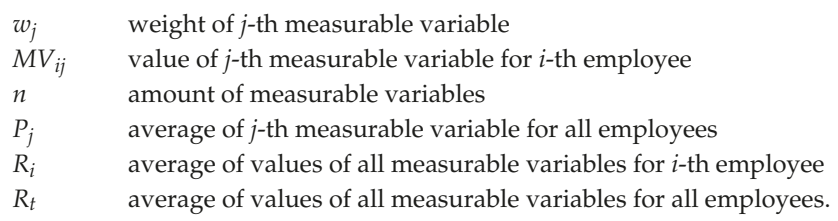

Latent variable is the result of the interaction of several measurable variables. Correlation analysis was used to investigate the dependencies between latent variables of HRSI model. Regression and correlation analysis, association analysis were used to assess the impact of demographic characteristics on employee satisfaction and loyalty.

For the purposes of calculating employee satisfaction indices for each latent variable was used Microsoft Excel ${ }^{\circledR}$. XLStat is the leading data analysis and statistical solution for Microsoft Excel ${ }^{\circledR}$, 
which offers a wide variety of functions to enhance the analytical capabilities of Excel, making it the ideal tool for data analysis and statistics requirements. The statistical software program XLStat was used to analyze the values of latent and measurable variables and for calculating correlations and regressions of individual variables.

\subsection{Profile of Respondents-Demographic Characteristic of the Sample}

The subject of our research was employees of a significant Slovak postal provider. Slovak Post (SP) has a dominant position in Slovak postal market and sustainability have become the important part of its strategy. The strategy of SP is in line with The Postal Policy for 2021, which aims, in addition to economic growth, for a sustainable universal service and general improvement in the quality of life in society [59].

SP, as a universal service provider, is the second largest employer in Slovakia. In 2016, SP provided services by 13246 employees in an average recalculated number. The number of employees working at the SP represents $85 \%$ of the total number of employees working in the postal sector in Slovakia. Questionnaire survey of employee satisfaction was carried out at the postal provider SP, covering the entire company, in October 2018. In cooperation with the Human Resource Division of SP, the questionnaire was distributed electronically, by the Intranet. The survey was attended by 1775 respondents, representing a $13.4 \%$ return. The demographic information of respondents is presented in Table 2.

Table 2. Demographic characteristic of the sample.

\begin{tabular}{|c|c|c|c|}
\hline \multicolumn{2}{|c|}{ Demographic Variable } & \multirow{2}{*}{$\begin{array}{c}\text { Number of Respondents } \\
160\end{array}$} & \multirow{2}{*}{$\begin{array}{c}\text { Percentage of Respondents } \\
9\end{array}$} \\
\hline \multirow{5}{*}{ Age } & $18-30$ years & & \\
\hline & $31-40$ years & 373 & 21 \\
\hline & $41-50$ years & 674 & 38 \\
\hline & $51-60$ years & 497 & 28 \\
\hline & over 61 & 71 & 4 \\
\hline \multirow{7}{*}{$\begin{array}{l}\text { Length of employment } \\
\text { for Slovak Post }\end{array}$} & up to 1 year & 89 & 5 \\
\hline & $1-5$ years & 355 & 20 \\
\hline & 6-10 years & 213 & 12 \\
\hline & $11-20$ years & 373 & 21 \\
\hline & $21-30$ years & 479 & 27 \\
\hline & $31-40$ years & 231 & 13 \\
\hline & over 40 years & 35 & 2 \\
\hline \multirow{4}{*}{ Job classification } & operation & 1083 & 61 \\
\hline & workers & 195 & 11 \\
\hline & technical and economics & 408 & 23 \\
\hline & other & 89 & 5 \\
\hline \multirow{8}{*}{ Place of work } & Banská Bystrica region & 373 & 15 \\
\hline & Bratislava region & 266 & 21 \\
\hline & Košice region & 213 & 12 \\
\hline & Nitra region & 213 & 12 \\
\hline & Prešov region & 231 & 13 \\
\hline & Trenčín region & 160 & 9 \\
\hline & Trnava region & 124 & 7 \\
\hline & Žilina region & 195 & 11 \\
\hline
\end{tabular}


The socio-demographic characteristics of the respondents show that most of the employees involved in the questionnaire survey were:

- In the age range: $41-50$ years

- With a length of employment in SP: 21-30 years

- In the job classification: operation

- Place of work in the region: Banská Bystrica
674 respondents

479 respondents

1083 respondents

373 respondents

\section{Results}

Using the theoretical knowledge and results of employee satisfaction survey, we got information about determinants which have an impact on the sustainability of the postal provider (Slovak Post) and its HRM. The application of the HRSI model consisted of the identification of measurable variables determining the quality of the HR department's services and assessment of their relevance by employees (employee satisfaction). The application of HRSI model enabled better understanding of the potentially complex relationships between employee loyalty and employee satisfaction which have an impact on the corporate sustainability of SP in labor market in the sector of postal services.

\subsection{Determining Measurable Variables and Its Assessment by Respondents}

For the application of the HRSI model, it was first necessary to define the variables that we will monitor and measure at the postal provider. In Table 3, we present individual sets of measurable variables (22) that we assigned to each of the six areas (latent variables) that the HRSI model monitors. Based on results of questionnaire survey, we have calculated employee satisfaction index for each measurable and latent variable (Table 3, Figure 3).

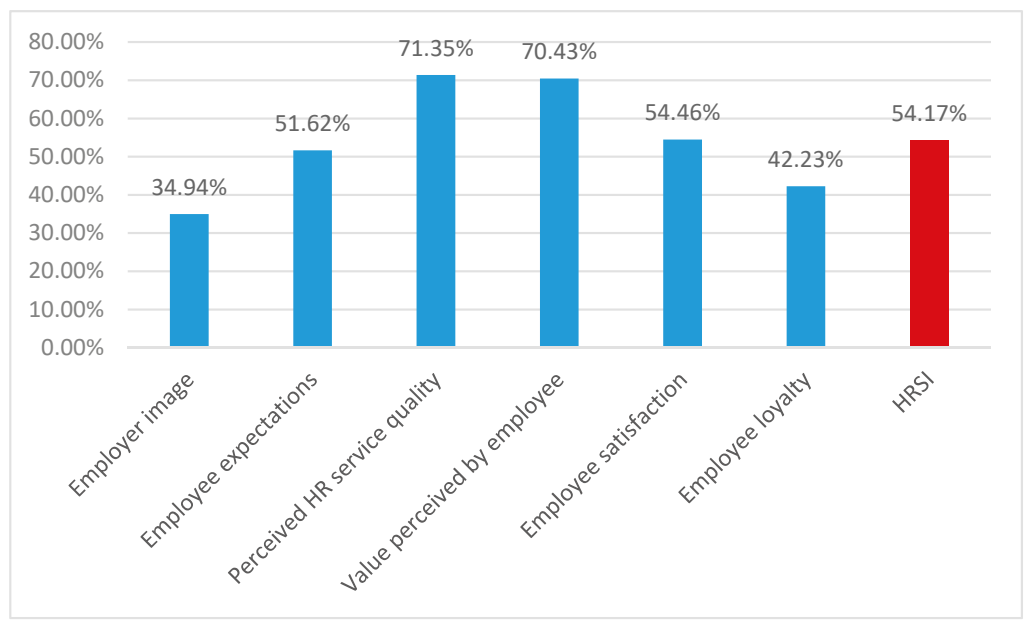

Figure 3. Human Resource Satisfaction Index (HRSI). 
Table 3. Latent variables and measurable variables in HRSI model and their assessment.

\begin{tabular}{|c|c|c|c|}
\hline Latent Variables & & Measurable Variables/Indicators & $\begin{array}{l}\text { Satisfaction } \\
\text { Index (\%) }\end{array}$ \\
\hline \multirow{4}{*}{ Employer image } & Img1 & $\begin{array}{l}\text { Overall confidence in the business activity of postal } \\
\text { provider and its HRM }\end{array}$ & 57.18 \\
\hline & Img2 & $\begin{array}{l}\text { Stability of the postal provider as an employer in the } \\
\text { labor market (tradition, reputation, quality) }\end{array}$ & 32.23 \\
\hline & Img3 & $\begin{array}{l}\text { Flexibility and innovation of postal provider in relation } \\
\text { to the needs and expectations of employees }\end{array}$ & 29.35 \\
\hline & Img4 & Employer branding & 21.01 \\
\hline \multirow{6}{*}{ Employee expectations } & Exp1 & $\begin{array}{l}\text { Fulfilling employee expectations in terms of workload } \\
\text { (order of importance 3) }\end{array}$ & 59.76 \\
\hline & Exp2 & $\begin{array}{l}\text { Fulfilling employee expectations in terms of } \\
\text { responsibility and decision-making powers (order of } \\
\text { importance 2) }\end{array}$ & 32.23 \\
\hline & Exp3 & $\begin{array}{l}\text { Fulfilling employee expectations in employee } \\
\text { rewarding (order of importance } 1 \text { ) }\end{array}$ & 33.51 \\
\hline & Exp4 & $\begin{array}{l}\text { Fulfilling employee expectations in professional and } \\
\text { career growth (order of importance 6) }\end{array}$ & 70.10 \\
\hline & Exp5 & $\begin{array}{l}\text { Fulfilling the employee expectations in organizational } \\
\text { and personal provision (order of importance 5) }\end{array}$ & 93.07 \\
\hline & Exp6 & $\begin{array}{l}\text { Fulfilling the employee expectations with regard to the } \\
\text { working environment, the atmosphere and the } \\
\text { equipment at the workplace (order of importance 4) }\end{array}$ & 75.53 \\
\hline \multirow{5}{*}{$\begin{array}{l}\text { Perceived HR } \\
\text { service quality }\end{array}$} & Qua1 & Employee awareness (access to information) & 82.48 \\
\hline & Qua2 & Quality of workplace communication & 75.53 \\
\hline & Qua3 & The quality of superior-subordinate relationships & 73.09 \\
\hline & Qua4 & Quality of team work & 65.48 \\
\hline & Qua5 & Quality of education system & 60.17 \\
\hline \multirow{2}{*}{$\begin{array}{l}\text { Value perceived } \\
\text { by employee }\end{array}$} & Val1 & $\begin{array}{l}\text { Assessing employee performance in relation to their } \\
\text { workload }\end{array}$ & 47.79 \\
\hline & Val2 & Evaluation of social services provided to employees & 93.07 \\
\hline \multirow{3}{*}{ Employee satisfaction } & Sat1 & Satisfaction with the job description & 59.76 \\
\hline & Sat2 & Satisfaction with employee remuneration & 33.51 \\
\hline & Sat3 & $\begin{array}{l}\text { Satisfaction with professional and career growth of } \\
\text { employees }\end{array}$ & 70.10 \\
\hline \multirow{2}{*}{ Employee loyalty } & Loy1 & Fidelity to postal provider & 64.23 \\
\hline & Loy2 & Staff turnover & 20.23 \\
\hline
\end{tabular}

For determine the impact of demographic characteristics to employee satisfaction and loyalty was necessary to determine the satisfaction index for each demographic characteristic (Table 4). 


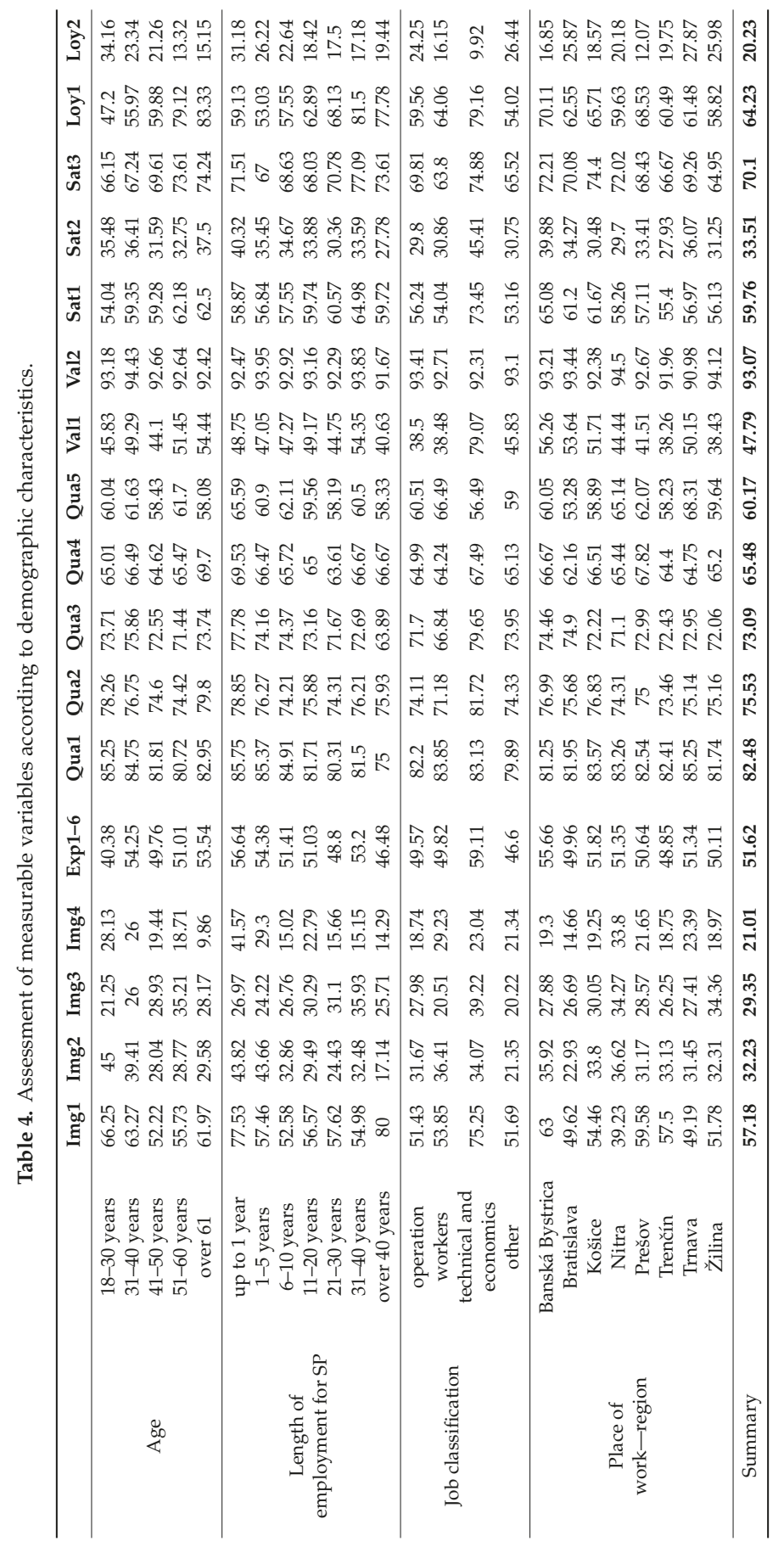




\subsubsection{Employer Image}

The overall satisfaction rate with the employer image is only $34.94 \%$. Respondents appreciate their employer's reliability (32.17\% of respondents), customer orientation (29.35\% of respondents), credibility (25.01\% of respondents) and prospect (19.32\% of respondents). A relatively high number of respondents perceive SP as an entrepreneurial successful employer (12.90\% of respondents) supporting professional development of employees (11.67\% of respondents).

On the other hand, up to $46.31 \%$ of respondents perceive their employer as not interested in the views and attitudes of employees. This opinion was expressed mainly by respondents in the age group of $41-50$ years (50.30\% of respondents), with employment in SP more than 40 years (57.14\% of respondents), with working position of operation (50.97\% of respondents) and workers in the Trenčín region. It follows that SP should focus more on its personnel policy and build the employer's brand.

\subsubsection{Employee Expectations}

The overall satisfaction rate with the expectations of employees is $51.62 \%$. When meeting the expectations of employees, we based it on the employees' priorities. According to the order of importance, the most important for employees is the wage and financial valuation of their work, followed by certainty of permanent employment, working conditions, interpersonal relationships at the workplace, benefits provided by the employer and, last but not least, training supporting professional and personal development. However, the order differs in individual employee segments. While in the age category of respondents 18-30 years working conditions are important in addition to wages and financial valuation of work, in other respondents' age categories it is a certainty of permanent employment. The same applies to the length of employment. Respondents working for SP less than 1 year appreciate working conditions in addition to wages and financial valuation. Other respondents prefer except for wage and financial valuation, a certainty of permanent employment.

\subsubsection{Perceived HR Service Quality}

The overall rate of satisfaction with the perceived quality of service provided by Human Resource Division is $71.35 \%$.

Employee awareness, access to information: The overall satisfaction rate with awareness by direct supervisor is high $(82.48 \%)$. Up to $81.92 \%$ of respondents rated it as positive. Only $1.01 \%$ of respondents showed great dissatisfaction. Good communication and awareness is the result of well-functioning relationships between the manager and employees, which were also positively evaluated in $89.01 \%$ of respondents.

SP uses various information channels to inform about SP events, about the implementation of its activities and programs. In-house magazine Poštové Zvesti is considered to be the main information channel providing information concerning personnel activities (e.g., implementation of social policy, social program, benefits provided to employees). Up to $60.11 \%$ of respondents use this as a base feed, followed by working meetings ( $53.58 \%$ of respondents) and intranet ( $53.30 \%$ of respondents). However, access to electronic information is limited for some employees, as evidenced by the low percentage of respondents using the electronic version of the eZvesti in-house magazine, e-mail communication and the SP website. Only $9.46 \%$ of respondents are looking for information on the employer's website. It is necessary to reflect on the design and recency of the website, as the intranet and the employer's website are the most widely used information channels of most companies.

Quality of workplace communications and relationships: Overall satisfaction rate with quality of workplace communications and relationships is $75.53 \%$. Informal relationships in the workplace and a good team are very important to employees and are considered satisfactory to $94.82 \%$ of respondents. The dissatisfaction was particularly apparent in the operating staff (5.86\%). They see the biggest shortcomings as being a bad atmosphere (slander, intrigue, envy, rivalry, etc.) resulting from the feeling 
of overloading, the opaque division of tasks and the requirements for individual plans, staff shortages and frequent representation.

Quality of relationships superior-subordinate: In terms of their relationship to a superior manager, most respondents rate highly, and overall satisfaction is $73.09 \%$. Following this, $89.01 \%$ of respondents consider it satisfactory or above standard. Satisfactory relationships with their superiors were the largest, ranging from $44.67-66.67 \%$. The percentage of respondents who rated relations with their senior manager as above-standard was in the range of $13.89-47.64 \%$. Above-standard relationships with the superior were mainly assessed by respondents in the $31-40$ age group (37.67\% of respondents), with employment up to 1 year (36.56\% of respondents), with technical-economic classification ( $47.64 \%$ of respondents) and in respondents from the Bratislava region (36.68\% of respondents). Good assessment of managers may also be due to the fact that most executives already have well-established work ties and are well-oriented in the work environment. Respondents attach great importance to the manager's personality, which was reflected in their assessment.

The percentage of respondents who rated relationships with senior managers as bad was in the range of $0.88-3.65 \%$. These bad relationships occurred mainly among respondents over 60 years of age (3.03\% of respondents), over 40 years of employment in SP (2.78\% of respondents), job classification-workers (3.65\% of respondents) and respondents working in the Nitra region $(3.21 \%$ of respondents). In the case of negative assessments, respondents were dissatisfied mainly with the way managers were managed.

Quality of team work: $89.07 \%$ of respondents evaluate the cooperation with colleagues on other sections of the company satisfactorily, and the overall satisfaction rate is $65.48 \%$. The largest proportion of respondents dissatisfied with cooperation with other departments is the category of operation employees. The biggest shortcomings were the poor organization of work on individual organizational units, reluctance, lack of communication, and lack of interest in their problems.

Quality of the education system: In terms of perceived quality of HR services, the lowest satisfaction was found in the quality of education $(60.17 \%)$. The extent and quality of education provided by the employer is considered to be insufficient, mainly by the respondents of category technical and economics (38.71\% of respondents), in the age category more than 60 years (37.88\% of respondents), working in SP more than 40 years ( $44.44 \%$ respondents), from the Bratislava region ( $43.24 \%$ of respondents).

\subsubsection{Value Perceived by Employee}

The overall satisfaction rate with value perceived by employees is $70.43 \%$.

Assessing employee performance in relation to their workload: Overall satisfaction rate with the performance evaluation system is low $(47.79 \%)$. Thus, $48.62 \%$ of respondents say that the indicators set are not in line with their job description or they are unable to achieve them, which can cause employee frustration. Following this, $10.25 \%$ of respondents say they have no indicators at all. The greatest dissatisfaction was found in respondents of category operation (61.85\% of respondents).

In assessing the quality of the evaluation system, we also focused on the regularity and frequency of the evaluation process. Most respondents said they are rated once a year ( $41.35 \%$ of respondents), $36.90 \%$ of respondents monthly. Up to $8.79 \%$ of respondents said that their senior manager do not evaluate at all and $4.90 \%$ of respondents do not know when they are evaluated. Mostly they are employees from the workers category. This suggests that these employees do not know the staff evaluation system and are not sufficiently informed about the results of their evaluation.

Evaluation of social services (benefits) provided to employees: Although in terms of importance the benefits provided by the employer are in fifth place, the overall satisfaction with the offer of benefits was the highest compared to other monitored indicators (93.07\%). Respondents said that the most beneficial reward for them is a financial contribution to supplementary pension saving or life insurance. Followed by the following: the financial allowance for meals and the weekly working time of $37.5 \mathrm{~h}$. Financial contributions to support the family is the least beneficial for respondents. Furthermore, $6.93 \%$ of respondents do not consider any social measures and benefits to be beneficial. 


\subsubsection{Employee Satisfaction}

The overall employee satisfaction rate is $54.46 \%$.

Satisfaction with the job description: The overall satisfaction rate with the job content is $59.76 \%$. The highest satisfaction was found in the age category of respondents over $60(62.50 \%)$, respondents in employment in SP 31-40 years (64.98\%), respondents in technical-economic classification (73.45\%), and in Košice region (61.67\%).

Satisfaction with employee remuneration: Although wages and financial valuation are ranked first in terms of importance, overall satisfaction with financial valuation is only $33.51 \%$. This discrepancy between the perception of the importance of wages and satisfaction with financial valuation can be a source of employee demotivation. Up to $83.21 \%$ of respondents consider financial valuation unsatisfactory. The most dissatisfied respondents are from the operation category $(87.56 \%$ of respondents), and the overall satisfaction rate is only $29.80 \%$. The lowest level of satisfaction was found in respondents from the Trenčín region (27.93\%).

Satisfaction with professional and career growth of employees: The overall satisfaction rate with professional and career growth is $70.10 \%$. The highest level of satisfaction was found in respondents of technical-economic classification (74.88\%), with employment in SP 31-40 years (77.09\%). This is a category of employees where rapid career growth is allowed, and a category of employees who already have sufficient experience obtained in SP.

\subsubsection{Employee Loyalty}

The results of loyalty and fluctuation tendencies are relatively favorable. Up to $64.23 \%$ of respondents do not consider changing their employer. Employee loyalty is directly proportional to the age structure of employees, i.e., the older the employee, the more loyal. From the point of view of the length of employment at SP, there are similar tendencies, the highest loyalty was found for employees with employment in SP 30-40 years (81.5\% of respondents). High loyalty was reflected in the respondents of technical and economics job classification (79.16\% of respondents). In terms of the place of work, the highest loyalty was found in respondents working in Banská Bystrica region (70.11\% of respondents), Prešov region (68.53\% of respondents) and Košice region (65.71\% of respondents). This is also due to the fact that these are regions where unemployment is highest in Slovakia.

Considering employees who are considering a change of employer within 1 year, the largest group consists of employees aged 18-30 (34.16\% of respondents), with employment up to 1 year (31.18\% of respondents); job classification-operation (26.44\% of respondents), with a place of work in Trnava region (27.87\% of respondents), Žilina region (25.98\% of respondents) and Bratislava region (25.87\% of respondents). These are regions where is the lowest unemployment rate in Slovakia and the labor market offers much more interesting job opportunities.

Figure 3 shows employee satisfaction index of six latent variables, and total Human Resource Satisfaction Index (HRSI). The results show that the total satisfaction of SP employees is only $54.17 \%$. The highest satisfaction was in the perceived HR service quality (71.43\%). The Human Resource Division is making great efforts to ensure quality personnel services. Personnel activities are constantly innovated, taking into account the results of employee satisfaction surveys. The lowest satisfaction was in the area of the employer image (34.94\%). Every postal company, knowingly or unconsciously, creates its own image, often independently of its own will. It is necessary that the postal company take care of its image, build it up and strengthen it. Due to increasing competition in the postal market, and especially after the liberalization process, the concept of image becomes an important tool for positive perception by the individual or society [60]. It is necessary for SP to focus its attention on building an employer brand. It is important to know what not only current but also potential employees think about SP. The attractive employer brand fulfills the different needs and expectations of potential and existing employees and can be a sustained competitive advantage of the SP in the postal market. 


\subsection{Regression and Correlation Analysis of Latent Variables in HRSI Model}

The questionnaire survey and calculation of overall satisfaction indices and satisfaction indices according to individual demographic characteristics were used as input data for dependence research of demographic characteristics to employee satisfaction and loyalty. The correlation, regression and association results have supported most of the expectations and the hypotheses in this study.

Figure 4 shows the results of correlations between individual latent variables of HRSI model. It is clear from the results that employee-perceived value has the highest impact on employee satisfaction. The coefficient 0.90 shows an almost perfect correlation. This means that the performance appraisal of the employees in relation to their workload and evaluation of the social services and benefits provided to employees significantly affects the overall employee satisfaction. However, satisfaction with performance appraisal of the employees in relation to their workload was very low (satisfaction index $47.79 \%$ ). The satisfaction with the offer of social services and benefits provided to employees was much higher $(93.07 \%)$. We expected that the greatest impact on employee satisfaction has the perceived quality of HR services $(\mathrm{E} 1)$. Based on the value of the correlation coefficient $(0.44<0.90)$ our expectation E1 has not been confirmed

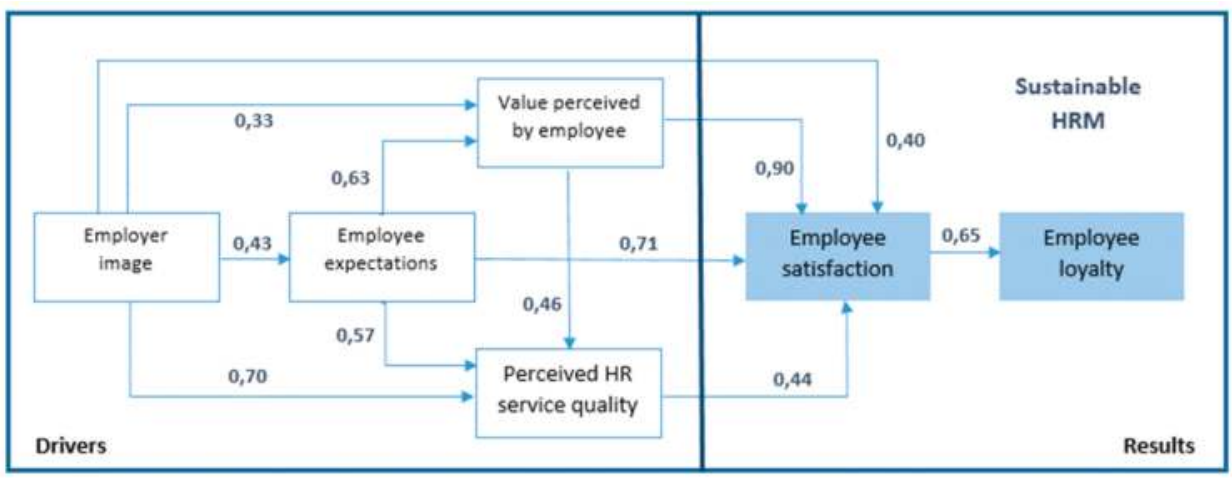

Figure 4. Structural model—results.

A large correlation affecting employee satisfaction was found in employee expectations (0.71). Fulfilling employee expectations in employee rewards, in terms of responsibility and decision-making powers, and in terms of workload, which has a significant priority for employees and fundamentally affect their satisfaction, was evaluated as being very low (satisfaction index $32.23-59.76 \%)$. Perceived HR service quality (0.44) and employer image (0.40) represent a moderate correlation to employee satisfaction.

We found a large correlation between employee satisfaction and loyalty (0.65). Based on this fact, our expectation E2 has been confirmed. As part of the latent variable "Loyalty", we also examined the employee turnover indicator. An indirect correlation was found between satisfaction and staff turnover (with the increase in satisfaction, the employee turnover decreases), showing a mean value $(-0.43)$.

\subsection{Impact of Demographic Characteristics to Employee Satisfaction and Loyalty}

The aim of our research was to investigate the impact of age, length of employment for SP, job classification and place of work on employee satisfaction and loyalty. Regression and correlation analysis (for quantitative characteristics: age, length of employment) and association analysis (for qualitative characteristics: job classification, place of work-region) were used to investigate dependency.

Figure 5 presents the dependence of satisfaction indicators (Sat1, Sat2, Sat3) from the employee's age. The relationship between employee age and satisfaction with work load (Sat1) has a slightly increasing linear course $(0.1235)$, while the determination coefficient value $\left(R^{2}=0.8285\right)$ points to a 
strong relationship. The satisfaction of the addressed employees (respondents) with their workload increases linearly with the employee's age; the expectation E3 has been confirmed. The relationship between the employee's age and satisfaction with the employee remuneration (Sat2) has a polynomial course, with the satisfaction of the employees of the 41-50 age group decreasing, while the satisfaction of other employees is increasing. The determination coefficient $\left(R^{2}=0.9882\right)$ points to a very strong relationship. The satisfaction of the respondents with their remuneration is polynomially changing with the employee's age; the expectation E4 has not been confirmed. The relationship between employee age and satisfaction with professional and career growth (Sat3) has a slightly increasing linear course (0.25), although higher than the Sat1 indicator. The determination indicator $\left(R^{2}=0.9397\right)$ points to a very strong relationship. The satisfaction of the respondents with professional and career growth of employees increases linearly with the employee's age; the expectation E5 has been confirmed.

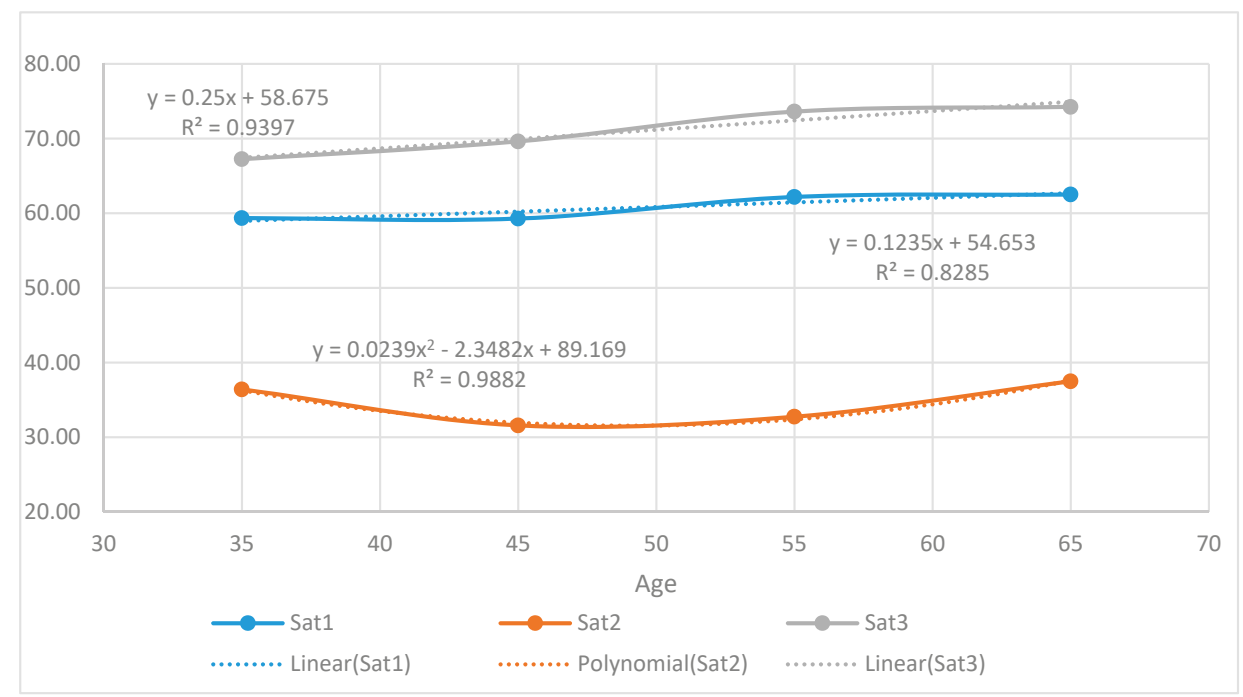

Figure 5. Dependence of satisfaction indicators (Sat1, Sat2, Sat3) on employee age.

Figure 6 presents the dependence of satisfaction indicators (Sat1, Sat2, Sat3) on the length of employment for SP. The relationship between length of employment and satisfaction with work load (Sat1) has a slightly increasing linear course (0.1779), the determination coefficient value $\left(R^{2}=0.9394\right)$ points to a strong relationship. Satisfaction of the respondents with their work load increases linearly with length of employment for SP; the expectation E6 has been confirmed. The relationship between length of employment and satisfaction with employee remuneration (Sat2) has a slightly decreasing linear course $(-0.2259)$, with the number of years worked for SP, the satisfaction decreases. The determination coefficient $\left(R^{2}=0.9355\right)$ points to a very strong relationship. Satisfaction of the respondents with their remuneration decreases linearly with length of employment for SP; the expectation E7 has not been confirmed. The relationship between length of employment and satisfaction with professional and career growth of employees (Sat3) has a slightly increasing linear course (0.1472). The determination coefficient $\left(\mathrm{R}^{2}=0.7876\right)$ points to a strong relationship. Satisfaction of the respondent with their professional and career growth increases linearly with length of employment for SP; the expectation E8 has been confirmed. 


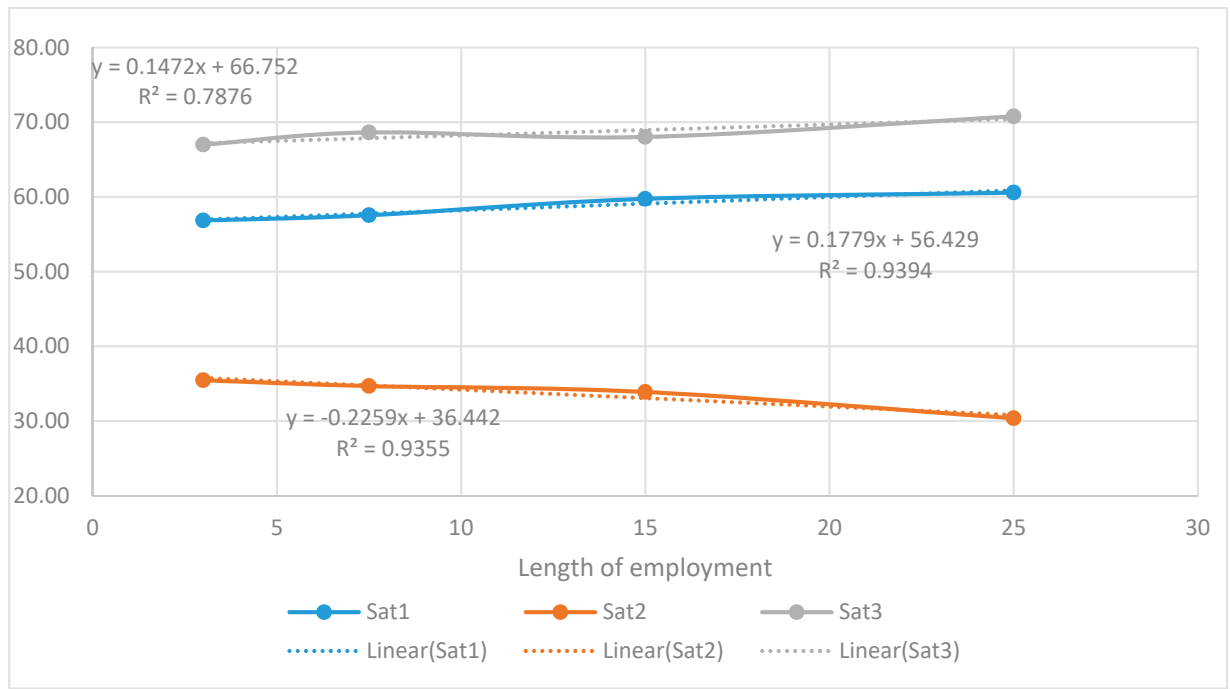

Figure 6. Dependence of satisfaction indicators (Sat1, Sat2, Sat3) on length of employment for SP.

Figure 7 presents the dependence of the loyalty indicators (Loy1, Loy2) from the employee's age. The relationship between employee's age and loyalty to SP (Loy1) has a slightly increasing linear course $(0.9541)$, the determination coefficient value $\left(R^{2}=0.9483\right)$ points to a very strong relationship. With an increase in the age of respondents, employee loyalty is increasing linearly; the expectation E9 has been confirmed. The relationship between employee age and staff turnover (Lyo2) has a slightly decreasing linear course $(-0.4804)$, the determination coefficient value $\left(R^{2}=0.8518\right)$ indicates a strong relationship, although is lower than the determination coefficient value of fidelity. With an increase in the age of respondents, employee turnover is decreasing linearly; the expectation E10 has been confirmed.

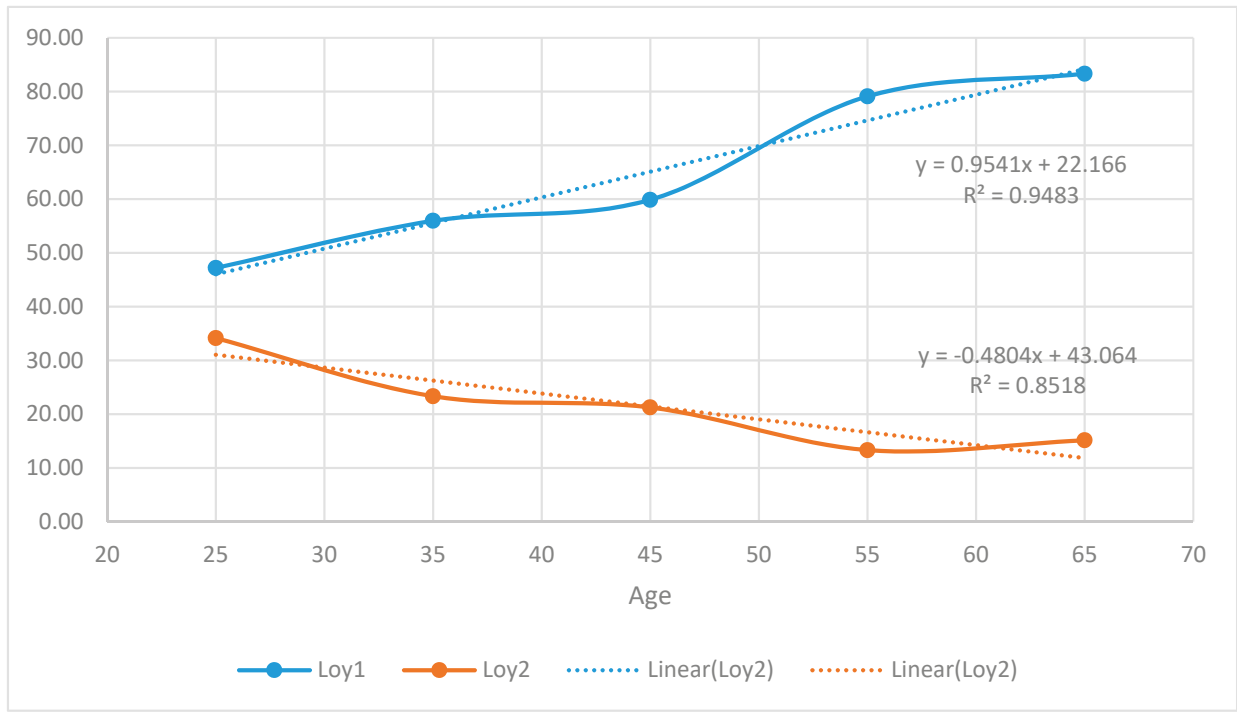

Figure 7. Dependence of loyalty indicators (Loy1, Loy2) on employee age. 
Figure 8 presents the dependence of loyalty indicators (Loy1, Loy2) on the length of employment for SP. The relationship between employment length and loyalty to SP (Loy1) has a slightly increasing linear progression $(0.5897)$, the determination coefficient value $\left(R^{2}=0.8772\right)$ points to a strong relationship. With the increase in employment in SP, respondents' loyalty is increasing linearly; the expectation E11 has been confirmed. The relationship between length of employment and staff turnover (Lyo2) has a polynomial course; for employees with employment length below 40 years, the fluctuation is decreasing, but for employees with employment length over 40 years, the fluctuation increases. The value of the determination coefficient $\left(R^{2}=0.951\right)$ points to a very strong relationship. With the increase in employment in SP, respondents' turnover decreases polynomially; the expectation E12 has not been confirmed.

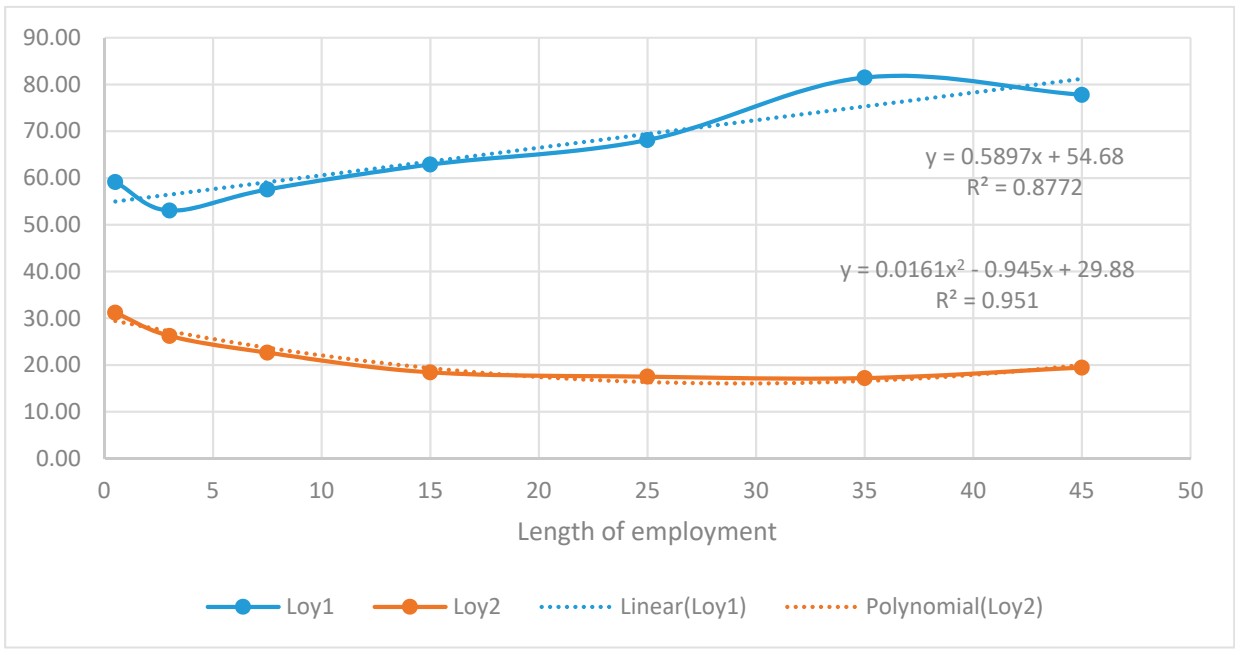

Figure 8. Dependence of loyalty indicators (Loy1, Loy2) on length of employment for SP.

The association analysis was used to explore dependencies between satisfaction levels and job classification. An examination of association confirmed the dependence between satisfaction with workload (Sat1) and job classification. However, the level of relationship is low (Pearson coefficient $\mathrm{C}=0.30$ ). Hypothesis $\mathrm{H} 1$ has been confirmed. An examination of association confirmed the dependence between satisfaction with employee remuneration (Sat2) and job classification. The level of relationship is lower (Pearson coefficient $\mathrm{C}=0.24$ ). Hypothesis $\mathrm{H} 2$ has been confirmed. An examination of association confirmed the dependence between satisfaction with professional and career growth of employees (Sat3) and job classification. The level of relationship is the lowest (Pearson coefficient $\mathrm{C}=0.17)$. Hypothesis $\mathrm{H} 3$ has been confirmed.

The association analysis was used to explore dependencies between satisfaction levels and place of work (region). An examination of association confirmed the dependence between satisfaction with workload (Sat1) and place of work. However, the level of relationship is low (Pearson coefficient $\mathrm{C}=0.17$ ). Hypothesis $\mathrm{H} 4$ has been confirmed. An examination of association confirmed the dependence between satisfaction with employee remuneration (Sat2) and place of work. The level of relationship is higher (Pearson coefficient $\mathrm{C}=0.18$ ). Hypothesis $\mathrm{H} 5$ has been confirmed. An examination of association confirmed the dependence between satisfaction with professional and career growth of employees (Sat3) and place of work. The level of relationship is the highest (Pearson coefficient $\mathrm{C}=0.20$ ). Hypothesis H6 has been confirmed.

The association analysis was used to explore dependencies between loyalty indicators and job classification. An examination of association confirmed the independence between the level of 
loyalty and job classification. Hypothesis H7 has not been confirmed. An examination of association confirmed the independence between staff turnover (Loy2) and job classification. Hypothesis H8 has not been confirmed.

The association analysis was used to explore dependencies between loyalty indicators and place of work (region). An examination of association confirmed the independence between employee loyalty (Loy1) and place of work. Hypothesis H9 has not been confirmed. An examination of association confirmed the independence between staff turnover (Loy2) and place of work. Hypothesis H10 has not been confirmed.

\section{Discussion}

Many companies are struggling with existential concerns, and disregard the needs of their employees. However, the interest in employees, their self-actualization, mutual expectations, and healthy labor relations are the preconditions for commitment, satisfaction, loyalty, and strong work ethic of employees and, thus, integral to the success of the entire company [17].

The purpose of this study was to review the satisfaction of employees in postal companies and consequently evaluate the impact of employee satisfaction on their loyalty to the employer. The aspects to be considered to reinforce job satisfaction are age, years of practice, job position and place of work. We investigated how these aspects affect employee satisfaction in the postal sector and compared our results with results of other authors' research.

The results of our research show that the total satisfaction of SP employees is only $54.17 \%$. It is not the best result, although we can see significant differences in satisfaction from the point of view of employees' individual categories. In terms of age, the most satisfied category is employees over 61 years of age. From the point of view of the length of employment, the most satisfied are employees with an age of 31-40 years for Slovak Post. Satisfaction also varies greatly depending on job position. Above-average satisfaction was found in technical and economics employees. The situation on the labor market, the development of employment in the regions also have an impact on the satisfaction and loyalty of Slovak Post employees. The highest satisfaction was found in the Banská Bystrica region. The result was probably influenced by the fact that the company is headquartered in Banská Bystrica.

The development of loyalty is similar to the development of satisfaction. High loyalty was found in employees over 61 years of age, with 31-40 years of work experience on Slovak Post, and technical and economics employees in Banská Bystrica region. On the contrary, a very high fluctuation of employees was found in young employees, aged 18-30, with a practice less than 1 year for Slovak Post, with job classification "other" (subsidiary staff) in Trnava region.

It would be advisable for management of Human Resource Divisions to consider these disproportions when choosing appropriate motivation tools that support the satisfaction of Slovak Post employees (new option of employee benefits-Cafeteria system).

According to Table 5, employee age has the greatest impact on satisfaction with employee remuneration $\left(R^{2}=0.9882\right)$; length of employment for SP has the greatest impact on employee turnover $\left(R^{2}=0.951\right)$. Job classification has the greatest impact on satisfaction with work load $(C=0.30)$; place of work-region has the greatest impact on satisfaction with professional and career growth $(C=0.20)$. The impact of qualitative characteristics (job classification, place of work-region) to loyalty indicators (Loy1, Loy2) has not been confirmed.

Table 5. Dependence of satisfaction and loyalty indicators from demographic characteristics.

\begin{tabular}{|c|c|c|c|c|c|c|}
\hline Characteristic/Indicator & Sat1 & Sat2 & Sat3 & Loy1 & Loy2 & Coefficient \\
\hline Age & 0.8285 & 0.9882 & 0.9397 & 0.9483 & 0.8518 & \multirow{2}{*}{$\begin{array}{l}\text { Determination } \\
\text { coefficient } R^{2}\end{array}$} \\
\hline Length of employment for SP & 0.9394 & 0.9355 & 0.7876 & 0.8772 & 0.9510 & \\
\hline Job classification & 0.30 & 0.24 & 0.17 & - & - & \multirow{2}{*}{$\begin{array}{c}\text { Pearson } \\
\text { coefficient C }\end{array}$} \\
\hline Place of work-region & 0.17 & 0.18 & 0.20 & - & - & \\
\hline
\end{tabular}


According to Figure 9, satisfaction with work load is most influenced by length of employment for SP and by job classification of employees. Satisfaction with employee remuneration is most influenced by age of employees and by job classification of employees. Satisfaction with professional and career growth is most influenced by age of employees and place of work-region. Loyalty of employees is most influenced by age of employees, staff turnover is most influenced by length of employment for SP.

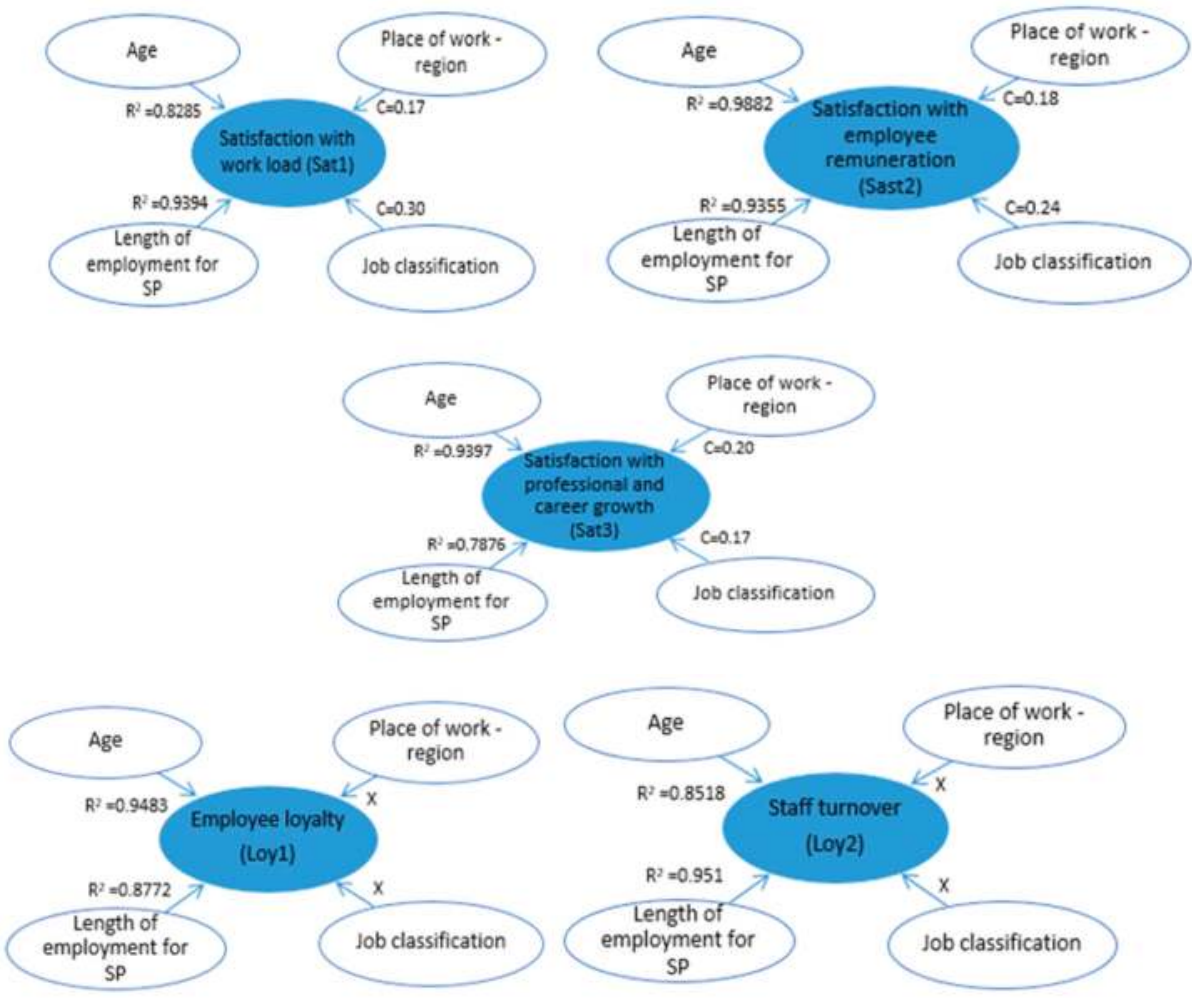

Figure 9. Impact of demographic characteristics to employee satisfaction and loyalty.

According to Lorincova et al. [17], Dirisu et al. [18], Razig and Maulabakhsh [19], Chinomona, and Dhurup [20], Bakotic and Babic [27], the quality of work life positively and significantly influences employee job satisfaction, and employee loyalty. The results of our research show that perceived quality (quality of workplace, quality of communications, quality of relationships, quality of teamwork, quality of education system) affect SP's employee satisfaction. Correlation coefficient 0.44 expresses the mean correlation. The value perceived by employees (assessing employee performance, evaluation of social services) and fulfilling of their expectations has a much greater impact on SP's employee satisfaction. Correlation coefficient 0.90 and 0.71 express very strong correlation. The fair evaluation of employee performance, social services, benefits and fulfilling their expectations in terms of rewarding, responsibility and workload, significantly affect the satisfaction of SP employees. The quality of working life is perceived by SP employees as a matter of course and they attach the highest priority to employee remuneration.

According to Chatzopoulou et al. [28], Kubala and Vetrakova [61], Sánchez-Sellero et al. [62], the employees satisfied with their reward and work environment do not have a need to leave the company; they are loyal. The results of our research show that the dependence between SP employee satisfaction and loyalty is strong (correlation coefficient 0.65). If SP wants to keep its employees, it is 
necessary to increase their satisfaction. The focus should be on employee remuneration. Satisfaction rate with employee remuneration is very low (33.51\%). The labor market analysis shows that the average nominal monthly wages of employees in the postal sector are long term below the average monthly wages of employees in the economy of the SR (Figure 1). Market opening and increased competition force Slovak Post to modernize their wage structure. Changes in minimum wages are an important driving force for salary development in the postal sector. If SP wants to increase loyalty and prevent employee fluctuation to competition, it needs to incorporate these facts into the creation of a new flexible employee remuneration system that takes into account these facts.

According to Giovanis [34], the positive causal effect from job classification on job satisfaction and employee loyalty is present. Our results partially confirmed this idea. The results of our examination of association confirmed the dependence between satisfaction of SP employees and job classification, however the level of relationship is low (Pearson coefficient 0.11-0.30). Based on the results of our research (Table 4) we can say that the most satisfied category of employees is technical and economics employees (satisfaction index $73.45 \%$ ). This category is made up of the most loyal employees (79.16\%). However, an examination of association confirmed the independence between loyalty and job classification.

Our results (Figure 8) are confirmed by the findings of survey by Kot-Radojewska and Timenko [35] who examined the relationship between employee loyalty to the employer and the form of employment. Their research results indicated that the employees who have an indefinite duration employment contract rated the degree of their own loyalty to the employer higher than people that have a fixed-term employment contract. We found out in our research, that the relationship between employment length and loyalty to SP has a slightly increasing linear progression; the determination coefficient value $\left(\mathrm{R}^{2}=0.8772\right)$ points to a strong relationship. This means that SP employees with longer experience (who have an indefinite employment contract) are more loyal than employees who work for a shorter period (predominantly have a fixed-term employment contract).

It is generally believed that job satisfaction increases linearly with age. The empirical analysis of the determinants of job satisfaction, provided by Clark et al. [38], confirmed that job satisfaction is U-shaped in relation to age. Our research has confirmed both claims. Examination of the dependences of satisfaction indicators on employee age (Figure 5) confirmed very strong relationships $\left(R^{2}=0.8285-0.9882\right)$. The satisfaction with work load and the satisfaction with professional and career growth increase linearly with age. Satisfaction with employee remuneration is U-shaped in relation to age (polynomial course), declining from a moderate level in the younger employees and then increasing steadily up to retirement.

According to Gazioglu and Tansel [36], the employees in managerial, professional and clerical occupations are more satisfied than sales employees. Our research in conditions of a postal company (Slovak Post) confirmed this statement (Table 4). The employees with job classification "operation and sales", "workers" and "others" (subsidiary staff) are less satisfied than "technical and economics" employees (management and administration). Slovak Post has the biggest lack of workforce in operation and sales. This is due to the low satisfaction of employees in this category. Satisfaction with workload is $56.24 \%$ and satisfaction with remuneration is only $29.8 \%$. Their work places high demands on professionalism, but wages are at the minimum wage level in Slovakia.

The topic of sustainable HRM has a broad scope. From creating appropriate working conditions, sustainable leadership, collaboration and teamwork, diversity and multiculturalism, ethics and governance, creating and inculcating values, health and safety, workforce engagement, employee training to environmental sustainability. Employee satisfaction and loyalty are key to making HRM sustainable. Slovak Post supports the idea for choosing sustainable HRM as a new approach for people management. The results of our research will used in the decision-making on future human resource development plans in Slovak Post. 


\section{Conclusions}

The postal sector is a very labor intensive sector and national postal operators have traditionally been the largest domestic employers. The employment in the postal sector is influenced by the two main market developments: letter volumes decline and parcel volumes growth. Additionally, new technologies and growing competition, driven by the increase in parcel volumes and postal market liberalization, have also had an effect on postal employment volume and working conditions.

This fact has led to two key changes in the labor market.

1. We observe an increase in new and more flexible employment models—on-call work, temporary agency work, performance-related pay contracts as well as outsourced models, such as sub-contracted workers and self-employment.

2. We observe changes in employment conditions-increased competition has forced national postal operators (Slovak Post) to modernize their wage structure, e.g., introduce performance pay and other types of more flexible contracts [43].

The biggest threat to the postal services sector today is the lack of manpower, especially in the field of postal operation. This problem is caused by the low level of average monthly wage, which is not appealing for jobseekers, especially in developed regions. The top ten risk factors also includes the inability to attract, and also maintain, talent.

It is necessary that the focus of sustainable HRM of postal companies should be contributing not only to financial outcomes, but the importance of human, social and ecological outcomes in terms of their contribution to business outcomes. The postal operators implemented many activities related to sustainable human resource management, mainly concerning decent working conditions and employee training. Great emphasis is placed on eco-friendly solutions that facilitate, among other things, the work of employees. Quality working conditions, motivated and satisfied employees are the priority for postal operators. SP solves the human, social and individual questions SP in the social program. The main goal of SP's social program is to enhance the quality of life of its employees, work conditions and their overall personal development. SP adheres to an equal opportunities policy-the employer treats all employees equally. SP adopts measures against discrimination in all areas of the employment relationship and treats employees in accord with the principle of equal treatment. Employees are provided with professional education to enhance their qualifications in the area of innovation and unification of the SP product range and education in the area of information technology and foreign languages. SP has its environmental management system certified. SP exerts a maximum effort in the search for solutions that minimize the impact of its activities on the environment and successfully continues the process of the application of environmental management in the company. However, as our research has shown, it is also necessary to address employee remuneration issues. This will increase their satisfaction and loyalty, which will support the employer's attractiveness.

Sustainable HRM offers many opportunities for researchers from variety of disciplines and an opportunity to improve management practice. With our research, we have tried to zoom in on the issue of sustainable HRM in the postal sector. The added value of this investigation is the designed and applied HRSI model. The proposed HRSI model can be used as a basic diagnostic tool for monitoring employee satisfaction and loyalty. Its regular application enables postal companies to monitor the trend of development of individual latent variables and to identify weaknesses negatively affecting employee satisfaction and loyalty. The HRSI model has a general application in the conditions of any enterprise, but it is important to correctly select the measurable variables, the number of which depends on the depth of the investigation.

Our findings have practical implications for organizational leaders or HR professionals. Regular monitoring of employee satisfaction by applying the HRSI model will demonstrate the relevance of decisions taken on the basis of the results of previous measurements. Organizational leaders or HR professionals can follow the trend of satisfaction development and evaluate the effectiveness of decisions taken regarding work life of employees. 
Employees' satisfaction enhancement is critical for the firm's sustainability and is the base of the company's sustained competitive advantage. The results of this study contribute to the sustainable HRM literature by application of a new diagnostic tool to increase the sustainable competitive advantage of postal company by making managerial decisions flexible in response to needs and expectations of employees and their satisfaction. Unlike the existing literature on sustainable HRM, we believe that our work can make a distinctive contribution to HRM research. The contribution for academics and professionals consists of mapping the development of employee satisfaction in the postal sector and comparing it with the results of other authors' research. The use of mathematical and statistical methods (regression and correlation analysis, association analysis) has contributed to a more accurate assessment of employee satisfaction based on socio-demographic characteristics.

It is necessary for postal operators to incorporate elements of sustainable HRM into their HR strategies, build upon the employer's brand, and become attractive employers who, in addition to financial remuneration, provide their employees with other benefits that outweigh the competitors. There is a need to strike a balance between free competition, consumer demands, the sustainability of the universal service and its funding, and the preservation of jobs. Employee satisfaction and employee loyalty form the basis of the sustainable HRM, and quality HRM has today had significant impacts on the future and sustainability of postal providers on the Slovak Postal market. Slovak Post, Human Resource Division, welcomed the cooperation and will use the results of our research in their decision-making on future human resource development plans.

Author Contributions: Conceptualization, M.S.; methodology, M.S.; validation, M.S. and K.A.; formal analysis, K.A.; investigation, M.S.; data curation, M.S. and K.A.; writing—original draft preparation, M.S.; writing-review and editing, M.S.; visualization, M.S.

Funding: This research was funded by projects VEGA 1/0518/19 Research of the digital economy development and its impact on the competitiveness of enterprises in the knowledge based society, and VEGA 1/0152/18 Business models and platforms in digital space.

Acknowledgments: This research was supported by projects VEGA 1/0152/18 Business models and platforms in digital space, and VEGA 1/0518/19 Research of the digital economy development and its impact on the competitiveness of enterprises in the knowledge based society.

Conflicts of Interest: The authors declare no conflict of interest.

\section{References}

1. App, S.; Merk, J.; Buttgen, M. Employer Branding: Sustainable HRM as a Competitive Advantage in the Market for High-Quality Employees. Manag. Rev. 2012, 23, 262-278. [CrossRef]

2. Stankeviciute, Z.; Savaneviciene, A. Designing Sustainable HRM: The Core Characteristics of Emerging Field. Sustainability 2018, 10, 4798. [CrossRef]

3. Freitas, W.R.D.; Jabbour, C.J.C.; Mangili, L.L.; Filho, W.L.; Caldeira de Oliveira, J.E. Building Sustainable Values in Organizations with the Support of Human Resource Management: Evidence from One Firm Considered as the "Best Place to Work" in Brazil. J. Hum. Values 2012, 18, 147-159. [CrossRef]

4. Labbour, C.J.C.; Santos, F.C.A. The central role of human resource management in the search for sustainable organizations. Int. J. Hum. Resour. Manag. 2008, 19, 2133-2154. [CrossRef]

5. Kramar, R. Beyond strategic human resource management: Is sustainable human resource management the next approach? Int. J. Hum. Resour. Manag. 2014, 25, 1069-1089. [CrossRef]

6. Esfahani, S.A.; Rezaii, H.; Koochmeshki, N.; Sharifi-Parsa, S. Sustainable and Flexible Human Resource Management for Innovative Organizations. Ad-Minister 2017, 30, 195-215. [CrossRef]

7. Ping, L. Research on the Innovation of Human Resource Management for Chinese Family Business Based on Sustainable Development. Risus J. Innov. Sustain. 2011, 2, 55-60. [CrossRef]

8. Liu, J.H.; Yu, Y. Research on Human Resources Management Based on Sustainable Development for SMEs. In Proceedings of the 3rd International Forum of Human Resource Strategy and Development, Jinan City, China, 1 October 2010.

9. Jaerlstrom, M.; Saru, E.; Vanhala, S. Sustainable Human Resource Management with Salience of Stakeholders: A Top Management Perspective. J. Bus. Eth. 2018, 152, 703-724. [CrossRef] 
10. Wu, Y.L.; Zhao, J.L.; Li, J.A.; Wei, X.T.; Zhao, J. The Harmony-Oriented Culture of Enterprise Human Resource Management and the Sustainable Development of Enterprise Management. In Proceedings of the International Conference of Production and Operation Management, Xiamen University, Xiamen, China, 8-10 December 2008; pp. 1520-1525.

11. Kazlauskaite, R.; Buciuniene, I. The Role of Human Resources and Their Management in the Establishment of Sustainable Competitive Advantage. Inzinerine Ekonomika Eng. Econ. 2008, 5, 78-84.

12. Kucharcikova, A.; Miciak, M.; Hitka, M. Evaluating the Effectiveness of Investment in Human Capital in E-Business Enterprise in the Context of Sustainability. Sustainability 2018, 10, 3211. [CrossRef]

13. Wang, J.J.; Wang, S. Research on countermeasure of region sustainable development based on strategic human resource management. In Proceedings of the 13th International Conference on Industrial Engineering and Engineering Management, Shandong University, Weihai, China, 12-14 August 2006; pp. 3554-3558.

14. Van der Heijden, B. "Als het getij verloopt, verzet men de bakens". Sustainable employability policy as being part of Strategic Human Resource Management. Gedrag Organisatie 2012, 25, 117-137.

15. Lis, B. The Relevance of Corporate Social Responsibility for a Sustainable Human Resource Management: An Analysis of Organizational Attractiveness as a Determinant in Employees' Selection of a (Potential) Employer. Manag. Rev. 2012, 23, 279-295. [CrossRef]

16. Macke, J.; Genari, D. Systematic literature review on sustainable human resource management. J. Clean. Prod. 2019, 208, 806-815. [CrossRef]

17. Lorincova, S.; Hitka, M.; Starchon, P.; Stachova, K. Strategic Instruments for Sustainability of Human Resource Management in Small and Medium-Sized Enterprises Using Management Data. Sustainability 2018, 10, 3687. [CrossRef]

18. Dirisu, J.; Worlu, R.; Osibanjo, A.; Salau, O.; Borishade, T.; Meninwa, S.; Atolagbe, T. An integrated dataset on organisational culture, job satisfaction and performance in the hospitality industry. Data Brief 2018, 19, 317-321. [CrossRef] [PubMed]

19. Raziq, A.; Maulabakhsh, R. Impact of working environment on job satisfaction. Proc. Econ. Financ. 2015, 23, 717-725. [CrossRef]

20. Chinomona, R.; Dhurup, M. The influence of the quality of working life on employee job satisfaction, job commitment and tenure intention in the SME sector in Zimbabwe. S. Afr. J. Econ. Manag. Sci. 2014, 17, 363-378. [CrossRef]

21. Al Mamun, A.; Ibrahim, M.D.; Yusoff, M.N.H.B.; Fazal, S.A. Entrepreneurial leadership, performance, and sustainability of micro-enterprises in Malaysia. Sustainability 2018, 10, 1591. [CrossRef]

22. Cantele, S.; Zardini, A. Is sustainability a competitive advantage for small businesses? An empirical analysis of possible mediators in the sustainability-financial performance relationship. J. Clean. Prod. 2018, 182, 166-176. [CrossRef]

23. Delmas, M.A.; Pekovic, S. Organizational configurations for sustainability and employee productivity: A qualitative comparative analysis approach. Bus. Soc. 2018, 57, 216-251. [CrossRef]

24. Pintão, S.; Chaves, C.; Branco, M.C. Employees' recognition of corporate sustainability: A case study. Corp. Gov. 2018, 18, 104-118. [CrossRef]

25. Dongho, K. Employee Motivation: “Just Ask Your Employees". Seoul J. Bus. 2006, 12, $19-35$.

26. Monusova, G.A. Job satisfaction: International comparisons. World Econ. Int. Relat. 2008, 12, 74-83.

27. Bakotic, D.; Babic, T.B. Relationship between working conditions and job satisfaction: The case of Croatian ship building company. Int. J. Bus. Soc. Sci. 2013, 4, 206-213.

28. Chatzopoulou, M.; Vlachvei, A.; Monovasilis, T. Employee's motivation and satisfaction in light of economic recession: Evidence of Grevena Prefecture-Greece. Proc. Econ. Financ. 2015, 24, 136-145. [CrossRef]

29. Chang, R.D.; Zuo, J.; Zhao, Z.Y.; Soebarto, V.; Lu, Y.; Zillante, G.; Gan, X.L. Sustainability attitude and performance of construction enterprises: A China study. J. Clean. Prod. 2018, 172, 1440-1451. [CrossRef]

30. Chatterjee, S.; DuttaGupta, S.; Upadhyay, P. Sustainability of microenterprises: An empirical analysis. Benchmarking 2018, 25, 919-931. [CrossRef]

31. Gianni, M.; Gotzamani, K.; Tsiotras, G. Multiple perspectives on integrated management systems and corporate sustainability performance. J. Clean. Prod. 2017, 168, 1297-1311. [CrossRef]

32. Roxas, B.; Ashill, N.; Chadee, D. Effects of entrepreneurial and environmental sustainability orientations on firm performance: A study of small businesses in the Philippines. J. Small Bus. Manag. 2017, 55, 163-178. [CrossRef] 
33. Chandrasekar, K. Workplace environment and its impact organizational performance in public sector organizations. Int. J. Enterp. Comput. Bus. Syst. 2011,1,1-19.

34. Giovanis, E. Do the flexible employment arrangements increase job satisfaction and employee loyalty? Evidence from Bayesian networks and instrumental variables. Int. J. Comput. Econ. Econom. 2019, 9, 84-115. [CrossRef]

35. Kot-Radojewska, M.; Timenko, I.V. Employee loyalty to the organization in the context of the form of employment. Oeconomia Copernicana 2018, 10, 511-527. [CrossRef]

36. Gazioglu, S.; Tansel, A. Job satisfacion in Britain: Individual and job related factors. Appl. Econ. 2006, 38, 1163-1171. [CrossRef]

37. Baumgardt, J.; Moock, J.; Rossler, W.; Kawohl, W. Cooperation, Job Satisfaction and Burn Out-Sustainability in Outpatient Mental Health Care among Medical Specialists in Germany. Psychiatrische Praxis 2017, 44, 154-162. [PubMed]

38. Clark, A.; Oswald, A.; Warr, P. Is job satisfaction U-shaped in age? J. Occup. Organ. Psychol. 1996, 69, 57-81. [CrossRef]

39. IPC Postal Sector Sustainability Report 2018. Available online: https://www.ipc.be/about-ipc/reports-library/ ipc-reports.../sr2018 (accessed on 8 July 2019).

40. Corejova, T.; Strenitzerova, M.; Madlenakova, L.; Margita, M.; Jankalova, M. Ekonomika Sietí; EDIS: Žilina, Slovakia, 2010; pp. 33-58. ISBN 978-80-554-0155-3.

41. Postal Services-European Commission-Europa.eu. Available online: https://ec.europa.eu/growth/sectors/ postal-services_sk (accessed on 30 March 2019).

42. Statistical Office of the Slovak Republic. STATdat. Economic Indicators for Transport and Storage by SK NACE. Available online: http://statdat.statistics.sk/cognosext/cgi-bin/cognos.cgi?b_action= cognosViewer\&ui.action=run\&ui.object=storeID (\%22i8EF93A78FDDF4A168F81191F461B3C23\%22) \&ui.name=Ekonomick \%c3\%a9\%20ukazovatele $\% 20 \mathrm{za} \% 20$ dopravu $\% 20 \mathrm{a} \% 20$ skladovanie $\% 20$ pod $\%$ c4 $\%$ bea $\% 20$ SK\%20NACE\%20Rev. $\% 202 \% 20 \% 5$ bdo1001rs\%5d\&run.outputFormat=\&run.prompt=true\&cv. header=false\&ui.backURL= $\% 2$ fcognosext $\% 2$ fcps $4 \% 2$ fportlets $\% 2$ fcommon $\% 2$ fclose.html (accessed on 30 March 2019).

43. Main Developments in the Postal Sector. Study for the European Commission, Directorate-General for Internal Market, Industry, Entrepreneurship and SMEs. Available online: https://publications.europa.eu/ en/publication-detail/-/publication/d22799b5-bbb7-11e8-99ee-01aa75ed71a1/language-en (accessed on 30 March 2019).

44. Stanovisko Výboru pre Zamestnanost' a Sociálne Veci pre Výbor pre Dopravu a Cestovný Ruch k Správe o Uplatňovaní Smernice o Poštových Službách. Available online: http://www.europarl.europa.eu/meetdocs/ 2014_2019/plmrep/COMMITTEES/EMPL/AD/2016/07-11/1098240SK.pdf (accessed on 30 March 2019).

45. Statistical Office of the Slovak Republic. DATAcube. Priemerná Nominálna Mesačná Mzda Zamestnanca v Doprave a Skladovaní Vrátane Pôšt-Štvrt'ročné Údaje. Available online: http://datacube.statistics.sk/\#!/view/sk/VBD_SLOVSTAT/do2006qs/Priemern\%C3\%A1\%20nomin\%C3\% A1lna $\% 20$ mesa $\%$ C4\%8Dn\%C3\%A1\%20mzda\%20zamestnanca $\% 20 \mathrm{v} \% 20$ doprave $\% 20 \mathrm{a} \% 20$ skladovan $\%$ C3\%AD \%20vr\%C3\%A1tane\%20p\%C3\%B4\%C5\%A1t\%20-\%20\%C5\%A1tvr\%C5\%A5ro\%C4\%8Dn \%C3\% A9\%20\%C3\%BAdaje\%20\%5Bdo2006qs\%5D (accessed on 30 March 2019).

46. Annual Report of Slovak Post. Available online: https://www.posta.sk/subory/39115/vyrocna-sprava-za-rok2016.pdf (accessed on 5 April 2019).

47. Spector, P.E. Job Satisfaction: Application, Assessment, Causes, and Consequences, 1st ed.; SAGE Publications Inc.: Thousand Oaks, CA, USA, 1997; 104p, ISBN-10 0761989234, ISBN-13 978-076198923.

48. Dhamija, P.; Gupta, S.; Bag, S. Measuring of job satisfaction: The use of quality of work life factors. Benchmark. Int. J. 2019, 26, 871-892. [CrossRef]

49. Fila, M.J.; Paik, L.S.; Griffeth, R.W.; Allen, D. Disaggregating Job Satisfaction: Effects of Perceived Demands, Control, and Support. J. Bus. Psychol. 2014, 29, 639-649. [CrossRef]

50. Macintosh, G.; Krush, M. Examining the link between salesperson networking behaviors, job satisfaction, and organizational commitment: Does gender matter? J. Bus. Res. 2014, 67, 2628-2635. [CrossRef]

51. Spagnoli, P.; Caetano, A.; Santos, S.C. Satisfaction with job aspects: Do patterns change over time? J. Bus. Res. 2012, 65, 609-616. [CrossRef] 
52. Kalawilapathirage, H.; Omisakin, O.; Zeidan, S. A Data Analytic Approach of Job Satisfaction: A Case Study on Airline Industry. J. Inf. Knowl. Manag. 2019, 18, 1950003. [CrossRef]

53. Steel, P.; Schmidt, J.; Bosco, F.; Uggerslev, K. The effects of personality on job satisfaction and life satisfaction: A meta-analytic investigation accounting for bandwidth-fidelity and commensurability. Hum. Relat 2019, 72 , 217-247. [CrossRef]

54. Hazriyanto, H.; Ibrahim, B. The Factor Analysis of Organizational Commitment, Job Satisfaction and Performance among Lecturers in Batam. J. Tech. Educ. Train. 2019, 11, 151-158. [CrossRef]

55. Maghsoodi, A.I.; Azizi-Ari, I.; Barzegar-Kasani, Z.; Azad, M.; Zavadskas, E.K.; Antucheviciene, J. Evaluation of the Influencing Factors on Job Satisfaction Based on Combination of PLS-SEM and F-MULTIMOORA Approach. Symmetry 2019, 11, 24. [CrossRef]

56. Weiss, D.J.; Dawis, R.V.; England, G.W.; Lofquist, L.H. Manual for the Minnesota Satisfaction Questionnaire. Available online: http://vpr.psych.umn.edu/sites/g/files/pua2236/f/monograph_xxii_-_manual_for_the_mn_ satisfaction_questionnaire.pdf (accessed on 12 April 2019).

57. Strenitzerova, M.; Gana, J. Customer Satisfaction and Loyalty as a Part of Customer-Based Corporate Sustainability in the Sector of Mobile Communications Services. Sustainability 2018, 10, 1657. [CrossRef]

58. Darena, F. Služba Výpočtu CSI pro PEF. Available online: \T1\textless\{\}https://akela.mendelu.cz/ \{\}darena/ CSI/TT1 \textgreater\{\}. (accessed on 15 January 2019).

59. Poštová Politika do Roku 2021. Available online: https://www.mindop.sk/ministerstvo-1/.../postova-politikado-roku-2021-pdf-295-kb (accessed on 15 January 2019).

60. Madleňáková, L.; Madleňák, R. Image measurement in postal corporation. MANEKO J. Manag. Econ. 2012, 4, 198-209.

61. Kubal'a, J.; Vetráková, M. Reasons of the employees' stabilization in hotels in Slovakia. Acta Oeconomica Univ. Selye 2018, 6, 90-100.

62. Sánchez-Sellero, M.C.; Sánchez-Sellero, P. Determinants of job satisfaction in Spain before and during the economic crisis of 2008. Intang. Cap. 2016, 12, 1192-1220. [CrossRef]

(C) 2019 by the authors. Licensee MDPI, Basel, Switzerland. This article is an open access article distributed under the terms and conditions of the Creative Commons Attribution (CC BY) license (http://creativecommons.org/licenses/by/4.0/). 


\title{
Article \\ Employee Motivation as a Tool to Achieve Sustainability of Business Processes
}

\author{
Silvia Lorincová ${ }^{1}$, Peter Štarchoň ${ }^{2}$, Dagmar Weberová ${ }^{3}$, Miloš Hitka ${ }^{1, *}$ and Martina Lipoldová ${ }^{1}$ \\ 1 Faculty of Wood Sciences and Technology, Technical University in Zvolen, Ul. T. G. Masaryka 24, \\ 96001 Zvolen, Slovakia \\ 2 Faculty of Management, Comenius University in Bratislava, Odbojárov 10, P.O. BOX 95 , \\ 82005 Bratislava, Slovakia \\ 3 Faculty of Multimedia Communications, Tomas Bata University in Zlín, Univerzitní 2431, 76001 Zlín, \\ Czech Republic \\ * Correspondence: hitka@tuzvo.sk; Tel.: +421-45-520-6433
}

Received: 31 May 2019; Accepted: 25 June 2019; Published: 26 June 2019

\begin{abstract}
Employee performance and their new ideas, as well as their efforts to promote the company in positive ways help build the values of an enterprise. Properly motivated managers, white-collar, and blue-collar workers use their performance to affect the business efficiency, and therefore the success and sustainability of the enterprise. Selecting the right structure of motivation factors, especially those aimed at job category and gender, is the main role of enterprise management. The aim of this study is to analyze and define differences in the perception of the preferred level of motivation in terms of gender and job category. The questionnaires were given to randomly selected employees working in Slovak enterprises in order to ensure variability and randomness of respondent selection which is necessary for relevant data acquisition. Following the average, the order of the importance of motivation factors of 3720 respondents was defined. The Student's t-test and Tukey's HSD test were used. We confirmed that there are statistically significant differences in the perception of the motivation in terms of job category. Moreover, we proved the significant differences between genders in the job category of blue-collar workers. We did not observe differences between genders in the other job categories studied. The results reported should be accepted and implemented in motivational programs by the employees of human resource departments as a way to keep up with strategic human resource management.
\end{abstract}

Keywords: strategic human resource management; sustainable work systems; employee motivation; job category; gender differences

\section{Introduction}

Sustainability in business process management is a key factor associated with the enterprise success [1,2]. Employees are considered one of the most important and leading factors in achieving sustainability [3-5], especially employees who move the business forward [6-9]. Managers, white-collar workers, and blue-collar workers are all involved in the company results. An employee's performance, their new ideas, as well as their efforts to promote the company in a positive way help build the values of an enterprise [10-13] and the success or failure of a business is affected by their productivity [14-21]. Employee productivity is influenced by employee motivation [22-25]. It is a complex and purposeful process to create a working environment and atmosphere that helps satisfy the aspirations, needs, and interests of employees and stimulates their action in a desirable way [26,27].

The quality of human potential plays an important role and it is a key factor that affects the running of a company, its prosperity, as well as sustainable development. A successful business is aware of the importance of its staff and their positive motivation; they are the greatest asset helping 
the company meet its goals. Currently, when advances in technology, information, and globalization occur most often, the human factor is becoming the biggest competitive advantage. The importance of human resources is considered strategic [28-32]. They become a part of strategic management of an enterprise and a factor important for sustainability. Effective employee management is supported by motivation.

A result assessment approach to employee management must focus on ways to encourage employee creativity, improve work performance, and create conditions that support team activity within the enterprise. It is connected with the employee performance in the workplace. Therefore, it is a specific task linked to the specific enterprise [33-37].

The motivation process is supported by setting realistic company goals and engaging employees. A motivational program focuses on the optimal use of the available workforce to meet company goals and, at the same time, on knowing and developing the personality of the employee. An effective motivational program covers the areas with low performance in a given period or those areas which seem to be significant for work activity due to another reason. The goal of the program is to create conditions encouraging motivation of all employees in the enterprise. Motivational programs affect employees in psychologically and economically ways, whereby the importance of both ways is equal. A motivational program is used especially as part of an adaptation programs. It is a document covering the set of facts affecting and motivating employees in accordance with the task relating to manufacturing, trade, and economic intentions of the enterprise [38].

We propose that motivation will be affected, besides other sociodemographic data (age, education, seniority, company strategic direction, region, and the size of an enterprise), by gender and job category. The aim of this study is to analyze and define differences in the perception of the preferred level of motivation in terms of gender and job category. The research is part of a long-term and extensive study on employee motivation in Slovakia dealing with the individual mentioned areas. In the future, the research results will be used to define the model of employee motivation in Slovak enterprises.

\section{Literature Review}

There is a wide range of tools used to motivate employees. F. Taylor defined money as the most important factor motivating employees to achieve higher productivity in industry $[39,40]$. This form of reward results in employee satisfaction and directly affects their performance. Salary is a valuable tool that plays an important role in the improvement of employee performance, as well as organizational productivity [41]. Studies [42-45] have shown that salary, promotion, bonuses, and other types of rewards are used by most enterprises to improve employee performance. Praise, setting realistic and achievable goals, appropriate workload definition, employee engagement, appropriate empowerment, responsibility, feedback, work equipment, expressing the positive personality features of a supervisor, appropriate leadership style, correctness by senior staff and company, and providing relevant information are considered to be other important motivation factors [46-54].

The role of business management is to define motivational factors that are used to manage and lead employees in an effective way. Current research has shown that the occurrence of differences in employee motivation depend on the employee's age [55-61]. However, in this process, the employee's position must be taken into account. With respect to the source of motivation for managers, they represent a specific group of employees [62]. Managers are motivated by financial motivational factors, as well as recognition and freedom in decision making $[63,64]$. Motivational factors for managers are often classified as "push" or "pull" factors. Push factors include the need to increase the family income, work dissatisfaction in terms of salary, difficulties finding a suitable job, and the need for flexibility due to family duties and responsibilities. Pull factors include the need for independence, self-actualization, and improvement of the current state and reputation in the society. White-collar workers are motivated through rewards or recognition [65]. Employees at lower level job are also motivated by financial rewards [66,67]. 
When defining motivational factors, the role of enterprise management is to choose an appropriate structure of motivational factors with an emphasis on gender. Differences in motivation follow the differences in gender. Men put more effort into achieving wealth or financial well-being while women prefer work-life balance [68]. In general, women are motivated by family needs more than men whose priority is a private financial situation $[69,70]$.

\section{Materials and Methods}

The level of employee motivation was investigated in this study conducted in 2018. The selection of respondents was proportionally allocated throughout Slovakia. All parts of Slovakia were covered by the research sample dataset. The questionnaires were given to randomly selected employees working in Slovak enterprises in order to ensure variability and randomness of respondent selection necessary for relevant data acquisition. A total of 3720 respondents, described in Table 1, participated in the research. Descriptive statistics were used to describe the primary sampling unit.

Table 1. Characteristics of respondents by job category.

\begin{tabular}{|c|c|c|c|c|c|c|}
\hline \multirow{2}{*}{$\begin{array}{c}\text { Job } \\
\text { Category }\end{array}$} & \multicolumn{2}{|c|}{ Male } & \multicolumn{2}{|c|}{ Female } & \multicolumn{2}{|c|}{ Total } \\
\hline & $\begin{array}{l}\text { Absolute } \\
\text { Frequency }\end{array}$ & $\begin{array}{c}\text { Relative } \\
\text { Frequency }\end{array}$ & $\begin{array}{l}\text { Absolute } \\
\text { Frequency }\end{array}$ & $\begin{array}{l}\text { Relative } \\
\text { Frequency }\end{array}$ & $\begin{array}{l}\text { Absolute } \\
\text { Frequency }\end{array}$ & $\begin{array}{l}\text { Relative } \\
\text { Frequency }\end{array}$ \\
\hline Manager & 225 & 12.04 & 182 & 9.83 & 407 & 10.94 \\
\hline $\begin{array}{l}\text { White-collar } \\
\text { worker }\end{array}$ & 588 & 31.46 & 1165 & 62.94 & 1753 & 47.12 \\
\hline $\begin{array}{l}\text { Blue-collar } \\
\text { worker }\end{array}$ & 1056 & 56.50 & 504 & 27.23 & 1560 & 41.94 \\
\hline Total & 1869 & 50.24 & 1851 & 49.76 & 3720 & 100.00 \\
\hline
\end{tabular}

The following 30 motivational factors were examined: atmosphere in the workplace, good work team, fringe benefits, physical effort at work, job security, communication in the workplace, name of the company, opportunity to apply one's own ability, workload and type of work, information about performance result, working hours, work environment, job performance, career advancement, competences, prestige, supervisor's approach, individual decision making, self-actualization, social benefits, fair appraisal system, stress, mental effort, mission of the company, region's development, personal growth, relation to the environment, free time, recognition, and basic salary. Respondents assigned each motivational factor one of the five degrees of importance according to the Likert scale (5-very important, 4-important, 3-medium important, 2-slightly important, and 1-unimportant). The data gathered were processed using the STATISTICA 12 software. The importance of the level of motivation was investigated using the weighted arithmetic average formula. The level of motivation of all respondents was defined in terms of gender. Subsequently, the ten most important motivational factors for individual job categories of employees were defined. The motivational factors that were mentioned most occurred as the most important motivational factors over a long period in present studies [71-78]. A random variable, $t$, with Student $t$ distribution was used as a test criterion for further testing. The following two hypotheses were tested at the level of significance $\alpha \leq 0.05$ :

Hypothesis 1. Statistically significant differences between genders are expected.

Hypothesis 2. Considering gender, statistically significant differences between job categories are expected.

The likelihood of motivating employees, in terms of their gender and job category, with similar motivational programs was tested. The chi-Square or Pearson-Fisher $\left(\chi^{2}\right)$ test was used to test the agreement or disagreement between observations. Due to the selective character of the gathered data, Tukey's HSD (honest significant difference) at the significance level of $5 \%$ was used to test the 
differences between the averages of the values for the importance of motivational factors of white-collar workers. The Tukey's HSD test is a single-step multiple comparison procedure. It is modified for various numbers of observations in individual groups. Independence between levels of factors, variance, and normality agreement was expected.

\section{Empirical Results}

First, the dependence of motivational factors in terms of job category was verified. Tukey's HSD test was used. The results are presented in Figure 1.

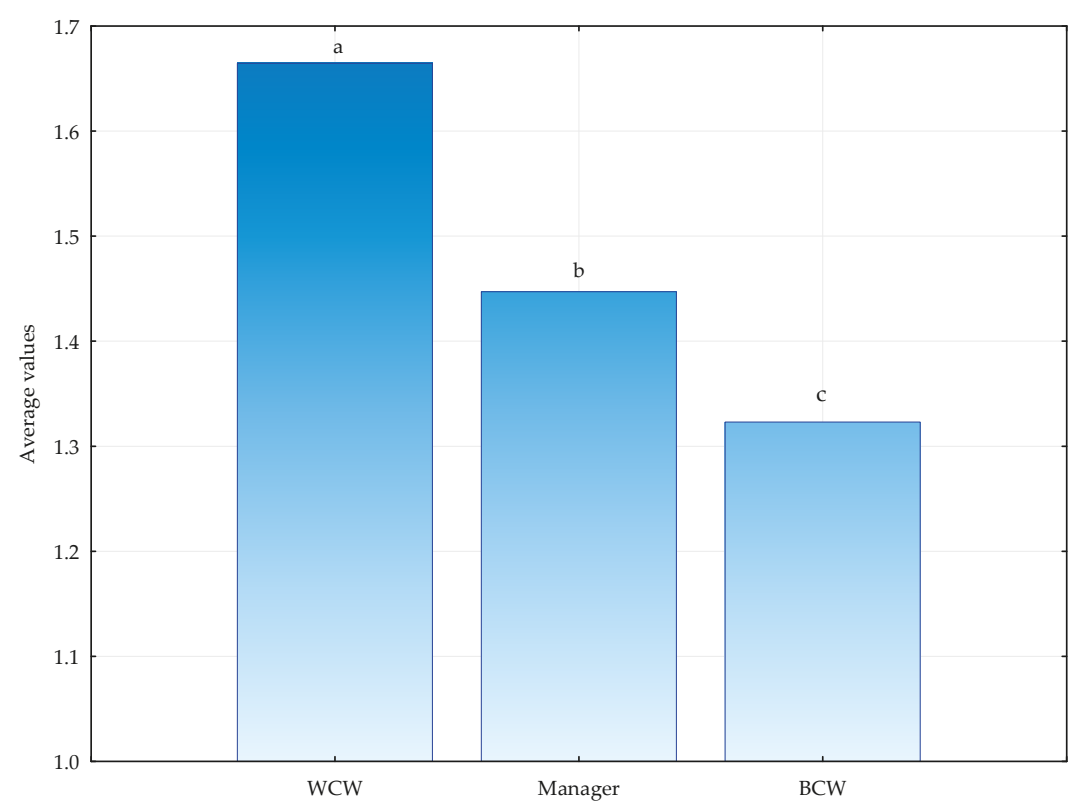

Figure 1. Testing the dependence of the average values between job categories. Note: WCW (white-collar worker), BCW (blue-collar worker).

The results in Figure 1 show that there were statistically significant differences in all job categories.

Subsequently, the importance of motivational factors in terms of gender was examined. The results are presented in Table 2.

The average values of 30 motivational factors in terms of gender are presented in Table 2. For men, the following 10 motivational factors were considered the most important: basic salary, atmosphere in the workplace, good work team, fringe benefits, fair appraisal system, supervisor's approach, job security, communication in the workplace, working hours, and work environment. For women, the motivational factors considered most important were: basic salary, atmosphere in the workplace, good work team, supervisor's approach, fair appraisal system, job security, fringe benefits, communication in the workplace, working hours, and work environment. The average values of these motivational factors were the highest rated.

When a detailed test at the level of $\alpha \leq 0.05$ was carried out, the occurrence of statistical dependence was confirmed for 17 out of 30 motivational factors. The statistically significant differences are highlighted in bold in Table 2. Following the results, the hypothesis, H1, was confirmed, i.e., there were statistically significant differences in the perception of the motivational level between men and women. 
Table 2. Testing the dependence of the average values between genders.

\begin{tabular}{|c|c|c|c|}
\hline Motivational Factor & Male & Female & $p$-Level \\
\hline Atmosphere in the workplace & 4.481 & 4.590 & $0.000015^{* * *}$ \\
\hline Good work team & 4.478 & 4.572 & $0.000864 * * *$ \\
\hline Fringe benefits & 4.414 & 4.407 & $0.014822 * *$ \\
\hline Physical effort at work & 3.868 & 3.770 & $0.000003 * * *$ \\
\hline Job security & 4.375 & 4.441 & 0.074098 \\
\hline Communication in the workplace & 4.299 & 4.377 & $0.015881 * *$ \\
\hline Name of the company & 3.971 & 3.978 & 0.220068 \\
\hline Opportunity to apply one's own ability & 4.044 & 4.082 & 0.121283 \\
\hline Workload and type of work & 4.094 & 4.185 & $0.000284^{* * *}$ \\
\hline Information about performance result & 4.014 & 4.053 & 0.135037 \\
\hline Working hours & 4.262 & 4.266 & 0.582611 \\
\hline Work environment & 4.220 & 4.232 & $0.005689 * *$ \\
\hline Job performance & 4.139 & 4.185 & $0.009677^{* *}$ \\
\hline Career advancement & 4.060 & 4.025 & $0.042093^{* *}$ \\
\hline Competences & 3.950 & 3.917 & 0.083130 \\
\hline Prestige & 3.871 & 3.778 & $0.002051^{* *}$ \\
\hline Supervisor's approach & 4.394 & 4.462 & $0.017969 * *$ \\
\hline Individual decision-making & 4.014 & 4.050 & 0.014293 ** \\
\hline Self-actualization & 4.017 & 4.055 & 0.065170 \\
\hline Social benefits & 4.213 & 4.204 & 0.099271 \\
\hline Fair appraisal system & 4.404 & 4.460 & 0.279517 \\
\hline Stress & 4.089 & 4.206 & $0.000226^{* * *}$ \\
\hline Mental effort & 4.027 & 4.101 & 0.006000 ** \\
\hline Mission of the company & 3.892 & 3.919 & $0.004789^{* *}$ \\
\hline Region's development & 3.804 & 3.822 & 0.224187 \\
\hline Personal growth & 4.056 & 4.083 & 0.025756 ** \\
\hline Relation to the environment & 3.914 & 3.854 & 0.030853 ** \\
\hline Free time & 4.137 & 4.096 & 0.346869 \\
\hline Recognition & 4.163 & 4.213 & 0.031894 \\
\hline Basic salary & 4.576 & 4.592 & 0.073355 \\
\hline
\end{tabular}

Note: Single, double, and triple asterisks $\left({ }^{*}, * *, * * *\right)$ indicate significance at $5 \%, 1 \%$, and $0.1 \%$ level. Source: Authors' compilation.

Furthermore, the importance of motivational factors in the case of job categories was examined in terms of gender.

\subsection{The Level of Motivation in Terms of Job Category of the Manager}

The job category, manager, was the first category analyzed. The results are presented in Table 3, indicating that the three most important motivational factors for men and women in the job category "manager" were the same. However, the order of importance was different. Male managers considered the basic salary the second most motivating factor, while, good work team was the second most important motivational factor for female managers.

The most important motivational factors for both men and women were chosen in order to test the dependence of motivational factors in terms of gender in the job category "manager". Following the Student t-test at the significance level $\alpha \leq 0.05$, statistically significant differences were not confirmed, i.e., there was no significant statistical dependence between selected motivational factors and gender in the job category "manager" (Table 4). On the basis of the results in the job category of manager, there was a high degree of similarity in motivational factors with a different order of preferences in motivational factors. 
Table 3. Average values of selected motivational factors in the job category "manager".

\begin{tabular}{ccccc}
\hline \multirow{2}{*}{ No. Male } & \multicolumn{2}{c}{ Female } \\
\cline { 2 - 5 } & Motivational Factor & Average & Motivational Factor & Average \\
\hline 1 & Atmosphere in the workplace & 4.569 & Atmosphere in the workplace & 4.654 \\
2 & Basic salary & 4.560 & Good work team & 4.604 \\
3 & Good work team & 4.542 & Basic salary & 4.604 \\
4 & Fair appraisal system & 4.533 & Supervisor's approach & 4.533 \\
5 & Supervisor's approach & 4.507 & Fair appraisal system & 4.522 \\
6 & Job security & 4.476 & Job security & 4.484 \\
7 & Communication in the workplace & 4.427 & Communication in the workplace & 4.478 \\
8 & Fringe benefits & 4.413 & Individual decision making & 4.396 \\
9 & Individual decision making & 4.369 & Fringe benefits & 4.385 \\
10 & Personal growth & 4.369 & Selfactualization & 4.363 \\
\hline \multicolumn{2}{l}{ Note: Single, double, and triple asterisks $(*, * *, * *)$} & indicate significance at 5\%, 1\%, and $0.1 \%$ level. Source: \\
Authors' compilation. & &
\end{tabular}

Table 4. Testing the dependence of the most important motivational factors in terms of gender in the job category "manager".

\begin{tabular}{cc}
\hline Motivation Factor & $p$-Level \\
\hline Atmosphere in the workplace & 0.585 \\
Good work team & 0.332 \\
Fringe benefits & 0.066 \\
Job security & 0.879 \\
Communication in the workplace & 0.931 \\
Supervisor's approach & 0.373 \\
Individual decision making & 0.573 \\
Self-actualization & 0.334 \\
Fair appraisal system & 0.198 \\
Personal growth & 0.447 \\
Basic salary & 0.994 \\
\hline Source: Authors' compilation
\end{tabular}

\subsection{The Level of Motivation in Terms of Job Category of the White-Collar Worker}

In the case of white-collar workers, basic salary, atmosphere in the workplace, and good work team were the three most important motivational factors for both men and women and the order of most importance factors was the same for both men and women. Further results are presented in Table 5.

Table 5. Average values of selected motivational factors in the job category "white-collar worker".

\begin{tabular}{ccccc}
\hline & \multicolumn{2}{c}{ Male } & & \multicolumn{2}{c}{ Female } \\
\cline { 2 - 5 } No. Average & Motivational Factor & Average \\
\hline 1 & Motivational Factor & 4.573 & Basic salary & 4.628 \\
2 & Basic salary & 4.457 & Atmosphere in the workplace & 4.603 \\
3 & Atmosphere in the workplace & 4.457 & Good work team & 4.596 \\
4 & Good work team & 4.425 & Fair appraisal system & 4.493 \\
5 & Fringe benefits & 4.374 & Supervisor's approach & 4.481 \\
6 & Supervisor's approach & 4.357 & Job security & 4.434 \\
7 & Fair appraisal system & 4.320 & Fringe benefits & 4.426 \\
8 & Communication in the workplace & 4.316 & Communication in the workplace & 4.400 \\
9 & Job security & 4.219 & Working hours & 4.276 \\
10 & Working hours & 4.204 & Recognition & 4.264 \\
\hline
\end{tabular}

Source: Authors' compilation.

Statistically significant dependence between motivational factors and gender in the job category of white-collar workers was verified for selected motivational factors. The results in Table 6 show that there were statistically significant differences in selected motivational factors depending upon gender. 
These factors included atmosphere in the workplace, good work team, job security, supervisor's approach, and fair appraisal system.

Table 6. Testing the dependence of the most important motivational factors in terms of gender in the job category "white-collar worker".

\begin{tabular}{cc}
\hline Motivational Factor & $p$-level \\
\hline Atmosphere in the workplace & $0.000^{* * *}$ \\
Good work team & $0.001^{* * *}$ \\
Fringe benefits & 0.226 \\
Job security & $0.025^{* *}$ \\
Communication in the workplace & 0.095 \\
Supervisor's approach & $0.004^{* *}$ \\
Working hours & 0.519 \\
Work environment & 0.694 \\
Fair appraisal system & $0.007^{* *}$ \\
Basic salary & 0.292 \\
\hline
\end{tabular}

Note: Single, double, and triple asterisks $\left({ }^{*},{ }^{* *},{ }^{* * *}\right)$ indicate significance at the $5 \%, 1 \%$, and $0.1 \%$ level. Source: Authors' compilation.

Testing the selected motivational factors with significant differences confirmed statistically are presented in Table 7.

Table 7. Testing the selected motivational factors in terms of gender in the job category "white-collar worker".

\begin{tabular}{|c|c|c|}
\hline Motivational Factor & \multicolumn{2}{|c|}{ Statistical Indicator } \\
\hline Atmosphere in the workplace & $\begin{array}{c}\text { Pearson's chi-square } \\
\text { Degree of freedom } \\
p \text {-level }\end{array}$ & $\begin{array}{c}22.3240 \\
\mathrm{df}=4 \\
p=0.000173^{* * * *}\end{array}$ \\
\hline Good work team & $\begin{array}{c}\text { Pearson's chi-square } \\
\text { Degree of freedom } \\
p \text {-level }\end{array}$ & $\begin{array}{c}18.3508 \\
\mathrm{df}=4 \\
p=0.001054^{* *}\end{array}$ \\
\hline Job security & $\begin{array}{c}\text { Pearson's chi-square } \\
\text { Degree of freedom } \\
p \text {-level }\end{array}$ & $\begin{array}{c}11.1819 \\
\mathrm{df}=4 \\
p=0.024594^{* *}\end{array}$ \\
\hline Supervisor's approach & $\begin{array}{c}\text { Pearson's chi-square } \\
\text { Degree of freedom } \\
p \text {-level }\end{array}$ & $\begin{array}{c}15.3366 \\
\mathrm{df}=4 \\
p=0.004052 * *\end{array}$ \\
\hline Fair appraisal system & $\begin{array}{c}\text { Pearson's chi-square } \\
\text { Degree of freedom } \\
p \text {-level }\end{array}$ & $\begin{array}{c}13.9748 \\
\mathrm{df}=4 \\
p=0.007376^{* *}\end{array}$ \\
\hline
\end{tabular}

Note: Single, double, and triple asterisks $(*, * * * *)$ indicate significance at $5 \%, 1 \%$, and $0.1 \%$ level. Source: Authors' compilation.

Five motivational factors with statistically significant differences and the overview of the values of importance assigned by respondents are shown in Table 8. Absolute and relative frequencies of responses are mentioned.

Selected motivational factors were considered important or very important by both men and women in the job category of white-collar workers. The value 5 (i.e., very important) was the value with the highest frequency of responses recorded in all motivational factors.

Average values, standard deviation, 95\% confidence intervals in the primary sampling unit are mentioned in Table 9. Following the results presented in Table 9 the findings are generalized. 
Table 8. The population proportion of individual score values of selected motivational factors in terms of gender in the job category "white-collar worker".

\begin{tabular}{|c|c|c|c|c|c|c|c|}
\hline \multirow{2}{*}{$\begin{array}{l}\text { Motivational } \\
\text { Factor }\end{array}$} & \multirow{2}{*}{ Gender } & \multicolumn{5}{|c|}{ Values of Importance } & \multirow[b]{2}{*}{ Total } \\
\hline & & $\begin{array}{c}1 \\
\text { Unimportant }\end{array}$ & $\begin{array}{c}2 \\
\text { Slightly Important }\end{array}$ & $\begin{array}{c}3 \\
\text { Medium Important }\end{array}$ & $\begin{array}{c}4 \\
\text { Important }\end{array}$ & $\begin{array}{c}5 \\
\text { Very Important }\end{array}$ & \\
\hline \multirow{5}{*}{$\begin{array}{l}\text { Atmosphere in } \\
\text { the workplace }\end{array}$} & \multirow{2}{*}{ Male } & 3 & 8 & 55 & 173 & 349 & 588 \\
\hline & & $1 \%$ & $1 \%$ & $9 \%$ & $29 \%$ & $59 \%$ & $100 \%$ \\
\hline & \multirow{2}{*}{ Female } & 3 & 6 & 53 & 327 & 776 & 1165 \\
\hline & & $0 \%$ & $1 \%$ & $5 \%$ & $28 \%$ & $67 \%$ & $100 \%$ \\
\hline & Total & 6 & 14 & 108 & 500 & 1125 & 1753 \\
\hline \multirow{5}{*}{ Good work team } & \multirow{2}{*}{ Male } & 3 & 7 & 41 & 204 & 333 & 588 \\
\hline & & $1 \%$ & $1 \%$ & $7 \%$ & $35 \%$ & $57 \%$ & $100 \%$ \\
\hline & \multirow{2}{*}{ Female } & 1 & 6 & 49 & 351 & 758 & 1165 \\
\hline & & $0 \%$ & $1 \%$ & $4 \%$ & $30 \%$ & $65 \%$ & $100 \%$ \\
\hline & Total & 4 & 13 & 90 & 555 & 1091 & 1753 \\
\hline \multirow{5}{*}{ Job security } & \multirow[b]{2}{*}{ Male } & 5 & 12 & 77 & 192 & 302 & 588 \\
\hline & & $1 \%$ & $2 \%$ & $13 \%$ & $33 \%$ & $51 \%$ & $100 \%$ \\
\hline & \multirow{2}{*}{ Female } & 10 & 12 & 107 & 369 & 667 & 1165 \\
\hline & & $1 \%$ & $1 \%$ & $9 \%$ & $32 \%$ & $57 \%$ & $100 \%$ \\
\hline & Total & 15 & 24 & 184 & 561 & 969 & 1753 \\
\hline \multirow{5}{*}{$\begin{array}{l}\text { Supervisor's } \\
\text { approach }\end{array}$} & \multirow{2}{*}{ Male } & 1 & 12 & 53 & 222 & 300 & 588 \\
\hline & & $0 \%$ & $2 \%$ & $9 \%$ & $38 \%$ & $51 \%$ & $100 \%$ \\
\hline & \multirow{2}{*}{ Female } & 7 & 18 & 82 & 359 & 699 & 1165 \\
\hline & & $1 \%$ & $2 \%$ & $7 \%$ & $31 \%$ & $60 \%$ & $100 \%$ \\
\hline & Total & 8 & 30 & 135 & 581 & 999 & 1753 \\
\hline \multirow{5}{*}{$\begin{array}{l}\text { Fair appraisal } \\
\text { system }\end{array}$} & \multirow{2}{*}{ Male } & 6 & 19 & 57 & 183 & 323 & 588 \\
\hline & & $1 \%$ & $3 \%$ & $10 \%$ & $31 \%$ & $55 \%$ & $100 \%$ \\
\hline & \multirow{2}{*}{ Female } & 12 & 18 & 86 & 317 & 732 & 1165 \\
\hline & & $1 \%$ & $2 \%$ & $7 \%$ & $27 \%$ & $63 \%$ & $100 \%$ \\
\hline & Total & 18 & 37 & 143 & 500 & 1055 & 1753 \\
\hline
\end{tabular}

Table 9. Descriptive statistics and 95\% confidence intervals for selected motivational factors in terms of gender in the job category "white-collar workers".

\begin{tabular}{ccccccc}
\hline \multirow{2}{*}{ Motivational Factor } & Gender & N & Average & Standard Deviation & \multicolumn{2}{c}{ Confidence Interval } \\
\cline { 5 - 7 } & & & & $\mathbf{9 5 . 0 0 \%}$ & $\mathbf{+ 9 5 . 0 0 \%}$ \\
\hline \multirow{2}{*}{ Atmosphere in the workplace } & Male & 588 & 4.457 & 0.761 & 4.396 & 4.519 \\
& Female & 1165 & 4.603 & 0.627 & 4.567 & 4.639 \\
\hline \multirow{2}{*}{ Good work team } & Male & 588 & 4.457 & 0.722 & 4.399 & 4.516 \\
& Female & 1165 & 4.596 & 0.605 & 4.561 & 4.631 \\
\hline \multirow{2}{*}{ Job security } & Male & 588 & 4.316 & 0.839 & 4.248 & 4.384 \\
& Female & 1165 & 4.434 & 0.771 & 4.390 & 4.479 \\
\hline \multirow{2}{*}{ Supervisor's approach } & Male & 588 & 4.374 & 0.747 & 4.314 & 4.435 \\
& Female & 1165 & 4.481 & 0.745 & 4.438 & 4.524 \\
\hline \multirow{2}{*}{ Fair appraisal system } & Male & 588 & 4.357 & 0.861 & 4.287 & 4.427 \\
& Female & 1165 & 4.493 & 0.784 & & 4.448 \\
\hline
\end{tabular}

Source: Authors' compilation.

The results presented in Table 9 indicate that the motivational factor atmosphere in the workplace was assigned a value ranging from 4.396 to 4.519 by men in the job category of white-collar worker. Women in the same job category assigned the same motivational factor an average value in the range from 4.567 to 4.639 at the $95 \%$ confidence level. The results show that atmosphere in the workplace was evaluated in a more positive way by women than men in the job category of white-collar worker. Moreover, all analyzed motivational factors were rated higher by women in the job category of white-collar worker than men in the same job category.

Expected and residual frequencies of selected motivational factors in terms of gender in the job category of white-collar worker are presented in Table 10. Residual frequencies are the difference between frequencies in the line (discovered values in Table 8) and the expected frequencies of the evaluation of selected motivational factors. 
Table 10. Expected and residual frequencies of selected motivational factors in terms of gender in the job category "white-collar worker".

\begin{tabular}{|c|c|c|c|c|c|c|c|}
\hline \multirow[b]{2}{*}{$\begin{array}{l}\text { Motivational } \\
\text { Factor }\end{array}$} & \multirow[b]{2}{*}{ Frequency } & \multirow[b]{2}{*}{ Gender } & \multicolumn{5}{|c|}{ Values of Importance } \\
\hline & & & $\begin{array}{c}1 \\
\text { Unimportant }\end{array}$ & $\stackrel{2}{\text { Slightly Important }}$ & $\begin{array}{c}3 \\
\text { Medium } \\
\text { Important }\end{array}$ & $\begin{array}{c}4 \\
\text { Important }\end{array}$ & $\begin{array}{c}5 \\
\text { Very } \\
\text { Important }\end{array}$ \\
\hline \multirow{4}{*}{$\begin{array}{l}\text { Atmosphere in } \\
\text { the workplace }\end{array}$} & \multirow{2}{*}{ Expected } & Male & 2 & 5 & 36 & 168 & 377 \\
\hline & & Female & 4 & 9 & 72 & 332 & 748 \\
\hline & \multirow{2}{*}{ Residual } & Male & 1 & 3 & 19 & 5 & -28 \\
\hline & & Female & -1 & -3 & -19 & -5 & 28 \\
\hline \multirow{4}{*}{ Good work team } & \multirow{2}{*}{ Expected } & Male & 1 & 4 & 30 & 186 & 366 \\
\hline & & Female & 3 & 9 & 60 & 369 & 725 \\
\hline & \multirow[b]{2}{*}{ Residual } & Male & 2 & 3 & 11 & 18 & -33 \\
\hline & & Female & -2 & -3 & -11 & -18 & 33 \\
\hline \multirow{4}{*}{ Job security } & \multirow{2}{*}{ Expected } & Male & 5 & 8 & 62 & 188 & 325 \\
\hline & & Female & 10 & 16 & 122 & 373 & 644 \\
\hline & \multirow{2}{*}{ Residual } & Male & 0 & 4 & 15 & 4 & -23 \\
\hline & & Female & 0 & -4 & -15 & -4 & 23 \\
\hline \multirow{4}{*}{$\begin{array}{l}\text { Supervisor's } \\
\text { approach }\end{array}$} & \multirow{2}{*}{ Expected } & Male & 3 & 10 & 45 & 195 & 335 \\
\hline & & Female & 5 & 20 & 90 & 386 & 664 \\
\hline & \multirow{2}{*}{ Residual } & Male & -2 & 2 & 8 & 27 & -35 \\
\hline & & Female & 2 & -2 & -8 & -27 & 35 \\
\hline \multirow{4}{*}{$\begin{array}{c}\text { Fair appraisal } \\
\text { system }\end{array}$} & \multirow{2}{*}{ Expected } & Male & 6 & 12 & 48 & 168 & 354 \\
\hline & & Female & 12 & 25 & 95 & 332 & 701 \\
\hline & \multirow{2}{*}{ Residual } & Male & 0 & 7 & 9 & 15 & -31 \\
\hline & & Female & 0 & -7 & -9 & -15 & 31 \\
\hline
\end{tabular}

As shown in Table 10, atmosphere in the workplace tends to be evaluated by male white-collar workers as medium important, on the other hand, it is evaluated by female white-collar worker as very important. Moreover, men in the job category of white-collar worker, tend to rate analyzed motivational factors lower, with a lower degree of importance (medium important, important) than women in the same job category. Male white collar-workers tend to evaluate all analyzed motivational factors (atmosphere in the workplace, good work team, job security, supervisor's approach, and fair appraisal system) as very important.

\subsection{The Level of Motivation in Terms of Job Category of the Blue-Collar Worker}

The job category of the blue-collar worker was the third area studied. Basic salary was considered by male blue-collar workers as the most important motivational factor. On the other hand, female blue-collar workers considered atmosphere in the workplace the most important motivational factor. The importance of other motivational factors is presented in Table 11.

Table 11. Average values of selected motivational factors in the job category "blue-collar worker".

\begin{tabular}{ccccc}
\hline \multirow{2}{*}{ No. Male } & \multicolumn{2}{c}{ Female } \\
\cline { 2 - 5 } & Motivational Factor & Average & Motivational Factor & Average \\
\hline 1 & Basic salary & 4.580 & Atmosphere in the workplace & 4.540 \\
2 & Atmosphere in the workplace & 4.475 & Basic salary & 4.524 \\
3 & Good work team & 4.475 & Good work team & 4.506 \\
4 & Fringe benefits & 4.408 & Job security & 4.440 \\
5 & Fair appraisal system & 4.403 & Supervisor's approach & 4.393 \\
6 & Job security & 4.385 & Fringe benefits & 4.371 \\
7 & Supervisor's approach & 4.382 & Fair appraisal system & 4.363 \\
8 & Working hours & 4.267 & Communication in the workplace & 4.288 \\
9 & Communication in the workplace & 4.259 & Working hours & 4.242 \\
10 & Social benefits & 4.252 & Social benefits & 4.212 \\
\hline
\end{tabular}

Source: Authors' compilation.

On the basis of the results of Student t-test shown in Table 12, we concluded that there were no statistically significant differences between the selected motivational factors and gender in terms of job category of the blue-collar worker. The research results in the job category of blue-collar worker show 
that there was a high degree of similarity in motivational factors with different order preferences of motivational factors.

Table 12. Testing the dependence of the most important motivational factors in terms of gender in the job category "blue-collar worker".

\begin{tabular}{cc}
\hline Motivational Factor & $p$-Level \\
\hline Atmosphere in the workplace & 0.256 \\
Good work team & 0.609 \\
Fringe benefits & 0.139 \\
Job security & 0.604 \\
Communication in the workplace & 0.408 \\
Supervisor's approach & 0.351 \\
Working hours & 0.625 \\
Fair appraisal system & 0.339 \\
Social benefits & 0.651 \\
Basic salary & 0.117 \\
\hline Source: Authors' compilation
\end{tabular}

Source: Authors' compilation.

\section{Discussion}

On the basis of the results of our research, we concluded that motivational factors such as basic salary, atmosphere in the workplace, as well as a good work team were highly motivating for all employees. However, men and women perceive the importance of these factors differently. Basic salary was a motivational factor of greater importance for men, whereas, women considered atmosphere in the workplace and a good work team more important. These findings correspond with the studies carried out in this field [68-70].

Further findings associated with the job category correspond with the research results of Bazydlo et al. [79] who showed that work environment, workplace comfort, and a good work team were the most motivating factors for managers. In Slovakia, employees with higher education are hired for manager positions. Their value orientation is due almost equally to their knowledge and gender equality [80-84]. In the case of managers, the results of our research show that a motivational program can be created regardless the gender and we did not observe any significant differences in motivational needs. The same conclusion was drawn in the case of blue-collar workers, especially when employees with primary and lower secondary education are hired for this job position. In addition, their value orientation is due almost equally to their knowledge and gender equality [80,85-87]. Following the analysis of motivation and education, similar results were observed.

In the case of white-collar workers, statistically significant differences in terms of gender were confirmed. Due to the statistically significant differences, the needs of individual groups had to be taken into account. Male white-collar workers tend to rate analyzed motivational factors lower as compared with women, who tend to evaluate analyzed motivational factors as very important.

There were statistically significant differences in perception of motivation among the three job categories mentioned in Figure 1. Therefore, a different motivational program must be created for each job category.

Furthermore, our research results indicate that blue-collar workers were motivated by the amount of money they receive in the form of basic salary. This was confirmed by other studies $[66,67,88,89]$.

In general, the fact that there were statistically significant differences in motivation between men and women is considered the main finding. In terms of job categories of managers and blue-collar workers, motivational programs can be created regardless of gender. In the case of white-collar workers, motivational program must vary due to gender. 


\section{Conclusions}

The statement that quality human resources have become an integral part of the company's strategy has been confirmed by $[90,91]$. Employees play a key role in the implementation of the overall business development strategy. The efficiency of business processes, and therefore the overall success of the enterprise is affected by the performance of properly motivated employees [92-97]. Results of our research show that there were statistically significant differences in perceiving the motivation in terms of gender. In the case of mixed employee teams, this fact must be taken into consideration in the process of designing motivational programs. Despite the similarity in the order of the importance of motivational factors in terms of men and women, both of them perceived the individual motivational factors in different ways.

The aim of this study was to define the differences in the perception of the level of motivation in terms of gender and job category. The fact that there are statistically significant differences in the perception of motivation in terms of job category was proven. The significant differences in the job category of blue-collar workers in terms of gender were proven as well. In the case of two other job categories, no significant differences between genders were observed. The fact that the aim of the study was met can be stated. The results should be accepted and implemented in motivational programs by the employees of the human resource department. In the future, we plan to find correlations between other sociodemographic data (age, education, seniority, company strategic direction, region, the size of an enterprise) and use our results to define a model for employee motivation in enterprises. However, further data collection and analysis is required.

Author Contributions: Conceptualization, S.L., P.Š., D.W., and M.H.; methodology, S.L., P.Š., D.W., M.H., and M.L.; data curation, S.L., P.Š., D.W., M.H., and M.L.; writing—original draft, S.L., P.Š., D.W., and M.H.; visualization, S.L., P.Š., D.W., and M.H.

Funding: This research was funded by VEGA 1/0024/17 “Computational model of motivation", and APVV 16-0297 "Updating of anthropometric database of Slovak population".

Conflicts of Interest: The authors declare no conflict of interest.

\section{References}

1. Dominguez, N. SME Internationalization Strategies: Innovation to Conquer New Markets; Wiley Backwell: Hoboken, NJ, USA, 2018.

2. Graa, A.; Abdelhak, S. A review of branding strategy for small and medium enterprises. Acta Oeconomica Universitatis Selye 2016, 5, 67-72.

3. Zaborova, E.; Markova, T. Human capital as a factor of regional development. In Proceedings of the 12th International Days of Statistics and Economics, Prague, Czech Republic, 6-8 September 2018.

4. Vetrakova, M.; Durian, J.; Sekova, M.; Kascakova, A. Employee retention and development in pulp and paper companies. BioResources 2014, 11, 9231-9243. [CrossRef]

5. Kucharčíková, A. Investment in the human capital as the source of economic growth. Period. Polytech. Soc. Manag. Sci. 2014, 22, 29-35. [CrossRef]

6. Stachova, K.; Stacho, Z.; Blstakova, J.; Hlatká, M.; Kapustina, L.M. Motivation of employees for creativity as a form of support to manage innovation processes in transportation-logistics companies. Nase More 2018, 65, 180-186. [CrossRef]

7. Jankelová, N.; Joniaková, Z.; Blštáková, J.; Némethová, I. Readiness of human resource departments of agricultural enterprises for implementation of the new roles of human resource professionals. Agric. Econ. 2017, 63, 461-470.

8. Lizbetinova, L. The quality of communication in the context of regional development. Deturope Cent. Eur. J. Reg. Dev. Tour. 2014, 6, 22-38.

9. Burton, K. A Study of Motivation: How to Get Your Employees Moving; SPEA honors: Bloomington, IN, USA, 2012.

10. Potkány, M.; Gejdoš, M.; Debnár, M. Sustainable innovation approach for wood quality evaluation in green business. Sustainability 2018, 10, 2984. [CrossRef] 
11. Kohnová, L.; Papula, J.; Papulová, Z.; Suchoba, M. Preparation for smart industry, introduction and comparative study. In Proceedings of the 2nd EAI International Summit, Smart City 360 2016, Bratislava, Slovakia, 22-24 November 2016.

12. Bartuska, L.; Hanzl, J.; Lizbetinova, L. Possibilities of using the data for planning the cycling infrastructure. Procedia Eng. 2016, 161, 282-289. [CrossRef]

13. Stacho, Z.; Potkány, M.; Stachová, K.; Marcineková, K. The organizational culture as a support of innovation processes' management: A case study. Int. J. Qual. Res. 2016, 10, 769-784. [CrossRef]

14. Bryson, A.; White, M. HRM and Small-Firm Employee Motivation: Before and After the Great Recession. ILR Rev. 2019, 72, 749-773. [CrossRef]

15. Korcsmaros, E. Forms of employment in SME sector-Example from Slovakia based on primary research. AD ALTA J. Interdiscip. Res. 2018, 8, 131-134.

16. Myšková, R.; Hájek, P. Sustainability and corporate social responsibility in the text of annual reports-The case of the IT services industry. Sustainability 2018, 10, 4119. [CrossRef]

17. Žul'ová, J.; Švec, M.; Madleňák, A. Personality aspects of the employee and their exploration from the GDPR perspective. Cent. Eur. J. Labour Law Pers. Manag. 2018, 1, 68-77. [CrossRef]

18. Joniaková, Z.; Blštáková, J.; Némethová, I.; Stachová, K.; Stacho, Z. Current approaches to employee training and their applications in business. In Proceedings of the Global Scientific Conference Management and Economics in Manufacturing, Zvolen, Slovakia, 5-6 October 2017.

19. Lašáková, A.; Bajzíková, L'.; Dedze, I. Barriers and drivers of innovation in higher education: Case study-based evidence across ten European universities. Int. J. Educ. Dev. 2017, 55, 69-79. [CrossRef]

20. Xu, Y.; Wang, Y.G.; Tao, X.B.; Lizbetinova, L. Evidence of Chinese income dynamics and its effects on income scaling law. Phys. A-Stat. Mech. Appl. 2017, 487, 143-152. [CrossRef]

21. Mura, L.; Rozsa, Z. The impact of networking on the innovation performance of SMEs. In Proceedings of the 7th International Days of Statistics and Economics, Prague, Czech Republic, 19-21 September 2013.

22. Anwar, P.M.; Budi, I. The influence of job satisfaction and motivation on the employee performance at PT. Era Media Informasi. IOP Conf. Ser. Mater. Sci. Eng. 2018, 453. [CrossRef]

23. Schwartz, M. The motivation of employees is becoming more and more important. Stahl und Eisen 2018, 138, 61-63.

24. Dongho, K. Employee motivation: Just ask your employees. Seoul J. Bus. 2006, 12, 19-35.

25. Björklund, C.H. Work Motivation-Studies of its Determinants and Outcomes; Stockholm School of Economics: Shockholm, Sweden, 2001.

26. Diefendorff, J.M.; Seaton, G.A. Work Motivation; The University of Akron: Akron, OH, USA, 2015.

27. Ahmad, F.; Abbas, T.; Latif, S.; Rasheed, A. Impact of transformational leadership on employee motivation in telecommunication Sector. J. Manag. Policies Pract. 2014, 2, 11-25.

28. Amberg, J.J.; McGaughey, S.L. Strategic human resource management and inertia in the corporate entrepreneurship of a multinational enterprise. Int. J. Hum. Resour. Manag. 2019, 30, 759-793. [CrossRef]

29. Iqbal, A. The strategic human resource management approaches and organisational performance: The mediating role of creative climate. J. Adv. Manag. Res. 2019, 16, 181-193. [CrossRef]

30. McClean, E.; Collins, C.J. Expanding the concept of fit in strategic human resource management: An examination of the relationship between human resource practices and charismatic leadership on organizational outcomes. Hum. Resour. Manag. 2019, 58, 187-202. [CrossRef]

31. Stankevičiūté, Ž.; Savanevičiené, A. Designing sustainable HRM: The core characteristics of emerging field. Sustainability 2018, 10, 4798. [CrossRef]

32. Szierbowski-Seibel, K. Strategic human resource management and its impact on performance-Do Chinese organizations adopt appropriate HRM policies? J. Chin. Hum. Resour. Manag. 2018, 9, 62-76. [CrossRef]

33. Jiang, C.; Yahiaoui, D. French multinational companies' HRM in China: Strategic orientation and integration approaches. Asia Pac. Bus. Rev. 2019, 25, 3-18. [CrossRef]

34. Hitka, M.; Lorincová, S.; Gejdoš, M.; Klarić, K.; Weberová, D. Management approach to motivation of white-collar employees in forest enterprises. BioResources 2019, 14, 5488-5505. [CrossRef]

35. Panday, J. Managing emotional labor for service employees: An HRM-based approach. Hum. Resour. Manag. Int. Dig. 2018, 26, 1-4. [CrossRef]

36. Zhao, Y. Managing Chinese millennial employees and their impact on human resource management transformation: An empirical study. Asia Pac. Bus. Rev. 2018, 24, 472-489. [CrossRef] 
37. Xing, Y.; Liu, Y.; Tarba, S.Y.; Cooper, C.L. Intercultural influences on managing African employees of Chinese firms in Africa: Chinese managers' HRM practices. Int. Bus. Rev. 2016, 25, 28-41. [CrossRef]

38. Hitka, M.; Lorincová, S.; Pajtinková Bartáková, G.; Ližbetinová, L.; Štarchoň, P.; Li, C.; Zaborova, E.; Markova, T.; Schmidtová, J.; Mura, L.; et al. Strategic tool of human resource management for operation of SMEs in the wood-processing industry. BioResources 2018, 13, 2759-2774. [CrossRef]

39. Bernad, L.C.; Walsh, R.P.; Mills, M. The motivation analysis test: An historical and contemporary evalutation. Psychol. Rep. 2005, 96, 464-492. [CrossRef]

40. Kovach, K.A. What motivates employees? Workers and supervisors give different answers. Bus. Horiz. 1987, 30, 58-65. [CrossRef]

41. Kampkötter, P. Performance appraisals and job satisfaction. Int. J. Hum. Resour. Manag. 2015, 28, 750-774. [CrossRef]

42. Bajziková, L'. The minimum wage in compensation systems in EU and the Slovak Republic. In Proceedings of the 31st International Business Information Management Association Conference, IBIMA 2018: Innovation Management and Education Excellence through Vision 2020, Milan, Italy, 25-26 April 2018.

43. Plessis, A.J.; Douangphichit, N.; Dodd, P. HRM in relation to employee motivation and job performance in the hospitality industry. J. Int. Bus. Res. Mark. 2016, 1, 12-21. [CrossRef]

44. Zameer, H.; Ali, S.; Nisar, W.; Amir, M. The impact of the motivation on the employee's performance in beverage industry of Pakistan. Int. J. Acad. Res. Account. Financ. Manag. Sci. 2014, 4, 293-298. [CrossRef]

45. Mani, V. Development of employee satisfaction index scorecard. Eur. J. Soc. Sci. 2010, 15, 129-139.

46. Kmecová, I. Educational process and motivation factors of university students and its analysis. In Proceedings of the 31st International Business Information Management Association Conference: Innovation Management and Education Excellence through Vision 2020, Milan, Italy, 25-26 April 2018.

47. Sanchez-Sellero, M.C.; Sanchez-Sellero, P. Determinants of job satisfaction in wood and paper industry: Study in spain and findings in other countries. Maderas-Ciencia Y Tecnologia 2018, 20, 641-660. [CrossRef]

48. Sánchez-Sellero, M.C.; Sánchez-Sellero, P.; Cruz-González, M.M.; Sánchez-Sellero, F.J. Determinants of job satisfaction in the spanish wood and paper industries: A comparative study across spain. Drvna Industrija 2018, 69, 71-80. [CrossRef]

49. Grenčíková, A.; Guščinskiene, J.; Španková, J. The role of leadership in motivating employees in a trading company. J. Secur. Sustain. Issues 2017, 2, 67-75. [CrossRef]

50. Nemec, M.; Kristak, L.; Hockicko, P.; Danihelova, Z.; Velmovska, K. Application of innovative P\&E method at technical universities in Slovakia. Eurasia J. Math. Sci. Technol. Educ. 2017, 13, 2329-2349. [CrossRef]

51. Machová, R. What motivates a human? Acta Oeconomica Universitatis Selye 2014, 3, 88-101.

52. Naile, I.; Selesho, J.M. The role of leadership in employee motivation. Mediterr. J. Soc. Sci. 2014, 5, 175-182. [CrossRef]

53. Muogbo, U.S. The impact of employee motivation on organisational performance (a study of some selected firms in Anambra state Nigeria). Int. J. Eng. Sci. 2013, 2, 70-80.

54. Kropivšek, J.; Jelačić, D.; Grošelj, P. Motivating employees of Slovenian and Croatian wood-industry companies in times of economic downturn. Drona Industrija 2011, 62, 97-103. [CrossRef]

55. Fratričová, J.; Kirchmayer, Z. Barriers to work motivation of generation Z. J. Hum. Resour. Manag. 2018, 2, 28-39.

56. Kirchmayer, Z.; Fratričová, J. What motivates generation $Z$ at work? Insights into motivation drivers of business students in Slovakia. In Proceedings of the Innovation management and education excellence through vision 2020, Milan, Italy, 25-26 April 2018.

57. Cagáňová, D.; Stareček, A.; Bednáriková, M.; Horňáková, N. Analysis of factors influencing the motivation of generations $\mathrm{Y}$ and $\mathrm{Z}$ to perform in the educational process. In Proceedings of the 15th IEEE International Conference on Emerging eLearning Technologies and Applications, Starý Smokovec, Slovakia, 26-27 October 2017.

58. Goić, S. Employees older than 50 on Croatian labour market-Need for a new approach. J. Hum. Resour. Manag. 2017, 2, 1-11.

59. Idrees, M.D.; Hafeez, M.; Kim, J.Y. Workers' age and the impact of psychological factors on the perception of safety at construction sites. Sustainability 2017, 9, 745. [CrossRef] 
60. Kooij, D.; Jansen, P.G.W.; Dikkers, J.E.; De Lange, A. The influence of age on the associations between HR practices and both affective commitment and job satisfaction: A meta-analysis. J. Organ. Behav. 2010, 31, 1111-1136. [CrossRef]

61. Rabl, T. Age, discrimination, and achievement motives-A study of German employees. Pers. Rev. 2010, 39, 448-467. [CrossRef]

62. Kuratko, D.; Hornsby, J.; Nafziger, D. An examination of owners' goals in sustaining entrepreneurship. J. Small Bus. Manag. 1997, 35, 24-33.

63. Mikkelsen, M.F.; Jacobsen, C.B.; Andersen, L.B. Managing employee motivation: Exploring the connections between managers' enforcement actions, employee perceptions, and employee intrinsic motivation. Int. Public Manag. J. 2017, 20, 183-205. [CrossRef]

64. Anderson, L.B.; Pallesen, T. "Not just for the money?" How financial incentives affect the number of publications at Danish Research Institutions. Int. Public Manag. J. 2008, 11, 28-47. [CrossRef]

65. Majumder, M.; Hossain, T. Human resource management practices and employees' satisfaction towards private banking sector in Bangladesh. Int. Rev. Manag. Mark. 2012, 2, 55-58.

66. Manzoor, Q.A. Impact of employees' motivation on organizational effectiveness. Eur. J. Bus. Manag. 2011, 3, 36-45. [CrossRef]

67. Kanfer, R.; Chen, G.; Pritchard, R.D. Work Motivation: Forging New Perspectives and Directions in the Post-Millenium; Taylor \& Francis: New York, NY, USA, 2008.

68. Almobaireek, W.N.; Manolova, T.S. Entrepreneurial motivations among female university youth in Saudi Arabia. J. Bus. Econ. Manag. 2013, 14, S56-S75. [CrossRef]

69. Inceoglu, I.; Segers, J.; Bartram, D. Age-related differences in work motivation. J. Occup. Organ. Psychol. 2012, 85, 300-329. [CrossRef]

70. Arnania-Kepuladze, T. Gender stereotypes and gender feature of job motivation: Differences or similarity? Probl. Perspect. Manag. 2010, 8, 84-93.

71. Lorincová, S.; Hitka, M.; Štarchoň, P.; Stachová, K. Strategic instrument for sustainability of human resource management in small and medium-sized enterprises using management data. Sustainability 2018, 10, 3687. [CrossRef]

72. Hitka, M.; Lorincová, S.; Ližbetinová, L.; Pajtinková Bartáková, G.; Merková, M. Cluster analysis used as the strategic advantage of human resource management in small and medium-sized enterprises in the wood-processing industry. BioResources 2017, 2, 7884-7897. [CrossRef]

73. Kampf, R.; Lorincová, S.; Kapustina, L.M.; Ližbetinová, L. Motivation level and its comparison between senior managers and blue-collar workers in small and medium-sized transport enterprises. Communications 2017, 19, 43-49.

74. Lorincová, S.; Hitka, M.; Čambál, M.; Szabó, P.; Javorčíková, J. Motivational factors influencing senior managers in the forestry and wood-processing sector in Slovakia. BioResources 2016, 11, 10339-10348. [CrossRef]

75. Myšková, R.; Hitka, M.; Lorincová, S.; Balážová, Ž. Regional motivation differences of service sector employees in urban and rural areas in Slovakia. Sci. Pap. Univ. Pardubic. Ser. D Fac. Econ. Adm. 2016, 37, 118-130.

76. Hitka, M.; Závadská, Z.; Jelačić, D.; Balážová, Z. Qualitative indicators of company employee satisfaction and their development in a particular period of time. Drona Industrija 2015, 66, 235-239. [CrossRef]

77. Kampf, R.; Hitka, M.; Potkány, M. Interannual differences in employee motivation in manufacturing enterprises in Slovakia. Commun. Sci. Lett. Univ. Zilina 2014, 16, 98-102.

78. Hitka, M.; Štípalová, L. Comparing of employees' motivation level in enterprises of wood working industry with other manufacturing enterprises in Slovak Republic. Drvna Industrija 2011, 62, 185-192. [CrossRef]

79. Bazydlo, A. What Motivates Managers? Money, Yes, but so Much More; Clark University and Center for Creative Leadership: Worcester, MA, USA, 2016.

80. Musa, H.; Debnárová, L.; Musová, Z.; Krištofík, P. Gender equality and corporate governance in Slovakia. Ekon. Manag. 2017, 20, 98-110. [CrossRef]

81. Nguyen, L.D.; Mujtaba, B.G.; Ruijs, A. Stress, task, and relationship orientations of Dutch: Do age, gender, education, and government work experience make a difference? Public Organ. Rev. 2014, 14, 305-324. [CrossRef] 
82. Freund, A.M. Age-differential motivational consequences of optimization versus compensation focus in younger and older adults. Psychol. Aging 2006, 21, 240-252. [CrossRef]

83. Peterson, M. What men and women value at work: Implications for workplace health. Gend. Med. 2004, 1, 106-124. [CrossRef]

84. Ryan, R.M.; Deci, E.L. Intrinsic and extrinsic motivations: Classic definitions and new directions. Contemp. Educ. Psychol. 2000, 25, 54-67. [CrossRef]

85. Hitka, M.; Kozubíková, L.; Potkány, M. Education and gender-based differences in employee motivation. J. Bus. Econ. Manag. 2018, 19, 80-95. [CrossRef]

86. Nadeem, M.; Rana, M.S.; Lone, A.H.; Maqbool, S.; Naz, K.; Ali, A. Teacher's competencies and factors affecting the performance of female teachers in Bahawalpur (Southern Punjab) Pakistan. Int. J. Bus. Soc. Sci. 2011, 2, 217-222.

87. Kanfer, R.; Ackerman, P.L. Aging, adult development, and work motivation. Acad. Manag. Rev. 2004, 29, 440-458. [CrossRef]

88. Poór, J.; Engle, A.D.; Blštáková, J.; Joniaková, Z. Internationalisation of Human Resource Management: Focus on Central and Eastern Europe; Nova Science Publishers: New York, NY, USA, 2018.

89. Kim, S.; Jin-Dong, K.; Yoonseok, S.; Gwang-Hee, K. Cultural differences in motivation factors influencing the management of foreign laborers in the Korean construction industry. Int. J. Proj. Manag. 2015, 33, 1534-1547. [CrossRef]

90. Klement, I.; Hurakova, T. Determining the influence of sample thickness on the high-temperature drying of beech wood (Fagus sylvatica L.). BioResources 2016, 11, 5424-5434. [CrossRef]

91. Vetrakova, M.; Holubekova, K.; Sebova, L. Use of intercultural differences in tourism marketing. In Proceedings of the 18th International Colloquium on Regional Sciences, Hustopece, Czech Republic, 17-19 June 2015.

92. Jigjiddorj, S.; Tsogbadrakh, T.; Choijil, E.; Zanabazar, A. The mediating effect of employee loyalty on the relationship between job satisfaction and organizational performance. In Proceedings of the 11th International Scientific Conference "Economics, Management and Technology in Enterprises 2019", Zvolen, Slovakia, 9-10 May 2019.

93. Stachová, K.; Papula, J.; Stacho, Z.; Kohnová, L. External partnerships in employee education and development as the key to facing industry 4.0 challenges. Sustainability 2019, 11, 345. [CrossRef]

94. Korcsmaros, E.; Simova, M. Factors affecting the business environment of SMEs in Nitra region in Slovakia. Oeconomia Copernicana 2018, 9, 309-331. [CrossRef]

95. Papula, J.; Kohnová, L.; Papulová, Z. Impact of national culture on innovation activities of companies: A case of Germany, Austria, Switzerland and the Czech Republic. Econ. Ann.-XXI 2018, 169, 26-30. [CrossRef]

96. Zaborova, E.N.; Glazkova, I.G.; Markova, T.L. Distance learning: Students' perspective. Sotsiologicheskie Issledovaniya 2017, 2, 131-139.

97. Kmecová, I. Didactic efficiency of the textbooks of technical education. In Proceedings of the Joint International IGIP-SEFI Annual Conference 2010, Trnava, Slovakia, 19-22 September 2010.

(C) 2019 by the authors. Licensee MDPI, Basel, Switzerland. This article is an open access article distributed under the terms and conditions of the Creative Commons Attribution (CC BY) license (http://creativecommons.org/licenses/by/4.0/). 


\title{
Markov-Chain Simulation-Based Analysis of Human Resource Structure: How Staff Deployment and Staffing Affect Sustainable Human Resource Strategy
}

\author{
Tamás Bányai ${ }^{1, *}$, Christian Landschützer ${ }^{2}$ and Ágota Bányai ${ }^{1}$ \\ 1 Institute of Logistics, University of Miskolc, 3515 Miskolc, Hungary; altagota@uni-miskolc.hu \\ 2 Institute of Logistics Engineering, Graz University of Technology, 8010 Graz, Austria; \\ landschuetzer@tugraz.at \\ * Correspondence: alttamas@uni-miskolc.hu; Tel.: +36-20-391-6585
}

Received: 8 September 2018; Accepted: 11 October 2018; Published: 15 October 2018

\begin{abstract}
Manufacturing and service processes are composed of several elements: Technical, financial, logistics, information and human resources. Staff deployment and staffing is an essential problem in the human resource management domain because the structure of employees would be continuously in an optimal relationship to the jobs to be performed. This paper proposes a conceptual model for the analysis of human resource deployment processes. After a systematic literature review, it was found that algorithms are important tools for the design and control of human resource problems since a wide range of models determines an optimization problem. According to that, the main focus of this research is the modelling and analysis of human resource deployment processes of manufacturing companies using Markov-chain mathematics, also taking into account the absorbing phenomena of employees' promotion. The main contribution of this article includes the model framework of Markov-chain simulation of a human resource deployment problem; the mathematical description of different human resource deployment strategies with subdiagonal and superdiagonal promotion matrices; the computational results of the described model with different datasets and scenarios. In the case of a given human resource strategy, the Markovian human resource deployment process of a company was analyzed. The analyzed model was the HR deployment of assembly line operators in a multinational company, including six levels of promotion. The results of the scenario analysis show that promotion and recruitment rates have a great impact on the future employees' structure.
\end{abstract}

Keywords: absorbing Markov-chain; career path; employee structure; machine operator; promotion of employees

\section{Introduction}

Each factory, manufacturing plant and service company needs a flexible and reliable resource supply to serve production and service processes efficiently. Manufacturing systems are composed of several elements: Technical, financial, logistics, information and human resources. Staff deployment is an essential problem in human resource management domain because the structure of employees and its labor costs would be continuously in an optimal relation to the jobs to be performed [1]. Human resource management can be described as a staffing problem, where the future needs and present situation of the organization have to be taken into consideration. However, the financial aspects have priority within the frame of a human resource deployment process, but the strategy has to be taken into consideration with other important policies, like respect of will, the significance of abilities and stable employment. Enterprises have to conduct necessary training and knowledge sharing activities for all the job grades in its in-house ranking system. What factors affect employees' decision to stay with or leave a company? Researchers have long delved into these questions and 
have put forth a huge number of scenarios to describe the relationship between human resource strategy and employee turnover. There are different programs to strengthen the relationship between employees and employers. The human resource strategy can be described and modified by the aid of the application of programs [2], like BambooHR, Zugata, Teamtailor or Zoho recruit. In the case of a given human resource strategy, it is possible to analyze the Markovian human resource deployment process of a company, and future development plans can be worked out to optimize the required human resource structure. There are different areas, where human resource management can improve the sustainability of a company: Leadership development, training and development, change management, collaboration and teamwork, talent management, diversity and multiculturalism, ethics and governance, creating and inculcating values, health and safety, workforce engagement [3].

The main goal of this research work is to develop a methodology, which makes it possible to analyze the impact of factors of different human resource strategies on the dynamic and structure of human resources. As the literature review shows, previous studies focused mainly on the optimization of human resource structure on conventional deterministic environment. However, studies on the human resource management on stochastic environment have barely been addressed.

This paper is organized as follows. Section 2 presents a literature review, which systematically summarizes the research background of human resource management and Markov-chain based optimization. Section 3 describes the model framework of Markov-chain simulation of human resource analysis of employees' deployment strategies. Section 4 demonstrates the analysis of numerical scenarios of the described Markov-chain simulation with different datasets, where results and outcomings are also illustrated. Based on this evaluation, it appears that the impact of the human resource development program on both short-term and long-term objectives can be clearly determined that will be helpful for decision making in the development of human resource strategies. Conclusions and future research directions are discussed in the last section.

\section{Literature Review}

Since our study embraces two related research streams, namely human resource management and Markov-chain models, we provide a brief review on each stream before elaborating on the model. Within the frame of this chapter, we are focusing on the previous research results. Our used methodology of a structured literature review includes four important aspects [4]: (1) Search for articles in databases and other sources, like Scopus; (2) reduce the number of articles by reading the abstract and identifying the main topic; (3) define a methodology to analyze the chosen articles; (4) describe the main scientific results and identify the scientific gaps and bottlenecks.

\subsection{Human Resources in Production and Logistics}

Firstly, the relevant terms were defined. It is a crucial phase of the review because there are excellent review articles in the field of human resource optimization and Markov-chain modelling and we did not want to produce an almost similar review, but we applied the presented methodology in reference [5]. Based on the topic of our research the following keywords were used to search in the Scopus database: "human resource" AND “optimization" OR "manufacturing" OR "logistics." Initially, 138 articles were identified. This list was reduced to 47 articles selecting journal articles only. Our search was conducted in June 2018; therefore, new articles may have been published since then. The reduced articles can be classified depending on the subject area. Figure 1 demonstrates the classification of these 47 articles considering seven subject areas. This classification shows the majority are engineering, business and computer sciences.

As Figure 2 shows, the human resource optimization in manufacturing and logistics domain has been researched in the past years. The first article in this field was published in 1990 in the field of production planning in flexible manufacturing systems [6] and it was focusing on the impact of the variable processing time of operators. The number of published papers has been increased in the last years; it shows the importance of this research field. 
The distribution of the most frequently used keywords, except keywords used to search in Scopus, is depicted in Figure 3. As the keywords show, the human resource optimization has a great impact on competition (e.g., in manufacturing and manufacturing related domains). A wide range of solution methods is based on decision-making tools and heuristic algorithms.

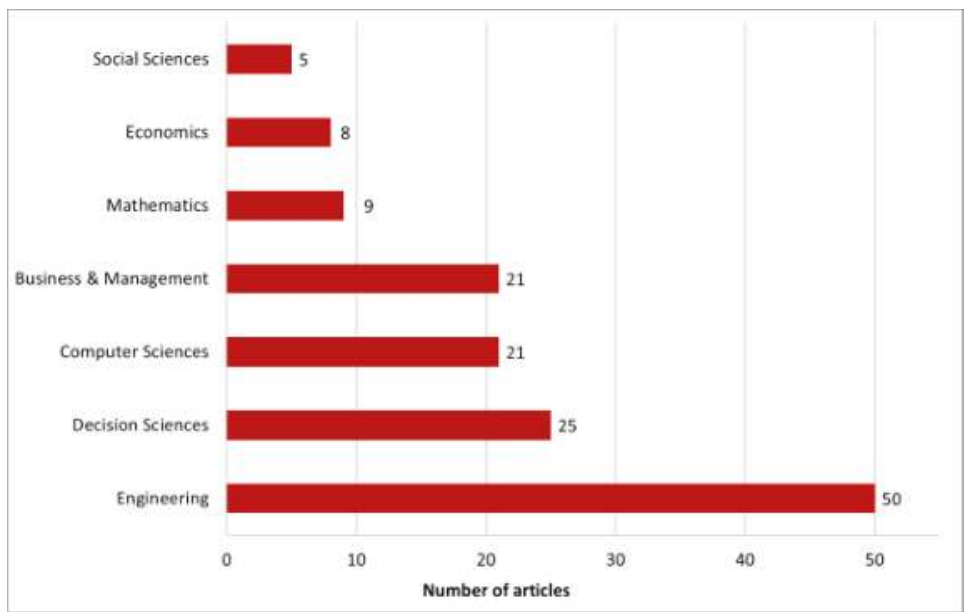

Figure 1. Classification of articles considering subject areas based on search in Scopus database.

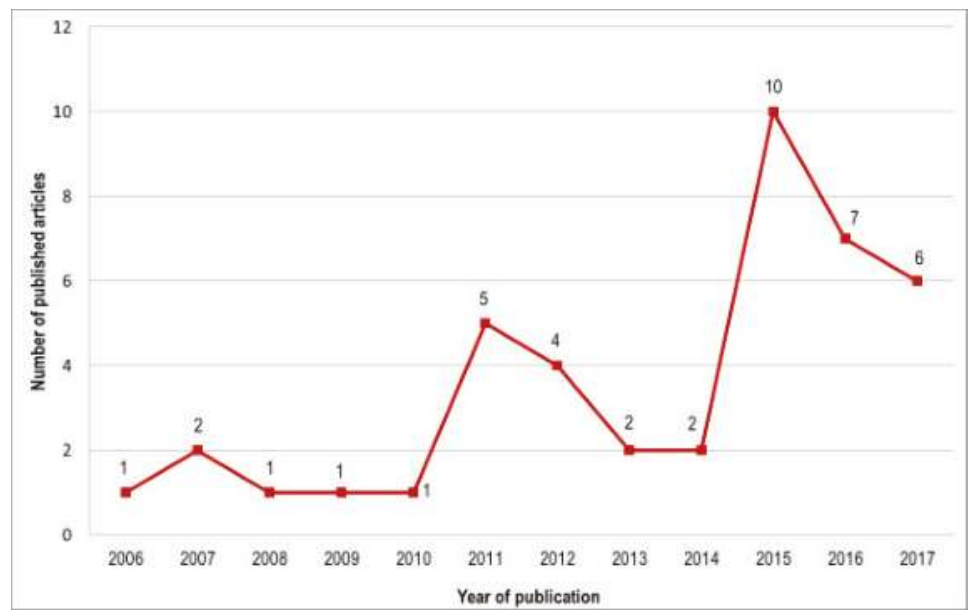

Figure 2. Classification of articles by year of publication.

We added five other articles selected through separated search, so the final list for classification and evaluation from the point of view of scientific results includes 52 articles related to human resource optimization. 


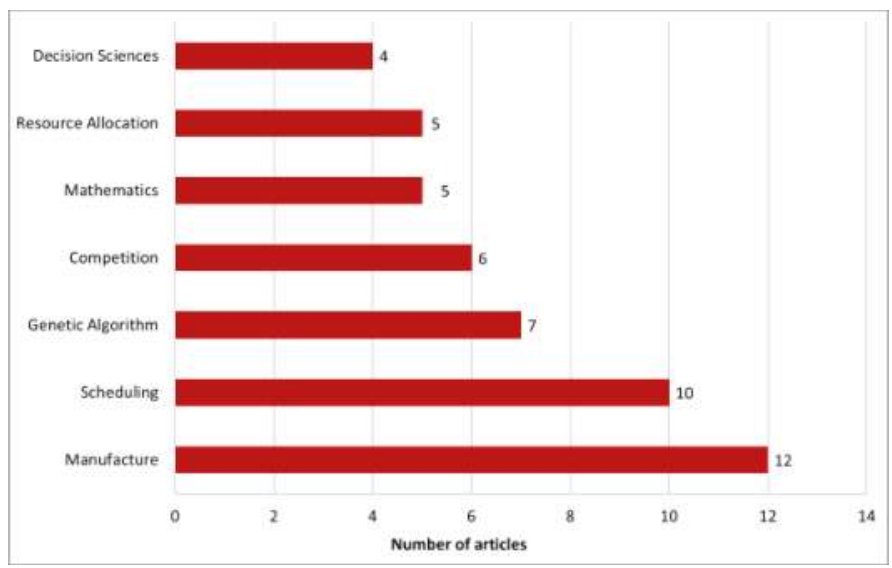

Figure 3. Classification of articles considering the used keywords.

\subsection{State of the Art in Human Resource Research}

The increased complexity of industrial and service processes led to the application of sophisticated solution methods and procedures to optimize the related human resource management problems. Heuristic optimization methods are used to solve NP-hard problems of human resource optimization [7]. The application of scheduling navigation system for optimization of mold-manufacturing scheduling problems [8] is based on genetic algorithm (GA).

Evolutionary heuristic methods make it possible to model dynamic integrated forward/reverse logistics network for 3rd party logistics (3PL) providers, where GA optimizes the network plan to help in the determination of resource plans for capacities of technical and human resources [9]. Ant colony based heuristics support open shop scheduling problems with a multi-skills resource constraint [10] and the solution of operating room surgery scheduling [11]. Scheduling of temporary and skilled-workers in dynamic cellular manufacturing systems can be solved by hybrid algorithms [12]. Bi-criteria and multi-criteria algorithms are also used to optimize employees' structure, like the allocation problem of cross-trained workers from the point of view of operational and human resource aspects [13]. Simulation-based methods support the optimization of online assignment of multi-skilled workers in manufacturing systems, where unpredictable events over time can be taken into consideration [14]. Fuzzy models are used to optimize the transportation of relief materials and human resources from distribution centers to delivery points, where total cost and time window of operations are taken into consideration as an objective function of the bi-criteria transportation problem [15]. Fuzzy mathematics is suitable for ERP system selection [16]. The management and operational success requirements of the 3PL industry include the professional capability of service personnel and the operational process optimization. The fuzzy quality function deployment (FQFD) approach can support the identification of these requirements for improving the management and operational success [17]. Artificial intelligence solutions, especially expert systems, are also used in the human resource management domain to support the adequate selection and appointment of jobs applicants and employees from the point of view job rotation, recruitment, training, evaluation and job classification.

The 3rd and 4th party logistics (3PL and 4PL) service is an area of research which has seen remarkable growth over the last few years. Researchers investigated the advantages of optimized human resource management focusing on supply chain networks [18,19], in-plant transportation processes in logistics facilities [20] and general logistics related operation [21]. The human resource optimization has a great impact on different logistics related design problems, like scheduling and routing. The routing problem means departure time optimization with a better assignment of human resources to required demands [22]. The scheduling related human resource optimization problems are 
focusing on the following fields: Assembly line balancing [23], human resources scheduling to improve the product quality according to exhaustion limit [24], scheduling and staffing of IT projects [25]. One of the first studies linking scheduling problem to the operators of machines described pseudo polynomial algorithms for two-machine and three-machine problems [26].

It remains a key challenge for companies to develop networking strategies for their technological and logistic operations required to fulfill customers' orders. In recent years, there have been many studies focusing on solving human resource domain of networking problems, like the analysis of the network structure of value activity in manufacturing clusters from the point of view value creation of human resources [27], optimization methodology to design networks of manufacturing facilities taking human resource competencies into account [28] and solving time-varying resource-constrained scheduling problems $[29,30]$.

There are different fields of human resource optimization, where the technological environment has a special impact on human resource strategies, like container terminals [31], coal mines [32], mold-manufacturing [33] or health care [34].

The globalization of production and service processes shows that enterprises have to change their human resource strategies. Case studies explain the importance of human resource optimization in almost all fields of economy all over the world: City e-commerce competitiveness evaluation in 32 cities of China describes the importance of economic, logistics, information, business, innovation and human resources [35], development of a human resource competency enhancement model of physical infrastructure and asset management in Taiwan [36] and resource allocation in worldwide sourcing planning [37].

In the last decades, human resource management practices have been developed, trying to integrate economical, ecological and quality related aspects. In this context, the principles of human resource management underline the importance of financial optimization based on minimum cost flow network [25], safety and ergonomics [38], quality of work life for staff and sustainability [39,40], sociotechnical relations [41] and the quality of products, services and processes [42]. The quality function deployment technique can be used to maximize overall customer satisfaction in product design, while human resource has to be taken into consideration [43]. Human resource management optimization is important not for multinational companies [44] but also for small and medium-sizes enterprises (SMEs) [45].

The design, development, re-engineering, and operation of production and service processes are based on the enterprise resource planning (ERP) system. The efficiency of ERP systems can be increased by the application of special tools and methods, like total quality; six sigma, kaizen, lean, production smoothing, production smoothing and design for manufacturability. These methods can support the human resource decision as an integrated part of the enterprise strategy [46].

Human resource management related studies include the subprocesses of the whole supply chain and hyperconnected logistic systems from product design [47] and product innovation [48], through manufacturing and assembly [49] to distribution [50], but we can find papers describing integrated approaches [51,52]. Integrated approaches are important because bottlenecks have a great impact on the efficiency of the whole supply chain [53]. Hyperconnected logistics and manufacturing systems have to train and cross-train more and more employees. The related decisions are often made in a qualitative fashion by human resource or personnel managers, especially in the field of flexible workforce development [54]. The linkages between personality and knowledge sharing behaviour in the workplace play an important role of this human resource deployment [55], while the specificity of knowledge management becomes more and more important in the different field of production and services [56].

\subsection{Markov-Chain Modelling}

The following keywords were used to search in the Scopus database: "Markov-chain" AND "optimization." The initially found documents were limited to the journal articles in English in the field of engineering and economic sciences. After reading the abstract, 17 articles were identified. 
Markov-chain is suitable to model a wide range of practical problems and applications in the field of informatics and telecommunication, electrical engineering, economics and engineering. Novel cloud data center resource scheduling optimization model was worked out based on the integration of kernel principal component analysis (KPCA) and Markov-chain modelling [57]. Electromagnetic topology optimization can be supported by a large-step Markov-chain (LSMC) based novel local optimization algorithm [58]. Markov-chain can be used to optimize the dual-index policy in the field of stochastic inventory control, where the results are generalizable to accommodate stochastic regular lead times and provide an approximate evaluation method [59].

Markov-chain is also used to optimize constrained problems both nonstationary [60] and stochastic systems [61,62], where radial basis function neural network (RBFNN) supports the optimization of stochastic constrained dynamic systems with embedded Markov-chain.

Algorithms including Markov models can solve multi-objective optimization problems [63] with non-homogeneous state space $[64,65]$ in a dynamic environment [66]. Simulation-based optimization algorithms for Markov-chains help to maximize the average reward of a parameterized Markov-chain $[67,68]$. Markov-chain models can be combined with Monte Carlo algorithms to solve global stochastic optimization problems defined over continuous domains [69]. An important scientific issue is the control of Markovian processes. Optimization-oriented algorithms can support the adaptive control of Markov-chains [70]. However, heuristic and metaheuristic algorithms are suitable tools for the optimization of objects and systems, especially in the case of NP-hard problems, but the comparison of them from the point of view of convergence and required computation time is essential.

Optimization problems can be also solved with algorithms based on Markov-chain modelling: Memory-based evolutionary approach was intended for applying the Bayesian optimization algorithm (BOA) in dynamic environments, where the run of BOA is modelled as the movements in a Markov-chain [71]; population-based heuristics, like particle swarm optimization (PSO) algorithm can be combined with Markov-chain analysis [72]; Markov-chain algorithm can be optimized to control the convergence [68]; group method of data handling (GMDH) optimization is Markovian.

\subsection{Consequences of Literature Review}

More than $50 \%$ of the articles were published in the last five years. This result indicates the scientific potential of this research field. The articles that addressed the optimization of human resource structure are focusing on conventional static and deterministic environment, but none of the articles aimed to identify the optimization aspects of dynamic, stochastic human resource deployment problems. Therefore, deployment and recruitment problems of human resource strategies still need more attention and research. It was found that algorithms are important tools for the design and control of human resource problems since a wide range of models determines an optimization problem. According to that, the main focus of this research is the modelling and analysis of human resource deployment processes of manufacturing companies using Markov-chain mathematics, also taking into account the absorbing phenomena of employees' promotion.

As a consequence, the main contributions of this article are the following: (1) The model framework of Markov-chain simulation of the human resource deployment problem; (2) mathematical description of different human resource deployment strategies with subdiagonal and superdiagonal promotion matrices; (3) computational results of the described model with various datasets and scenarios.

\section{Materials and Methods}

In this section, we present the basic ideas which allow us to model and simulate the deployment of human resources through a time window based on absorbing Markov-chain simulation in the case of superdiagonal, subdiagonal and standard promotion matrices.

The promotion matrix describes the promotion possibilities of employees. There are three different strategies in a hierarchical HR promotion system. In the case of the first strategy employees can promote to the next level of employment; therefore, the promotion matrix is superdiagonal: 


$$
\boldsymbol{P}=\left[p_{i, j}\right] \text { where }\left\{\begin{array}{ll}
p_{i, j} \geq 0 & j=i \curlyvee j=i+1 \\
p_{i, j}=0 & j \neq i \curlywedge j \neq i+1
\end{array} \curlywedge i, j=1 \ldots m\right.
$$

In the second case, employees can promote to the next level, but there are also backtrack possibilities to the preceding level. In this case, the promotion matrix consists of diagonal, superdiagonal and subdiagonal elements. Diagonal elements represent that employees remain in the same position; superdiagonal elements describe the possibilities of promoting to the next employment level, while subdiagonal elements show the options of backtrack to the preceding level:

$$
\boldsymbol{P}=\left[p_{i, j}\right] \text { where }\left\{\begin{array}{ll}
p_{i, j} \geq 0 & j=i \curlyvee j=i \pm 1 \\
p_{i, j}=0 & j \neq i \curlywedge j \neq i \pm 1
\end{array} \curlywedge i, j=1 \ldots m .\right.
$$

In the third case, employees can promote and backtrack more levels in the hierarchical structure of positions. Equation (3) shows the structures of superdiagonal and subdiagonal promotion matrices in the case of three possible levels.

$$
\boldsymbol{P}_{\text {supdiag }}=\left[\begin{array}{ccc}
p_{1,1} \geq 0 & p_{1,2} \geq 0 & 0 \\
0 & p_{2,2} \geq 0 & p_{2,3} \geq 0 \\
0 & 0 & p_{3,3} \geq 0
\end{array}\right] \quad \boldsymbol{P}_{\text {subdiag }}=\left[\begin{array}{ccc}
p_{1,1} \geq 0 & 0 & 0 \\
p_{2,1} \geq 0 & p_{2,2} \geq 0 & 0 \\
0 & p_{3,2} \geq 0 & p_{3,3} \geq 0
\end{array}\right] .
$$

In this approach, we can use either absorbing or non-absorbing promotion matrices depending on the promotion strategy. If employees can departure from an employment level and leave the system, then we are using absorbing promotion matrix, and the model can be described as an absorbing Markov-chain (AMC). In the case of absorbing Markov-chain, we can define an additional promotion matrix describing absorbing states of the chain:

$$
A=\left[\begin{array}{lll}
a_{1,1} & a_{1,2} & a_{1,3} \\
a_{2,1} & a_{2,2} & a_{2,3} \\
a_{3,1} & a_{3,2} & a_{3,3}
\end{array}\right]
$$

where

$$
\sum_{j=1}^{m} a_{i, j}=1-\sum_{j=1}^{m} p_{i, j} \forall j
$$

The most important factors of a human resource strategy are the following: Legal requirement, employee engagement, career advancement programs, corporate image and performance management system [73]. We can describe these factors and their sub-factors through the aid of matrices representing the opportunities of their occurrence. As an example, Table 1 depicts an extended promotion matrix including transitive and absorbing components and their stochastic variables. The above-mentioned factors influence the promotion and deployment of human resources. This process is described with the extended promotion matrix. If there is a difference between simulated and planned HR number and structure, we can modify our HR strategy. This change in the HR strategy leads to changes in the extended promotion matrix, and the Markov-chain based simulation gives the modified number and structure of human resources.

Table 1. Extended promotion matrix.

\begin{tabular}{cccccccc}
\hline & Operator & Technician & Supervisor & $\begin{array}{c}\text { Line } \\
\text { Manager }\end{array}$ & $\begin{array}{c}\text { Unchallenged by } \\
\text { the Work }\end{array}$ & $\begin{array}{c}\text { Lack of } \\
\text { Recognition }\end{array}$ & $\begin{array}{c}\text { Financial } \\
\text { Reasons }\end{array}$ \\
\hline Operator & 0.80 & 0.15 & 0.00 & 0.00 & 0.02 & 0.01 & 0.02 \\
Technician & 0.00 & 0.85 & 0.12 & 0.00 & 0.01 & 0.01 & 0.01 \\
Supervisor & 0.00 & 0.00 & 0.80 & 0.05 & 0.02 & 0.03 & 0.10 \\
Line Manager & 0.00 & 0.00 & 0.00 & 0.80 & 0.04 & 0.11 \\
\hline
\end{tabular}


For example, if the simulated number of supervisors is smaller than the planned, then the promotion possibility of technicians to become a supervisor must be increased.

The employer structure $E=\left(e_{k, i}\right)$ describes the number of employees in the $k$ th iteration of Markov-chain simulation. The recruitment rate $\bar{r}=\left(r_{i}\right)$ defines the possibilities of recruiting a given level of employers, where

$$
\sum_{i=1}^{m} r_{i}=1
$$

The recruitment rate can be taken into consideration either as a vector or as a matrix. If the recruitment rate is given as a vector, then it is constant in the time window of simulation. If we define the recruitment rate as a matrix, we can take into consideration the dynamic changes through the Markov-chain simulation, where the recruitment rate can be calculated as follows:

$$
\boldsymbol{R}=\left[r_{k, i}\right], \text { where }\left\{\begin{array}{ll}
r_{k, i}=r_{i} & i=1 \\
r_{k, i}=\frac{e_{k-1, i}}{\sum_{i=1}^{m} e_{k-1, i}} & 1<i \leq m
\end{array} \text { ᄉ } k=1 \ldots n\right.
$$

and

$$
\sum_{i=1}^{m} r_{k, i}=1 \forall k
$$

Table 2 demonstrates the recruitment rate matrix. The first row shows the initial recruitment rate in the case of four different position. For example, the 0.25 value in the first line defines that $25 \%$ of the recruited persons is suitable to hold down the job as technician. The following rows describe the dynamic characteristics of the recruitment rate, which means that the recruitment rates can be changed through the simulation time window.

Table 2. Recruitment rate.

\begin{tabular}{ccccc}
\hline & Operator & Technician & Supervisor & Line Manager \\
\hline $\mathbf{1}$ & 0.60 & 0.25 & 0.10 & 0.05 \\
$\mathbf{2}$ & 0.62 & 0.23 & 0.11 & 0.04 \\
$\mathbf{. .}$ & 0.65 & 0.20 & 0.10 & 0.05 \\
$\mathbf{n}$ & 0.70 & 0.18 & 0.08 & 0.04 \\
\hline
\end{tabular}

The planned HR structure of employers $\bar{p}=\left(p_{i}\right)$ is based on the HR strategy of the company and consists of the planned number of employees for each level. The deployment of the total number of employees can be calculated as a linear function as follows:

$$
p_{k}^{d e p}=\sum_{i=1}^{m} e_{1 i}+(k-1) \frac{\sum_{i=1}^{m} p_{i}-\sum_{i=1}^{m} e_{1, i}}{n-1}, 1 \leq k \leq n
$$

For the difference between the planned and simulated number of employees in the $k$ th iteration we write

$$
e_{k}^{d i f}=\sum_{i=1}^{m} e_{k, i}-p_{k}^{d e p}
$$

Now the difference between the planned and simulated number of employees at the end of the simulation will be

$$
e_{n}^{\text {dif }}=p_{n}^{\text {dep }}-\sum_{i=1}^{m} e_{n, i} .
$$

The number of employees to be recruited depends on two different parameters. The first one is the required deployment rate to have reached the planned number and structure of employees until the end of the time window. The number of employees to be recruited in the $k$ th stage of the time window can be calculated as follows:

$$
\Delta p_{k}^{d e p}=p_{k}^{d e p}-p_{k-1}^{d e p}, 1 \leq k \leq n .
$$


For the other parameter, that is the number of employees left the system, we write

$$
\boldsymbol{L}=\left[l_{k, i}\right], \text { where }\left\{\begin{array}{ll}
l_{k, i}=e_{k-1, i} \sum_{j=1}^{m} a_{i, j} & 2 \leq k \leq n \\
l_{k, i}=0 & k=1
\end{array} \text { 人 } i=1 \ldots m .\right.
$$

The number of employees to be recruited in the $k$ th time window can be calculated as follows:

$$
\boldsymbol{e}_{\boldsymbol{k}}=\sum_{i=1}^{m} l_{k, i}+\Delta p_{k}^{d e p} \quad \text { where } 1 \leq k \leq n
$$

The structure of employees calculated with the recruitment rate in the $k$ th time window is posed as follows:

$$
e_{k, i}^{*}=e_{k} r_{k, i} \text { where } 1 \leq k \leq n
$$

Within the frame of the next section, two scenarios demonstrate the practical usability of the above described mathematical model.

\section{Results}

The above described Markov-chain model makes it possible to analyze the deployment of human resource through time, depending on a wide range of parameters influencing the deployment process, like recruitment rate, the structure of promotion matrix, planned structure size of human resources or relationship among transitions and absorbing elements of promotion matrix. Within the frame of this section, two scenarios will be analyzed.

\subsection{Scenario 1: Superdiagonal Promotion Matrix with Dynamic Recruitment Rate}

Scenario 1 describes a general model of the HR deployment of assembly line operators in a multinational company. There are six levels of promotion: Machine operator, high-priority operator, equipment technician, field service technician, assembly supervisor, operations manager. Employees can promote only to the next level of employment; therefore, the promotion matrix can be described as a superdiagonal matrix (Equation (16) $\boldsymbol{P}$ matrix), where, e.g., $p_{4,4}=0.80$ means that there is an $80 \%$ of probability that a field service technician will not be promoted within the time window. Additionally, the $p_{4,5}=0.10$ means, that there is a $10 \%$ of probability that a field service technician will be promoted to an assembly supervisor. The elements of this matrix describe transitive states of the deployment process. The employees leave the firm for many reasons, like unchallenged by the work, no path to continued growth, financial reasons and lack of recognition of performance. The additional promotion matrix (Equation (16) $A$ matrix) consists of the absorbing elements of this scenario describing the process and reasons why employees quit their job:

$$
\boldsymbol{P}=\left[\begin{array}{llllll}
0.80 & 0.05 & 0.00 & 0.00 & 0.00 & 0.00 \\
0.00 & 0.70 & 0.10 & 0.00 & 0.00 & 0.00 \\
0.00 & 0.00 & 0.70 & 0.20 & 0.00 & 0.00 \\
0.00 & 0.00 & 0.00 & 0.80 & 0.10 & 0.00 \\
0.00 & 0.00 & 0.00 & 0.00 & 0.70 & 0.20 \\
0.00 & 0.00 & 0.00 & 0.00 & 0.00 & 0.60
\end{array}\right] A=\left[\begin{array}{llll}
0.050 & 0.025 & 0.025 & 0.050 \\
0.020 & 0.020 & 0.030 & 0.030 \\
0.025 & 0.025 & 0.050 & 0.000 \\
0.050 & 0.000 & 0.050 & 0.000 \\
0.000 & 0.060 & 0.000 & 0.040 \\
0.120 & 0.080 & 0.105 & 0.095
\end{array}\right]
$$

where e.g., $a_{2,3}=0.03$ means that $3 \%$ of the employees quit their job by reason of financial instability.

The company has 25 machine operators, 17 high-priority operators, 15 equipment technicians, 14 field service technicians, 12 assembly supervisors and seven operations managers. The company wants to reach, at the end of the time window of 20 months, a total number of 280 employees, while they need 20 machine operators, 42 high-priority operators, 33 equipment technicians, 98 field service technicians, 52 assembly supervisors and 35 operations managers. The initial recruitment rate for the six different positions is given by the first row of the recruitment rate matrix: 


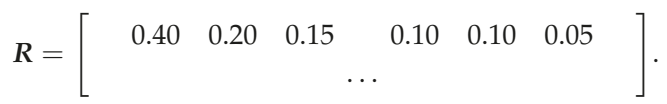

The simulation of the described absorbing Markov-chain model makes it possible to analyze the career path of the employees and the success of the company's HR strategy and HR deployment process. As Table 3 shows, the AMC simulation calculates the future distribution of human resources and the last column of the employment matrix describes the final results of HR deployment. In this scenario, the simulated number of employees is the following at the end of the time window: A total of 71 machine operators, 26 high-priority operators, 21 equipment technicians, 80 field service technicians, 48 assembly supervisors and 34 operations managers. The recruitment rate was changed through the AMC simulation by Equation (7). As the simulated recruitment rate matrix shows (Table 3), the recruitment rate is dynamic because it is a function of the total number of employees and the recruited number of employees for a given position.

Table 3. Employment matrix and recruitment rate matrix calculated by AMC simulation.

\begin{tabular}{cccccccccccccc}
\hline $\mathbf{E}$ & $\mathbf{1}$ & $\mathbf{2}$ & $\mathbf{3}$ & $\mathbf{4}$ & $\mathbf{5}$ & $\mathbf{6}$ & $\mathbf{R}$ & $\mathbf{1}$ & $\mathbf{2}$ & $\mathbf{3}$ & $\mathbf{4}$ & $\mathbf{5}$ & $\mathbf{6}$ \\
\hline $\mathbf{1}$ & 25 & 17 & 15 & 14 & 12 & $\mathbf{7}$ & $\mathbf{1}$ & 0.4 & 0.2 & 0.15 & 0.1 & 0.1 & 0.05 \\
$\mathbf{2}$ & 42.6 & 23.6 & 20.1 & 19.4 & 15 & 9.22 & $\mathbf{2}$ & 0.33 & 0.18 & 0.15 & 0.15 & 0.12 & 0.07 \\
$\mathbf{3}$ & 45.6 & 23.7 & 20.7 & 23.7 & 15.7 & 10.5 & $\mathbf{3}$ & 0.33 & 0.17 & 0.15 & 0.17 & 0.11 & 0.08 \\
$\mathbf{4}$ & 48.5 & 23.9 & 21.2 & 28.1 & 16.7 & 11.7 & $\mathbf{4}$ & 0.32 & 0.16 & 0.14 & 0.19 & 0.11 & 0.08 \\
$\mathbf{5}$ & 51.2 & 24.1 & 21.6 & 32.5 & 17.9 & 12.7 & $\mathbf{5}$ & 0.32 & 0.15 & 0.14 & 0.2 & 0.11 & 0.08 \\
$\mathbf{6}$ & 53.7 & 24.3 & 21.9 & 36.9 & 19.4 & 13.8 & $\mathbf{6}$ & 0.32 & 0.14 & 0.13 & 0.22 & 0.11 & 0.08 \\
$\mathbf{7}$ & 57.6 & 25.2 & 22.8 & 42.4 & 21.7 & 15.3 & $\mathbf{7}$ & 0.31 & 0.14 & 0.12 & 0.23 & 0.12 & 0.08 \\
$\mathbf{8}$ & 59.8 & 25.4 & 22.9 & 46.7 & 23.7 & 16.5 & $\mathbf{8}$ & 0.31 & 0.13 & 0.12 & 0.24 & 0.12 & 0.08 \\
$\mathbf{9}$ & 60.4 & 25 & 22.4 & 49.7 & 25.2 & 17.4 & $\mathbf{9}$ & 0.3 & 0.13 & 0.11 & 0.25 & 0.13 & 0.09 \\
$\mathbf{1 0}$ & 61.7 & 25.1 & 22.2 & 53.2 & 27.1 & 18.6 & $\mathbf{1 0}$ & 0.3 & 0.12 & 0.11 & 0.26 & 0.13 & 0.09 \\
$\mathbf{1 1}$ & 62.7 & 25 & 22 & 56.4 & 29.1 & 19.9 & $\mathbf{1 1}$ & 0.29 & 0.12 & 0.1 & 0.26 & 0.14 & 0.09 \\
$\mathbf{1 2}$ & 64.5 & 25.4 & 22 & 60.1 & 31.5 & 21.5 & $\mathbf{1 2}$ & 0.29 & 0.11 & 0.1 & 0.27 & 0.14 & 0.1 \\
$\mathbf{1 3}$ & 64.8 & 25.2 & 21.6 & 62.4 & 33.3 & 22.7 & $\mathbf{1 3}$ & 0.28 & 0.11 & 0.09 & 0.27 & 0.14 & 0.1 \\
$\mathbf{1 4}$ & 68.8 & 26.5 & 22.4 & 68.1 & 36.9 & 25.3 & $\mathbf{1 4}$ & 0.28 & 0.11 & 0.09 & 0.27 & 0.15 & 0.1 \\
$\mathbf{1 5}$ & 68.7 & 26.2 & 21.9 & 69.9 & 38.6 & 26.7 & $\mathbf{1 5}$ & 0.27 & 0.1 & 0.09 & 0.28 & 0.15 & 0.11 \\
$\mathbf{1 6}$ & 70.3 & 26.6 & 22 & 73.3 & 41.1 & 28.6 & $\mathbf{1 6}$ & 0.27 & 0.1 & 0.08 & 0.28 & 0.16 & 0.11 \\
$\mathbf{1 7}$ & 71.3 & 26.9 & 22 & 76 & 43.4 & 30.5 & $\mathbf{1 7}$ & 0.26 & 0.1 & 0.08 & 0.28 & 0.16 & 0.11 \\
$\mathbf{1 8}$ & 71.3 & 26.7 & 21.6 & 77.5 & 45 & 31.9 & $\mathbf{1 8}$ & 0.26 & 0.1 & 0.08 & 0.28 & 0.16 & 0.12 \\
$\mathbf{1 9}$ & 70.8 & 26.4 & 21.2 & 78.3 & 46.2 & 33.1 & $\mathbf{1 9}$ & 0.26 & 0.1 & 0.08 & 0.28 & 0.17 & 0.12 \\
$\mathbf{2 0}$ & 70.8 & 26.3 & 20.9 & 79.7 & 47.7 & 34.5 & $\mathbf{2 0}$ & 0.25 & 0.09 & 0.07 & 0.28 & 0.17 & 0.12 \\
\hline
\end{tabular}

Figure 4 shows the deployment of employees for each position and demonstrates that the number of employees is a non-linear function. Figure 5 describes the difference between the planned and simulated number of employees. The difference between the planned and the simulated number of employees is the following: Machine operators (448\%), high-priority operators (79\%), equipment technicians (80\%), field service technicians $(24 \%)$, assembly supervisors $(110 \%)$ and operations managers $(140 \%)$. Several cases can cause the high difference between planned and simulated HR distribution, like the wrong recognition of employees' job performance, a bad career path (described by the promotion matrix), or the high rate of employees that left the company (described by the additional promotion matrix). 


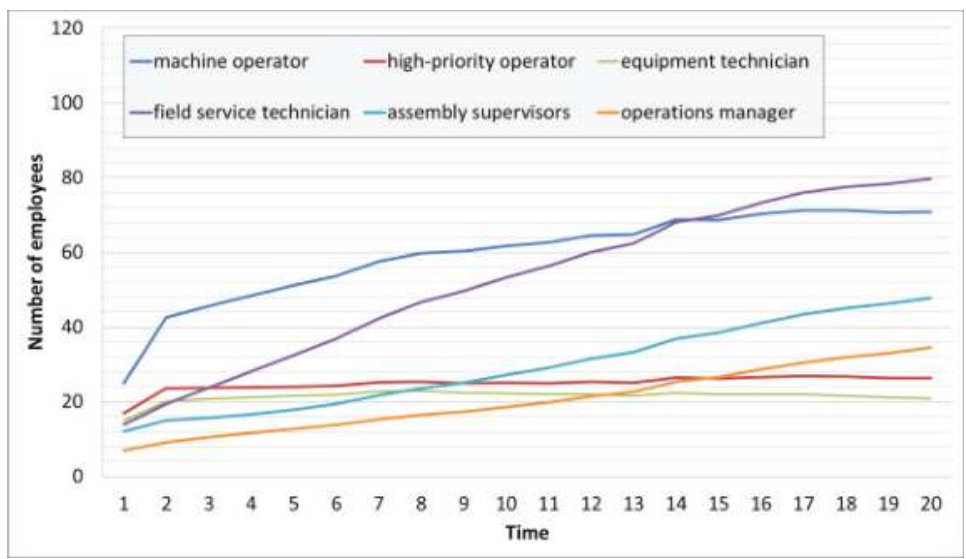

Figure 4. Results of AMC simulation of Scenario 1 with the original dataset: Distribution of employees through the time window.

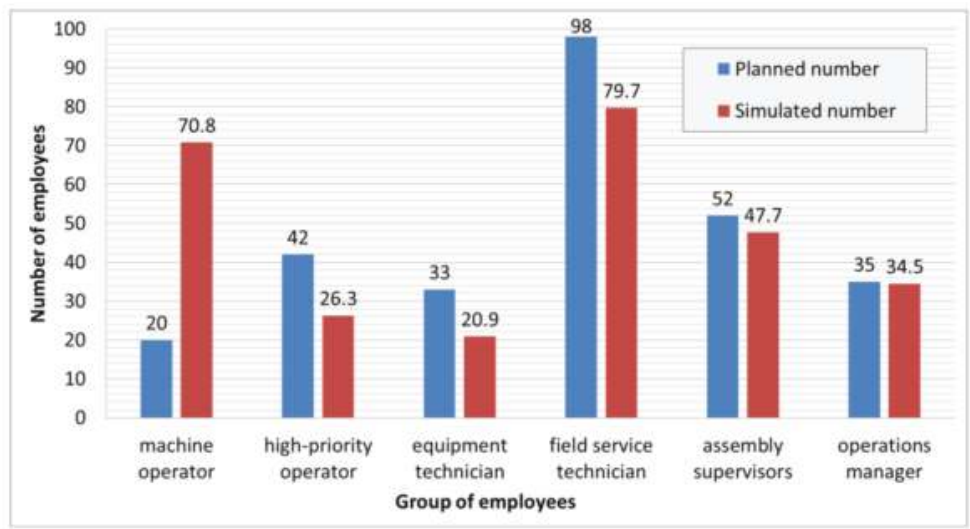

Figure 5. Results of AMC simulation of Scenario 1 with the original dataset: Planned and simulated number of employees in each group.

By modifying the elements of the promotion matrix, it is possible to change the career path of employees and restructure their distribution (Figures 6 and 7).

Increasing the promotion probability of machine operators to high-priority operators from $5 \%$ to $25 \%$, and increasing the non-promotion actions within the frame of the time window from $80 \%$ to $60 \%$, the AMC simulation led to a restructured human resource distribution, as shown in Table 3.

The difference between the planned and the simulated number of employees is the following in the case of the modified dataset: Machine operators (97\%), high-priority operators (100\%), equipment technicians (101\%), field service technicians $(100 \%)$, assembly supervisors $(101 \%)$ and operations managers $(101 \%)$. As these proportions show, the restructuring and deployment of promotion strategy can be influenced by the human resource promotion strategy. 


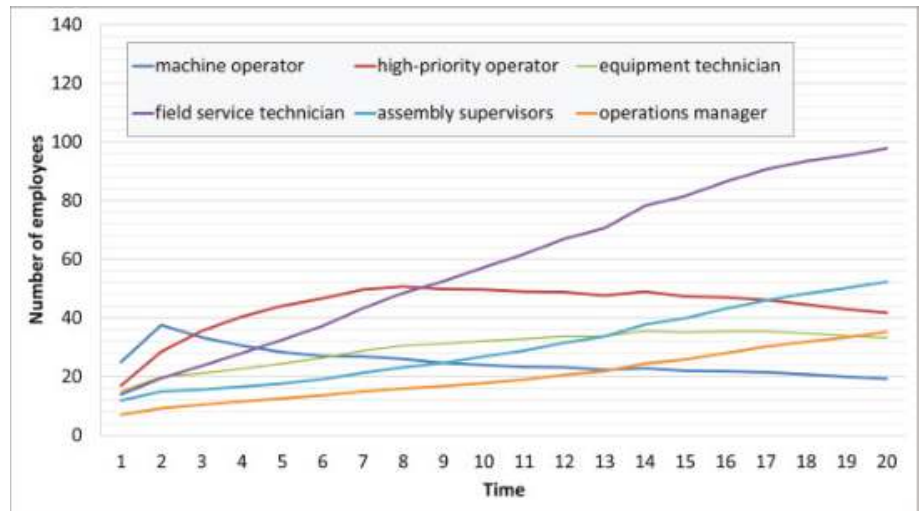

Figure 6. Results of AMC simulation of Scenario 1 with the original dataset: Distribution of employees through the time window.

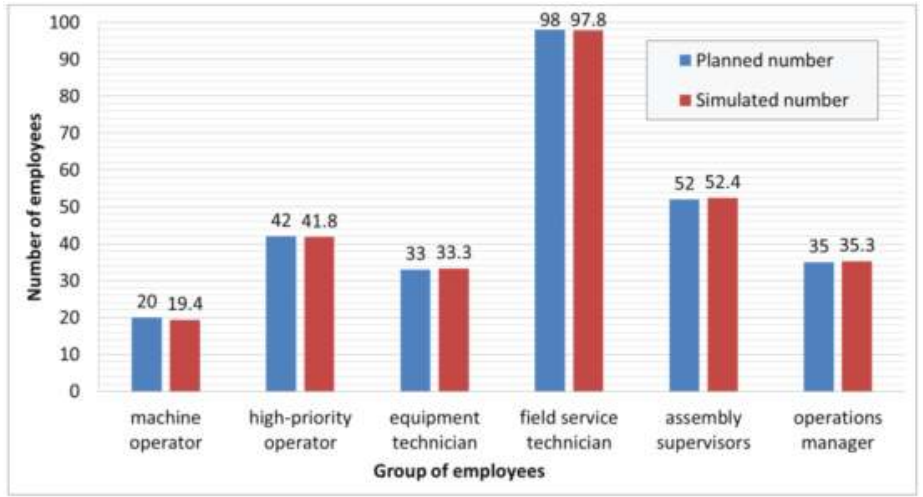

Figure 7. Results of AMC simulation of Scenario 1 with the original dataset: Planned and simulated number of employees in each group.

\subsection{Scenario 2: Promotion Matrix with Sub-and Superdiagonal Elements with Dynamic Recruitment Rate}

Scenario 2 describes a general model of the HR deployment of assembly line operators in a multinational company, where the promotion has the same six levels as in Scenario 1 and employees can promote only one level up and down, therefore, the promotion matrix can be described as a matrix with sub- and superdiagonal elements, while the additional promotion matrix including probabilities of leave the firm has the same structure:

$$
\boldsymbol{P}=\left[\begin{array}{llllll}
0.60 & 0.05 & 0.00 & 0.00 & 0.00 & 0.00 \\
0.10 & 0.60 & 0.10 & 0.00 & 0.00 & 0.00 \\
0.00 & 0.10 & 0.60 & 0.20 & 0.00 & 0.00 \\
0.00 & 0.00 & 0.30 & 0.50 & 0.10 & 0.00 \\
0.00 & 0.00 & 0.00 & 0.20 & 0.50 & 0.20 \\
0.00 & 0.00 & 0.00 & 0.00 & 0.10 & 0.30
\end{array}\right] A=\left[\begin{array}{llll}
0.050 & 0.225 & 0.025 & 0.050 \\
0.050 & 0.050 & 0.030 & 0.070 \\
0.025 & 0.025 & 0.050 & 0.000 \\
0.050 & 0.000 & 0.050 & 0.000 \\
0.000 & 0.060 & 0.100 & 0.040 \\
0.120 & 0.280 & 0.105 & 0.095
\end{array}\right] .
$$

The company has 35 machine operators, 25 high-priority operators, 22 equipment technicians, 15 field service technicians, 10 assembly supervisors and three operations managers. The company wants to reach, at the end of the time window of 20 months, a total number of 300 employees, while they need 100 machine operators, 50 high-priority operators, 75 equipment technicians, 50 field service 
technicians, 16 assembly supervisors and nine operations managers. The initial recruitment rate for the six different positions is given by the first row of the recruitment rate matrix:

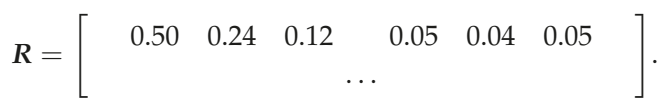

In this Scenario the simulated number of employees is the following at the end of the time window: A total of 23 machine operators, 51 high-priority operators, 114 equipment technicians, 78 field service technicians, 25 assembly supervisors and nine operations managers. The recruitment rate shows the same dynamic characteristics as in the case of Scenario 1 (Table 4).

Table 4. Employment matrix and recruitment rate matrix calculated by AMC simulation.

\begin{tabular}{|c|c|c|c|c|c|c|c|c|c|c|c|c|c|}
\hline $\mathbf{E}$ & 1 & 2 & 3 & 4 & 5 & 6 & $\mathbf{R}$ & 1 & 2 & 3 & 4 & 5 & 6 \\
\hline 1 & 35 & 25 & 22 & 15 & 10 & 3 & 1 & 0.5 & 0.24 & 0.12 & 0.05 & 0.04 & 0.05 \\
\hline 2 & 45.4 & 29.5 & 25.5 & 16.1 & 8.55 & 5.09 & 2 & 0.35 & 0.23 & 0.196 & 0.124 & 0.066 & 0.039 \\
\hline 3 & 44.1 & 31.5 & 30.8 & 19.8 & 9.01 & 4.8 & 3 & 0.31 & 0.23 & 0.22 & 0.141 & 0.064 & 0.034 \\
\hline 4 & 42.4 & 33.3 & 36.5 & 23.6 & 9.57 & 4.63 & 4 & 0.28 & 0.22 & 0.243 & 0.157 & 0.064 & 0.031 \\
\hline 5 & 40.4 & 34.9 & 42.4 & 27.5 & 10.2 & 4.58 & 5 & 0.25 & 0.22 & 0.265 & 0.172 & 0.064 & 0.029 \\
\hline 6 & 38.3 & 36.4 & 48.2 & 31.5 & 11 & 4.62 & 6 & 0.23 & 0.21 & 0.284 & 0.185 & 0.065 & 0.027 \\
\hline 7 & 37.3 & 38.7 & 55.5 & 36.4 & 12.2 & 4.88 & 7 & 0.2 & 0.21 & 0.3 & 0.197 & 0.066 & 0.026 \\
\hline 8 & 35.2 & 39.9 & 61.3 & 40.4 & 13.1 & 5.07 & 8 & 0.18 & 0.2 & 0.315 & 0.207 & 0.067 & 0.026 \\
\hline 9 & 32.3 & 40 & 65.4 & 43.3 & 13.8 & 5.18 & 9 & 0.16 & 0.2 & 0.327 & 0.217 & 0.069 & 0.026 \\
\hline 10 & 30.2 & 40.7 & 70.2 & 46.8 & 14.7 & 5.42 & 10 & 0.15 & 0.2 & 0.338 & 0.225 & 0.071 & 0.026 \\
\hline 11 & 28.3 & 41.2 & 74.5 & 49.8 & 15.5 & 5.66 & 11 & 0.13 & 0.19 & 0.346 & 0.232 & 0.072 & 0.026 \\
\hline 12 & 27.1 & 42.3 & 79.5 & 53.5 & 16.6 & 6.01 & 12 & 0.12 & 0.19 & 0.353 & 0.238 & 0.074 & 0.027 \\
\hline 13 & 25.5 & 42.5 & 82.6 & 55.8 & 17.3 & 6.23 & 13 & 0.11 & 0.18 & 0.359 & 0.243 & 0.075 & 0.027 \\
\hline 14 & 24.7 & 43.7 & 87.4 & 59.2 & 18.4 & 6.6 & 14 & 0.1 & 0.18 & 0.364 & 0.247 & 0.077 & 0.027 \\
\hline 15 & 24.1 & 44.9 & 92 & 62.6 & 19.4 & 6.97 & 15 & 0.1 & 0.18 & 0.368 & 0.25 & 0.078 & 0.028 \\
\hline 16 & 23.7 & 46.1 & 96.5 & 65.9 & 20.5 & 7.35 & 16 & 0.09 & 0.18 & 0.371 & 0.253 & 0.079 & 0.028 \\
\hline 17 & 23.4 & 47.4 & 101 & 69 & 21.5 & 7.72 & 17 & 0.09 & 0.18 & 0.374 & 0.256 & 0.08 & 0.029 \\
\hline 18 & 23.2 & 48.7 & 105 & 72.2 & 22.5 & 8.09 & 18 & 0.08 & 0.17 & 0.376 & 0.258 & 0.08 & 0.029 \\
\hline 19 & 23.2 & 50.1 & 109 & 75.2 & 23.5 & 8.46 & 19 & 0.08 & 0.17 & 0.377 & 0.259 & 0.081 & 0.029 \\
\hline 20 & 23.3 & 51.5 & 114 & 78.2 & 24.5 & 8.82 & 20 & 0.08 & 0.17 & 0.379 & 0.261 & 0.082 & 0.029 \\
\hline
\end{tabular}

Figure 8 shows the deployment of employees for each position and demonstrates that the number of employees is a non-linear function. Figure 9 describes the difference between the planned and simulated number of employees.

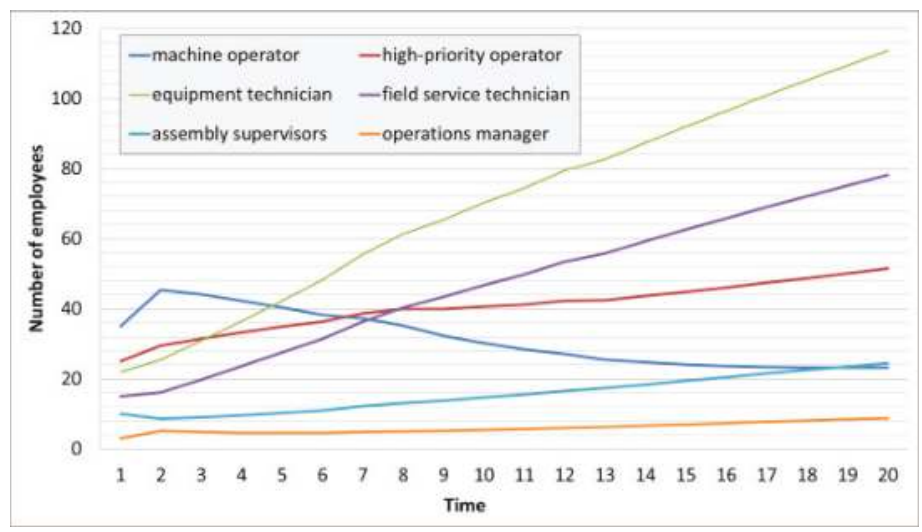

Figure 8. Results of AMC simulation of Scenario 2 with the original dataset: Distribution of employees through the time window. 


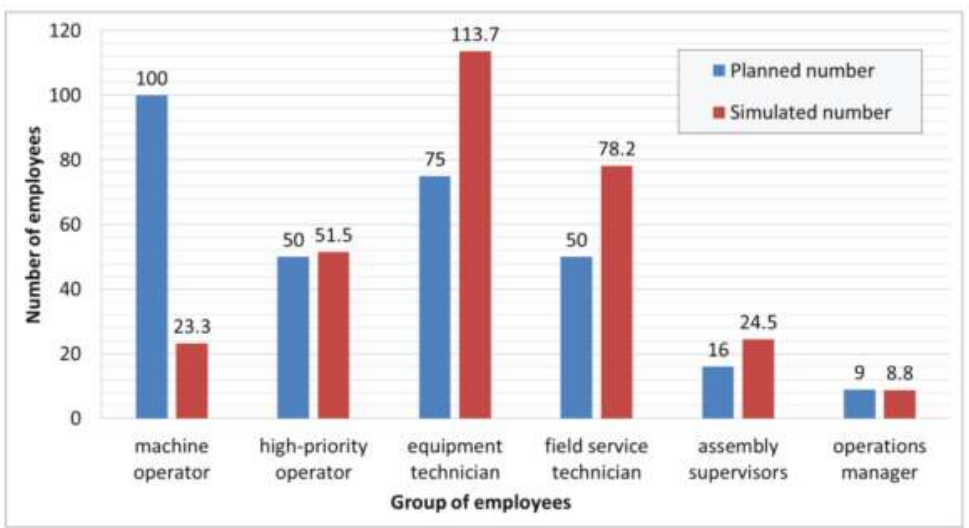

Figure 9. Results of AMC simulation of Scenario 2 with the original dataset: Planned and simulated number of employees in each group.

The difference between the planned and the simulated number of employees is not as high as in the case of Scenario 1, but not eligible, especially in the case of high positions in the career path: Machine operators (102\%), high-priority operators (114\%), equipment technicians (139\%), field service technicians $(75 \%)$, assembly supervisors $(58 \%)$ and operations managers $(41 \%)$.

$$
\boldsymbol{P}=\left[\begin{array}{llllll}
0.80 & 0.05 & 0.00 & 0.00 & 0.00 & 0.00 \\
0.10 & 0.60 & 0.10 & 0.00 & 0.00 & 0.00 \\
0.00 & 0.10 & 0.60 & 0.20 & 0.00 & 0.00 \\
0.00 & 0.00 & 0.15 & 0.65 & 0.10 & 0.00 \\
0.00 & 0.00 & 0.00 & 0.10 & 0.50 & 0.20 \\
0.00 & 0.00 & 0.00 & 0.00 & 0.10 & 0.50
\end{array}\right] A=\left[\begin{array}{llll}
0.050 & 0.025 & 0.025 & 0.050 \\
0.050 & 0.050 & 0.030 & 0.070 \\
0.025 & 0.025 & 0.050 & 0.000 \\
0.050 & 0.000 & 0.050 & 0.000 \\
0.000 & 0.060 & 0.100 & 0.040 \\
0.120 & 0.080 & 0.105 & 0.095
\end{array}\right] .
$$

The high difference between the planned and simulated HR distribution is caused by the high rate of backtracking of field service technicians to equipment technicians and the high rate of leaving firm by operation managers through no path to continued growth. Modifying the critical parameters of the career path (Equation (20)) we can modify the HR structure, as Figures 10 and 11 describe.

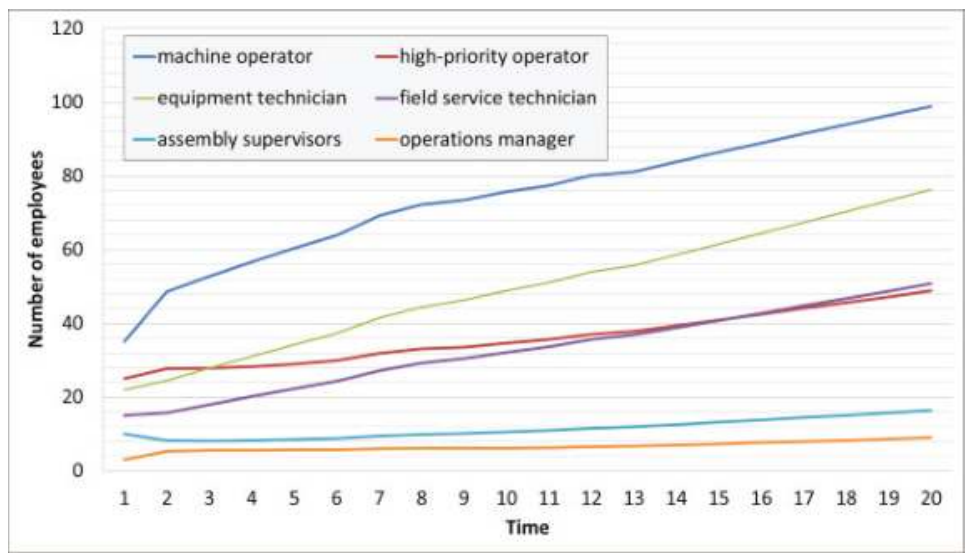

Figure 10. Results of AMC simulation of Scenario 2 with the original dataset: Distribution of employees through the time window. 


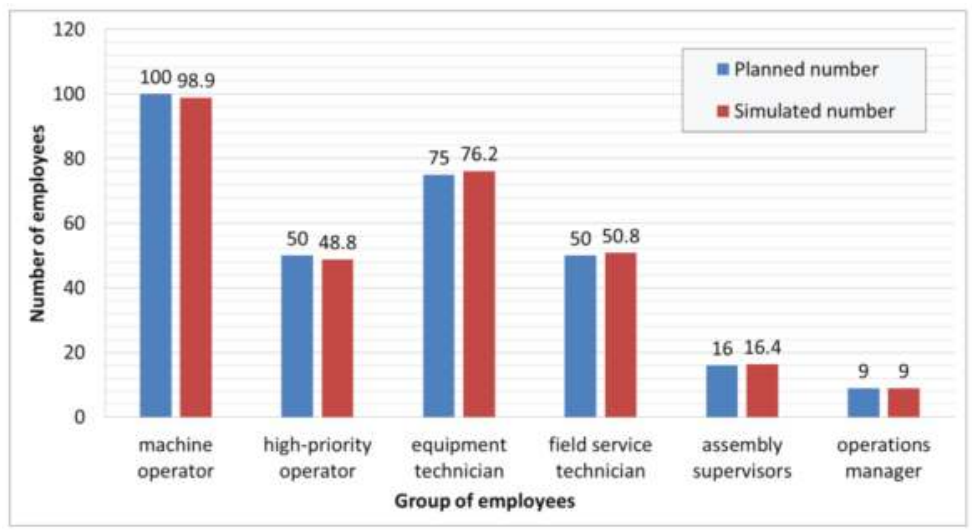

Figure 11. Results of AMC simulation of Scenario 2 with the original dataset: Planned and simulated number of employees in each group.

The difference between the planned and the simulated number of employees is the following in the case of the modified dataset: Machine operators (99\%), high-priority operators (98\%), equipment technicians $(102 \%)$, field service technicians $(101 \%)$, assembly supervisors $(102 \%)$ and operations managers $(100 \%)$. As these proportions show, the above described restructuring and deployment of promotion strategy has a great impact on the final structure of human resources.

As Figures 12 and 13 demonstrate, the recruitment rate changed through time, while the number of employees that left the company continuously increased.

The above described scenarios validated the presented model based on Markov-chain simulation and justify the fact that the promotion of employees and the future structure of human resources are strongly influenced by the HR strategy.

To summarize, the proposed simulation model based on absorbing Markov-chain makes it possible to analyze the impact of human resource strategies in stochastic environment, where the effects of HRM factors can be described as statistical variables.

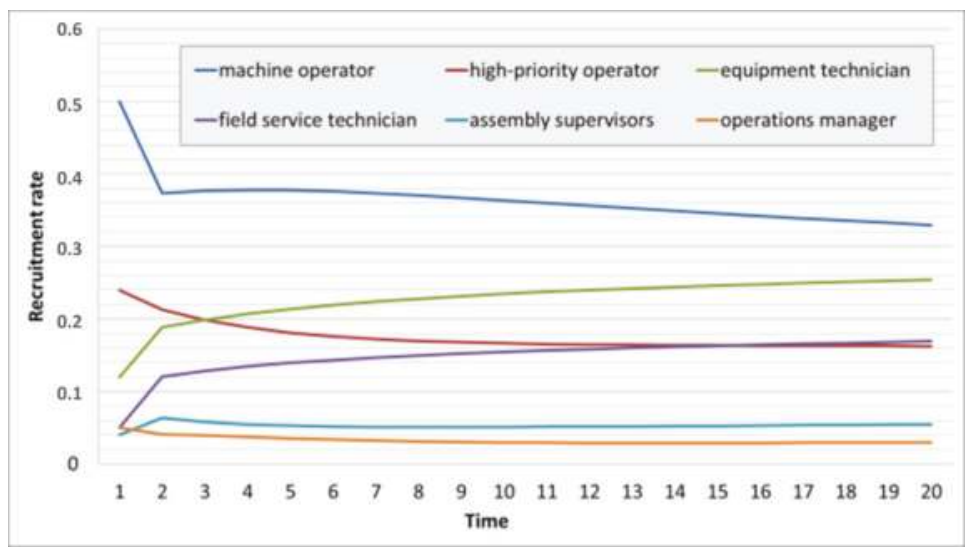

Figure 12. Dynamic of parameters in Scenario 2: Dynamic of the recruitment rate. 


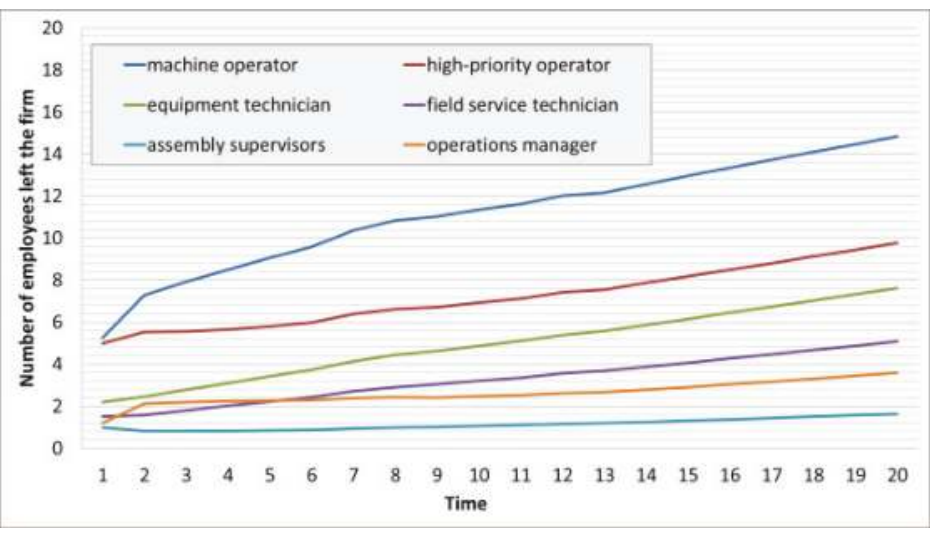

Figure 13. Dynamic of parameters in Scenario 2: Number of employees left the firm through the time window of analysis.

As the findings of the literature review show, the articles that addressed the analysis of human resource are focusing on conventional static and deterministic environments, but none of the articles aimed to identify the optimization aspects of dynamic, stochastic human resource deployment problems. The comparison of our results with those from other studies shows that the deployment and recruitment problems of human resource strategies still need more attention and research. The reason for this is that, in the case of large-sized stochastic systems, where the dynamic of the economic environment influences the required human resources, the stochastic parameters of strategy factors must be taken into consideration.

In spite of the small size of the demonstrated problems, these results show that the proposed method using absorbing Markov-chain simulation performs better than the traditional formal models to evaluate human resource management related problems. Traditional formal models are generally focusing on a special field of human resource management: Evaluation of various worker training scenarios for developing a flexible workforce [73], or the analysis of cognitive and psychosocial skills required for semi-skilled jobs [74], while our proposed evaluation method makes it possible to analyze a given human resource management strategy from different points of view: Aligning business and HR needs, required organizational performance, organizational design and structure, available resources, organizational development, compensation and benefits and organizational culture [75]. As the Markov-chain based mathematical model (see Equations (1)-(15)) shows, these aspects can be described by promotion matrices representing the different parts of the human resource strategy. The promotion matrices have elements, which are probability variables, so it is possible to describe human resource strategies in stochastic environments. The models were intended to assist human resource managers in deciding optimum strategic and tactical plans for human resource development according to the forecasted number and structure of human resources for a definite time window. The proposed method can obtain different promotion systems in a company. If employees can promote only to the next level of employment, then the promotion matrix can be described as a superdiagonal matrix, while in the case of backtrack possibilities, the promotion matrix has both subdiagonal and superdiagonal elements.

Our model is based on absorbing Markov-chains. This means that not only transitive but also absorbing sub-processes-reasons why employees quit their job—can also be taken into consideration. By modifying the elements of the promotion matrix, it is possible to change the career path of employees and restructure their distribution. The results of the Markov-chain simulations of both scenarios validate that the difference between the planned and the simulated number of employees can be decreased through changes in the promotion strategy. 


\section{Conclusions}

Within the frame of this research work the authors developed a Markov-chain based simulation method, which makes it possible to simulate and analyze a given human resource strategy. More generally, this paper focused on the mathematical description of the framework of human resource strategies including financial, social, and technical factors and show their impact on the planned structure of human resources. Why is so much effort being put into this research? The role of the human resource management has changed in the last few years from the traditional "hire and fire" arm of the business to a strategic position [76].

The added value of the paper is the description of the absorbing Markov-chain based model of human resource deployment process, which makes it possible to describe the impact of pillars of human resource strategy when developing or refining them. The scientific contribution of this paper for researchers in this field is the mathematical modelling of stochastic human resource deployment processes based of absorbing Markov-chain. The results can be generalized, because the model can be applied for different fields of human resource management from small and middle-sized service companies to multinational production companies. Therefore, today's human resource managers play a strategic role in the day-to-day operations of the business. The described method makes it possible to support managerial decisions; the human resource strategy can be influenced by the results of the above described contribution.

The corporate social responsibility and the sustainability of human resource management are generally integrated into a business model. This business model's purpose of a company is to maximize returns to its shareholders while aspects of corporate social responsibilities are also taken into consideration. The analyses performed with the described Markov-chain based simulation makes it possible to optimize the human resource structure, while CSR aspects can be also considered.

However, there are also limitations of the study and the described model which shows directions for further research. Within the frame of this Markov-chain based model there are no optimization possibilities. The model makes it possible to analyze different human resource strategies (mathematically represented by matrices). In further studies, the model can be extended to a more complex model including optimization methods to find the optimal factors of the human resource management strategy, which means the optimization of promotion matrix. Second, this study only considered the stochastic parameters as probability variables. Fuzzy models can be also suitable for the description of stochastic environment, because Fuzzy models are based on degrees of truth while probability theory is interested in trying to make predictions about events from a state of partial knowledge [77]. This should be also considered in future research. The theory of perception driven process analysis is also a future research direction for the described topic [78].

Author Contributions: All of the authors have contributed equally in the research design and development, the data analysis, and the writing of the paper.

Funding: This project has received funding from the European Union's Horizon 2020 research and innovation programme under grant agreement No 691942. This research was partially carried out in the framework of the Center of Excellence of Mechatronics and Logistics at the University of Miskolc.

Conflicts of Interest: The authors declare no conflict of interest. The funders had no role in the design of the study; in the collection, analyses, or interpretation of data; in the writing of the manuscript, or in the decision to publish the results.

\section{References}

1. Houdek, P.; Koblovský, P. Behavioural economics of organization: Employees and managers. Ekon. Manag. 2017, 20, 4-15. [CrossRef]

2. Ibrahim, O.; Nossei, A. A Combined AHP and Source of Power Schemes for Prioritising Requirements Applied on a Human Resources. MATEC Web Conf. 2016, 76, 04016. [CrossRef]

3. Mazur, B. Sustainable human resource management in theory and practice. Econ. Manag. 2014, 1, 158-170. [CrossRef] 
4. Lage, M.; Filho, G. Variations of the Kanban system: Literature review and classification. Int. J. Prod. Econ. 2010, 125, 13-21. [CrossRef]

5. Fiorini, P.C.; Jabbour, C.J.C. Information systems and sustainable supply chain management towards a more sustainable society: Where we are and where we are going. Int. J. Inform. Manag. 2017, 37, 241-249. [CrossRef]

6. Dean, B.V.; Yu, Y.-M.; Schniederjans, M.J. A goal programming approach to production planning for flexible manufacturing systems. J. Eng. Technol. Manag. 1990, 6, 207-220. [CrossRef]

7. Delgoshaei, A.; Ali, A. An applicable method for scheduling temporary and skilled-workers in dynamic cellular manufacturing systems using hybrid ant colony optimization and tabu search algorithms. J. Ind. Prod. Eng. 2017, 34, 425-449. [CrossRef]

8. Jong, W.-R.; Lai, P.-J. The navigation process of mould-manufacturing scheduling optimisation by applying genetic algorithm. Int. J. Comput. Integr. Manuf. 2015, 28, 1331-1349. [CrossRef]

9. Ko, H.J.; Evans, G.W. A genetic algorithm-based heuristic for the dynamic integrated forward/reverse logistics network for 3PLs. Comput. Oper. Res. 2007, 34, 346-366. [CrossRef]

10. Campos Ciro, G.; Dugardin, F.; Yalaoui, F.; Kelly, R. Open shop scheduling problem with a multi-skills resource constraint: A genetic algorithm and an ant colony optimisation approach. Int. J. Prod. Res. 2016, 54, 4854-4881. [CrossRef]

11. Xiang, W.; Yin, J.; Lim, G. An ant colony optimization approach for solving an operating room surgery scheduling problem. Comput. Ind. Eng. 2015, 85, 335-345. [CrossRef]

12. Delgoshaei, A.; Ariffin, M.K.A.; Ali, A. A multi-period scheduling method for trading-off between skilled-workers allocation and outsource service usage in dynamic CMS. Int. J. Prod. Res. 2017, 55, 997-1039. [CrossRef]

13. Brusco, M.J. A bicriterion algorithm for the allocation of cross-trained workers based on operational and human resource objectives. Eur. J. Oper. Res. 2015, 247, 46-59. [CrossRef]

14. Ferjani, A.; Ammar, A.; Pierreval, H.; Elkosantini, S. A simulation-optimization based heuristic for the online assignment of multi-skilled workers subjected to fatigue in manufacturing systems. Comput. Ind. Eng. 2017, 112, 663-674. [CrossRef]

15. Pramanik, S.; Jana, D.K.; Maiti, M. Bi-criteria solid transportation problem with substitutable and damageable items in disaster response operations on fuzzy rough environment. Soc. Econ. Plan. Sci. 2016, 55, 1-13. [CrossRef]

16. Karande, P.; Chakraborty, S. A fuzzy-MOORA approach for ERP system selection. Decis. Sci. Lett. 2012, 1, 11-22. [CrossRef]

17. Liao, M.-S.; Lin, S.-C.; Liang, G.-S.; Chen, C.-Y. Improving the management and operational success of the third party logistics industry in Taiwan: Application of fuzzy quality function deployment. J. Test. Eval. 2015, 43, 201-211. [CrossRef]

18. Addo-Tenkorang, R.; Helo, P.T.; Kantola, J. Concurrent enterprise: A conceptual framework for enterprise supply-chain network activities. Enterp. Inf. Syst. 2017, 11, 474-511. [CrossRef]

19. Pathak, S.; Mondal, S.S. A fuzzy optimization model to the aggregate production/distribution planning decision in a multi-item supply chain network. Int. J. Manag. Eng. Manag. 2012, 7, 163-173. [CrossRef]

20. Lewczuk, K. The concept of genetic programming in organizing internal transport processes. Arch. Transp. 2015, 34, 61-74. [CrossRef]

21. Stajniak, M.; Guszczak, B. Analysis of logistics processes according to BPMN Methodology. Adv. Eng. Res. 2011, 537-549. [CrossRef]

22. Kramer, R.; Maculan, N.; Subramanian, A.; Vidal, T. A speed and departure time optimization algorithm for the pollution-routing problem. Eur. J. Oper. Res. 2015, 247, 782-787. [CrossRef]

23. Koltai, T.; Tatay, V.; Kalló, N. Application of the results of simple assembly line balancing models in practice: The case of a bicycle manufacturer. Int. J. Comput. Integr. Manuf. 2014, 27, 887-898. [CrossRef]

24. Jamshidi, R.; Seyyed Esfahani, M.M. Human resources scheduling to improve the product quality according to exhaustion limit. TOP 2013, 22, 1028-1041. [CrossRef]

25. Kolisch, R.; Heimerl, C. An efficient metaheuristic for integrated scheduling and staffing IT projects based on a generalized minimum cost flow network. Nav. Res. Log. 2012, 59, 111-127. [CrossRef]

26. Chen, J.; Lee, C.-Y. General multiprocessor task scheduling. Nav. Res. Logist. 1999, 46, 72-74. [CrossRef] 
27. Wang, W.; Huang, X.; Xie, J. Study on optimizing resources configuration of value activity network of manufacturing clusters. Kybernetes 2012, 41, 953-962. [CrossRef]

28. Paquet, M.; Martel, A.; Montreuil, B. A manufacturing network design model based on processor and worker capabilities. Int. J. Prod. Res. 2008, 46, 2009-2030. [CrossRef]

29. Forrai, M.K.; Kulcsár, G. A new scheduling software for supporting automotive component manufacturing. Lect. Notes Eng. 2017, F12, 257-274. [CrossRef]

30. Forrai, M.K.; Kulcsár, G. Modelling and Solving an Extended Parallel Resource Scheduling Problem in the Automotive Industry. Acta Politech. Hung. 2017, 14, 27-46.

31. Di Francesco, M.; Manca, A.; Zanda, S.; Zuddas, P. Planning and optimising manpower management in a transshipment container terminal. Eur. J. Ind. Eng. 2016, 10, 777-793. [CrossRef]

32. Fang, L.; Li, X.; Li, A. Analysis of the symbiotic relationship between managers and staff with an application for coal mine safety management. Int. J. Eng. Res. Afr. 2015, 16, 156-165. [CrossRef]

33. Jong, W.-R.; Lai, P.-J.; Lo, C.-W. Applying ant colony system algorithm in the navigation process for plastic injection mould manufacturing scheduling optimization. Int. J. Prod. Res. 2014, 52, 2530-2549. [CrossRef]

34. Calciolari, S.; Ferrari, D.; Ortiz, L.G.; Meneguzzo, M. Organizing healthcare in remote rural areas: Comparing experiences of service delivery re-design. Int. J. Healthc. Manag. 2016, 9, 190-200. [CrossRef]

35. Huang, L.; Zhao, W.; Xie, G.; Xie, H.; Yi, Q. Evaluating and optimizing city E-commerce competitiveness based on FA-CA Model: A case from 32 cities in China. Revista de la Facultad de Ingenieria 2017, 32, 298-308.

36. Lee, K.K.; Shan, R.M.Y.; Leung, H.C.H.; Li, J.W.H. Competency enhancement model of physical infrastructure and asset management in compliance with PAS-55 for Hong Kong automotive manufacturing engineers. Lect. Notes Mech. Eng. 2015, 19, 729-737. [CrossRef]

37. Lebreton, B.G.M.; Van Wassenhove, L.N.; Bloemen, R.R. Worldwide sourcing planning at Solutia's glass interlayer products division. Int. J. Prod. Res. 2010, 48, 801-819. [CrossRef]

38. Labuttis, J. Ergonomics as Element of Process and Production Optimization. Procedia Manuf. 2015, 3, 4168-4172. [CrossRef]

39. Shibin, K.T.; Gunasekaran, A.; Papadopoulos, T.; Childe, S.J.; Dubey, R.; Singh, T. Energy sustainability in operations: An optimization study. Int. J. Adv. Manuf. Technol. 2016, 86, 2873-2884. [CrossRef]

40. Ardeleanu, M.P. Corporate environmental sustainability. Qual. Access Success 2011, 12, 347-351.

41. Huber, V.L.; Brown, K.A. Human resource issues in cellular manufacturing: A sociotechnical analysis. J. Oper. Manag. 1991, 10, 138-159. [CrossRef]

42. Boon, B.H.; Sierksma, G. Team formation: Matching quality supply and quality demand. Eur. J. Oper. Res. 2003, 148, 277-292. [CrossRef]

43. Lai, X.; Xie, M.; Tan, K.-C. QFD optimization using linear physical programming. Eng. Optim. 2006, 38, 593-607. [CrossRef]

44. Marksberry, P.; Parsley, D. Managing the IE (Industrial Engineering) mindset: A quantitative investigation of Toyota's practical thinking shared among employees. J. Ind. Eng. Manag. 2011, 4, 771-779. [CrossRef]

45. Tamošiūnas, A. The integrative management model for restructuring small and medium-sized enterprises. Ekon. Manag. 2017, 20, 36-51. [CrossRef]

46. Bányai, Á. How to support purchasing with ERP systems as integrator of novel logistic tools? Adv. Log. Syst. 2013, 7, 7-12.

47. Dröge, C.; Jayaram, J.; Vickery, S.K. The ability to minimize the timing of new product development and introduction: An examination of antecedent factors in the North American automobile supplier industry. J. Prod. Innov. Manag. 2000, 17, 24-40. [CrossRef]

48. Zhao, Z.; Wang, Y.; Sun, L. Study of integrated management mechanism and implement ways in reengineering product innovation process of manufacturing enterprises. Chin. J. Mech. Eng. 2000, 13, 127-132. [CrossRef]

49. Chen, F.; Sekiyama, K.; Huang, J.; Sun, B.; Sasaki, H.; Fukuda, T. An assembly strategy scheduling method for human and robot coordinated cell manufacturing. Int. J. Intell. Comput. Cybern. 2011, 4, 487-510. [CrossRef]

50. Cai, Y.; Huo, Y.-Z. Simulation and optimization of container terminal logistics system: An overview. J. Syst. Simul. 2009, 21, 2119-2124.

51. Bányai, Á.; Illés, B.; Schenk, F. Supply chain design of manufacturing processes with blending technologies. Solid State Phenom. 2017, 261, 509-515. [CrossRef] 
52. Sandrea, M.; Boscán, M. The value chain in the clothing sector. Rev. Venez. Gerenc. 2004, 9, 336-353.

53. Korponai, J.; Bányai, Á.; Illés, B. The effect of the safety stock on the occurrence probability of the stock shortage. Manag. Prod. Eng. Rev. 2017, 8, 69-77. [CrossRef]

54. Manley, K.; Martin, A.; Jackson, C.; Wright, T. A realist synthesis of effective continuing professional development (CPD): A case study of healthcare practitioners' CPD. Nurs. Educ. Today. 2018, 69, 134-141. [CrossRef] [PubMed]

55. Anwar, C.M. Linkages between personality and knowledge sharing behaviour in workplace: Mediating role of affective states. Ekon. Manag. 2017, 20, 102-115. [CrossRef]

56. Firlej, K.; Żmija, D. The specificity of knowledge management in the food industry in Poland. Ekon. Manag. 2017, 20, 83-97. [CrossRef]

57. Jin, Z.; Xu, G.; Li, Y.; Liu, P. A novel cloud data center resource scheduling optimization model based on KPCA and Markov chain. Rev. Tec. Fac. Ing. Univ. 2016, 39, 87-95. [CrossRef]

58. Im, C.-H.; Kim, H.-K.; Jung, H.-K. Electromagnetic topology optimization using large-step Markov chain method with novel local optimization algorithm. Int. J. Appl. Electromagn. 2003, 18, 259-267.

59. Arts, J.; Van Vuuren, M.; Kiesmüller, G. Efficient optimization of the dual-index policy using Markov chains. IIE Trans. 2011, 43, 604-620. [CrossRef]

60. Sragovich, V.G. Optimization with constraints on finite homogeneous Markov chains. Sov. J. Comput. Syst. Sci. 1985, 23, 96-102.

61. Cheng, K.; Zhang, K.-J. Potentials based optimization with embedded Markov chain for stochastic constrained system. Nonlinear Dyn. 2012, 67, 1067-1073. [CrossRef]

62. Svoboda, M. Stochastic model of short-term prediction of stock prices and its profitability in the Czech Stock Market. Ekon. Manag. 2016, 19, 188-200. [CrossRef]

63. Clempner, J.B.; Poznyak, A.S. Multiobjective Markov chains optimization problem with strong Pareto frontier: Principles of decision making. Expert Syst. Appl. 2017, 68, 123-135. [CrossRef]

64. Cao, X.-R. Optimization of average rewards of time nonhomogeneous Markov chains. IEEE Trans. Autom. Control 2015, 60, 1841-1856. [CrossRef]

65. Cao, X.-R. State classification of time-nonhomogeneous Markov chains and average reward optimization of multi-chains. IEEE Trans. Autom. Control 2016, 61, 3001-3015. [CrossRef]

66. Koutras, V.P.; Platis, A.N.; Gravvanis, G.A. On the optimization of free resources using non-homogeneous Markov chain software rejuvenation model. Reliab. Eng. Syst. Saf. 2007, 92, 1724-1732. [CrossRef]

67. Campos-Náñez, E.; Patek, S.D. Dynamically identifying regenerative cycles in simulation-based optimization algorithms for Markov chains. IEEE Trans. Autom. Control 2004, 49, 1022-1025. [CrossRef]

68. Meyn, S. Algorithms for optimization and stabilization of controlled Markov chains. Sadhana Acad. Proc. Eng. Sci. 1999, 24, 339-367. [CrossRef]

69. Lecchini-Visintini, A.; Lygeros, J.; MacIejowski, J.M. Stochastic optimization on continuous domains with finite-time guarantees by Markov chain monte carlo methods. IEEE Trans. Autom. Control 2010, 55, 2858-2863. [CrossRef]

70. Milito, R.A.; Cruz, J.B. An optimization-oriented approach to the adaptive control of Markov chains. IEEE Trans. Autom. Control 1987, 32, 754-762. [CrossRef]

71. Kaedi, M.; Ghasem-Aghaee, N.; Ahn, C.W. Biasing the transition of Bayesian optimization algorithm between Markov chain states in dynamic environments. Inf. Sci. 2016, 334-335, 44-64. [CrossRef]

72. Xu, G.; Wu, Z.-H.; Jiang, M.-Z. Premature convergence of standard particle swarm optimisation algorithm based on Markov chain analysis. Int. J. Wirel. Mob. Comput. 2015, 9, 377-382. [CrossRef]

73. Stewart, B.D.; Webster, D.B.; Ahmad, S.; Matson, J.O. Mathematical models for developing a flexible workforce. Int. J. Prod. Econ. 1994, 36, 243-254. [CrossRef]

74. Caple, D. Impact of New Technology on Job Design, Skill Profiling and Assessing the Physical, Cognitive and Psychosocial Impacts on the Workforce. Adv. Intell. Syst. 2019, 821, 87-91. [CrossRef]

75. Developing HR Strategy: 8 Steps towards Delivering a Successful HR Strategy. Available online: https:/ / www.personneltoday.com/hr/developing-hr-strategy-8-steps-towards-delivering-a-successfulhr-strategy/ (accessed on 9 October 2018).

76. Thiefels, J. Five Pillars of Successful HR Strategy. Available online: https://www.achievers.com/blog/2018/ 01/5-pillars-successful-hr-strategy/ (accessed on 29 September 2018). 
77. Mark, C.C. Fuzzy Logic vs. Probability. Available online: http://goodmath.scientopia.org/2011/02/02/ fuzzy-logic-vs-probability / (accessed on 8 October 2018).

78. Gubán, Á.; Kása, R.; Gubán, M. The theory of perception driven process logistification. In Proceedings of the 18th International Working Seminar of Production Economics, Innsbruck, Austria, 24-28 February 2014; Grubbström, R.W., Hinterhuber, H.H., Eds.; University Innsbruck: Innsbruck, Austria, 2014; pp. 1-12.

(c) 0 BY
(C) 2018 by the authors. Licensee MDPI, Basel, Switzerland. This article is an open access article distributed under the terms and conditions of the Creative Commons Attribution (CC BY) license (http:/ / creativecommons.org/licenses/by/4.0/). 
Article

\title{
Strategic Human Resource Management in the Afghanistan Ministry of Mines and Petroleum: A Network Perspective
}

\author{
Khwaja Abdul Naim Latifi ${ }^{1}$ and Seunghoo Lim ${ }^{2, *}$ \\ 1 Department of Human Resources, Ministry of Mines and Petroleum, Kabul 1001, Afghanistan \\ 2 Public Management and Policy Analysis Program, Graduate School of International Relations, International \\ University of Japan, Niigata 949-7277, Japan \\ * Correspondence: seunghoo.lim@gmail.com
}

Received: 31 May 2019; Accepted: 5 July 2019; Published: 12 July 2019

\begin{abstract}
The focus of this paper is to examine the strategic role of human resource (HR) management in organizational level goal-setting and decision-making processes and to determine how the Human Resources department collaborates with other departments or outside organizations to execute its practices both within and outside the Afghanistan Ministry of Mines and Petroleum (MoMP). In this study, social network analysis (SNA) is utilized to analyse the formation of networks for each practice of human resources management (HRM) in the Ministry of Mines and Petroleum. This research has found that although public organizations in Afghanistan lack a modern administrative system due to the unsuccessful implementation of administrative reform, some features of strategic HRM are apparent in the current HRM within public organizations in Afghanistan, particularly in the MoMP. This finding provides insight into the strategic HRM concept, which can contribute more than traditional HRM to improving the sustainability of the MoMP.
\end{abstract}

Keywords: strategic human resource management; collaboration; HRM practices; stakeholders; social network analysis; Afghanistan Ministry of Mines and Petroleum

\section{Introduction}

The Ministry of Mines and Petroleum (MoMP) is one of the leading ministries of the Afghanistan government and is responsible for managing and controlling natural resources in Afghanistan [1]. The Human Resources (HR) department is one of the vital departments of the MoMP. It is responsible for managing HR according to the civil servant law and the national strategy for the mining sector in Afghanistan and particularly for the MoMP. The HR department of the MoMP initially functioned as a traditional administrative personnel department and was designed primarily to follow Soviet norms and procedures. In 2001, when the Taliban regime collapsed, a new provisional government was established based on the Bonn agreement. Subsequently, the Independent Administrative Reform and Civil Service Commission was established in June 2003, and it became responsible for civil service management and public administration reform [2]. The commission developed legislation, policies, and procedures that intended to modernize human resource management (HRM) practices in Afghanistan's public organizations. However, the implementation of this reform was challenging due to certain factors such as low personnel capacity in the newly formed HR departments of Afghanistan's public organizations, particularly the MoMP. Nevertheless, through implementation of the reformed HRM policies and procedures throughout public organizations in Afghanistan, some positive changes occurred in terms of organizational structures and employee performance [2]. Due to the current conditions of the public sector in Afghanistan, however, the implemented reforms were unable to satisfy the public. Therefore, a need to apply more reforms and introduce new concepts of administrative 
systems remains, particularly in the HRM field. These are necessary to improve the productivity of public organizations, while providing services to satisfy the Afghan public.

In this study, the primary focus is the current state of HRM in Afghan public organizations, particularly the MoMP, to determine whether there are any strategic human resource management (SHRM) aspects such as collaboration among HR departments and other stakeholders both inside and outside the organization. In addition, this paper examines how the HR department within the MoMP collaborates with other departments or outside organizations and stakeholders to execute its practices. Furthermore, this paper discusses whether the HR department is involved in organizational goal-setting and decision-making processes, which are other aspects of SHRM. Finally, the primary aim of this study is to evaluate current HRM in Afghan public organizations, particularly in the MoMP, to determine the gaps between HRM and SHRM and provide remedies and recommendations for expanding the HRM landscape concerning SHRM in Afghan public organizations-again, particularly with regard to the MoMP. Therefore, this paper seeks to answer the following research questions: First, how does the HR department collaborate with other departments and organizations in the ministry-level goal-setting of the MoMP? Second, how—and with which departments and stakeholders-does the HR department collaborate to develop and implement HRM practices, including recruitment, training, appraisal, and rewards, within the MoMP?

\section{Strategic Human Resource Management (SHRM)}

The basic concept underlying HRM is addressing individuals' issues by focusing on traditional practices, including recruitment, performance appraisal, rewards, and training from a micro viewpoint [3]. Because of new trends in recent years, the HRM field has incorporated strategic management processes to develop a new concept referred to as SHRM [4].

The SHRM model represents an advanced model of HRM that can help HR departments to become proactive and effective parts of the decision-making processes of organizations [5]. The relationship between HRM and strategic planning has been found to be a critical component of many aspects of SHRM [6]. HRM practices can play a role in supporting strategy execution because the HR department can help the agency determine whether the organizational strategy is realistic given the present levels of human resources. Under SHRM, HR practices that play a strategic role tend to be distinguished by their focus on the contributions of HR practices to organizational long-term goal-setting, and on linking HR practices to the overall directions of organizational objectives and plans [7,8]. HRM can be proactive in developing a two-way relation, where its influence on strategic planning, strategy formulation, and goal-setting will be recognized because every task that is completed in an organization requires some type of resource (e.g., people (HR) and money) [9]. Therefore, according to Lim et al. [5], organizations should consider that the HR department is important for determining its overall strategic goals and priorities. Likewise, one of the main focuses of SHRM is to support the involvement of HRM in developing strategic organizational goals $[10,11]$.

Basically, five differences have been identified between traditional HRM and SHRM (see Table 1) [5]. First, traditional HRM pays more attention to individual characteristics such as job performance, level of job satisfaction, and what an employee actually needs to be successful within an organization. SHRM concentrates on the relation between organizational strategic plans and HR practices, and the impact of its relation with organizational performance. Second, traditional HRM focuses on HRM practices from a micro-level point of view, whereas SHRM aims to promote more widespread optimization through the vertical and horizontal alignment of HR practices and is based on a macro-level viewpoint $[12,13]$. Third, the time horizon is extended. Traditional HRM is more concerned with solving current organizational problems, which requires less time to address; in contrast, SHRM involves launching organizational policies and strategic plans to develop human capital from a long-term perspective [5]. Thus, fostering the human assets of an organization will ensure that it is well organized and that all of its tasks are coordinated. HRM works with individual departments to help them attain their goals but also seeks to have a positive impact on organizational objectives as well. Fourth, traditional HRM functions 
are assumed to have no connection to attaining organizational objectives and are considered to have a minor and limited role in overall organizational aims. SHRM involves HR professionals and top managers in the development and implementation of organizational policies and strategies, seeks to steadily improve and boost the strategic function of HR, and empowers organizational members rather than solely monitoring them [5]. Therefore, HR practices need to play a more strategic role in facilitating collaborations with non-HR practices. The goal is to develop and execute HRM practices that are aligned with organizational goals, thus expanding HRM beyond its traditional administrative role as a peripheral supporting function within an organization.

Table 1. A Comparison of traditional HRM and SHRM (adapted from Lim et al. [5]).

\begin{tabular}{ccc}
\hline & Traditional HRM & Strategic HRM \\
\hline $\begin{array}{c}\text { Focus of } \\
\text { Analysis }\end{array}$ & $\begin{array}{c}\text { Individuals' psychological or } \\
\text { motivational needs }\end{array}$ & $\begin{array}{c}\text { Developing linkages between HRM practices } \\
\text { and organizational strategies, and having an } \\
\text { impact on organizational performance }\end{array}$ \\
\hline $\begin{array}{c}\text { Scope of } \\
\text { Analysis }\end{array}$ & $\begin{array}{c}\text { Micro and fragmented view } \\
\text { pursuing local optimization of } \\
\text { individual HRM practices) }\end{array}$ & $\begin{array}{c}\text { Macro and comprehensive view (pursuing } \\
\text { global optimization through the vertical and } \\
\text { horizontal integration of HRM practices) }\end{array}$ \\
\hline $\begin{array}{c}\text { Span of Time } \\
\text { Roles of HRM }\end{array}$ & $\begin{array}{c}\text { Short-term } \\
\text { problem-solving processes }\end{array}$ & $\begin{array}{c}\text { Long-term development of human capital } \\
\text { Not involved in organizational } \\
\text { goals and strategies }\end{array}$ \\
\hline HR Practices' Status and Relationship & Peripheral, supportive & Incentives for empowerment and autonomy \\
with Non-HR Practices & Core, collaborative
\end{tabular}

The aforementioned primary differences between traditional HR and SHRM clearly indicate that SHRM has the ability to ensure that all HR practices are aligned with organizational missions, visions, and goals, which can help it achieve its goals and objectives. HR professionals can play a critical role in determining organizational strategies, and goals and must be considered at higher levels (such as departmental or organizational) [4]. However, it would not be possible for SHRM to help the organization reach its goals unless the HR department effectively collaborates with other departments that are a part of the organization. Looking back at the main theories of SHRM, the so-called Michigan model by Fombrun et al. [14] paid attention to how contextual factors influence HRM practices, and the so-called Harvard model by Beer et al. [15] explicitly focused on the impacts of interactions between stakeholder interests and situational factors on setting HRM priorities in organizations. That is, under the SHRM paradigm, the HR department does not work independently, but rather interacts and cooperates with other departments in the organization as well as with stakeholders outside of the organization to understand their goals and to create strategies aligned with those objectives and those of the organization $[5,16]$. Scholars agree that organizations must value the collaboration between HR and other departments and external stakeholders, and well-coordinated HRM can improve organizational effectiveness $[17,18]$. Additionally, HR managers are occasionally involved in developing SHRM plans and policies together with senior line and top management officials for the execution of policies and procedures [19]. In some countries, HR managers do not make decisions on HR practices alone, while in other cases HR managers have even been excluded from participating in HRM practices [20]. For HRM to be involved in organizational goal-setting, it is better to shift from HRM to SHRM and consider how this change could contribute to the roles and functions of HRM in setting goals and being involved in organizational decision-making processes.

Furthermore, based on stakeholder theory [21,22], the definition of SHRM has recently been expanded to incorporate the concept of sustainability in order to emphasize how to achieve organizational effectiveness not only from internal organizational members' (including managers' and employees') perspectives, but also from external stakeholders' (including public service recipients', citizens', external fund providers', and donors') needs, expectations, and desires [16,23-27] (for recent empirical research on sustainable HRM, see an entire special issue of Sustainability $[28,29])$. Therefore, 
SHRM approaches focus more on the interactions among multiple internal and external stakeholders comprising and influencing the HRM functions of an organization and organizational long-term survival and sustainability. However, despite the advent of an era of collaborative multi-organizational settings [30,31], the roles and relationships of key internal and external stakeholders, which directly or indirectly affect or are influenced by HRM systems, have not been empirically examined [16].

\section{Traditional and Reformed HRM in Afghan Public Organizations}

The agency in charge of HRM issues was previously called the Personnel Management Department (PMD) and acted as a general management office for all the public organizations in Afghanistan. When political changes occurred in Afghanistan, the governance system also changed. The new provisional government was established based on the Bonn agreement in 2001, then the Independent Administrative Reform and Civil Service Commission (IARCSC) was established in 2003 to focus on civil service management and public administrative reform [32].

The IARCSC was decisive in accomplishing significant enhancements throughout the public administration, specifically in establishing the norms and practices of merit-based HRM functions [33]. The IARCSC has accomplished many achievements, particularly those related to HRM, in public service institutions over the last 15 years [2]. One significant achievement of the IARCSC is the shift from traditional HRM, which was implemented by the PMD, to reformed HRM (see Table 2). Before the reform, most HR practices were completed in their primitive form in Afghan public organizations, which operated under the most basic HRM rules and procedures.

Table 2. A comparison of traditional HR (PMD) and reformed HRM in Afghanistan.

\begin{tabular}{ccc}
\hline Focus of Analysis & Traditional HR & Reformed HRM \\
\hline Scope of Analysis & $\begin{array}{c}\text { Memi-micro-fragmented view that trational aspects } \\
\text { considers only two practices } \\
\text { (recruiting and rewarding) }\end{array}$ & $\begin{array}{c}\text { Employee motivation and } \\
\text { capacity-building aspects }\end{array}$ \\
\hline Timespan & $\begin{array}{c}\text { Problem-solving is limited to } \\
\text { (pursuing local optimization of } \\
\text { individual HRM practices) }\end{array}$ \\
\hline recruiting and rewarding practices & problem-solving processes \\
\hline Functions and Roles of HRM & $\begin{array}{c}\text { No freedom to set goals for the } \\
\text { department except those } \\
\text { regarding the recruitment function }\end{array}$ & $\begin{array}{c}\text { HRM goals are set in alignment } \\
\text { with the organizations' needs }\end{array}$ \\
\hline
\end{tabular}

The previous HRM system that was instituted by the PMD changed slightly after reform programmes were implemented (see Table 2). There were minor changes made between the traditional HRM and the reformed HRM in Afghan public organizations, particularly in the MoMP. These changes were evaluated based on four aspects: focus of analysis, scope of analysis, span of time, and the functions and roles of HRM. In Afghan public organizations, traditional HRM typically addressed more traditional aspects; for instance, before the reform, tests or examinations were not required for becoming a public official. One could become a public official merely by obtaining approval from the minister or deputy minister, and the PMD was responsible only for processing the employee's recruitment documents. The focus of the PMD was only on hiring employees based on the minister's approval. The process did not consider an individual's characteristics or aspects such as job performance and employee motivation. After the reformation of HRM, exams became compulsory, and the focus expanded to consider individuals' characteristics and other important aspects such as job performance, employee incentives, and capacity-building.

The previous traditional HRM system was responsible for only two practices: recruitment and reward. These two practices were implemented not according to a merit system, but according to a primitive form and traditional methods. In contrast, reformed HRM aims to become more effective 
and focus on what the employees need to be successful within organizations [2]. The traditional HRM emphasized short-term programmes that were limited to recruiting and rewarding practices, while the reformed HRM focuses on short-term goals and problem-solving that include all the practices of HRM. In the last stage, traditional HRM activities were limited to setting goals only for recruitment practices. In contrast, the reformed HRM involves establishing goals for the whole HR department that align with organizational-level goals and objectives [2].

\section{Research Design}

To answer the research questions of this study and provide implications for expanding the HRM landscape to include SHRM in Afghan public organizations (particularly in the MoMP), the following steps were used to conduct this research:

1. Face-to-face interviews were conducted with 31 high- and mid-ranking public officials representing each department of the MoMP (i.e., internal stakeholders) and with agents of 10 external stakeholders outside of the MoMP;

2. The collected data were analysed using social network analysis (SNA) methods; and

3. Relevant reports were compiled to show the results of the research.

In this study, SNA was utilized to analyse the formation of networks for each practice of HRM that was identified in the MoMP. SNA uses graph theory to explain the structure of networks and analyse the links among the actors in the networks [34]. SNA can also be defined as a set of systematic tools used to build networks of actors that can be effectively used to measure and foster collaboration in strategically critical groups such as agencies [35]. Organizations, people, and participants can all be considered as nodes in the SNA [36]. Network analysis assesses actors and their relationships in an interconnected process. In this study, each organization or department is regarded as an actor.

In SNA, a powerful and important actor in a network can be detected by centrality measures. Centrality measures represent the levels of collaboration, cooperation, connectivity, and communication that constitute typical goals for forming network structures [37]. Three types of centrality measures were used in this paper: in-degree, in-closeness, and betweenness. Each measure reveals the location and importance of actors from several different viewpoints [37]. The in-degree centrality measure identifies the most significant actors by counting the number of incoming ties from the other actors in a specific network [38]. The more links an actor has in a network, the more pivotal that actor is in the network. Collaboration and cooperation can be sustained through strong actors with more connections with other actors in a network; therefore, an actor with more and stronger ties would likely be a more important actor in a collaborative network [37,39]. For example, in the performance and appraisal network, the coordinator of the performance appraisal programme, as an actor, would likely have more ties than other actors in the network.

The closeness centrality measure is used to identify the main actor by determining how close an actor is to other actors in terms of distance. In-closeness centrality indicates "the extent to which an actor is close to, or can easily reach, all the other actors in the network and is usually measured by averaging the path distances of the direct and indirect links to all others" [35]. In other words, the in-closeness centrality measure is used to examine the level of communication under the assumption that the smaller the distance between an actor and other actors is, the faster the communication will be [40].

The betweenness measure identifies important mediating actors in terms of their positional power in a network. In other words, betweenness indicates "the extent to which an actor mediates, or falls between, any other two actors on the shortest path between those two actors and is usually averaged across all possible pairs in the network" [32]. More profoundly, an actor with betweenness power can provide communication linkage between two other actors in a network. Notably, the isolate concept is also used in this study to identify actors with no connections to any other actors in the network [35]. 
To collect the relational data indicating the connections among the actors involved, face-to-face interviews were first conducted with 31 public officials of the MoMP selected by purposive snowball sampling $[39,41,42]$. Purposive snowball sampling aims to (i) identify the relevant stakeholders and define the appropriate boundaries of their networks, and (ii) determine their relationships with other stakeholders [43]. More specifically, this sampling method first requires careful selection of initial actors with the most relevant knowledge and reliable information about the researchers' targeted topics of the study, then having those initial actors recommend or nominate other critical actors who could be added to capture the more exact boundary of the networks. The actors nominated by the initial actors are also given an equal opportunity to respond to surveys and reveal their links with other actors involved in the targeted networks. Rounds of referrals and recommendations continue until the names of actors become saturated and the boundary of the targeted networks has been expanded for investigating more comprehensive and representative relationships among the actors.

The initial respondents and interviewees were 31 heads of departments within the MoMP, representing the inside stakeholders of this study. Because 10 outside actors were recommended to be included in our target networks, interviews were additionally held with (i) representative officials, who were all heads of their departments but did not work for the MoMP, (ii) representatives of nongovernmental organizations consisting of domestic agencies that shared goals with the MoMP, and (iii) representatives of the international agencies supporting the HR department in their efforts to improve practices. The MoMP's stakeholders were categorized into four groups: (1) governmental organizations within the MoMP, (2) governmental organizations outside the MoMP, (3) domestic nongovernmental agencies, and (4) international organizations (see Table 3).

A questionnaire was designed to collect the required information from respondents regarding the HR department's collaboration with other stakeholders both inside and outside the MoMP (i.e., horizontal alignment of HR practices with other stakeholders) and the involvement of the HR department in setting ministry-level goals (i.e., vertical alignment of HR practices with broad organizational goals) $[5,27]$. The overall goal of designing the questionnaire was to identify whether there are any aspects of SHRM apparent in the MoMP or not. The survey included six questions that were used to (i) determine whether the HR department performs a strategic role by actively engaging in the organizational goal-setting process of the MoMP (i.e., "With which departments/organizations does your organization/department collaborate to set the Ministry-level organizational goals within the Ministry of Mines and Petroleum or outside stakeholders?"), and (ii) assess the interactions between the HR department and its inside and outside stakeholders in the networks of four main HR practices with the funding for capacity-building network (for example, in the case of the recruitment practices network, "With which agencies/departments does your organization/department collaborate regularly concerning human resource activities/practices for the purpose of designing and implementing a recruitment system of civil servants in the Ministry of Mines and Petroleum?"). The respondents were asked to list three to five main partners based on their understanding of each network, including the ministry-level goal-setting network, recruitment practices network, training practices network, performance appraisal practices network, reward practices network, and funding for capacity-building network. 
Table 3. Acronym list for departments and organizations.

\begin{tabular}{|c|c|c|}
\hline No. & Acronyms & Department/Organization \\
\hline 1 & MoMP_D1 & Office of the Minister \\
\hline 2 & MoMP_D2 & Department of Internal Inspections \\
\hline 3 & MoMP_D3 & Department of Information and Public Communication \\
\hline 4 & MoMP_D4 & Department of State-Owned Enterprises \\
\hline 5 & MoMP_D5 & Human Resources Department \\
\hline 6 & MoMP_D6 & Admin and Services Department \\
\hline 7 & MoMP_D7 & Information Technology Department \\
\hline 8 & MoMP_D8 & Finance and Accounting Department \\
\hline 9 & MoMP_D9 & Procurement Department \\
\hline 10 & MoMP_D10 & Gender Department \\
\hline 11 & MoMP_D11 & Afghanistan Geological Survey Admin and Finance Department \\
\hline 12 & MoMP_D12 & Department of Legal Services \\
\hline 13 & MoMP_D13 & Department of Marketing \\
\hline 14 & MoMP_D14 & Department of Economic Analysis and Policy Design \\
\hline 15 & MoMP_D15 & Department of Collaboration and Programs Inspection \\
\hline 16 & MoMP_D16 & General Directorate of Petroleum \\
\hline 17 & MoMP_D17 & Department of Inspection on Oil and Gas Contracts \\
\hline 18 & MoMP_D18 & Department of Oil and Gas Projects \\
\hline 19 & MoMP_D19 & Department of Survey and Oil and Gas Technical Services \\
\hline 20 & MoMP_D20 & Cadastre Department \\
\hline 21 & MoMP_D21 & Department of Provincial Mining Coordination \\
\hline 22 & MoMP_D22 & Department of Technical Inspections on Mines \\
\hline 23 & MoMP_D23 & General Directorate of Solid Mines \\
\hline 24 & MoMP_D24 & Department of Small Scale Mining \\
\hline 25 & MoMP_D25 & Department of Solid Mines' Contracts and inspections \\
\hline 26 & MoMP_D26 & General Directorate of Geological Surveys \\
\hline 27 & MoMP_D27 & Department of Geological Information \\
\hline 28 & MoMP_D28 & Department of Geological Environment \\
\hline 29 & MoMP_D29 & Mineral Survey Department \\
\hline 30 & MoMP_D30 & Laboratory Department \\
\hline 31 & MoMP_D31 & Kabul Province Mining Department \\
\hline 32 & PMU & Project Management Unit \\
\hline 33 & PSU & Project Support Unit \\
\hline 34 & MIDAS & Mining Investment and Development for Afghanistan Sustainability \\
\hline 35 & GIZ & German Society for International Cooperation \\
\hline 36 & MoIT & Ministry of Information and Technology \\
\hline 37 & $\mathrm{MoF}$ & Ministry of Finance \\
\hline 38 & IARCSC & Independent Administration Reform and Civil Service Commission \\
\hline 39 & CSI & Civil Service Institute \\
\hline 40 & OPA & Administrative Office of the President \\
\hline 41 & MoHE & Ministry of Higher Education \\
\hline
\end{tabular}

\section{Results}

This study found that the 41 actors were involved in six different networks and different collaborative activities with the HR department of the MoMP. Network Figures 1-6 indicate the 
networks of the 41 actors. Tables 1-6 present a summary of the centrality measures for the top five ranked actors in each network.

\subsection{Main Actors in the Organizational Goal-Setting Network}

Table 4 shows the five leading actors ranked based on their centrality measures for in-degree centrality, in-closeness, and betweenness in the organizational goal-setting network. The top five actors in the organizational goal-setting network had different positions. For example, the HR department (MoMP_D5) ranked first for the in-degree measure. MoMP_D5 was indicated by 31 actors (who represented either the ministry departments or outside stakeholders) to be the most important actor in the ministry-level goal-setting process. Furthermore, MoMP_D5 also ranked first for both the in-closeness and betweenness measures. This result indicates that most of the departments within the MoMP communicate with each other through the HR department. In other words, if one department needs to contact another one, it needs to pass through the HR department. In addition, according to Figure 1, the size of MoMP_D5's node and its central position in the network indicate its importance for ministry-level goal-setting. The results for the centrality measures indicate that MoMP_D5 is the most significant and powerful communicator in the network. Figure 1 indicates that MoMP_D5 has the highest centrality values and is a central actor for setting ministry-level goals; this also indicates that this department is an active and powerful communicator. These results indicate that the SHRM feature of being involved with and determining the primary goals of agencies is noticeable in the MoMP.

Another example is the Office of the Minister (MoMP_D1), which ranked second for both the in-degree and in-closeness measures; however, it ranked third for the betweenness measure. Additionally, as demonstrated in Figure 1, MoMP_D1 has the second-largest node in the network, which indicates that it is the second-most dominant actor in this network. Indeed, because of procedures and hierarchy, MoMP_D1 was expected to be a central player in setting ministry-level goals. However, MoMP_D5 engages in a higher level of collaboration and coordination both within and outside the MoMP for setting ministry-level goals; therefore, it is in the leading position in this network.

Table 4. Key actors in the organizational goal-setting network.

\begin{tabular}{|c|c|c|c|c|c|c|}
\hline No. & Actors & In-Degree & Actors & In-Closeness & Actors & Betweenness \\
\hline 1 & MoMP_D5 & 31 & MoMP_D5 & 50 & MoMP_D5 & 243.585 \\
\hline 2 & MoMP_D1 & 28 & MoMP_D1 & 53 & MoMP_D14 & 148.576 \\
\hline 3 & MoMP_D8 & 25 & MoMP_D8 & 55 & MoMP_D1 & 135.445 \\
\hline 4 & MoMP_D14 & 15 & MoMP_D14 & 67 & MoMP_D16 & 131.912 \\
\hline 5 & MoMP_D26 & 12 & MoMP_D26 & 68 & MoMP_D8 & 61.39 \\
\hline
\end{tabular}

As shown in Table 4, the finance and accounting department (MoMP_D8) appears to be the third-most influential actor in this network. Because this department manages the finances used for setting the ministry's goals and ensuring their achievement, MoMP_D8 ranked as the third key actor in this network. In addition, the Department of Economic Analysis and Policy Design (MoMP_D14) ranked fourth for both the in-degree and in-closeness measures, and ranked second for the betweenness measure. Therefore, MoMP_D14 is the fourth-most important actor in the network for setting ministry-level goals. The General Directorate of Geological Surveys (MoMP_D26) is among the top five actors in Table 4. The results for the in-degree and in-closeness measures indicate that MoMP_D26 is important. This department did not rank among the top five actors for the betweenness measure, but can be considered the fifth-most significant actor for the organizational goal-setting network. MoMP_D26 is a general directorate in the MoMP and is responsible for surveying all the mines in Afghanistan. Therefore, these results indicate that this department is a central actor in the organizational goal-setting network. 


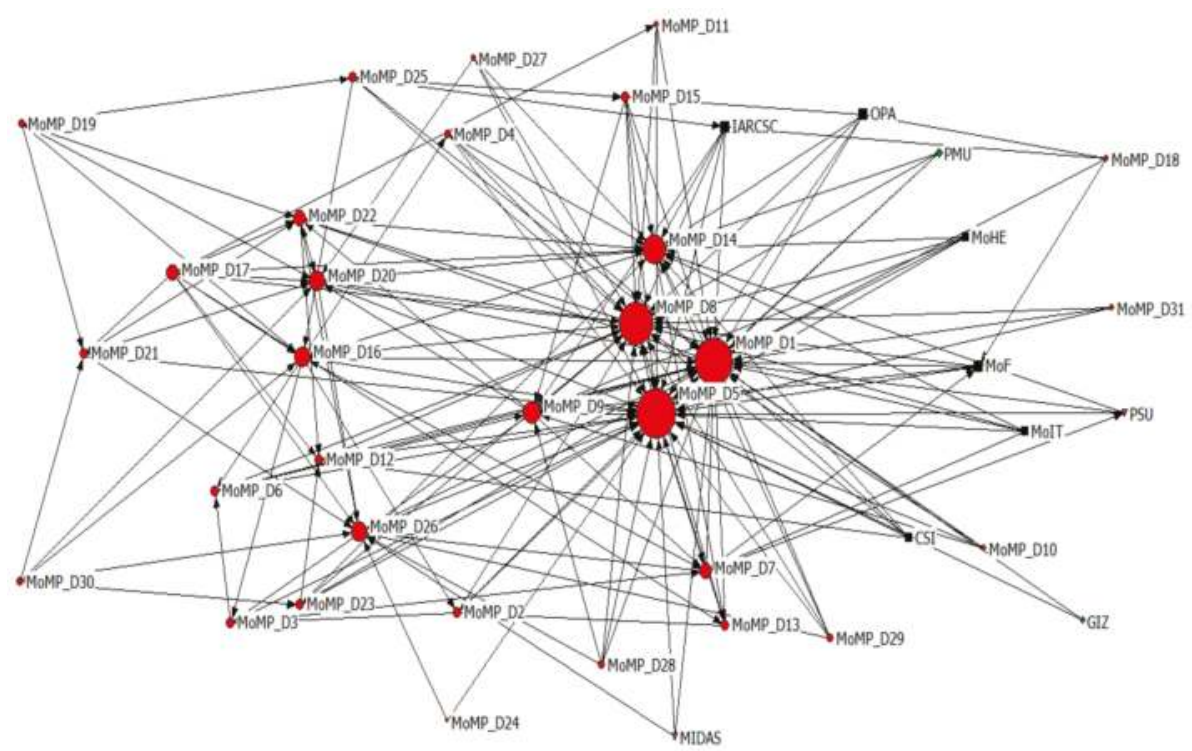

Figure 1. Organizational goal-setting network. The shapes and colours of nodes are based on each actor's ownership. A red circle represents a department-level actor within the MoMP. A black square represents a ministry-level actor. A pink downward triangle represents the non-governmental-level actors. A green diamond represents the international actors.

\subsection{Key Actors in the Recruitment Practices Network}

According to the procedures for the reform published by the IARCSC, the HR department is responsible for managing the recruitment process for each public organization. As a practice of HRM, recruitment is most likely to be the responsibility of the HR department. Therefore, the HR department has been found to be the most significant actor in the recruitment-practices network (see Table 5). Table 5 shows the top five actors in the recruitment-practices network based on the three centrality measures (in-degree, in-closeness, and betweenness). Various actors are engaged in the recruitment and selection process of the MoMP. Figure 2 also shows that several actors collaborate with the MoMP regarding recruitment practices. For instance, MoMP_D5 ranked first for all the centrality measures, with the highest in-degree and betweenness, and the lowest in-closeness. Additionally, as shown in Figure 2, MoMP_D5 has the largest node compared to the other actors in the network. These results indicate that MoMP_D5 is a dominant actor in the recruitment process of the MoMP.

In addition, MoMP_D1 ranked in the second position for both the in-degree and in-closeness measures, making it is the second-most dominant actor in this network. Because a representative of the minister or deputy minister is responsible for all recruitment according to the merit system, MoMP_D1 could be recognized as the most important actor after MoMP_D5.

Table 5. Major actors in the recruitment practices network.

\begin{tabular}{ccccccc}
\hline No. & Actors & In-Degree & Actors & In-Closeness & Actors & Betweenness \\
\hline $\mathbf{1}$ & MoMP_D5 & 31 & MoMP_D5 & 70 & MoMP_D5 & 591.167 \\
\hline $\mathbf{2}$ & MoMP_D1 & 22 & MoMP_D1 & 79 & MoMP_D21 & 412.75 \\
\hline $\mathbf{3}$ & IARCSC & 16 & IARCSC & 85 & MoMP_D20 & 179.333 \\
\hline $\mathbf{4}$ & MoMP_D10 & 7 & MoF & 100 & MoMP_D7 & 164.689 \\
\hline $\mathbf{5}$ & MoF & 5 & MoMP_D11 & 104 & MoMP_D9 & 152.917 \\
\hline
\end{tabular}


One outside stakeholder, the IARCSC, is also highly important in this network. The IARCSC ranked third for the in-degree and in-closeness centrality measures in the recruitment practices network. This actor seems to be the third-most influential actor in this network. The IARCSC plays a vital role in Afghan public organizations because of the implementation of public administration reform it performs, and because it collaborates with the HR department of the MoMP to execute HR practices. Thus, it was expected that the IARCSC would be among the top five actors in this network.

Moreover, another actor among the top five key actors is the Gender Department (MoMP_D10). Due to recruitment and selection law and procedures, it is mandatory that public agencies have at least one female member in each recruitment committee. These policies were instituted to protect the rights of women in public agencies in Afghanistan. Table 5 indicates that MoMP_D10 ranked fourth for the in-degree centrality measure, although it ranked very low for the other two centrality measures. This department is considered to be a pivotal actor in the recruitment-practices network. The Ministry of Finance $(\mathrm{MoF})$ is another important actor in this network. The MoF is an outside actor who ranks fifth for the in-degree centrality measure and fourth for the in-closeness measure.

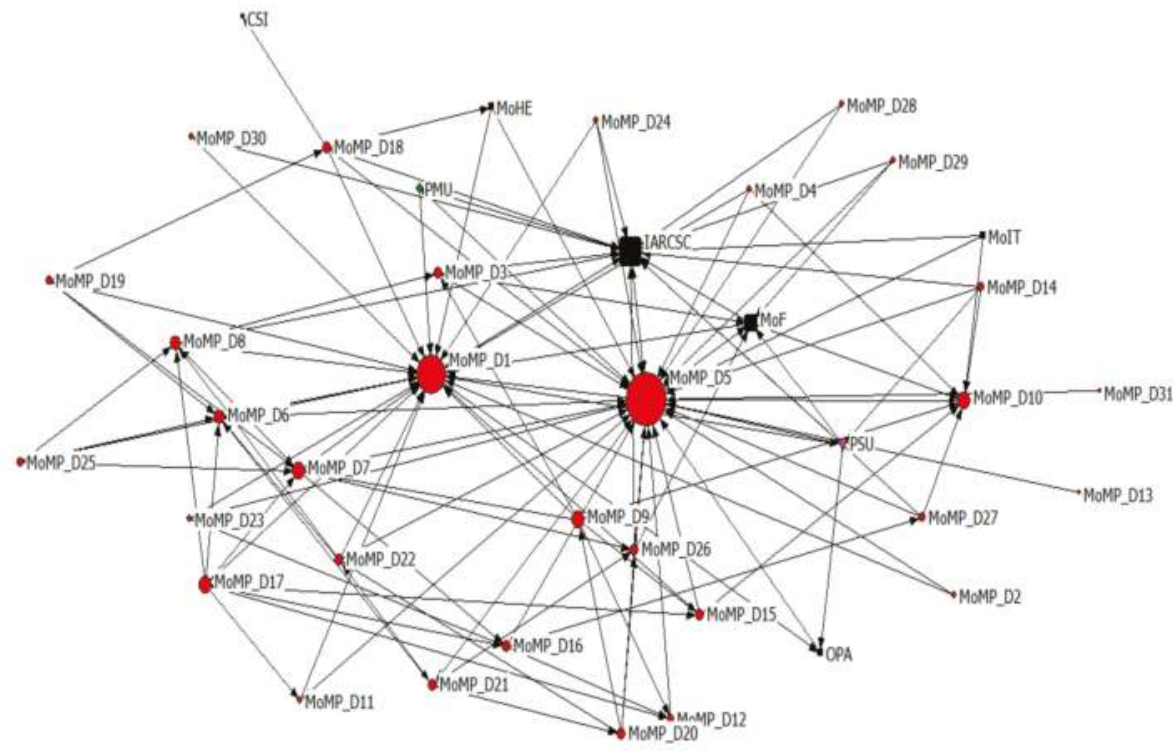

Figure 2. Recruitment practices network.

\subsection{Key Actors in the Training Practices Network}

Table 6 lists the five most dominant actors in the training practices network. These five key actors are arranged based on the results of the centrality measures. MoMP_D5 ranked first for all three measures: the highest in-degree, highest betweenness, and lowest in-closeness. As shown in Figure 3, MoMP_D5 has the largest node size compared to the other actors in this network. Since training is one of the four major practices of HRM, MoMP_D5 could be the leading actor in this network. In addition, according to civil servant law in Afghanistan, the HR department is responsible for four tasks in a public agency, and training is one of those tasks. Therefore, it appears that MoMP_D5 is a dominant actor in the training practices network.

German Society for International Cooperation (GIZ) is an international organization that provides technical and financial support for implementing training throughout the MoMP, and that collaborates with the HR department. Consequently, GIZ could be the second dominant actor in this network, as it placed second for both the in-degree and the in-closeness measures. 
Another outside stakeholder ranked among the top five actors in the training practices network is the IARCSC, which holds the third position for both in-degree centrality and in-closeness centrality, and holds fifth place for the betweenness measure.

Table 6. Major actors in the training practices network.

\begin{tabular}{ccccccc}
\hline No. & Actors & In-Degree & Actors & In-Closeness & Actors & Betweenness \\
\hline $\mathbf{1}$ & MoMP_D5 & 33 & MoMP_D5 & 47 & MoMP_D5 & 235.344 \\
\hline $\mathbf{2}$ & GIZ & 14 & GIZ & 66 & MoMP_D1 & 48.378 \\
\hline $\mathbf{3}$ & IARCSC & 14 & IARCSC & 67 & MoMP_D16 & 43.5 \\
\hline $\mathbf{4}$ & MoMP_D1 & 13 & MoMP_D1 & 68 & MoMP_D7 & 41.789 \\
\hline $\mathbf{5}$ & CSI & 11 & CSI & 70 & IARCSC & 26.467 \\
\hline
\end{tabular}

Furthermore, the actor who ranked in the fourth position in Table 6 was MoMP_D1. This actor ranked fourth for both the in-degree and in-closeness measures, but for the betweenness measure, it ranked second. In addition, Figure 3 shows that MoMP_D1 has the fourth largest node size. Hence, this actor is considered to be the fourth dominant actor in the training practices network. Since MoMP_D1 is the Office of the Minister and based on the hierarchical structure, it is a top-level department of the MoMP that can influence all the department activity throughout the MoMP, and was expected to be among the top five actors in this network. The Civil Service Institute (CSI) is another active outside stakeholder in this network. The CSI holds the fifth position for the in-degree and in-closeness measures. MoMP_D7 and MoMP_D16 appear in Table 6 only for the betweenness measure, indicating that there is a linkage role between two actors in the training practices network.

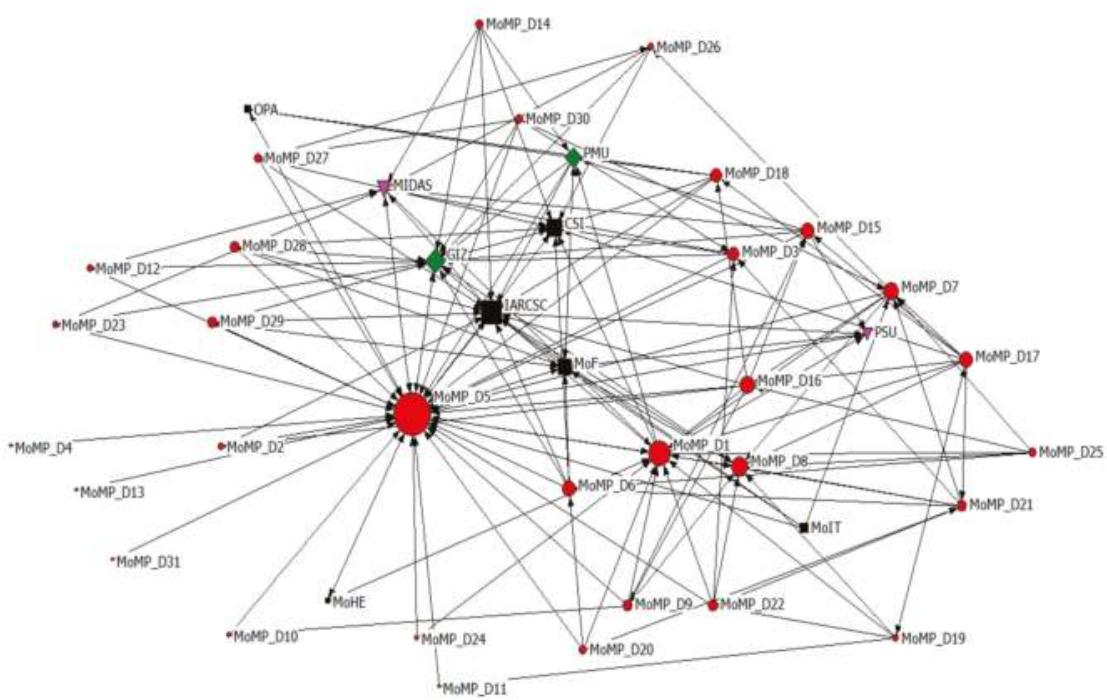

Figure 3. Training practices network.

\subsection{Key Actors in the Performance Appraisal Practices Network}

In Table 7, five actors are noted more frequently by other actors as those most dominant in the performance appraisal practices network. These actors are ranked according to the centrality measures-in-degree, in-closeness, and betweenness. According to the results, which align with civil service law and HRM procedures, three departments of the MoMP and one outside stakeholder are 
engaged in performance and appraisal activities within the MoMP: the HR department, as the leading actor; the minister or deputy minister (i.e., the Office of the Minister); the IARCSC; the heads of the departments whose employees are appraised; and the Department of Finance should all be members of the performance and appraisal committee.

According to the findings of this study, all these same departments are listed as the most important actors in the performance appraisal practices network (see Table 7). For instance, MoMP_D5 ranked first for all measures, with the highest in-degree and betweenness, and the lowest in-closeness. As shown in Figure 4, MoMP_D5 has the largest node compared to the other actors in this network. Therefore, MoMP_D5 is a key actor in HR appraisal practices within the MoMP.

In addition, MoMP_D1 ranked second for both the in-degree and in-closeness measures and appears to be the second key actor in this network. Notably, there is an outside stakeholder in this network-IARCSC. IARCSC holds the third position for the in-degree and in-closeness measures, as shown in Table 7. Additionally, it ranked fourth for the betweenness measure in the performance appraisal practices network. The IARCSC has a substantial role in the performance appraisal practices network because of its supervisory role over the reforms implemented throughout all public organizations.

Table 7. Key actors in the performance appraisal practices network.

\begin{tabular}{ccccccc}
\hline No. & Actors & In-Degree & Actors & In-Closeness & Actors & Betweenness \\
\hline $\mathbf{1}$ & MoMP_D5 & 28 & MoMP_D5 & 71 & MoMP_D5 & 92.7 \\
\hline $\mathbf{2}$ & MoMP_D1 & 13 & MoMP_D1 & 85 & MoMP_D16 & 15.4 \\
\hline $\mathbf{3}$ & IARCSC & 12 & IARCSC & 86 & MoMP_D8 & 15.317 \\
\hline $\mathbf{4}$ & MoMP_D8 & 8 & MoMP_D8 & 99 & IARCSC & 11.667 \\
\hline $\mathbf{5}$ & MoMP_D16 & 3 & MoMP_D10 & 104 & MoMP_D21 & 10.333 \\
\hline
\end{tabular}

Moreover, according to Table 7, the fourth key actor is MoMP_D8, which ranked fourth for the in-degree and in-closeness measures. MoMP_D8 is responsible for increasing employees' salaries after performance appraisals have been successfully completed. Considering the involvement of MoMP_D8 in the appraisal practices and the given results, this department could be considered as the fourth main actor in the performance appraisal practices network.

According to Figure 4, the other actors did not indicate that GIZ, Mining Investment and Development for Afghanistan Sustainability (MIDAS), Ministry of Higher Education (MoHE), Project Management Unit (PMU), or Project Support Unit (PSU) participate in this network. As these actors are not engaged in the implementation of appraisal practices within the MoMP, they are considered unconnected actors (i.e., isolates) in the network. 


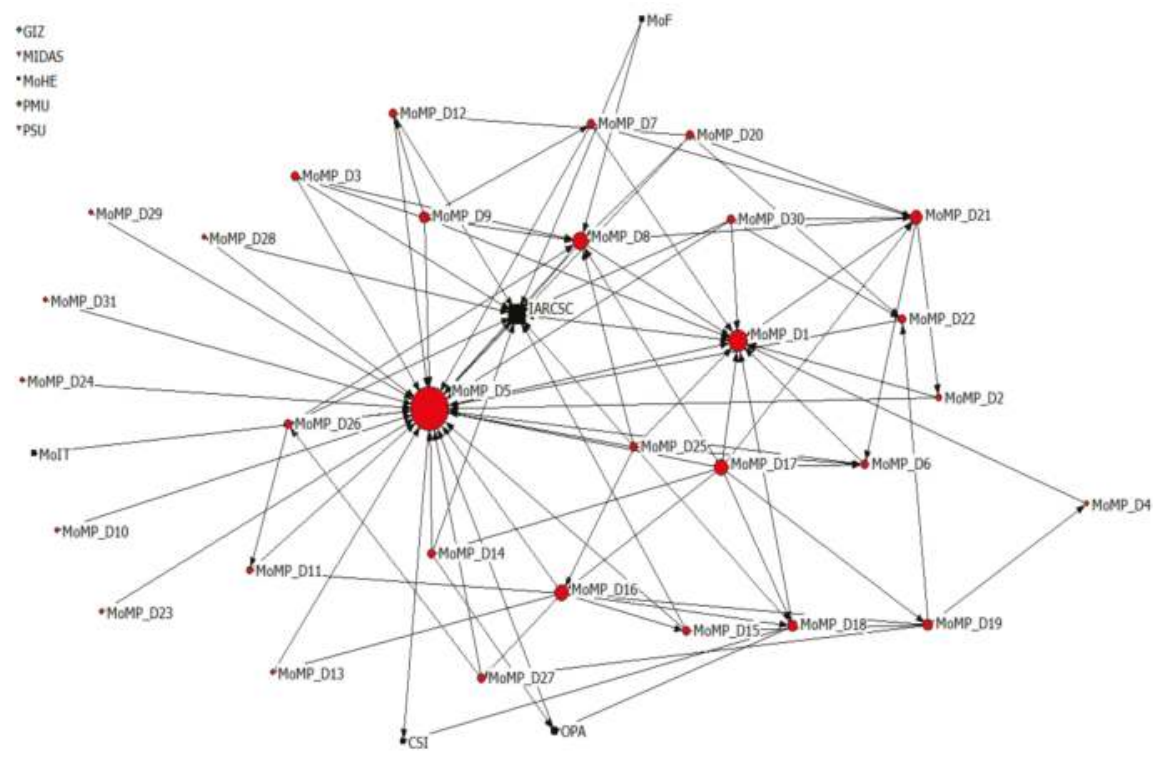

Figure 4. Performance appraisal practices network.

\subsection{Key Actors in the Reward Practices Network}

According to Table 8, five main actors were indicated by the others as major actors in the reward practices network. The actors are ranked according to the centrality measures: in-degree, in-closeness, and betweenness. The empirical results show that MoMP_D5 ranked first for all three measures because it has the highest in-degree, highest betweenness, and lowest in-closeness. Figure 5 also shows that MoMP_D5 has a larger node than the other actors in the network. Therefore, MoMP_D5 is a dominant actor in the reward processes of the MoMP.

In addition, MoMP_D8 ranked second for all three measures. Considering the financial responsibility of MoMP_D8 for the implementation of the rewards practice in collaboration with MoMP_D5 and the study results, MoMP_D8 is the second most important actor in this network. Furthermore, MoMP_D1 ranked third for both the in-degree and in-closeness measures, and fourth for the betweenness measure. Thus, according to the findings, MoMP_D1, which has been mentioned in the earlier part of this chapter, can be recognized as the third-most influential actor in this network. Moreover, MoF, which is an outside stakeholder, is also among the top five actors in this network. This department holds the fourth position for both in-degree and in-closeness. Therefore, $\mathrm{MoF}$ is recognized as the fourth dominant actor in this network.

Table 8. Key actors in the reward practices network.

\begin{tabular}{ccccccc}
\hline No & Actors & In-Degree & Actors & In-Closeness & Actors & Betweenness \\
\hline $\mathbf{1}$ & MoMP_D5 & 30 & MoMP_D5 & 58 & MoMP_D5 & 108.25 \\
\hline $\mathbf{2}$ & MoMP_D8 & 24 & MoMP_D8 & 64 & MoMP_D8 & 18.667 \\
\hline $\mathbf{3}$ & MoMP_D1 & 16 & MoMP_D1 & 72 & MoMP_D16 & 12.833 \\
\hline $\mathbf{4}$ & MoF & 10 & MoF & 79 & MoMP_D1 & 11.667 \\
\hline $\mathbf{5}$ & MoMP_D6 & 6 & IARCSC & 84 & MoMP_D26 & 7 \\
\hline
\end{tabular}


Figure 5 shows that SCI, GIZ, MIDAS, and PMU are considered to be isolated actors in the reward practices network, as they are not indicated by other actors to be involved in any activities regarding rewards practices within the MoMP.

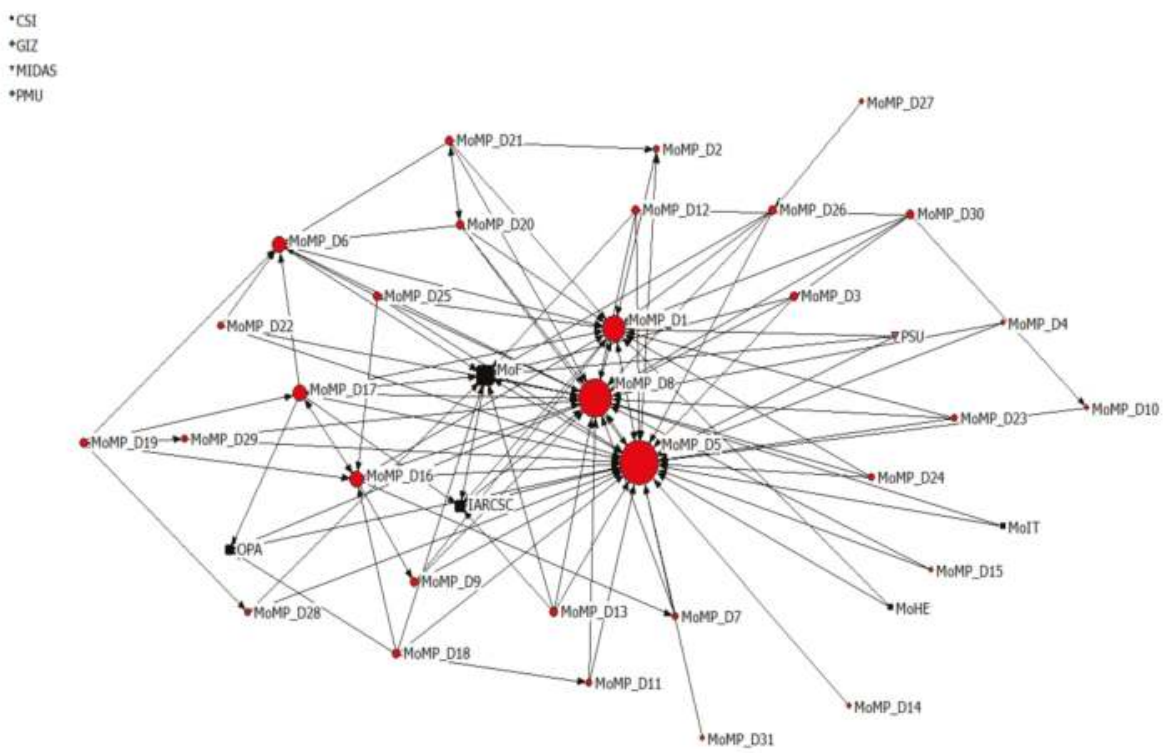

Figure 5. Reward practices network.

5.6. Key Actors in the Funding for Capacity-Building Network

One of the main focuses of SHRM is to invest in human capital (i.e., HR) from a long-term perspective, and it considers HR to be a strategic asset and typically accepts that it is essential for developing and investing in these organizational-specific assets $[44,45]$. Therefore, to sustain capacity development programmes in the MoMP, it was considered important to determine the major financial supporters of capacity development programmes of the MoMP HR department. Table 9 shows the five main actors in the funding for capacity-building network. The actors were ranked based on the centrality measures. The top five actors in this network represent the most influential actors for providing training programmes and funds to the HR capacity-building department of the MoMP.

The MoF ranked first for the in-degree and in-closeness measures, which means the MoF has been noted by other actors and stakeholders to be a pivotal actor in this network. Indeed, the MoF is responsible for managing and providing the annual simple budget and developing budgets for every governmental organization, meaning that most of the capacity-building programmes' expenses are covered by the yearly development budget provided by the MoF. Thus, based on the study results and the actual situation, the MoF is considered to be the most dominant actor in the funding for capacity-building network.

GIZ (an international organization) ranked second for both the in-degree and in-closeness measures, but third for the betweenness measure. Thus, it represents the second-most dominant actor in this network. MIDAS, which is a nongovernmental organization, is another active actor in this network and ranked third for both the in-degree and in-closeness measures in this network. 
Table 9. Key actors in the funding for capacity-building network.

\begin{tabular}{ccccccc}
\hline No. & Actors & In-Degree & Actors & In-Closeness & Actors & Betweenness \\
\hline $\mathbf{1}$ & MoF & 32 & MoF & 48 & IARCSC & 62.926 \\
\hline $\mathbf{2}$ & GIZ & 29 & GIZ & 52 & MoF & 48.417 \\
\hline $\mathbf{3}$ & MIDAS & 23 & MIDAS & 57 & GIZ & 26.826 \\
\hline $\mathbf{4}$ & IARCSC & 21 & IARCSC & 59 & PSU & 13.26 \\
\hline $\mathbf{5}$ & PMU & 20 & PMU & 61 & PMU & 13.21 \\
\hline
\end{tabular}

According to the results, the IARCSC is considered to be the fourth-most-dominant actor in this network. PMU, which is an international actor, is among the top five actors in this network, ranks fifth for all the measures in Table 9, and is considered to be the fifth dominant actor in the funding for capacity-building network (Figure 6).

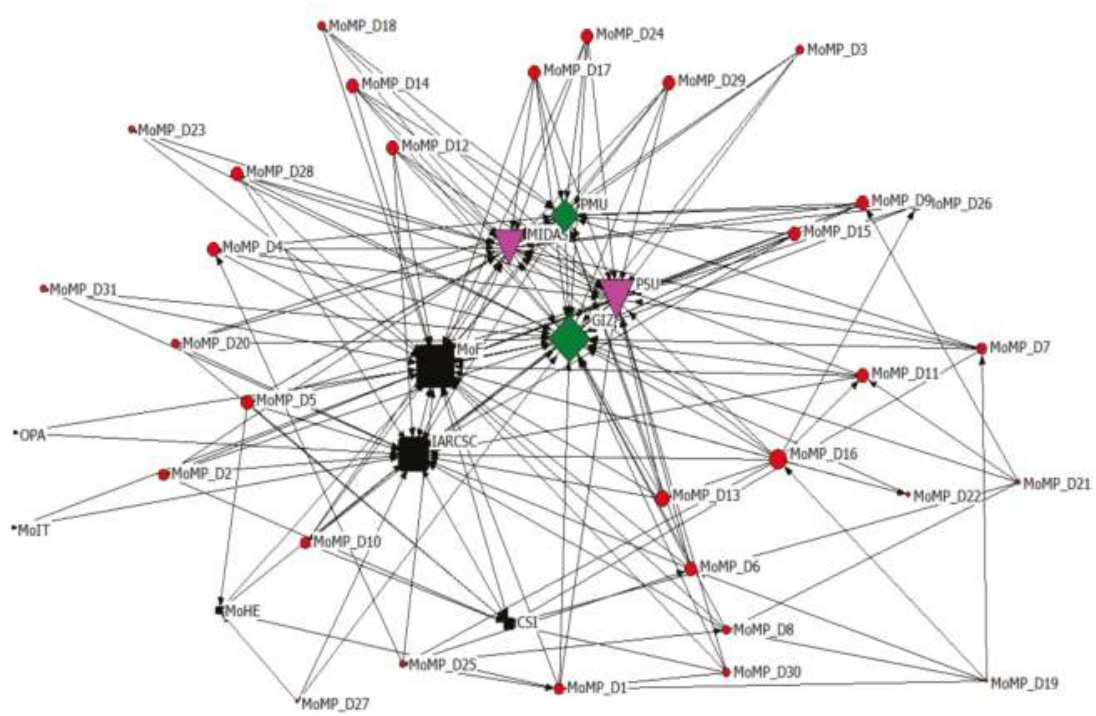

Figure 6. Funding for capacity-building network.

\section{Conclusions}

Since 2001, Afghan public organizations, particularly the MoMP, have lacked modern administrative systems at all levels. Over the past 15 years, the IARCSC has made important achievements in terms of administrative reforms in public service institutions in Afghanistan, particularly those related to HRM; however, more reforms are needed for effective public administration in Afghanistan.

According to the findings of this study, the HR department collaborates with other departments within the MoMP, as well as with outside stakeholders, to set ministry-level goals and make decisions (see Figure 7). Figure 7 indicates that the HR department interacts with its stakeholders and other departments within the MoMP. This figure also indicates that stakeholders interact among themselves to improve the implementation of HRM practices within the MoMP.

In Figure 7, ministry-level and department-level issues are separated by horizontal lines, and governmental and nongovernmental organizations are separated by vertical lines. The governmental organizations include the MoMP and other line ministries that are involved in the implementation of HR practices in the MoMP. In addition, non-governmental organizations (NGOs) and international 
agencies are also involved in execution of some HR practices. Line ministries, NGOs, and international agencies are all involved at the ministry level, as described in Figure 7. They collaborate to develop and implement HR practices. Additionally, the MoMP's departments, including its HR department, NGOs, and international agencies, interact at the department level.

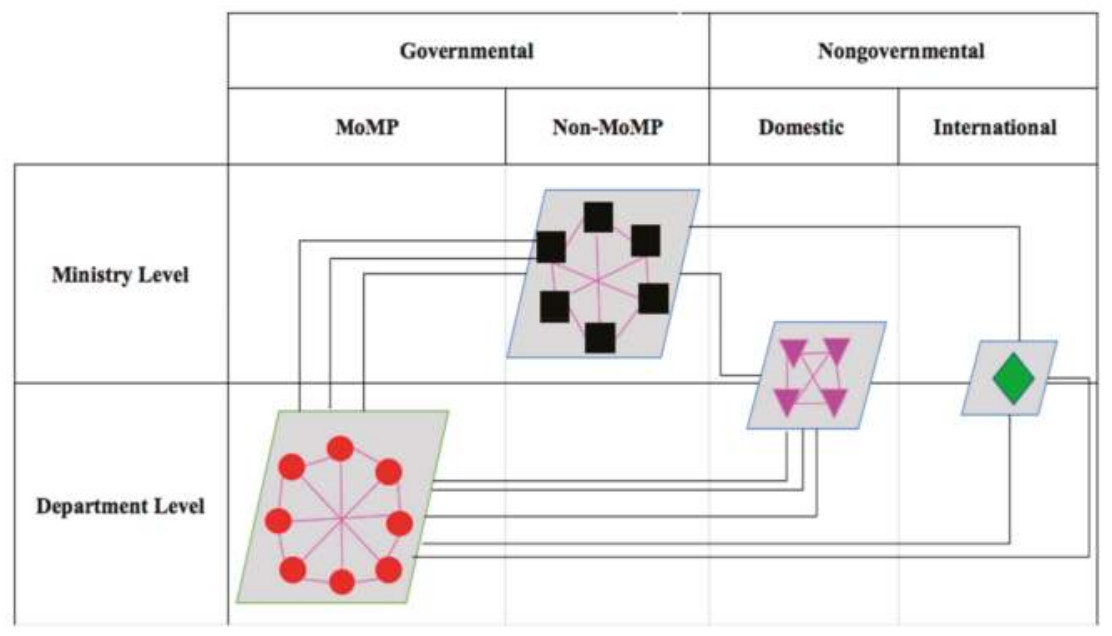

Figure 7. Interaction between the HR department and its stakeholders within and outside the MoMP.

In conclusion, this research has found that although public organizations in Afghanistan lack a modern administrative system due to the unsuccessful implementation of administrative reforms, some features of SHRM are apparent in the current HRM within the public organizations in Afghanistan, particularly in the MoMP. Because some of the characteristics of SHRM include being involved in determining the primary goals of an organization and the organizational decision-making process, this result confirms that SHRM is notably present in the MoMP. SHRM emphasizes the importance of HR professionals as strategic partners on executive teams, thus helping HRM contribute to the alignment between HRM practices and organizational strategic goals, beyond simply regulating and monitoring the workforce $[5,27,46,47]$. Hence, the presence of certain features of SHRM in the MoMP are evident in this research, and if we better emphasize SHRM aspects in the MoMP, we can effectively ensure that all of the MoMP's objectives align with the mission, vision, and goals of the organization. Additionally, by focusing on SHRM concepts, the HR department could actively participate in developing organizational strategies and making and implementing policies in the MoMP.

From a stakeholder theory perspective on human resource management, our study empirically shows that the HR department of the MoMP incorporates and addresses not only those concerns of insider MoMP stakeholders, but also those of its outside stakeholders—such as non-profit and international organizations_-in making and implementing its main HR practices. Regarding our future research agenda exploring the role of contexts and situations in the HRM-to-performance relationships [48,49], we need to examine how such connectedness between the HR department and other stakeholders in the formation and implementation of HR policies could affect organizational long-term effectiveness and sustainability. Then, we must identify which specific structural contexts or configurations of relationships among these actors could lead to higher organizational performance.

Author Contributions: K.A.N.L. drafted the manuscript and contributed to all other aspects of the study. S.L. performed the critical revision of the manuscript. All authors read and approved the final manuscript.

Funding: This research received no external funding.

Conflicts of Interest: The authors declare no conflict of interest. 


\section{References}

1. Afghanistan National Development Strategy. A strategy for security: Governance, economic growth and poverty reduction. Available online: http://mcn.gov.af/Content/files/Afghanistan $\% 20 \mathrm{National} \%$ 20Development\%20Strategy.pdf (accessed on 3 January 2018).

2. IARCSC. Public Administration Country Profile. Independence Administration Reform and Civil Service Commission. Available online: http://unpan1.un.org/intradoc/groups/public/documents/un/unpan023299. pdf (accessed on 19 July 2018).

3. Mahoney, T.A.; Deckop, J.R. Evolution of concept and practice in personnel administration/human resource management. J. Manag. 1986, 12, 223-241. [CrossRef]

4. Wright, P.M.; McMahan, G.C. Theoretical perspectives for strategic human resource management. J. Manag. 1992, 18, 295-320. [CrossRef]

5. Lim, S.; Wang, T.K.; Lee, S.Y. Shedding new light on strategic human resource management: The impact of human resource management practices and human resources on the perception of federal agency mission accomplishment. Publ. Person. Manag. 2017, 46, 91-117. [CrossRef]

6. Thakur, M.; Calingo, L.M.R. Strategic thinking is hip, but does it make a difference? Bus. Horiz. 1992, 35, 47-54. [CrossRef]

7. Truss, C. Strategic HRM: enablers and constraints in the NHS. Int. Jo. Pub. Sect. Manag. 2003, 16, 48-60. [CrossRef]

8. Truss, C.; Gratton, L.; Hope-Hailey, V.; Stiles, P.; Zaleska, J. Paying the piper: Choice and constraint in changing HR functional roles. Hum. Resour. Manag. J. 2002, 12, 39-63. [CrossRef]

9. Martell, K.; Carroll, S.J. How strategic is HRM? Hum. Resour. Manag. 1995, 34, 253-267. [CrossRef]

10. Mesch, D.J.; Perry, J.L.; Wise, L.R. Bureaucratic and strategic human resource management: An empirical comparison in the federal government. J. Pub. Adm. Res. Theory 1995, 5, 385-402.

11. Rogers, S.E.; Jiang, K.; Rogers, C.M.; Intindola, M. Strategic human resource management of volunteers and the link to hospital patient satisfaction. Nonprofit Volunt. Sect. Q. 2016, 45, 409-424. [CrossRef]

12. Garavan, T.N. A strategic perspective on human resource development. Adv. Develop. Human Resourc. 2007, 9, 11-30. [CrossRef]

13. Way, S.A.; Johnson, D.E. Theorizing about the impact of strategic human resource management. Hum. Resour. Manag. Rev. 2005, 15,1-19. [CrossRef]

14. Fombrun, C.; Tichy, N.M.; Devanna, M.A. (Eds.) Strategic Human Resource Management. John Wiley and Sons: New York, NY, USA, 1984.

15. Beer, M.; Spector, B.; Lawrence, P.R.; Mills, D.Q.; Walton, R.E. Managing Human Assets. The Free Press: New York, NY, USA, 1984.

16. Jackson, S.E.; Schuler, R.S.; Jiang, K. An aspirational framework for strategic human resource management. Acad. Manag. Ann. 2014, 8,1-56. [CrossRef]

17. Bos-Nehles, A.C. The Line Makes the Difference: Line Managers as Effective HRM Partners. Ph.D. Thesis, University of Twente, Enschede, The Netherlands, 2010.

18. Rimi, N.; Yusliza, M.-Y.; Walters, T.; Rubel, M.R.B. The role of devolution in HR-line manager collaboration and HRM effectiveness relationship: A study of private commercial banks. Glob. Bus. Organ. Excel. 2017, 36, 43-51. [CrossRef]

19. Chen, Y.P.; Hsu, Y.S.; Yip, F.W.K. Friends or rivals: comparative perceptions of human resource and line managers on perceived future firm performance. Int. J. Hum. Resour. Manag. 2011, 22, 1703-1722. [CrossRef]

20. Berber, N.; Morley, M.J.; Slavić, A.; Poór, J. Management compensation systems in Central and Eastern Europe: A comparative analysis. Int. J. Hum. Resour. Manag. 2017, 28, 1661-1689. [CrossRef]

21. Freeman, R.E. Strategic Management: A Stakeholder Approach; Pitman Publishing: New York, NY, USA, 1984.

22. Ferrary, M. A stakeholder perspective of human resource management. In Stakeholder Theory: A European Perspective; Bonnafous-Boucher, M., Pesqueux, Y., Eds.; Palgrave Macmillan: New York, NY, USA, 2005.

23. Ehnert, I.; Harry, W. Recent developments and future prospects on sustainable human resource management. Manag. Revue 2012, 23, 221-238. [CrossRef]

24. Kramar, R. Beyond strategic human resource management: Is sustainable human resource management the next approach? Int. J. Hum. Resour. Manag. 2014, 25, 1069-1089. [CrossRef] 
25. Rees, G.; Smith, P.E. Strategic Human Resource Management: An International Perspective; Sage: Thousand Oaks, CA, USA, 2017.

26. Stankevičiūtè, Ž.; Savanevičienè, A. Designing sustainable HRM: The core characteristics of emerging field. Sustainability 2018, 10, 4798. [CrossRef]

27. Jacobson, W.S.; Lambright, K.T. The development of county HR policies: The perspectives of counties in two states. Pub. Person. Manag. 2018, 47, 398-418. [CrossRef]

28. Bányai, T.; Landschützer, C.; Bányai, Á. Markov-chain simulation-based analysis of human resource structure: How staff deployment and staffing affect sustainable human resource strategy. Sustainability 2018, 10, 3692. [CrossRef]

29. Manzoor, F.; Wei, L.; Bányai, T.; Nurunnabi, M.; Subhan, Q.A. An examination of sustainable HRM practices on job performance: An application of training as a moderator. Sustainability 2019, 11, 2263. [CrossRef]

30. Bedwell, W.L.; Wildman, J.L.; DiazGranados, D.; Salazar, M.; Kramer, W.S.; Salas, E. Collaboration at work: An integrative multilevel conceptualization. Hum. Resour. Manag. Rev. 2012, 22, 128-145. [CrossRef]

31. Park, S.; Lim, S. Are networks flat or vertical?: Developing a multi-level multi-dimension network model. Pub. Rev. 2018, 18, 223-243. [CrossRef]

32. Securing Afghanistan's Future. Accomplishments and the Strategic Path Forward. Transitional Islamic State of Afghanistan. Available online: http://www.af/recosting/index.html (accessed on 10 July 2018).

33. Civil Servant Law. Enacted by the Legislative Branch of Afghanistan on July 2008. Available online: https://iarcsc.gov.af/fa/wp-content/uploads/sites/2/2017/11/\%D9\%82\%D8\%A7\%D9\%86\%D9\%88\%D9\%86\%DA\%A9\%D8\%A7\%D8\%B1\%DA\%A9\%D9\%86\%D8\%A7\%D9\%86-\%D8\%AE\%D8\%AF\%D9\%85\%D8\% A7\%D8\%AA-\%D9\%85\%D9\%84\%DA\%A9\%DB\%8C.pdf (accessed on 29 March 2018).

34. Borgatti, S.P.; Everett, M.G.; Johnson, J.C. Analyzing Social Networks; Sage: London, UK, 2013.

35. Brass, D. A social network perspective on human resources management. In Research in Personnel and Human Resources Management; Rob, C., Andrew, P., Lisa, S., Eds.; JAI Press: Greenwich, UK, 1995.

36. Monge, P.R.; Contractor, N.S. Theories of Communication Networks; Oxford University Press: New York, NY, USA, 2003.

37. Kapucu, N.; Demiroz, F. Measuring performance for collaborative public management using network analysis methods and tools. Pub. Perform. Manag. Rev. 2014, 34, 549-579. [CrossRef]

38. Htein, M.K.; Lim, S.; Zaw, T.N. The evolution of collaborative networks towards more polycentric disaster responses between the 2015 and 2016 Myanmar floods. Int. J. Disaster Risk Reduct. 2018, 31, 964-982. [CrossRef]

39. Ebrahimi, M.H.; Lim, S. Network structures of inter-agency collaboration among counter-narcotics stakeholders in Afghanistan. Roman. J. Polit. Sci. 2018, 18, 8-42.

40. Comfort, L.K.; Haase, T.W. Communication, coherence, and collective action: The impact of Hurricane Katrina on communications infrastructure. Pub. Works Manag. Policy 2006, 10, 328-343. [CrossRef]

41. Prell, C. Social Network Analysis: History, Theory, and Methodology; Sage: Thousand Oaks, CA, USA, 2012.

42. Koet, V.; Lim, S. Voluntary environmental collaborations and corporate social responsibility in Siem Reap City, Cambodia. Sustain. Account. Manag. Policy J. 2019, 1-25. [CrossRef]

43. Borgatti, S.P.; Everett, M.G.; Johnson, J.C. Analyzing Social Networks, 2nd. ed; Sage: Thousand Oaks, CA, USA, 2018.

44. Mueller, F. Human resources as strategic assets: An evolutionary resource-based view. J. Manag. Stud. 1996, 33, 757-785. [CrossRef]

45. Barney, J.B. Is the resource-based "view" a useful perspective for strategic management research?: Yes. Acad. Manag. 2001, 26, 41-56.

46. Schuler, R.S.; Jackosn, S.E. Strategic Human Resource Management, 2nd. ed; Blackwell Publishing: Malden, MA, USA, 2007.

47. Boxall, P.; Purcell, J.; Wright, P. (Eds.) The Oxford Handbook of Human Resource Management; Oxford University Press: New York, NY, USA, 2007. 
48. Kinnie, N.J.; Swart, J.; Purcell, J. Influences on the choice of HR system: The network organization perspective. Int. J. Hum. Resour. Manag. 2005, 16, 1004-1028. [CrossRef]

49. Allen, M.R.; Wright, P. Strategic management and HRM. In The Oxford Handbook of Human Resource Management; Boxall, P., Purcell, P., Wright, P., Eds.; Oxford University Press: New York, NY, USA, 2007.

(c) (1)

(C) 2019 by the authors. Licensee MDPI, Basel, Switzerland. This article is an open access article distributed under the terms and conditions of the Creative Commons Attribution (CC BY) license (http://creativecommons.org/licenses/by/4.0/). 
Article

\title{
An Analysis of the Corporate Social Responsibility and the Industry 4.0 with Focus on the Youth Generation: A Sustainable Human Resource Management Framework
}

\author{
Annibal Scavarda ${ }^{1}$, Gláucya Daú ${ }^{2, *}$, Luiz Felipe Scavarda ${ }^{3}$ and \\ Rodrigo Goyannes Gusmão Caiado ${ }^{3}$ \\ 1 Production Engineering School, Federal University of the State of Rio de Janeiro-UNIRIO, Rio de Janeiro \\ 22290-240, Brazil; annibal.scavarda@unirio.br \\ 2 Health Economic and Technological Evaluation Laboratory, Federal University of the State of Rio de \\ Janeiro-UNIRIO, Rio de Janeiro 22290-180, Brazil \\ 3 Industrial Engineering Department, Pontifical Catholic University of Rio de Janeiro-PUC-Rio, Rio de \\ Janeiro 22451-000, Brazil; lf.scavarda@puc-rio.br (L.F.S.); rodrigoggcaiado@gmail.com (R.G.G.C.) \\ * Correspondence: glaucyadau@gmail.com; Tel.: +55-219-7202-8136
}

Received: 24 June 2019; Accepted: 6 September 2019; Published: 19 September 2019

\begin{abstract}
The global movement around themes like sustainability on its triple bottom line and industry 4.0 allows for the establishment of a ground of connection with corporate responsibility towards society. This current research study was developed between 1 March 2019 to 2 September 2019, through a literature review involving human resources and terms related to the concept of sustainability, industry 4.0, corporate social responsibility, and the youth generation. Its target audience is the world's youth generation. Two proposals were created after the literature review and data collection, which allowed the elaboration of "an analysis of the corporate social responsibility and the industry 4.0 with focus in the youth generation: a sustainable human resource management framework." Regarding conclusions, the authors of this research study contribute with theoretical and practical educational purposes to insert the youth citizen into society. This contribution also involves the work of companies on planning and preparing their staffs to develop activities in the communities in their neighborhood. Future studies are stimulated, which will allow the creation of new proposals to be presented, so that the nations can incorporate their youth people on the transitional job market and have a sustainable view for the future generations.
\end{abstract}

Keywords: sustainable human resources; industry 4.0; corporate social responsibility; conceptual framework; youth generation

\section{Introduction}

Human resource management enables a holistic view involving concepts and practices presented in many research studies [1,2]; sustainability [3,4], industry $4.0[5,6]$, and corporate social responsibility (CSR) $[7,8]$ are among these concepts. The implementation of sustainable practices, together with the disruptive technologies presented by the fourth industrial revolution, make possible the enhancement of professional activities and creation of new job opportunities. Disruptive technologies are present in the population's day-to-day life and are especially present regarding the youth of the new millennium. On one hand, this presence can positively impact knowledge structure and educational activities. Haines et al. [9] presented the positive impact promoted by the use of technology on their research. The authors also showed that human resource management and the relationship between the delivery of knowledge and technologies help to support human resources. 
On the other hand, disruptive technologies can impact negatively if the use of these digital tools is not appropriate. The construction of knowledge and the stimulus to learn can be done by the tools coming from the fourth industrial revolution, but their indiscriminate use, without any educational purpose, should not be stimulated. Therefore, these technologies should work as learning facilitators and as propagators of information, either local and globally. Technology is a tool that can be used as a support within the teaching process [10]. The Internet of Things (IoT) enables it through an auxiliary disruptive purpose, in which youth people can be inserted in the digital context, allowing for the integration among software, systems, and people. The actions that allow for communion between sustainability and industry 4.0 concepts may transform economic outlooks, leading to improvement under economic aspects, through the insertion of these youth people into workplaces and society.

The World Economic Forum [11] affirmed that the work population nowadays is primarily made up of youth people, but they are not appropriately represented in global subjects. The most recent edition of the World Economic Forum has conducted research aiming to learn how these youth people see the world. They consider career opportunities and growth as compensation, the sense of the purpose, and social impact. Some disadvantages they have pointed out include lack of experience to obtain one's first job, excessive competition, and the availability of job positions. Two major points were observed by this millennium generation and highlighted; these include the corporative values of sustainability and social responsibility. This integration between sustainable practices and CSR allows for the amplification of institutional actions, making these companies' jobs easier in order to strengthen the corporative environment with CSR and corporate sustainability [12]. Then, the institutions can collaborate with the implementation of 2030 United Nations (UN) Agenda [13] and contribute to the achievement of the 17 Sustainable Development Goals (SDGs) [13] proposed in 2015 by the same organization.

Among the 17 Sustainable Development Goals, goal eight-“decent work and economic growth" [13] - is analyzed in the current research study. For this goal, the UN established some targets such as productive and decent work for women and men with equal payment and value. Reducing youth unemployment, as well as educating and training this population, are other targets for this goal. The relationship between human resource management and sustainability is currently present in society and establishes many paths [2] for sustainable development. The authors propose a conceptual framework involving the world's youth population in the global context, presenting two proposals related to sustainable human resource. Figure 1 shows the sustainable human resource management framework with focus on the youth generation. 


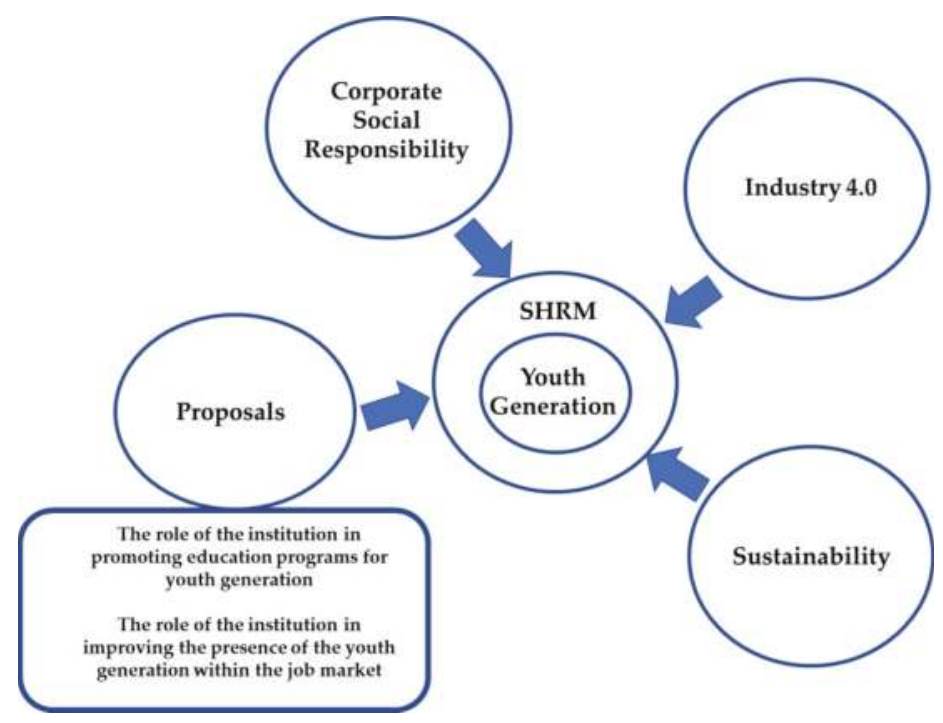

Figure 1. Sustainable human resource management framework with focus on the youth generation.

The world's youth population is characterized by people between 15 and 24 years old [14]. According to data provided by the Brazilian Institute for Geography and Statistics (IBGE) [15], in 2017, the female population between 15 and 19 years old represented the second biggest population, only after those between the ages of 35 and 39. The Brazilian male population had a higher concentration at this stage ( 15 and 19 years old). The reference to the Brazilian youth brought by the institute was based on $50 \%$ of the population between zero and 34 years old; yet this is changing as a result of a decrease in the birth rate and increase in life expectancy of the Brazilian population.

The problems of the youth generation have impacted the previous generation, promoting dynamism in society [16]. The global datum highlights the constant search for the youth generation and the digital world, but in fact, around one third of the population did not have access to the internet in 2017 [15]. This number signifies the need to improve internet access for the youth population. The Agency Brazil - Brazilian Company of Communication [17] presents the statistics of countries, showing that $46.8 \%$ of schools have information technology spaces for students, and $65.6 \%$ of schools can access the internet, with $53.5 \%$ accessing through broadband connection. The agency still reinforces the notion that half of the schools cannot provide students with access to technology.

The stimulus for youth people to study and work helps make them capable of working and thus offers better work conditions. It allows for the integration of these youth citizens into society and the construction of a new culture. Sivathanu and Pillai [18] observed that companies must be prepared for the absorption of technologies in attention to the demands of the so called, Generation (Gen) $Y$ and Gen Z. The authors present the age groups for these generations; Gen Y are those born between 1980 and 2000 and Gen $Z$ are those born after the year 2000. The youth population must be remembered by companies during planning, so that they can be included in the job market.

From this rational, the authors establish the following research questions: Can institutions contribute to the inclusion of youth people into society through CSR? How can institutional management of the youth and sustainable human resources promote a partnership with local communities? How can institutions promote industry 4.0 educational practices for youth people, aiming at partnerships with local communities?

In order to allow the world's youth people access to the internet, improvement of learning, exercise of skills, and interaction with the world, the authors of this research study present two proposals: 
"the role of the institution in promoting education programs for youth generation" and "the role of the institution in improving the presence of the youth generations within the job market." These proposals can be approached by partner companies and singly with local communities. They enable the insertion of the youth population and stimulate the improvement of the study and search for job positions. From structuring the educational programs, the partnership with communities brings the youth people to a new world, making them aware of new activities and enabling study, and job opportunities.

The educational programs of information technology companies can bring youth people into the corporative environment and study laboratories where they can apply technology concepts learned previously, which are ways to enhance the fourth industrial revolution. This activity contributes to the consolidation of the fourth industrial revolution concepts in countries where it is necessary. The institutions can establish opportunities by making partnership with technical schools and including these youth people in the job market.

In order to answer the questions of the current research, the authors present the information regarding the strategy used for data search and collection, as well as the literature available in the Materials and Methods, and Results sections, respectively. The Results section shows the product of this strategy and data collection. The two proposals are presented in the Discussion section. At the end, the authors present the study's limitations, suggest future studies and make their own contributions regarding the theme approached in the Conclusions section.

\section{Theoretical Background}

\subsection{Corporate Social Responsibility, Industry 4.0, the Youth Generation, and Human Resource Management}

\subsubsection{Corporate Social Responsibility and the Human Resource Management}

The relationship between CSR and human resource management can create internal and external values for the institution. Social responsibility, climate organization, and how employees perceive the CSR [19] open doors to promote ways to plan a structure for involving the workforce in this context. De Stefano et al. [1] referred to human resource contributions to CSR in their study and attributed a lack of clarity caused by the characteristics and different dimensions. The same authors included the concept of the corporate sustainability in addition to the CSR concept. Corporate sustainability is discussed by many researches [20-22] and addresses points about the training [23], behavior [23], and perception of employees [21]. The implementation of sustainable practices and integration with the human resources should thus be done [22].

Once the country stimulates these practices through the government by reducing taxes and duties, it leads other companies to practice CSR. This action becomes circular, since its implementation induces companies to help the population and the government. Sharma and Tewari [24] indicated that India was the first country in which the government mandated CSR practices and implemented guidelines regarding the subject.

Human resources can contribute to CSR implementation. Gond et al. [25] analyzed responsible leadership and revealed that human resources has many roles in this kind of leadership. These roles might be interrelated to three dimensions described by the authors: functional, practical, and relational. It is important to reinforce the search for CSR applicability, supported by many groups, which means, the government, institutions, and human resources. Wilcox [26] referred to changes in the regulation of social, economic, and institutional fields.

CSR may benefit institutions by accelerating the implementation of actions related to sustainability and the fourth industrial revolution [27]. Therefore, institutions should exceed their territorial limits and develop actions involving CSR and engage with the local population, as well as spread practices and help other institutions by doing so. An aspect approached by López-Fernández et al. [28] was the perception of the employee regarding social responsibility. Therefore, not only does the institution have its responsibility, but also the collaborator needs to have a perception of the institutional practices and policies. 


\subsubsection{Industry 4.0 and Human Resource Management}

Service education is present either in knowledge stages, or the stages that are necessary to base this knowledge. New technologies come up all the time in the job market, and new careers are planned to attend to the needs of the market [5]. Human resources should own their careers and lives, aiming to improve its abilities and experiences. Harris [29] approached emerging technologies and the need of reeducation back in the 1980s. Nessler [30] showed three basic categories in relation to virtual technologies: recruiting, onboarding, and training education.

The impact of information technology needs more study, according to Stone et al. [31]. These technologies interfere in daily practices and the work itself, but the interference can be either positive or negative, depending on its use. The insertion of human resources in the fourth industrial revolution brings corporative benefits, apart from the job itself inserting and reinserting the professional in a new context and allowing job maintenance, with resulting economic balance for the country.

Technology is a driver [32] that can promote and impact the future of the jobs and create an innovative movement [33]. Burita and Ondryhal [34] worked with a methodology that contains digital information for the preparation of students. The same authors say that students are still not ready for innovative thinking and work. According to the global and Brazilian data presented in this research study, there is still a lack of data which needs to be filled when it comes to digital insertion. Both schools and the government can look for partnerships to provide computers and internet access through companies that partake in CSR. These opportunities can represent a lever for some countries, especially those with low involvement of youth people, so that they can eliminate gaps and mitigate risks that may come up regarding unemployment.

Whysall et al. [35] showed that the fourth industrial revolution enabled fast technological growth, demanded collaborators to search for adaptation, and quickly developed a new job market. The authors present that the development of new talents should also be considered. For Sivathanu and Pillai [18], emerging technologies are connected with a new generation of employees with aspects relative to talent development. This way, preparing students and future workers to think in an innovative bridge, and their insertion into the job market creates opportunities. These opportunities can be exemplified by digital insertion in schools, the use of teaching methods through disruptive technologies aimed at the creation of innovative thinking, and the insertion of family in the preparation context for the fourth industrial revolution.

\subsubsection{The Youth Generation and Human Resource Management}

Yadollahzadeh et al. [36] approached the competitive environment of the 21st century and the need of a corporative culture, with defined strategies being chosen. The authors bring the development of the emerging markets, the environmental factors, the high technology, and the development of businesses that aim the success of these topics.

Regarding experience required by the job market, a study by Stankiewicz et al. [37] presented the work of youth people of the third sector, who promoted civic attitude as well as the opportunity to develop abilities and professional experience. Then, the stimulus aimed at having the youth notice that activities of this nature adds value both to the community and youth generation formation; thus becoming a signal of cultural changes. The volunteers' work is an opportunity to include the youth generation in the many areas of the society and in according Stankiewicz et al. [37] citizens work with volunteers in democratic societies. For Bombiak [38], in order to achieve cultural changes regarding sustainable practices, the development of politics for green human resources starts with awareness and the dissemination of knowledge, bringing a positive impact to the corporation [39]. Chaudhary [40] showed the human aspect of environmental sustainability.

Another concern is retaining talent. This theme is discussed in a study developed by Ljupco and Andrijana [39] in the Republic of North Macedonia. The youth generation, specifically Gen Y, was studied in the research of Williams and Turnbull [41] who presented the skills and reflexive knowledge like a path to the sustainable point of development of this generation. Molloy and 
Johnson [42] approached the topic of managing attraction and retaining new generations at Nova Scotia municipalities. In a high-quality human resources study, concerns about education, high costs, and the "brain drain" in Africa were the focus of research by Savino et al. [43].

Human resource management needs to look forward and cannot recover the traditional model [44,45]. This current point of view was brought forward in 1982 and remains current in the new millennium. Ray and Singh [46] approached the transition between the baby boomers and Gen $\mathrm{Z}$ and the transformation of recruitment, selection, and performance. The many topics that were brought in this subsection allow for understanding the possibilities of the insertion of the youth generation, companies, and the social responsibility of citizens.

\subsection{Sustainable Human Resources and Human Resources Management}

Sustainability has been widely discussed due to global issues and environmental impact [47-49] and its applicability with the aim of accomplishing the 2030 Agenda of the United Nations. The search for adding value in social responsibility and environmental sustainability should be developed by human resources. Sustainability, applied to human resources, involves the social base of the triple bottom line (environmental, social, and economical). The job process and physical environment can influence the final results. Sadatsafavi and Walewski [50] dealt with the physical environment, discussing behavior and attitude improvement and raising the human potential of healthcare institutions. The creation of a culture to perform sustainable practices can be stimulated by managers, aiming the reflection of the professionals towards their corporative, domestic, and community environments.

There is a relationship between human resources management and sustainability. The organizations can bring their focus for this topic to achieve a sustainable way [51]. Parakandi and Behery [52] highlighted that sustainable practices and politics are more and more present inside industries' routines. The search to create a balanced life culture is also present in industries. These strategies offer productivity and the satisfaction and retention of employees. The perception of employees was reinforced and discussed by López-Fernández et al. [28]. The disruptive tools brought by industry 4.0 may be implemented as a means to educate staff while on duty, to spread sustainable practices, and to insert process control to be done by human resources. The adoption of sustainable practices requires the involvement of all staff, being led by service education, protocols, and control.

\section{Materials and Methods}

The authors made a literature search from 1 March to 2 September, 2019. The aim created by the use of this strategy was to know the interface presented by the scientific publishing, focusing on the following: human resource and sustainability; human resource and industry 4.0; human resource and corporate social responsibility; and human resource and the youth generation. The acronymous for human resource (HR) and human resource management (HRM) were also added into the search equations. From this view, the authors were able to know the contributions made by other authors and establish an analysis to create a sustainable human resource management framework with focus on youth generation. The focus on youth people was raised by the possibility of new initiatives, which are able to prepare and insert the youth population in today's society. This kind of action promotes changes that allow society to absorb the sustainability concept and insert industry 4.0 day-by-day. This type of cultural change is expected and should be supported by institutions, whatever their nature.

For research purposes, the equations searched were as follows: (Human resource OR Human resources OR HR OR HRM) AND (Disruptive OR Disrupting); (Human resource OR Human resources OR HR OR HRM) AND (Triple Bottom Line OR 3BL OR TBL OR Quadruple Bottom Line OR QBL OR 4BL OR Bottom line OR Reverse OR Waste OR (Economy AND Society) OR (Economic AND Social) OR (Economy AND Environment) OR (Economic AND Environmental)); (Human resource OR Human resources OR HR OR HRM) AND (Smart), (Human resource OR Human resources OR HR OR HRM) AND (Young OR Youth OR Generation OR World Economic Forum); (Human resource OR Human resources OR HR OR HRM) AND (Internet OR Digital OR Virtual OR Virtualization OR 
Artificial intelligence OR Big data OR 4.0 OR Machine learning OR Automation); (Human resource OR Human resources OR HR OR HRM) AND (Responsible OR Responsibility OR Responsibilities OR CSR); (Human resource OR Human resources OR HR OR HRM) AND (Technology OR Technologies OR Technological); (Human resource OR Human resources OR HR OR HRM) AND (Sustainability OR Sustainable OR CS OR MDG OR SDG OR Circular economy OR Millennium). The equations aimed to integrate human resources with the concepts involved in CSR, industry 4.0, sustainability, and the youth generation.

The literature review did not aim to restrain the years which papers were published; inclusion criteria included the choice of papers written in English, with the research terms presented as previously mentioned and which are present in the title, and with peer reviewed journals. The research included the following Science Publishers: Academy of Economic Studies (Bucharest, Romania); Allied Business Academies (London, England); Associação Nacional de Pós-Graduação e Pesquisa em Administração-ANPAD (Paraná, Brazil); Institute of Management Accountants, Inc. (New Jersey, United States of America); AOSIS Publishing (Cape Town, South Africa); Bookseller Media Ltd. (London, England); Benthan Open (Sharjah, United Arab Emirates); Bucharest Academy of Economic Studies Publishing House (Bucharest, Romania); Centre of Sociological Research (Szczecin, Poland); Društvo za Regionalne Nauke (Subotica, Serbia); Editura ASE (Bucharest, Romania); Editura Universităţii din Oradea (Bucharest, Romania); EDP Sciences-Web of Conferences (Les Ulis, France); Elsevier (Amsterdam, Netherlands); Emerald (Bingley, England); Electrotechnical and Eletronic Engineer Institute - IEEEXplore Digital Library (New Jersey, United States of America); Faculties of Medical Sciences (Belgrade, Serbia); Fundação Cesgranrio (Rio de Janeiro, Brazil); Hong Kong Bao Long Accounting and Secretarial Limited (Hong Kong Island, Hong Kong); Idea Group Publishing (Michigan, United States of America); Internext (São Paulo, Brazil); Institute of Physics—IOP—Publishing (Bristol, England); Iranian Research Institute for Information and Technology (Tehran, Iran); JSTOR (New York, United States of America); Limited Liability Company "Consulting Publishing Company_LLC CPC Business Perspectives (Sumy, Ukraine); MDPI (Basel, Switzerland); Michigan Publishing (Michigan, United States of America); Mona Campus and St. Augustine Campus (Kingston, Jamaica); National Taiwan University (Taipei, Taiwan); Omnia Science (Barcelona, Spain); Ovidius University Press (Constanta, Romania); Oxford University Press-OUP (Oxford, England); SAGE (Newcastle upon Tyne, England); Science Publishing Group (New York, United State of America); Sciendo (Warsaw, Poland); Scientific Journal Publishers Limited (Wuhan, China); Shri Ram Centre for Industrial Relations and Human Resources (Michigan, United States of America); Slovenian Academy of Management (Ljubljana, Slovenia); Singapore Institute of Management (Singapore, Singapore); Springer Nature (Berlin, Germany); Society for Personality Research (Palmerston North, New Zealand); Stefan cel Mare University of Suceava (Suceava, Romania); Taylor and Francis (Abingdon, England); TECSI Laboratório de Tecnologia e Sistemas de Informação-School of Economics, Business and Accounting of the University of Sao Paulo (São Paulo, Brazil); The David Follmer Group (Illinois, United States of America); The London School of Hygiene and Tropical Medicine and Oxford University Press (London, England); The Society of Digital Information and Wireless Communications-SDIWC (United States of America); University of Technology, Sydney - UTS ePress (Haymarket, Australia); Universidad Autónoma del Estado de México, Centro de Investigación y Estudios Avanzados de la Población (Toluca de Lerdo, Mexico); Universitas Gadjah Mada (Yogyakarta, Indonesia); Universitas Indonesia (Jawa Barat, Indonesia); University of Agricultural Sciences and Veterinary Medicine Bucharest (Bucharest, Romania); University of Zagreb, Faculty of organization and informatics (Zagreb, Croatia); Virtus (Sumy, Ukraine); Willey (New Jersey, United States of America); World Scientific Publishing Co. Pte. Ltd. (Singapore, Singapore). In total, 450 papers were found in many combinations of the search terms. Of these 450 papers, the authors identified papers that appeared in two and three search equations. The data is shown in the Results section, where we present the number of papers found, the literature support, and their profiles, for each of the search equations. An outlook is obtained by using the equations research presented, which will be discussed in the Discussion section. The findings allowed 
the elaboration of two proposals, enabling the integration between literature findings and the purposes brought by the authors of this research study.

\section{Results}

The authors of the current research study present the search results of the papers considering the pre-established search equations and create a legend for the search equations in order to present each one. Figure 2 shows the legend.

\begin{tabular}{|c|c|}
\hline (Human resource OR Human resources OR HR OR HRM) AND (Disruptive OR Disrupting) & A \\
\hline $\begin{array}{c}\text { (Human resource OR Human resources OR HR OR HRM) AND (Triple Bottom Line OR 3BL OR TBL OR Quadruple Bottom Line OR QBL } \\
\text { OR 4BL OR Bottom line OR Reverse OR Waste OR (Economy AND Society) OR (Economic AND Social) OR (Economy AND Environment) } \\
\text { OR (Economic AND Environmental)) }\end{array}$ & в \\
\hline (Human resource OR Human resources OR HR OR HRM) AND (Smart) & $\mathrm{C}$ \\
\hline (Human resource OR Human resources OR HR OR HRM) AND (Young OR Youth OR Generation OR World Economic Forum) & D \\
\hline $\begin{array}{l}\text { (Human resource OR Human resources OR HR OR HRM) AND (Internet OR Digital OR Virtual OR Virtualization OR Artificial intelligence } \\
\text { OR Big data OR 4.0 OR Machine learning OR Automation) }\end{array}$ & $\mathrm{E}$ \\
\hline (Human resource OR Human resources OR HR OR HRM) AND (Responsible OR Responsibility OR Responsibilities OR C & $\mathbf{F}$ \\
\hline (Human resource OR Human resources OR HR OR HRM) AND (Technology OR Technologies OR Technological) & G \\
\hline $\begin{array}{l}\text { (Human resource OR Human resources OR HR OR HRM) AND (Sustainability OR Sustainable OR CS OR MDG OR SDG OR Circular } \\
\text { economy OR Millennium) }\end{array}$ & $\mathrm{H}$ \\
\hline
\end{tabular}

Figure 2. Search equation legend.

Figure 3 shows the eight search equations and the number of papers found. In total, 450 papers were discovered. The results show that the biggest number of papers recovered (144 papers, $32 \%$ ) were related to the $\mathrm{H}$ search equation. The second biggest number of papers found (133 papers, 29.55\%) was related to the $\mathrm{G}$ search equation. For the $\mathrm{F}$ search equation, 86 papers were recovered. These three equations represent $80.67 \%$ of the total number of papers. The E, D, C, B, and A search equations brought respectively $54,18,8,5$ and 2 papers. In relation to the total number, these four equations represent $19.33 \%$.

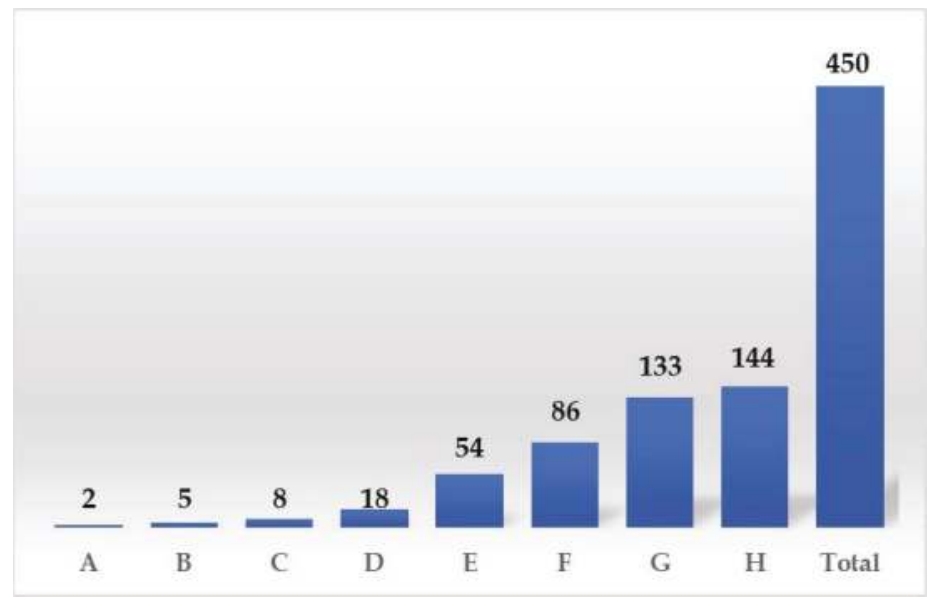

Figure 3. Literature review: number of papers recovered.

Analyzing the $\mathrm{H}$ search equation for the term "sustainability", the approach is checked, especially regarding topics related to ethics, green human resources, hospitality, healthcare, motivation, talent, 
tourism, training, young Polish companies, work environment, methodologies from the industry, and holistic look. The studies for specific regions like the Adriatic area, Central Himalayas, Maldives, Sub-Saharan Africa, and countries like Albania, Australia, Barbados, Brazil, China, India, Hong Kong, Japan, Mozambique, Tanzania, Ukraine, and the United Arab Emirates are highlighted. Figure 4 presents the $\mathrm{H}$ search equation and the number of papers recovered per year.

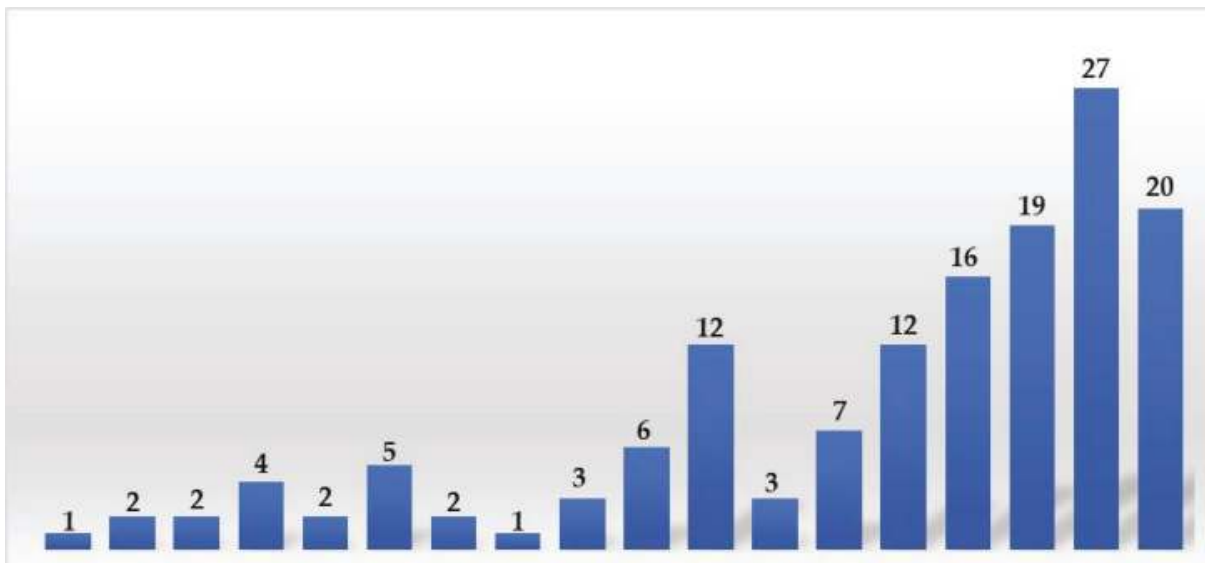

199719981999200320042005200620072010201120122013201420152016201720182019

Figure 4. The $\mathrm{H}$ search equation: number of papers recovered per year.

The G search equation highlights the digital era, educational sector, healthcare organization, hospitality, information communication and technology (ICT), mobile communication technology, and value creation. Many countries and regions were approached in the studies involving this equation: Africa, Asia, Belarus, Bangladesh, Canada, China, Croatia, India, Korea, Malaysia, The Netherlands, Great Britain, Palestine, Sri Lanka, Thailand, Spain, Hungary, Turkey, and Yugoslavia. Figure 5 presents the $\mathrm{G}$ search equation and the number of papers recovered per year.

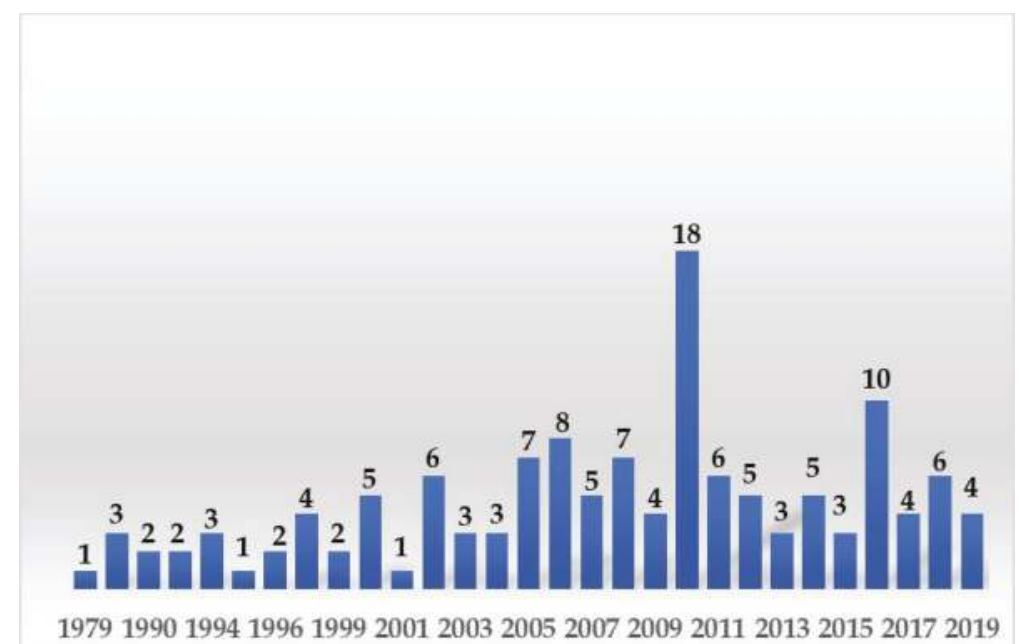

Figure 5. The G search equation: number of papers recovered per year. 
The F search equation brings the themes that involve citizenship behavior, gender, health, intellectual capital, job satisfaction, social responsibility, tourism, and hospitality. Some countries targeted in the studies include Colombia, India, Poland, and Spain. Among the regions are Europe and the European Union, Ibero-America, and Western Romania. Figure 6 presents the F search equation and the number of papers recovered per year.

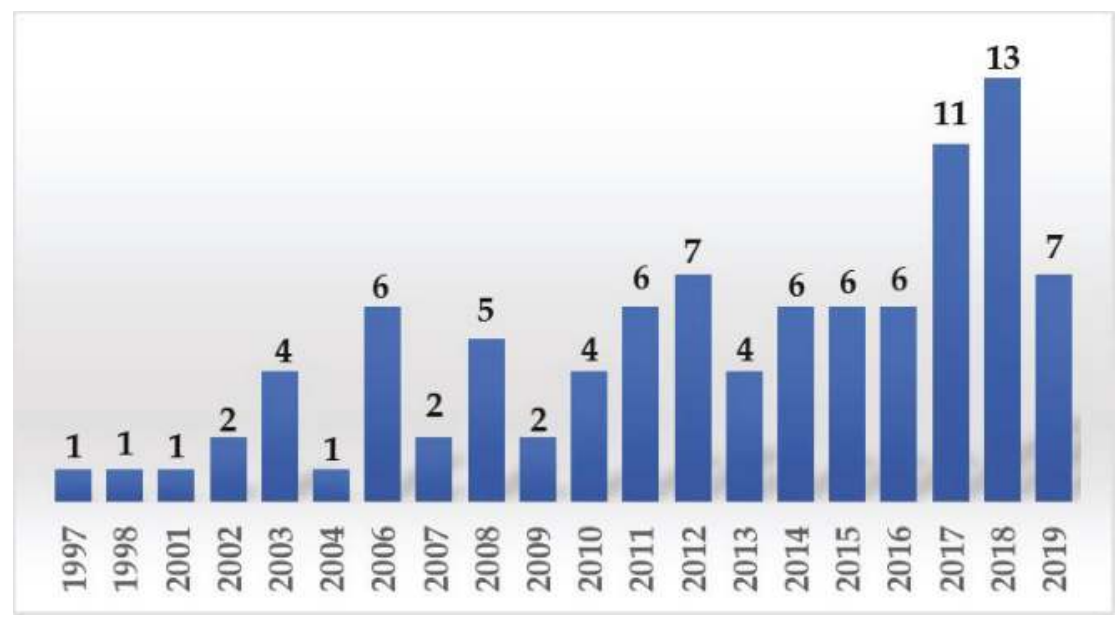

Figure 6. The F search equation: number of papers recovered per year.

Using the E search equation, the authors recovered papers related to the fourth industrial revolution. These papers approach topics like global virtual teams, virtual leadership, digital age, organizational innovation, information technology, digital transformation, and digital engagement. Figure 7 presents the E search equation and the number of papers recovered per year.

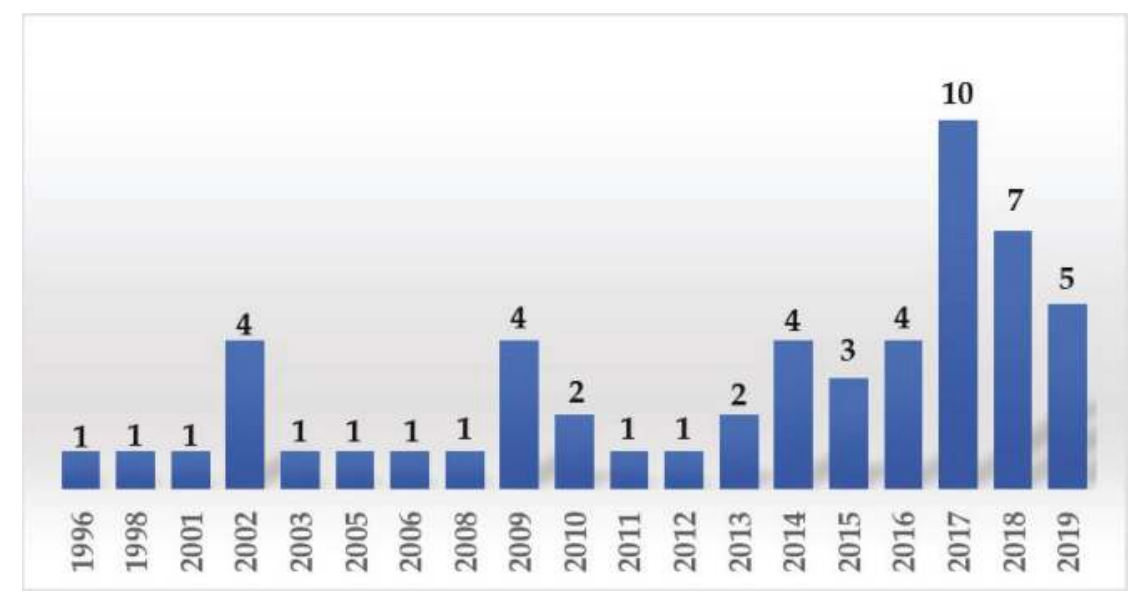

Figure 7. The E search equation: number of papers recovered per year.

For the $\mathrm{D}$ search equation, the authors found papers with the following topics including, Gen $Z$, Gen $Y$, hospital nursing, health research, green human resource management, the third sector, and 
young Polish companies. The countries and the regions were China, Nova Scotia, and the Western Azerbaijan Province. Figure 8 presents the D search equations and the number of papers recovered.

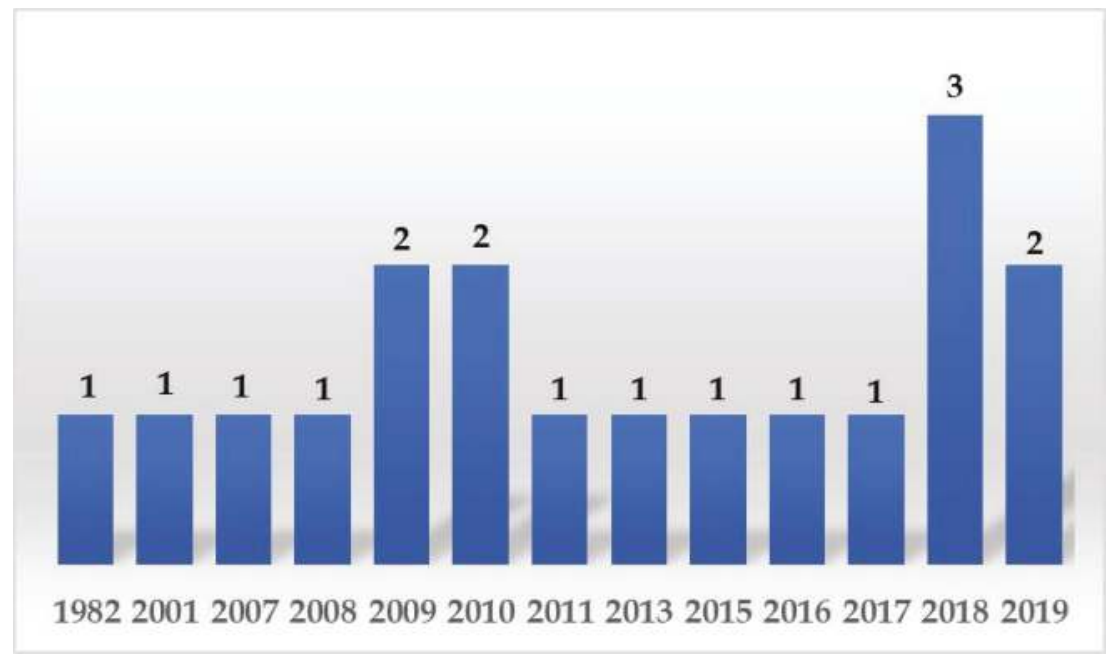

Figure 8. The D search equation: number of papers recovered per year.

The $\mathrm{C}, \mathrm{B}$, and $\mathrm{A}$ search equations present eight, five, and two papers. The $\mathrm{C}$ search equation shows innovation, information communication and technology, HR 4.0, HRM 4.0, and industry 4.0. The B search equation presented the triple bottom line, waste collection system and health impact, workaholism and productivity, waste, and work of employees. Finally, the A search equation represented by (Human resource OR Human resources OR HR OR HRM) AND (Disruptive OR Disrupting) brought papers connected among disrupting HR, disrupting technology, smart HR 4.0, and industry 4.0. Figures 9-11 show the search equations $C, B$, and $A$ and the number of papers recovered per year.

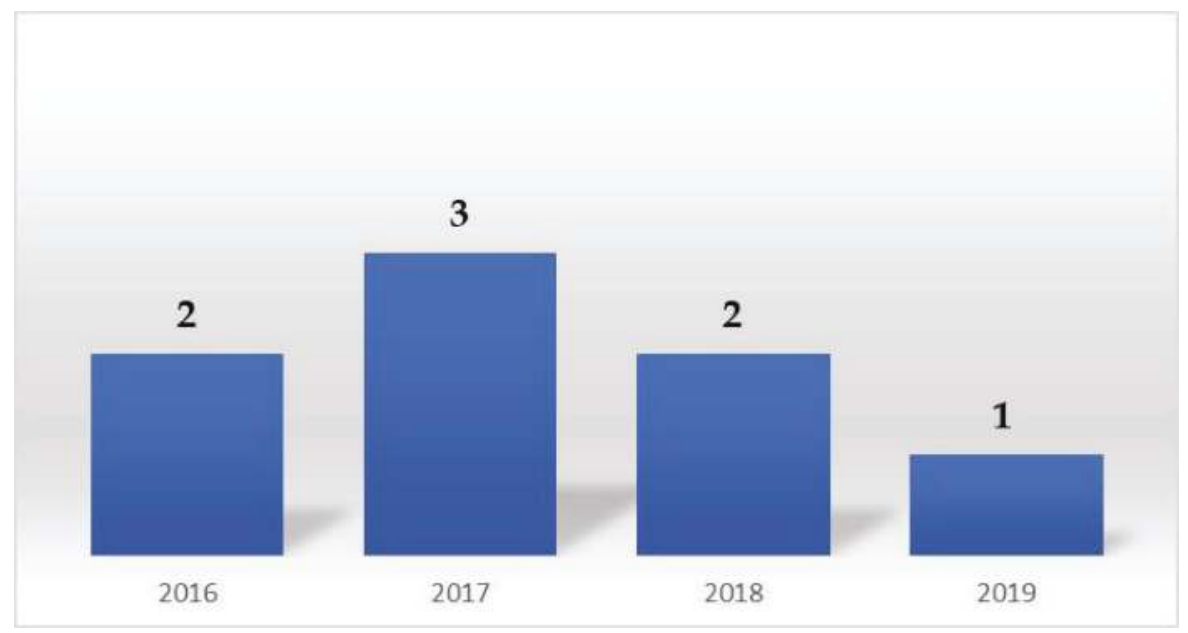

Figure 9. The $C$ search equation: number of papers found per year. 


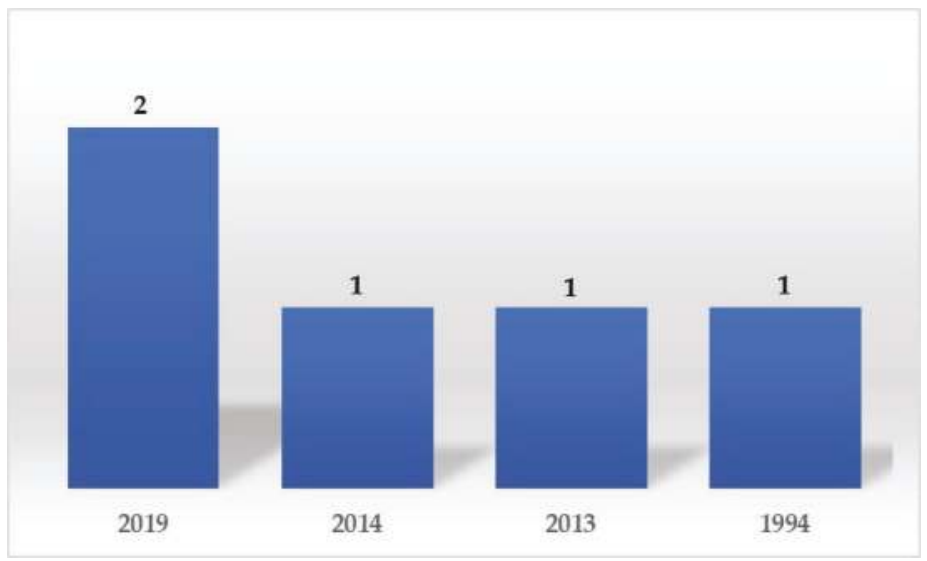

Figure 10. The B search equation: number of papers found per year.

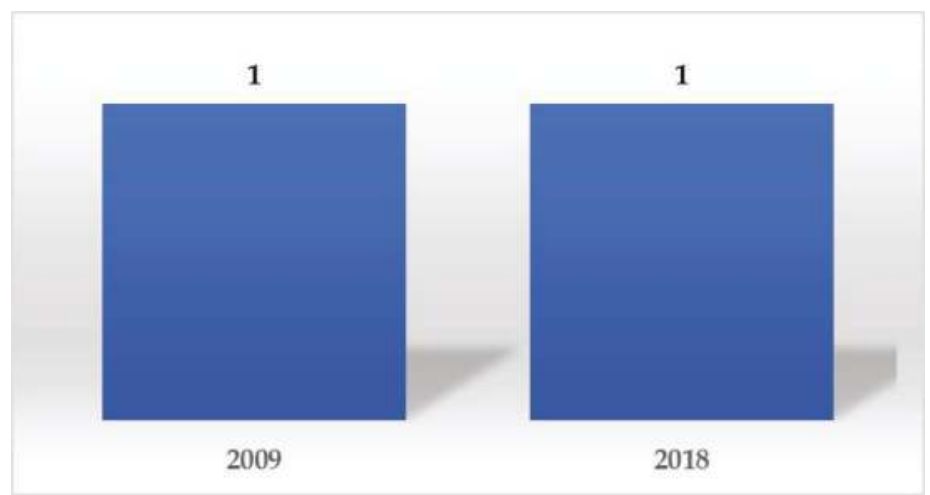

Figure 11. The A search equation: number of papers recovered per year.

The number of papers found about sustainability establishes a relation between the 2030 Agenda Goals and the growth absorption of disruptive technologies brought by the fourth industrial revolution. This presence is observed in the work environment and daily in society, becoming a healthy practice to share knowledge and search for new findings in future research. The connection with the eighth Sustainable Development Goal—“decent work and economic growth" — can be established and leads to the Discussion section, which is divided into two subsections.

The number of the papers published in 2019 in comparison to 2018 can be analyzed like a tendency for increasing the publications. An example is the $G$ search equation that represents the topic of sustainability. The number of papers recovered in 2019 was 20, in comparison to the number of papers recovered in 2018 (27 papers). Fourteen papers attend two search equations and three papers attend three search equations. They were considered in the final account of this research paper. The authors who appear the most in the 450 papers recovered were Asta Savaneviciene, Charbel José Chiappetta Jabbour, Tanya Bondarouk, and Jie Shen (three papers); Jesus Barrena-Martinez and Marco Guerci (four papers); Sugumar Mariappanadar (five papers); and Macarena Lopez-Fernandez and Pedro M. Romero-Fernandez (six papers). The five countries represented the most include the United States of America with 163 authors (21.59\%), England with 55 (7.28\%), Australia with 54 (7.15\%), Spain with 52 $(6.89 \%)$, and China with 36 (4.77\%). Figure 12 presents the papers in the ResearchGate with 100 or more citations (in total 18 papers). 


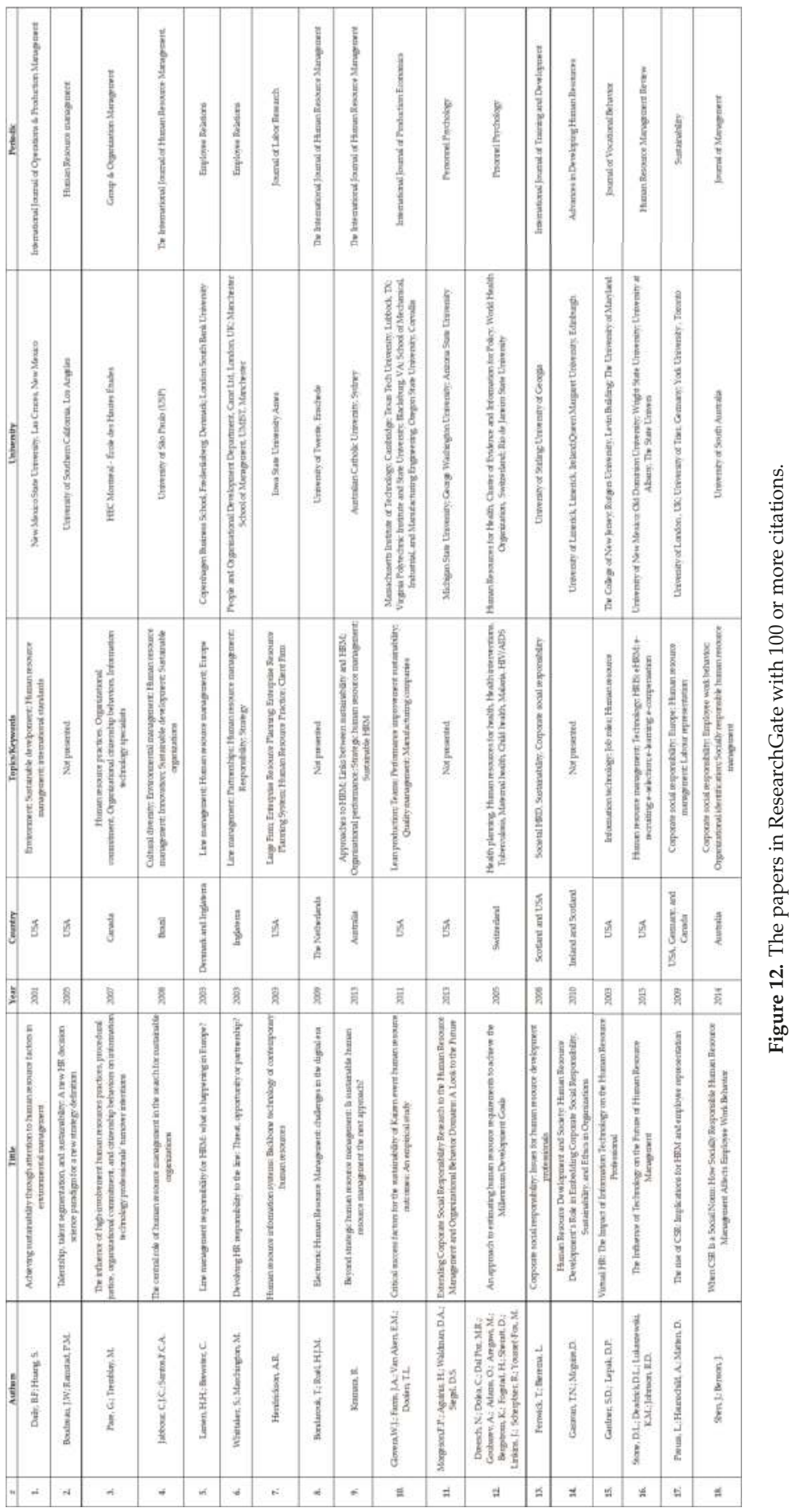




\section{Discussion}

The section shows two proposals that were developed through the literature review. The topics of hospitality [53-55], information technology [35,56,57], and health [35,50,58] were highlighted in at least three of the major search equations. The digital era and the 21 st century have been the subject of studies as well as educational programs involving the information technology field. From this perspective, the authors have established two proposals: "the role of the institution in promoting education programs for youth generation" and "the role of the institution in improving the presence of the youth generations within the job market." They are ways to help achieve sustainable practices and disruptive technology use for the insertion of youth citizens into the job market.

\subsection{The First Proposal - The Role of the Institution in Promoting Educational Programs for the Youth Generation}

Apart from providing sustainable business practice, the role of institutions is to bring about actions related to CSR. Rosolen and Maclennan [59] discussed the positive impact between sustainable human resource and CSR. The authors also reinforce human resource department for creating behaviors and an ethics culture. For Lopez-Cabrales and Valle-Cabrera, human resources practices can have sustainable structure, considering the triple bottom line [60]. One of the challenges presented by the public during the research made by the World Economic Forum [11] is related to access to first job experience. Companies usually seek experienced employees, but how does any citizen acquire experience without being given an opportunity first? This binomial first job and experience goes through the uncertainty of a future foundation. If the data show that the world is going to increase in the number of elderly people [61] and whether there are not any actions implemented in order to change this situation, in the future, the elderly population will not have quality of life. By quality of life we refer to health conditions, basic care, basic sanitation, and education.

Human resource professionals must be prepared to receive Gen Z into the job market. Part of this preparation aims to culturally involve the many generations present and implement policies aiming at the future job market [62]. Taking youth people away from criminality leads to a cultural change and a new society. This change creates an educational reverse movement and it can be implemented through CSR practices. What the authors call reverse movement is every action that goes from kids to parents, aiming a cultural change that transforms society.

The companies of many segments can create intern volunteer programs involving their own employees. These programs, while implemented in poor communities, can contribute to the youth generation and improvement of their knowledge. For example, the authors of the present research study bring three segments: information technology companies $[63,64]$, healthcare companies $[65,66]$, and hospitality companies $[67,68]$. From the structuring of an educational program, the partnerships made with communities bring the youth into a whole new universe, making them eager to partake in new activities and allowing new work and study opportunities.

The choice of these segments was established based on the following criteria: the authors of this research study analyzed the 1,674 keywords from the papers recovered and found seven sectors (in the sequence from the most frequent and the last frequent): information technology, health, tourism and hospitality, artisanal fisheries, banking, automobile industry, and textile industry. Among these sectors, three sectors appeared most frequently in the papers and were integrated into this discussion: information technology (23 times), health (15 times), and tourism and hospitality (12 times). The companies of information technology count on professionals who can help insert youth people into the digital world. These professionals hold technical knowledge in different levels, from basic to complex problem solving in the information technology area. Healthcare institutions, one of the attention areas of the authors, can combine education for health and its relationship with sicknesses and prevention. The absorption of the youth generation in the administration areas, for example, is another point. The hospitality sector can present the youth generation with the opportunities in administration, front desk, and hotel governance. Recreational tourism and hospital tourism have been highlighted worldwide lately. 
Educational programs of information technology companies can bring the youth generation to the corporative environment and allow them to access study laboratories where they can apply technology concepts of the digital world and the fourth industrial revolution. These activities also allow the fourth industrial revolution to take more and more space in the countries that still need to strengthen these concepts. Healthcare institutions can establish opportunities for partnerships with technical schools for the insertion of these youth people in the job market.

Information technology companies can work with the implementation of the computer laboratory in communities close to the institutions which insert the youth in the digital world. Some purposes, like the offer of basic computer skills courses, allow youth people to be better inserted in the job market, since professionals should have minimum previous knowledge of handling disruptive tools nowadays. Healthcare companies can offer courses aimed at those youth people who search for jobs in nutrition and stock control who may have initial contact with the job. The aim can be graduation to the university level, in area like nutrition and administration. Hospitality companies can organize the learning process for room service, restaurant service, and front desk attendance. These are some of the points that can be inserted by the hospitality companies, so that the youth generation may have the option to be inserted in the job market.

Celma et al. [69] indicated that the service sector emerged and offered more responsibility to human resources. These services include education, health, retail, transport, and hospitality. These proposals can be developed by partner companies or singly with local communities. They enable not only the insertion of these youth people, but the stimulus to study, enhancement, and search for work.

\subsection{The Second Proposal-The Role of the Institution in Improving the Presence of the Youth Generations within the Job Market}

The job market demands more and more effort so that the youth generation and people of different ages are prepared for the transformation brought by the fourth industrial revolution [70], like the insertion of disruptive technologies [71]. Raising educational level is maybe the greatest challenge for a country with continental dimensions. In addition, in some countries, there are huge crises in the sectors like environmental, social, ethical, political, and economical. Garavan and McGuire [72] presented in their study an approach with CSR, sustainability, and ethics.

During crisis periods, many times it is possible to observe corporative competitiveness situations, in which companies need to show their differences in the market by gathering value to their own business [73]. CSR brings a variety of contributions to institutions, and specifically, as shown in this paper, it creates a two-way road in which companies and youth generation are involved in the practice of the model proposed for cultural change. Barman and Das [74] referred to disruptive technologies and how the change of business models created a path to search for innovation and technologic investments. Liboni et al. [75] showed changes in the relationship between people and how they develop their relationship with business, models, technologies, and innovations. These relations highlight the importance of human resources management with industry 4.0. The authors still focus on cultural changes regarding people, the man/machine relationship and its connection with technological aspects, and the relationship between people and organizations.

The institution then promotes educational programs with the youth generation [76], which is the second proposal presented for the insertion of them in the job market. The idea is to recognize those youth people who highlighted their abilities and showed dedication during the process. This dedication is directly related to the assessments and attendance during the course. The use of this youth generation labor may determine the job field and its absorption at companies. The program is not exclusive and it should offer opportunities to all members included, with recognition of virtue as a stimulus to those who thrive in their positions.

For those who did not reach the results expected, it is possible to offer psychological support as a tool. The purpose is always to try to understand, to help, and to insert these youth people into the job market and society. In Brazil, programs like "Young Apprentice Program" [76] allow many 
possibilities in different job markets, by the insertion of the youth people and the stimulus to search for new opportunities. Ensuring that the youth generation has an opportunity after the end of the course is a way to break the vicious circle of the chain "no experience-no job." The first experience may be acquired by means of the first job or internship programs offered by the companies at the end of the course. Carvalho et al. [77] showed the importance among human, organizational, and technological aspects. The authors reinforce these elements as essential for the production process. In this case it is possible to establish the relation with this subsection.

\subsection{Sustainable Human Resource Management Framework with Focus on the Youth Generation}

The conceptual proposal aims to attend the needs of the world's youth population, as highlighted by the World Economic Forum in 2019 [11]. The search for a spot in the job market goes through subjects discussed internationally, like education, experience, and job opportunities. So, the authors aimed to structure a sustainable human resource management framework, focusing on the youth population.

The proposal presented that the youth generation should be taken as the focus of the subject and first positioned in this conceptual proposal. These youth people are involved in actions created in the Discussion section: "the role of the institution in promoting education programs for youth generation" and "the role of the institution in improving the presence of the youth generations within the job market." These proposals reflect the creation of educational programs and the insertion of the youth population in the job market. This is the reason why the industry 4.0 , the corporate social responsibility, and the sustainability are positioned right above the youth people. These concepts, inserted in the conceptual framework all the time, will facilitate the implementation of both of the actions proposed.

The social responsibility, either regarding corporative public and private sector, gathers efforts of many natures with a holistic view for the future of the youth in the job market and consequent future of nations, once it is implemented. Creating national programs that push educational and social practices allows the youth population to follow more stable paths in the future.

\section{Conclusions}

The implementation of sustainable practices and technologies brought by the fourth industrial revolution is globally highlighted [13]. The attention for the use of these concepts is important, bringing the possibility to absorb a workforce of youth people in the job market. In order to do so, the CSR concept integrates with this conceptual triple established by the authors of the current research study. The UN on their eighth SDG, call for the context analysis to be applied to the youth population [13] and The World Forum [11] also refers to this theme.

This context aims to present a sustainable human resource management framework, focusing on the youth generation, from the research questions: Can the institutions contribute with the insertion of the youth people in the society through CSR? How can the institutional management of youth sustainable human resources promote a partnership with local communities? How can institutions promote industry 4.0 educational practices for youth people, creating a partnership with local communities? After the literature review, in order to answer the research questions, two proposals were presented: "the role of the institution in promoting education programs for youth generation" and "the role of the institution in improving the presence of the youth generations within the job market."

The presence of CSR is highlighted as a facilitator for the implementation of sustainability and industry 4.0 concepts. In order to do so, institutions may plan and promote educational projects for the youth population through volunteer work of their own employees. The authors bring information technology, health, and tourism and hospitality institutions to the Discussion section, because these sectors were frequently found in the keywords. These projects bring the possibility of the youth generation to acquire and improve their knowledge and skills, as well as to arouse curiosity for new opportunities in the job market. Initiatives related to projects aiming the insertion of the youth generation in the job market may be attached to partnerships with public and private educational institutions. The donation of computers allows accessibility to information, research, and the integration 
of the youth population with technology. This integration raises knowledge and aspirations, making a cultural change possible. These outlooks can help to allow for sustainable development goal \#8 as proposed by the 2030 UN Agenda.

The companies should work on their territorial domains, as well as out of them, preparing and mobilizing their staff and taking theoretical and practical education for the youth citizens of the communities in their neighborhood. This action impacts the triple bottom line, strengthening the country for the future. In this way, the institutions can promote sustainable human resources by CSR practice [19]. This contribution presented by CSR helps for the insertion of youth people into society and reinforces the brand of institution through CSR. Rosolen and Maclennan [59] showed that CSR practices are increasing and have impact on strategic and operational levels. For this, the authors present human resource as the essential factor.

The limitation of this research study can be the use of only papers in English. Thus, future research studies can develop by considering papers in other languages and sources like books and magazines. This limitation does not affect the scope of the paper but can be a stimulus to new research studies. The authors stimulate new studies, including new proposals that work or which include other educational purposes, involving the youth population. These studies can be shared, since CSR actions create a wave of positive impact on changes for the current generation and the next ones.

Author Contributions: Conceptualization, A.S., G.D., L.F.S., and R.G.G.C.; methodology, A.S., G.D., L.F.S., and R.G.G.C.; project administration, A.S., G.D., L.F.S., and R.G.G.C.; supervision, A.S., G.D., L.F.S., and R.G.G.C.; validation, A.S., G.D., L.F.S., and R.G.G.C.; visualization, A.S., G.D., L.F.S., and R.G.G.C.; writing-original draft, A.S., G.D., L.F.S., and R.G.G.C.; writing—review and editing, A.S., G.D., L.F.S., and R.G.G.C.

Funding: This work was supported by the Coordenação de Aperfeiçoamento de Pessoal de Nível Superior-Brazil-CAPES (Finance Code 001) and the Brazilian National Council for Scientific and Technological Development-CNPq (grant number 311757/2018-9).

Acknowledgments: The authors would like to acknowledge the Health Economic and Technological Evaluation Laboratory (HETEL) of the Federal University of the State of Rio de Janeiro, where they developed this research study. This work was supported by the Coordenação de Aperfeiçoamento de Pessoal de Nível Superior-Brazil-CAPES (Finance Code 001) and the Brazilian National Council for Scientific and Technological Development-CNPq (grant number 311757/2018-9)

Conflicts of Interest: The authors declare no conflicts of interest.

\section{References}

1. De Stefano, F.; Silvia Bagdadli, S.; Camuffo, A. The HR role in corporate social responsibility and sustainability: A boundary-shifting literature review. Hum. Resour. Manag. 2018, 57, 549-566. [CrossRef]

2. Kramar, R. Beyond strategic human resource management: Is sustainable human resource management the next approach? Int. J. Hum. Resour. Manag. 2014, 25, 1069-1089. [CrossRef]

3. Järlström, M.; Saru, E.; Vanhala, S. Sustainable Human Resource Management with Salience of Stakeholders: A Top Management Perspective. J. Bus. Ethics 2018, 152, 703-724. [CrossRef]

4. Longoni, A.; Cagliano, R. Human resource and customer benefits through sustainable operations. Int. J. Oper. Prod. Manag. 2016, 36, 1719-1740. [CrossRef]

5. Strohmeier, S. Smart HRM-A Delphi study on the application and consequences of the Internet of Things in Human Resource Management. Int. J. Hum. Resour. Manag. 2018, 1-30. [CrossRef]

6. Mishra, A.; Akman, I. Information Technology in Human Resource Management: An Empirical Assessment. Public Pers. Manag. 2010, 39, 271-290. [CrossRef]

7. Morgeson, F.P.; Aguinis, H.; Waldman, D.; Siegel, D. Extending corporate social responsibility research to the human resource management and organizational behavior domains: A look to the future. Pers. Psychol. 2013, 66, 805-824. [CrossRef]

8. Fuentes-Garcia, F.J.; Nuñez Tabales, J.M.; Ricardo Veroz-Herradón, R. Applicability of Corporate Social Responsibility to Human Resources Management: Perspective from Spain. J. Bus. Ethics 2008, 82, 27-44. [CrossRef]

9. Haines, V.Y.; Lafleur, G. Information technology usage and human resource roles and effectiveness. Hum. Resour. Manag. 2008, 47. [CrossRef] 
10. Al-Ruz, J.A.; Khasawneh, S. Jordanian Pre-Service Teachers' and Technology Integration: A Human Resource Development Approach. Educ. Technol. Soc. 2011, 14, 77-87.

11. World Economic Forum. Youth Perspectives. 2019. Available online: https://www.weforum.org/agenda/ archive/demographic-dividend/ (accessed on 18 June 2019).

12. Scavarda, A.; Daú, G.L.; Scavarda, L.F.; Korzenowski, A.L. A proposed healthcare supply chain management framework in the emerging economies with the sustainable lenses: The theory, the practice, and the policy. Resour. Conserv. Recycl. 2019, 141, 418-430. [CrossRef]

13. United Nations-Sustainable Development Goals. 2016. Available online: https://www.un.org/ sustainabledevelopment/sustainable-development-goals/ (accessed on 19 May 2019).

14. United Nations. Available online: https://nacoesunidas.org/unicef-um-terco-dos-jovens-do-mundo-naotem-acesso-a-internet/ (accessed on 11 July 2019).

15. Brazilian Institute of Geography and Statistics-IBGE. Pesquisa Nacional De Saneamento Básico Brasil. 2000. Available online: https://educa.ibge.gov.br/jovens/conheca-o-brasil/populacao/18318-piramide-etaria.html (accessed on 17 June 2019).

16. Mannheim, K. The problem of generations. In Essays on the Sociology of Knowledge; Mannheim, K., Ed.; Routledge: London, UK, 1952; pp. 276-322.

17. Agency Brazil-Brazilian Company of Communication. Available online: https://www.agenciabrasil.ebc. com.br/tags/acesso-internet (accessed on 11 July 2019).

18. Sivathanu, B.; Pillai, P. Smart HR 4.0-How industry 4.0 is disrupting HR. Hum. Resour. Manag. Int. Dig. 2018, 26, 7-11. [CrossRef]

19. Shen, J.; Zhang, H. Socially Responsible Human Resource Management and Employee Support for External CSR: Roles of Organizational CSR Climate and Perceived CSR Directed Toward Employees. J. Bus. Ethics 2019, 156, 875-888. [CrossRef]

20. Martin, G.; Farndale, E.; Paauwe, J.; Stiles, P.G. Corporate governance and strategic human resource management: Four archetypes and proposals for a new approach to corporate sustainability. Eur. Manag. J. 2016, 34, 22-35. [CrossRef]

21. Guerci, M.; Radaelli, G.; Siletti, E.; Cirella, S.; Rami Shani, A.B. The impact of human resource management practices and corporate sustainability on organizational ethical climates: An employee perspective. J. Bus. Ethics 2015, 126, 325-342. [CrossRef]

22. Pellegrini, C.; Rizzi, F.; Frey, M. The role of sustainable human resource practices in influencing employee behavior for corporate sustainability. Bus. Strat. Environ. 2018, 27, 1221-1232. [CrossRef]

23. Zhang, L.; Guo, X.; Lei, Z.; Lim, M.K. Social Network Analysis of Sustainable Human Resource Management from the Employee Training's Perspective. Sustainability 2019, 11, 380. [CrossRef]

24. Sharma, E.; Tewari, R. Engaging Employee Perception for Effective Corporate Social Responsibility: Role of Human Resource Professionals. Glob. Bus. Rev. 2018, 19, 111-130. [CrossRef]

25. Gond, J.-P.; Igalens, J.; Swaen, V.; El Akremi, A. The Human Resources Contribution to Responsible Leadership: An Exploration of the CSR-HR Interface. J. Bus. Ethics 2011, 98 (Suppl. 1), 115-132. [CrossRef]

26. Wilcox, T. Human resource development as an element of corporate social responsibility. Asia Pacific J. Hum. Resour. 2006, 44, 184-196. [CrossRef]

27. Daú, G.; Scavarda, A.; Scavarda, L.F.; Portugal, V.L.T. The Healthcare Sustainable Supply Chain 4.0: The Circular Economy Transition Conceptual Framework with the Corporate Social Responsibility Mirror. Sustainability 2019, 11, 3259. [CrossRef]

28. López-Fernández, M.; Romero-Fernández, P.M.; Aust, I. Socially Responsible Human Resource Management and Employee Perception: The Influence of Manager and Line Managers. Sustainability 2018, 10, 4614. [CrossRef]

29. Harris, P.R. The Impact of New Technologies on Human Resource/Management Development. Leadersh. Organ. Dev. J. 1983, 4, 1-34. [CrossRef]

30. Nessler, M. Three Ways Virtual Technologies Are Making a Difference in HR. Employ. Relat. Today 2014, 40, 47-52. [CrossRef]

31. Stone, D.L.; Deadrick, D.L.; Lukaszewski, K.M.; Johnson, R. The influence of technology on the future of human resource management. Hum. Resour. Manag. Rev. 2015, 25, 216-231. [CrossRef]

32. Ashbaugh, S.; Miranda, R. Technology for Human Resources Management: Seven Questions and Answers. Public Pers. Manag. 2002, 31, 7-20. [CrossRef] 
33. Tursunbayeva, A. Human resource technology disruptions and their implications for human resources management in healthcare organizations. BMC Health Serv. Res. 2019, 19,1-8. [CrossRef]

34. Burita, L.; Ondryhal, V. Human resources preparation for digital information processing. Int. J. Digit. Inf. Wirel. Commun. 2013, 3, 35.

35. Whysall, Z.; Owtram, M.; Brittain, S. The new talent management challenges of Industry 4.0. J. Manag. Dev. 2019, 38, 118-129. [CrossRef]

36. Yadollahzadeh, R.; Kashef, M.M.; Mohamadzadeh, H.; Hefzollesan, M. Evaluation of strategic management fields culture, capability, information and human resources of youth and sport offices of West Azerbaijan Province. Pedagog. Psychol. Med. Biol. Probl. Phys. Train. Sports 2013. [CrossRef]

37. Stankiewicz, J.; Seiler, B.; Bortnowska, H. Young people as a subject of human resources management in the third sector organizations. Management 2017, 21, 62-74. [CrossRef]

38. Bombiak, E. Green Human Resource Management as a Tool for the Sustainable Development of Enterprises: Polish Young Company Experience. Sustainability 2018, 10, 1739. [CrossRef]

39. Ljupco, E.; Andrijana, R. The Role of Human Resource Management in Retaining Talent: Empirical Analysis of youth in the Republic of North Macedonia. Dyn. Relatsh. Manag. J. 2019, 8, 29-39. [CrossRef]

40. Chaudhary, R. Can green human resource management attract young talent? An empirical analysis Evid. Based Hrm Glob. Forum Empir. Scholarsh. 2018, 6, 305-319. [CrossRef]

41. Williams, S.; Turnbull, S. Developing the Next Generation of Globally Responsible Leaders: Generation Y Perspectives and the Implications for Green HRD. Adv. Dev. Hum. Resour. 2015, 17, 504-521. [CrossRef]

42. Molloy, A.; Johnson, D. New Professionals on tap? The human resource challenges in developing a new generation of municipal and local government managers in Nova Scotia. Commonw. J. Local Gov. 2010. [CrossRef]

43. Savino, W.; Jani, I.V.; Fumane, J.; Buss, P.M.; Leal, M.C. Local generation of high-quality human resources for health research. Bull. World Health Organ. 2008, 86, 910. [CrossRef]

44. Miles, R.E.; Rosenberg, H.R. The human resources approach to management: Second-generation issues. Organ. Dyn. 1982, 10, 26-41. [CrossRef]

45. Walmsley, P. Playing the workforce generation game: Meeting the HR challenges of changing workforce expectations. Strateg. HR Rev. 2007, 6, 32-35. [CrossRef]

46. Ray, P.; Singh, M. HR Transformation for the New Generation in the Work Force. Indian J. Ind. Relat. 2016, 52, 336-349.

47. Stalcup, L.D.; Deale, C.S.; Todd, S.Y. Human Resources Practices for Environmental Sustainability in Lodging Operations. J. Hum. Resour. Hosp. Tour. 2014, 13, 389-404. [CrossRef]

48. Azevedo, B.D.; Scavarda, L.F.; Caiado, R.G.G. Urban solid waste management in developing countries from the sustainable supply chain management perspective: A case study of Brazil's largest slum. J. Clean. Prod. 2019, 233, 1377-1386. [CrossRef]

49. Magon, R.B.; Thomé, A.M.T.; Ferrer, A.L.C.; Scavarda, L.F. Sustainability and performance in operations management research. J. Clean. Prod 2018, 190, 104-117. [CrossRef]

50. Sadatsafavi, H.; Walewski, J. Corporate Sustainability: The Environmental Design and Human Resource Management Interface in Healthcare Settings. HERD Health Environ. Res. Des. J. 2013, 6, 98-118. [CrossRef]

51. Bombiak, E.; Marciniuk-Kluska, A. Socially Responsible Human Resource Management as a Concept of Fostering Sustainable Organization-Building: Experiences of Young Polish Companies. Sustainability 2019, 11, 1044. [CrossRef]

52. Parakandi, M.; Behery, M. Sustainable human resources: Examining the status of organizational work-life balance practices in the United Arab Emirates. Renew. Sustain. Energy Rev. 2016, 55, 1370-1379. [CrossRef]

53. Ahmad, R.; Scott, N. Technology innovations towards reducing hospitality human resource costs in Langkawi, Malaysia. Tour. Rev. 2019, 74, 547-562. [CrossRef]

54. Alcaraz, J.M.; Susaeta, L.; Suarez, E.; Colón, C.; Gutiérrez-Martínez, I.; Cunha, R.; Leguizamón, F.; Idrovo, S.; Weisz, N.; Correia, M.F.; et al. The human resources management contribution to social responsibility and environmental sustainability: Explorations from Ibero-America. Int. J. Hum. Resour. Manag. 2017, 1-24. [CrossRef]

55. Rok, M.; Mulej, M. CSR-based model for HRM in tourism and hospitality. Kybernetes 2014, 43, $346-362$. [CrossRef] 
56. Turulja, L.; Bajgoric, N. Information technology, knowledge management and human resource management: Investigating mutual interactions towards better organizational performance. Vine J. Inf. Knowl. Manag. Syst. 2018, 48. [CrossRef]

57. Apanasovich, N.; Alcalde-Heras, H.; Parrilli, M.D. A new approach to business innovation modes: The 'Research, Technology and Human Resource Management (RTH) model' in the ICT sector in Belarus. Eur. Plan. Stud. 2017, 25, 1976-2000. [CrossRef]

58. Howells, A.; Sauer, K.; Shanklin, C. Evaluating Human Resource and Financial Management Responsibilities of Clinical Nutrition Managers. J. Acad. Nutr. Diet. 2016, 116, 883-1891. [CrossRef] [PubMed]

59. Rosolen, T.; Maclennan, M.L.F. Strategic human resource management and corporate social responsibility: Evidence from Emerging Markets. Internext 2016, 11, 66-80. [CrossRef]

60. Lopez-Cabrales, A.; Valle-Cabrera, R. Sustainable HRM strategies and employment relationships as drivers of the triple bottom line. Hum. Resour. Manag. Rev. 2019. [CrossRef]

61. United Nations-Brazil. Available online: https://nacoesunidas.org/em-dia-internacional-onu-pede-fim-dopreconceito-e-melhores-condicoes-de-vida-para-idosos/ (accessed on 18 June 2019).

62. Lanier, K. 5 things HR professionals need to know about Generation Z: Thought leaders share their views on the HR profession and its direction for the future. Strateg. HR Rev. 2017, 16, 288-290. [CrossRef]

63. Fenech, R.; Baguant, P.; Ivanov, D. The Changing Role of Human Resource Management in an Era of Digital Transformation. J. Manag. Inf. Decis. Sci. 2019, 22, 166-175.

64. Demir, O. Digital Skills, Organizational Behavior and Transformation of Human Resources: A Review. Ecoforum 2019, 8, 1-6.

65. Pinzone, M.; Guerci, M.; Lettieri, E.; Redman, T. Progressing in the change journey towards sustainability in healthcare: The role of 'Green' HRM. J. Clean. Prod. 2016, 122, 201-211. [CrossRef]

66. Meskó, B.; Hetényi, G.; Győrffy, Z. Will artificial intelligence solve the human resource crisis in healthcare? BMC Health Serv. Res. 2018, 18, 545. [CrossRef]

67. Kokkranikal, J.; Baum, T. Human resources development and sustainability? The case of Indian tourism. Int. J. Tour. Res. 2000, 2, 403-421. [CrossRef]

68. Tesone, D.V. Development of a sustainable tourism hospitality human resources management module: A template for teaching sustainability across the curriculum. Int. J. Hosp. Manag. 2004, 23, 207-237. [CrossRef]

69. Celma, D.; Martínez-Garcia, E.; Coenders, G. Corporate Social Responsibility in Human Resource Management: An analysis of common practices and their determinants in Spain. Corp. Soc. Responsib. Environ. Manag. 2014, 21, 82-99. [CrossRef]

70. DiRomualdo, A.; El-Khoury, D.; Girimonte, F. HR in the digital age: How digital technology will change HR's organization structure, processes and roles. Strateg. HR 2018, 17, 234-242. [CrossRef]

71. Fitz-Enz, J. Disruptive technology for human resources. Employ. Relat. Today 2009, 35, 1-10. [CrossRef]

72. Garavan, T.N.; Mcguire, D. Human Resource Development and Society: Human Resource Development's Role in Embedding Corporate Social Responsibility, Sustainability, and Ethics in Organizations. Adv. Dev. 2010, 12, 487-507. [CrossRef]

73. Martínez-Garcia, E.; Sorribes, J.; Celma, D. Sustainable development through CSR in human resource management practices: The effects of the economic crisis on job quality. Corp. Soc. Responsib. Environ. Manag. 2018, 25, 441-456. [CrossRef]

74. Barman, A.; Das, K. Disruptive Technology in Human Resource Management-From the Bloggers Spectacle. Int. J. Res. Eng. Appl. Manag. 2018, 3. [CrossRef]

75. Liboni, L.B.; Cezarino, L.O.; Jabbour, C.J.C.; Oliveira, B.G.; Stefanelli, N.O. Smart industry and the pathways to HRM 4.0: Implications for SCM. Supply Chain Manag. Int. J. 2019, 124-146. [CrossRef]

76. Brazil-Law 10097. 19 December 2000. Available online: http://www.planalto.gov.br/ccivil_03/leis/110097.htm (accessed on 18 June 2019).

77. Carvalho, A.; Scavarda, L.F.; Lustosa, L.J. Implementing finite capacity production scheduling: Lessons from a practical case. Int. J. Prod. Res. 2014, 52, 1215-1230. [CrossRef]

(C) 2019 by the authors. Licensee MDPI, Basel, Switzerland. This article is an open access article distributed under the terms and conditions of the Creative Commons Attribution (CC BY) license (http://creativecommons.org/licenses/by/4.0/). 


\title{
Article
}

\section{Integration in the Organizational Environment of the Spanish National Police}

\author{
Alexandra Marcos ${ }^{1}$, María del Carmen Pérez-Llantada ${ }^{2}$ and Gabriela Topa ${ }^{1,3, *}$ \\ 1 Department of Social and Organizational Psychology, National Distance Education University UNED, \\ 28015 Madrid, Spain \\ 2 Department of Methodology of Behavioral Sciences, National Distance Education University UNED, \\ 28015 Madrid, Spain \\ 3 Faculty of Health Sciences, Universidad Politécnica y Artística del Paraguay, Asunción 1628, Paraguay \\ * Correspondence: gtopa@psi.uned.es
}

Received: 4 June 2019; Accepted: 20 August 2019; Published: 29 August 2019

\begin{abstract}
In the present study, a model of relations is tested between the dimensions of socialization, personal resources such as optimism and self-efficacy, and the resources obtained during integration into the organization such as social support or collective efficacy in the prediction of the attitudes and behaviors of the Spanish National Police. Participants were members of the Spanish National Police $(N=123)$. The findings confirm some of the hypotheses, although other findings are contrary to the predictions. The percentage of variance explained in the regression analyses varies between $48 \%$ of the variance of stress and $24 \%$ of the variance of task commitment. The findings open new lines of research for the future given the positive impact of human resource management on satisfaction and commitment at work, as well as job stress and excellent performance.
\end{abstract}

Keywords: organizational socialization; social support; personal resources; job satisfaction; occupational stress

\section{Introduction}

Police work is one of the most comprehensive public services offered to citizens, ranging from the penal and repressive area to that of welfare and humanitarianism. At present, this task also includes administrative and even civil issues, and therefore very high specialization and capacity for adaptation may be demanded of the agents. In addition, being a police officer implies "being with people in the worst moments of their lives" whether they are victims or criminals, and, in any case, being guarantors of their safety and even their integrity (Organic Law 2/1986 on Security Forces and Corps; Organic Law 10/1995, Penal Code and its subsequent amendments).

The level of alert that the police officers must maintain and the demands to which they are subjected are therefore considered high, as recent studies [1] on this same group point out. These demands can lead to a high level of occupational stress experienced by police officers, which may result in personal distress and harm for their health. The authors [1] emphasize that when the demands of the task overwhelm professionals, their resources may prove insufficient. From the approach of Positive Psychology, which postulates the ability of individuals and groups to optimize their resources, this study aims to explore the police force resources to face their daily task and whether such resources contribute to an excellent performance in police work and, at the same time, to the workers' personal well-being. 
The reason why the Spanish National Police is chosen in this study is that, among the professionals dedicated to get in touch with the public in emergencies, they are responsible for citizen security in a scenario in which the antiterrorist alert level has been raised to four (out of five) in the country since 2015 , thus concurring the conditions of the accused level of demands related to threat of death and safety for the general public and themselves, and also the long term effects of the same demands.

The research gap, which this article means to fill, is about creating a new and inexpensive path to solve stress problems in the work environment with the resources at hand, as human resources are. Additionally in this article, it is understood that social networks with its origin in human resources contribute to the sustainability of organizations.

The relationship between employees' health and well-being continues to receive empirical attention, as do business strategies aimed at promoting them [2,3], as human resources are the manpower and the most important source of effectiveness of organizations. Based on the theory of Job Demands and Resources (hereinafter JDR) of Bakker and Demerouti [4], reviewed by these same authors in 2013 [5], we propose that workers' personal and job resources influence their commitment through a positive process, and their exhaustion through a negative process, and these, in turn, influence job performance.

The models of demands and control at work, precursors of the JDR, proposed that the interactions between the levels of job demands and control produce different types of psychosocial experiences at work, such as high-stress and low-stress jobs, and active and passive jobs [6] (p. 31). The jobs in which high stress is experienced are characterized by high job demands and low control, while low stress jobs are located at the opposite end. Passive jobs are characterized by low demands and low control, whereas those with high demands and high control are called active jobs. The extension of this model with the dimension of social support proposes a buffering effect of the negative effects of high stress at work [7].

The above-mentioned models have been used as predictors of health problems, such as cardiovascular risk [7], burnout syndrome [8], and diseases of the digestive system [6] (p. 135). They have also been associated with organizational outcomes and behaviors. For example, high-stress jobs, characterized by high demands and low control, have been linked to higher levels of work harassment [9], lower workers' psychological empowerment, and lower job satisfaction [10]. Fink and Schaubroeck [11] also found that the interaction between demands, support, and control predicted symptoms of health, sick leave, organizational commitment, and satisfaction with the supervisor. Hagedoorn and Van Yperen [12], in a study carried out with 555 nurses, suggested that control at work reduced fatigue in high-demand jobs. In addition, high levels of support produced high levels of intrinsic motivation, regardless of the levels of demands and control.

Later on, Bakker et al. [4] also contemplated the impact of the job on personal well-being. This idea is based on the statements of Hobfoll [13] about the conservation and accumulation of positive resources sought by individuals. What can be indicated as a valuable resource to conserve? According to Karasek $[6,14]$, social support is the variable that develops the most potential within the possible scenarios of his Demands-Control model. Such support is one of the possible social resources that, according to Gruman and Saks [15], can be acquired through socialization. Although some authors [6] have stated that the organizational culture provides the individual with extraordinary resources [16], the influence of the organization on the demands-resources relationship, on the one hand, and workers' outcomes, on the other, have received less attention. Although some empirical studies have analyzed the influence of organizational variables such as the climate of safety and have related them to demands and resources and their influence on employees' health and commitment [17], in general, empirical research has paid little attention to the combination of predictors of different levels, as Schaufeli and Taris [18] requested. 
Socialization in the National Police is a long-term process. This process implies, firstly, a formal and intentional training in the National Police School and, secondly, in the jobs to which police members are destined during the first year of work. This training continues through regulated and formal actions and also through an informal, interpersonal process. This process allows the person to integrate progressively into the police culture. This is another reason to choose the Spanish National Police as an organization, because the emphasis made in training of the human resources begins quite early (even before the state exam) and continues throughout the whole of the police officer career. In addition, the training goes beyond just pure knowledge and is focused as well on interpersonal skills, thus reflected on the curriculum and personnel laws and regulations made to rule the corporation. Considering this explanation, we are going to declare that one of the aims of the socialization process for these professionals and the organization will integrate the anonymous applicant into the social internal network of the National Police, furthermore, taking advantage of this network to improve the results and efficacy in everyday work by counting on the significant others (from which borrowing external resources) and the social background and support from the environment. Ultimately, if the named social network is correctly assembled, the whole of the organization should work as a living being and so being sustainable, therefore being able to maintain the environmental requirements to keep employees' well-being and also to help recover those who can't achieve welfare.

In short, the present study aims to test the relations between the dimensions of socialization, personal resources-optimism, self-efficacy_and the resources obtained during integration into the organization-social support and collective efficacy—-to predict the attitudes and behaviors of National Police officers.

Based on the literature reviewed to date, in the present study, the following hypotheses are proposed.

Hypothesis 1. Organizational socialization, social support, and professional resources—optimism, self-efficacy and collective effectiveness - will predict commitment to police work. It will be tested if the level of commitment of police officers is influenced by or has variations depending on the environmental and professional resources that the participants can count on.

Hypothesis 2. Organizational socialization, social support, and professional resources-optimism, self-efficacy and collective effectiveness - will predict police agents' job stress. It will be tested if the level of stress of police officers is influenced by or has variations depending on the environmental and professional resources that the participants can count on.

Hypothesis 3. Organizational socialization, social support, and professional resources—optimism, self-efficacy and collective effectiveness - will predict police agents' job satisfaction. It will be tested if the level of satisfaction of police officers is influenced by or has variations depending on the environmental and professional resources that the participants can count on.

Hypothesis 4. Organizational socialization, social support, and professional resources-optimism, self-efficacy and collective effectiveness - will predict excellent performance in police work. It will be tested if the level of excellent task performance of police officers is influenced by or has variations depending on the environmental and professional resources that the participants can count on.

The hypotheses are displayed in Figure 1. (Please, see Figure 1). 


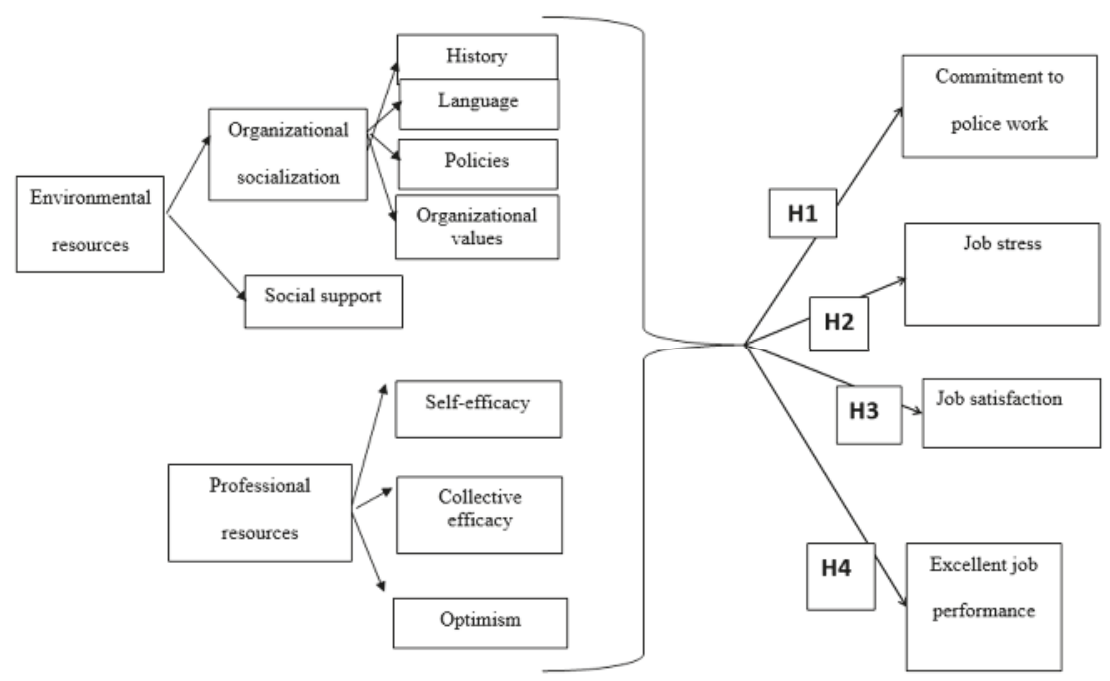

Figure 1. Study hypotheses.

\section{Method}

\subsection{Participants}

Members of the National Police (NP) participated in the study. The sample comprised 123 participants from all over Spain, whose mean age was 39.77 years $(S D=8.7)$ and of whom $91.9 \%$ were men. Concerning education, $30.9 \%$ had university studies, and $22.8 \%$ combined their work with some kind of studies. Of them, $40.7 \%$ had a family member in the NP. They worked an average of $41.87 \mathrm{~h}(S D=12.9)$ a week (ordinary) and $1.64 \mathrm{~h}(S D=6.3)$ a week (extraordinary); $32.5 \%$ worked in shifts, whereas $32.5 \%$ worked in shifts including the night shift, $22.1 \%$ in alternate shifts, and $12.2 \%$ in shifts but without the night shift. The mean job tenure in the institution was 171 months $(S D=111.2)$.

\subsection{Instruments}

The survey built for the occasion was given the name of "Occupational Health Questionnaire", and was to be taken in $20 \mathrm{~min}$ (average). As it is going to be specified, most of the questions in the survey were rated in a five-point Likert type with a closed number or answers.

\subsubsection{Socio-Demographic Data}

Participants were asked about their age, gender, province of origin, among other data (weekly hours of work, shift on which they worked, etc.).

\subsubsection{Organizational Socialization}

To evaluate this variable, we used the Organizational Socialization Scale [19], which contains 34 items, of which, in this questionnaire, we included those pertaining to the dimensions of history, language, policy, and organizational values. The reliability of the dimensions was equal to or greater than $\alpha=0.78$ in prior studies (19). In the present study, the reliability was $\alpha=0.64$ for History, $\alpha=0.74$ for Language, $\alpha=0.63$ for Policy, and $\alpha=0.68$ for Organizational Values. Examples of the items used are: "I would be a good source of information about the background of the police" (History), "I understand most of the Police acronyms and abbreviations" (Language), "I know what is important in the police to get things done" (Policy), or "The goals of the police are my goals" (Organizational Values). 


\subsubsection{Social Support}

To evaluate this variable, we used the MOS (Medical Outcomes Study) scale (Sherbourne \& Stewart, 1991) to assess the perceived social support, validated in Spanish by Bailón, Luna, Medina, and Revilla [20]. Participants are asked how often they have the support of people like those described in the six items that are rated on a five-point Likert type scale ranging from one (never) to five (always). An example item is: "How often do you have the following types of support when you need them-someone whose advice you really want". In the validation of Bailón et al. (2005), the reliability was $\alpha=0.94$, whereas in this study, it was $\alpha=0.96$.

\subsubsection{Self-Efficacy}

The scale on beliefs about personal efficacy proposed by Knight and Riggs was used to evaluate this variable [21]. It consists of six items whose reliability was $\alpha=0.64$, with the original alpha ranging between 0.81 and 0.87 in various applications made in the same study and varying the professions and organizational levels. An item example is: "When my performance is poor, it is due to my lack of capabilities."

\subsubsection{Collective Efficacy}

This variable was assessed with the scale on beliefs about the collective effectiveness of Knight and Riggs [21], which contains four items and has been previously used, showing adequate psychometric properties, with alpha values between 0.81 and 0.87 in various applications made in the same study and varying the professions and organizational levels. An item example is: "Members of this department have excellent work skills." In the questionnaire we used, reliability was $\alpha=0.70$.

\subsubsection{Optimism}

We used the LOT (Life Orientation Test) scale of Scheier and Carver (1985) in its adaptation to Spanish of the LOT-R [22], with seven items. In this study, we inverted the negative items and used the global measure of optimism that included all seven items, with adequate reliability $(\alpha=0.77)$ compared with $\alpha=0.70$ the original study. An item example is: "In difficult times, I usually expect the best".

\subsubsection{Commitment to Police Work}

To evaluate this variable, we used the Commitment Implication Scale (Cognitive Component) of Betanzos and Paz [23], which measures, through five items, the degree to which a person identifies psychologically with his/her work. Examples of items are: "Most of my interests are centered around police work" and "My personal goals have to do with my work on the police force". The reliability of the original questionnaire was $\alpha=0.84$, and in the present study, it was $\alpha=0.79$.

\subsubsection{Job Stress}

To evaluate this variable, we used the scale of Garland and Ivie [24] which includes items referring to stress-related work and burnout, with a total of eight items. Global reliability was $\alpha=0.75$ compared with $\alpha=0.87$ of the original study. Examples of items are: "I feel that I cannot go on anymore" or "I'm in a bad mood, irritable or impatient about little problems".

\subsubsection{Job Satisfaction}

We used the Brief Index of Affective Job Satisfaction proposed by Phua and Thompson [25] and adapted to Spain by Fernández and Topa [26], which contains four items and was designed to assess emotional satisfaction, as a global and positive emotional response towards the job in general. Despite its brevity, the scale has shown adequate reliability $(\alpha=0.83)$ in the original study of Phua and Thompson [25]. In this work, reliability was also acceptable $(\alpha=0.80)$. An example item is: "I enjoy my work". 


\subsubsection{Excellent Work in the Police Force}

To evaluate this variable, we used the translated version of the Task Performance Scale, which is part of the Individual Work Performance (IPW) questionnaire [27] and includes five items that evaluate a person's ability to perform the task according to indicators such as the quality of work done, planning and organization, and the ability to prioritize. The five items obtained a reliability of $\alpha=0.71$ compared to $\alpha=0.78$ of the original study. Examples of the items are: "I have managed my work well so that it was done on time", "The planning of my work has been adequate".

All the response scales were the five-point Likert-type, ranging from one (totally disagree) to five (totally agree).

\section{Procedure}

The protocol of this study was approved by the Ethics committee of the UNED. The data from this research were collected through the application of the questionnaire called the "Occupational Health Questionnaire". Participants were recruited among members subscribed to the NP-related web forums. The potential participants received an invitation email, with the link to the online survey. The invitations were sent by the web administrators of the forums, without the members of the research team having access to the email addresses of the potential participants, in order to maintain their anonymous identities.

In the online survey, prior to completion, participants received information about the guarantee of anonymity and data protection to which their replies would be submitted, in addition to a summary of the objectives of the investigation, and they were requested to give their informed consent to participate in the study.

\section{Results}

\subsection{Correlational and Descriptive Analysis}

The central tendency and dispersion measures and Pearson correlations of the study variables were calculated and are shown in Table 1 . The sample scores of the variables commitment to police work $(M=4.43, S D=1.88)$ and collective efficacy $(M=2.61, S D=0.63)$ stood out, as the former had the highest mean standard deviation, and the latter had the lowest mean and the second lowest standard deviation (See Table 1).

\subsection{Statistical Hypothesis Test}

To continue with the statistical analyses to test the hypothesis, Hierarchical Regression Analyses was used on the "outcome variables", this technique is meant to see which of the variables are involved in the results and which are not adding anything to it.

Related to Hypothesis 1, the organizational socialization (History, Language, Policy, and Organizational Values) accounted for $10 \%$ of the variance of commitment to police work. After introducing the collective efficacy and self-efficacy, the model accounted for $22 \%$ and, after adding optimism, the global model explained $24 \%$ of the variance of the commitment to police work. The variables whose contribution to the prediction of the equation was statistically significant were Policy, as part of the Organizational Socialization, and Collective Efficacy (See Table 2). 
Sustainability 2019, 11, 4706

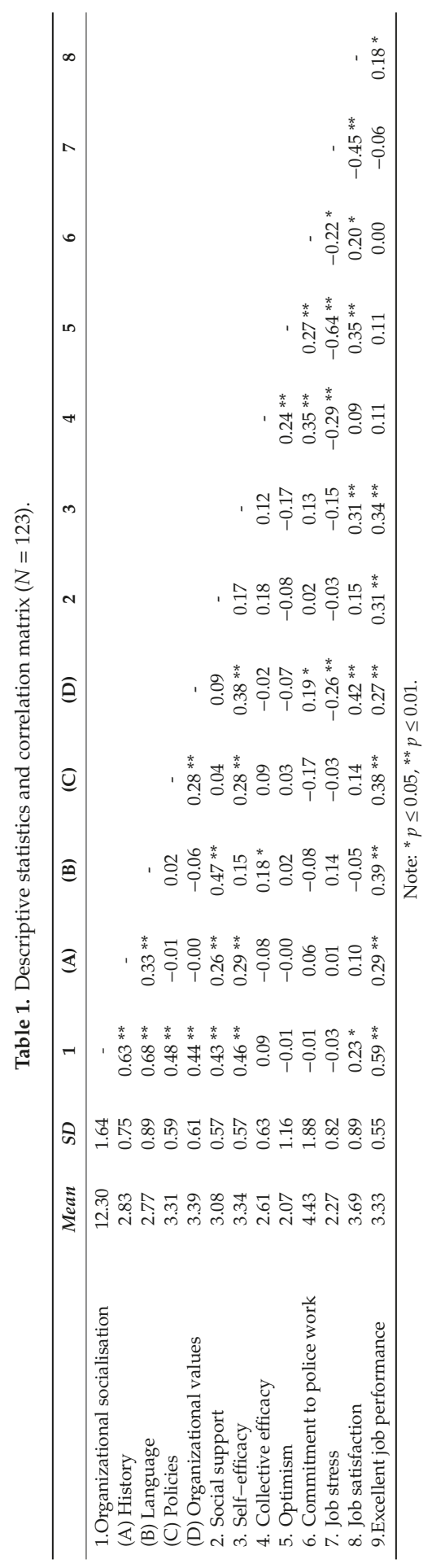


Table 2. Hierarchical regression analyses on Commitment to police work.

\begin{tabular}{cccc}
\hline & Model 1 & 2 & 3 \\
\hline Predictor variables & $\beta^{\mathrm{a}}$ & $\beta^{\mathrm{a}}$ & $\beta^{\mathrm{a}}$ \\
\hline Organizational socialization & & & \\
History & 0.08 & -0.02 & -0.01 \\
Language & -0.10 & -0.06 & -0.05 \\
Policies & $-0.24^{*}$ & $-0.24^{*}$ & $-0.23^{*}$ \\
Organizational values & $0.25^{*}$ & 0.17 & 0.18 \\
Social support & 0.04 & 0.08 & 0.06 \\
Self-efficacy & & 0.17 & 0.14 \\
Collective efficacy & & $-0.35^{* *}$ & $-0.31^{*}$ \\
Optimism & & & 0.15 \\
$\mathrm{R}^{2}$ & 0.10 & 0.22 & 0.24 \\
$\Delta \mathrm{R}^{2}$ & 0.10 & 0.12 & 0.02 \\
$\mathrm{~F}(8,114)$ & 2.63 & $4.67^{* *}$ & $4.51^{* *}$ \\
$\Delta \mathrm{F}$ & 2.63 & $8.92^{* *}$ & $2.84^{* * *}$ \\
\hline
\end{tabular}

Note: ${ }^{*} p<0.01,{ }^{* *} p<0.001,{ }^{* * *} p<0.095$ tendency value.

To test Hypothesis 2, Organizational Socialization (History, Language, Policy, and Organizational Values) was introduced. The model explained $9 \%$ of the job stress variance, which increased to $18 \%$ when adding collective efficacy and self-efficacy, and after adding optimism, the global model explained $48 \%$ of the variance of job stress. The variable whose contribution to the prediction of the equation was statistically significant was optimism (See Table 3).

Table 3. Hierarchical regression analyses on job stress.

\begin{tabular}{cccc}
\hline & Model 1 & 2 & 3 \\
\hline Predictor variables & $\beta^{\mathrm{a}}$ & $\beta^{\mathrm{a}}$ & $\beta^{\mathrm{a}}$ \\
\hline Organizational socialization & & & \\
History & -0.03 & 0.06 & -0.01 \\
Language & 0.17 & 0.13 & 0.12 \\
Policies & 0.04 & 0.04 & -0.00 \\
Organizational values & $-0.25^{*}$ & -0.19 & -0.19 \\
Social support & -0.08 & -0.12 & -0.04 \\
Self-efficacy & & -0.14 & -0.00 \\
Collective efficacy & & $0.31^{*}$ & 0.14 \\
Optimism & & & $-0.58^{* *}$ \\
$\mathrm{R}^{2}$ & 0.09 & 0.18 & 0.48 \\
$\Delta \mathrm{R}^{2}$ & 0.09 & 0.09 & 0.30 \\
$\mathrm{~F}(8,114)$ & 2.27 & $3.60^{*}$ & $13.16^{* *}$ \\
$\Delta \mathrm{F}$ & 2.27 & $6.40^{*}$ & $65.832^{* *}$ \\
\hline
\end{tabular}

Note: ${ }^{*} p<0.01,{ }^{* *} p<0.001$.

In order to test Hypothesis 3, Organizational Socialization was introduced. The model explained $21 \%$ of the variance of job satisfaction and increased to $24 \%$ with the addition of collective efficacy and self-efficacy, and reached $31 \%$ of the variance of job satisfaction when optimism was added. The variables whose contribution to the prediction of the equation was statistically significant were values within the organizational socialization and optimism (See Table 4). 
Table 4. Hierarchical regression analyses on Job satisfaction.

\begin{tabular}{cccc}
\hline & Model 1 & 2 & 3 \\
\hline Predictor variables & $\beta^{\mathrm{a}}$ & $\beta^{\mathrm{a}}$ & $\beta^{\mathrm{a}}$ \\
\hline Organizational socialization & & & \\
History & 0.11 & 0.04 & 0.08 \\
Language & -0.12 & -0.12 & -0.11 \\
Policies & 0.02 & 0.00 & 0.02 \\
Organizational values & $0.39^{* * *}$ & $0.34^{* * *}$ & $0.34^{* * *}$ \\
Social support & 0.14 & 0.15 & 0.10 \\
Self-efficacy & & 0.17 & 0.09 \\
Collective efficacy & & -0.10 & -0.02 \\
Optimism & & & $0.29^{* * *}$ \\
$\mathrm{R}^{2}$ & 0.21 & 0.24 & 0.31 \\
$\Delta \mathrm{R}^{2}$ & 0.21 & 0.03 & 0.08 \\
$\mathrm{~F}_{(8,114)}$ & $6.15^{* * *}$ & $5.06^{* *}$ & $6.52^{* *}$ \\
$\Delta \mathrm{F}$ & $6.15^{* *}$ & 2.05 & $13.04^{* *}$ \\
\hline
\end{tabular}

Note: ${ }^{* *} p<0.01,{ }^{* * *} p<0.001$

To test Hypothesis 4, Organizational Socialization was introduced. The model explained $37 \%$ of the variance of excellent performance in police work. After introducing the variables collective efficacy and self-efficacy, the model explained $38 \%$ of the variance. Finally, after adding optimism, the global model explained $39 \%$ of the variance of the criterion variable. The change of $R^{2}$ when adding the last variable was 0.01 , assuming that optimism accounts for $1 \%$ of the variance of excellent performance in police work, with a significance of $p=0.18$, that is, not significant. The model barely improved its explanatory efficiency when adding variables, and it lost the significance of $p=0.000$ that it had at the first step. Therefore, we only considered Block 1 of the model, that is, organizational socialization, which explained $37 \%$ of the variance of excellent performance (See Table 5).

Table 5. Hierarchical regression analyses on Excellent Job performance.

\begin{tabular}{cccc}
\hline & Model 1 & 2 & 3 \\
\hline Predictor variables & $\beta^{\text {a }}$ & $\beta^{\text {a }}$ & $\beta^{\text {a }}$ \\
\hline Organizational socialization & & & \\
History & 0.17 & 0.15 & 0.17 \\
Language & $0.30^{*}$ & $0.29^{*}$ & $0.29^{*}$ \\
Policies & $0.32^{* *}$ & $0.30^{* *}$ & $0.31^{* *}$ \\
Organizational values & 0.19 & 0.16 & 0.16 \\
Social support & 0.09 & 0.09 & 0.08 \\
Self-efficacy & & 0.09 & 0.06 \\
Collective efficacy & & 0.02 & 0.05 \\
Optimism & & & 0.11 \\
$\mathrm{R}^{2}$ & 0.37 & 0.38 & 0.39 \\
$\Delta \mathrm{R}^{2}$ & 0.37 & 0.01 & 0.01 \\
$\mathrm{~F}(8,114)$ & $13.82^{* *}$ & 9.95 & 9.00 \\
$\Delta \mathrm{F}$ & $13.82^{* *}$ & 0.54 & 1.86 \\
\hline \multicolumn{2}{c}{ Note: ${ }^{*} p<0.05 ;{ }^{* *} p<0.01}$. &
\end{tabular}

The variables whose contribution to the prediction of the equation was statistically significant were language and policy, both as part of organizational socialization. 


\section{Discussion}

\subsection{Summary and Interpretation of Findings}

The purpose of the present study was to analyze the socialization of National Police officers in their organization through a model in which the resources of socialization, social support, and professional resources predicted attitudes and behaviors, specifically, commitment to police work, job stress, job satisfaction, and task performance. In view of the findings, we can conclude that the goal has been met, as some of the hypotheses were confirmed and, although others have revealed findings that were contrary to our expectations, they open new horizons of future research. We can confirm the general statement according to which, when dealing with their work, National Police officers can count on a number of personal and professional resources and products of the socialization process, which were analyzed in the study. Some of them were very efficient and others less so.

Regarding the JDR model, findings are aligned with it so that personal resources contribute to a positive spiraling way upwards in which social networks improve workers wellbeing and on the contrary, the lack of social support and sense of effectiveness spirals downwards letting workers exhausted.

\subsection{Theoretical and Practical Implications}

In the case of environmental resources, socialization was an important factor in the prediction of all the proposed results: Commitment, stress, job satisfaction and excellent performance. The relationship with excellent task performance is stronger, which might imply that the higher the socialization, the National Police officers feel that their performance is better, they feel like "real" police officers. This finding could lead to a possible exploration of individuals' identification and identity and their relationship with task performance, as, in this study, social support was shown to influence the outcomes, but conjointly with other variables, and it was not a sole determinant of any particular outcome [28]. Therefore, there is the opportunity to keep on researching to find out if the role of socialization is central because is related to identity or it is training and the emphasis along the integration of the police officer on interpersonal skills, which makes socialization entwined into the Spanish National Police officers' so called DNA.

On the other hand, we found that job stress and job satisfaction have the same referents, that is, they are influenced by external and internal resources, giving rise to the idea of a parallel and inverse path of these relations [29]. This means that the National Police officers will feel stressed or satisfied with their work depending on the distribution of the same resources they take as referents, as other studies recently stated [30]. As for commitment, except that optimism is not one of the available resources when the officer feels and behaves with a higher level of commitment to police work.

Finally, it was disconcerting to find that, when organizational socialization has advanced, the role of social support is less significant for National Police employees, contrary to the predictions of our model. This finding could be interpreted in various ways, but perhaps one of them is associated with the limitation of how this variable was measured. The present study did not use a specific scale to assess the different types of social support at work, but instead, we used an instrument for assessing support in general, which comes from research in the field of health, and focuses on the existence of social support in general. In this regard, it is suggested that future research should use a support measure specifically designed for the work environment.

\subsection{Limitations and Suggestions for Future Research}

Some of the limitations of this work are due to the sample size and data collection procedure. Given the cross-sectional nature of this study, the results must be taken with caution. As it is not an experimental or longitudinal design, the studied relations cannot be considered as a successive process of correspondence among variables, or in terms of antecedents and consequences. Causal relationships cannot be established from the present findings. 
This study clears the way to the specific exploration of the different ways in which socialization becomes a procedure by which new employees acquire valuable resources that will help them to cope with their tasks better in the future. It also provides evidence, albeit preliminary, of the differential role of the different types of learning produced by socialization in the different types of indicators of personal well-being and of quality in task performance. Among other future horizons for research, our study suggests the possibility that organizational culture, specifically power distance orientation and perceived status could also influence employees' outcomes [31].

It is interesting to bring to the reader's attention that police organizations are mostly composed by males, which could be a variable to study in the future, even considering partial subcultural references that can influence the socialization process.

\subsection{Conclusions of the Findings}

Finally, to sum up, the present study provides initial evidence on the impact of Human resource management on satisfaction and commitment at work, as well as job stress and excellent performance, following the suggestion of other recent studies [32]. For investigation and daily work, it will mean that the importance of creating a social network to support employees' needs is capital. Furthermore, socialization is a landmark when the intention of the organization is to integrate a member and improve their efficiency. The reason for it is that the single employee has its resources amplified by counting on the "significant others" in the work environment; thus integration and sustainability in organizations would be possible and profitable, and investing in social training, an interesting new horizon for corporations. In fact, the idea of sustainable organizations as the ones providing resources beyond the classic and entering in psychological domains is feasible [33].

Author Contributions: Conceptualization, A.M. and G.T.; Data curation, M.d.C.P.-L.; Methodology, M.d.C.P.-L.; Project administration, A.M. and G.T.; Visualization, M.d.C.P.-L.; Writing-original draft, A.M. and G.T.; Writing-review and editing, A.M. and G.T.

Funding: This research did not receive any funding.

Conflicts of Interest: The authors declare no conflict of interest.

\section{References}

1. Deschênes, A.A.; Desjardins, C.; Dussault, M. Psychosocial factors linked to the occupational psychological health of police officers: Preliminary study. Cogent Psychol. 2018, 5, 1426271. [CrossRef]

2. Manzoor, F.; Wei, L.; Bányai, T.; Nurunnabi, M.; Subhan, Q.A. An Examination of Sustainable HRM Practices on Job Performance: An Application of Training as a Moderator. Sustainability 2019, 11, 2263. [CrossRef]

3. Stankevičiūtè, Ž.; Savanevičienè, A. Designing sustainable HRM: The core characteristics of emerging field. Sustainability 2018, 10, 4798. [CrossRef]

4. Bakker, A.B.; Demerouti, E. The Job Demand Resources Model: A state of the art. J. Manag. Psychol. 2007, 22, 309-328. [CrossRef]

5. Bakker, A.B.; Demerouti, E. Teoría de las demandas y recursos laborales [Job Demand Resources Model]. J. Work Organ. Psychol. 2013, 29, 107-115.

6. Karasek, R.A.; Theorell, T. Healthy Work: Stress, Productivity and the Reconstruction of Working Life; Basic Books: Nueva York, NY, USA, 1990.

7. Johnson, J.V.; Hall, E.M. Job strain, work place social support and cardiovascular disease: A cross-sectional study of a random sample of the Swedish working population. Am. J. Public Health 1988, 78, 1336-1342. [CrossRef] [PubMed]

8. Landsbergis, P.A. Occupational stress among health care workers: A test of the job demands-control model. J. Organ. Behav. 1988, 9, 217-239. [CrossRef] 
9. Baillien, E.; De Cuyper, N.; De Witte, H. Job autonomy and workload as antecedents of workplace bullying: A two-wave test of Karasek's Job Demand Control Model for targets and perpetrators. J. Occup. Organ. Psychol. 2010, 84, 191-208. [CrossRef]

10. Finegan, J.; Laschinger, H.K.; Shamian, J. Promoting Nurses' Health: Effect of Empowerment on Job Strain and Work Satisfaction. Nurs. Econ. 2001, 19, 42-52.

11. Fink, L.S.; Schaubroeck, J. Facilitating and inhibiting effects of Job Control and Social Support on Stress Outcomes and Role Behavior: A Contingency Model. J. Organ. Behav. 1998, 19, 167-195.

12. Hagedoorn, M.; Van Yperen, N.W. Do high Job Demands increase Intrinsic Motivation or Fatigue or both? The Role of Job Control and Job Social Support. Acad. Manag. J. 2003, 46, 339-348.

13. Hobfoll, S.E. Stress, Culture, and Community; Plenum: New York, NY, USA, 1998.

14. Karasek, R.A. Job demands, job decision latitude and mental strain: Implications for job redesign. Adm. Sci. Q. 1979, 24, 285-308. [CrossRef]

15. Gruman, J.A.; Saks, A.M. Organizational socialization and positive organizational behaviour: Implications for theory, research and practice. Can. J. Adm. Sci. 2010, 28, 14-26.

16. Peters, L.; Waterman, R.H. Search for Excellence; Harper \& Row: New York, NY, USA, 1982.

17. Bakker, A.B.; Dollard, M.F. Psychosocial safety climate as a precursor to conductive work environments, psychological health problems and employee engagement. J. Occup. Organ. Psychol. 2010, 83, 579-599.

18. Schaufeli, W.B.; Taris, T.W. A critical review of the Job Demands-Resources Model: Implications for improving work and health. In Bridging Occupational, Organizational and Public Health; Bauery, G.F., Hämmig, O., Eds.; Springer: Dordrecht, The Netherlands, 2014; en prensa.

19. Chao, G.T.; Gardner, P.D.; Klein, H.J.; O’Leary-Kelly, A.M.; Wolf, S. Organizational socialization: Its content and consequences. J. Appl. Psychol. 1994, 79, 730-743. [CrossRef]

20. Bailón, E.; Luna, J.; Medina, I.; De la Revilla, L. Validación del cuestionario MOS de apoyo social en Atención Primaria. Med. Fam. 2005, 6, 10-18.

21. Knight, P.A.; Riggs, M.L. The Impact of Perceived Group Success-Failure on Motivational Beliefs and Attitudes. J. Appl. Psychol. 1994, 79, 755-766.

22. García-Naveira, A.; Ortín, F.J.; Ruiz-Barquín, R. Optimismo y competitividad en jóvenes atletas de rendimiento. Rev. Latinoam. Psicol. 1998, 47, 124-135. [CrossRef]

23. Betanzos Díaz, N.; Paz Rodríguez, F. Análisis Psicométrico del Compromiso Organizacional como Variable Actitudinal. An. Psicol. 2008, 23, 207-215.

24. Garland, B.; Ivie, D. Stress and burnout in policing: Does military experience matter? Polic. Int. J. Police Strateg. Manag. 2011, 34, 49-66.

25. Phua, F.T.T.; Thompson, E.R. A Brief Index of Affective Job Satisfaction. Group Organ. Manag. 2012, 37, 275-307.

26. Fernández, J.J.; Topa, G. Older Workers and Affective Job Satisfaction: Gender Invariance in Spain. Front. Psychol. 2018, 9, 930. [CrossRef] [PubMed]

27. Bernaards, C.M.; Boot, C.R.; Coffeng, J.K.; De Vet, H.C.; Hildebrandt, V.H.; Koopmans, L.; Van Deer Beek, A.J. Responsiveness of the Individual Work Performance Questionnaire. BMC Public Health 2014, 14, 513-534.

28. Bregenzer, A.; Jiménez, P.; Winkler, B. Developing Sustainable Workplaces with Leadership: Feedback about Organizational Working Conditions to Support Leaders in Health-Promoting Behavior. Sustainability 2017, 9, 1944. [CrossRef]

29. Zhang, Q.; Sun, S.; Zheng, X.; Liu, W. The Role of Cynicism and Personal Traits in the Organizational Political Climate and Sustainable Creativity. Sustainability 2019, 11, 257. [CrossRef]

30. Barello, S.; Bianchi, M.; Bonetti, L.; Ghizzardi, G.; Graffigna, G.; Tolotti, A.; Pedrazzani, C.; Valcarengh, D. Burnout Precursors in Oncology Nurses: A Preliminary Cross-Sectional Study with a Systemic Organizational Analysis. Sustainability 2019, 11, 1246.

31. Zheng, X.; Li, L.; Zhang, F.; Zhu, M. The Roles of Power Distance Orientation and Perceived Insider Status in the Subordinates' Moqi with Supervisors and Sustainable Knowledge-Sharing. Sustainability 2019, 11, 1421. [CrossRef] 
32. Park, J.; Jung, D.; Lee, P. How to Make a Sustainable Manufacturing Process: A High-Commitment HRM System. Sustainability 2019, 11, 2309. [CrossRef]

33. Amaya, C.A.; Garzón, D.M.; Óscar Castellanos, D. Modelo Conceptual E Instrumental De Sostenibilidad Organizacional a Partir De La Evaluación Del Tejido Social Empresarial. Innovar Rev. De Cienc. Adm. Y Soc. 2004, 24, 82-92.

(C) 2019 by the authors. Licensee MDPI, Basel, Switzerland. This article is an open access article distributed under the terms and conditions of the Creative Commons Attribution (CC BY) license (http://creativecommons.org/licenses/by/4.0/). 


\title{
People Analytics of Semantic Web Human Resource Résumés for Sustainable Talent Acquisition
}

\author{
Sabina-Cristiana Necula * and Cătălin Strîmbei \\ Department of Accounting, Business Information Systems and Statistics, Faculty of Economics and Business \\ Administration, Alexandru Ioan Cuza University of Iasi, 700505 Iași, Romania \\ * Correspondence: sabina.necula@uaic.ro
}

Received: 31 May 2019; Accepted: 23 June 2019; Published: 27 June 2019

\begin{abstract}
The purpose of this study was to define a data science architecture for talent acquisition. The approach was to propose analytics that derive data. The originality of this paper consists in proposing an architecture to work within the process of obtaining semantically enriched data by using data science and Semantic Web technologies. We applied the proposed architecture and developed a case study-based prototype that uses analytics techniques for résumé data integrated with Linked Data technologies. We conducted a case study to identify skills by applying classification via regression, k-nearest neighbors ( $\mathrm{k}-\mathrm{NN})$, random forest, naïve Bayes, support vector machine, and decision tree algorithms to résumé data that we previously described with terms from publicly available ontologies. We labeled data from résumés using terms from existing human resource ontologies. The main contribution is the extraction of skills from résumés and the mining of data that was previously described with the Semantic Web.
\end{abstract}

Keywords: data science; talent management; Semantic Web; skills; analytics

\section{Introduction}

People analytics is fast becoming a key instrument in talent management. Human resource analytics, also called talent analytics, is the application of considerable data mining and business analytics techniques to human resources data [1,2]. A key aspect of people analytics is represented by data about people or human resources. In recent years, there has been an increasing interest in data science and analytics on data. Evidence [3-6] suggests that data science supports organizations by providing descriptive, predictive, and prescriptive analytics. Talent management could benefit from all these techniques, especially in the phase of talent acquisition. Talent acquisition is an integral part of talent management. Unfortunately, there is limited literature in human resource analytics to guide the use of machine learning algorithms [7]. Even if the skills and ability to conduct these analyses are present, it is still a challenge to gather the data necessary to turn information into results [8].

To date there has been little agreement on the necessary data for talent analytics, but there is a common agreement that skills, work experience, and education form the basis of building a résumé. Websites like LinkedIn, Indeed, Jobup, and others try to achieve better matching between job positions and résumés. LinkedIn applies, for example, machine learning to individual profiles, and extracts features like skills, seniority, and industry. Similar features are extracted from the content on the job listing. Furthermore, logistic regression models are used to rank relevant jobs for a given member using these features [9].

Firstly, we analyzed the literature existent in human resource analytics. Secondly, we studied the subject from the perspective of the Semantic Web. In the last decade, the nonparametric methods (machine learning algorithms) have gained great attention in human resource management practice field. Examples of the use of analytics in talent management are data mining (extracting and 
examining data from large databases), sentiment analysis, and controlled tests such as $\mathrm{A} / \mathrm{B}$ testing [10]. However, despite the benefits of using and implementing these technologies, little is known about how to benefit from the Semantic Web and analytics on data, specifically about how to link and derive data from people's résumés. In this study, we proposed a Semantic Web data science architecture and validated it on résumés described with the Semantic Web.

Srivastava et al. [11] provided several predictive analytics to address talent acquisition needs such as predicting joining delay, selection likelihood, and offer acceptance likelihood. Dutta et al. [12] used data mining for getting insights and text mining for talent acquisition efficiency improvement. Faliagka et al. $[13,14]$ proposed a system that implements candidate ranking, using objective criteria that are made available from the applicant's LinkedIn profile. The candidate's personality features are also extracted from their social activity using linguistic analysis. Faliagka et al. [14] used text mining of LinkedIn for creating profiles and linguistic analysis for inferring personality characteristics. Palshikar et al. [15] extracted attributes from candidate résumés while planning to combine information from multiple online and social platforms for the technical and domain skills using extraction tools. Mooney and Bunescu [16] applied knowledge extraction from unstructured text using text mining. With increased use of machine learning and natural language processing techniques, Téllez-Valero et al. [17] and other researchers tried to solve this problem of automatic extraction. With résumés, different extraction techniques are used to make the candidate selection process [18] easier and more automatic.

Previous studies [19] reported a machine learning application for the human resource data mining problem. Xie and Tang [20] used fuzzy neural networks for human resource. With respect to recruitment data mining, there are studies that use clustering and classification algorithms [20] to prove that fuzzy C-means and K-means clustering techniques are not suitable for this type of data distribution. It has been observed that trees constructed with the C4.5 algorithm (decision tree algorithm) have better accuracies. Another type of application is that of profile development [21].

Aldarra and Munoz [22] applied J48 algorithm to construct a Linked Data-based decision tree classifier to review movies. They used the SPARQL Protocol and RDF Query Language (SPARQL) queries to derive features. Mehenni and Moussaoui [23] built a regression model for predicting the most useful links that will be connected to build a multi-relational decision tree for heterogeneous databases. Sanchez-Marono et al. [24] discussed the use of decision trees learned from questionnaire data as behavioral models for the agents comparing various pre-processing methods and exploring their differences.

There is very little scientific understanding of skills from résumés. In addition, to the best of our knowledge, only a limited number of research papers comparing and evaluating the performance of different analytics algorithms with different training sample strategies using résumé data have been published.

Current implementations of Linked Data mining are promising $[18,25,26]$. However, the full potential of the Semantic Web and Linked Open Data for data mining and knowledge database discovery is still to be unlocked [27].

Now, there are some developments of human resource ontologies, such as the Human Resources Management Ontology [28]. The literature notes that the current concerns are [29]: (1) publishing job postings and applicant profiles enriched through domain ontologies/controlled vocabularies, (2) pre-selection of the candidates based on semantic matching techniques implemented in addition to these ontologies and the associated automated reasoning, and (3) delivering interview recommendations to employers or suitable open positions to job seekers based on the semantic matching of the annotated applicant profiles with the job postings [30]. Our work addresses applicant skills profiles enriched through domain ontologies and analytics in the context of data analytics Semantic Web architecture.

The major objective of this study was to investigate the possibilities that data analytics offers for skills identification. The research goal of this paper is to increase the efficiency of the analytical data processing through semantically described data and query processing. The term efficiency, in this 
paper, is understood in a broader sense: by semantically describing data, the analytical processing is improved.

Methodologically, the research presented in this article follows the design science research paradigm [31]. It uses data from a case study to define its solution objectives. The artifact, the information system architecture, is constructed based on the analogy to the human resource process, the literature, and data from the case study. To evaluate the information system architecture, a prototype is developed and its limitations are analyzed through accuracy measures.

The case study takes into consideration résumé data described with ontologies. We identified the candidates' skills by discovering relationships between the employee's skills, work experience, and education on one side, and the current position held on the other side. The structure of this paper is as follows: Section 2, Materials and Methods, presents the research methodology, Resource Description Framework (RDF) knowledge base construction, and feature engineering, Section 3 discusses the results, and Section 4 presents the discussions.

\section{Materials and Methods}

The "validation in context" is a key feature. Therefore, we first proposed a Semantic Web data science architecture and, after deciding that the proper context is résumés websites, we validated the artifact.

Our article proposes analytics in an architecture that also includes Semantic Web technologies with the specific objective of identifying and quantifying the contribution of these technologies, starting from the idea that potential relationships established on the semantic basis can contribute to the analytical model of data.

\subsection{Research Hypothesis}

Our work is guided by the following research questions: (1) Is it possible to obtain semantically improved data by using data science on Semantic Web-described data? and (2) What will the necessary architecture to support data science on Semantic Web data look like?

We hypothesized that for the process of linking résumés data a Semantic Web data science architecture can be established. This design is based on a set of architectural decisions made to discover links between Linked Data, specifically between résumés data described with ontologies terms (H1). We tested this architecture on a case study based prototype. We validated the results by analyzing the accuracies, receiver operating characteristic (ROC) and precision recall curve (PRC) values of different classification algorithms applied on the dataset and on the dataset that we enriched with features obtained by aggregating data.

We further hypothesized that using this architecture discovers links between data (H2). We derived links between data by discovering the best predictors for every skill. We validated the results by analyzing the accuracies and ROC and PRC values of the decision tree algorithm applied on the dataset that we enriched with features obtained by aggregating data.

Figure 1 presents the structure of a résumé. Each résumé contains information about work experience (responsibilities and position held), education, and additional information such as technical skills.

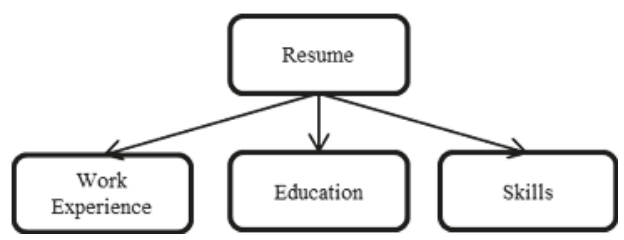

Figure 1. The structure of a résumé from Indeed résumé website. 
The main idea was to structure résumés on semantic basis. Figure 2 provides an overview of the architecture as it is currently implemented. The components of the architecture arise from the corresponding architectural decisions made for pragmatic, technical and scientific reasons.

(1) The web scraper component seeks résumé data across the Indeed résumé website [30]. It extracts data from résumés written in HTML and saves data in the comma-separated-value (CSV) format.

(2) The mapping engine integrates data published using different vocabularies from the human resource ontology published by the Ontology Engineering Group. It transforms data from CSV to RDF by using terms defined as classes, sub-classes, and properties from other RDF files that represent ontologies.

(3) The résumé RDF processor labels different features of the data mining classifier model. It uses SPARQL to query data from RDF and derives the features.

(4) The classifier models use data and derive the prediction rules.

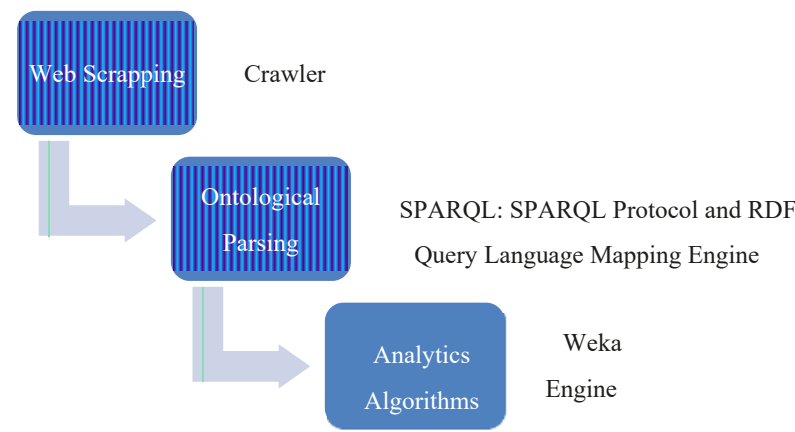

Figure 2. The architecture. Source: Our own projection.

The source code is available at https://github.com/catalinstrimbei/rdf-mining-hr [32].

\subsection{Data Acquisition}

Currently, there are no public linked datasets that contain human resource data, about competences or résumé data. Therefore, we obtained the dataset to build our classifiers by creating a web scraper on the Indeed résumé web site (https://www.indeed.com/resumes) and transformed the data into Turtle/Resource Description Framework by using OpenRefine [33]. We scraped data from Indeed, a website that contains data about people résumés publicly accessible in html online format. Résumés' acquiring must relate to a keyword to search for résumés. We intended to obtain résumés for people belonging to the same field of work. Therefore, we limited our searches to résumés related to the Java industry keyword. We used a word cloud to identify the main keywords encountered in the skills section from every résumé. This way we extracted 677 web addresses that link to résumés from the Java industry. We parsed these HTML pages and extracted information from 213 résumés. Specifically, only 213 résumés from the 677 résumés presented information structured according to Figure 2. We processed data and initially stored it in comma-separated-value (CSV).

The résumés data had to be transformed in RDF according to public ontologies found in the human resource field. Therefore, we mapped data from résumés to ontology's concepts and properties according to our own human resource ontology that extends the human resource ontology published by Ontology Engineering Group (OEG). The aim of this ontology is to represent knowledge related to the human resource hiring process. The human resource ontology developed by the Ontology Engineering Group is suitable for our purpose and is available at http://mayor2.dia.fi.upm.es/oeg-upm/ index.php/en/ontologies/99-hrmontology/ [34]. 
We used the following ontologies: JobSeeker, Occupation, Education, Competence, and Skill. The public URIs do not work and therefore we adapted the namespaces of every ontology file. We also combined the JobSeeker, Occupation, and Education ontologies into a single ontology, (e.g., JobSeeker) because the fine granularity of Education and Occupation did not present findings of interest with respect to the research scope. The focus is on work experience and skills. The knowledge base consists of 213 résumés with data described by the JobSeeker, Competence, and Skill ontologies, which are accessed using SPARQL queries to generate our set of features to train the classifiers.

Figure 3 presents the key classes and properties of the ontologies used. A job seeker has work experience, candidacy, education, competence, and skill as a subclass of competence. Central to the ontology is the WorkExperience concept and its object properties that relate the concept of Work Experience to Candidacy and JobSeeker. The Candidacy concept requires Competence, and Skill is a subclass of Competence.

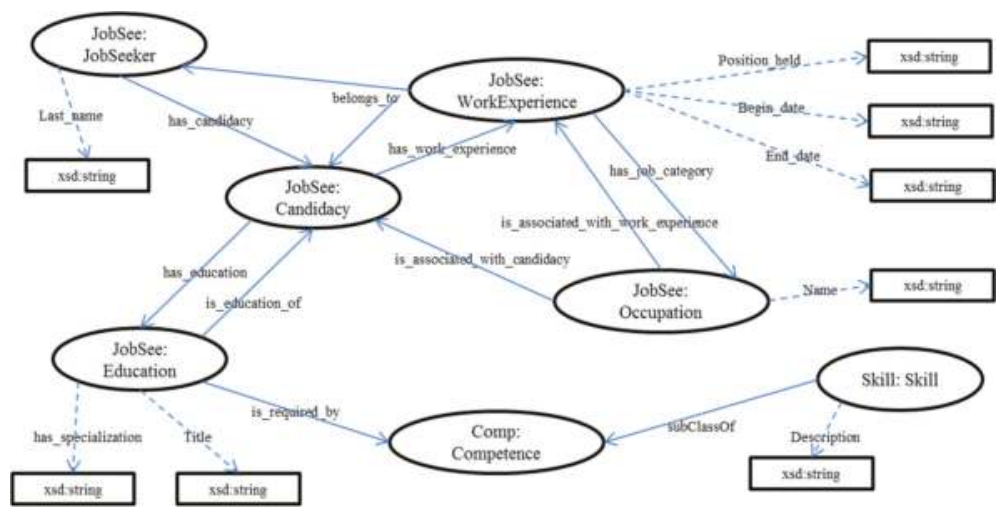

Figure 3. Key classes and properties of the ontology. Source: Our own projection.

The data properties (depicted with dashed arrows in Figure 2) allow the values of Work Experience, Education, and JobSeeker to be specified.

Every resource in our dataset is identified using a uniform resource identifier (URI). URIs have been designed with simplicity and manageability principles in mind.

The matching between a résumé and the terms from ontologies is presented in Figure 4.

The major purpose of data processing was to access data about work experience, education and skills. Besides storing raw data and transforming it to RDF, we also derived some new features, like the total years of experience, the years of experience in the current job position, and the average experience (measured in years) in every position held. These features were derived by using SPARQL. Operationalization of variables is described in Table 1.

For processing Semantic Web data, we identified two different types of features: (1) features derived with SPARQL and (2) features derived with SPARQL by aggregating data.

The information concerning skills splits between different technical skills. We restricted the skills that presented interest at SOA, NoSQL, SQL, Java, Java Web, and Java Persistence. We derived these categories by using a word cloud. Therefore, we queried the RDF data through SPARQL queries to find out which candidates have these kind of skills. 


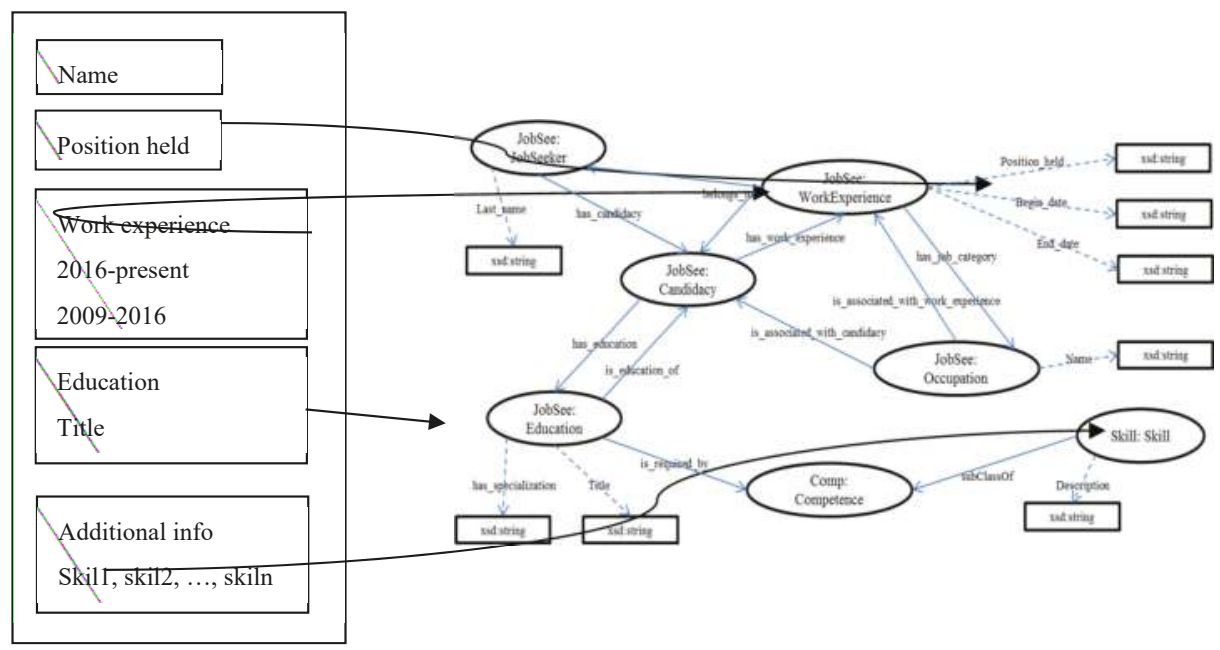

Figure 4. Indeed résumé match with ontologies concepts. Source: Our own projection.

Table 1. The operationalization of variables.

\begin{tabular}{ccc}
\hline Feature & Ideas & Details \\
\hline $\begin{array}{c}\text { Total years of } \\
\text { experience [35] }\end{array}$ & $\begin{array}{c}\text { Extensive experience of } \\
\text { activities in a domain is } \\
\text { necessary to reach very high } \\
\text { levels of performance }\end{array}$ & $\begin{array}{c}\text { "Expert performance is acquired gradually and the } \\
\text { effective improvement of performance requires the } \\
\text { opportunity to find suitable training tasks that the } \\
\text { performer can master sequentially" }\end{array}$ \\
$\begin{array}{c}\text { The years of experience } \\
\text { at the current job } \\
\text { position [36] }\end{array}$ & $\begin{array}{c}\text { Values that are too big or too } \\
\text { small are subject to further } \\
\text { analysis }\end{array}$ & $\begin{array}{c}\text { "Job satisfaction is positively correlated with mission } \\
\text { valence, commitment, person-job fit, flexible work, } \\
\text { pay, innovation, and a variety of other individual and } \\
\text { organizational factors" }\end{array}$ \\
$\begin{array}{c}\text { The average of the } \\
\text { years of experience in } \\
\text { every position held [37] }\end{array}$ & $\begin{array}{c}\text { Variety in work experiences } \\
\text { might influence forming high } \\
\text { performers }\end{array}$ & $\begin{array}{c}\text { "According to 50 senior executive search } \\
\text { professionals the study surveyed, the average } \\
\text { executive today will work in five companies; in } \\
\text { another 10 years, it might be seven". }\end{array}$ \\
\hline $\begin{array}{c}\text { The total number of } \\
\text { positions held }\end{array}$ & $\begin{array}{c}\text { The total number of positions } \\
\text { might influence forming high } \\
\text { (Position_count) [38] }\end{array}$ & $\begin{array}{c}\text { or low performers } \\
\text { "Ineffective people often stay in position for years". }\end{array}$ \\
\hline & $\begin{array}{c}\text { "Job satisfaction more strongly determines } \\
\text { orgational performance than organizational } \\
\text { performance determines job satisfaction" }\end{array}$ \\
\hline
\end{tabular}

The information related to work experience splits in different positions held and their corresponding beginning and ending dates. We queried the data through SPARQL queries to obtain the last position held, the total years of experience and the average time spent at one position. In addition, we queried the data to find out the total number of positions held.

The information concerning education splits between the education level and the corresponding specialization. We identified computer science, information technology, electronics, computer engineering, software engineering, computer applications, and other specializations that we grouped as OTHER. We queried the data to obtain the education level (master or bachelor) and the corresponding specialization field. We derived 15 features extracted from data using SPARQL queries. The next section presents the obtained results.

Features defining and SPARQL specifications are presented in Table 2.

In order to obtain the current position held, we created a SPARQL query that extracts the positions held by each job seeker. After querying the data, the provided sample consists of 120 résumés 
along with the anonymized URIs, objective (position held), work experience, education, and skills. Our resulting RDF knowledge base comprises 14,206 RDF triples.

Table 2. Features and their corresponding SELECT clauses from SPARQL queries.

\begin{tabular}{|c|c|c|}
\hline Features (Attributes) & Types/Values & SPARQL SELECT Clauses \\
\hline Job_Seeker & String & \\
\hline Education_Title (f1) & & Master's, Bachelor's, Other \\
\hline Education_Title_Spec (f2) & $\begin{array}{l}\text { Computer science, information } \\
\text { technology, electronics, computer } \\
\text { engineering, software engineering, } \\
\text { computer applications, OTHER }\end{array}$ & $\begin{array}{c}\text { Computer science, information } \\
\text { technology, electronics, computer } \\
\text { engineering, software engineering } \\
\text { Master's, Bachelor's, Other, } \\
\text { computer applications, OTHER }\end{array}$ \\
\hline Java_Programming_Skills (f3) & True, False & Java, JEE, JSE, J2SE, J2EE \\
\hline SQL_Programming_Skills (f4) & True, False & SQL, Oracle \\
\hline NOSQL_Programming_Skills (f5) & True, False & NOSQL, Mongo DB \\
\hline UML_Skills (f6) & True, False & UML \\
\hline SOA_Developer_Skills (f7) & True, False & $\begin{array}{l}\text { Web Service, SOA, REST, SOAP, } \\
\text { JAX-RS, JAX-WS }\end{array}$ \\
\hline Java_Web_Developer (f8) & True, False & Servlet, JSP, JSF, Struts \\
\hline Web_Developer_Skills (f9) & True, False & $\begin{array}{l}\text { HTML, Javascript, JQuery, } \\
\text { Angular }\end{array}$ \\
\hline DB_Developer_Skills (f10) & True, False & SQL, Oracle, MySQL, Postgres \\
\hline Java_Persistence_Skills (f11) & True, False & $\begin{array}{c}\text { JDBC, JPA, Java Persistence API, } \\
\text { Hibernate }\end{array}$ \\
\hline Years_Experience_last (f12) & Numeric & MAX(end_date)-MAX(begin_date) \\
\hline Position_count (f13) & Numeric & COUNT(Position_held) \\
\hline Years_experience_position (f14) & Numeric & $\begin{array}{l}\text { AVERAGE(MAX(end_date) } \\
\text {-MIN(begin_date), Position_count) }\end{array}$ \\
\hline Position_held (f15) & $\begin{array}{l}\text { JAVA developer, JEE developer, } \\
\text { software engineer, other developer, } \\
\text { other programmer, analyst, other } \\
\text { engineer, other }\end{array}$ & $\begin{array}{c}\text { JAVA developer, JEE developer, } \\
\text { software engineer, other developer, } \\
\text { other programmer, analyst, other } \\
\text { engineer, other }\end{array}$ \\
\hline
\end{tabular}

Source: Our own projection.

Our features contain mixed continuous (numerical) and dichotomous (categorical) types that can be handled by the data mining techniques. Figure 5 summarizes the features used in this work.

Concerning the size of the sample, we studied the learning curve (Figure 6). Learning curves are a tool to do a quick check on the models at every point in the machine learning workflow. Bias and variance are inherent properties of estimators and we usually have to select learning algorithms and hyper parameters so that both bias and variance are as low as possible. In order to study the learning curve, we applied regression on our data. For regression, the perfect scenario is when both curves converge toward an MSE of 0.

The training data is fitted very well by the estimated model. If the model fits the training data very well, it means it has low bias with respect to that set of data. Therefore, we decided that the sample size is proper. We consider that the sample size is sufficient for generalization, as replication with other populations or conditions helps to define parameters related to education, work experience and skills.

To date, various methods have been developed and introduced to mine data.

We used the k-nearest neighbors algorithm (k-NN), naive Bayes classifiers, support-vector machine, random forest, regression, and the decision trees technique. The C 4.5 classifier, a well-liked tree based 
classifier, is used to generate a decision tree from a set of training examples. Nowadays C4.5 is renamed as J48 classifier in WEKA tool, which is an open source data mining tool. The heuristic function used in this classifier is based on the concept of information entropy [39]. We used WEKA to build our classifiers. To test the algorithms we choose 10-folds cross-validation method.

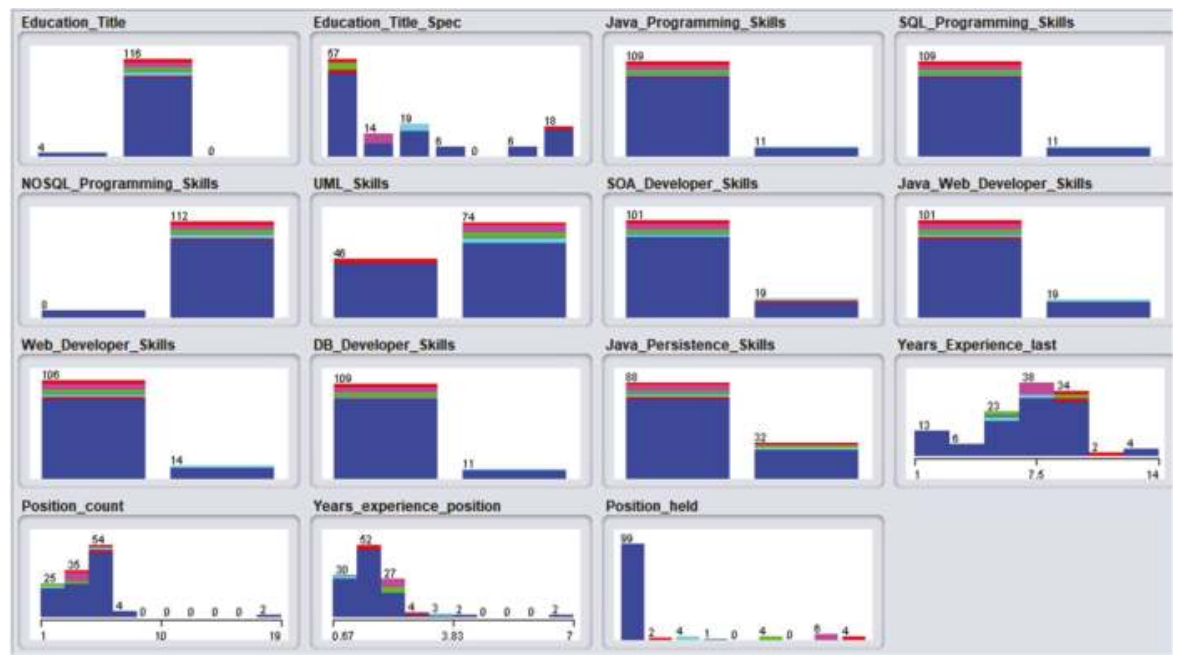

Figure 5. Visualization of attributes. Source: Weka visualization of attributes.

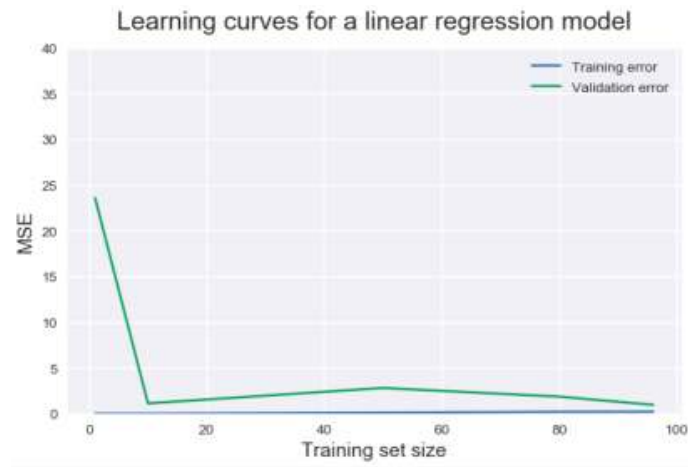

Figure 6. The learning curve. Source: Our own projection realized in Python on our dataset.

In our study, we chose the J48 algorithm to construct the decision tree. J48 implementation is widely used in research papers [40].

\section{Results}

The proposed task was to predict skills that a job seeker has.

We applied different algorithms on data. The accuracies, ROC, and PRC values for every algorithm are presented in Table 3.

In order to study the performance of the algorithms, we presented also the receiver operator characteristic (ROC) (Figure 7) and the precision recall curve (PRC) values. Davis and Goadrich [41] studied ROC and PRC. They explained that for skewed datasets the PRC values are more informative than ROC values. An optimal classifier will have ROC and PRC area values approaching 1, with 0.5 being comparable to random guessing. 
Table 3. Algorithms and their accuracies. ROC: receiver operating characteristic; PRC: precision recall curve; k-NN: k-nearest neighbor.

\begin{tabular}{cccccccc}
\hline Algorithm & $\begin{array}{c}\text { Accuracy for the } \\
\text { Dataset Containing } \\
\text { Aggregated Features }\end{array}$ & ROC & PRC & $\begin{array}{c}\text { Accuracy for the } \\
\text { Dataset not } \\
\text { Containing } \\
\text { Aggregated Features }\end{array}$ & ROC & PRC \\
\hline $\begin{array}{c}\text { Classification via } \\
\text { Regression }\end{array}$ & 0.94 & 0.836 & 0.950 & 0.86 & 0.667 & 0.888 \\
\hline $\begin{array}{c}\text { Support vector } \\
\text { machine }\end{array}$ & 0.86 & 0.661 & 0.875 & 0.85 & 0.696 & 0.887 \\
\hline k-NN & 0.95 & 0.936 & 0.983 & 0.87 & 0.907 & 0.979 \\
\hline Naïve Bayes & 0.84 & 0.784 & 0.941 & 0.76 & 0.573 & 0.863 \\
\hline Random forest & 0.98 & 0.998 & 1.000 & 0.87 & 0.904 & 0.979 \\
\hline Decision tree & 0.80 & 0.822 & 0.953 & 0.82 & 0.474 & 0.818 \\
\hline & Source: Our own analysis realized with Weka. & &
\end{tabular}

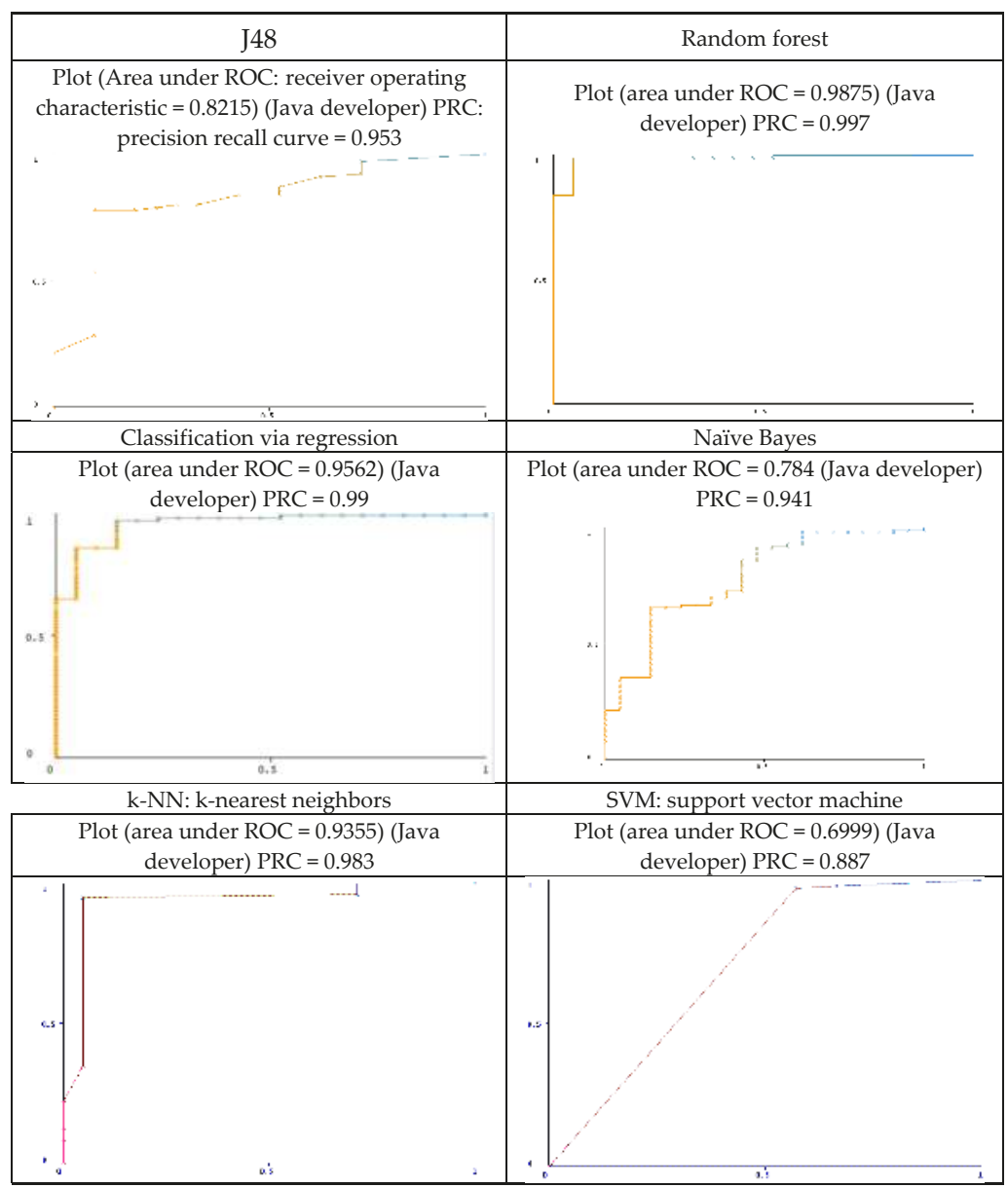

Figure 7. ROC and PRC of different algorithms for the Java-developer class (with aggregate features) Source: Our own projection realized with Weka. 
It is important to notice that the accuracy of the decision tree applied on the features that do not include aggregations is greater than the accuracy of the decision tree applied on the features that include aggregations with 0.02 . This is the only algorithm that presented this behavior of accuracies. We also mention that the ROC value is only 0.474 and the PRC is 0.818 ; therefore, we concluded that the classifiers models performed better on data enriched with features obtained through aggregations.

Java-developer class has the highest number of instances. We noticed that for Java developer class J48, k-NN and random forest have good ROC curves.

For the $\mathrm{J} 48$ algorithm, we used a pruned tree, meaning that we tried to avoid overfitting. In addition, we used binary split for nominal attributes. We applied J48 classification algorithm, by using a pruned tree method, binarySplits, on nominal attributes, a 0.25 confidence factor, and a 10 -fold cross validation method for testing the model. Table 4 presents the values for J48.

Table 4. Precision, Recall and the F-Measure for the J48.

\begin{tabular}{cccc}
\hline & Precision & Recall & F-Measure \\
\hline Java developer & 0.858 & 0.919 & 0.888 \\
\hline JEE developer & 0 & 0 & 00 \\
\hline Software engineer & 0 & 0 & 0 \\
\hline Other-Developer & 0 & 0 & 0 \\
\hline Other-Programmer & 0 & 0 & 0 \\
\hline Analyst & 0 & 0 & 0 \\
\hline Other-Engineer & 0.857 & 1.0 & 0
\end{tabular}

Note: The features of the vector are represented by all the attributes, except for Job_Seeker. The class attribute/target is Position_held Source: Our own projection realized with Weka.

The confusion matrix of the J48 classifier is presented in Table 5.

Table 5. The confusion matrix for the Position_held J48 classifier.

\begin{tabular}{cccccccccc}
\hline & $\mathbf{a}$ & $\mathbf{b}$ & $\mathbf{c}$ & $\mathbf{d}$ & $\mathbf{e}$ & $\mathbf{f}$ & $\mathbf{g}$ & $\mathbf{h}$ & Accuracy \\
\hline $\mathrm{a}$ = Java developer & 91 & 0 & 4 & 0 & 0 & 1 & 1 & 2 & $97 / 120=80.83$ \\
\hline $\mathrm{b}=$ JEE developer & 2 & 0 & 0 & 0 & 0 & 0 & 0 & 0 & \\
\hline $\mathrm{c}=$ Software engineer & 4 & 0 & 0 & 0 & 0 & 0 & 0 & 0 & \\
\hline $\mathrm{d}=$ Other-Developer & 1 & 0 & 0 & 0 & 0 & 0 & 0 & 0 & \\
\hline $\mathrm{e}=$ Other-Programmer & 0 & 0 & 0 & 0 & 0 & 0 & 0 & 0 & \\
\hline $\mathrm{f}=$ Analyst & 3 & 0 & 0 & 0 & 0 & 0 & 0 & 1 & \\
\hline $\mathrm{g}=$ Other-Engineer & 0 & 0 & 0 & 0 & 0 & 0 & 6 & 0 & \\
\hline $\mathrm{h}=$ Other & 4 & 0 & 0 & 0 & 0 & 0 & 0 & 0 &
\end{tabular}

It can be noticed that the model has a good value of prediction, so we proceeded to analyze further.

We observed that the attribute splitting the data is Years_experience_position. Moreover, the Java developers, the class that has the highest number of correctly classified instances is determined by being skilled in Java programming and SOA. Therefore, in order to determine the related skills, there is the need to analyze data for every skill.

We started to build the decision trees for every skill. Table 6 presents the accuracy details for every skill classifier. 
Table 6. Detailed accuracy metrics for every skill (ROC: receiver operating characteristic, PRC: precision recall curve).

\begin{tabular}{|c|c|c|c|c|c|}
\hline Precision & Recall & F-Measure & ROC & PRC & Class \\
\hline \multicolumn{6}{|c|}{ Java_Programming_Skills (output) $=(\mathrm{f1}, \mathrm{f2}, \mathrm{f4}, \mathrm{f5}, \mathrm{f6}, \mathrm{f7}, \mathrm{f8}, \mathrm{f9}, \mathrm{f10}, \mathrm{f11}, \mathrm{f12}, \mathrm{f13}, \mathrm{f14}, \mathrm{f15})$} \\
\hline 1.0 & 1.0 & 1.0 & 1.0 & 1.0 & True \\
\hline 1.0 & 1.0 & 1.0 & 1.0 & 1.0 & False \\
\hline \multicolumn{6}{|c|}{ SQL_Programming_Skills (output) $=(\mathrm{f} 1, \mathrm{f} 2, \mathrm{f3}, \mathrm{f} 4, \mathrm{f} 6, \mathrm{f7}, \mathrm{f8}, \mathrm{f9}, \mathrm{f10}, \mathrm{f11}, \mathrm{f12}, \mathrm{f13}, \mathrm{f14}, \mathrm{f15})$} \\
\hline 1.0 & 1.0 & 1.0 & 1.0 & 1.0 & True \\
\hline 1.0 & 1.0 & 1.0 & 1.0 & 1.0 & False \\
\hline \multicolumn{6}{|c|}{ NOSQL_Programming_Skills (output) $=(\mathrm{f} 1, \mathrm{f} 2, \mathrm{f3}, \mathrm{f} 4, \mathrm{f} 6, \mathrm{f} 7, \mathrm{f8}, \mathrm{f9}, \mathrm{f10}, \mathrm{f11}, \mathrm{f} 12, \mathrm{f} 13, \mathrm{f} 14, \mathrm{f} 15)$} \\
\hline 0.806 & 0.543 & 0.649 & 0.804 & 0.747 & True \\
\hline 0.764 & 0.919 & 0.834 & 0.804 & 0.845 & False \\
\hline \multicolumn{6}{|c|}{ SOA_Developer_Skills (output) $=(\mathrm{f} 1, \mathrm{f} 2, \mathrm{f} 3, \mathrm{f} 4, \mathrm{f5}, \mathrm{f6}, \mathrm{f} 8, \mathrm{f} 9, \mathrm{f} 10, \mathrm{f} 11, \mathrm{f} 12, \mathrm{f} 13, \mathrm{f} 14, \mathrm{f} 15)$} \\
\hline 0.962 & 1.0 & 0.981 & 0.932 & 0.976 & True \\
\hline 1.0 & 0.789 & 0.882 & 0.932 & 0.872 & False \\
\hline \multicolumn{6}{|c|}{ Java_Web_Developer_Skills (output) $=(\mathrm{f} 1, \mathrm{f2}, \mathrm{f} 3, \mathrm{f} 4, \mathrm{f} 5, \mathrm{f} 6, \mathrm{f} 7, \mathrm{f} 9, \mathrm{f} 10, \mathrm{f} 11, \mathrm{f} 12, \mathrm{f} 13, \mathrm{f} 14, \mathrm{f} 15)$} \\
\hline 0.980 & 0.960 & 0.970 & 0.954 & 0.948 & True \\
\hline 0.810 & 0.895 & 0.850 & 0.954 & 0.803 & False \\
\hline \multicolumn{6}{|c|}{ Web_Developer_Skills (output) = (f1, f2, f3, f4, f5, f6, f7, f8, f10, f11, f12, f13, f14, f15) } \\
\hline 0.972 & 1.0 & 0.986 & 0.893 & 0.972 & True \\
\hline 1.0 & 0.766 & 0.880 & 0.893 & 0.811 & False \\
\hline \multicolumn{6}{|c|}{ DB_Developer_Skills (output) = (f1, f2, f3, f4, f5, f6, f7, f8, f9, f11, f12, f13, f14, f15) } \\
\hline 1.0 & 1.0 & 1.0 & 1.0 & 1.0 & True \\
\hline 1.0 & 1.0 & 1.0 & 1.0 & 1.0 & False \\
\hline \multicolumn{6}{|c|}{ Java_Persistence_Skills (output) = (f1, f2, f3, f4, f5, f6, f7, f8, f9, f10, f12, f13, f14, f15) } \\
\hline 0.863 & 0.932 & 0.896 & 0.793 & 0.883 & True \\
\hline 0.760 & 0.594 & 0.667 & 0.793 & 0.670 & False \\
\hline
\end{tabular}

J48 predicts good models with high accuracy for every identified skill. We observe that for Java programming skills, SQL programming skills, and database developer skills the accuracy is the highest. In fact, the classifiers predicted that those who have Java programming skills have SQL programming skills and vice versa. Those that have Java programming skills have also database skills.

J48 predicted better than the baseline models for the rest of the skills. The J48 classifier built for Java programming skills identified that SQL programming skills is the node that splits instances. In addition, by running different tests, we found out that a good predictor for SQL programming skills and for database programming skills is Java programming skills.

The Java web programming skills J48 classifier (Figure 8), identified that Java programming skills, Java persistence skills and NOSQL programming skills are the features that split the data.

The NOSQL programming skills J48 classifier (Figure 9) identified that Java persistence skills, UML skills and Java web developer skills are features related to skills that split the data. 


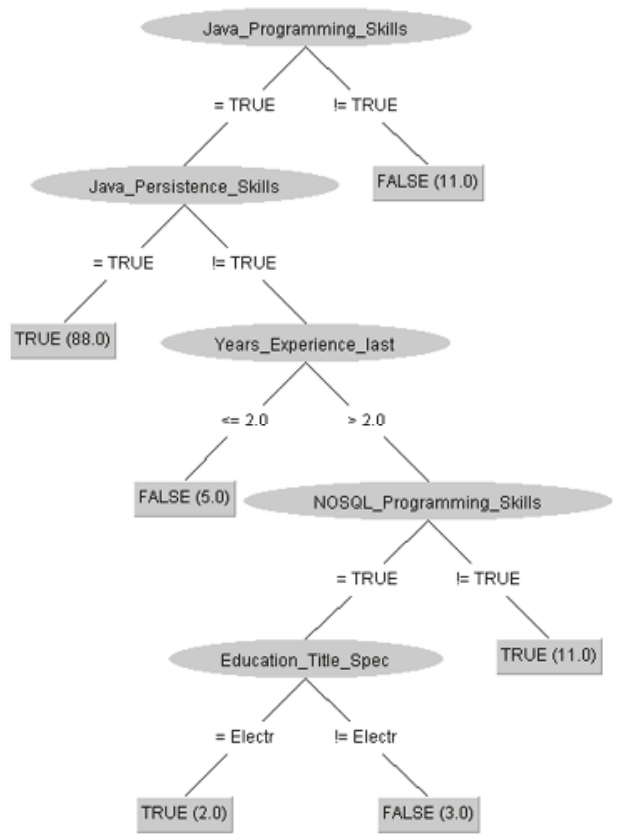

Figure 8. Java web developer skills. Source: Our own projection realized with Weka.

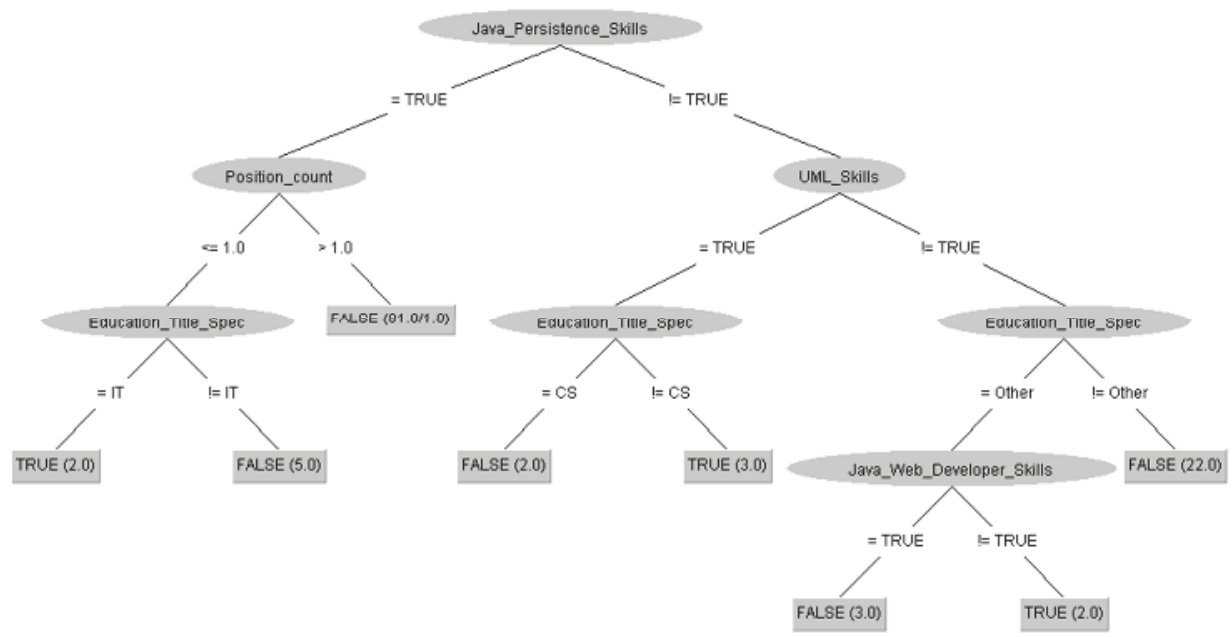

Figure 9. NOSQL programming skills decision tree. Source: Our own projection realized with Weka.

The SOA programming skills J48 classifier (Figure 10) identified that Java programming skills are related to SOA. In addition, it seems that experience at job positions that are not designed for JEE developers is important in classifying instances as having SOA programming skills. 


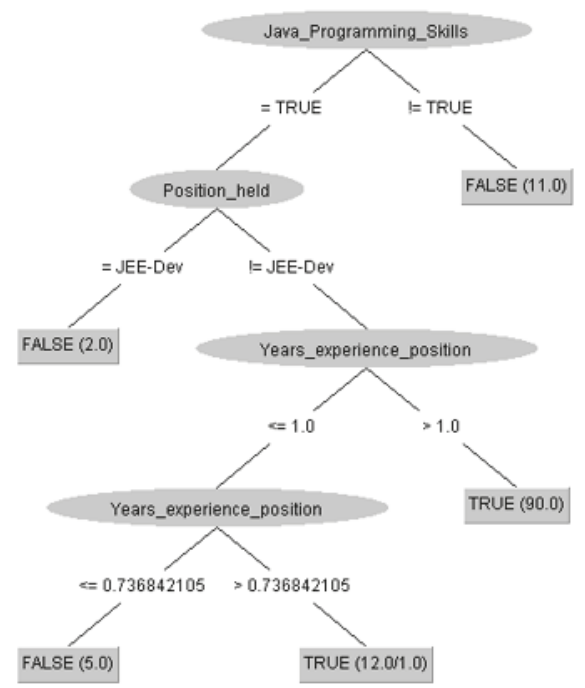

Figure 10. SOA decision tree. Source: Our own projection realized with Weka.

These findings further support the idea of using ontologies to better describe data from people résumé data.

\section{Discussion}

As we mentioned in the literature review, employees' skills are of great concern to talent management. A rich body of the literature has focused on the importance of competences for business, but little is known about how to identify skills that employees have starting from data presented in job seekers' profiles. The exploration and development of new skills, career paths and education levels require scientists and human resource experts to extract knowledge from multiple sources of information.

This study contributes to the existing literature by specifically analyzing how to discover links between data by using Semantic Web technologies and analytics.

Mining data from people résumés brings to surface relations between résumés data and employability. Our approach states that starting from the relation between work experience, education, and skills on one side and position held on the other side it is possible to derive links between skills. This approach uses data about skills represented in a Linked Data structured representation format.

We compared the results with the findings of previous work. The main contributions of our work presented in relationship with other studies results are surveyed in Table 7.

Our current study found that the J48 classifier built for Position_held identified that the specialization chosen for studying, UML skills, Java programming skills, the number of years spent in average for every position held and the number of years spent at the last position held are the features that split the data. We built the classifier by using binary split for nominal features.

The most interesting finding was that when we built the same classifier without binary splitting the data of nominal features, we observed that the features that split the data are: number of years spent in average at every position held, Java programming skills, SOA programming skills, the number of positions held, and the number of years spent at the last position held. 

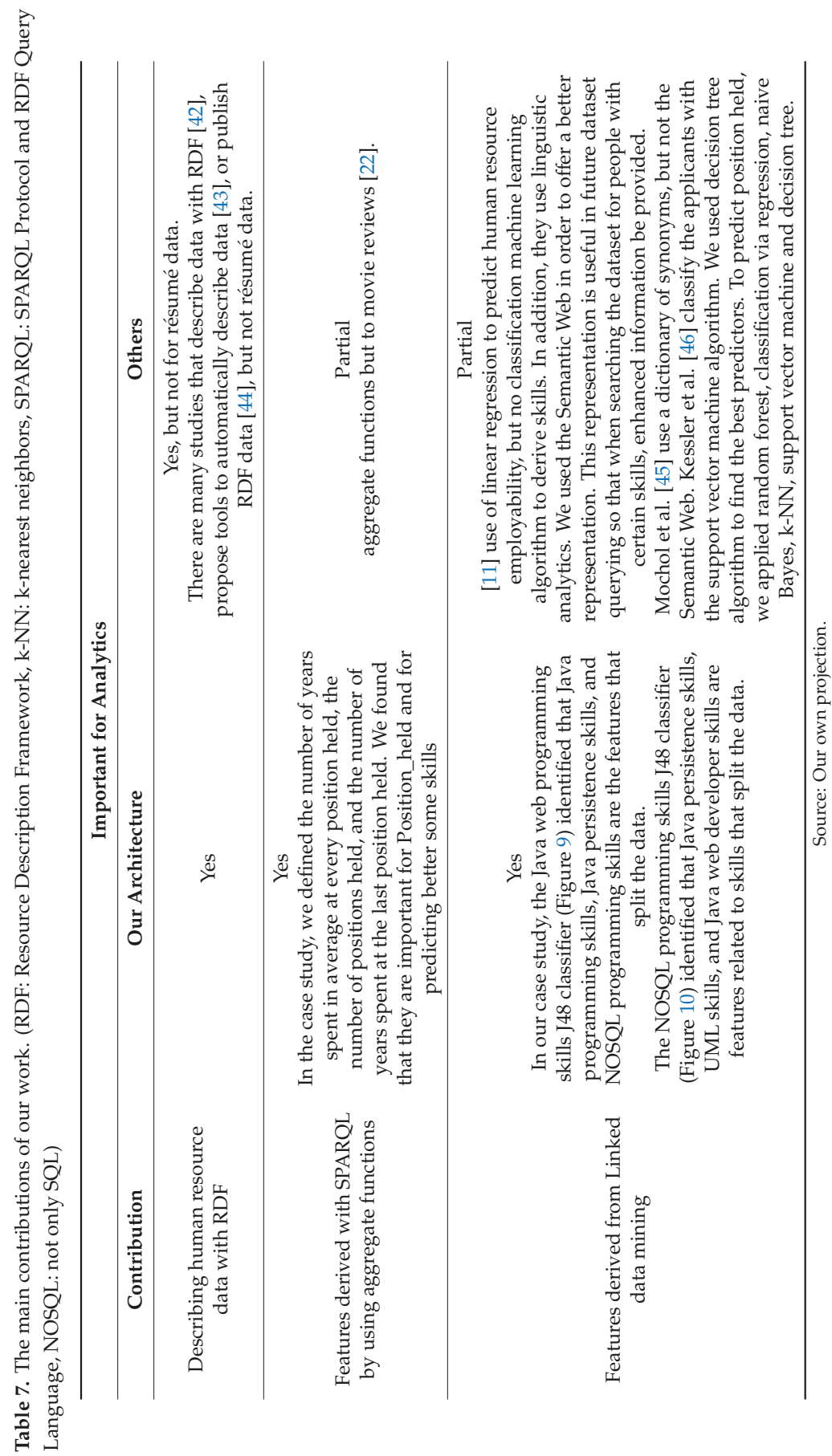
Table 8 shows examples of the three types of features that our study analyzed with the aim of better describing the results of the paper.

Table 8. Types of feature examples.

Features derived with SPARQL queries
JobSeeker has_average_work_experience xsd:integer
Features derived from other features (skills related to data from people résumé)
Java_Web_Developer_Skills is_related_to SOA_programming_skills
Attribute selection by using data mining
SOA_programming_skills isImportant in hiring Java developers

Source: Our own projection.

In this study, all classification algorithms performed better when they were applied on the dataset previously enriched with features resulted from aggregating data, like: years of experience at the last position, the total number of position held, the average years of experience on each position. The accuracies, ROC and PRC values proved that predicting the position held is improved when using features derived by aggregations.

Furthermore, describing data in terms belonging to ontologies provided the possibility to derive links between skills. Starting from a compact description of skills, we queried with SPARQL each skill, we labeled with terms from ontologies for future analysis. The results proved that different skills are determined by the existence of other skills. In addition, the features derived by aggregations are predictors for some skills, becoming normal to infer that some skills come with experience or by implying in diverse activities during changing jobs.

Taken together, these results suggest that linking terms and properties from diverse vocabularies help inferencing on data belonging to eRecruitment websites.

In this study, we described an approach for automatically detecting the important attributes for the process of hiring job seekers. Our approach is able to detect three types of features. We described the method used in our approach: (1) using the Indeed résumé database, (2) describing data with concepts belonging to ontologies, (3) querying data with SPARQL, (4) defining features, and (5) mining data with analytics.

The main contributions of our work are as follows. Firstly, we proposed analytics for discovering the important features for hiring job seekers starting from résumé data. The method operates by selecting attributes with a high information gain ratio. The attributes were previously defined with SPARQL queries. Secondly, an experimental analysis was conducted on Indeed's résumé data with the aim of applying the method.

This study has shown that analytics on features derived with Semantic Web technologies help identify better links between data. Furthermore, identifying which skills determine other skills at the level of an entire population also has a large impact on the data analysis.

Organizations tend to select project teams based on experience, availability, and past individual performance. One future application would be to predict the success rate of a team based on team composition and context variables.

Finally, we mention the impact of using the results of our work on graph database from the LinkedIn website together with other personal job seeker web pages or other job website portals. We believe that the granularity of skills' descriptions will impact on the results of analytics.

Author Contributions: S.-C.N. and C.S. contributed equally.

Funding: This research received no external funding.

Conflicts of Interest: The authors declare no conflict of interest. 


\section{References}

1. Carlson, K.D.; Kavanagh, M.J. HR metrics and workforce analytics. In Human Resource Information Systems: Basics Applications and Future Directions, 1st ed.; Kavanagh, M.J., Thite, M., Eds.; Sage Publishing: Thousand Oaks, CA, USA, 2012; pp. 150-174.

2. Bányai, T.; Landschützer, C.; Bányai, Á. Markov-chain simulation-based analysis of human resource structure: How staff deployment and staffing affect sustainable human resource strategy. Sustainability 2018, 10, 3692. [CrossRef]

3. Lunsford, D.L. An Output Model for Human Resource Development Analytics. Perform. Improv. Q. 2019, 32, 13-35. Available online: https://onlinelibrary.wiley.com/doi/abs/10.1002/piq.21284 (accessed on 15 June 2019). [CrossRef]

4. Fotache, M. Data Processing Languages for Business Intelligence. SQL vs. R. Inform. Econ. 2016, 20 , 48-61. Available online: http://revistaie.ase.ro/content/77/05\%20-\%20Fotache.pdf (accessed on 15 June 2019). [CrossRef]

5. Păvăloaia, V.D.; Georgescu, M.R.; Popescul, D.; Radu, L.D. ESD for Public Administration: An Essential challenge for inventing the future of our society. Sustainability 2019, 11, 880. [CrossRef]

6. Minastireanu, E.A.; Mesnita, G. Light GBM Machine Learning Algorithm to Online Click Fraud Detection. J. Inform. Assur. Cybersecur. 2019, 2019. Available online: https://ibimapublishing.com/articles/JIACS/2019/ 263928/ (accessed on 15 June 2019).

7. King, K.G. Data Analytics in Human Resources: A Case Study and Critical Review. Hum. Resour. Dev. Revi. 2016, 15, 487-495. Available online: https://journals.sagepub.com/doi/abs/10.1177/1534484316675818 (accessed on 15 June 2019). [CrossRef]

8. Fitz-Enz, J.; Mattox, J. Predictive Analytics for Human Resources; John Wiley: Hoboken, NJ, USA, 2014.

9. Purohit, S.R. How LinkedIn Knows What Jobs You Are Interested In. UDACITY, 2014. Available online: https://blog.udacity.com/2014/05/how-linkedin-knows-what-jobs-you-are.html (accessed on 15 June 2019).

10. Claus, L. HR disruption-Time Already to Reinvent Talent Management. BRQ Bus. Res. Q. 2019, in press, corrected proof. Available online: https://www.sciencedirect.com/science/article/pii/S2340943619302129 (accessed on 15 June 2019). [CrossRef]

11. Srivastava, R.; Palshikar, G.K.; Pawar, S. Analytics for Improving talent acquisition processes. In Proceedings of the International Conference on Advanced Data Analysis, Business Analytics and Intelligence, Ahmedabad, India, 11-12 April 2015. ICADABAI 2015.

12. Dutta, D.; Mishra, S.; Manimala, M.J. Talent Acquisition Group (TAG) atHCL Technologies: Improving the Quality of Hire Through Focused Metrics; Technical Report; IIMB-HBP: Bengaluru, India, 2015; Available online: http://research.iimb.ernet.in/handle/123456789/6698 (accessed on 15 June 2019).

13. Faliagka, E.; Tsakalidis, A.; Tzimas, G. An Integrated e-Recruitment System for Automated Personality Mining and Applicant Ranking. Int. Res. 2012, 22, 551-568. Available online: https://www.emeraldinsight. com/doi/abs/10.1108/10662241211271545 (accessed on 15 June 2019). [CrossRef]

14. Faliagka, E.; Ramantas, K.; Tsakalidis, A.; Tzimas, G. Application ofMachine Learning Algorithms to an online Recruitment System. In Proceedings of the ICIW 2012: The Seventh International Conference on Internet and Web Applications and Services, IARIA, Stuttgart, Germany, 27 May-1 June 2012; pp. 216-220.

15. Palshikar, G.K.; Srivastava, R.; Pawar, S.; Hingmire, S.; Jain, A.; Chourasia, S.; Shah, M. Analytics-Led Talent Acquisition for Improving Efficiency and Effectiveness. In Advances in Analytics and Applications; Springer: Singapore, 2019; pp. 141-160.

16. Mooney, R.J.; Bunescu, R. Mining Knowledge from Text Using Information Extraction. ACM SIGKDD Explor. Newsl. 2005, 7, 3-10. Available online: https://www.cs.utexas.edu/ \{\}ml/papers/text-kddexplore-05.pdf (accessed on 15 June 2019). [CrossRef]

17. Téllez-Valero, A.; Montes-y-Gómez, M.; Villaseñor-Pineda, L.A. Machine learning approach to information extraction. In Computational Linguistics and Intelligent Text Processing. CICLing Lecture Notes in Computer Science; Gelbukh, A., Ed.; Springer: Berlin/Heidelberg, Germany, 2005; pp. 539-547. Available online: https://link.springer.com/chapter/10.1007/978-3-540-30586-6_58 (accessed on 15 June 2019).

18. Tomassetti, F.; Rizzo, G.; Vetro, A.; Ardito, L.; Torchiano, M.; Morisio, M. Linked data approach for selection process automation in systematic reviews. In Proceedings of the 15th Annual Conference on Evaluation \& Assessment in Software Engineering, Durham, UK, 11-12 April 2011; Institution of Engineering and Technology (IET): Sunnyvale, CA, USA, 2011; pp. 31-50. 
19. Xu, Z.; Song, B.H. A machine learning application for human resource data mining problem. In Proceedings of the Advances in Knowledge Discovery and Data Mining, Singapore, 9-12 April 2006; Ng, W.K., Kitsuregawa, M., Li, J., Chang, K., Eds.; Lecture Notes in Computer Science. Springer: Berlin/Heidelberg, Germany, 2006; Volume 3918, pp. 847-856.

20. Xie, F.; Tang, Q. Human resource development by fuzzy neural networks. In Proceedings of the 4th International Conference on Wireless Communications, Networking and Mobile Computing, Dalian, China, 12-14 October 2008; IEEE: Piscataway, NJ, USA, 2008; Volumes 1-31.

21. Sivaram, N.; Ramar, K. Applicability of Clustering and Classification Algorithms for Recruitment Data Mining. Inte. J. Comput. Appl. 2010, 4, 23-28. Available online: https://pdfs.semanticscholar.org/22e3/ 1564b13413c537f246e7d59e9075df0db7f8.pdf (accessed on 15 June 2019). [CrossRef]

22. Aldarra, S.; Muñoz, E. A Linked Data-Based Decision Tree Classifier to Review Movies. In Proceedings of the Know@LOD 2015, 4th Workshop on Knowledge Discovery and Data Mining Meets Linked Open Data co-located with 12th Extended Semantic Web Conference (ESWC 2015), Portoroz, Slovenia, 31 May 2015; Available online: http://ceur-ws.org/Vol-1365/paper10.pdf (accessed on 15 June 2019).

23. Mehenni, T.; Moussaoui, A. Data Mining from Multiple Heterogeneous Relational Databases Using Decision Tree Classification. Pattern Recognit. Lett. 2012, 33, 1768-1775. Available online: https://dl.acm.org/citation. $\mathrm{cfm}$ ?id=2343166 (accessed on 15 June 2019). [CrossRef]

24. Sanchez-Marono, N.; Alonso-Betanzos, A.; Fontenla-Romero, O.; Polhill, J.G.; Craig, T. Empirically-Derived Behavioral Rules in Agent-Based Models Using Decision Trees Learned from Questionnaire Data. In Agent-Based Modeling of Sustainable Behaviors. Understanding Complex Systems; Alonso-Betanzos, A., Sánchez Maroño, N., Fontenla-Romero, O., Polhill, G.J., Craig, T., Bajo, J., Corchado, J.M., Eds.; Springer: Cham, Switzerland, 2017; pp. 53-76.

25. Bizer, C.; Heese, R.; Mochol, M.; Oldakowski, R.; Tolksdorf, R.; Eckstein, R. The Impact of Semantic Web Technologies on Job Recruitment. In Proceedings of the 7 Internationale Tagung Wirtschaftsinformatik, Bamberg, Germany, 23-25 February 2005.

26. Ristoski, P.; Petrovski, P.; Mika, P.; Paulheim, H. A Machine Learning Approach for Product Matching and Categorization. Semant. Web 2018, 1-22, Preprint. Available online: http://www.semantic-web-journal.net/ system/files/swj1470.pdf (accessed on 15 June 2019).

27. Ristoski, P.; Paulheim, H. Semantic Web in Data Mining and Knowledge Discovery: A Comprehensive Survey. Web Semant. Sci. Serv. Agents World Wide Web 2016, 36, 1-22. Available online: https://www. sciencedirect.com/science/article/pii/S1570826816000020 (accessed on 15 June 2019). [CrossRef]

28. Min, H.; Emam, A. Developing the Profiles of Truck Drivers for Their Successful Recruitment and Retention: A Data Mining Approach. Int. J. Phys. Distrib. Logist. Manag. 2003, 33, 149-162. Available online: https://www.emeraldinsight.com/doi/abs/10.1108/09600030310469153 (accessed on 15 June 2019). [CrossRef]

29. Gomez-Perez, A.; Fernández-López, M.; Corcho, O. Ontological Engineering: With Examples from the Areas of Knowledge Management, E-Commerce and the Semantic Web; Springer: Heidelberg, Germany, 2006.

30. Simperl, E. A Case Study in Building Semantic eRecruitment Applications. In Semantic Web for Business: Cases and Applications; Garcia, R., Ed.; IGI Global: Hershey, PA, USA, 2008.

31. Gregor, S.; Hevner, A.R. Positioning and Presenting Design Science Research for Maximum Impact. MIS Q. 2013, 37, 337-355. Available online: https://pdfs.semanticscholar.org/82a8/ 6371976aaf181a477745148eab07bb9ed143.pdf (accessed on 15 June 2019). [CrossRef]

32. The Source Code. Available online: https://github.com/catalinstrimbei/rdf-mining-hr (accessed on 15 June 2019).

33. Open Refine. Available online: http://openrefine.org/ (accessed on 15 June 2019).

34. Ontology Engineering Group, Human Resource Ontology. Available online: http://mayor2.dia.fi.upm.es/ oeg-upm/index.php/en/ontologies/99-hrmontology/ (accessed on 15 June 2019).

35. Ericsson, K.A. The influence of experience and deliberate practice on the development of superior expert performance. In The Cambridge Handbook of Expertise and Expert Performance; Cambridge University Press: Cambridge, UK, 2006; Volume 38, pp. 685-705.

36. Langer, J.; Feeney, M.K.; Lee, S.E. Employee Fit and Job Satisfaction in Bureaucratic and Entrepreneurial Work Environments. Rev. Public Pers. Adm. 2019, 39, 135-155. Available online: https://journals.sagepub. com/doi/abs/10.1177/0734371X17693056 (accessed on 15 June 2019). [CrossRef] 
37. Chambers, E.G.; Foulon, M.; Handfield-Jones, H.; Hankin, S.M.; Michaels, E.G. The War for Talent. McKinsey Q. 1998, 44-57. Available online: http://www.executivesondemand.net/managementsourcing/images/stories/ artigos_pdf/gestao/The_war_for_talent.pdf (accessed on 15 June 2019).

38. Bakotić, D. Relationship Between Job Satisfaction and Organisational Performance. Econ. Res. Ekon. Istraž. 2016, 29, 118-130. Available online: https://www.tandfonline.com/doi/full/10.1080/1331677X.2016.1163946 (accessed on 15 June 2019). [CrossRef]

39. Mahmood Ali, M.; Qaseem, M.; Rajamani, L.; Govardhan, A. Extracting Useful Rules Through Improved Decision Tree Induction Using Information Entropy. Int. J. Inf. Sci. Tech. 2013, 3. Available online: https://arxiv.org/ftp/arxiv/papers/1302/1302.2436.pdf (accessed on 15 June 2019). [CrossRef]

40. Melillo, P.; Orrico, A.; Chirico, F.; Pecchia, L.; Rossi, S.; Testa, F.; Simonelli, F. Identifying Fallers Among Ophthalmic Patients Using Classification Tree Methodology. PLoS ONE 2017. Available online: https: //journals.plos.org/plosone/article?id=10.1371/journal.pone.0174083 (accessed on 15 June 2019). [CrossRef]

41. Davis, J.; Goadrich, M. The Relationship Between Precision-Recall and ROC Curves. In Proceedings of the 23 International Conference on Machine Learning, Pittsburgh, PA, USA, 25-29 June 2006.

42. Kalampokis, E.; Zeginis, D.; Tarabanis, K. On Modeling Linked Open Statistical Data. J. Web Semant. 2019, 55, 56-68. Available online: https://www.sciencedirect.com/science/article/pii/S1570826818300544 (accessed on 15 June 2019). [CrossRef]

43. Michel, F.; Zucker, C.F.; Corby, O.; Gandon, F. Enabling Automatic Discovery and Querying of Web APIs at Web Scale using Linked Data Standards. In Proceedings of the LDOW/LDDL Workshop of the 2019 World Wide Web Conference (WWW'19), San Francisco, CA, USA, 13-17 May 2019.

44. Modi, K.J.; Garg, S.; Chaudhary, S. An Integrated Framework for RESTful Web Services Using Linked Open Data. Int. J. Grid High Perform. Comput. 2019, 11, 24-49. Available online: https://www.igi-global.com/article/ an-integrated-framework-for-restful-web-services-using-linked-open-data/224029 (accessed on 15 June 2019). [CrossRef]

45. Mochol, M.; Wache, H.; Nixon, L. Improving the Accuracy of Job Search with Semantic Techniques. In Proceedings of the 10th International Conference Business Information Systems, Poznan, Poland, 25-27 April 2007; Springer: Berlin/Heidelberg, Germany, 2007.

46. Kessler, R.; Torres-Moreno, J.; El-Beze, M. E-Gen: Automatic job offer processing system for human resources. In Proceedings of the Artificial Intelligence 6th Mexican International Conference on Advances in Artificial Intelligence (MICAI'07), Aguascalientes, Mexico, 4-10 November 2007; Rauch, J., Ras, Z., Berka, P., Elomas, T., Eds.; Springer: Berlin/Heidelberg, Germany, 2007; pp. 985-995. 
Article

\title{
Sustainable Social and Individual Implications of Telework: A New Insight into the Romanian Labor Market
}

\author{
Alina-Mihaela Dima ${ }^{1, *}$, Claudia-Elena Țuclea ${ }^{2, *}$, Diana-Maria Vrânceanu ${ }^{3}$ and Gabriela Tigu ${ }^{2}$ \\ 1 UNESCO Chair for Business Administration, Bucharest University of Economic Studies, \\ 010731 Bucharest, Romania \\ 2 Department of Tourism and Geography, Bucharest University of Economic Studies, \\ 010404 Bucharest, Romania \\ 3 Department of Marketing, Bucharest University of Economic Studies, 010404 Bucharest, Romania \\ * Correspondence: alina.dima@fabiz.ase.ro (A.-M.D.); claudia.tuclea@com.ase.ro (C.-E.T.)
}

Received: 31 May 2019; Accepted: 24 June 2019; Published: 26 June 2019

\begin{abstract}
This research aims to evaluate the individual and social implications of telework, along with the foreseeable permanent result that could be generated. Consistent with this objective, a survey has been carried out on a sample of 1180 Romanian employees, on which a model has been developed, based on structural equation modelling. The model includes five latent variables, on the one hand targeting telework features and on the other hand, its possible effects on individuals and society. At an individual level, the study results emphasize that telework could contribute to a better work-life balance and could also help teleworkers to develop specific teleworking abilities. At a social level, telework could generate sustainable effects targeting the long-term management of the work force and providing solutions to potential problems at local community levels. The managerial implications of this study are directed toward the need to implement a series of sustainable human resource management strategies and efficient employee training and development programs. Moreover, organizations need to be more proactive in assuming corporate social responsibilities.
\end{abstract}

Keywords: telework; work-life balance; autonomy; teleworkers' abilities; social implications of telework

\section{Introduction}

While telework is a well-known and relatively established concept, in Romania it has been recognized only as of April 2018, when regulations have been issued specifically dedicated to telework. Whereas prior to these regulations, telework has been put into practice due to the real needs of companies and their employees, the pragmatic potential of telework has been ignored and the scarce academic research mostly focused on labor legal issues [1,2].

One could easily notice that the results of a large series of studies conducted over the past three decades are non-convergent, and sometimes even inconsistent, in terms of the effects of telework on employees [3-8]. Even though a significant number of studies show the benefits of telework for employees [9-12], there are also numerous studies that highlight the negative outcomes [13,14].

The research done in this field can be categorized into 3 main categories: (a) the effects of telework on employees and their behavior as teleworkers, (b) the enterprises' attitude towards telework and the managerial challenges determined by telework, and (c) the social, organizational, and individual consequences of telework.

The present research aims to identify to what degree Romanian employees are familiar with the concept of telework, how they relate to the concept in terms of potential advantages and disadvantages, 
which are the objective conditions in which telework can be applied, and what is the willingness of the Romanian employees to accept such a work style. Additionally, this study attempts to diagnose the real situation regarding telework in Romanian companies. Moreover, the paramount objective of the present research is to verify whether the relationships existing in traditional work contexts are also preserved in telework contexts. Therefore, the link between work-life balance (WLB) and work satisfaction is revised, as well as the impact of autonomy on WLB. Additionally, connections between work autonomy and a series of abilities required to perform telework will be highlighted. The present study provides additional knowledge in the field via the conceptual model that targets the social implications of telework.

\section{Literature Review and Hypotheses}

Even though in Romania telework is in its initial development stages, in the advanced economies, the concept has been widely researched. However, researchers opinions have not always been convergent in terms of the effects telework has on employees, organizations, and societies overall.

Wojcak et al. [7] shows that the implementation of this new way to organize work activities brings new challenges for leadership, while Onken-Menke et al. [15] present evidence that flexible work schedules, including telework, increase the organization's attractiveness. Managers have to be trained in relation to the ways in which employees that work remotely could be efficiently managed, and new and effective methods to supervise remote workers are required [16].

Several studies additionally investigated the impact of telework on the environment and on the society as a whole. A special interest was generated by the relationship between telework and traffic jams and pollution generated by cars used to commute [17-19]. While Nakanishi [20] questions whether telework has a real contribution to save energy, Shabanpour et al. [21] shows that telework makes a contribution to the decrease of the total daily vehicle miles traveled and the total vehicle hours traveled, as well as the decline in greenhouse gas and particulate matter emissions.

These different results show that the effects of telework are not fully known, hence further investigation is required. In this context, our study aims to explore the effects of telework on Romanian employers and employees since the first regulations of telework have been issued. This research has not favored certain sectors of activity, but has investigated the perception of Romanian employees on telework in general.

\subsection{Telework, Work-Life Balance and Teleworkers' Skills}

A significant number of studies have revealed a strong connection between telework and personal-professional life balance in the case of individuals working from home. From the beginning, telework has been associated with a flexible work schedule, as numerous studies emphasize that flexibility in choosing the time and the place to work not only supports WLB [22-25] but also it is frequently a key factor when choosing an employer [24].

In traditional work contexts, there is a positive connection between WLB and work satisfaction level [26]. Consequently, Haar et al. [27] show a positive connection between WLB and professional satisfaction and a negative connection with anxiety and depression. Furthermore, every individual factor of WLB is an essential predictor of the professional satisfaction while professional satisfaction is, conversely, an important indicator of WLB [28].

In the present research, work satisfaction is defined by using the components identified by Zamfir [29], except for those concerning the presence of the employee inside of the enterprise. Consequently, determinant factors of satisfaction will be analyzed, such as: career opportunities, training opportunities, work conditions, and wage [30]. Accordingly, the present study suggests a first hypothesis:

H1. Telework satisfaction sources are positively related to work-life balance. 
According to other studies, an important issue related to telework is the autonomy concerning the performance of activities. For organizations that grant organizational support and autonomy to employees, telework is an efficient solution [31]. Furthermore, the connection between flexible work practices (FWP) and the organizational attachment is mediated by the autonomy that employees might think they have regarding the structure and control of how, when, and where they can work [15]. A benefit of telework for both employees and employers consists in the increase in the flexibility and autonomy of workers [32,33]. Specifically, teleworkers own the freedom to organize their own activities and to decide where and how to work [6,34]. Consequently, teleworkers feel that they have more control over their activities and more flexibility in scheduling both their regular working hours as well as extra working hours. This flexibility has been positively associated with WLB, specifically as a result of circumstance that family duties are no longer neglected as opposed to professional responsibilities $[35,36]$.

In this context, the present study puts forward a second hypothesis:

H2. The autonomy of teleworkers is positively related to work-life balance.

In order to achieve the WLB goals, teleworkers need to possess specific abilities, one of them being the ability to work and to solve problems independently [37]. McNaughton et al. [38] highlighted the need to train remote workers in digital skills and Golden [39] analyzes the effects of telework on burnout. Previously, a number of researchers have associated burnout with a set of negative results such as growing absenteeism, employees' high turnover, illnesses, decreasing work satisfaction, and low performances [40]. Hence, reducing burnout could become an objective where telework might make its own contribution [41]. Therefore, an important asset for teleworkers should be the ability to manage the signs of exhaustion, as well as the ability to manage distractions from work.

All these abilities have a positive impact on work satisfaction. The same positive impact is associated with work autonomy [42]. Lopes et al. [43] showed that an increased level of work autonomy is related with an increased well-being of the employees, including an increase of vitality, psychological flexibility, and self-accomplishment.

To conclude, it can be noted that both specific abilities of telework, as well as work autonomy, can generate the increase of work satisfaction for remote workers, which leads to the assumption of the third hypothesis:

H3. The autonomy of teleworkers is positively related to telework abilities.

\subsection{Social Implications of Telework}

The social implications of telework are scrutinized in numerous studies. A series of researchers have analyzed the impact of telework on women with children. Sullivan and Lewis [44] revealed that the main reason for which women accept to work remotely is to take care of their children. This issue has a major impact on WLB since it addresses the possibility to take care of family responsibilities, which is an important indicator of WLB [45]. WLB can also be achieved through better time management $[46,47]$ and through stress reduction [48-50]. All these aspects can have a positive influence on employees' health $[47,51]$. In this way, the positive effects of telework on the individuals become real social implications, by increasing the number of employees and reducing health care costs (in Romania they are paid especially by national health insurance budget), to mention just these examples.

Various researchers investigated the durable effects of telework. Hynes [52] (p. 237) analyzes "the true social and environmental implications of individuals working from home". Also, Hynes [53] shows that, in Ireland, telework was an important incentive for shifting toward a sustainable transport model. Telework is perceived as having a positive impact on the environment and climate on account of its sustainable effects on energy consumption [54].

An additional social impact of telework is the decrease in unemployment among people with disabilities and other categories of vulnerable people [31]. The present research focuses on the decline 
in unemployment among inhabitants of rural areas, who, in Romania, represent a vulnerable social category [55].

Another highly researched consequence is the traffic decrease on the national roads $[31,56,57]$. Moreover, Chakrabarti [58] shows that telework (on average, at least once a week) is associated with a $15 \%$ increase of walking in the time span of a week.

In accordance with, first, the connection between telework and WLB, and second, the social consequences of telework, hypothesis $\mathrm{H} 4$ is submitted:

H4. WLB is positively related to the social sustainable implications of telework.

As it has been highlighted in the previous sections of this paper, the social consequences of telework are: professional opportunities for women with children, reducing unemployment in rural areas, and decreasing traffic on national roads. These positive effects of telework are constrained by the extent to which employees possess the requisite abilities. Upon analysis of the implementing stages of telework in a number of Japanese companies, Higa and Shin [59] showed that at an early stage, the right employees were selected for telework and additionally, they attended a special training for this new type of work context. Consequently, considering the social consequences of telework and the need for special abilities for such a work context, we suggest the following hypothesis:

H5. Telework abilities are positively related to the social sustainable implications of telework.

As a result of the provided hypotheses, the theoretical model that will be tested is presented in Figure 1.

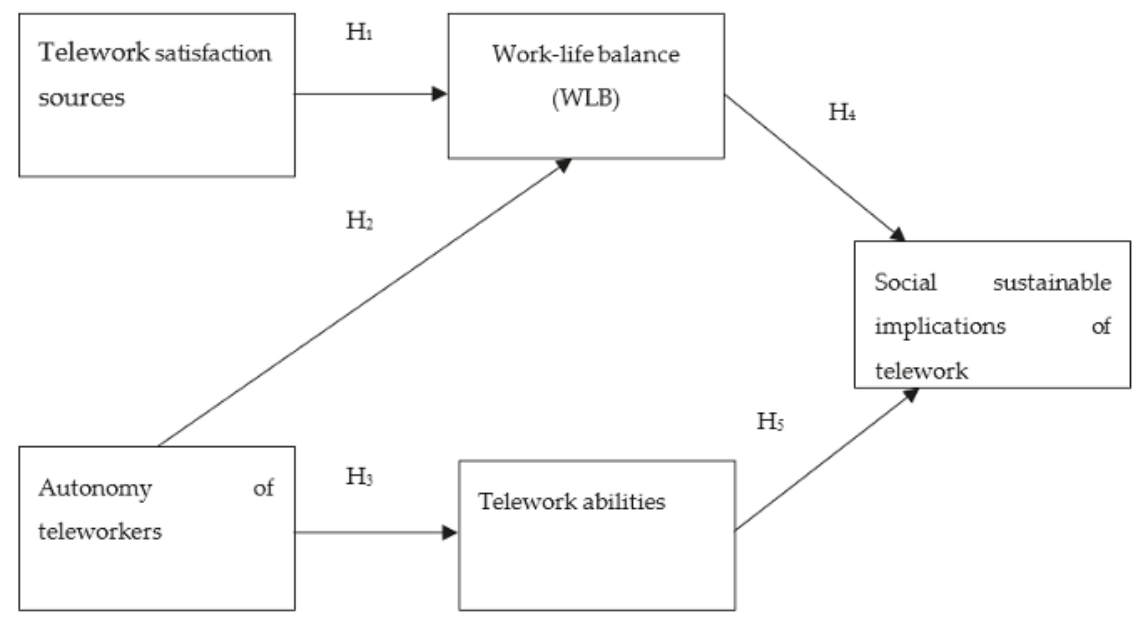

Figure 1. The conceptual model of telework implications.

\section{Research Methodology}

The research goal is to estimate the social implications and the sustainable effects that could be generated by telework. To achieve this goal, a national survey was carried out on a sample of 1180 employees. The statistical population for this study is represented by Romanian employees, the sampling variables being: age, gender, education, and type of employer. The sample structure is presented in Table 1.

Data was collected between 15 May and 4 June 2018 using field operators. They were trained on research purpose, objectives, and the criteria for selecting the sample. Data management was performed using Excel, whereas for data analysis a structural equation modelling (SEM) was designed 
by use of Warp PLS 5.0 software. Structural equation modelling aims to estimate the dependence relationships among a set of constructs that are incorporated into a model [60] (p. 796).

Table 1. The sample structure.

\begin{tabular}{cccc}
\hline & Variables of the Sample & Number of Employees & Percent \\
\hline \multirow{3}{*}{ Age } & $18-25$ years & 191 & $16.2 \%$ \\
& $26-35$ years & 270 & $22.9 \%$ \\
& $36-45$ years & 261 & $22.1 \%$ \\
& $46-55$ years & 241 & $20.4 \%$ \\
Gender & Over 55 years & 217 & $18.4 \%$ \\
\hline \multirow{3}{*}{ Education } & Memale & 593 & $50.3 \%$ \\
& High school & 587 & $49.7 \%$ \\
\hline \multirow{3}{*}{ Type of Employer } & Post-secondary school & 209 & $17.7 \%$ \\
& Pniversity & 93 & $7.9 \%$ \\
& Postgraduate studies & 659 & $55.8 \%$ \\
& Multinational company & 219 & $18.6 \%$ \\
\hline & Large Romanian company & 293 & $24.8 \%$ \\
& Small and medium-sized & 257 & $21.8 \%$ \\
& Romanian company & 460 & $39.0 \%$ \\
& Micro-firm & 170 & $14.4 \%$ \\
\hline
\end{tabular}

In the present study, a type of structural equation modelling, Path Least Square (PLS), was used. It involves defining latent variables (constructs) as aggregates of observed variables, while the structural model describes the relationships between these latent variables [61]. All the latent variables incorporated into the model were reflective. The model adequacy was assessed by evaluating the construct reliability and validity.

\subsection{Construct Reliability}

To validate the designed conceptual model, five latent variables were defined via items measured with a Likert scale (ranging from 1-Strongly disagree to 5-Strongly agree). As shown in Table 2, the composite variables are: satisfaction sources in telework (defined by four items), autonomy of teleworkers (defined by three items), abilities for telework (defined by three items), work-life balance (defined by four items), and social implications of telework (defined by three items).

To assess the internal consistency reliability of the constructs, composite reliability and Cronbach's Alpha coefficient were estimated. For PLS-SEM the composite reliability is more likely to be applied since Cronbach's Alpha coefficient presents some limitations [61]. The acceptance threshold for a good reliability is 0.7 [60]. In our research, the values for composite reliability are higher than 0.8 , showing a high level of reliability. This idea is also supported by the levels of Cronbach's Alpha coefficients that are higher than 0.7 [61], except for one latent variable whose value was very close to 0.7 , values above 0.5 being considered acceptable [62]. 
Table 2. Reliability for latent variables.

\begin{tabular}{|c|c|c|c|c|}
\hline Construct & Item & $\begin{array}{l}\text { Cronbach's } \\
\text { Alpha }\end{array}$ & $\begin{array}{l}\text { Composite } \\
\text { Reliability }\end{array}$ & AVE \\
\hline $\begin{array}{c}\text { Telework } \\
\text { satisfaction sources } \\
\text { (Source) }\end{array}$ & $\begin{array}{l}\text { Source } 1 \\
\begin{array}{c}\text { The career options of teleworkers are similar to those of the } \\
\text { employees that do not work remotely. } \\
\text { Source } 2\end{array} \\
\text { Teleworkers have the same training opportunities as employees } \\
\text { that work in offices. } \\
\text { Source } 3\end{array}$ & 0.71 & 0.821 & 0.535 \\
\hline $\begin{array}{l}\text { Autonomy of } \\
\text { teleworkers } \\
\text { (Auton) }\end{array}$ & $\begin{array}{c}\text { Auton } \mathbf{1} \\
\text { Teleworkers feel they have more control over their activities. } \\
\text { Auton } 2 \\
\text { Teleworkers have more flexibility to arrange their working } \\
\text { schedule. } \\
\text { Auton } 3\end{array}$ & 0.712 & 0.840 & 0.640 \\
\hline $\begin{array}{c}\text { Telework abilities } \\
\text { (Abil) }\end{array}$ & $\begin{array}{c}\text { Abil 1 } \\
\text { Teleworkers need to solve their problems independently. } \\
\text { Abil } 2 \\
\text { Teleworkers need digital literacy skills. } \\
\text { Abil } 3 \\
\text { Abil } 4 \\
\text { Teleworkers must be able to manage the burnout tendency. } \\
\text { Teleworkers must manage the work distractions. }\end{array}$ & 0.722 & 0.828 & 0.546 \\
\hline $\begin{array}{l}\text { Work-life balance } \\
\text { (Equil) }\end{array}$ & $\begin{array}{c}\text { Equil 1 } \\
\begin{array}{c}\text { Teleworkers can face better the family responsibilities than office } \\
\text { employees. } \\
\text { Equil } 2\end{array} \\
\text { Teleworkers can manage time more efficiently than office workers. } \\
\text { Equil } 3 \\
\text { Teleworkers face less stress. } \\
\text { Equil } 4\end{array}$ & 0.743 & 0.839 & 0.565 \\
\hline $\begin{array}{l}\text { Sustainable social } \\
\text { implications of } \\
\text { telework (Implic) }\end{array}$ & $\begin{array}{c}\text { Implic } 1 \\
\text { Telework offers professional opportunities to young mothers. } \\
\text { Implic } 2 \\
\text { Telework can reduce unemployment rate in the rural areas. } \\
\text { Implic } 3\end{array}$ & 0.694 & 0.831 & 0.621 \\
\hline
\end{tabular}

\subsection{Construct Validity}

In order to evaluate construct validity, convergent and discriminant validity should be assessed. The convergent validity signifies the extent to which a "scale correlates positively with other measures of the same construct" and all factors loadings should be higher than 0.5 (ideally higher than 0.7 ) and should be statistically significant [63] (p. 702). According to data shown in Table 3, for the items included into the latent variables, the factor loadings are statistically significant $(p<0.01)$ and exceed 0.7 , except for two items that exceed 0.65 , which conveys a very good convergent validity. Another measure applied to assess this dimension of validity is the average variance extracted (AVE). This indicator evaluates how much of the variance of the observed variables is explained by the latent variables, the minimum acceptable level being 0.5 [61]. In Table 2, it can be seen that for all latent variables, the values for average variance extracted (AVE) are higher than 0.5 , with the latent variables explaining more than $50 \%$ of the variance of the observed variables. 
Table 3. Combined loadings and cross-loadings.

\begin{tabular}{cccccccc}
\hline Variab Item & Source & Auton & Abil & Equil & Impl & S.E. & $p$ Value \\
\hline Source 1 & $(0.764)$ & 0.096 & -0.035 & -0.073 & 0.026 & 0.027 & $<0.001$ \\
Source 2 & $(0.722)$ & -0.122 & -0.093 & 0.148 & 0.031 & 0.027 & $<0.001$ \\
Source 3 & $(0.712)$ & 0.015 & 0.055 & -0.076 & 0.037 & 0.027 & $<0.001$ \\
Source 4 & $(0.725)$ & 0.006 & 0.076 & 0.004 & -0.094 & 0.027 & $<0.001$ \\
Auton 1 & 0.016 & $(0.657)$ & -0.046 & 0.500 & -0.013 & 0.028 & $<0.001$ \\
Auton 2 & 0.008 & $(0.856)$ & 0.018 & -0.213 & -0.002 & 0.027 & $<0.001$ \\
Auton 3 & -0.020 & $(0.869)$ & 0.017 & -0.169 & 0.012 & 0.027 & $<0.001$ \\
Abil 1 & 0.029 & 0.066 & $(0.726)$ & -0.059 & 0.029 & 0.027 & $<0.001$ \\
Abil 2 & 0.023 & 0.044 & $(0.687)$ & -0.024 & -0.030 & 0.027 & $<0.001$ \\
Abil 3 & -0.021 & -0.124 & $(0.755)$ & 0.106 & -0.007 & 0.027 & $<0.001$ \\
Abil 4 & -0.027 & 0.020 & $(0.785)$ & -0.028 & 0.007 & 0.027 & $<0.001$ \\
Equil 1 & -0.031 & 0.201 & 0.099 & $(0.749)$ & 0.002 & 0.027 & $<0.001$ \\
Equil 2 & 0.012 & 0.193 & 0.024 & $(0.742)$ & 0.037 & 0.027 & $<0.001$ \\
Equil 3 & 0.006 & -0.072 & -0.079 & $(0.777)$ & 0.000 & 0.027 & $<0.001$ \\
Equil 4 & 0.013 & -0.322 & -0.041 & $(0.738)$ & -0.040 & 0.027 & $<0.001$ \\
Implic 1 & 0.013 & 0.154 & 0.078 & -0.120 & $(0.821)$ & 0.027 & $<0.001$ \\
Implic 2 & 0.028 & 0.007 & -0.113 & -0.019 & $(0.799)$ & 0.027 & $<0.001$ \\
Implic 3 & -0.045 & -0.178 & 0.035 & 0.154 & $(0.742)$ & 0.027 & $<0.001$ \\
\hline
\end{tabular}

Discriminant validity measures the distinctiveness of a construct from other constructs [60]. The loadings of an item with the associated latent variable should be higher than the cross-loadings with other latent variables [61]. As Table 3 shows, this condition is accomplished. By assessing the convergent and discriminant validity, we may conclude that the construct is valid.

\section{Results and Discussion}

To test the prior suggested hypotheses, a conceptual model was designed which evaluates the relationships between a series of latent variables, in terms of direction, strength, and statistical significance. The path coefficient $(\beta)$ evaluates the strength of the relationship between two variables, the sign of the path coefficient (positive or negative) indicates the direction of the relationship, and the $p$-value assesses the statistical significance of this relationship. In order to test the designed model and to determine the path coefficients between the variables of the model, a structural equation modelling procedure was performed, using WarpPLS 5.0 (ScriptWarp Systems, Laredo, TX, USA) software. The resulting model is presented in Figure 2.

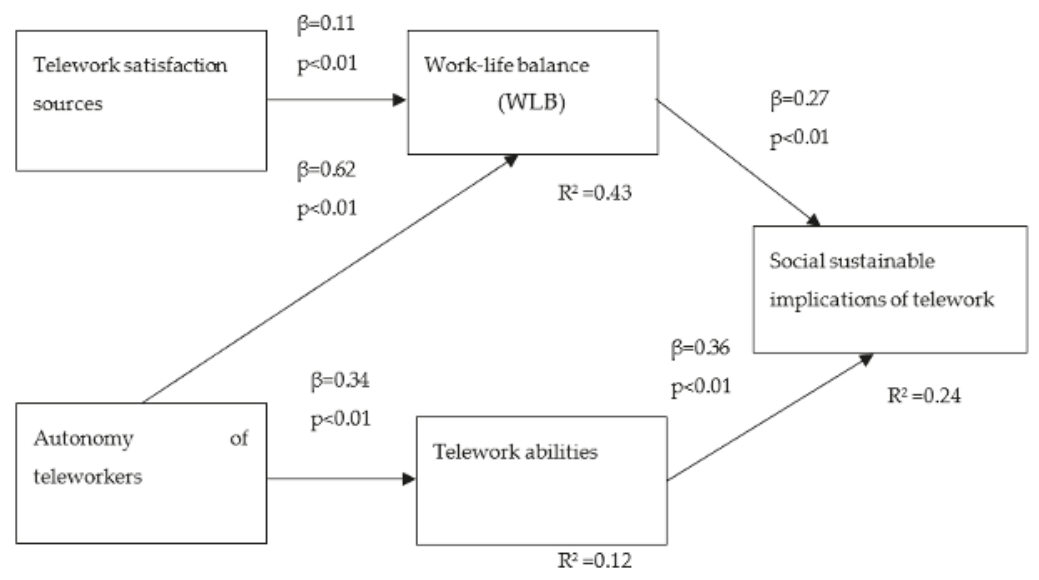

Figure 2. The tested model of telework implications. 
The probabilities $(\mathrm{p})$ associated with path coefficients are lower than 0.01 , meaning that the relationships between the latent variables are statistically significant. Figure 2 further presents the coefficients of determination $\mathrm{R}^{2}$, which indicate "the proportion of change in the dependent variable that is associated with changes in the independent variable" [64] (p. 296).

Figure 2 shows that the sources of satisfaction in telework have a significant effect on the work-life balance, with the path coefficient $\beta=0.11, p<0.01$, but the strength of the relationship is weak. Therefore, hypothesis $\mathrm{H} 1$ is accepted, which means that the type of satisfaction sources in telework do have an influence on the employees' work-life balance.

The autonomy of teleworkers has a positive influence on work-life balance, with a path coefficient of $\beta=0.62, p<0.01$. The autonomy of teleworkers and work-life balance are strongly positively related. Thus, the more employees perceive a greater autonomy associated with telework, the more they have a better work-life balance. Consequently, hypothesis $\mathrm{H} 2$ is supported by the results. The sources of satisfaction associated with telework and the autonomy of teleworkers contribute significantly to work-life balance, the coefficient of determination being $R^{2}=0.43$. Thus, the two variables explain $43 \%$ of the variation of work-life balance variable.

The autonomy of teleworkers has a positive influence, of moderate strength, over the telework abilities $(\beta=0.34, p<0.01)$, thus hypothesis H3 is accepted. The greater autonomy teleworkers have in performing their professional and personal activities, the more they gain the required abilities for telework, both technical and non-technical. However, the low value of the coefficient of determination $\mathrm{R}^{2}=0.12$ shows that the autonomy in performing professional and personal activities only accounts for $12 \%$ of telework ability variation. This low value can be explained by the existence of other endogenous variables that could influence the acquiring of necessary abilities in telework.

Between work-life balance and sustainable social implications of telework there is a positive relationship of moderate strength, the value of the path coefficient being $\beta=0.27, p<0.01$. Consequently, a stable balance between professional and personal life associated with telework conveys positive social implications. The more telework balances the professional and personal life of an employee, the more the society has specific benefits such as: an increased rate of employment among young mothers, a decrease in unemployment rates in rural areas, and traffic decongestion on public roads. Therefore, hypothesis $\mathrm{H} 4$ is accepted.

Between telework abilities and sustainable social implications of telework there is a positive relationship of moderate strength $(\beta=0.36, p<0.01)$, therefore $\mathrm{H} 5$ is accepted. The required technical and personal abilities for telework contribute to the personal development of the employees, in turn, this allows the involvement in work of categories of people that did not have the possibility to work within a traditional work frame before. Work-life balance and telework abilities account for $24 \%$ of the variation of sustainable social implications of telework. This result reveals an outstanding contribution of these variables to the positive effects that telework could generate.

\section{Conclusions, Managerial Implications, and Limitations of the Research}

The first research outcome shows a significant relationship between sources of telework satisfaction and work-life balance. According to our results, satisfaction sources, such as opportunities for career development and work conditions and remuneration, have a similar impact on WLB in telework as in traditional work activities. This conclusion aligns with other studies that focus on work satisfaction and WLB $[27,28]$. Moreover, the present study highlights the importance of this relationship in a telework context. A first implication at the organizational level is that managers can use the same motivational tools in teleworking contexts to increase work satisfaction and WLB. Another important implication is that teleworkers do not consider themselves a vulnerable socio-professional category. Quite the opposite, the flexible working schedule could become a competitive advantage for the organization. This perspective is highlighted by Maruyama et al. [24] when analyzing the importance of flexible schedule as a source of employees' satisfaction. 
Another conclusion underlines the assumption that the level of telework autonomy significantly influences WLB. The employee's control over their professional and personal activities has positive effects on time management, stress level, and other health issues. This perspective is consistent with Chung and Van der Horst's study [36] on the influence of flexible working hours on managing domestic issues. This result suggests that telework autonomy could increase the employees' attachment to the organization which consequently could decrease staff turnover and absenteeism, and also promotes the design of sustainable human resource management strategies. Such a strategy could aim, for example, to increase the capacity of enterprises to adapt to Industry 4.0 requirements by adopting digitalization of business in all its aspects [65].

The present research additionally highlights the relationship between the teleworkers' autonomy and their abilities. Thus, a high degree of autonomy determines employees to develop specific abilities in order to reduce their professional dependence on peers or managers. This perspective is addressed by another study [66] which correlates work autonomy—as a form of job resources—with perceived work abilities. An implication of this result is that teleworkers gain an intrinsic motivation to develop themselves professionally and personally. This could lead to an increase in the efficiency of staff training and development programs supported by the organization and could be a sustainable professional career strategy for the individual.

The final significant conclusion of the study concerns sustainable social implications of telework. Telework proves itself a sustainable work system that allows the access into the labor market of certain socio-professional categories that would otherwise have less employment opportunities (mothers with small children, people living in rural areas etc.). Following the directions set by other researchers $[31,44,56,57]$, the model designed in this paper highlights that telework could generate sustainable social effects both in terms of human resources management (e.g., job opportunities for women with children, reducing unemployment in rural areas), as well as rendering other activities with social implications more efficient (e.g., reducing traffic on public roads). The issue of traffic on public roads has also been investigated from the point of view of time traffic [67], which can be considered a determinant of subjective well-being [68]. This suggests the possibility of biunivocal analysis of the relationship between the individual and social implications of telework. As a consequence, organizations could be more involved in corporate social responsibility activities and try to provide a long-term solution to the problems of the communities they belong to.

The results of the present research can be extrapolated cautiously to other countries, with telework implementation being influenced by various factors (legislative, cultural, technological, and demographic) specific to each country. For example, in Slovakia the employees perceive telework as an informal advantage with a potential positive impact on productivity and satisfaction [69]. Although the telework valence to create a better work-life balance seems quite universal, in France work-life balance is slightly perceived as a favorable factor for telework adoption [67]. However, telework becomes a valid option for large cities where the time spent on travel is high [67]. Corroborating these few examples with our research, a new hypothesis may arise: telework could be perceived more favorable in the Central and Eastern European countries than in Western Europe. This could be a new direction of research. The main limitation of the present study is that the model does not include all factors that could explain the social implications of telework. Therefore, future studies could include other organizational variables (e.g., attitudes of management towards telework) and individual variables (type of personality, socio-demographic variables, etc.).

Author Contributions: Conceptualization, C.-E.T.; methodology, D.-M.V.; formal analysis, C.-E.T. and D.-M.V.; investigation, C.-E.T. and G.T.; data curation, D.-M.V.; writing-original draft preparation, C.-E.T. and D.-M.V.; writing-review and editing, A.-M.D. and G.T.; supervision, A.-M.D. and G.T.; project administration, A.-M.D.; funding acquisition, A.-M.D.

Funding: The research published in this article has been supported by the Romanian government through the CERTRAN project-The Upgrade of the Research Capacity in Economics through Development of a Transdisciplinary Research Infrastructure. 
Conflicts of Interest: The authors declare no conflict of interest.

\section{References}

1. Popescu, R.R. Aspecte controversate cu privire la noua reglementare a telemuncii. Rev. Română Dreptul Muncii 2018, 3, 50-55.

2. Dimitriu, R. Munca în spațiul privat. Rev. Română Dreptul Muncii 2013, 9, 23-32.

3. DeSanctis, G. Attitudes toward telecommuting: Implications for work-at-home programmes. Inf. Manag. 1984, 7, 133-139. [CrossRef]

4. Haddon, L.; Lewis, A. The experience of teleworking: An annotated review. Int. J. Hum. Resour. Manag. 1994, 5, 193-223. [CrossRef]

5. Pinsonneault, A.; Boisvert, M. The impacts of telecommuting on organizations and individuals: A review of the literature. In Telecommuting and Virtual Offices: Issues and Opportunities; Johnson, N.J., Ed.; Idea Group Publishing: Hershey, PA, USA, 2001; pp. 163-185.

6. Gajendran, R.S.; Harrison, D.A. The Good, the Bad, and the Unknown About Telecommuting: Meta-Analysis of Psychological Mediators and Individual Consequences. J. Appl. Psychol. 2007, 92, 1524-1541. [CrossRef] [PubMed]

7. Wojcak, E.; Bajzikova, L.; Sajgalikova, H.; Polakova, M. How to Achieve Sustainable Efficiency with Teleworkers: Leadership Model in Telework. Proceedings of the 5th International Conference on Leadership, Technology, Innovation and Business Management. Procedia Soc. Behav. Sci. 2016, 229, 33-41. [CrossRef]

8. Sarbu, M. The role of telecommuting for work-family conflict among German employees. Res. Transp. Econ. 2018, 70, 37-51. [CrossRef]

9. Hill, E.J.; Ferris, M.; Märtinson, V. Does it matter where you work? A comparison of how three work venues (traditional office, virtual office, and home office) influence aspects of work and personal/family life. J. Vocat. Behav. 2003, 63, 220-241. [CrossRef]

10. Golden, T.D.; Veiga, J.F. The impact of extent of telecommuting on job satisfaction: Resolving inconsistent findings. J. Manag. 2005, 31, 301-318. [CrossRef]

11. Fonner, K.L.; Roloff, M.E. Why teleworkers are more satisfied with their jobs than are office-based workers: When less contact is beneficial. J. Appl. Commun. Res. 2010, 38, 336-361. [CrossRef]

12. Vega, R.P.; Anderson, A.J.; Kaplan, S.A. A within-Person Examination of the Effects of Telework. J. Bus. Psychol. 2015, 30, 313-323. [CrossRef]

13. Golden, T.D.; Veiga, J.F.; Dino, R.N. The Impact of Professional Isolation on Teleworker Job Performance and Turnover Intentions: Does Time Spent Teleworking, Interacting Face-to-Face, or Having Access to Communication-Enhancing Technology Matter? J. Appl. Psychol. 2008, 93, 1412-1421. [CrossRef] [PubMed]

14. Morganson, V.J.; Major, D.A.; Oborn, K.L.; Verive, J.M.; Heelan, M.P. Comparing telework locations and traditional work arrangements: Differences in work-life balance support, job satisfaction, and inclusion. J. Manag. Psychol. 2010, 25, 578-595. [CrossRef]

15. Onken-Menke, G.; Nüesch, S.; Kröll, C. Are you attracted? Do you remain? Meta-analytic evidence on flexible work practices. Bus. Res. 2018, 11, 239-277. [CrossRef]

16. Ansong, E.; Boateng, R. Organisational adoption of telecommuting: Evidence from a developing country. Electron. J. Inf. Sys. Dev. Ctries. 2018, 84, e12008. [CrossRef]

17. Nilles, J.M. Telecommuting and urban sprawl: Mitigator or inciter? Transportation 1991, 18, 411-432. [CrossRef]

18. Lund, J.R.; Mokhtarian, P.L. Telecommuting and residential location: Theory and implications for commute travel in monocentric metropolis. Transport. Res. Rec. 1994, 1463, 10-14.

19. Jaff, M.M.; Hamsa, A.A. Estimating commute-travel implications of telecommuting by female employees in Kuala Lumpur, Malaysia. J. Traffic Transp. Eng. 2018, 5, 148-155. [CrossRef]

20. Nakanishi, H. Does Telework Really Save Energy? Int. Manag. Rev. 2015, 11, 89-97.

21. Shabanpour, R.; Golshani, N.; Tayarani, M.; Auld, J.; Mohammadian, A. Analysis of telecommuting behavior and impacts on travel demand and the environment. Transport. Res. Part D Transp. Environ. 2018, 62, 563-576. [CrossRef] 
22. Duxbury, L.; Higgins, C.; Neufeld, D. TeleWork and the Balance between Work and Family: Is TeleWork Part of the Problem or Part of the Solution? In The Virtual Workplace; Igbaria, M., Tan, M., Eds.; Idea Group Publishing: Hersey, PA, USA, 1998; pp. 218-255.

23. Johnson, N.J. Case Study of the St. Paul Companies' Virtual Office for the Risk Control Division. In Telecommuting and Virtual offices: Issues and Opportunities; Johnson, N.J., Ed.; Idea Group Publishing: London, UK, 2001; pp. 148-161.

24. Maruyama, T.; Hopkinson, G.P.; James, P.W. A multivariate analysis of work-life balance outcomes from a large-scale telework programme. New Technol. Work Employ. 2009, 24, 76-88. [CrossRef]

25. Chung, H.; van der Lippe, T. Flexible Working, Work-Life Balance, and Gender Equality: Introduction. Soc. Indic. Res. 2018, 1-17. [CrossRef]

26. Malik, M.I.; Saleem, F.; Ahmad, M. Work-Life Balance and Job Satisfaction among Doctors in Pakistan. South Asian J. Manag. 2010, 17, 112-123.

27. Haar, J.M.; Russo, M.; Suñe, A.; Ollier-Malaterre, A. Outcomes of work-life balance on job satisfaction, life satisfaction and mental health: A study across seven cultures. J. Vocat. Behav. 2014, 85, 361-373. [CrossRef]

28. Kumari, L. Employees' Perception on Work Life Balance and its Relation with Job Satisfaction in Indian Public Sector Banks. Int. J. Eng. Manag. 2012, 2, 1-13.

29. Zamfir, C. Un Sociolog Despre Muncă şi Satisfacţie; Editura Politică: Bucureşti, România, 1980; pp. 15-40.

30. Emilian, R., (coord.). Managementul Resurselor Umane; Editura ASE: București, Romania, 2014; Available online: http://www.biblioteca-digitala.ase.ro/biblioteca/carte2.asp?id=48\&idb (accessed on 12 April 2019).

31. Gálvez, A.; Martínez, M.J.; Pérez, C. Telework and Work-Life Balance: Some Dimensions for Organisational Change. J. Workplace Rights 2012, 16, 273-297. [CrossRef]

32. Gregg, M. Work's Intimacy; Polity Press: Cambridge, UK, 2011; pp. 23-55.

33. Tremblay, D.G.; Thomsin, L. Telework and Mobile Working: Analysis of Its Benefits and Drawbacks. Int. J. Work Innov. 2012, 1, 100-113. [CrossRef]

34. Pyöriä, P. Managing Telework: Risks, Fears and Rules. Manag. Res. Rev. 2011, 34, 386-399. [CrossRef]

35. Deery, M.; Jago, L. A framework for work-life balance practices: Addressing the needs of the tourism industry. Tour. Hosp. Res. 2009, 2, 97-108. [CrossRef]

36. Chung, H.; Van der Horst, M. Women's employment patterns after childbirth and the perceived access to and use of flexitime and teleworking. Hum. Relat. 2018, 71, 47-72. [CrossRef]

37. Omari, M.; Standen, P. Selection for telework. In Managing Telework: Perspectives from Human Resource Management and Work Psychology; Thompson Learning: New York, NY, USA, 2000; pp. 113-124.

38. McNaughton, D.; Rackensperger, T.; Dorn, D.; Wilson, N. Home is at work and work is at home: Telework and individuals who use augmentative and alternative communication. Work J. Prev. Assess. Rehabil. 2014, 48, 117-126.

39. Golden, D.T. Altering the Effects of Work and Family Conflict on Exhaustion: Telework during Traditional and Nontraditional Work Hours. J. Bus. Psychol. 2012, 27, 255-269. [CrossRef]

40. Carson, R.L.; Baumgartner, J.J.; Mathews, R.A.; Tsouloupas, C.N. Emotional exhaustion, absenteeism, and turnover intentions in childcare teachers: Examining the impact of physical activity behaviors. J. Health Psychol. 2010, 15, 905-914. [CrossRef] [PubMed]

41. Sardeshmukh, R.S.; Sharma, D.; Golden, D.T. Impact of telework on exhaustion and job engagement: A job demands and job resources model. New Technol. Work Employ. 2012, 27, 193-207. [CrossRef]

42. Blount, Y. Pondering the Fault Lines of Anywhere Working (Telework, Telecommuting): A Literature Review. Found. Trends Inf. Syst. 2015, 1, 163-276. [CrossRef]

43. Lopes, H.; Lagoa, S.; Calapez, T. Work autonomy, work pressure, and job satisfaction: An analysis of European Union countries. Econ. Labour Relat. Rev. 2014, 25, 306-326. [CrossRef]

44. Sullivan, C.; Lewis, S. Home-based telework, gender and the synchronization of work and family: Perspective of teleworkers and their co-residents. Gender Work Organ. 2001, 8, 123-145. [CrossRef]

45. Russo, M.; Shteigman, A.; Carmeli, A. Workplace and family support and work-life balance: Implications for individual psychological availability and energy at work. J. Posit. Psychol. 2016, 11, 173-188. [CrossRef]

46. Yu, X.; Meng, X.; Chen, Y.; Chen, Y.; Nguyen, B. Work-family conflict, organizational ambidexterity and new venture legitimacy in emerging economies. Technol. Forecast. Soc. Chang. 2018, 135, 229-240. [CrossRef] 
47. Hofmann, V.; Stokburger-Sauer, N.E. The impact of emotional labor on employees' work-life balance perception and commitment: A study in the hospitality industry. Int. J. Hosp. Manag. 2017, 65, 47-58. [CrossRef]

48. Cho, E.; Allen, T.D. The transnational family: A typology and implications for work family balance. Hum. Resour. Manag. Rev. 2019, 29, 76-86. [CrossRef]

49. Zhao, X.R.; Ghiselli, R. Why do you feel stressed in a "smile factory"? Hospitality job characteristics influence work-family conflict and job stress. Int. J. Contemp. Hosp. Manag. 2016, 28, 305-326. [CrossRef]

50. Razak, M.I.; Yusof, N.M.; Azidin, R.A.; Latif, M.M.; Ismail, I. The impact of work stress towards work life balance in Malaysia. Int. J. Econ. Commer. Manag. 2014, 2, 1-16.

51. Gamor, E.; Amissah, E.F.; Boakye, K. Work-family conflict among hotel employees in Sekondi-Takoradi Metropolis, Ghana. Tour. Manag. Perspect. 2014, 12, 1-8. [CrossRef]

52. Hynes, M. What's 'Smart' About Working from Home? Telework and the sustainable consumption of distance in Ireland. In Internet Research, Theory, and Practice: Perspectives from Ireland; Fowley, C., English, C., Thouësny, S., Eds.; Research-Publishing: Dublin, Ireland, 2013; pp. 225-243.

53. Hynes, M. Telework Isn't Working: A Policy Review. Policy Paper. Econ. Soc. Rev. 2014, 45, 579-602.

54. Van Lier, T.; de Witte, A.; Macharis, C. How worthwhile is teleworking from a sustainable mobility perspective? The case of Brussels capital region. Eur. J. Transp. Infrastruct. Res. 2014, 14, 244-267. [CrossRef]

55. Anghelache, C.; Anghel, M.G.; Marinescu, A.I. Analiza ratei de ocupare a populaţiei şi a costului lunar al forţei de muncă. Rev. Română Stat. Supl. 2018, 10, 3-16.

56. Wang, S.J.; Moriarty, P. Can new communication technology promote sustainable transport? Energy Procedia 2017, 142, 2132-2136. [CrossRef]

57. Hynes, M. Developing (tele) work? A multi-level sociotechnical perspective of telework in Ireland. Res. Transp. Econ. 2016, 57, 21-31. [CrossRef]

58. Chakrabarti, S. Does telecommuting promote sustainable travel and physical activity? J. Transp. Health 2018, 9, 19-33. [CrossRef]

59. Higa, K.; Shin, B. The Telework Experience in Japan. Commun. ACM 2003, 46, 233-242. [CrossRef]

60. Malhotra, N.K.; Nunan, D.; Birks, D.F. Marketing Research: An Applied Approach, 5th ed.; Pearson: New York, NY, USA, 2017; pp. 795-826.

61. Hair, J.F.; Hult, T.M.; Ringle, C.; Sarstedt, M. A Primer on Partial Least Squares Structural Equation Modeling (PLS-SEM); Sage: Los Angeles, CA, USA, 2017; pp. 95-115.

62. Hinton, P.R.; Brownlow, C.; McMurray, I.; Cozens, B. SPSS Explained; Routledge: London, UK, 2004; pp. 355-364.

63. Malhotra, N. Marketing Research. An Applied Orientation, 6th ed.; Pearson Prentice Hall: Upper Saddle River, NJ, USA, 2010; pp. 690-719.

64. Proctor, T. Essentials of Marketing Research, 4th ed.; Prentice Hall/Financial Times: Harlow, UK, 2005; pp. 296-312.

65. Trașcă, D.L.; Ștefan, G.M.; Sahlian, D.N.; Hoinaru, R.; Șerban-Oprescu, G.-L. Digitalization and business activity. The Struggle to Catch Up in CEE Countries. Sustainability 2019, 11, 2204. [CrossRef]

66. McGonagle, A.K.; Fisher, G.G.; Barnes-Farrell, J.L.; Grosch, J.W. Individual and work factors related to perceived work ability and labor force outcomes. J. Appl. Psychol. 2015, 100, 376-398. [CrossRef] [PubMed]

67. Aguilera, A.; Lethiais, V.; Rallet, A.; Proulhac, L. Home-based telework in France: Characteristics, barriers and perspectives. Transp Res. Part A Policy Pract. 2016, 92, 1-11. [CrossRef]

68. Serban-Oprescu, G.-L.; Dedu, S.; Serban-Oprescu, A.-T. An Integrative Approach to Assess Subjective Well-Being. A Case Study on Romanian University Students. Sustainability 2019, 11, 1639. [CrossRef]

69. Bajzikovaa, L.; Sajgalikovab, H.; Wojcakc, E.; Polakovad, M. How far is contract and employee telework implemented in SMEs and large enterprises? (Case of Slovakia). Procedia Soc. Behav. Sci. 2016, 235, 420-426. [CrossRef]

(C) 2019 by the authors. Licensee MDPI, Basel, Switzerland. This article is an open access article distributed under the terms and conditions of the Creative Commons Attribution (CC BY) license (http://creativecommons.org/licenses/by/4.0/). 


\title{
The Roles of Power Distance Orientation and Perceived Insider Status in the Subordinates' Moqi with Supervisors and Sustainable Knowledge-Sharing
}

\author{
Xingshan Zheng ${ }^{1}$, Lan $\mathrm{Li}^{1, *}$, Fangyu Zhang ${ }^{2}$ and Mengyuan Zhu ${ }^{3}$ \\ 1 Antai College of Economics and Management, Shanghai Jiao Tong University, Shanghai 200030, China; \\ xszheng@sjtu.edu.cn \\ 2 International Business School Suzhou, Xi'an Jiaotong-Liverpool University, Suzhou 215123, China; \\ Fangyu.Zhang17@student.xjtlu.edu.cn \\ 3 School of Economics and Management, Harbin Institute of Technology, Weihai 264209, China; \\ 150320123@stu.hit.edu.cn \\ * Correspondence: summer10038@sjtu.edu.cn
}

Received: 28 January 2019; Accepted: 1 March 2019; Published: 7 March 2019

\begin{abstract}
Although knowledge-sharing, an important facet of knowledge management, has been encouraged for the sustainable development of organizations, this kind of behavior is still not prevalent among group members. To enrich the literature and contribute to its practical usage, this research proposed a model based on the fit theory to examine the roles of perceived insider status (PIS) and power distance orientation in subordinates' Moqi with supervisors (SMS) and knowledge-sharing. Survey data from eight firms in China contained 196 samples and was analyzed by MPLUS software to justify the hypotheses. The results showed that: first, SMS predicted knowledge-sharing and perceived insider status; second, perceived insider status positively mediated the relationship between SMS and knowledge-sharing; third, power distance orientation not only positively moderated the relationship between SMS and perceived insider status, but also positively moderated the relationship between SMS and knowledge-sharing. This study enriched the literature on the antecedents of knowledge-sharing and application of SMS. Additionally, this study proposes a few suggestions to practitioners and researchers for establishing sustainable organizations.
\end{abstract}

Keywords: subordinates' Moqi with supervisors; perceived insider status; knowledge-sharing; power distance orientation; sustainable organization

\section{Introduction}

As one of the main contributors to the sustainability of society as a whole, organizations are asked to change strategies to maintain long-term development [1]. How to efficiently allocate and use resources determines the performance of organizations. Knowledge, the key content of knowledge management, is a kind of important intangible resource that keeps organizations competitive in markets [2,3]. As one of the business strategies for sustainable purposes, knowledge management emphasizes on the use of knowledge and helps organizations transfer and create intellectual capital to maintain long-term comparative advantages and stand out in fierce competition in the markets. It is believed that the organizational sustainability relies on active interactions among employees and efficient knowledge management in teams [4-6]. Past scholars point out that the implementation of inter-member coordination and knowledge management greatly depends on employees' motivations or intentions in knowledge-sharing [7,8]. Knowledge-sharing is defined as a process that allows members to share ideas, information, and suggestions with each other and identify problems and 
propose solutions through formal or informal channels [9-11]. Past literature has verified that knowledge-sharing predicts high organizational performance, innovation capabilities and conversion rate of investment [12]. Although a series of incentives have been adopted in a wide range of organizations to encourage knowledge-sharing behaviors, employees are still reluctant to share knowledge with others [13]. Therefore, to prompt knowledge-sharing for the sustainable development of organizations, it is important to explore how to inspire knowledge-sharing behavior within organizations [14].

Recent literature about how to inspire knowledge-sharing behavior in organizations can be roughly categorized into two streams. One stream tries to explore the effects of various types of leadership including empowerment leadership [10], transformational and transactional leadership [15], and abusive leadership [16]. The other stream examines the effects of individual characteristics including individual personalities or dispositions, greed, openness, self-efficacy, age, gender, and tenure $[12,13,17-19]$. Besides the above two parties, some researchers try to explore how interactions between employees and supervisors influence knowledge-sharing behavior, however, their findings are mostly concluded from Western countries' cases and cannot be referred to the Eastern context. Compared with the Western countries, the indirectness and euphemism in interpersonal communication are higher in Eastern countries. On most occasions, Eastern people are less willing to share their real thoughts with others and they used to let others "guess". Since most Eastern countries (e.g., Japan, Korea) are significantly influenced by Chinese culture in history, this study takes China as a representative of the Eastern countries to explore how interactions between subordinates and their supervisors influence knowledge-sharing behavior.

This research adopts a concept named "subordinates' Moqi with supervisors (SMS)" from Zheng et al. [20] to describe the relationship between subordinates and supervisors in the Eastern context. Moqi is "a state of unspoken or tacit understanding between two parties" [20] (p.956). SMS reflects the idea that interpersonal interactions and cooperation are achieved based on tacit understandings instead of speaking out between subordinates and supervisors [20]. If the subordinates have high "Moqi" with their supervisors, they will better understand what their leaders really want and achieve cooperation. Stamper and Masterson [21] assert that subordinates usually consider supervisors as the representatives of the organization and their intentions in conducting the extra-role behaviors depend on whether inferring themselves as insiders of groups [22]. If they think that they are the real "teammates" with their supervisors, they will voluntarily perform well and take responsibilities beyond their duties to support the supervisors. Perceived insider status (PIS) can be defined as the employees' perceptions of interpersonal distance and to what extent they are accepted as organizational insiders by the groups [23]. If the employees of groups perceive that they are accepted by the organizations, they may be willing to spare no effort to support the development of organizations.

Subsequently, given the influence of cultural difference on the perceptions of employees toward interpersonal relationships, this study adopts the "power distance" to narrate the relationship between subordinates and supervisors. Past literature has confirmed that power distance orientation (PDO) is a dimension of culture and can influence the behaviors of individuals and groups in organizations [24]. Power distance orientation is defined as the extent to which people accept inequality between classes $[25,26]$ and this concept has been applied to evaluate the individual difference between countries. Additionally, Farh et al. [27] believe that the values of PDO are different from individual to individual even when in the same country. In the organizational context, the difference in PDO will influence employees' perceptions and behaviors. If individuals have high PDO, they will keep a longer distance from their supervisors and obey the orders more.

This study attempts to explore the roles of perceived insider status and power distance orientation in the influential mechanism between SMS and knowledge-sharing behavior. The rest of this study is organized as follows. In Section 2, a brief background is provided, followed by the proposition of a series of hypotheses. In Section 3, this research describes the research method. In Section 4, the results of the model hypotheses are explained. In Section 5, the findings are summarized and the relationships 
among SMS, knowledge sharing, and sustainable development are demonstrated. In Section 6 the main conclusions, limitations of this paper, and further studies are discussed.

\section{Background and Research Model}

Sustainable development is widely concerned with having a positive effect on enterprises' long-term interest [28]. If enterprises neglect this issue, they will not only miss the opportunities for development, but also face the risk of being eliminated by markets [29]. Past literature points out that enterprises should try to save and reuse the resource, avoiding waste and over-exploitation [29]. To realize sustainable development, enterprises should consider the effects of the operation on society, environment and stakeholder interests [30]. Generally, the patterns of development determine the direction of sustainable development [31]. Many scholars have discussed the organizational sustainability from the perspectives of entrepreneurship [32-36], human resources [29,37], the path of knowledge capability [31,38-40], and corporate social responsibility [30], and suggest that organizations design a sustainable development plan according to their own conditions. For example, to realize sustainable innovation, manufacturing organizations should concern problems in technology; while service organizations should be concerned with issues about the structure and business model [41]. Among different elements for sustainable development, knowledge capability has been concerned by researchers and practitioners, because this kind of capability can offer long-term resources to the organizations for innovation [31]. As organizations acquire this capability, they will better react to new opportunities and take chances to realize further development by utilizing knowledge and upgrading the present technology [40]. On most occasions, organizations cannot reach high knowledge capability without efficient human resource management. Since everyone's capability and knowledge are different, organizations may try to integrate these recourses to make full use of the knowledge [31] to improve the productivity [37] and innovation [42] for long-term development [34]. Given the high cost of training and hiring new talent, knowledge management is proposed to help organizations realize the reuse of resources in teams.

Efficient knowledge management enables organizations to better utilize different kinds of information and initiate comparative advantages [2,3,43]. As the key part of knowledge management, knowledge-sharing behavior influences the diffusion of information, establishment of cooperation and innovation [12,44]. Knowledge-sharing can help organizations to reuse the intangible resource and improve the efficiency of organizations. Past literature has verified the positive effect of knowledge-sharing in the cooperation and performance of organizations [44]. However, it is not easy to transfer knowledge accurately and completely due to its adherence to individuals' egos and occupations [45]. Therefore, it is necessary to explore how to inspire individuals' knowledge-sharing behaviors.

\subsection{Knowledge-Sharing}

Knowledge-sharing occurs among individuals and organizations. In the organizational context, knowledge is often shared among employees in the form of various work-related documents, organizational rules, procedures, personal experiences, and technical tips [13]. During this process, many factors influence individuals' intentions to share knowledge. Past literature finds that the difference among individuals can influence their sharing behaviors. Connelly and Kelloway [17] find that age, gender and tenure of working significantly influence individuals' knowledge-sharing. For example, the interaction climate has a greater effect on female than male in sharing knowledge. Subsequently, self-efficacy and openness to self-experience can influence knowledge sharing $[18,46,47]$. Lin [47] finds that norms of reciprocity, self-efficacy and helping others can motivate knowledge sharing.

Besides, leadership and organizational factors also are verified to be correlated with knowledge-sharing. Authorized leaders can inspire subordinates to participate in knowledge-sharing through empowering more power and resources to subordinates [10]. As employees perceive 
care [37], support [17,46], commitment [14,47] and fairness [48] in the groups, they are more willing to participate in knowledge-sharing. Additionally, the climate and environment in working places are also considered to influence knowledge sharing. An active communication climate can enhance the individuals' willingness to communicate and share information with each other [14]. In a multi-language working environment, language convergence will positively affect knowledge-sharing [48].

Although past literature has verified many influential factors on knowledge-sharing, there are still disputes over several factors. For example, the effect of trust on knowledge sharing is disputed $[48,49]$. Some researchers find that social trust has no significant effect on employees' intention in sharing knowledge. However, general trust is verified to contribute to knowledge-sharing.

\subsection{Subordinates' Moqi with Supervisors and Knowledge Sharing}

One of the main streams exploring the antecedents of knowledge-sharing is from the perspective of leaders. It is found that leaders may motivate the members to share knowledge in teams [10]. Scholars have verified the positive effects of the behaviors of leaders on employees' knowledge-sharing, such as empowering leader behavior, ethical leadership behavior, management support and trust $[10,12,50]$. However, past literature merely focuses on the direct effects of the leaders' behaviors on knowledge-sharing, few of they explain the phenomenon from the perspective of the influence of the tacit interactions between leaders and subordinates on knowledge-sharing. Supervisors create the most immediate environment for employees through various kinds of behaviors at the workplaces, indirectly influencing the attitudes of subordinates [22,51]. Therefore, it is necessary to study the behaviors of supervisors and the consequences of these behaviors. Person-supervisor fit theory reflects on the consistent and complementary compatibility between subordinates and supervisors [52]. To be specific, subordinates can get more invisible information and assistance through establishing tacit understandings with supervisors, which reflects the complementarity in information resources and abilities between supervisors and subordinates. Moreover, subordinates' understandings about their supervisors' work expectations and tasks reflect the consistency of their work goals. Therefore, the degree of SMS reveals the extent of match between subordinates and supervisor [20]. As the subordinates reach high matching degree with their supervisors, the subordinates will adapt to work with less pressure. On this occasion, subordinates will generate a stronger senses of safety, pleasant mood, and then improve job satisfaction [53] and enhance emotional commitment and recognition of the organization. Furthermore, subordinates' proactive behaviors will increase as their defensiveness decreases [54]. Past literature shows that subordinates with high SMS level seem to be more cooperative and perceptive toward supervisors' expectations and learn more beyond their duties [53], help their colleagues [55], and perform more organizational citizenship behavior [53]. Past literature has been verified that the close relationships that are established during the daily games can improve the employees' sense of belonging and intention to share knowledge [56]. However, if the SMS level is maintained at a low level, subordinates may fail to accurately and fully understand their supervisors' tacit information and expectation and they will fail to satisfactorily finish the task [20].

Since subordinates with high-level SMS have more tacit interactions with their supervisors, they can acquire more responses from their supervisors and may feel being accepted, trusted, and supported by their supervisors [20]. On this occasion, supervisors' acceptance, trust and supports can greatly reduce subordinates' perceived cost in sharing knowledge, indirectly encouraging subordinates to devote themselves to voluntary roles (e.g., knowledge-sharing) [12,55]. However, if SMS stays at a low level, the failure interactions between subordinates and supervisors may lead to employees' divergence and resistance. On this occasion, subordinates may be negative toward the work and less willing to devote themselves in in-role and extra-role contributions (e.g., knowledge sharing). Therefore, it may be inferred that as subordinates have Moqi with their supervisors, and the knowledge-sharing will happen. As reasoned above, this study hypothesizes: 
Hypothesis 1. SMS can predict knowledge sharing.

\subsection{Subordinates' Moqi with Supervisors, Perceived Insider Status and Knowledge-Sharing}

Perceived insider status can be described as to what extent employee perceive that they are accepted and recognized by the teams. Stamper and Masterson [21] propose two ways to define an "insider" and "outsider" in groups. First, according to social exchange theory, organizations will provide "insiders" with more resources or better remuneration; while "outsiders" cannot get the same treatment. Second, according to organizational socialization strategy, employees can establish psychological contracts with the organizations as they perceive that they are "insiders". Therefore, as employees receive more treatment than others, they will define themselves as "insiders" [57].

The SMS consists of two important traits including the abilities in understanding tacit information and prominent coordination [20]. Specifically, subordinates with high-level SMS can read invisible information from supervisors' unspoken "words" via observing and analyzing supervisors' expressions in eyes, tones of voice, and body language. Then, the ability of understanding supervisors' real intentions, expectations and job requirements may help members to cooperatively conduct tasks with proper and satisfying approaches. Person-supervisor fit theory emphasizes the compatibility among people may give another angle to explain the "good match" between subordinates and supervisors. In this study, perceived insider status can be introduced in the model. As mentioned above, "insiders" may acquire status if they are accepted by the organizations [21]. Person-supervisor fit theory believes that the degree of compatibility between employees' and supervisors' characteristics (e.g., values, personality, job demands, and behavioral styles) significantly influences individuals' cognitions and the outcomes of teams (e.g., organizational citizenship behavior) [53,54,58]. SMS shows the conformance in job expectations and job demands between supervisors and subordinates, which make subordinates feel closely connected with their supervisors as insiders of the organizations [21]. To be specific, the cooperative actions of subordinates with high-level SMS may help them be accepted by organizations [20]. On this occasion, the SMS can make subordinates feel that they match the organizations and they are insiders of the groups [55,59]. Moreover, high SMS may help subordinates get more information and other interests from their supervisors, which leads them to consider themselves as "insiders" [20,21]. Through cooperatively solving problems and accomplishing tasks in work, both supervisors and the subordinates will recognize their contribution to the organizations, indirectly enhancing the sense of being in-group [60]. Thus, this study hypothesizes:

\section{Hypothesis 2. SMS can predict perceived insider status.}

Past literature has verified that perceived insider status can inspire employees' sense of belonging which reflects the degree of the individual's connection with others [23]. Thus, an individual may feel that he/she is close to other members and establish interpersonal trust with them [12,19]. Although there is evidence supporting the correlation between perceived insider status and extra-role behavior (e.g., citizenship behavior) [21], knowledge-sharing that is one kind of extra-role behavior has not been previously examined. As individuals trust their teammates and consider themselves as insiders of organizations, they may not only try to get some rights but also to take certain responsibilities and conduct organizational citizenship behavior [60]. To be specific, individuals with high perceived insider status can more easily perceive trust, support and respect so that they will take the responsibilities of positions and perform some altruistic behaviors beyond the requirements of their job duties (e.g., knowledge sharing) $[10,21,37]$. Past literature has verified that people with high-level perceived insider status perform better in job satisfaction, organizational commitment, organizational citizenship behaviors, and innovation [59].

By contrast, individuals with low perceived insider status may consider that they are abandoned by the organizations because they hardly feel the commitment, trust and acceptance [21]. They will 
consider themselves as outsiders and care less about the goals and interests of the organizations. On this occasion, employees' organizational citizenship behaviors are hindered, and they will try to maintain their advantages and interest to avoid being caught up by others [21]. Since knowledge-sharing may threaten their advantages in skills or social capital [61], they will be reluctant to share knowledge. According to the above, this study hypothesizes:

\section{Hypothesis 3. Perceived insider status can predict knowledge sharing.}

Furthermore, perceived insider status may play a mediator role in SMS and knowledge sharing. As subordinates have strong SMS, they may maintain close relationships with their supervisors and consider themselves as the insiders of the groups. Perception of being accepted by the organizations can inspire individuals to trust others and contribute to the development of the groups [62]. On this occasion, the more individuals perceive that they match with members and supervisors, the more they trust others and conduct in-role and extra-role behaviors. Therefore, this study hypothesizes:

Hypothesis 4. Perceived insider status positively mediates the relationship between SMS and knowledge-sharing.

\subsection{The Moderating Role of Power Distance Orientation}

Power distance, as a culture value orientation [62], is closely correlated with the cross-class relationship. Compared with Westerners, Easterners are more sensitive to the gaps between classes and their behaviors are more obviously influenced by the responses of high ranks [26]. This study focuses on the moderating effect of power distance at the individual level, namely power distance orientation (PDO) [63]. Power distance orientation means the degree of acceptance of unequal distribution in organizations among people [64]. Individuals with high power distance orientation feel that the subordinates should obey supervisors without query $[62,65]$ and keep a proper distance from the supervisors [66]. However, people with low power distance orientation believe that members in the groups should be generally equal and the relationships between ordinates and supervisors should not be estranged.

Person-supervisor fit theory emphasizes "compatibility" that is about the relationships between subordinates and supervisors. In these relationships, the degree of perceived distance determines the extent of cooperation. Subordinates holding high-power-distance value may show deference, respect, and loyalty to the authority (i.e., supervisors), at the same time, they prefer to maintain greater social distance with the higher ranks $[27,67]$. On this occasion, supervisors' responses generally have greater influences on subordinates' attitudes and behaviors [67]. Any favor from supervisors to subordinates will narrow the gap and strengthen the bonds between them [68].

SMS can help subordinates establish close links with supervisors to achieve cooperation as teams. However, people with high PDO perceive that subordinates should keep distance with supervisors. According to social comparison theory [69], people will pre-assess the distance with supervisors through balancing the perception of "should keep distance" and the intention of "shorten perceived distance". For people with high PDO, they may be more sensitive to a change of distance (i.e., SMS) and they are more likely to consider themselves as insiders. Compared with people with high-level PDO, people with low-level PDO overestimate their relationships between their supervisors, and they react less to a change of distance. To some extent, the higher the level of the PDO is, the more change of the effect of SMS on PIS will be perceived. Together, this study postulates that PDO amplifies the impact of SMS on PIS. Thus, this study hypothesizes:

Hypothesis 5. Power distance orientation positively moderates the relationship between SMS and perceived insider status. 
Subsequently, for the people with high-level PDO, they may hold positive attitudes to "being insiders" and tend more to behave proactively. In contrast, people with the low-level PDO may have fewer reactions to the degree of being accepted by the groups and they will have less attachment to their supervisors and teams. Thus, they are less willing to be engaged in performing extra-role behavior, such as knowledge sharing. Thus, this study hypothesizes:

Hypothesis 6. Power distance orientation positively moderates the relationship between SMS and knowledge sharing.

\section{Materials and Methods}

\subsection{Study Design}

A quantitative research method was adopted in this study by statistically analyzing the survey data. All questions were designed as "required questions" and uploaded to one of Chinese biggest online survey websites (www.wjx.cn) in advance. After discussing with the CEOs of 8 firms located in Shanghai, Beijing, Zhejiang, Guangdong and Jiangsu provinces in China, the authors of this research sent the electronic link of the online survey to managers to distribute to the subordinates to fill in. Respondents were required to submit the surveys only after they finished all the questions from 10 July to 15 July in 2018. Finally, this study collected 196 valid data samples $(60.5 \%$ of the whole distributed surveys). Since these firms were in the cities with main clusters of industries in China and they were the representative firms in manufacturing and service industries, the samples to some extent were representative.

\subsection{Measurement}

The survey consisted of two parts, including demographic variables (gender, age, education, the tenure of work) and scales of the constructs (subordinates Moqi with supervisors, perceived insider status, knowledge sharing, and power distance orientation). The measurements adopted in this research were selected from past literature and translated from English into Chinese by professional translators. The whole translation process followed the suggestion of Brislin [70]. This study invited two bilingual professors of management to check the translation validity of the Chinese version. The measurements for constructs were all seven-point Likert scales (from $1=$ strongly disagree to 7 = strongly agree).

Subordinates Moqi with supervisors was measured by an 8-item scale developed by Zheng et al. [20]. Each subordinate was asked to independently report the state between him (her), and his (her) supervisors. The scale was reliable in this study (Cronbach's alpha was 0.933).

PIS was measured by a 6-item scale [21]. Each subordinate was asked to objectively evaluate her (his) perceptions on to what extent they were accepted by her (his) group. Cronbach's alpha was 0.945, which satisfied the requirement of reliability.

Knowledge-sharing was measured by an 8-item scale developed by Lu et al. [13]. Subordinates were asked to report their intention to knowledge share behaviors objectively. The observed reliability coefficient was satisfying (Cronbach's $\alpha=0.946$ ).

Power distance orientation was measured by a 6-item scale [71]. Subordinates were asked to objectively report their perceptions of power distance. The Cronbach's $\alpha$ of this scale was 0.865 in this study.

The demographic variables were settled as control variables to avoid their influence on dependent variables $[72,73]$. 


\subsection{Participants}

In the analysis stage 196 valid samples were involved. The percentage of male (67.3\%) was higher than females $(32.7 \%)$. In terms of the age, the percentage of people who were at 31-40 was the highest $(58.2 \%)$, the second was people who were at 26-30 (29.6\%), and rest people were between 31 and over $50(12.3 \%)$. Regarding education, most of the subordinates were holders of Bachelor degree $(63.3 \%)$, followed by holders of Associate degree (16.8\%), holders of Master degrees (15.3\%), holders of high school degree $(3.6 \%)$, and holders of Doctor Degree (1\%). Finally, by the tenure of work, $27.6 \%$ the subordinates had worked for 1 to 3 years, followed by beyond 8 years $(23.5 \%)$, 5-8 years $(19.9 \%)$, $3-5$ years $(18.4 \%)$ and less than 1 year $(10.7 \%)$. Furthermore, $19.4 \%$ of the participants had worked with their supervisors for less than 1 year, $36.7 \%$ of the participants had worked with their supervisors for 1 to 3 years, and $43.7 \%$ of the participants had worked with their supervisors for beyond 3 years.

\section{Results}

\subsection{Descriptive Statistics and Correlations}

The results of descriptive statistics (i.e., means and standard deviations) and correlations analysis among constructs are presented in Table 1 . As Table 1 shows: SMS was positively correlated with PIS ( $\mathrm{r}=0.549, p=0.000)$ and knowledge-sharing behavior $(\mathrm{r}=0.717, p=0.000)$, respectively. Then, PIS was positively correlated with knowledge-sharing behavior $(r=0.547, p=0.000)$. Finally, there was no significant correlation between PDO and PIS $(r=-0.047, p=0.513)$, and between PDO and knowledge-sharing behavior $(\mathrm{r}=-0.064, p=0.374)$.

Table 1. Means, standard deviations, and correlations.

\begin{tabular}{lccccc}
\hline \multicolumn{1}{c}{ Indicator } & Means & S.D. & $\mathbf{1}$ & $\mathbf{2}$ & $\mathbf{3}$ \\
\hline 1 SMS & 5.82 & 0.85 & - & & \\
2 PIS & 5.61 & 1.20 & $0.549^{* *}$ & - & - \\
3 PDO & 3.19 & 1.16 & 0.011 & -0.047 & - \\
4 knowledge sharing & 5.71 & 1.03 & $0.717^{* *}$ & $0.547^{* *}$ & -0.064 \\
\hline
\end{tabular}

Note: $\mathrm{N}=196 .{ }^{*} p<0.05 ;{ }^{* *} p<0.01$. SMS = subordinates' Moqi with supervisors; $\mathrm{PDO}=$ power distance orientation; PIS $=$ perceived insider status.

\subsection{Confirmatory Factor Analysis}

Confirmatory factor analysis (CFA) was conducted by Mplus in this study to check the quality of the measurement model. Mplus has been applied for latent variable modeling (e.g., Zhang et al.) [74] and its comprehensive function in dealing with different kinds of data has been confirmed by academia. Mplus can be used to run onfirmatory factor analysis and a structural equation model (SEM) based on various kinds of data (e.g., cross-sectional data, longitudinal data, single-tier data, and multi-tier data). Since the data in this study is cross-sectional and continuous, Mplus can be used to examine the hypotheses based on the collected data.

According to the suggestions of past literature [75,76], a series of indexes are adopted to measure to what extent the model reproduces the data, including the values of $\chi^{2}$ goodness-of-fit test $\left(\chi^{2} / \mathrm{df}\right)$, the comparative fit index (CFI), the Tucker-Lewis index (TLI), the root mean square error of approximation (RMSEA), and the standardized root mean square residual (SRMR).

Before testing our hypotheses, this study performed CFAs in MPLUS software. At first, it set up a four-latent-factor model including SMS, perceived insider status, knowledge sharing behavior and PDO $\left(\mathrm{M}_{0}\right)$. Then this study compared the above model $\left(\mathrm{M}_{0}\right)$ with other three alternative models. These alternative models were: three-latent-factor model $\left(\mathrm{M}_{1}\right.$ : SMS + PIS, PDO and knowledge sharing behavior); two-latent-factor model ( $\mathrm{M}_{2}$ : SMS + PIS + PDO, and knowledge-sharing behavior); and one-latent-factor model $\left(\mathrm{M}_{3}\right.$ : SMS + PIS + PDO + knowledge-sharing behavior). 
Table 2 showed that the results of four-latent-factor model $\left(\chi^{2} \mathrm{df}=344, \mathrm{~N}=196=630.74 ; \mathrm{CFI}=0.928\right.$; $\mathrm{TLI}=0.921 ; \mathrm{RMSEA}=0.065 ; \mathrm{SRMR}=0.051$ ) revealed superior fit and good discriminative validity of main variables in this study [77].

Table 2. Confirmatory factor analysis (CFA) results for predicting discriminant validity of main variables.

\begin{tabular}{cccccccc}
\hline Model & $\chi^{2}$ & $D f$ & $\Delta \chi^{2}$ & CFI & TLI & SRMR & RMSEA \\
\hline Quality Criteria & & & & $>0.9$ & $>0.9$ & $<0.08$ & $<0.08$ \\
four-factor model (M0) & 630.74 & 344 & & 0.928 & 0.921 & 0.051 & 0.065 \\
three-factor model (M1) & 1253.96 & 347 & 623.22 & 0.773 & 0.753 & 0.085 & 0.115 \\
two-factor model (M2) & 1679.13 & 349 & 1048.39 & 0.667 & 0.639 & 0.128 & 0.139 \\
one-factor model (M3) & 2072.90 & 350 & 1442.16 & 0.569 & 0.534 & 0.138 & 0.158 \\
\hline
\end{tabular}

Note: $\mathrm{N}=196 . \mathrm{M}_{0}=$ "subordinates' Moqi with supervisors, perceived insider status, power distance orientation, and knowledge sharing behavior"; $\mathrm{M}_{1}=$ "subordinates' Moqi with supervisors + perceived insider status, power distance orientation, and knowledge-sharing behavior"; $\mathrm{M}_{2}=$ "subordinates' Moqi with supervisors+ perceived insider status + power distance orientation, and knowledge sharing behavior"; $\mathrm{M}_{3}$ = "subordinates' Moqi with supervisors + perceived insider status + power distance orientation + knowledge sharing behavior".

\subsection{Results of Hypotheses Testing}

This study took gender, age, education, organizational time, and the working time with supervisors as control variables, and used the linear regression method to test the Hypotheses 1-3. Then, this study tested H4 through using 1000-time bootstrapping approach. Finally, this study took demographic variables as control variables and tested $\mathrm{H} 5$ and $\mathrm{H} 6$ by conducting the moderating regression. Results were listed in Table 3.

\subsubsection{Main Effects}

Hypothesis 1 said that SMS could predict knowledge sharing behavior. According to the results of model 1 in Table 3, SMS was positively correlated with knowledge sharing behavior $(\beta=0.87$, $p=0.000)$. Thus, $\mathrm{H} 1$ was supported.

Hypothesis 2 stated that SMS could predict PIS. The outcomes of model 6 in Table 3 indicated that SMS was positively correlated with PIS $(\beta=0.77, p=0.000)$. Thus, H2 was supported.

Hypothesis 3 proposed that PIS could predict knowledge sharing behavior. The outcomes of model 2 in Table 3 indicated that PIS was positively correlated with knowledge sharing behavior ( $\beta=0.45, p=0.000)$. Thus, H3 was supported. 
Sustainability 2019, 11, 1421

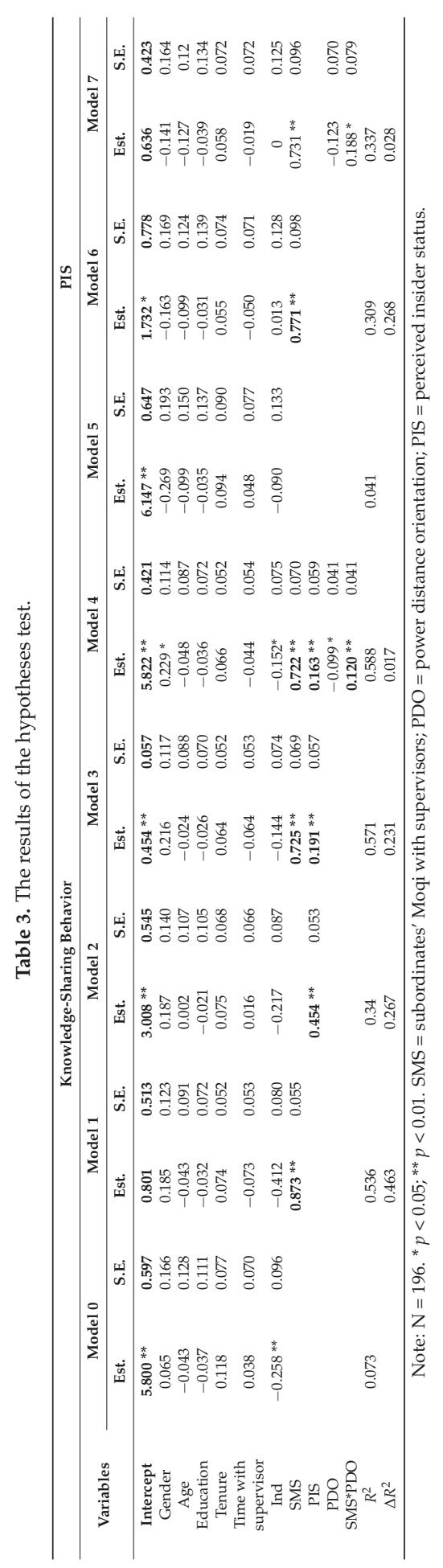




\subsubsection{Indirect Effects}

Hypothesis 4 predicted that PIS mediated the effect of SMS on knowledge sharing behavior. The results of model 6 in Table 3 showed that SMS was positively correlated with PIS ( $\beta=0.77, p=$ $0.000)$. In addition, SMS was positively correlated with knowledge-sharing behavior ( $\beta=0.87, p=$ 0.000 ) as shown in model 1 in Table 3. The results of model 3 showed that PIS was positively correlated with knowledge-sharing behavior ( $\beta=0.19, p=0.001$ ); while SMS was still positively correlated with knowledge-sharing behavior ( $\beta=0.73, p=0.000$ ). The results in Table 4 indicated that the mediating effect of PIS in SMS and knowledge-sharing behavior was significant. The $95 \%$ confidence interval of the mediating effect of PIS was [0.064, 0.218], excluding zero. Thus, the mediating effect of PIS was significant. Hypothesis 4 was supported.

Table 4. Mediating effect test results.

\begin{tabular}{|c|c|c|c|c|c|}
\hline Relationship & A & $\mathbf{b}$ & Indirect Effect & Direct Effect & $95 \%$ conf. \\
\hline $\begin{array}{l}\text { SMS-PIS-Knowledge } \\
\text { sharing behavior }\end{array}$ & $0.771 * *$ & $0.191^{* *}$ & $0.147^{* *}$ & $0.725 * *$ & {$[0.050,0.237]$} \\
\hline
\end{tabular}

Hypothesis 5 stated that PDO moderated the relationship between SMS and PIS. The result of model 7 in Table 3 showed that PDO positively moderated the effect of SMS on PIS ( $\beta=0.19, p=0.018$ ). Figure 1 presented this moderating effect of PDO through exhibiting changes of the slopes [77]. As PDO was maintained at a high level (1 standard deviation above the mean), SMS was positively correlated with PIS ( $\beta=0.95, t=7.07, p=0.000)$. As PDO was maintained at a low level ( 1 standard deviation above the mean), the positive effect of SMS on PIS was still significant ( $\beta=0.51, t=3.83$, $p=0.000$ ). Compared with two coefficients, it could be inferred that the higher PDO reached, the stronger effect of SMS on PIS would be. Together, these results provided support for Hypothesis 5.

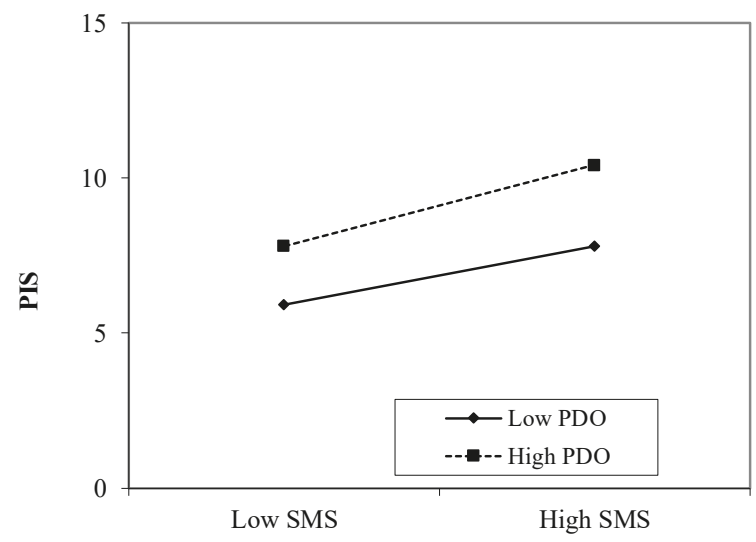

Figure 1. Moderating Effect 1.

Hypothesis 6 predicted that PDO positively moderated the effect of SMS on knowledge-sharing behavior. Model 4 in Table 3 (M4) showed that PDO positively moderated the relationship between SMS and knowledge sharing behavior $(\beta=0.12, p=0.004)$. Figure 2 presents this moderating effect through exhibiting changes of the slopes. As PDO was maintained at a high level ( 1 standard deviation above the mean), SMS was positively correlated with knowledge sharing behavior $(\beta=0.58, t=6.89$, $p=0.000)$. When maintained at a low level (1 standard deviation above the mean), the relationship was still significant $(\beta=0.86, \mathrm{t}=10.18, p=0.000)$. Compared with two coefficients, it could be inferred 
that the higher PDO reached, the stronger the effect of SMS on knowledge-sharing behavior would be. Together, these results provided support for Hypothesis 6.

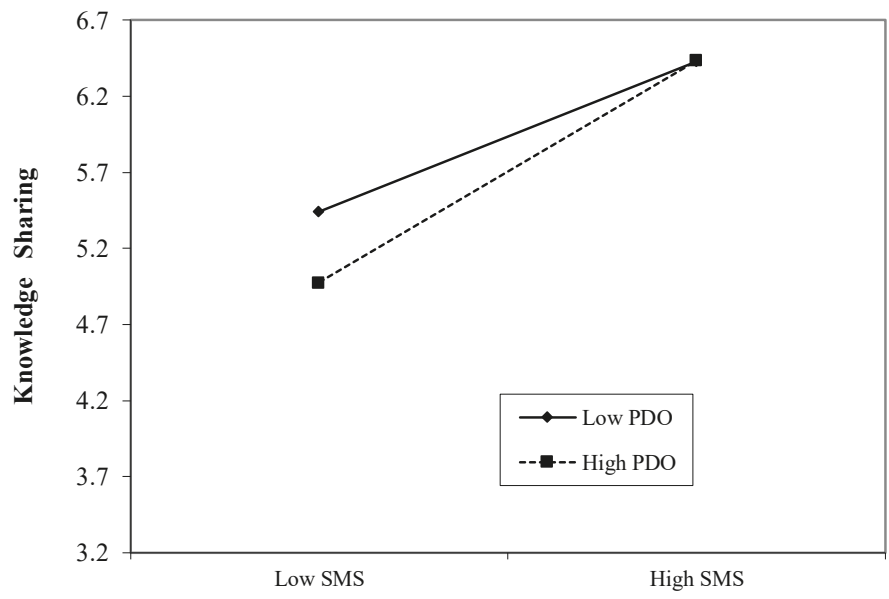

Figure 2. Moderating effect 2.

\section{Discussions}

\subsection{Findings}

The aim of this study is to understand how subordinates' Moqi with supervisors affects knowledge-sharing behavior. According to the person-supervisor fit theory, this study proposes PIS as the mediating factor and power distance orientation as the moderating factor in the subordinates' Moqi with supervisors and knowledge-sharing behavior. Results show that: (1) Moqi between subordinates and supervisors can inspire subordinates' perception of being insiders of the groups and intentions to share knowledge; (2) as subordinates consider they are insiders of the groups and the trusted followers of their supervisors, they will conduct extra-role behaviors, including knowledge sharing behavior; (3) perceived insider status mediates the effect of SMS on subordinates' knowledge sharing behavior; (4) power distance orientation positively moderates the relationship between subordinates' Moqi with supervisors and perceived insider status; (5) the indirect effect of subordinates' Moqi with supervisors on knowledge-sharing through perceived insider status is positively moderated by PDO.

\subsection{Subordinates' Moqi with Supervisors, Knowledge-Sharing Behavior and Sustainability}

Subordinates' Moqi with supervisors is a vital factor in motivating teamwork and development of organizations [20]. A good understanding between subordinates and their supervisors can not only establish closer relationships but also inspire identification and working motivation. On this occasion, members of the team will be more willing to behave altruistically to take more responsibilities. As a kind of altruistic behavior, knowledge sharing is the engine of accumulating and creating of intangible capital. Efficient knowledge sharing not only enhances the relationships among members but also generates more opportunities for innovation and reformation, indirectly prompting the whole organizations to be sustainable.

\section{Conclusions}

This study explores the mechanism of how subordinates' Moqi with supervisors (SMS) influences knowledge sharing behavior. In the path, perceived insider status is regarded as a mediator and power distance orientation is considered as a moderator. The results show that, first, SMS positively 
predicted knowledge sharing behavior and perceived insider status; second, perceived insider status positively mediated the relationship between SMS and knowledge sharing behavior; third, power distance orientation positively moderated the relationship between SMS and perceived insider status as well as the relationship between SMS and knowledge-sharing behavior. This study not only enriches the literature, but also can be referred to by practitioners.

\subsection{Implications}

Compared with past literature, this study does not apply the prevalent theories that have been widely adopted (e.g., social exchange theory), instead, this study adopts the person-supervisor fit theory to explore the antecedent of knowledge sharing behavior from the perception of interaction between subordinates and supervisors. The study verifies the predictive effect of person-supervisor fit theory in explaining the knowledge-sharing behavior, which can be referred to by other scholars.

Subsequently, this study expands the finding of Zheng and his colleagues who examine the influence of SMS on role behavior (e.g., task performance) [20], revealing the potential effect of SMS on a specific extra-role behavior (e.g., knowledge-sharing behavior). This study extends the influence of SMS from role behavior to extra-role behavior and provides a more comprehensive understanding of SMS.

Additionally, this study explores the mechanism from antecedent to knowledge-sharing from a different angle. Past scholars mainly explore the influential mechanisms of antecedents on knowledge-sharing from the perspective of social capital, motivation, social network and social exchange, enrolling trust, identification and social interaction [78], greed and perceived self-efficacy [13], expected organizational rewards, reciprocal benefits, knowledge self-efficacy, enjoyment in helping others and justice [12,19,79]. Based on person-supervisor fit theory, this study develops the findings of Zheng et al. [20], proposes the potential effect of a self-concept strategy (i.e., perceived insider status) and reveal its effect in self-concept and knowledge sharing [58]. It is consistent with the view of Shamir who proposes that work behavior may be an expression of individual self-concept that employees want to affirm in work [80].

Finally, this study verifies the moderating effect of culture (i.e., power distance orientation). High power distance reflects greater social distance orientation and low power distance emphasizes equality in power [68]. Past literature believes that good work outcomes may be achieved if individuals' PDO stay at a low level. For example, PDO can moderate the positive cross-level relationship between transformational leadership and procedural justice. The relationship is stronger at low-level PDO rather than high-level PDO [65]. The results of the current study show the positive moderating effect of PDO on the relationship between SMS and PIS. High PDO amplifies the influence of SMS on PIS and knowledge-sharing. The results specify the effect of interaction between subordinates and supervisors on employees' behaviors in the Eastern context.

The present findings have several managerial implications. Firstly, the results of this study reveal that SMS can predict knowledge-sharing. It is suggested that SMS is an important factor that promotes employees' outcomes. To inspire more subordinates' knowledge sharing for organizational sustainability, organizations may encourage employees to build SMS with their supervisors. High SMS can inspire employees to share their knowledge and capital with the organizations, indirectly contributing to the innovation and development of quality of human resources. High-quality and frequent knowledge-sharing can help organizations build high-skill and innovative teams to survive in the competitions and maintain sustainable development in the future. Secondly, the results of this study show that subordinates with high PDO are likely to share knowledge. In multicultural background teams, managers may apply different strategies to promote employees' knowledge-sharing so that the teams can be innovative, flexible and sustainable in a complex environment. Thirdly, findings show that PIS is positive to knowledge-sharing. Thus, supervisors and organizations may pay attention to managerial practices related to PIS of subordinates, such as organizational support, justice and delegation $[21,60,62]$. Through inspiring the perceived insider status, the teams can cultivate a climate 
of trust so that the members may help each other to work more sustainably. Finally, other strategies that can promote the PIS of subordinates may be integrated into leadership training programs [62].

\subsection{Limitations and Future Research}

The present study has several limitations that should be noticed in future research. Firstly, this study conducts self-reported surveys which may lead to common method variance. To reduce the threat of common method variance, future research may collect data at several different time stages. Secondly, the data of SMS is collected from subordinates. Future research should measure SMS from both subordinates' and supervisors' perspective in order to get a more objective measure of the constructs [81]. Thirdly, this study only explores the mediating effect of one dimension of self-concept (i.e., PIS). Future research may examine the influence of SMS on employees' others behavior via self-esteem (i.e., another dimension of self-concept) [82]. Finally, this study only examines the influence of SMS on knowledge sharing in the Chinese context; future research can test the model in different cultural contexts or through a comparative approach in different countries.

Author Contributions: Conceptualization, L.L. and X.Z.; methodology, L.L.; Resources, X.Z.; writing-original draft preparation, L.L. and F.Z; writing-review and editing, F.Z. and M.Z.

Funding: This research received no external funding.

Acknowledgments: We would like to thank the anonymous reviewers and editors for commenting on this paper.

Conflicts of Interest: The authors declare no conflict of interest.

\section{References}

1. Jennings, P.D.; Zandbergen, P.A. Ecologically Sustainable Organizations: An Institutional Approach. Acad. Manag. Rev. 1995, 20, 1015-1052. [CrossRef]

2. Stewart, T.; Ruckdeschel, C. Intellectual capital: The new wealth of organizations. Perform. Improv. 1998, 37, 56-59. [CrossRef]

3. Nonaka, I.; Takeuchi, H. The Knowledge Creating Company: How Japanese Companies Create the Dynamics of Innovation; Oxford University Press: New York, NY, USA, 1995.

4. Gloet, M. Knowledge management and the links to HRM developing leadership and management capabilities to support sustainability. Manag. Res. News 2006, 29, 402-413. [CrossRef]

5. Clark, W.C.; Kerkhoff, L.V.; Lebel, L.; Gallopin, A.G.C. Crafting usable knowledge for sustainable development. Proc. Natl. Acad. Sci. USA 2016, 113, 4570-4578. [CrossRef] [PubMed]

6. Kim, W.; Park, J. Examining structural relationships between work engagement, organizational procedural justice, knowledge sharing, and innovative work behavior for sustainable organizations. Sustainability 2017, 9, 205. [CrossRef]

7. Gagné, M. A model of knowledge-sharing motivation. Hum. Resour. Manag. 2009, 48, 571-589. [CrossRef]

8. Gibbert, M.; Krause, H. Practice exchange in a best practice marketplace. In Knowledge Management Case Book: Siemens Bestpractices; Davenport, T.H., Probst, G.J.B., Eds.; Publicis Corporate Publishing: Erlangen, Germany, 2002; pp. 89-105.

9. Ipe, M. Knowledge sharing in organizations: A conceptual framework. Hum. Resour. Dev. Rev. 2003, 2, 337-359. [CrossRef]

10. Srivastava, A.; Bartol, K.M.; Locke, E.A. Empowering leadership in management teams: Effects on knowledge sharing, efficacy, and performance. Acad. Manag. J. 2006, 49, 1239-1251. [CrossRef]

11. Meese, N.; Mcmahon, C. Knowledge sharing for sustainable development in civil engineering: A systematic review. Ai Soc. 2012, 27, 437-449. [CrossRef]

12. Wang, S.; Noe, R.A. Knowledge sharing: A review and directions for future research. Hum. Resour. Manag. Rev. 2010, 20, 115-131. [CrossRef]

13. Lu, L.; Leung, K.; Koch, P.T. Managerial knowledge sharing: The role of individual, interpersonal, and organizational factors. Manag. Organ. Rev. 2006, 2, 15-41. [CrossRef]

14. Hooff, B.V.D.; Ridder, J.A.D. Knowledge sharing in context: The influence of organizational commitment, communication climate and CMC use on knowledge sharing. J. Knowl. Manag. 2004, 8, 117-130. [CrossRef] 
15. Bryant, S.E. The role of Transformational and Transactional Leadership in Creating, Sharing and Exploiting Organizational Knowledge. J. Leadersh. Organ. Stud. 2003, 9, 32-44. [CrossRef]

16. Lee, S.; Kim, S.L.; Yun, S. A moderated mediation model of the relationship between abusive supervision and knowledge sharing. Leadersh. Q. 2018, 29, 403-413. [CrossRef]

17. Connelly, C.E.; Kelloway, E.K. Predictors of employees' perceptions of knowledge sharing cultures. Leadersh. Organ. Dev. J. 2013, 24, 294-301. [CrossRef]

18. Cabrera, Á.; Collins, W.C.; Salgado, J.F. Determinants of individual engagement in knowledge sharing. Int. J. Hum. Resour. Manag. 2006, 17, 245-264. [CrossRef]

19. Lin, C.P. To share or not to share: Modeling tacit knowledge sharing, its mediators and antecedents. J. Bus. Ethics 2007, 70, 411-428. [CrossRef]

20. Zheng, X.; Li, N.; Harris, T.B.; Liao, H. Unspoken yet understood: An introduction and initial framework of subordinates' moqi with supervisors. J. Manag. 2019, 45, 955-983. [CrossRef]

21. Stamper, C.L.; Masterson, S.S. Insider or outsider? How employee perceptions of insider status affect their work behavior. J. Organ. Behav. 2002, 23, 875-894. [CrossRef]

22. Eisenberger, R.; Stinglhamber, F.; Vandenberghe, C.; Sucharski, I.L.; Rhoades, L. Perceived supervisor support: Contributions to perceived organizational support and employee retention. J. Appl. Psychol. 2002, 87, 565-573. [CrossRef] [PubMed]

23. Masterson, S.S.; Stamper, C.L. Perceived organizational membership: An aggregate framework representing the employee-organization relationship. J. Organ. Behav. 2003, 24, 473-490. [CrossRef]

24. Khatri, N.; Templer, K.J.; Budhwar, P. Consequences of power distance orientation in organizations. Manag. Dev. Inst. 2009, 13, 1-9.

25. Bochner, S.; Hesketh, B. Power distance, individualism/collectivism, and job-related attitudes in a culturally diverse work group. J. Cross-Cult. Psychol. 1994, 25, 233-257. [CrossRef]

26. Henry, F.; Michael, K.H.; Kevin, A.; Michael, H.B. Moderation Effects of Power Distance on the Relationship Between Types of Empowerment and Employee Satisfaction. J. Cross-Cult. Psychol. 2013, 44, 281-298.

27. Farh, J.L.; Hackett, R.D.; Liang, J. Individual-level cultural values as moderators of perceived organizational support-employee outcome relationships in china: Comparing the effects of power distance and traditionality. Acad. Manag. J. 2007, 50,715-729. [CrossRef]

28. Moisescu, O.I. From perceptual corporate sustainability to customer loyalty: A multi-sectorial investigation in a developing country. Ekon. Istraživanja 2018, 31, 55-72. [CrossRef]

29. Stankevičiūtè, Ž.; Savanevičienè, A. Designing Sustainable HRM: The Core Characteristics of Emerging Field. Sustainability 2018, 10, 4798. [CrossRef]

30. Van Marrewijk, M. Concepts and definitions of CSR and corporate sustainability: Between agency and communion. J. Bus. Ethics 2003, 44, 95-105. [CrossRef]

31. Ponce, R.S.; Cancio, J.A.P.; Sánchez, J.E. The capabilities approach and values of sustainability: Towards an inclusive Pedagogy. J. Innov. Knowl. 2018, 3, 76-81. [CrossRef]

32. Kyvik, O. The global mindset: A must for international innovation and entrepreneurship. Int. Entrep. Manag. J. 2018, 14, 309-327. [CrossRef]

33. Lortie, J.; Cox, K.C. On the boundaries of social entrepreneurship: A review of relationships with related research domains. Int. Entrep. Manag. J. 2018, 14, 1-10. [CrossRef]

34. Huarng, K.H. Entrepreneurship for Long-Term Care in Sharing Economy. Int. Entrep. Manag. J. 2018, 14, 97-104. [CrossRef]

35. Méndez-Picazo, M.; Galindo-Martín, M.A.; Ribeiro-Soriano, D. Governance, entrepreneurship and economic growth. Entrep. Reg. Dev. 2012, 24, 865-877. [CrossRef]

36. Rey-Martí, A.; Ribeiro-Soriano, D.; Palacios-Marqués, D. A bibliometric analysis of social entrepreneurship. J. Bus. Res. 2016, 69, 1651-1655. [CrossRef]

37. Vargas, N.; Lloria, M.B.; Roig-Dobo'n, S. Main drivers of human capital, learning and performance. J. Technol. Transf. 2016, 41, 961-978. [CrossRef]

38. Berbegal-Mirabent, J.; Ribeiro-Soriano, D.E.; García, J.L.S. Can a magic recipe foster university spin-off creation? J. Bus. Res. 2015, 68, 2272-2278. [CrossRef]

39. Berbegal-Mirabent, J.; García, J.L.S.; Ribeiro-Soriano, D.E. University-industry partnerships for the provision of R\&D services. J. Bus. Res. 2015, 68, 1407-1413. 
40. García-Cabrera, A.M.; García-Soto, M.G.; Suárez-Ortega, S.M. Macro-level spillovers and micro-level capabilities as antecedents of young SMEs' propensity to export and to become a born global. Int. Entrep. Manag. J. 2017, 13, 1199-1220. [CrossRef]

41. Parellada, F.S.; Soriano, D.R.; Huarng, K.H. An overview of the service industries' future (priorities: Linking past and future). Serv. Ind. J. 2011, 31, 1-6. [CrossRef]

42. Höflinger, P.J.; Nagel, C.; Sandner, P. Reputation for technological innovation: Does it actually cohere with innovative activity? J. Innov. Knowl. 2018, 3, 26-39. [CrossRef]

43. Khyzer Bin Dost, M.; Rehman, C.A.; Gilaninia, S.; Ismail, K.B.; Wasim Akram, M. The impact of knowledge management's practices on supply chain performance of the dairy sector in Central Punjab: A mediating role of decentralization. Econ. Res. Ekon. Istraživanja 2018, 31, 290-312. [CrossRef]

44. Cummings, J.N. Work groups, structural diversity, and knowledge sharing in a global organization. Manag. Sci. 2004, 50, 352-364. [CrossRef]

45. Davenport, T.H.; De Long, D.W.; Beers, M.C. Successful knowledge management projects. Sloan Manag. Rev. 1998, 39, 43-57.

46. Lin, H.F. Knowledge sharing and firm innovation capability: An empirical study. Int. J. Manpow. 2007, 28, 315-332. [CrossRef]

47. Lin, H.F. Effects of extrinsic and intrinsic motivation on employee knowledge sharing intentions. J. Inf. Sci. 2007, 33, 135-149. [CrossRef]

48. Ahmad, F.; Widén, G. Knowledge sharing and language diversity in organisations: Influence of code switching and convergence. Eur. J. Int. Manag. 2018, 12, 351-373. [CrossRef]

49. Chiu, C.; Wang, E.T.G.; Shih, F.; Fan, Y. Understanding Knowledge Sharing in Virtual Communities: An Integration of Expectancy Disconfirmation and Justice Theories. Online Inf. Rev. 2011, 35, 134-153. [CrossRef]

50. Bavik, Y.L.; Tang, P.M.; Shao, R.; Lam, L.W. Ethical leadership and employee knowledge sharing: Exploring dual-mediation paths. Leadersh. Q. 2017, 29, 322-332. [CrossRef]

51. Li, J.; Fan, J.J. The influence of person-supervisor fit on organizational citizenship behavior: A case of service industry. In Proceedings of the International Conference on Management Science \& Engineering, Melbourne, VIC, Australia, 24-26 November 2010.

52. Jansen, K.J.; Kristofbrown, A. Toward a multidimensional theory of person-environment fit. J. Manag. Issues 2006, 18, 193-212.

53. Gregory, B.T.; Albritton, M.D.; Osmonbekov, T. The mediating role of psychological empowerment on the relationships between P-O Fit: Job satisfaction and in-role Performance. J. Bus. Psychol. 2010, 2, 117-126. [CrossRef]

54. Astakhova, M.N. Explaining the effects of perceived person-supervisor fit and person-organization fit on organizational commitment in the u.s. and Japan. J. Bus. Res. 2016, 69, 956-963. [CrossRef]

55. Nerstad, C.G.; Searle, R.; Černe, M.; Dysvik, A.; Škerlavaj, M.; Scherer, R. Perceived mastery climate, felt trust, and knowledge sharing. J. Organ. Behav. 2018, 39, 429-447. [CrossRef]

56. Allal-Chérif, O.; Bidan, M. Collaborative open training with serious games: Relations, culture, knowledge, innovation, and desire. J. Innov. Knowl. 2017, 2, 31-38. [CrossRef]

57. Armstrong-Stassen, M.; Schlosser, F. Perceived organizational membership and the retention of older workers. J. Organ. Behav. 2011, 32, 319-344. [CrossRef]

58. Vianen, A.E.M.V.; Shen, C.; Chuang, A. Person-organization and person-supervisor fits: Employee commitments in a Chinese context. J. Organ. Behav. 2011, 32, 906-926. [CrossRef]

59. Chen, Z.X.; Aryee, S. Delegation and employee work outcomes: An examination of the cultural context of mediating processes in china. Acad. Manag. J. 2007, 50, 226-238. [CrossRef]

60. Wang, J.; Kim, T.Y. Proactive socialization behavior in china: The mediating role of perceived insider status and the moderating role of supervisors' traditionality. J. Organ. Behav. 2013, 34, 389-406. [CrossRef]

61. Jarvenpaa, S.L.; Staples, D.S. Exploring perceptions of organizational ownership of information and expertise. J. Manag. Inf. Syst. 2001, 18, 151-183. [CrossRef]

62. Tiffany, R.G.; Daniel, S.; John, F. The role of Hofstede's individualism in national-level creativity. Creat. Res. J. 2012, 25, 129-136.

63. Kirkman, B.L.; Lowe, K.B. Individual power distance orientation and follower reactions to transformational leaders: A cross-level, cross-cultural examination. Acad. Manag. J. 2009, 52, 744-764. [CrossRef] 
64. Clugston, M.; Howell, J.P.; Dorfman, P.W. Does cultural socialization predict multiple bases and foci of commitment? J. Manag. 2000, 26, 5-30. [CrossRef]

65. Lam, S.S.K.; Aryee, S.S. Relationship between organizational justice and employee work outcomes: A cross-national study. J. Organ. Behav. 2002, 23, 1-18. [CrossRef]

66. Loi, R.; Long, W.L.; Chan, K.W. Coping with job insecurity: The role of procedural justice, ethical leadership and power distance orientation. J. Bus. Ethics 2012, 108, 361-372. [CrossRef]

67. Oh, I.; Guay, R.P.; Kim, K.; Harold, C.M.; Lee, J.; Hur, C.; Shin, K.H. Fit happens globally: A meta-analytic comparison of the relationships of person-environment fit dimensions with work attitudes and performance across east Asia, Europe, and north America. Pers. Psychol. 2014, 67, 99-152. [CrossRef]

68. Farh, J.L.; Earley, P.C.; Lin, S.C. Impetus for action: A cultural analysis of justice and organizational citizenship behavior in Chinese society. Adm. Sci. Q. 1997, 42, 421-444. [CrossRef]

69. Festinger, L. A theory of social comparison processes. Hum. Relat. 1954, 7, 117-140. [CrossRef]

70. Brislin, R.W. The wording and translation of research instrument. In Field Methods in Cross-Cultural Research; Lonner, W.J., Berry, J.W., Eds.; Beverly Hills: Sage, CA, USA, 1986; pp. 137-164.

71. Dorfman, P.W.; Howell, J.P. Dimensions of national culture and effective leadership in patterns. Adv. Int. Comp. Manag. 1988, 3, 127-150.

72. Liden, R.C.; Wayne, S.J.; Stilwell, D. A longitudinal study on the early development of leader-member exchanges. J. Appl. Psychol. 1993, 78, 662-674. [CrossRef]

73. Ng, T.W.; Feldman, D.C. The relationship of age to ten dimensions of job performance. J. Appl. Psychol. 2008, 93, 392-423. [CrossRef] [PubMed]

74. Zhang, Q.; Sun, S.; Zheng, X.; Liu, W. The Role of Cynicism and Personal Traits in the Organizational Political Climate and Sustainable Creativity. Sustainability 2019, 11, 257. [CrossRef]

75. Hu, L.; Bentler, P.M. Cutoff criteria for fit indexes in covariance structure analysis: Conventional criteria versus new alternatives. Struct. Equ. Model. 1999, 6, 1-55. [CrossRef]

76. Hinkin, T.R. A brief tutorial on the development of measures for use in survey questionnaires. Organ. Res. Methods 1998, 1, 104-121. [CrossRef]

77. Liu, W.; Wei, Q.; Huang, S.Q.; Tsai, S.B. Doing Good Again? A Multilevel Institutional Perspective on Corporate Environmental Responsibility and Philanthropic Strategy. Int. J. Environ. Res. Public Health 2017, 14, 1283. [CrossRef] [PubMed]

78. Chang, H.H.; Chuang, S.S. Social capital and individual motivations on knowledge sharing: Participant involvement as a moderator. Inf. Manag. 2011, 48, 9-18. [CrossRef]

79. Huang, J.; Shi, H.; Liu, W. Emotional intelligence and subjective well-being: Altruistic behavior as a mediator. Soc. Behav. Personal. 2018, 46, 749-758. [CrossRef]

80. Shamir, B. Meaning, self and motivation in organizations. Organ. Stud. 1991, 12, 405-424. [CrossRef]

81. Schriesheim, C.A.; Neider, L.L.; Scandura, T.A. Delegation and leader-member exchange: Main effects, moderators, and measurement issues. Acad. Manag. J. 1998, 41, 298-318.

82. Gecas, V. The self-concept. Annu. Rev. Sociol. 1982, 8, 1-35. [CrossRef]

(C) 2019 by the authors. Licensee MDPI, Basel, Switzerland. This article is an open access article distributed under the terms and conditions of the Creative Commons Attribution (CC BY) license (http:/ / creativecommons.org/licenses/by/4.0/). 


\title{
The Role of Cynicism and Personal Traits in the Organizational Political Climate and Sustainable Creativity
}

\author{
Qi Zhang ${ }^{1}$, Siwei Sun ${ }^{2}$, Xingshan Zheng ${ }^{1, *}$ and Wei Liu ${ }^{3, *}$ \\ 1 Antai College of Economics and Management, Shanghai Jiao Tong University, Shanghai 200030, China; \\ chyizhang@sjtu.edu.cn \\ 2 International Business School Suzhou, Xi'an Jiaotong-Liverpool University, Suzhou 215123, China; \\ Siwei.Sun17@student.xjtlu.edu.cn \\ 3 Discipline of International Business, The University of Sydney, Sydney 2006, Australia \\ * Correspondence: xszheng@sjtu.edu.cn (X.Z.); wei.liu2@sydney.edu.au (W.L.)
}

Received: 18 December 2018; Accepted: 2 January 2019; Published: 7 January 2019

\begin{abstract}
Innovation, as the key concern of sustainable human resource management, is one of the motivators of the sustainable development of organizations. However, past literature believes that innovation may be hindered by the organizational political climate. Based on the self-determination theory, this study proposes a new perspective to transfer the effect of this climate on innovation through the mediating role of cynicism and the moderating role of personal trait regulatory focus. Findings from 341 seven-point Likert survey questionnaires of employees in a Chinese automobile enterprise revealed that: first, the organizational political climate (expect interpersonal relationships) negatively predicted radical creativity and incremental creativity; second, organizational cynicism mediates the negative relationship between the organizational political climate and radical creativity and incremental creativity; third, the mediating effect of the organizational cynicism relationship between the organizational political climate and dualistic creativity could be affected by the personal trait regulatory focus. This study fills the gap in the relationship between organizational political climate and innovation. Additionally, this study proposes several suggestions for the practitioners and further research.
\end{abstract}

Keywords: sustainable human resource management; organizational political climate; organizational cynicism; personal trait regulatory focus; employee innovation

\section{Introduction}

The appeal of the sustainable development of society motivates enterprises to change their model and strategies into more long-term objects related to human issues [1,2]. Although past literature continuously explores the issues related to sustainability [3], the concept of sustainability still remains disputed in different research fields [4,5]. People, the environment and profitability are the three main focuses of the sustainability of enterprises [6]. As one research stream that focuses on how to influence individuals and groups in developing attitudes and behaviors consistent with a sustainable approach [7], human resource management that has been verified to contribute to the development of enterprises, initiating a new research direction in human resource management: sustainable human resource management, covering a comprehensive scope [8,9]. In the study of sustainability, the contents of sustainable human resource management are also widely discussed [10-13]. In this study, the main tasks of sustainable human resource management are narrowed into attracting and retaining talented employees with establishing a healthy and open work environment to motivate the organization to achieve long-term development [12]. On this occasion, how to find individuals 
with talents and inspire employees' potential talents is extremely important $[14,15]$. Talent is not only a term referring to people but also the characteristics of people, such as abilities, knowledge and competencies [15]. Innovation as an important capability is the scope of management and the motivator of the development of an organization [16]. However, the existence of an organizational political climate that initiates in enterprises the self-interest behaviors of employees, a scarcity of resources and the ambiguity of managerial policies have been considered to negatively influence the attitude and behaviors of employees, including innovative behavior [17]. Although most researchers believe that the organizational political climate may decrease the innovation of employees, the mechanism between their relationships still needs more discussion. For example, the negative effect of organizational cynicism derived from the organizational environment may turn weak, indirectly promoting the attitudes of employees [18].

Based on self-determination theory, this study attempts to explore the mechanism by which organizational political climate influences creativity, including radical creativity and incremental creativity. In this paper, research will answer the following questions: what is the role of the organizational cynicism in the organizational political climate and how it affects employees' creativity? Can the personal trait regulatory focus be regarded as the boundary condition of analyzing the relationship between organizational political climate and creativity? How do organizational cynicism and personal trait regulatory focus work on the way organizational political climate affects creativity? The rest of this paper is organized into five sections. Section 2 reviews previous studies to give a brief introduction of background and develops a conceptual model framework. Section 3 describes the research method. Section 4 shows the results of the model hypotheses and path coefficient analysis. Section 5 discusses the relationship between innovation, talent management and sustainable business development. Section 6 summarizes the main conclusions and insights of this paper and discusses shortages and further studies. Organizational innovation is the core force of the sustainable development of organizations.

\section{Background and Research Model}

\subsection{Organizational Political Climate and Employee Creativity}

Organizational political climate is the shared perceptions of practices associated with organizational recruitment, organizational decision-making, the achievement of goals, and the allocation of resources and rewards [19]. Although the effect of organizational political climate on individuals and organizations may not always be negative, the scarcity of resources and the ambiguity of managerial policies may cause negative competition among members of organizations and self-interested behavior that may lead to negative behavior $[19,20]$. A negative organizational political climate tends to destroy the contract between employees and the organization, indirectly destroying communication among individuals, performance and the proactive intentions of individuals, and the establishment of shared values in the organization $[19,21,22]$. To be specific, in a high-level organizational political climate context, the operation of an organization will be affected by many other factors (such as power and relationship), making people attach too much importance to self-interest, salary and welfare, and interpersonal relationships. After all these factors, the internal relationship between employees and the organization will be weakened, leading to passive behaviors. Therefore, as employees are in a high organizational political climate, their innovative behavior will be curbed.

In addition, the appearance of organizational politics is often accompanied by certain uncertainty and ambiguity in policies, leading to a low level of employee safety and engagement due to doubt in guarantees and supports from organizations [19]. As a kind of behavior, innovation behaviours of employees are influenced by organizational climate [23]. If the organizational political climate is maintained at a high level, the attitudes of employees will be passive, and the intentions of innovation will decrease.

Previous studies have shown that the boundary conditions should be considered by researchers studying the influential process of organizational political climate [24]. Therefore, this study explores 
the effect of organizational political climate from three dimensions (self-interest, salary and promotion and interpersonal relationship). In terms of creativity, it is also hard to measure through a single dimension $[25,26]$. Therefore, this research classifies creativity into radical creativity and incremental creativity, aiming to better understand the role of certain factors and related influences [27-29]. Radical creativity refers to innovative practice that is totally different from the existing condition, and incremental creativity refers to a minor change in the existing framework for improvement [27]. According to the above, this study hypothesizes that:

Hypothesis 1a. Self-interested behavior negatively predicts radical creativity and incremental creativity respectively.

Hypothesis $1 \mathrm{~b}$. Salary and promotion negatively predict radical creativity and incremental creativity respectively.

Hypothesis 1c. Interpersonal relationship negatively predicts radical creativity and incremental creativity respectively.

\subsection{Organizational Cynicism}

At the end of the last century, scholars first proposed organizational cynicism based on a philosophical concept and extended the study of cynicism in a new direction [30]. Organizational cynicism referring to the negative and negative attitude of employees towards the organization generally exists in the organizational environment and occurs in the initial stage of the contract relationship [31]. Organizational cynicism has three aspects, including employees' beliefs, feelings and behaviors towards the organization [32]. The appearance of organizational cynicism can be attributed to problems within the organization, such as technical defects in the organizational system, leadership, environment, etc. [33].

The characteristics of organizational cynicism are as follows: the first is perniciousness. As a negative psychological state (e.g., disappointment, anger, frustration, etc.), cynicism can reduce the performance of employees in the organization and the willingness and efficiency of labor [30,34]. Second is diffusivity. The appearance of cynical individuals within the organization will further affect the specific performance of other employees in the organization [35]. Third is multi-dimension: organizational cynicism may reflect three aspects: belief, emotion and behavior [36]. Fourth is adherence: organizational cynicism exists in organizational contexts, directly affecting the employment relations [37]. Fifth is dynamics: organizational cynicism is derived from the organizational environment and can be accompanied by the dynamic change of organizational environment, time and organizational structure [30]. On the one hand, the antecedents of organizational cynicism are the perceptions of the workplace, such as political perception, fairness, psychological contract breath, and organizational support perception [38].

As this study argues that the organizational political climate will negatively influence the perceptions of employees, organizational cynicism, a negative attitude towards the workplace, will increase. On the other hand, consequences of organizational cynicism are considered as negative perception towards workplace, organizational citizenship behavior and performance [30,32]. Therefore, it can be inferred that the high level of organizational cynicism creative behavior may decrease. As organizational cynicism is maintained at a high degree, employees may lose confidence in the organization, accompanied by a series of adverse behaviors such as lying, burnout [39]. On the contrary, if few employees show negative attitudes to the organization and work, they may be more willing to work efficiently and spare no effort in making use of their talents and knowledge for innovation [38]. Furthermore, the effect of organizational cynicism may change with time and organizational situation $[40,41]$. According to the above, this study hypothesizes that:

Hypothesis 2a. Organizational cynicism mediates the relationship between self-interest behavior and creativity. 
Hypothesis 2b. Organizational cynicism mediates the relationship between salary and promotion and creativity.

Hypothesis 2c. Organizational cynicism mediates the relationship between the interpersonal relationship and creativity.

\subsection{Personal Trait Regulatory Focus}

Most studies explore the outcome of the organizational political climate and organizational cynicism from the perspective of their negative effects [42]. However, the cynicism is changing all the time because of its adherence to the organizational environment, time and organizational structure. Additionally, the negative effect of organizational political climate and organizational cynicism may be improved due to the improvement of what has been regarded as the key of competitiveness of enterprise " $\mathrm{H}$ ". Enterprise " $\mathrm{H}$ " provided a rich situation. According to self-determination theory, individuals may be proactive in order to change their life situation. Some scholars consider organizational cynicism as a personal trait and the negative psychological situation can be changed [18,30]. Employees have two different self-regulatory tendencies in the process of pursuing goals: facilitating personal trait regulatory focus and defensive personal trait regulatory focus [43].

Individuals with facilitating personal trait regulatory focus are more sensitive to the acquisition of positive results as they pursue self-realization, and therefore they have stronger motivations to achieve goals. By contrast, individuals with defensive focus are afraid of loss and they are more sensitive to negative outcomes, and therefore, they have stronger incentives to avoid loss. As a stable individual characteristic, the personal trait regulatory focus has been proved to be an important moderator the attitude and behavior of employees in many studies [44]. Employees with facilitating regulatory focus may easier to identify potential opportunities with decreasing the negative effects of lacking self-efficacy [45].

From the perspective of self-determination theory, people with different personal trait regulatory focus have various attitudes toward pressure due to the political climate, indirectly influencing their attitudes toward innovation. The employees with facilitating personal trait regulatory focus will devote their enthusiasm to conduct actions to overcome the problems [46]. The employees with facilitating personal trait regulatory focus are more self-confident and radically creative [47]. Besides, these people will be more willing to modify the improper situation based on their knowledge [48]. By contrast, people with defensive personal trait regulatory focus are more willing to avoid huge change to avoid uncertain results [49]. Therefore, they may be more willing to modify gradually to undermine negative effects. Thus, this study hypothesizes that:

Hypothesis 3a. Facilitating personal trait regulatory focus moderates the relationship between organizational cynicism and radical creativity.

Hypothesis 3b. Defensive personal trait regulatory focus moderates the relationship between organizational cynicism and incremental creativity.

Personal trait regulatory focus can be adopted as a kind of intervention to guide the psychological situation of individuals [42]. Therefore, this study adopts personal trait regulatory focus as a moderator in the whole path by which political climate influences creativity. To be specific, the negative effects of organizational cynicism on incremental creativity cannot be effectively moderated when individuals intervene by facilitating personal trait regulatory focus. Also, the negative effects of organizational cynicism on radical creativity cannot be effectively moderated when individuals intervene by defensive personal trait regulatory focus. This paper finds out the boundary conditions of the path of organizational political climate loss by personal trait regulatory focus. Thus, this study hypothesizes that:

Hypothesis 4a. Facilitating personal trait regulatory focus moderates the relationships among organizational cynicism, self-interest behavior creativity and radical creativity. 
Hypothesis $\mathbf{4 b}$. Defensive personal trait regulatory focus moderates the relationships among organizational cynicism, self-interest behavior and incremental creativity.

Hypothesis 4c. Facilitating personal trait regulatory focus moderates the relationships among organizational cynicism, salary and promotion and radical creativity.

Hypothesis 4d. Defensive personal trait regulatory focus moderates the relationships among organizational cynicism, salary and promotion and incremental creativity.

Hypothesis 4e. Facilitating personal trait regulatory focus moderates the relationships among organizational cynicism, interpersonal relationship and radical creativity.

Hypothesis 4f. Defensive personal trait regulatory focus moderates the relationships among organizational cynicism, interpersonal relationship and incremental creativity.

Figure 1 shows the conceptual framework of the study which portrays the impact of organizational political climate, organizational cynicism, personal trait regulatory focus and dual innovation.

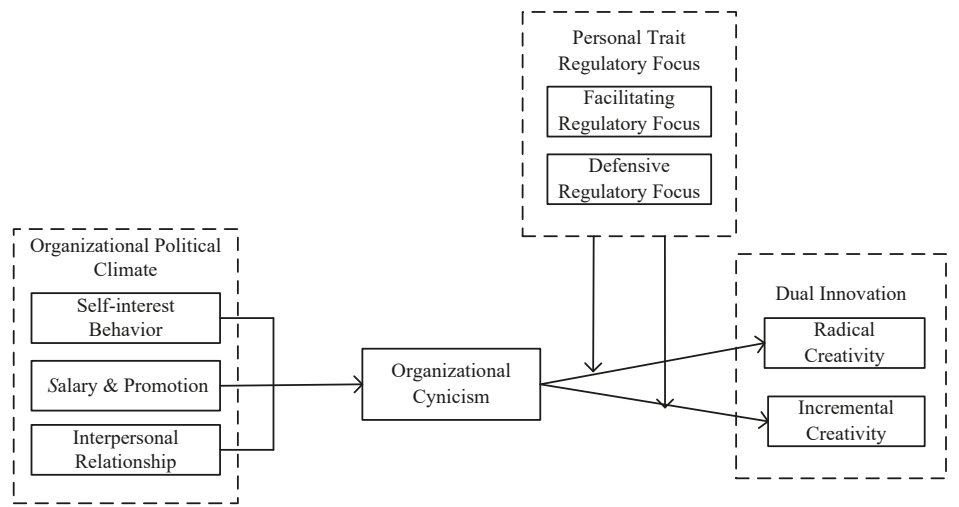

Figure 1. Conceptual framework.

\section{Materials and Methods}

\subsection{Study Design}

A quantitative research method with a survey questionnaire was adopted to explore the constructs

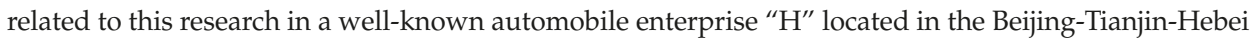
economic circle region in China. As a famous high-tech enterprise in the industry, independent research and independent innovation ability have been regarded as the key to the competitiveness of enterprise " $\mathrm{H}^{\prime}$. Enterprise " $\mathrm{H}$ " provided a rich number of samples for this study because it offered abundant job types, including research and development (R\&D) positions and design positions, and these positions required different types of innovations. Employees from R\&D and design positions could provide a sample source for measuring radical creativity. Employees from production positions provided a rich sample for this study to measure incremental creativity. Therefore, to some extent, the samples used in this study were representative.

\subsection{Measurement}

A survey questionnaire was applied in this research, covering demographic variables (age, gender, educational level, the tenure of work, position), organizational political climate, organizational cynicism, dual innovation and personal trait regulatory focus. 
The measurements adopted in this research were selected from past literature and translated from English into Chinese by professional translators. This study invited two bilingual professors of business to check the accuracy of the Chinese version to ensure translation validity. Additionally, a pilot test among 25 people was applied for the pre-test. The measurements for constructs were all seven-point Likert scales (from $1=$ strongly disagree to $7=$ strongly agree) and were verified to be reliable (Cronbach's alpha $>0.6$ ).

The organizational political climate was measured by a 13-item scale from Kacmar et al. [50]. This measurement was divided into three dimensions, including self-serving behavior (4 items), compensation benefits and promotions (5 items) and the relationship between colleagues (4 items). The Cronbach's alpha of this measurement was 0.949 .

Dualistic innovation was measured by a 6-item scale from Madjar et al. [27]. This measurement was divided into two dimensions, including radical creativity (Cronbach's alpha of this dimension was 0.866) and incremental creativity (Cronbach's alpha of this dimension was 0.799).

Organizational cynicism was measured by a 13-item scale from Dean et al. [30]. This measurement was divided into three dimensions, including organizational cynicism belief, organizational cynicism emotion and organizational cynicism behavior. The Cronbach's alpha of this measurement was 0.834.

Personal trait regulatory focus was measured by a 12-item scale from Wallace et al. [48]. This measurement was divided into two dimensions, including accelerative focus (6 items) and defensive focus (6 items). The Cronbach's alpha of this measurement was 0.90 .

Demographic variables were marked as control variables in this study to decline their influences on constructs [51]. To be specific, this study marked female as " 0 " and male as " 1 ". In addition, this study marked the position as a dummy variable (including operations, research and development, design, research and development support, research and development management, general staff and others) to define the difference between positions.

\subsection{Participants and Procedures}

This study used two methods to reduce common method bias. First, the supervisors were invited to assess the performance of their followers in creativity (radical creativity and incremental creativity). In the meantime, the employees were invited to respond to the survey about the political climate, the organizational cynicism and personal trait regulatory focus (facilitating regulatory focus and defensive regulatory focus). Secondly, this study collected data in three time periods. In the first period, 480 employees were invited to enroll the survey consisting of three parts: organizational political climate, organizational cynicism, and demographic variables. Three weeks later, the researchers sent questionnaires to the same group of employees to measure their personal trait regulatory focus. A month later, the researchers invited supervisors of the employees who filled the questionnaires at time periods 1 and 2 to rate the performance of employees in creativity. Finally, 341 effective samples were obtained after eliminating the incomplete response and the incomplete response, with a $91.6 \%$ effective response rate. To be specific, 89.2 percent were males and the rest were females. The average age of participants was 30.6 years old and the average length of work in the company was 3.8 years. Additionally, 68.1 percent of participants were bachelor's degree holders.

\section{Results}

\subsection{Descriptive Statistics and Correlations}

According to Table 1, descriptive statistics and correlation coefficients can be checked. There was a positive correlation between organizational political climate and organizational cynicism $(\mathrm{r}=0.378$, $p<0.001)$. The organizational political climate is negatively correlated with radical creativity and incremental creativity $(\mathrm{r}=-0.130, p<0.05)$. Organizational cynicism was negatively correlated with radical $(\mathrm{r}=-0.243, p<0.001)$ and incremental creativity $(\mathrm{r}=-0.229, p<0.001)$. 
Sustainability 2019, 11, 257

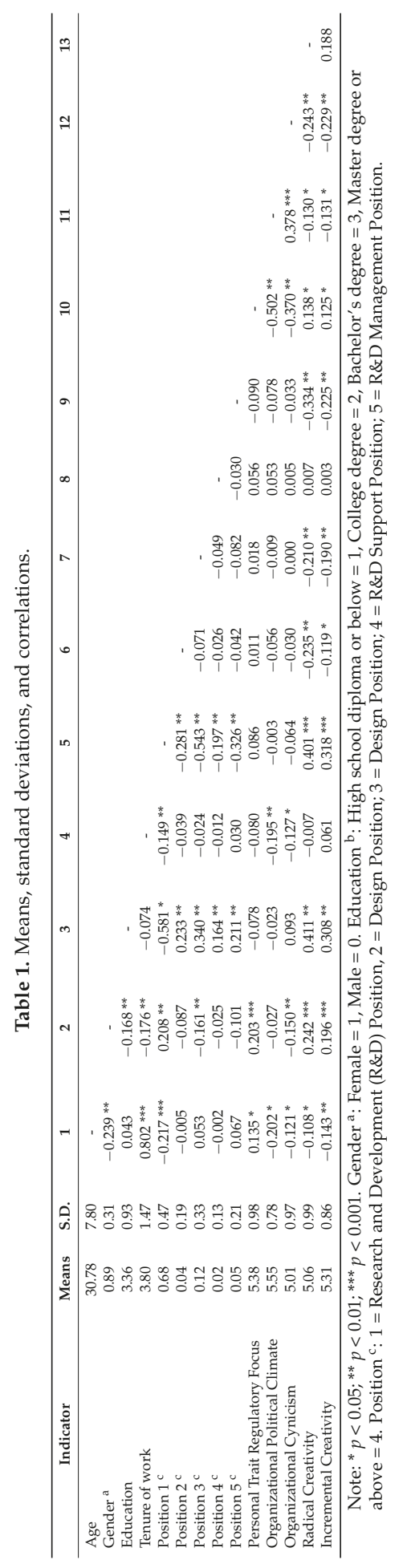




\subsection{Confirmatory Factor Analysis}

In this study, Mplus 6.0 was used for confirmatory factor analysis to examine the measurement model. Mplus is the mainstream analysis software for latent variable modeling. The software can deal with confirmatory factor analysis (CFA) and structural equation modelling (SEM) through simple programming techniques. It can be applied to measure different types of variables (e.g., continuous, censored, binary, ordered categorical, unordered categorical) by analyzing diversified data including cross-sectional data, longitudinal data, single-tier data and multi-tier data. In this study, the variables can be measured by cross-sectional and continuous data. Therefore, Mplus is an appropriate tool for analysis.

According to the suggestions, the values of $\chi^{2}$ goodness-of-fit test $\left(\chi^{2} / \mathrm{df}\right)$, the comparative fit index (CFI), Tucker-Lewis index (TLI), the root mean square error of approximation (RMSEA) and standardized root mean square residual (SRMR) could be adopted to explain the model fit $[52,53]$. The model fit indices reveal that to what extent the model reproduces the data.

$\chi^{2} / \mathrm{df}$ is used to measure the similarity between the observed covariance matrix and the expected variance matrix. It is believed that for an accepted model, the valued of $\chi^{2} / \mathrm{df}$ should be less than 5. CFI and TLI are used to compare the difference between the default model and the independent model. If the values of CFI and TLI are greater than 0.900 , and close to 1 , the model fit is satisfying. The RMSEA value is used to measure to what extent the model does not fit well. The value of this index should be less than 0.08 . The closer it is to 0 , the higher the goodness of fit. SRMR is the square root of the difference between the sample covariance matrix and the model covariance matrix. The value of SRMR should be less than 0.08 .

Table 2 showed that compared with the results of five-latent-factor model $(\mathrm{r}=157.955, p<0.01)$, four-latent-factor model $(\mathrm{r}=166.85, p<0.01)$, three-latent-factor model $(\mathrm{r}=483.271, p<0.01)$, two-latent-factor model $(\mathrm{r}=930.725, p<0.01)$, single-latent-factor model $(\mathrm{r}=1638.318, p<0.01)$. The results of the eight-latent-factor model indicates that $(499, \mathrm{~N}=341)=985.904, p=0.000$, RMSEA $=0.053, \mathrm{CFI}=0.932, \mathrm{TLI}=0.923,=1.976$, suggesting that the measurement model was well established to realize discriminant validity. In addition, all the above abbreviations are shown in the Appendix A.

Table 2. Structural model fit and model comparison.

\begin{tabular}{ccccccc}
\hline Model & $\boldsymbol{\chi}^{\mathbf{2}}$ & $\boldsymbol{\chi}^{\mathbf{2}} / \mathbf{d f}$ & CFI & TLI & RMSEA & SRMR \\
\hline Quality Criteria & $>0$ & $<5$ & $>0.9$ & $>0.9$ & $<0.08$ & $<0.08$ \\
Eight-factor Model & 985.904 & 2.908 & 0.932 & 0.923 & 0.056 & 0.054 \\
Five-factor Model & 1060.790 & 2.955 & 0.899 & 0.886 & 0.071 & 0.071 \\
Four-factor Model & 1253.565 & 3.397 & 0.824 & 0.804 & 0.093 & 0.077 \\
Three-factor Model & 1887.520 & 5.047 & 0.785 & 0.785 & 0.102 & 0.091 \\
Two-factor Model & 2210.855 & 5.849 & 0.76 & 0.73 & 0.132 & 0.108 \\
One-factor Model & 2426.440 & 6.389 & 0.491 & 0.455 & 0.155 & 0.128 \\
\hline
\end{tabular}

\subsection{Results of Hypotheses Testing}

\subsubsection{Main Effects}

H1a-1c aimed to explore the influences of each dimension of organizational political climate on radical creativity and incremental creativity. The table below shows the results of regression and $\mathrm{H} 1 \mathrm{a}-1 \mathrm{~b}$ were supported; however, the H1c was partially supported. To be specific, model 1 in the table showed that self-interest was negatively correlated with radical creativity and incremental creativity respectively $(\beta=-0.111, p=0.041 ; \beta=-0.098, p=0.046)$. Model 2 in the table showed that salary promotion was negatively correlated with radical creativity and incremental creativity respectively $(\beta=-0.092, p=0.008 ; \beta=-0.106, p=0.005)$. Model 3 in the Table 3 showed that interpersonal relationships were not associated with incremental creativity $(\beta=-0.122, p=0.008)$, while, interpersonal relationships were negatively related to radical creativity $(\beta=-0.153, p=0.055)$. 


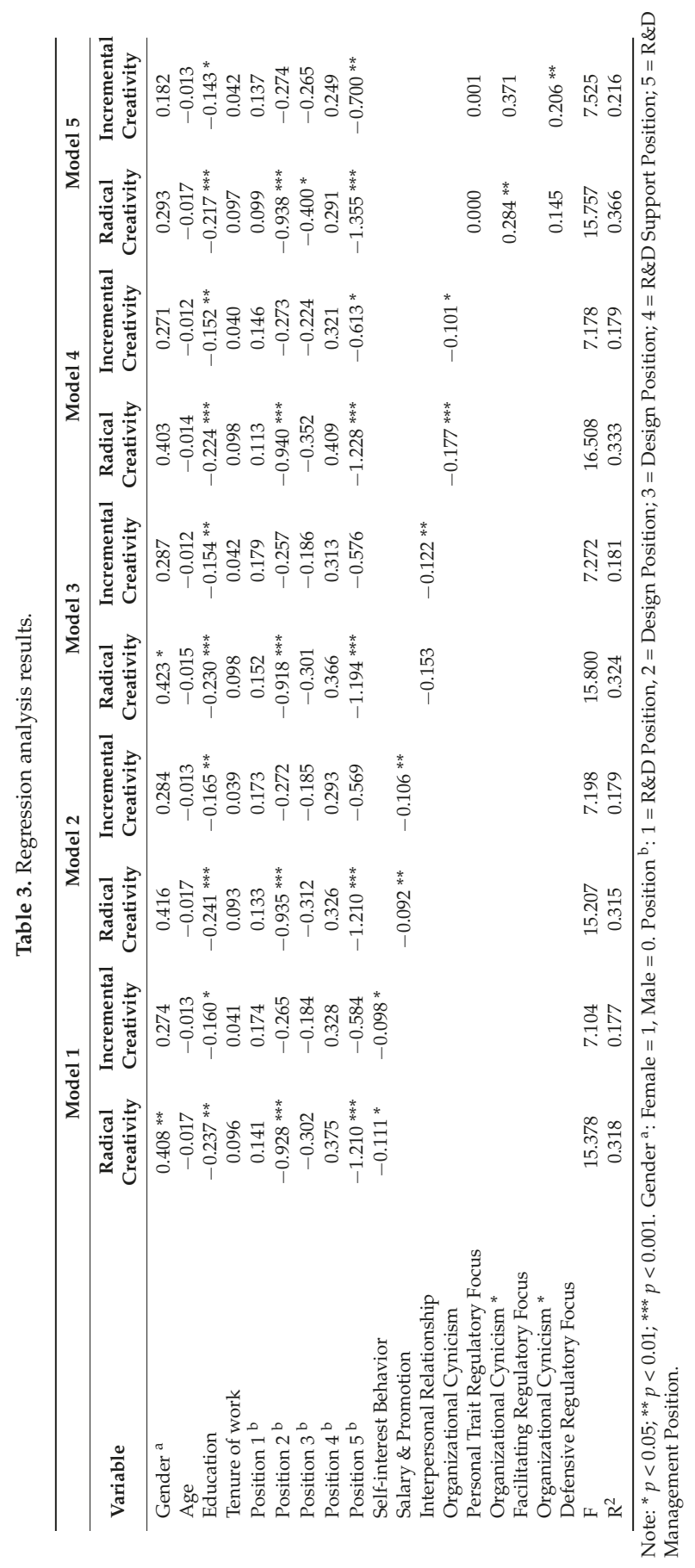




\subsubsection{Mediating Effects}

The PROCESS program proposed was used by applying a bootstrap 5000 times to test the mediating effect $(\mathrm{H} 2 \mathrm{a}-2 \mathrm{~d})$ [54]. The table showed that $\mathrm{H} 2 \mathrm{a}-2 \mathrm{~d}$ were all supported. H2a predicted that organizational cynicism positively mediated the effect of intellectual stimulation on radical creativity. The results showed that the $95 \%$ confidence interval for direct effect was $[-0.0658,0.1540]$, containing 0 ; while the $95 \%$ confidence interval for indirect effect was [0.0307, 0.1147], excluding 0 . Therefore, organizational cynicism mediated self-serving behavior and radical creativity. $\mathrm{H} 2 \mathrm{~b}$ predicted that the organizational cynicism positively mediated the effect of encouraging incentive on incremental creativity. The results showed that the $95 \%$ confidence interval for direct effect was [-0.0491, 0.1565], containing 0 , while the $95 \%$ confidence interval for indirect effect was $[0.0179,0.0979]$, excluding 0 . Therefore, organizational cynicism positively mediated the effect of encouraging incentives for incremental creativity. $\mathrm{H} 2 \mathrm{c}$ predicted that organizational cynicism mediated the positive correlation between the idealized influence and radical creativity. The results showed that the confidence interval of $95 \%$ of the direct effect was [-0.0421, 0.1948], including 0 , while the confidence interval of $95 \%$ of the indirect effect was $[0.0337,0.1326]$, excluding 0 . Therefore, organizational cynicism positively mediated the effect of salary promotion on radical creativity. In the meantime, H2c also predicted that the organizational cynicism mediated the positive correlation between the idealized influence and incremental creativity. The results showed that the confidence interval of $95 \%$ of the direct effect was $[-0.0545,0.1716]$, containing 0 , while, the confidence interval of $95 \%$ of the indirect effect was [0.0224, 0.1159], excluding 0 . Therefore, organizational cynicism positively mediated the effect of salary promotion on incremental creativity. H2d predicted that organizational cynicism mediated the positive correlation between the interpersonal relationship and radical creativity. The results showed that the $95 \%$ confidence interval for direct effect was [0.0058, 0.2189], excluding 0 , while the $95 \%$ confidence interval for indirect effect was [0.0239, 0.1172], excluding 0 . Therefore, organizational cynicism positively mediated the effect of interpersonal relationship on radical creativity. $\mathrm{H} 2 \mathrm{~d}$ also predicted that organizational cynicism mediated the positive correlation between the interpersonal relationship and incremental creativity. Table 4 showed that the confidence interval of direct effect $95 \%$ was [-0.0614, 0.1429], containing 0 , while the confidence interval of indirect effect 95\% was [0.0211, 0.1101], excluding 0 . Therefore, organizational cynicism positively mediated the effect of interpersonal relationship on incremental creativity.

Table 4. Mediation effect test results.

\begin{tabular}{ccccc}
\hline Relationship & Direct & $\mathbf{9 5 \% ~ C o n f . ~}$ & Indirect & $\mathbf{9 5 \% \text { Conf. }}$ \\
\hline $\begin{array}{c}\text { Self-interested Behavior } \rightarrow \text { Organizational } \\
\quad \text { Cynicism } \rightarrow \text { Radical Creativity }\end{array}$ & 0.0441 & {$[-0.0658,0.1540]$} & 0.0668 & {$[0.0307,0.1147]$} \\
$\begin{array}{c}\text { Self-interested Behavior } \rightarrow \text { Organizational } \\
\quad \text { Cynicism } \rightarrow \text { Incremental Creativity }\end{array}$ & 0.0537 & {$[-0.0491,0.1565]$} & 0.0525 & {$[0.0179,0.0979]$} \\
$\begin{array}{c}\text { Salary and Promotion } \rightarrow \text { Organizational } \\
\quad \text { Cynicism } \rightarrow \text { Radical Creativity }\end{array}$ & 0.0763 & {$[-0.0421,0.1948]$} & 0.0763 & {$[0.0337,0.1326]$} \\
$\quad \begin{array}{c}\text { Salary and Promotion } \rightarrow \text { Organizational } \\
\quad \text { Cynicism } \rightarrow \text { Incremental creativity }\end{array}$ & 0.0586 & {$[-0.0545,0.1716]$} & 0.0639 & {$[0.0224,0.1159]$} \\
$\begin{array}{c}\text { Interpersonal Relationships } \rightarrow \text { Organizational } \\
\quad \text { Cynicism } \rightarrow \text { Radical Creativity }\end{array}$ & 0.1124 & {$[0.0058,0.2189]$} & 0.0644 & {$[0.0239,0.1172]$} \\
$\begin{array}{c}\text { Interpersonal Relationships } \rightarrow \text { Organizational } \\
\text { Cynicism } \rightarrow \text { Incremental Creativity }\end{array}$ & 0.0407 & {$[-0.0614,0.1429]$} & 0.0606 & {$[0.0211,0.1101]$} \\
\hline
\end{tabular}

\subsubsection{Moderating Effect}

To better test $\mathrm{H} 3 \mathrm{a}-3 \mathrm{~b}$, two actions were conducted according to the suggestions [55]. First, the cynicism, accelerative focus, and restrictive focus were centralized to calculate the interaction terms. Second, the cynicism, accelerative focus, restrictive focus, the interaction terms and control variables were enrolled in the regression stage. Table 3 showed that the accelerative focus positively moderated the effect of cynicism on radical creativity $(\beta=0.284, p=0.001)$. Therefore, H3a was supported. 
Additionally, Table 3 showed that the restrictive focus significantly moderated the effect of cynicism on incremental creativity ( $\beta=0.206, p=0.004$ ). Therefore, H3b was supported. However, the accelerative focus did not significantly moderate the effect of cynicism on radical creativity $(\beta=0.371, p=0.057)$, and the restrictive focus did not significantly moderate the effect of cynicism on incremental creativity $(\beta=0.145, p=0.054)$. Figure 2 presented the moderating effects of defensive regulatory focus $(\mathbf{a}, \mathbf{b})$ and facilitating regulatory focus $(\mathbf{c}, \mathrm{d})$.

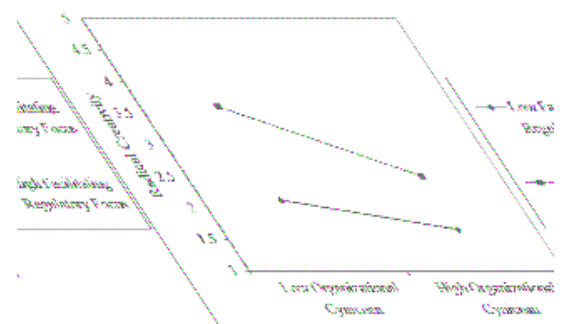

(a)

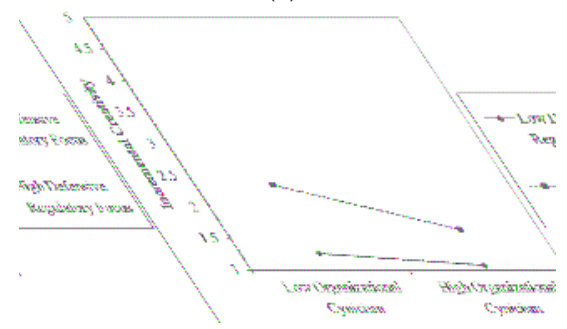

(c)

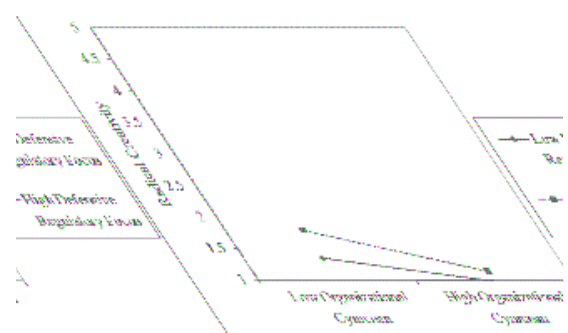

(b)

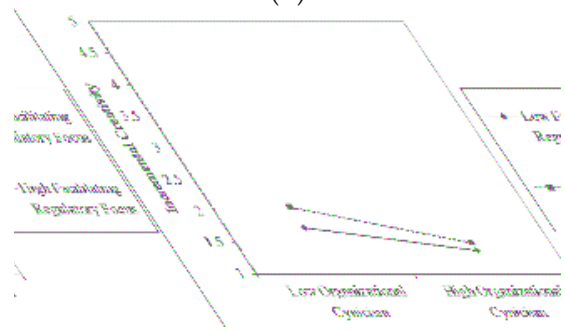

(d)

Figure 2. Graphic presentations of the moderating effects of defensive regulatory focus (a,b) and facilitating regulatory focus $(\mathbf{c}, \mathbf{d})$.

\subsubsection{Mediating Effect with Moderators on the Main Path}

H4a predicted that the accelerative focus moderated the mediating effect of organizational cynicism on the effect of self-serving behavior on radical creativity. The results showed that the $95 \%$ confidence interval was [0.0225, 0.0977], excluding 0. Therefore, the H4a was supported. H4b predicted that the restrictive focus moderated the mediating effect of organizational cynicism on the effect of self-serving behavior on incremental creativity. The results showed that the $95 \%$ confidence interval range is $[0.0114,0.0783]$, excluding 0 . Therefore, H4b was supported. H4c predicted that the accelerative focus moderated the mediating effect of organizational cynicism on the effect of salary promotion on radical creativity. The results showed that the 95\% confidence interval range was [0.0277, 0.1127], excluding 0 . Therefore, the $\mathrm{H} 4 \mathrm{c}$ was supported. H4d predicted that the accelerative focus moderated the mediating effect of organizational cynicism on the effect of salary promotion on incremental creativity. The results showed that the $95 \%$ confidence interval range was [0.0138, 0.0932], excluding 0 . Therefore, $\mathrm{H} 4 \mathrm{~d}$ was supported. H4e predicted that the accelerative focus moderated the mediating effect of organizational cynicism on the effect of interpersonal relationships on radical creativity. The results showed that the $95 \%$ confidence interval range was $[0.0249,0.1038]$, excluding 0 . Therefore, the H4e was supported. H4f predicted that the restrictive focus moderated the mediating effect of organizational cynicism on the effect of interpersonal relationship on incremental creativity. The results showed that the $95 \%$ confidence interval range was [0.0118, 0.0867], excluding 0 . Therefore, the H4f was supported. 


\section{Discussion}

\subsection{Findings}

This study explores the influence of organizational political climate on employees' dual creativity based on self-determination theory and the role of organizational cynicism. The findings can be summarized as follows:

\subsubsection{The Negative Effect of Organizational Political Climate and the Mediating Effect of Organizational Cynicism}

The research finds that the dimensions of organizational political climate about self-interested behavior and salary and promotion are negative to employees' performance in innovation. Additionally, organizational cynicism is considered to mediate the effect of self-interested behavior on creativity and mediates the effect of salary and promotion on creativity. As employees are immersed in a high degree organizational political climate, they will be sensitive to issues about self-interested behavior and salary and promotion, and they may less devote themselves into work and innovation and creation as they feel unjust about their treatment.

However, interpersonal relationships are only negatively related to incremental creativity and not obviously related to radical creativity. This reveals that the high-degree political climate may influence the innovative behaviours more in reformations of the present situation than in comprehensive innovation. Furthermore, organizational cynicism is considered to mediate the effect of interpersonal relationships on incremental creativity. This shows that employees' passion for reformation is influenced by their perceptions about relationships among colleagues. If they perceive that the relationships among colleagues are distant, they may less care about others' opinions and conduct less reformative actions in their work places.

\subsubsection{Moderating Effect of Personal Trait Regulatory Focus}

The findings show that as people have a facilitating personal trait regulatory focus, the negative effect of cynicism on radical creativity can decline. However, as people have a defensive personal trait regulatory focus, the negative effect of cynicism on incremental creativity can decline. Additionally, facilitating personal trait regulatory focus can moderate the mediating effect of cynicism on the relationship between organizational political climate and radical creativity, while defensive personal trait regulatory focus can moderate the mediating effect of cynicism on the relationship between organizational political climate and incremental creativity.

\section{Conclusions}

The research shows that the negative effects of organizational political climate and organizational cynicism on employees' performance are not irreversible. This study regards cynicism as a dynamic variable and the personal trait regulatory focuses as a moderating variable in the organizational political climate. The results show that: first, self-interested behavior and salary and promotion are negatively related to creativity. However, interpersonal relationships are only negatively related to incremental creativity and not obviously related to radical creativity. Second, organizational cynicism mediates the effect of self-interested behavior on creativity and mediates the effect of salary and promotion on creativity. However, organizational cynicism only mediates the effect of interpersonal relationships on incremental creativity. Third, as people have the facilitating personal trait regulatory focus, the negative effect of cynicism on radical creativity can decline. As people have the defensive personal trait regulatory focus, the negative effect of cynicism on incremental creativity can decline. Fourth, a facilitating personal trait regulatory focus can moderate the mediating effect of cynicism on the relationship between organizational political climate and radical creativity, while a defensive personal trait regulatory focus can moderate the mediating effect of cynicism on the relationship 
between organizational political climate and incremental creativity. This study not only fills the gap in the literature, but also can be referred to by practitioners for management.

\subsection{Implications}

The theoretical contributions of this study are as follows. First, this study provides a new research perspective for understanding "how to restrain the negative effects of organizational political climate" and expands the research scope of the relationship between "organizational climate-creativity" [56,57]. Secondly, this study enriches the research on antecedents and their influencing mechanisms of the two types of creativity. At present, most studies on creativity focus on the exploration of antecedents [58], however, few studies discuss a certain antecedent and its mediating mechanism. This study enriches the research in creativity by exploring how the mechanism of organizational cynicism mediates the relationship between organizational political climate and creativity from the perspective of the organizational environment. Third, this study expands the research of personal trait regulatory focus. Past literature mostly discusses the effect of personal trait regulatory focus on satisfaction [59], performance [60] and motivation [49], while few studies discuss the effect of focus on creativity. This study verifies the moderating effect of personal trait regulatory focus, a kind of personal trait, on the relationship between organizational cynicism and creativity, enriching the relevant research and providing a possible perspective for future studies on the theoretical boundary of creativity.

This study also can be referred to for practice. First, organizations may help employees to inspire innovation. As employees work in a position that they are adept in, they may be more willing to contribute to organizations [61]. If the employees recognize their role in contributing to innovation and transformation, they may be more proactive and innovative. In addition, organizations may conduct different policies to inspire their innovation and motivation according to the types of employees. For the talented employees and knowledge employees, facilitating policies may be carried out to encourage radical innovation. Compared with general workers, talented employees and knowledge employees usually acquire skills faster and apply knowledge more flexibly, and therefore, the positive climate and policy may inspire their talents to contribute to innovation and creation for the transformation of organizations. For general workers, perceptions about interpersonal relationships should consider which influences incremental creativity. Since general workers used to be the people who know the emerging problems of work, their attitudes determine the performance of organizations. Thus, organizations should be concerned with the feelings of those workers and assist these employees in setting work goals and balancing their work and life well according to their personal characteristics. Furthermore, organizations may encourage general workers to reform ways of working to overcome problems in daily work.

Second, organizations may develop systematic staff training courses about personal trait regulatory focus to cultivate the values of employees and build positive climates for employees. Third, organizations may optimize staff deployment and recruitment by arranging for employees to have a facilitating personal trait regulatory focus to different departments to decrease the negative effect of the organizational political climate. In addition, organizations may deploy people with defensive focuses to risk-control departments, while assigning people with facilitating focus to more innovative and open positions.

\subsection{Limitation and Future Research}

As with all studies, this study has some limitations. First, this study only explores the perceptions of employees from one automobile industry in China. The limitation in sample size and cultural and industrial diversity of the case cannot be omitted. Future research can test the model with broad contexts and a larger sample size. Second, this study applies quantitative research (survey-based) for collecting data, however, a single research method cannot reflect the whole phenomenon. Therefore, future research may apply a mixed method to explore similar phenomena. Moreover, this study was not concerned with contextual factors and individual factors completely, and individual factors, 
contextual factors and their interactions may influence creativity [62]. Therefore, future research may explore the interactive effect of individual factors and contextual factors, motivation, psychological empowerment and committees in the study of creativity.

Author Contributions: Conceptualization, Q.Z. and X.Z.; methodology, Q.Z. and S.S.; resources, X.Z.; writing - original draft preparation, Q.Z. \& S.S.; writing-review and editing, X.Z. \& W.L.; funding acquisition, W.L.

Funding: This research is supported by the National Social Science Foundation of China (Grant No. 17CGJ002).

Acknowledgments: We would like to thank the governments and institutes who offered funds for this research, and the students and colleagues who gave support for the data collection. Furthermore, we also would like to thank the anonymous reviewers and editors for commenting on this paper.

Conflicts of Interest: The authors declare no conflict of interest.

\section{Appendix A}

Table A1. Abbreviations.

\begin{tabular}{cc}
\hline Full Name of Terms & Abbreviations \\
\hline Research and development & R\&D \\
Standard deviation & S.D. \\
Confirmatory factor analysis & CFA \\
Structural equation modelling & SEM \\
$\chi^{2}$ goodness-of-fit test & $\chi^{2} / \mathrm{df}$ \\
The comparative fit index & CFI \\
Tucker-Lewis index & TLI \\
The root mean square error of approximation & RMSEA \\
Standardized root mean square residual & SRMR \\
\hline
\end{tabular}

\section{References}

1. Ehnert, I.; Parsa, S.; Roper, I.; Wagner, M.; Muller-Camen, M. Reporting on sustainability and HRM: A comparative study of sustainability reporting practices by the world's largest companies. Int. J. Hum. Resour. Manag. 2016, 27, 88-108. [CrossRef]

2. Ozolina-Ozola, I. The impact of human resource management practices on employee turnover. Procedia-Soc. Behav. Sci. 2014, 156, 223-226. [CrossRef]

3. Taylor, S.; Beechler, S.; Napier, N. Toward an integrative model of strategic international human resource management. Acad. Manag. Rev. 1996, 21, 959-985. [CrossRef]

4. Presley, A.; Meade, L.; Sarkis, J. A strategic sustainability justification methodology for organizational decisions: A reverse logistics illustration. Int. J. Prod. Res. 2007, 45, 4595-4620. [CrossRef]

5. Becker, B.; Gerhart, B. The impact of human resource management on organizational performance: Progress and prospects. Acad. Manag. J. 1996, 39, 779-801.

6. Dao, V.; Langella, I.; Carbo, J. From green to sustainability: Information Technology and an integrated sustainability framework. J. Strateg. Inf. Syst. 2011, 20, 63-79. [CrossRef]

7. Boudreau, J.W.; Ramstad, P.M. Talentship, talent segmentation, and sustainability: A new HR decision science paradigm for a new strategy definition. Hum. Resour. Manag. Publ. Cooperation Sch. Bus. Adm. Univ. Mich. Alliance Soc. Hum. Resour. Manag. 2005, 44, 129-136. [CrossRef]

8. Lee, M.D.P. A review of the theories of corporate social responsibility: Its evolutionary path and the road ahead. Int. J. Manag. Rev. 2008, 10, 53-73. [CrossRef]

9. Kramar, R. Beyond strategic human resource management: Is sustainable human resource management the next approach? Int. J. Hum. Resour. Manag. 2014, 25, 1069-1089. [CrossRef]

10. Järlström, M.; Saru, E.; Vanhala, S. Sustainable human resource management with salience of stakeholders: A top management perspective. J. Bus. Ethics 2018, 152, 703-724. [CrossRef]

11. Hobelsberger, C. Sustainability and HRM in international supply chains. In Sustainability and Human Resource Management; Springer: Berlin/Heidelberg, Germany, 2014; pp. 379-400. 
12. Ehnert, I. Sustainable human resource management. In A Conceptual and Exploratory Analysis from a Paradox Perspective; Springer: Heidelberg, Germany, 2009.

13. Baum, T. Sustainable human resource management as a driver in tourism policy and planning: A serious sin of omission? J. Sustain. Tour. 2018, 26, 873-889. [CrossRef]

14. Lewis, R.E.; Heckman, R.J. Talent management: A critical review. Hum. Resour. Manag. Rev. 2006, 16, $139-154$. [CrossRef]

15. Gollan, P.J. High involvement management and human resource sustainability: The challenges and opportunities. Asia Pac. J. Hum. Resour. 2005, 43, 18-33. [CrossRef]

16. Lawson, B.; Samson, D. Developing innovation capability in organisations: A dynamic capabilities approach. Int. J. Innov. Manag. 2001, 5, 377-400. [CrossRef]

17. Chang, C.-H.; Rosen, C.C.; Levy, P.E. The relationship between perceptions of organizational politics and employee attitudes, strain, and behavior: A meta-analytic examination. Acad. Manag. J. 2009, 52, 779-801. [CrossRef]

18. Chiaburu, D.S.; Peng, A.C.; Oh, I.-S.; Banks, G.C.; Lomeli, L.C. Antecedents and consequences of employee organizational cynicism: A meta-analysis. J. Vocat. Behav. 2013, 83, 181-197. [CrossRef]

19. Landells, E.; Albrecht, S.L. Organizational political climate: Shared perceptions about the building and use of power bases. Hum. Resour. Manag. Rev. 2013, 23, 357-365. [CrossRef]

20. Drory, A.; Romm, T. The definition of organizational politics: A review. Hum. Relat. 1990, 43, 1133-1154. [CrossRef]

21. Rosen, C.C.; Harris, K.J.; Kacmar, K.M. The emotional implications of organizational politics: A process model. Hum. Relat. 2009, 62, 27-57. [CrossRef]

22. Kacmar, K.M.; Bachrach, D.G.; Harris, K.J.; Zivnuska, S. Fostering good citizenship through ethical leadership: Exploring the moderating role of gender and organizational politics. J. Appl. Psychol. 2011, 96, 633. [CrossRef]

23. Yu, C.; Yu, T.-F.; Yu, C.-C. Knowledge sharing, organizational climate, and innovative behavior: A cross-level analysis of effects. Soc. Behav. Pers. Int. J. 2013, 41, 143-156. [CrossRef]

24. Landells, E.M.; Albrecht, S.L. The positives and negatives of organizational politics: A qualitative study. J. Bus. Psychol. 2017, 32, 41-58. [CrossRef]

25. Sternberg, R.J. A propulsion model of types of creative contributions. Rev. Gen. Psychol. 1999, 3, 83. [CrossRef]

26. Kaufman, J.C.; Beghetto, R.A. Beyond big and little: The four c model of creativity. Rev. Gen. Psychol. 2009, 13, 1. [CrossRef]

27. Madjar, N.; Greenberg, E.; Chen, Z. Factors for radical creativity, incremental creativity, and routine, noncreative performance. J. Appl. Psychol. 2011, 96, 730. [CrossRef]

28. Unsworth, K. Unpacking creativity. Acad. Manag. Rev. 2001, 26, 289-297. [CrossRef]

29. Gilson, L.L.; Madjar, N. Radical and incremental creativity: Antecedents and processes. Psychol. Aesthetics Creativity Arts 2011, 5, 21. [CrossRef]

30. Dean, J.W., Jr.; Brandes, P.; Dharwadkar, R. Organizational cynicism. Acad. Manag. Rev. 1998, 23, 341-352. [CrossRef]

31. Johnson, J.L.; O'Leary-Kelly, A.M. The effects of psychological contract breach and organizational cynicism: Not all social exchange violations are created equal. J. Organ. Behav. Int. J. Ind. Occup. Organ. Psychol. Behav. 2003, 24, 627-647. [CrossRef]

32. Neves, P. Organizational cynicism: Spillover effects on supervisor-subordinate relationships and performance. Leadersh. Q. 2012, 23, 965-976. [CrossRef]

33. Andersson, L.M.; Bateman, T.S. Cynicism in the workplace: Some causes and effects. J. Organ. Behav. Int. J. Ind. Occup. Organ. Psychol. Behav. 1997, 18, 449-469. [CrossRef]

34. Harrell-Cook, G.; Ferris, G.R.; Dulebohn, J.H. Political behaviors as moderators of the perceptions of organizational politics-Work outcomes relationships. J. Organ. Behav. 1999, 20, 1093-1105. [CrossRef]

35. Wilkerson, J.M.; Evans, W.R.; Davis, W.D. A test of coworkers' influence on organizational cynicism, badmouthing, and organizational citizenship behavior. J. Appl. Soc. Psychol. 2008, 38, 2273-2292. [CrossRef]

36. Brandes, P.; Castro, S.L.; James, M.S.; Martinez, A.D.; Matherly, T.A.; Ferris, G.R.; Hochwarter, W.A. The interactive effects of job insecurity and organizational cynicism on work effort following a layoff. J. Leadersh. Organ. Stud. 2008, 14, 233-247. [CrossRef] 
37. Treadway, D.C.; Hochwarter, W.A.; Ferris, G.R.; Kacmar, C.J.; Douglas, C.; Ammeter, A.P.; Buckley, M.R. Leader political skill and employee reactions. Leadersh. Q. 2004, 15, 493-513. [CrossRef]

38. Koseoglu, G.; Liu, Y.; Shalley, C.E. Working with creative leaders: Exploring the relationship between supervisors' and subordinates' creativity. Leadersh. Q. 2017, 28, 798-811. [CrossRef]

39. Hochwarter, W.A.; James, M.; Johnson, D.; Ferris, G.R. The Interactive Effects of Politics Perceptions and Trait Cynicism on Work Outcomes. J. Leadersh. Organ. Stud. 2004, 10, 44-57. [CrossRef]

40. Gkorezis, P.; Petridou, E.; Xanthiakos, P. Leader positive humor and organizational cynicism: LMX as a mediator. Leadersh. Organ. Dev. J. 2014, 35, 305-315. [CrossRef]

41. Nazir, T.; Ahmad, U.N.B.U.; Nawab, S.; Shah, S.F.H. Mediating role of organizational cynicism in relationship between role stressors and turnover intention: Evidence from healthcare sector of Pakistan. Int. Rev. Manag. Mark. 2016, 6, 199-204.

42. Jiang, H.; Chen, Y.; Sun, P.; Li, C. Authoritarian leadership and employees' unsafe behaviors: The mediating roles of organizational cynicism and work alienation. Curr. Psychol. 2017, 1-11. [CrossRef]

43. Higgins, E.T. Beyond pleasure and pain. Am. Psychol. 1997, 52, 1280. [CrossRef] [PubMed]

44. Idson, L.C.; Liberman, N.; Higgins, E.T. Distinguishing gains from nonlosses and losses from nongains: A regulatory focus perspective on hedonic intensity. J. Exp. Soc. Psychol. 2000, 36, 252-274. [CrossRef]

45. Tumasjan, A.; Braun, R. In the eye of the beholder: How regulatory focus and self-efficacy interact in influencing opportunity recognition. J. Bus. Ventur. 2012, 27, 622-636. [CrossRef]

46. Tuncdogan, A.; Van Den Bosch, F.; Volberda, H. Regulatory focus as a psychological micro-foundation of leaders' exploration and exploitation activities. Leadersh. Q. 2015, 26, 838-850. [CrossRef]

47. Manczak, E.M.; Zapata-Gietl, C.; McAdams, D.P. Regulatory focus in the life story: Prevention and promotion as expressed in three layers of personality. J. Pers. Soc. Psychol. 2014, 106, 169. [CrossRef] [PubMed]

48. Wallace, J.C.; Johnson, P.D.; Frazier, M.L. An examination of the factorial, construct, and predictive validity and utility of the regulatory focus at work scale. J. Organ. Behav. Int. J. Ind. Occup. Organ. Psychol. Behav. 2009, 30, 805-831. [CrossRef]

49. Peng, A.C.; Dunn, J.; Conlon, D.E. When vigilance prevails: The effect of regulatory focus and accountability on integrative negotiation outcomes. Organ. Behav. Hum. Decis. Processes 2015, 126, 77-87. [CrossRef]

50. Kacmar, K.M.; Carlson, D.S. Further validation of the perceptions of politics scale (POPS): A multiple sample investigation. J. Manag. 1997, 23, 627-658. [CrossRef]

51. Ng, T.W.; Feldman, D.C. The relationship of age to ten dimensions of job performance. J. Appl. Psychol. 2008, 93, 392. [CrossRef] [PubMed]

52. Medsker, G.J.; Williams, L.J.; Holahan, P.J. A review of current practices for evaluating causal models in organizational behavior and human resources management research. J. Manag. 1994, 20, 439-464. [CrossRef]

53. Wang, M.; Russell, S.S. Measurement equivalence of the job descriptive index across Chinese and American workers: Results from confirmatory factor analysis and item response theory. Educ. Psychol. Meas. 2005, 65, 709-732. [CrossRef]

54. Bolin, J.H. Hayes, Andrew F. (2013). Introduction to Mediation, Moderation, and Conditional Process Analysis: A Regression-Based Approach. New York, NY: The Guilford Press. J. Educ. Meas. 2014, 51, 335-337. [CrossRef]

55. Dawson, J.F.; Richter, A.W. Probing three-way interactions in moderated multiple regression: Development and application of a slope difference test. J. Appl. Psychol. 2006, 91, 917. [CrossRef] [PubMed]

56. Kaya, N.; Aydin, S.; Ongun, G. The impacts of servant leadership and organizational politics on burnout: A research among mid-level managers. Int. J. Bus. Adm. 2016, 7, 26. [CrossRef]

57. Lau, P.Y.Y.; Tong, J.L.T.; Lien, B.Y.-H.; Hsu, Y.-C.; Chong, C.L. Ethical work climate, employee commitment and proactive customer service performance: Test of the mediating effects of organizational politics. J. Retail. Consum. Serv. 2017, 35, 20-26. [CrossRef]

58. Wallace, J.C.; Butts, M.M.; Johnson, P.D.; Stevens, F.G.; Smith, M.B. A multilevel model of employee innovation: Understanding the effects of regulatory focus, thriving, and employee involvement climate. J. Manag. 2016, 42, 982-1004. [CrossRef]

59. Zhao, X.R.; Namasivayam, K. The relationship of chronic regulatory focus to work-family conflict and job satisfaction. Int. J. Hosp. Manag. 2012, 31, 458-467. [CrossRef]

60. Zhang, S.; Cornwell, J.F.; Higgins, E.T. Repeating the past: Prevention focus motivates repetition, even for unethical decisions. Psychol. Sci. 2014, 25, 179-187. [CrossRef] 
61. Benner, M.J.; Tushman, M.L. Exploitation, exploration, and process management: The productivity dilemma revisited. Acad. Manag. Rev. 2003, 28, 238-256. [CrossRef]

62. Woodman, R.W.; Sawyer, J.E.; Griffin, R.W. Toward a theory of organizational creativity. Acad. Manag. Rev. 1993, 18, 293-321. [CrossRef]

(C) 2019 by the authors. Licensee MDPI, Basel, Switzerland. This article is an open access article distributed under the terms and conditions of the Creative Commons Attribution (CC BY) license (http:/ / creativecommons.org/licenses/by/4.0/). 
Article

\title{
Why Do Companies Choose Female CEOs?
}

\author{
Shuo Han ${ }^{1}$, Weijun Cui ${ }^{1,2, *}$, Jin Chen ${ }^{3,4}$ and $\mathrm{Yu} \mathrm{Fu}^{1}$ \\ 1 Business School, Nanjing University of Information Science \& Technology, Nanjing 210044, China \\ 2 China Institute of Manufacturing Development, Nanjing University of Information Science \& Technology, \\ Nanjing 210044, China \\ 3 School of Economics and Management, Tsinghua University, Beijing 100085, China \\ 4 Research Center for Technological Innovation, Tsinghua University, Beijing 100085, China \\ * Correspondence: cuiweijun@nuist.edu.cn
}

Received: 27 April 2019; Accepted: 25 July 2019; Published: 27 July 2019

\begin{abstract}
For the career development of chief executive officers (CEOs), the existing literature lacks research from the perspectives of gender and the environment. Starting with the perspective of the environment, and through the adoption of the World Bank Survey Data on Chinese Enterprises and China's Comprehensive Social Survey (CGSS), this paper addresses the question: "Why do companies choose female CEOs?" The analysis examines 15 aspects, including enterprise scale, age, industry, owner, product market, market environment, city level, etc. The research findings are as follows. (1) The corporate environment has an impact on CEO gender, and there are differences in its nature and the degree of impact. Enterprise size, state-owned shareholding, radiation effect, market environment, and gender culture have a significant negative impact on female CEOs, while product features, industry characteristics, and female owners have a significantly positive impact on female CEOs. (2) In terms of the impact mechanism, the impact of the meso-environment on female CEOs is significantly adjusted by the macro-environment. This paper extends the existing theory from the perspectives of gender and the environment. Relevant policy recommendations are proposed to provide a theoretical basis for the government to promote women's employment policies and provide effective suggestions for promoting women's career development.
\end{abstract}

Keywords: female CEOs; environment; regulating effect; gender culture

\section{Introduction}

Women are an important force in achieving sustainable development, and gender balance is very important for enterprise development. In recent years, with the improvement of women's education levels, social and economic development, and the progress of science and technology, the proportion and number of female executives are also increasing. This phenomenon has also aroused widespread concern in academia [1]. However, as we have observed, the position of corporate chief executive officers (CEO) is still dominated by males and rarely held by women.

As the existing theories of career development are concerned, neither occupational status attainment theory nor human resource theory can reasonably explain why there are fewer female CEOs. Both theories emphasize the importance of personal factors to career development. According to the occupational status attainment theory, with economic growth and rising education levels, people's career development will depend on individual efforts, namely, their achievement factor, rather than such ascribed factors as family background, etc. Human capital theory holds that education, work experience, and skills are all rare resources of economic value and of great importance to career development. However, as we see, with women's education levels going up and their years of working and working experience increasing, their positions and levels have not improved accordingly. Only a few women have made their way to $\mathrm{CEO}$, breaking through the glass ceiling. Therefore, the few women who break through the glass ceiling and become CEOs are more worthy of our research. 
So, from what perspective should we look at and understand the unusual behavior of companies employing female CEOs? Theoretically, the drawback of the existing theories consists of the ignorance of the impact of the company's environment. The company's workplace revolves around men, and as a result, women have to learn through socialization and adapt to the environment to meet the demand of enterprise development. Therefore, the environment is the key to understanding companies recruiting female CEOs and breaking through the existing theories. In summary, we should study the gender of CEOs from the perspective of corporate environment, namely: how does the environment affect the gender of CEOs? The answer to this question will help us better understand and evaluate female CEOs and promote sustainable enterprise development.

In view of the factors affecting CEO genders, scholars have carried out research regarding women's own features [1], company characteristics [2], industry environment [3], cultural differences [4], and other different perspectives, and have drawn many useful conclusions. These studies have both strengths and shortcomings. First of all, there is a hypothesis behind previous studies that males have stronger management ability than their female counterparts. However, gender is a kind of social construction, and gender culture has a profound impact on the viewpoints toward males and females. In fact, as Simone de Beauvoir, pioneer of the world feminist movement, put it like this, "Women are not born, but acquired" [5]. Thus, the stereotyped cognition of women may more or less affect existing research. Secondly, existing research studies lack an overall analysis framework, and the mechanism analysis of the impacts of each factor is insufficient. Although different impact factors feature in in-depth research studies, few studies in the literature have put different factors into a framework. In fact, the designation of CEOs is a strategic issue that may be affected by the environment. However, little of the existing literature has analyzed it from the perspective of the environment. In summary, existing research studies rarely provide clear and credible answers to this issue [6].

Based on the above analysis, the core viewpoint of this paper is that there are no differences between male and female CEOs in terms of ability, and the choice of female CEOs is a result that may be affected by the corporate environment. The purpose of this paper is, on the basis of relaxing the original hypothesis and considering that there are no differences between male and female CEOs in terms of ability, to construct an overall framework of the corporate micro-environment, industry meso-environment, and regional macro-environment from the perspective of the environment, and conduct studies that ask: "why do companies choose female CEOs?" In response, this paper mainly answers from two aspects. (1) What environmental factors have a significant impact on female CEOs? (2) What is the impact mechanism of the environment on CEO gender?

The main approach adopted in this paper is to start with the corporate environment and conduct research by selecting the World Bank Survey Data on Chinese Enterprises 2010 and China's Comprehensive Social Survey (CGSS 2012). To be specific, the corporate micro-environment is described in relation to enterprise size, enterprise age, company attributes, industry characteristics, female owners, and other aspects. The industry meso-environment in which enterprises are located is described in relation to competition order, market environment, and other aspects. The regional macro-environment in which enterprises are located is described from an urban economic level, radiation effect, city level, gender culture, and other aspects. In short, the impact of the corporate environment on CEO genders and its mechanisms have been studied.

The research findings are as follows. (1) The environment in which enterprises are located has a significant impact on CEO genders. In the corporate micro-environment, compared with other factors, enterprise size, state-owned shareholding, product features, industry characteristics, and female owners have significant impacts on female CEOs. In the industry meso-environment, the market environment is more important, yet it has a significantly negative impact on female CEOs. In the macro-environment, the radiation effect and gender culture have significantly impacts on female CEOs. (2) As far as the mechanism of action is concerned, CEO genders are by no means impacted between various environments separately, but there is a kind of regulating effect. The gender 
culture in the macro-environment has a positive regulating effect on the market environment in the industry environment.

The main contributions of this paper comprise the following. (1) The existing human resource theory has been supplemented in a positive way. The existing human resource theory and occupational status attainment theory both stress the individual's own value and its realization, but ignore the external environment, which is instead the key to explaining and understanding a company's employment of female CEOs. Therefore, from the perspective of gender and the environment, this essay makes up for the shortcomings of the existing research and theories, and expands the existing theoretical framework. (2) In terms of research design, this paper argues that there are no differences between males and females in business management ability, which relaxes the original research hypothesis, and provides a complete environment analysis framework for analysis of female executives, especially female CEOs, from an environmental perspective, and clarifies the impact mechanism between environments. This paper argues that gender is the result of social construction, and it is impacted by the gender culture. Thus, there are no differences in ability between males and females. Meanwhile, corporate characteristics and the environment serve as the key factors to explain how women break through the ceiling and enter into the top management of businesses [7]. Therefore, this paper provides a complete environment analysis framework, further clarifies the impact mechanism of different environments on CEO genders, and enriches existing research studies. (3) This paper is conducive to a reasonable view, understanding, and evaluation of female CEOs, thus providing a reference for women's career development. The results of this paper show that female CEOs are impacted by gender culture, industry differences, corporate characteristics, and other aspects. Females' assumption of the office of CEO is the result of the environment. Thus, there is need to treat female CEOs more fairly and rationally, so as to provide a good development space for female executives' career development and also provide reference for women's career development. (4) This paper also supplies an effective reference experience for countries with economies in transition through the use of Chinese data. From the perspective of sample selection, there are few existing studies on China. The Chinese economy is in a critical period of transformation and development, and its market mechanism is not yet sound, thus providing a broad space for exploring new concepts, theories, and insights [8]. Combined with the economic background of China's transition period, this paper provides an effective reference experience for countries with transition economies or countries with imperfect market mechanisms with regard to the increase of the proportion of female CEOs and the exertion of female CEOs' abilities, and also provides more empirical evidence for deepening the cognition of female CEOs.

The main structure of this paper is as follows. Firstly, the relevant literature is reviewed from the micro, meso, and macro perspectives, and shortcomings in existing research studies are analyzed. Secondly, a relatively complete analysis framework is constructed from the perspective of the enterprise environment, and empirical analysis is conducted to test the robustness of the regression results. Finally, the research conclusions are summarized, and policy recommendations are proposed.

\section{Literature Review}

\subsection{Sex and Gender Socialization}

Sex is an objective fact. With the development of productivity, gender culture was gradually formed. It is well-known that sex is caused by physiological differences, which is an objective fact that cannot be changed and must be recognized. In the primitive society, the basic needs of existence formed a desire for reproduction. Due to the ignorance of reproductive science, since women can bear children, respect and worship for women was formed in primitive societies. With the improvement of productivity level and the gradual formation of the social division of labor, men gradually mastered the dominant positions in production and life due to their innate advantages. After that, family and marriage patterns also underwent major changes, and this change was also gradually strengthened, thus forming the male-dominated gender culture [9]. 
Under this gender culture, people gradually formed their understandings and even prejudices against male and female. Therefore, gender is the inevitable outcome of the socialization process of sex. The essence of gender is social construction. Gender culture is a basic component of human society and culture, and it had a major impact on people's productivity and lives [10]. Gender culture refers to the values, ethics, knowledge experience, customs, system norms, and other ideologies and their manifestations developed on the basis of social characteristics, social behaviors, and social relations between males and females [10]. Its core is to divide human beings into males and females, assign them different roles with separate connotations, identify different cultural instructions, and standardize different behavioral logic and development paths. Thus, the essence of gender is social construction, and it is influenced by gender culture [11].

\subsection{Female and Sustainable Development}

In terms of the relationship between women and sustainable development, women and sustainable development promote each other and influence each other, as shown in Figure 1. On the one hand, promoting women's development and gender equality are inevitable choices for sustainable development. Sustainable development is inseparable from women's participation. The level of development of women will not only affect the coordinated development of society, it will also affect the way in which generations can achieve sustainable development. On the other hand, sustainable development further protects the legitimate rights and interests of women. Women will also develop themselves in the process of participating in sustainable development.

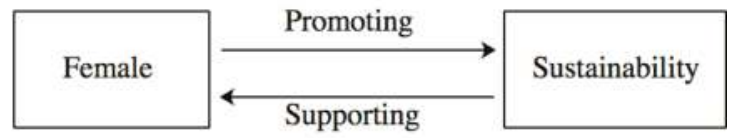

Figure 1. Relationship between women and sustainable development.

So, how can women promote sustainable development? As shown in Figure 2, first of all, in politics, respecting and protecting women's interests is one of the standards of social progress. Women's right to education and protection needs to be further strengthened. In terms of goals, gender equality is an inevitable option for achieving sustainable development. In September 2015, the United Nations Conference on Sustainable Development was held and officially approved, which was called Transforming our World: The 2030 Agenda for Sustainable Development and proposed the goal of "realizing gender equality and empowering all women and girls". Today, gender discrimination is prevalent, as the gap between women and men remains in employment, medical care, and political rights, etc. The United Nations statistics show that as of 2014, 143 countries have guaranteed gender equity in their constitutions, but 52 countries have yet to take the step.

Second, in terms of economics, female CEOs can reduce corporate risk, promote corporate innovation, increase corporate value, and promote sustainable economic development. At the enterprise level, the executive ladder theory [12,13] holds that the heterogeneity of the executive's characteristics affects corporate policies, risks, and performances [14]. In light of the relationship between women and a company's sustainable development, on the one hand, women constitute an important part of corporate governance from the inside and increasing the number of women on the board of directors raises the value of enterprises [15]. Female CEOs have improved the performance of businesses [2]. In companies under complex environments, when the proportion of female executives is high, it can indeed produce positive and significant returns [16] compared to other companies with fewer female executives. At the same time, female CEOs promote corporate technological innovation more than male CEOs [9]. On the other hand, as for the outside the company, the increase in the number of female executives improves the quality of corporate information disclosure [17]. Therefore, the female CEO is conducive to improving the enterprise's value, promoting its innovation, and ensuring its sustainable development. 


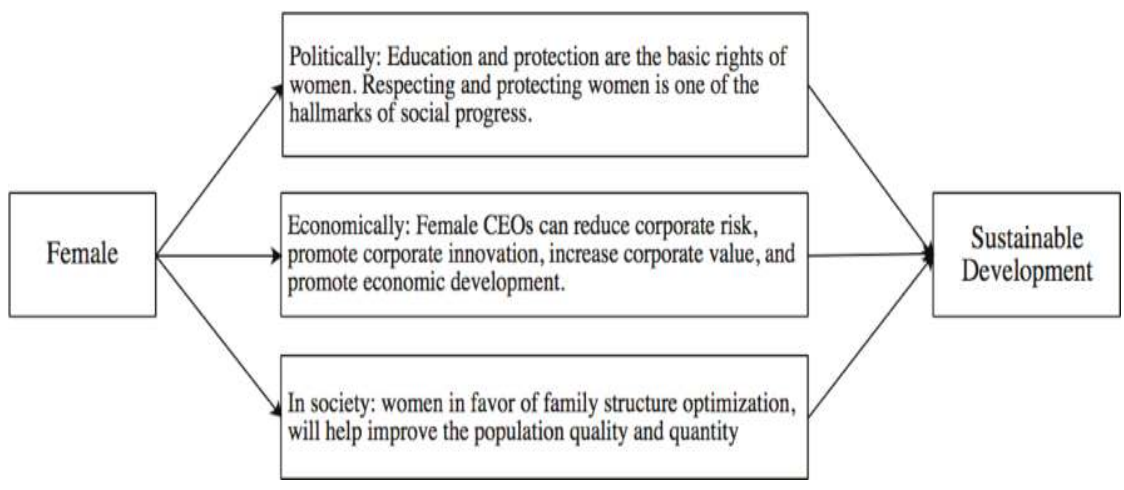

Figure 2. Mechanism for women to promote sustainable development.

Third, from a social perspective, women can promote the optimization of family structures and improve the quality and quantity of the population. Sustainable development requires the broad participation of the whole society in light of the driving force, and women are an important force in achieving sustainable development. Women and girls make up half of the world's population and therefore takes up half of the world's potential. As far as sustainable development is concerned, the relationship between population quantity and quality needs to be coordinated. In light of physiological function, women are essential to sustainable development, as population growth is the inexhaustible driving force. At the same time, in terms of population quality, women play a crucial role in the education and bringing up the next generation. A lack of maternal love affects the healthy growth of children.

In summary, women are an important driving force for the sustainable development of the whole society, to which the participation of women is more favorable. Therefore, it is necessary to give full play to the role of women in the sustainable development of the whole society. At the same time, corporate governance requires a new sustainable governance model that effectively unleashes the combined potential of men and women in the enterprise [18]. In this model, the CEO is at the core, and thus CEO gender is of great significance in corporate sustainability.

\subsection{Environment and CEO Gender}

\subsubsection{Definition and Composition of the Environment}

The environment has a major influence on enterprise operation and management. The environment provides conditions for the survival and development of enterprises. From the perspective of system theory, as an open system, an enterprise is a subsystem that is subordinate to the industry, society, country, and even the whole world. In enterprise management, a correct understanding and analysis of the environment is a prerequisite for the correct formulation of the strategy. In management research, the environment has an imperceptible but considerable influence on organizational behavior [19].

For a company, the position of CEO is very important, and generally will not be easily replaced. This means that the selection of CEO is a major strategic decision that affects the development of the company. During the process of research on female executives, corporate characteristics play a key role in accounting for women's entry into management [7]. At the same time, the selection and appointment of senior executives is a typical strategic behavior and organizational result that is subject to the level of industry and social and economic development. Therefore, building an integrated environment is very helpful for studying the gender of CEOs.

We believe that the environment is a collection of factors that influence and constrain the production and operation activities of enterprises. The environment includes not only the individual micro-environment, but also the macro-environment such as the country, and the meso-environment 
between individuals and countries [20]. Therefore, according to the sphere of influence of the environment, the environment can be divided into micro factors, meso factors, and macro factors $[19,20]$. In this essay, the micro-environment mainly refers to the internal characteristics of the enterprise, including the age and scale of the enterprise, shareholding structure, the scope of sales of the products, etc. The meso-environment refers to the characteristics of the sector and industry, including the market environment and competition order. The macro-environment mainly includes the characteristics of a country or city, specifically containing economic level, political level, cultural environment, etc., as shown in Figure 3.

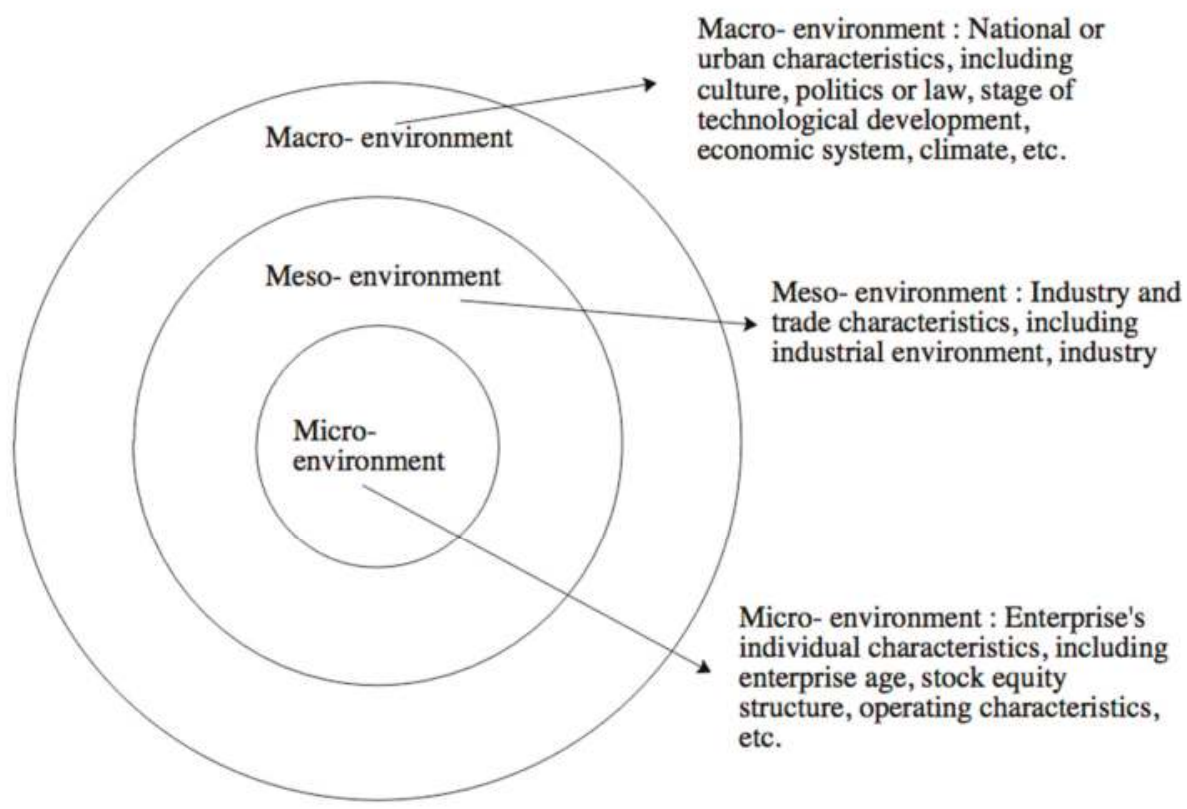

Figure 3. Classification of Environment.

2.3.2. The Importance of the Influence of the Environment on the Gender of the CEO

As shown in Figure 4, the environment has a major impact on the gender of the CEO. First, the environment calls for new requirements on enterprise development. Changes in the environment have forced enterprises to adjust their business strategies to meet the requirements of their development, and those that actively respond to changes in the external environment are the ultimate successful enterprises. Therefore, the environment can impose new requirements on CEO abilities, in which only those who meet the new requirements can become CEOs. Second, the environment is the implementer of women's socialization. In the process of women's socialization, families, schools, work units, newspapers, books, movies, and networks are all providers of women's socialization, and they are all part of the environment. 


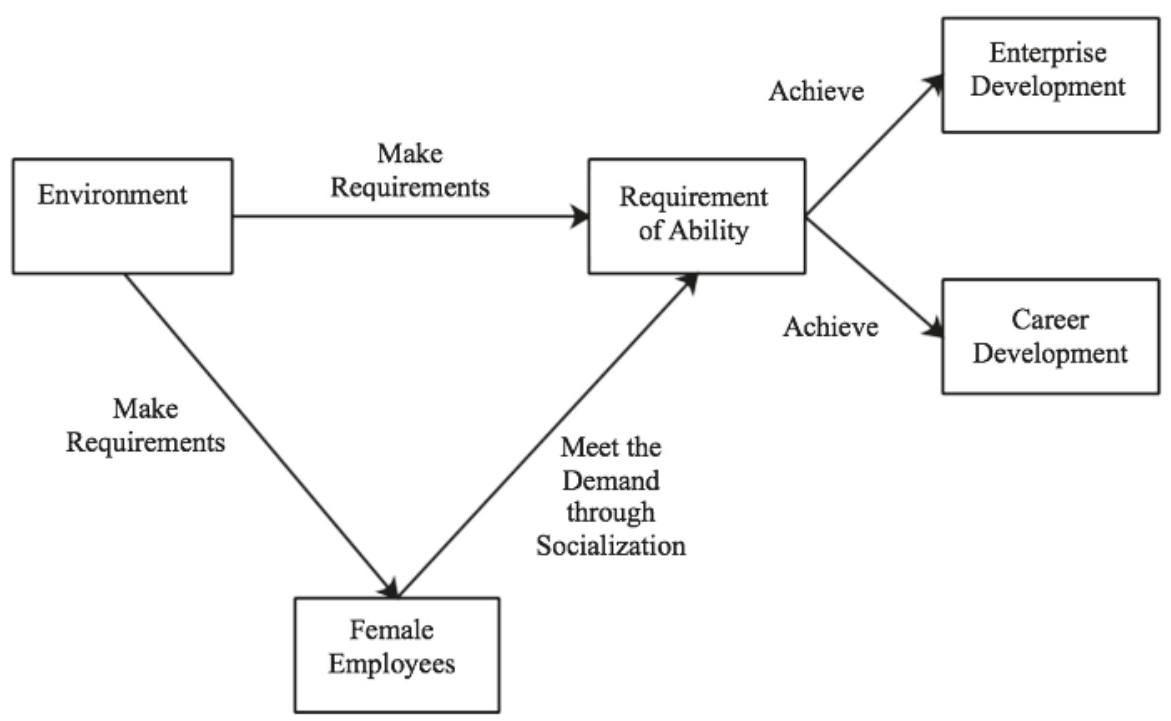

Figure 4. Illustration of the impact of the environment.

Therefore, the environment influences women to achieve socialization through learning, interaction, and education. Only those women who meet the requirements of the environment can meet the requirements of enterprise development and become CEOs.

\subsubsection{Impact of Environment on CEO Gender}

At the micro level, the existing research mainly involves the impact of enterprise internal characteristics on the CEO's gender, including enterprise age, performance, scale, and corporate investors. As regards corporate performance and risk, it was discovered that white women and women of color are more likely to be appointed as CEOs by companies with poor performance, while white men may replace these white women and women of color when business risk increases and performance declines [21]. In terms of corporate size, the academic community has not yet reached a consensus, which is probably because there are differences in the measurement of corporate size [22]. Some researchers believe that bigger companies are more favorable toward female CEOs [23], while others have noted that smaller companies are more likely to employ female CEOs [23]. In terms of company age, Gul, Srinidhi, and Ng found that among the United States (U.S.) listed companies, the older the company, the more female senior managers are employed [23]. However, Morikawa found that among the listed companies in Japan, the younger a company is, the more likely it is to choose female senior managers [24]. With regard to exterior perspectives, Brinkhuis and Scholtens researched from the perspective of investors and found that investors have no impact on which gender should be chosen for the position of a CEO [25]. Female CEOs and female-biased recruitment strategies are significantly more favorable for women to become managers. However, these studies also found that corporate internationalization and foreign investment have a negative impact on female senior managers [7]. Moreover, the subsidiaries of parent companies and companies with trade unions have a negative impact on female senior managers [24].

At the meso level, the existing research mainly focuses on the impacts of industry on the CEO's gender, yet the impacts from different industries on the CEO's gender are different. In the United States, there are more female senior managers in service industries than in other industries, especially in health and social services [26]. Other studies have also revealed that there are more female directors in retail sectors and fewer female directors in STEM (STEM is the abbreviation of the initials of science, 
technology, engineering and mathematics.) and financial sectors [27]. From the market point of view, a sound market system can make a comprehensive assessment of the company's development. However, existing studies show that financial markets cannot accurately evaluate the tenure performance of female CEOs [28], the stock market does not pay enough attention to the turnover of female CEOs, and the negative market reflection is small [3].

At the macro level, the existing research mainly focuses on the impacts of the culture, system, and political system on the CEO's gender. With respect to culture, the degree of cultural equality alleviates the differences in career development between women and men [29], and religion does not affect the status of women on the board of directors [4]. Countries with less emphasis on family values have more women directors [30,31]. As regards institution, transnational differences in institutional structures and gender systems have affected women's chances of entry onto boards of directors [32]. At the same time, Grosvold, Rayton, and Brammer chose 23 countries as samples and found that family, education, economy, and government have significant positive impacts on women's entries onto boards of directors [29]. In terms of political systems, it is found that countries with a long tradition of women's political representations are unlikely to have a high level of female board representatives [33].

In summary, the existing research is not complete in the following aspects.

First, they did not lay particular emphasis on the CEO's gender as much as they focused on the number and proportion of female senior managers. There are few in-depth studies on the quality of employment of female senior managers. However, as women gradually become a major force of social and economic development, attention should be paid to not only the number and proportion of female senior managers, but also the quality of their employment. Only when the ratio of CEO genders is improved can talents be fully utilized. In general, companies will choose male CEOs, but few women will be CEOs. So, what are the reasons for choosing women as CEOs compared to men? Existing research has failed to give a clear answer.

Second, they did not have a systematic analytical framework, and the analysis of the influence mechanism of each environment was not sufficient. Although in-depth studies have been conducted in micro, meso, and macro environments, few studies have placed micro, meso, and macro environments into one framework. The process of recruiting senior managers, and CEOs in particular, may be influenced by the corporate-level micro environment, the industry-level meso environment, and the regional-level macro environment. Thus, it is quite necessary to place micro, meso, and macro environments into one framework for analysis purposes.

Third, from the perspective of sample selection, existing studies are mainly concentrated in countries and regions such as Europe and the United States, yet few studies have been conducted on China. As the world's second largest economy and a non-immigrant country, China has a different cultural tradition and connotation compared with that of the Western world. The particularities of China are mainly reflected in the following aspects. (1) Economically, China is now at the critical period of transformation and development. In view of China's large economic volume and difficulty in transformation, it is important to pay attention to the processes required to efficiently utilize feminine human power capital. (2) There is an imbalance in China's economy; that is, there is a relatively large regional gap in China's economy, which provides a good test ground for studies of economic differences and female senior managers. (3) Culturally, China is a unified and multi-ethnic country, rather than a non-immigrant country, thus presenting the characteristics of multiculturalism featured with great cultural differences within the region and attitudes toward women. Therefore, in the context of transformation and development, China's economic imbalance and cultural diversity are of great significance to the studies conducted on the quality of employment of female senior managers during the transition period.

Based on the above analysis, this paper constructs an overall framework featured with a micro environment that is mainly represented by corporate characteristics, a meso environment that mainly includes the industrial environment, and a macro environment that mainly involves regional economy, gender culture, and so on. This paper analyzes the impacts of the corporate-level micro environment, 
industry-level meso environment, and regional-level macro environment on the quality of employment of female senior managers in the Chinese context, supplementing the insufficiencies in existing research studies.

\section{Research Design}

\subsection{Data Source}

The empirical data in this paper are derived from the World Bank's Questionnaire Survey on Chinese Enterprises 2012 and CGSS 2012, Report on China's Provincial Marketization Index 2016, Google Maps, and Sample City Statistics Yearbook

The collection of World Bank Survey Data on Chinese Enterprises 2012 was conducted from December 2011 to February 2013, and the World Bank adopted the stratified sampling method in China to investigate 2848 Enterprises across 23 cities (the provinces and cities mainly involved in the World Bank's Survey include Beijing, Shanghai, Guangdong: Guangzhou, Shenzhen, Foshan, Dongguan, Anhui: Hefei, Hebei: Shijiazhuang, Tangshan, Henan Province: Zhengzhou City, Luoyang City, Hubei Province: Wuhan City, Jiangsu Province: Nanjing City, Wuxi City, Suzhou City, Nantong City, Liaoning Province: Shenyang City, Dalian City, Shandong Province: Jinan City, Qingdao City, Yantai City Sichuan Province: Chengdu, Zhejiang Province: Hangzhou, Ningbo, and Wenzhou) and within 12 provinces (i.e., municipalities), including Beijing, Shanghai, and Guangdong province. Among them, there were 2700 private enterprises and 148 state-owned enterprises. The survey provided the data and additional information corresponding to one complete fiscal year of the chosen enterprises. The reasons for choosing the data from the World Bank's Questionnaire Survey on Chinese Enterprises 2012 were based on the following three aspects. First, due to the availability of data, micro-data at the enterprise level is difficult to obtain publicly in China, and such data is the latest data from the World Bank Survey on Chinese Enterprises that is publicly available at present. Second, in terms of sample selection, the reason why the data of listed companies was not selected in this paper is because non-listed companies constitute the main body of the Chinese market. As of 2016, there were 3337 enterprises in the Shanghai and Shenzhen Stock Exchanges, whereas there were 87.054 million market entities of various kinds in China (statistics on the Number of Private Enterprises in China, www.chinabgao.com, http://www.chinabgao.com/k/qiye/37764.html). Thus, the proportion of listed companies in China remains relatively low, while the market entities are non-listed companies. Third, compared with the non-listed companies, the Chinese listed companies have better corporate governance characteristics and a more advanced system. Therefore, based on the comprehensive consideration of the market and enterprise entities and the situation of corporate governance, the data from the World Bank's Questionnaire Survey on Chinese Enterprises 2012 can reflect the real situation of Chinese enterprises in a more objective manner.

To ensure the accuracy of gender culture data, this paper chooses the authoritative and accurate data from CGSS. There are two main reasons for the selection of this data. First, CGSS data can guarantee the authoritativeness. Founded in 2003 and implemented by Renmin University of China, CGSS is the earliest nationwide comprehensive and continuous academic investigation project in China. In accordance with international standards, since 2003, CGSS has conducted continuous cross-sectional surveys of more than 10,000 households throughout provinces, municipalities, and autonomous regions of China every year. CGSS systematically and comprehensively collects data from multiple levels—-the society, community, family, and individual—summarizes the trends of social changes, and probes into issues of great scientific and practical significance. Articles based on CGSS data have also been published in more than 1000 academic journals. In 2007, CGSS represented China and became a member of the International Social Survey Program and served as a window of China for international exchanges and cooperation in social surveys. Moreover, CGSS data is considered to be at par with the World Bank's survey data. CGSS provides the data from all provinces, municipalities, and autonomous regions throughout mainland China, including those sample cities surveyed by the World 
Bank. However, unfortunately, due to confidentiality requirements, CGSS data only published the province information of samples, while the information about the prefecture-level cities of samples remains unpublished. Therefore, the variables of gender culture in this paper reflect the overall perspective of residents of such province toward women.

The market environment data is derived from the data of 2012 in Report on China's Provincial Marketization Index prepared by Fan Gang and Wang Xiaolu. The Report on China's Provincial Marketization Index evaluates the overall progress of market-oriented reforms in various provinces, autonomous regions, and municipalities directly under the central government throughout China from 2008 to 2014, and charts progress from different aspects. Such data is widely quoted by both Chinese and foreign scholars.

The center distance comes from Google Maps. We used Google Maps to measure the nearest road distance from the sample cities to Beijing, Shanghai, Guangzhou, and Chongqing, and conducted the normalization processing. The four central cities of Beijing, Shanghai, Guangzhou, and Chongqing were chosen because the planning and positioning of the five national central cities of Beijing, Tianjin, Shanghai, Guangzhou, and Chongqing were clarified in the National Urban System Planning (2010-2020) issued by the Ministry of Housing and Urban-Rural Construction in February 2010. As the capital of China, Beijing is about $137 \mathrm{~km}$ away from Tianjin. To avoid complicating the research process, this paper did not choose Tianjin as a central city. The reason for choosing highway distance is that people have not yet realized the convenience of high-speed railway due to the limited routes of China's high-speed railways in 2012 and the railway network that is in progress. For this reason, we selected highway distance instead of high-speed railway time.

The economic levels of sample cities are derived from the statistical yearbooks of each region.

\subsection{Sample Selection}

For the sake of efficient research, the raw data from the World Bank were screened and processed in this paper. The main steps are as follows. (1) In consideration of the matching attributes of questionnaire and samples, sample data marked with "No, does not match" are deleted according to Question A5 (Question A5: Sector match between screener information and sample frame; three options are given: 1. Yes, the screener and sample frame info match; 2 . No, the screener and sample frame do not match, but the establishment still does activities that match the sample frame; and 3. No, does not match). (2) In consideration of the authenticity and validity of the data, the sample data marked with "Not truthful" and "Are arbitrary and unreliable numbers" are deleted according to questions A16 (Question A16: It is my perception that the responses to the questions regarding opinions and perceptions; three options are given: 1. Truthful; 2. Somewhat truthful; 3. Not truthful) and A17 (Question A17: In responses to the questions regarding figures (productivity and employment numbers), three options are given: 1 . Are taken directly from establishment records; 2 . Are estimates computed with some precision; and 3. Are arbitrary and unreliable numbers). (3) For the sake of prudence, the missing values were deleted among all the models, and no method was used for replacements.

The treatment processes of CGSS in this paper are as follows. (1) Samples of missing values that did not answer the question were deleted. (2) For question A423 (Question A423 in CGSS: Do you agree with the following statements: A good husband is better than a good job? Four answers are provided for this question: "Completely disagree", "Partially disagree", "It doesn't matter whether I agree or disagree", "Partially agree", and "Completely agree"), reflecting the gender culture, the average value was obtained by provinces, that is, the sample data in the same province was aggregated to obtain the average values by which the degree of gender culture corresponding to such province can be measured.

Other data processing are as follows: (1) market environment data was derived from the data of 2012 in the Report on China's Provincial Marketization Index; (2) economic development level is represented by the per capita gross domestic product $(\mathrm{GDP})$ in the statistical yearbook of every region; 
and (3) central distance is the highway distance between sample cities and central cities as measured on Google Maps.

\subsection{Empirical Model}

Since this paper mainly analyzes the internal characteristics and external environments of enterprises, no control variables were set in the empirical model. In this paper, the following models are constructed: $y=\alpha_{0}+\alpha_{1}$ Micro $+\alpha_{2}$ Meso $+\alpha_{3}$ Macro $+\varepsilon$.

Among them, $y$ denotes the core variable of the CEO's gender, micro denotes the corporate-level micro environment, Meso denotes the industry-level meso environment, macro denotes the macro environment of economy, politics, culture, and so on, $\alpha_{0} 0$ denotes the constant term, and $\varepsilon$ denotes the random error term.

\subsection{Design and Description of Variables}

The specific contents of variable design are reported in Table 1. In this paper, the CEO's gender is taken as the explained variable, while the micro, meso, and macro environment in which an enterprise is involved are taken as the explaining variables. The descriptive statistical results of the samples are reported in Table 2 .

\subsubsection{Micro-Environment: Company Characteristics}

As regards the corporate-level micro-environment, this paper sets variables such as the basic company characteristics, stock equity characteristics, and operating characteristics.

In terms of basic features, this paper refers to the research outcomes of Morikawa [24] and Kirsch [6], and sets variables such as enterprise size, enterprise age, corporate attributes, industry characteristics, stock equity characteristics, and operating characteristics. The enterprise size is set as the logarithm of the number of regular employees. It is very important to measure the development level and capability of an enterprise by its scale, and there are many different ways of setting up the enterprise [22]. However, it is subject to the questionnaire setting and data availability, referring to previous studies [34]. With regard to the enterprise age, one sample out of all the samples was established in 2012, while three samples were established in 2011. Considering that the survey was conducted from 2011 to 2012, the enterprise age of all these three samples was set as 1 . Meanwhile, the enterprise age is set to add 1 after the logarithm was taken, for eliminating the effect of heteroscedasticity. In terms of company attributes, when the enterprise is a subsidiary company, the value of enterprise attributes is 1 ; otherwise, it is 0 . In terms of industry characteristics, this paper refers to the industry classification methods proposed by Zeng and $\mathrm{Wu}[35]$ and judges whether they are consumer goods industries according to S\&P Global Industry Classification Standard ("Yes" = 1; "No" $=0$ ). 


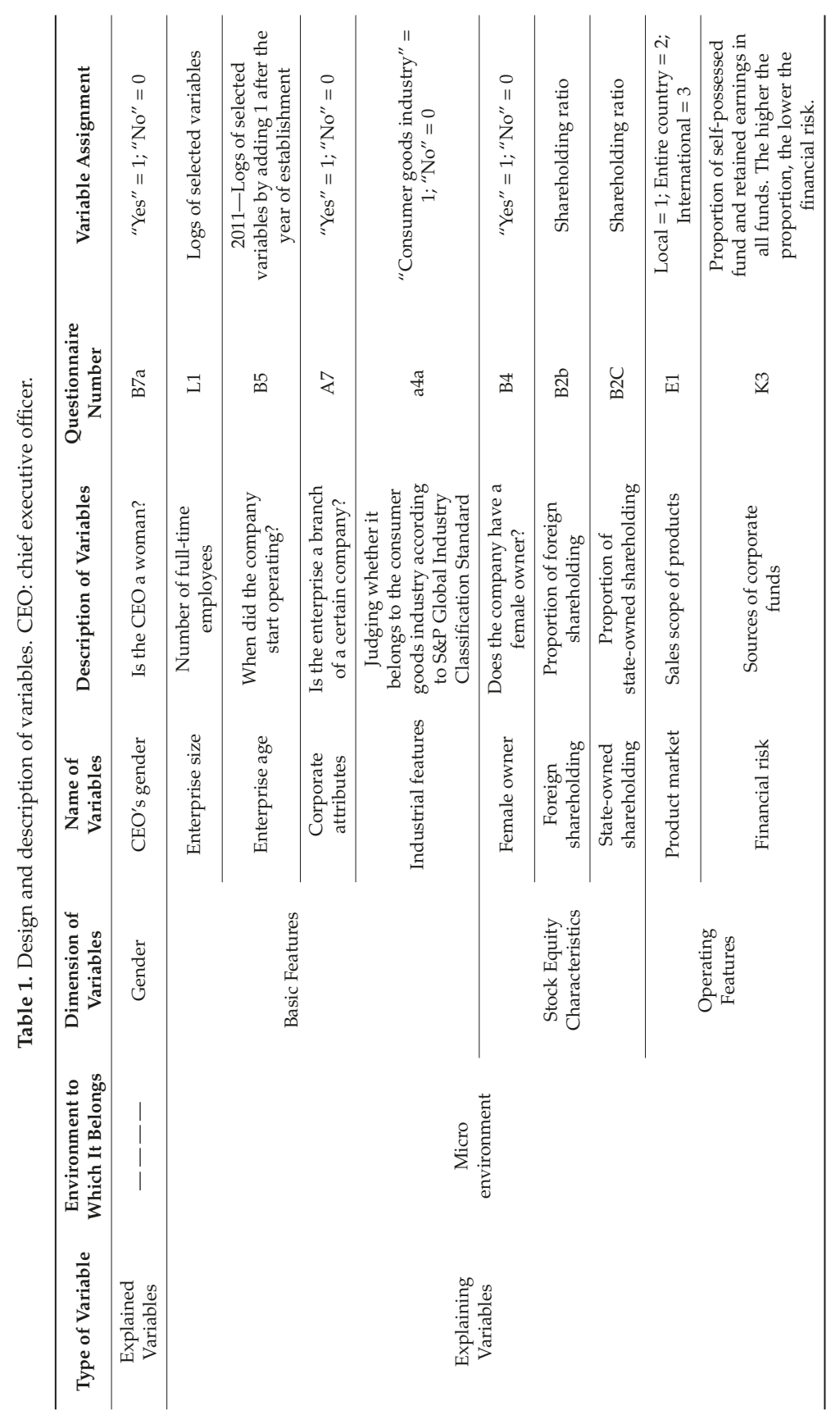




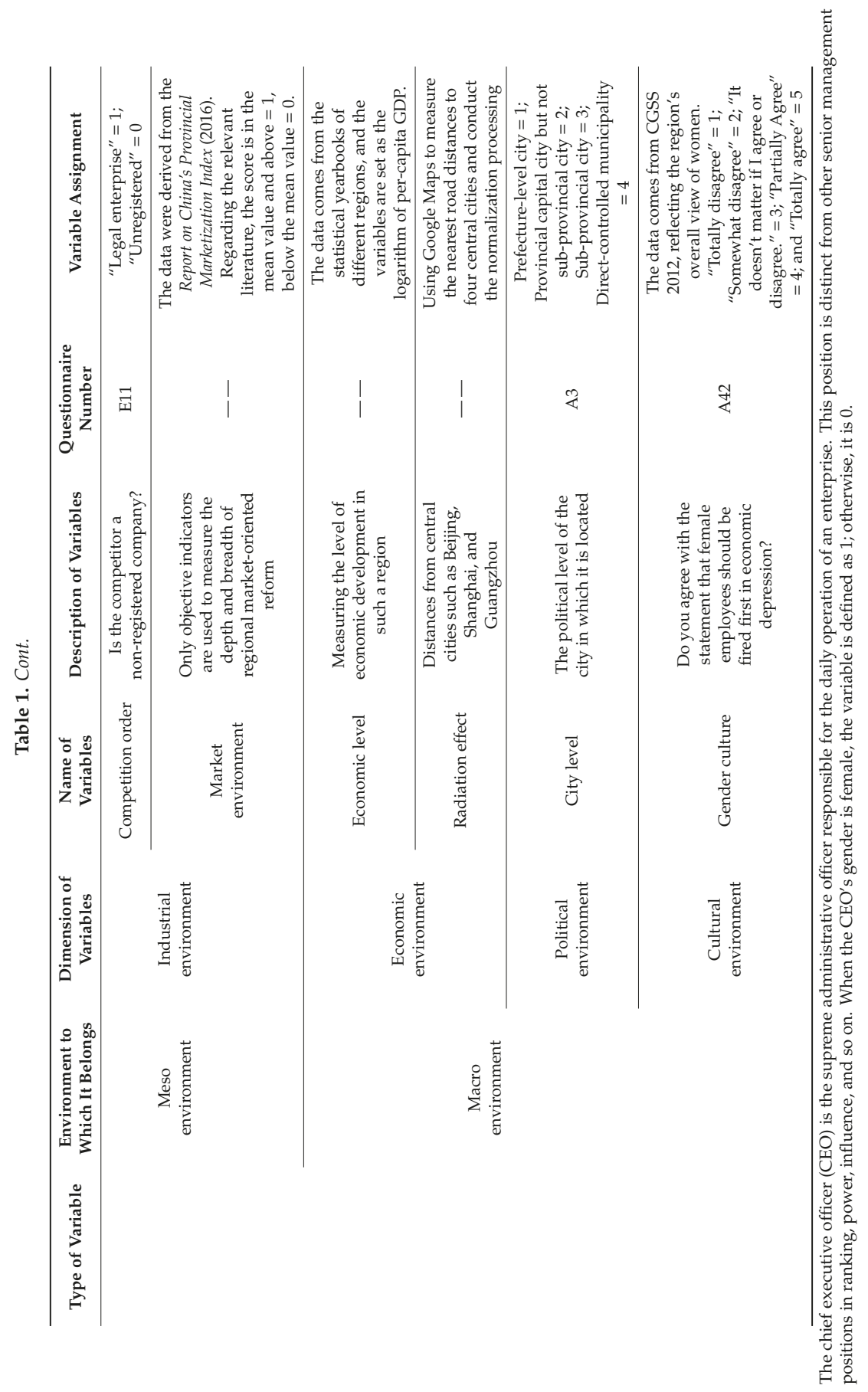


Table 2. Table of descriptive statistical analysis.

\begin{tabular}{cccccc}
\hline Variables & $\begin{array}{c}\text { Sampling } \\
\text { Size }\end{array}$ & $\begin{array}{c}\text { Average } \\
\text { Value }\end{array}$ & $\begin{array}{c}\text { Standard } \\
\text { Deviation }\end{array}$ & $\begin{array}{c}\text { Minimum } \\
\text { Value }\end{array}$ & $\begin{array}{c}\text { Maximum } \\
\text { Value }\end{array}$ \\
\hline CEO's gender & 2559 & 0.108 & 0.311 & 0 & 1 \\
Enterprise size & 2562 & 4.151 & 1.355 & 4 & 30,000 \\
Enterprise age & 2493 & 2.553 & 0.978 & 1 & 124 \\
Corporate attributes & 2562 & 0.132 & 0.339 & 0 & 1 \\
Industry characteristics & 2562 & 0.338 & 0.473 & 0 & 1 \\
Female ownership & 2562 & 0.608 & 0.488 & 0 & 1 \\
Foreign shareholding & 2555 & 0.039 & 0.171 & 0 & 1 \\
State-owned shareholding & 2555 & 0.032 & 0.158 & 0 & 3 \\
Product market & 1621 & 1.907 & 0.516 & 1 & 1 \\
Financial risk & 2510 & 0.889 & 0.206 & 0 & 1 \\
Competition order & 2467 & 0.448 & 0.497 & 0 & 1 \\
Market environment & 2562 & 0.497 & 0.500 & 0 & 1 \\
Economic level & 2562 & 11.147 & 0.300 & 10.595 & 4 \\
Radiation function & 2562 & 0.260 & 0.236 & 0 & 1 \\
City level & 2562 & 2.161 & 1.001 & 1.788 & 2.420 \\
Gender culture & 2562 & 2.131 & 0.128 & & 1 \\
\hline
\end{tabular}

In terms of stock equity characteristics, as an effective incentive means, equity promotes enterprise development [36]. Therefore, equity characteristics are one of the factors affecting CEO gender. This paper chooses three variables: female owners, foreign shareholding, and state-owned shareholding. Regarding female owners, the main measurement criterion is to see whether there are female owners ("Yes" $=1 ; " \mathrm{No}^{\prime \prime}=0$ ). Foreign and state-owned shareholdings mainly reflect the company's shareholding situation, which is set as the proportion of foreign and state-owned shareholding.

In terms of operating characteristics, this paper sets two variables: product market and financial risk. The product market reflects the scope of the product sales of an enterprise, with local sales set as 1 , and national and international sales set as 2 and 3, respectively. Overall, the women's risk preference is lower compared with the men's risk preference. Thus, this paper sets up financial risk variables to measure the impact of operating risk on the CEO's gender. Financial risk is mainly measured by the company's sources of funds, and it is set as the ratio of self-possessed funds and retained earnings in all funds. The higher the ratio, the lower the financial risk.

\subsubsection{Meso-Environment: Industrial Environment}

In terms of meso environment, this paper mainly considers the industrial environment as the main variable. The industrial environment includes competition order and market environment.

In terms of competition order, which has a profound impact on corporate operating performance and corporate governance $[37,38]$, competition is the most prominent feature of the market economy, and it is an external feature that cannot be ignored. This paper refers to the research outcomes of Han, Cui, Chen, and Fu [9], and selects the legitimacy of competitors as the object of investigation. When the main competitor facing an enterprise is a legally registered enterprise, the variable assignment is set as 1 . When it is an unregistered enterprise, the variable assignment is set as 0 .

In terms of market environment, as China is in a period of transformation and development, the market environment will have a great impact on enterprise behaviors. Therefore, this paper refers to the practices proposed by Liu, Yang, and Yang [39], and sets the market environment variable in which only objective indicators are adopted to measure the depth and breadth of market-oriented reforms in various regions. The value assignment is 1 if scores are the average value and above. Otherwise, the assignment value is 0 . 


\subsubsection{Macro-Environment: Regional Economy and Political and Cultural Environment}

In this paper, the macro-environment is measured mainly from the aspects of the regional economy and the political and cultural environment.

In terms of economic environment, this paper mainly considers two aspects: economic level and radiation effect. The economic level is set as the logarithm of GDP per capita in the region. In terms of radiation function, central cities have a radiation effect on surrounding cities. The Chinese government made Beijing, Shanghai, Guangzhou, and Chongqing central cities to enhance their economic influence on neighboring cities. To investigate the economic radiation effects of these national central cities on other cities, the central distance variable is set in this paper. Since China's high-speed rail was still in the construction stage during 2011-2012, and the public acceptance level remains low, the central distance variable is thus set as the road distance between the company's location and Beijing, Shanghai, and Guangzhou, and normalized processing is conducted.

In terms of political environment, unlike Western countries, the Chinese government has classified major cities at different levels, meaning that the higher the level, the more attention and support from the central government. The city level affects a city's procurement of resources. Thus, the city level variable is set in this paper to measure the city's political status, and the higher level corresponds to a higher score.

In terms of culture, the influence of culture on people is imperceptible and lasting, and the process of CEO recruitment is influenced by gender culture. Therefore, the gender culture variable is set in this paper. The higher the score, the lower the gender equality, and the less favorable it is to females and vice versa.

\section{Distribution Characteristics of the CEO's Gender in China}

\subsection{Geographical Distribution Characteristics of the CEO's Gender in China}

In Figure 5, the distribution characteristics of female CEOs in China are reported. The black circle is used to represent the proportion of local female CEOs to all local CEOs. The larger the black circle, the higher the proportion of female CEOs in such regions will become. If observed from the north-south direction (Qinling-Huaihe is always considered as the demarcation between the north and the south of China. In this paper, samples of the south include: Shanghai, Nanjing, Wuxi, Suzhou, Nantong, Hefei, Hangzhou, Ningbo, Wenzhou, Guangzhou, Shenzhen, Foshan, Dongguan, Wuhan, and Chengdu; samples of the north include: Beijing, Shijiazhuang, Tangshan, Jinan, Qingdao, Yantai, Zhengzhou, Luoyang, Shenyang, Dalian, the same below), the distribution of female CEOs presents characteristics more in the south compared with the north, and there are more female CEOs in the Yangtze River Delta than in the Pearl River Delta. If observed from the east-west direction (in the east-west direction, China can be divided into three parts: east, middle, and west. The eastern part in this paper mainly refers to the eastern coastal areas of China, the central part mainly refers to the areas adjacent to the hinterland of the Central Plains, and the western area mainly refers to the provinces where western development policy is implemented. Samples from the eastern region include Shanghai, Nanjing, Wuxi, Suzhou, Nantong, Hefei, Hangzhou, Ningbo, Wenzhou, Guangzhou, Shenzhen, Foshan, Dongguan, Beijing, Jinan, Qingdao, Yantai, Shenyang, and Dalian. Samples from the central region include Wuhan, Shijiazhuang, Tangshan, Zhengzhou, and Luoyang. The western region mainly includes Chengdu, and the same is indicated below), the eastern coastal areas obviously have more female CEOs than in the central and western areas, showing the distribution characteristics to be more prevalent in the east than in the west. In summary, the distribution characteristics of the CEO's gender in China are more concentrated in the south and the east than in the north and the west. 


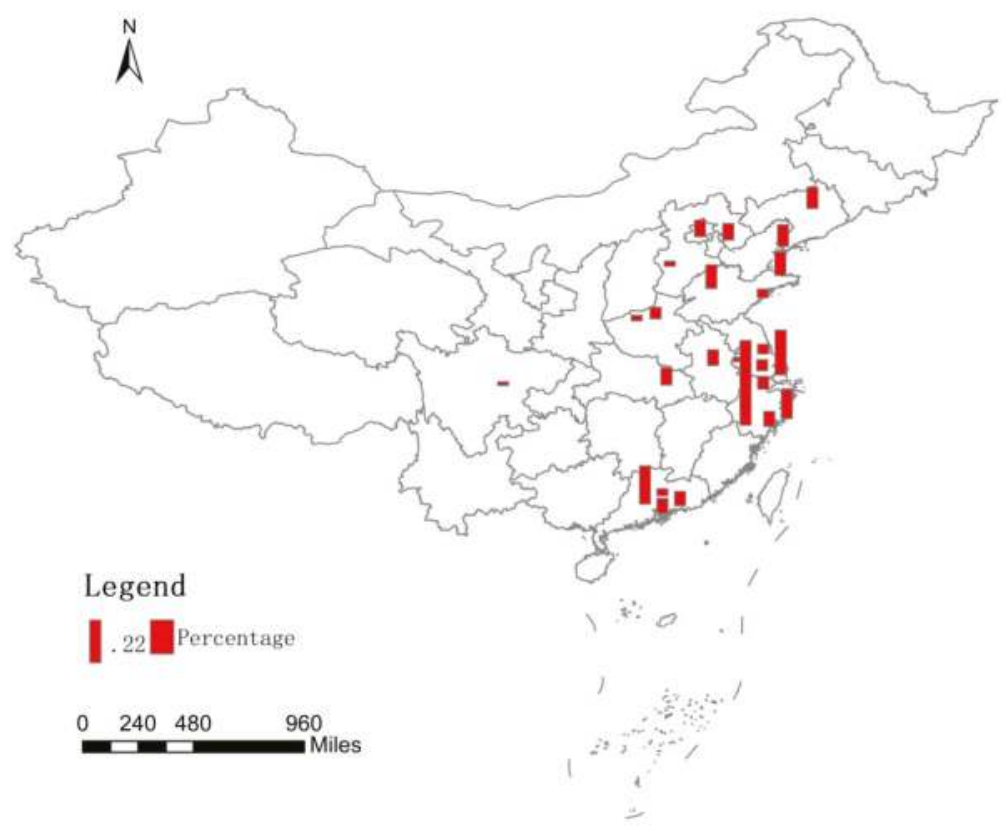

Figure 5. Distribution characteristics of the CEO's gender in China.

\subsection{Micro-Environment and the CEO's Gender}

To visualize the relationship between company characteristics and the CEO's gender, this paper classifies and summarizes CEO gender situations according to company micro-environment. The results are reported in Table 3. As the enterprise size, enterprise age, financial risk, and operating performance are continuous variables, this paper categorizes them into five groups. Regarding foreign and state-owned shareholding, this paper subdivides samples that gave the answer of "having" foreign or state-owned shareholding into five groups. Other variables are grouped according to the rules for variable assignment.

First, we assess the following basic company characteristics. (1) Enterprise size: the number and proportion of female CEOs have shown a downward trend with the constant expansion of enterprise size as indicated in the table above. Thus, in an enterprise with four to 17 employees, female CEOs are more likely to be promoted. (2) Enterprise age: the number and proportion of female CEOs in an enterprise with one to six years in top management. (3) Corporate attributes: subsidiaries have obvious advantages over non-subsidiaries. (4) Industry characteristics: the number and proportion of female CEOs in consumer goods industries are higher than those in non-consumer goods industries.

Second, we assess the corporate shareholding characteristics. (1) In enterprises with female owners, the number and proportion of female CEOs are significantly higher than in those without female owners. (2) Foreign shareholding: First, this paper compares the difference between having shareholding and not, and finds that the proportion of female CEOs in enterprises with foreign shareholding is significantly higher than those enterprises without. Second, this paper further compares the impacts of different shareholding proportions on CEO's gender, and finds that the proportion of female CEOs is the highest among companies with a shareholding ratio between $80-90 \%$; (3) State-owned shareholding: First, the number and proportion of female CEOs in enterprises without state-owned shares are significantly higher than those enterprises having state-owned holdings. Second, in enterprises with state-owned shareholding, the lower the proportion is, the higher the number of female CEOs. 
Table 3. Micro-environment and CEO's gender.

\begin{tabular}{|c|c|c|c|c|c|}
\hline Variables & Meaning of Variables & Male & Female & Summary & $\begin{array}{l}\text { Proportion of } \\
\text { Female CEOs }\end{array}$ \\
\hline \multirow{6}{*}{ Enterprise size } & 4-17 persons & 415 & 70 & 485 & $14.433 \%$ \\
\hline & $18-48$ persons & 470 & 63 & 533 & $11.820 \%$ \\
\hline & $49-88$ persons & 453 & 59 & 512 & $11.523 \%$ \\
\hline & $89-180$ persons & 474 & 42 & 516 & $8.140 \%$ \\
\hline & $182-30,000$ persons & 470 & 43 & 513 & $8.382 \%$ \\
\hline & Summary & 2282 & 277 & 2559 & $10.825 \%$ \\
\hline \multirow{6}{*}{ Enterprise age } & $1-6$ & 400 & 63 & 463 & $13.607 \%$ \\
\hline & $7-8$ & 352 & 40 & 392 & $10.204 \%$ \\
\hline & $9-10$ & 416 & 59 & 475 & $12.421 \%$ \\
\hline & $11-14$ & 513 & 57 & 570 & $10.000 \%$ \\
\hline & $12-124$ & 537 & 53 & 590 & $8.983 \%$ \\
\hline & Summary & 2218 & 272 & 2490 & $10.924 \%$ \\
\hline \multirow{3}{*}{$\begin{array}{l}\text { Corporate } \\
\text { attributes }\end{array}$} & Non-subsidiary companies & 1992 & 228 & 2220 & $10.270 \%$ \\
\hline & Subsidiaries & 290 & 49 & 339 & $14.454 \%$ \\
\hline & Summary & 2282 & 277 & 2559 & $10.825 \%$ \\
\hline \multirow{3}{*}{$\begin{array}{c}\text { Industry } \\
\text { characteristics }\end{array}$} & $\begin{array}{l}\text { Non-consumer goods } \\
\text { industry }\end{array}$ & 1554 & 139 & 1693 & $8.210 \%$ \\
\hline & Consumer goods industry & 728 & 138 & 866 & $15.935 \%$ \\
\hline & Summary & 2282 & 277 & 2559 & $10.825 \%$ \\
\hline \multirow{3}{*}{$\begin{array}{c}\text { Female } \\
\text { ownership }\end{array}$} & Not have & 986 & 18 & 1004 & $1.793 \%$ \\
\hline & Have & 1296 & 259 & 1555 & $16.656 \%$ \\
\hline & Summary & 2282 & 277 & 2559 & $10.825 \%$ \\
\hline \multirow{8}{*}{$\begin{array}{c}\text { Foreign } \\
\text { shareholding }\end{array}$} & Not have & 2140 & 256 & 2396 & $10.684 \%$ \\
\hline & Have & 137 & 19 & 156 & $12.179 \%$ \\
\hline & $5-25 \%$ & 19 & 1 & 20 & $5.000 \%$ \\
\hline & $30-40 \%$ & 34 & 7 & 41 & $17.073 \%$ \\
\hline & $45-71$ & 30 & 2 & 32 & $6.250 \%$ \\
\hline & $80-90$ & 3 & 1 & 4 & $25.000 \%$ \\
\hline & $100 \%$ & 51 & 8 & 58 & $13.793 \%$ \\
\hline & Summary & 2277 & 275 & 2552 & $10.776 \%$ \\
\hline \multirow{8}{*}{$\begin{array}{l}\text { State-owned } \\
\text { shareholding }\end{array}$} & Not have & 2172 & 272 & 2444 & $11.129 \%$ \\
\hline & Have & 105 & 3 & 108 & $2.778 \%$ \\
\hline & $5-50 \%$ & 14 & 1 & 15 & $6.667 \%$ \\
\hline & $51-80 \%$ & 25 & 1 & 26 & $3.846 \%$ \\
\hline & $85-88 \%$ & 21 & 0 & 21 & $0.000 \%$ \\
\hline & $89-89 \%$ & 10 & 0 & 10 & $0.000 \%$ \\
\hline & $90-95 \%$ & 35 & 1 & 36 & $2.778 \%$ \\
\hline & Summary & 2282 & 277 & 2559 & $10.825 \%$ \\
\hline \multirow{4}{*}{ Product market } & Local & 274 & 24 & 298 & $8.054 \%$ \\
\hline & Domestic & 1088 & 85 & 1173 & $7.246 \%$ \\
\hline & International & 124 & 23 & 147 & $15.646 \%$ \\
\hline & Summary & 1486 & 132 & 1617 & $8.163 \%$ \\
\hline \multirow{7}{*}{ Financial risk } & $100 \%$ & 1554 & 161 & 1715 & $9.388 \%$ \\
\hline & $98-90 \%$ & 97 & 12 & 109 & $11.009 \%$ \\
\hline & $89-77 \%$ & 204 & 23 & 227 & $10.132 \%$ \\
\hline & $75-65 \%$ & 129 & 23 & 152 & $15.132 \%$ \\
\hline & $60-35 \%$ & 170 & 37 & 207 & $17.874 \%$ \\
\hline & $34-0 \%$ & 84 & 13 & 97 & $13.402 \%$ \\
\hline & Summary & 2238 & 269 & 2507 & $10.730 \%$ \\
\hline
\end{tabular}

Third, we assess the enterprise operating characteristics. (1) Product market: there are more female CEOs in enterprises whose scope of sales is located in their home country and significantly higher 
than enterprises with a scope of sales located in their home country and abroad. As to proportion, the proportion of female CEOs in international enterprises with their scope of sales located abroad is significantly higher than those enterprises with a scope of sales located at home and in local areas. (2) Financial risk: A lower value means a higher financial risk. Thus, with the increase of financial risk, the proportion and number of female CEOs increase at first and then decrease, and reach the maximum when the financial risk falls in the range of $35 \%$ to $60 \%$.

\subsection{Meso-Environment and the CEO's Gender}

The meso-environment and the CEO's gender distribution are reported in Table 4 . Since competition order and market environment are both 0,1 variables, this paper mainly groups according to the meaning of variables.

Table 4. Meso-environment and CEO's gender.

\begin{tabular}{cccccc}
\hline Variables & Meaning of Variables & Male & Female & Summary & $\begin{array}{c}\text { Proportion of } \\
\text { Female CEOs }\end{array}$ \\
\hline $\begin{array}{c}\text { Competition } \\
\text { order }\end{array}$ & $\begin{array}{c}\text { Competitors' unregistered } \\
\text { enterprises }\end{array}$ & 1214 & 147 & 1361 & $10.801 \%$ \\
& $\begin{array}{c}\text { Competitors' unregistered } \\
\text { enterprises }\end{array}$ & 986 & 117 & 1103 & $10.607 \%$ \\
\hline Summary & 2200 & 264 & 2464 & $10.714 \%$ \\
\hline Market & Lower than the average value & 1171 & 118 & 1289 & $9.154 \%$ \\
environment & Higher than the average value & 1111 & 159 & 1270 & $12.520 \%$ \\
& Summary & 2282 & 277 & 2559 & $10.825 \%$ \\
& Summary & 2282 & 277 & 2559 & $10.825 \%$ \\
\hline
\end{tabular}

First, in terms of competition order, the number of female CEOs in companies whose competitors are unregistered enterprises is higher than companies whose competitors are legally registered enterprises, and there is little difference in the proportion of female CEOs. Second, in terms of market environment, the number and proportion of female CEOs in those samples with a better-than-average market environment is significantly higher than those in the lower-than-average market environment. Thus, a good market environment is more conducive to the growth of female CEOs.

\subsection{Macro-Environment and the CEO's Gender}

Corporate macro characteristics and the CEO's gender distribution are reported in Table 5. Since the economic level, radiation effect, and gender culture are continuous variables, the above variables are divided into five groups in this paper.

First, we look at the economic environment. (1) Along with the improvement of economic level, the number and proportion of female CEOs showed a trend of increasing at first and then slightly decreasing, reaching the maximum when the per capita GDP was RMB 81,658-91,202. (2) In terms of radiation effect, as the distance to central cities increases, the proportion of female CEOs showed the trend of increasing at first and then decreasing, reaching the maximum $14.286 \%$ when the distance is between $135.6-174.5 \mathrm{~km}$. Such distance is equivalent to that from Shanghai to Wuxi, Nantong, or Hangzhou, or from Guangzhou to Shenzhen. The minimum 8.606\% is reached when the distance is in the range of 694 to $840.1 \mathrm{~km}$. Such distance is equivalent to that from Beijing to Zhengzhou or Shenyang, or from Guangzhou to Wuhan. 
Table 5. Macro environment and CEO's gender.

\begin{tabular}{|c|c|c|c|c|c|}
\hline Variables & Meaning of Variables & Male & Female & Summary & $\begin{array}{l}\text { Proportion of } \\
\text { Female CEOs }\end{array}$ \\
\hline \multirow{6}{*}{ Economic level } & RMB 39,919-48,755 & 515 & 31 & 546 & $5.678 \%$ \\
\hline & RMB 56,005-68,315 & 471 & 48 & 519 & $9.249 \%$ \\
\hline & RMB 70,380-76,263 & 491 & 54 & 545 & $9.908 \%$ \\
\hline & RMB 81,658-91,202 & 312 & 78 & 390 & $20.000 \%$ \\
\hline & RMB 91,295-110,421 & 493 & 66 & 559 & $11.807 \%$ \\
\hline & Summary & 2282 & 277 & 2559 & $10.825 \%$ \\
\hline \multirow{6}{*}{ Radiation effect } & $0-102.1 \mathrm{~km}$ & 495 & 71 & 566 & $12.544 \%$ \\
\hline & $135.6-174.5 \mathrm{~km}$ & 348 & 58 & 406 & $14.286 \%$ \\
\hline & $176.7-304.5 \mathrm{~km}$ & 362 & 41 & 403 & $10.174 \%$ \\
\hline & $410.8-661.9 \mathrm{~km}$ & 397 & 43 & 440 & $9.773 \%$ \\
\hline & $694-840.1$ km & 680 & 64 & 744 & $8.602 \%$ \\
\hline & Summary & 2282 & 277 & 2559 & $10.825 \%$ \\
\hline \multirow{5}{*}{ City level } & Prefecture-level city & 905 & 72 & 977 & $7.369 \%$ \\
\hline & Provincial capital city & 300 & 27 & 327 & $8.257 \%$ \\
\hline & Sub-provincial city & 968 & 155 & 1123 & $13.802 \%$ \\
\hline & $\begin{array}{l}\text { Municipalities directly under } \\
\text { the central government }\end{array}$ & 109 & 23 & 132 & $17.424 \%$ \\
\hline & Summary & 2282 & 277 & 2559 & $10.825 \%$ \\
\hline \multirow{5}{*}{ Gender culture } & $1.787-1.988$ & 307 & 80 & 387 & $20.672 \%$ \\
\hline & $2.0025-2.0375$ & 576 & 76 & 652 & $11.656 \%$ \\
\hline & $2.11-2.194514$ & 498 & 36 & 534 & $6.742 \%$ \\
\hline & $2.202783-2.42$ & 901 & 85 & 986 & $8.621 \%$ \\
\hline & Summary & 2282 & 277 & 2559 & $10.825 \%$ \\
\hline
\end{tabular}

Second, in terms of political environment, along with improvement at the city level, the number of female CEOs showed a trend of increasing at first and then slightly decreasing. However, considering the difference in sample sizes, the proportion of female CEOs presents the upward trend, and the proportion of female CEOs in municipalities directly under the central government is significantly higher than in other cities. Therefore, a higher city level is better for female CEOs.

Third, regarding gender culture, the higher the score, the more gender inequality and the more it is unfair to women. Therefore, in regions with the lowest gender culture score, the proportion of female CEOs will be higher. That is, the gender culture of such regions is fairer to women and more favorable for women to grow into CEOs.

To sum up, the general characteristics of enterprises with high CEOs gender scores are summarized as below in this paper.

1. In terms of micro-environment, the enterprise has a small size, with four to 17 employees. It is relatively new and has been established within one to six years. It is a subsidiary company. It belongs to the consumer goods industry. It has female owners. It has $80-90 \%$ of foreign shareholding and no state-owned shareholding. The product sales are mainly focused on the international market. Its financial risk is high, and the proportion of its self-owned funds is within $35-60 \%$.

2. In terms of meso-environment, the company's competitors are mainly unregistered enterprises, and the company is in a better market environment than the average.

3. In terms of macro-environment, the company is located in areas with good economic development level, with GDP per capita ranging between RMB 81,658-91,202. It is 135.6 to $174.5 \mathrm{~km}$ away from Beijing, Shanghai, Guangzhou, Chongqing, and other national central cities, and is located in municipalities directly under the central government. Moreover, it is located in areas with equal gender culture where women are treated more equally. 


\section{Empirical Analysis}

To further test the impact of the corporate-level micro-environment, the industry-level meso environment, and the regional-level macro environment on the CEO's gender, this paper conducts empirical analysis. First, the impacts of the micro, meso, and macro environment on the CEO's gender are studied through the benchmark regression, and these three environments are analyzed within the same framework. Second, the moderating role of the meso-environment on the macro-environment is further analyzed, revealing the complexity of impacts of the macro-environment and meso-environment on the CEO's gender. Subsequently, through the application of marginal effect analysis, the extent to which the changes in environment factors may influence the CEO's gender is further studied. Finally, a robustness test is conducted in this paper.

\subsection{Benchmark Regression}

In this paper, Stata 14.0 is used for empirical analysis. Since the explained variable is binary variables of 0 and 1 , logit model is thus used. Meanwhile, to reduce the influence of heteroscedasticity, robust regression analysis is used in the regression analysis of this paper. The outcomes of benchmark regression are reported in Table 6, while the impact outcomes of the micro-environment, meso-environment, and macro-environment on the CEO's gender are reported in models $1-3$, and the overall impact outcomes of the micro-environment, meso-environment, and macro-environment on the CEO's gender are reported in Model 4. All the models in Table 6 are overall significant. Compared with models 1 to 3, the Chi-2 and pseudo R2 values of Model 4 are significantly improved, indicating that the degree of model optimization is continuously improved and the degree of model interpretation is continuously improved. The mechanism of how the environment affects the gender of CEOs is shown in Figure 6.

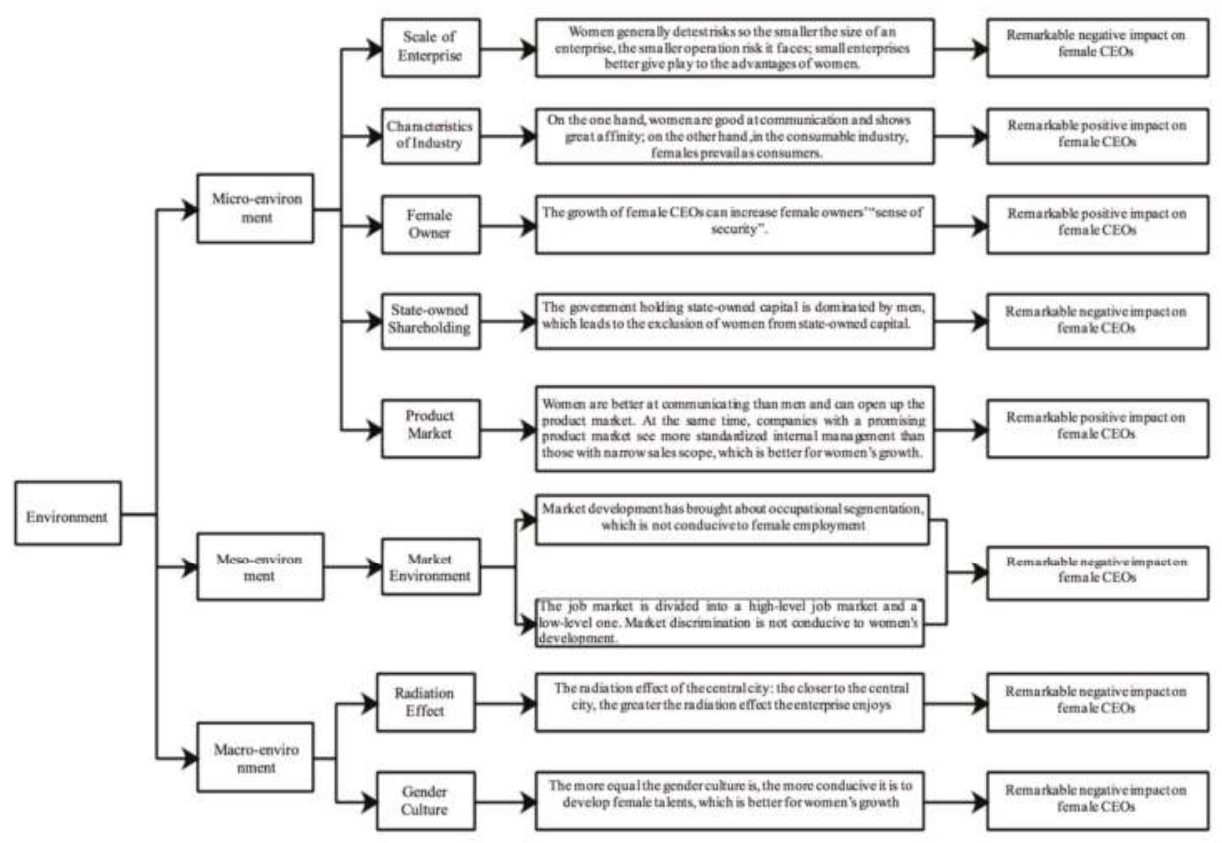

Figure 6. Schematic diagram of the mechanism of the environment's impact on CEO gender. 
Table 6. Main empirical results of the impact of environment on CEO gender.

\begin{tabular}{|c|c|c|c|c|}
\hline Variables & Model 1 & Model 2 & Model 3 & Model 4 \\
\hline Enterprise size & $\begin{array}{c}-0.203 \text { ** } \\
(-2.52)\end{array}$ & & & $\begin{array}{c}-0.219^{* *} \\
(-2.52)\end{array}$ \\
\hline Enterprise age & $\begin{array}{l}-0.102 \\
(-0.58)\end{array}$ & & & $\begin{array}{l}-0.0524 \\
(-0.29)\end{array}$ \\
\hline Corporate attributes & $\begin{array}{l}0.264 \\
(0.82)\end{array}$ & & & $\begin{array}{l}0.207 \\
(0.57)\end{array}$ \\
\hline Industry characteristics & $\begin{array}{c}0.622 * * * \\
(3.13)\end{array}$ & & & $\begin{array}{c}0.627^{* * * *} \\
(2.95)\end{array}$ \\
\hline Female ownership & $\begin{array}{c}2.257^{* * *} \\
(6.71)\end{array}$ & & & $\begin{array}{c}2.393 * * * \\
(6.35)\end{array}$ \\
\hline Foreign shareholding & $\begin{array}{l}0.638 \\
(1.45)\end{array}$ & & & $\begin{array}{l}0.426 \\
(0.82)\end{array}$ \\
\hline State-owned shareholding & $\begin{array}{c}-1.658 * \\
(-1.90)\end{array}$ & & & $\begin{array}{l}-1.813^{*} \\
(-1.96)\end{array}$ \\
\hline Product market & $\begin{array}{c}0.476^{* *} \\
(2.46)\end{array}$ & & & $\begin{array}{c}0.462^{* *} \\
(2.41)\end{array}$ \\
\hline Financial risk & $\begin{array}{c}-0.689 * \\
(-1.78)\end{array}$ & & & $\begin{array}{l}-0.684 \\
(-1.52)\end{array}$ \\
\hline Competition order & & $\begin{array}{c}0.0236 \\
(0.18)\end{array}$ & & $\begin{array}{c}0.0280 \\
(0.13)\end{array}$ \\
\hline Market environment & & $\begin{array}{c}0.319^{* *} \\
(2.43)\end{array}$ & & $\begin{array}{l}-0.764 * \\
(-1.81)\end{array}$ \\
\hline Economic level & & & $\begin{array}{l}0.205 \\
(0.79)\end{array}$ & $\begin{array}{l}0.155 \\
(0.38)\end{array}$ \\
\hline Radiation effect & & & $\begin{array}{c}-1.013^{* * *} \\
(-3.12)\end{array}$ & $\begin{array}{c}-1.973 \text { **** } \\
(-2.60)\end{array}$ \\
\hline City level & & & $\begin{array}{c}0.296^{* * * *} \\
(4.33)\end{array}$ & $\begin{array}{l}0.142 \\
(1.19)\end{array}$ \\
\hline Gender culture & & & $\begin{array}{l}-1.017^{*} \\
(-1.69)\end{array}$ & $\begin{array}{c}-2.729^{* *} \\
(-2.53)\end{array}$ \\
\hline Constant term & $\begin{array}{c}-3.622 \text { *** } \\
(-5.01)\end{array}$ & $\begin{array}{c}-2.296^{* * *} \\
(-19.78)\end{array}$ & $\begin{array}{l}-2.681 \\
(-0.79)\end{array}$ & $\begin{array}{l}0.822 \\
(0.15)\end{array}$ \\
\hline $\mathrm{Chi}^{2}$ & $83.55^{* * *}$ & $5.90 *$ & $52.43^{* * *}$ & $103.75^{* * *}$ \\
\hline Pseudo $\mathrm{R}^{2}$ & 0.128 & 0.0035 & 0.0299 & 0.153 \\
\hline Log-pseudolikelihood & -373.675 & -836.056 & -851.085 & -339.321 \\
\hline Sample size & 1534 & 2464 & 2559 & 1465 \\
\hline
\end{tabular}

Note: The values in parentheses are $t$ values; ${ }^{*}, * *$, and ${ }^{* * *}$ sub-tables represent significance at $10 \%, 5 \%$, and $1 \%$ levels.

\subsubsection{Micro-Environment}

\section{Basic Features}

There is a significantly negative correlation between the enterprise size and the CEO's gender, that is, the smaller an enterprise remains, the greater possibility that female CEOs may be hired. Perhaps the smaller the enterprise size, the less operational risk it may face, which is just in line with women's low risk appetite.

There is no significantly positive correlation between the enterprise age and the CEO's gender. Considering that the coefficient is too small, and the enterprise age has little impact on the CEO's gender, the reason why the impact coefficient is positive may be that the longer the company operates, the more standardized its internal management system may become, which provides a better environment for female CEOs.

In terms of corporate attributes, subsidiaries have no significant impact on the CEO's gender, yet its influencing coefficient is positive. 
Regarding industry characteristics, the consumer goods industry significantly impacts the CEO's gender, i.e., compared with other industries, companies in the consumer goods industry are more likely to choose female CEOs. This is mainly because of industry variance. The consumer goods industries are dominated by clothing, leisure, media, daily products, food, drug retail, and so on. Thus, the consumer goods industries are more family-oriented, and female CEOs are more aware of the needs of family and better at communicating with customers than male CEOs.

\section{Stock Equity Characteristics}

Female ownership significantly promoted the employment of female CEOs, raising the CEO's gender. This is mainly because of female owners' mentality of "penguin huddle" toward other females. At the top management of a company, females are a scarcity, and the increase in the same gender may enhance the sense of "security" among female owners [2]. The actual situation in China also affirmed this. According to the survey data of Chinese women entrepreneurs, in female-led enterprises, the proportion of female employees and female mid-level and senior-level managers exceeds that of male-led enterprises [40], and the extant literature indicates that female directors have significantly positive impacts on the increase of female senior managers [33].

Foreign shareholding has no significant impact on the CEO's gender, while state-owned shareholding has a significantly negative impact on the CEO's gender; that is, the lower the proportion of state-owned shareholding, the more likely it is for the company to choose male CEOs. This is mainly because government officials holding state-owned capitals are generally male officials, which leads to the exclusion of females from state-owned capitals.

\section{Operating Characteristics}

In terms of the product market, it has a significantly positive impact on the CEO's gender. That is, the broader the product sales scope, the more likely it is for the company to choose female CEOs. This is mainly because female CEOs are better at communication compared with male CEOs and can open up the product market more efficiently.

In terms of financial risk, there is a significantly negative correlation between the company's financial risk and the CEO's gender. Considering the value assignment of financial risk variables, this indicates that the higher the company's financial risk, the more likely it is to choose a female CEO. Women have lower risk preferences, so high-risk companies may choose low-risk females to defuse risks.

\subsubsection{Meso-Environment}

\section{Competition Order}

The competition order has a negative impact on the CEO's gender, but it is not significant. This is mainly related to the women's personality. Studies have found that female senior managers may significantly reduce corporate violations [41], so companies in industries rife with illegal competition are unlikely to choose female CEOs.

\section{Market Environment}

The impact of market environment variables on the CEO's gender is more complicated. In Model 2 , it was found that the market environment has a significantly positive impact on the CEO's gender; that is, the better the market environment, the more favorable it is for females to become CEOs. In Model 4, the market environment has a significantly negative impact on the CEO's gender; that is, the better the market environment, the more unfavorable for women to become CEOs. Generally, the better the market environment, the fairer the market will be, and the friendlier to women it will become.

Then, why does the market environment have a remarkably negative impact on female CEOs? This essay holds that there are two different mechanisms, as shown in Figure 6. First of all, the division 
of labor in the market brings about occupational segregation, which is not conducive to women's growth. As Adam Smith emphasized in The Wealth of Nations, the division of labor drives the economy. Therefore, with the continuous development of the economy, the division of labor in the market is continuously becoming specific and specialized. However, due to the physiological differences between women and men, some occupations are more suitable for men, not women, such as steel mill workers, maritime seafarers, etc., while secretarial, teachers, and other occupations are more suitable for women. In the long run, the market has weakened the professional status of women, while drawing on the advantages of men, which is solidified through the market system. This causes the occupational segregation of women as a result.

Second, the differentiation of the labor market shapes discrimination against women. The labor market theory holds that the labor market is not a simple unified market, but rather a differentiated market. The labor market can be divided into a high-level labor market and a secondary labor market. The high-level labor market is composed of people with a high level of education and technical expertise, and the secondary labor market is composed of people with no technical expertise. The differentiation of the labor market refers to the mutual exclusion of different labor markets. It is impossible to enter the high-level labor market from the secondary labor market, and the high-level labor market excludes the secondary labor market. Due to gender discrimination, women are less educated in the early stages of market development and do not have the ability to enter the advanced labor market. From then on, it is relatively difficult for women to enter the advanced labor market. In the secondary labor market, according to institutional economics theory, the secondary labor market is a market of incomplete information, and market entities decide recruitment according to gender, race, education level, and professional experience. When people generally believe that women's education levels are lower than men's and women do not need professional development, women face more discrimination. Therefore, gender is one of the signs of labor market segregation, and it influences different classified labor markets, thus putting women in a weak position.

As for the reason why two different results appeared, we believe that in this paper, there are other variables that regulate the impact of market environment on the CEO's gender, and this kind of moderating role will be further discussed in a later section.

\subsubsection{Macro-Environment}

\section{Economic Environment}

In terms of economic level, there is no significant correlation between economic level and the CEO's gender, but the economic level has a positive impact on the CEO's gender: that is, the higher the economic level, the more likely it is for the company to choose a female CEO. The economic level can reflect the overall situation of regional development. In areas with higher economic levels, systems are relatively sound, and thus conducive to the promotion of the CEO's gender.

In terms of radiation effect, the radiation effect has a significantly negative impact on the CEO's gender. That is, the closer the company is located to central cities such as Beijing, Shanghai, Guangzhou, and Chongqing, the more likely it is to choose female CEOs. This may be because the closer the company is to central cities, the more radiation it may receive, and the friendlier it is to women.

\section{Political Environment}

There is a significantly positive correlation between urban political level and the CEO's gender, which indicates that the higher the urban political level, the more likely it is for the company to choose a female CEO. The city level is a common phenomenon in China, and the Chinese government allocates resources by determining city levels. The higher the city level, the more resources it may acquire. Subsequently, the increase of city population is driven and systems are improved, which in turn helps women receive promotions and increases the CEO gender ratio. 


\section{Cultural Environment}

In terms of cultural environment, there is a significantly negative correlation between gender culture and the CEO's gender, and such a negative direction is due to the variable assignment. That is, the more females are respected in gender culture, the more equal it is to females and the easier it is for women to become CEOs, as it is mainly because the equal cultural environment provides a broad space for women's development and reduces discrimination against women.

\subsection{Further Analysis: The Moderating Role of Macro Environment in Meso Environment}

In models 2 and 4 of Table 6, there are two opposite outcomes of market environment on the CEO's gender. In fact, the more perfect the market environment is, the more favorable it is for women to become CEOs. Therefore, it is argued in this paper that other variables might regulate the impact of market environment on the CEO's gender, which needs to be further studied.

As shown in Figure 7, the gender culture in the macro-environment adjusts the market environment in the meso-environment, mainly adjusting the influence of the market environment on the gender of CEO by respecting and understanding gender differences, recognizing women's social values, and promoting women's socialization.

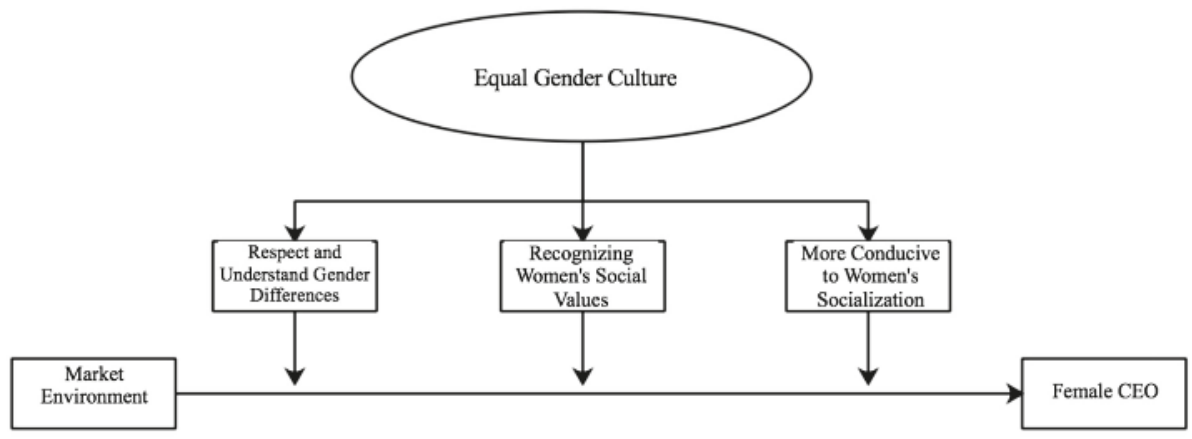

Figure 7. Illustration of how the gender culture adjusts the market environment.

First, an equal gender culture is conducive to creating an atmosphere of respecting and understanding gender differences. The differences in physiological functions between men and women and the social values behind them are the basis of market discrimination. In an equal gender culture, men's willingness to listen, recognize, understand, and accept women's physiological differences will largely help develop women's talents.

Second, an equal gender culture helps enterprises recognize women's social values. The reason enterprises are reluctant to hire women lies in the conflict between women's social values and corporate values. Women have the social function and value of breeding offspring, which is not available to men and only women can do it. Therefore, when a woman gives birth, her family and social value is increased. However, a female employee's giving birth does not directly increase the corporate value. On the contrary, the mandatory provisions such as maternity leave and maternity benefits have a negative impact on the company. Therefore, the company reduces female employment. However, when the gender culture is more and more equal, the company actively carry out a sense of social responsibility and assumes the necessary corporate social responsibility [42,43]. Recognizing the social value of women can benefit women's growth.

Finally, an equal gender culture is more conducive to the socialization of women and the development of female talents. Socialization is a process in which women learn from and integrate into the surrounding men. The external environment makes new requirements for women's development. Women are socialized through learning mechanisms, interactive mechanisms, and educational 
mechanisms to finish the process of learning from men and gradually adapt to the requirements of the external environment. Therefore, the more equal the gender culture of an enterprise is, the more women can display their unique charm and develop their talents.

A previous study conducted by $\mathrm{Han}$, Cui, Chen, and Fu found that gender culture significantly regulated the impact of female CEOs on corporate innovation behaviors [9]. Thus, by referring to the practices of such literature, this paper studies the gender culture of the cultural environment as a moderating variable. The empirical results are reported in Table 7 , and the model is significant as a whole. Models 5 and 6 are empirical results after increasing the moderating role of gender culture. To facilitate comparison, we placed models 2 and 4 from Table 6 into Table 7.

Table 7. Empirical results of the moderating effect of gender culture on market environment.

\begin{tabular}{|c|c|c|c|c|}
\hline Variables & Model 2 & Model 5 & Model 4 & Model 6 \\
\hline Competition order & $\begin{array}{c}0.0236 \\
(0.18)\end{array}$ & $\begin{array}{c}-0.0840 \\
(-0.63)\end{array}$ & $\begin{array}{c}0.0280 \\
(0.13)\end{array}$ & $\begin{array}{c}0.0183 \\
(0.08)\end{array}$ \\
\hline Market environment & $\begin{array}{c}0.319^{* *} \\
(2.43)\end{array}$ & $\begin{array}{c}12.06^{* * *} \\
(4.77)\end{array}$ & $\begin{array}{c}-0.764 * \\
(-1.81)\end{array}$ & $\begin{array}{l}2.722 \\
(0.51)\end{array}$ \\
\hline Gender culture & & $\begin{array}{l}0.251 \\
(0.33)\end{array}$ & $\begin{array}{c}-2.729^{* * *} \\
(-2.53)\end{array}$ & $\begin{array}{l}-2.119 \\
(-1.50)\end{array}$ \\
\hline Market environment * Gender culture & & $\begin{array}{c}-5.692^{* * * *} \\
(-4.74)\end{array}$ & & $\begin{array}{l}-1.622 \\
(-0.66)\end{array}$ \\
\hline Enterprise size & & & $\begin{array}{c}-0.219 \text { ** } \\
(-2.52)\end{array}$ & $\begin{array}{c}-0.218 \text { ** } \\
(-2.52)\end{array}$ \\
\hline Enterprise age & & & $\begin{array}{c}-0.0524 \\
(-0.29)\end{array}$ & $\begin{array}{c}-0.0539 \\
(-0.30)\end{array}$ \\
\hline Company attributes & & & $\begin{array}{l}0.207 \\
(0.57)\end{array}$ & $\begin{array}{l}0.203 \\
(0.56)\end{array}$ \\
\hline Industry characteristics & & & $\begin{array}{c}0.627^{* * *} \\
(2.95)\end{array}$ & $\begin{array}{c}0.636^{* * *} \\
(2.98)\end{array}$ \\
\hline Female ownership & & & $\begin{array}{c}2.393^{* * *} \\
(6.35)\end{array}$ & $\begin{array}{c}2.378^{* * *} \\
(6.28)\end{array}$ \\
\hline Foreign shareholding & & & $\begin{array}{l}0.426 \\
(0.82)\end{array}$ & $\begin{array}{l}0.416 \\
(0.79)\end{array}$ \\
\hline State-owned shareholding & & & $\begin{array}{c}-1.813 \text { * } \\
(-1.96)\end{array}$ & $\begin{array}{c}-1.787^{*} \\
(-1.91)\end{array}$ \\
\hline Product market & & & $\begin{array}{c}0.462 * * \\
(2.41)\end{array}$ & $\begin{array}{c}0.443^{* * *} \\
(2.33)\end{array}$ \\
\hline Financial risk & & & $\begin{array}{l}-0.684 \\
(-1.52)\end{array}$ & $\begin{array}{l}-0.639 \\
(-1.39)\end{array}$ \\
\hline Economic level & & & $\begin{array}{l}0.155 \\
(0.38)\end{array}$ & $\begin{array}{l}0.325 \\
(0.63)\end{array}$ \\
\hline Radiation effect & & & $\begin{array}{c}-1.973^{* * * *} \\
(-2.60)\end{array}$ & $\begin{array}{c}-1.608 \text { * } \\
(-1.79)\end{array}$ \\
\hline City level & & & $\begin{array}{l}0.142 \\
(1.19)\end{array}$ & $\begin{array}{l}0.106 \\
(0.81)\end{array}$ \\
\hline Constant term & $\begin{array}{c}-2.296^{* * *} \\
(-19.78)\end{array}$ & $\begin{array}{c}-2.789 * \\
(-1.66)\end{array}$ & $\begin{array}{l}0.822 \\
(0.15)\end{array}$ & $\begin{array}{l}-2.438 \\
(-0.32)\end{array}$ \\
\hline $\mathrm{Chi}^{2}$ & $5.90 *$ & $42.99 * * *$ & $103.75^{* * *}$ & $103.69^{* * *}$ \\
\hline Pseudo $\mathrm{R}^{2}$ & 0.0035 & 0.0242 & 0.1528 & 0.1534 \\
\hline Log-pseudolikelihood & -836.056 & -818.670 & -339.321 & -339.097 \\
\hline Sample size & 2464 & 2464 & 1465 & 1465 \\
\hline
\end{tabular}

Note: The values in parentheses are $t$ values; ${ }^{*}, * *$, and ${ }^{* * *}$ sub-tables represent significance at $10 \%, 5 \%$, and $1 \%$ levels.

In Model 5, the moderating variable of gender culture is added. Compared with Model 2, the coefficient of the market environment variable is significantly improved, and the interaction items are significantly negative (mainly due to the value assignment structure of the gender culture variable), showing that the more fair the environment that the gender culture enjoys, the more likely it is for a 
company to choose female CEOs, increasing the $\mathrm{CEO}$ gender ratio. Thus, we find that the interaction between the meso-environment and macro environment can significantly promote the CEO's gender. In Model 6, the moderating variable of gender culture is also added. Compared with Model 4, the market environment variable changes from negative to positive, but the impact is not significant.

This illustrates two issues. First, the environment in which a company is placed does not affect the CEO's gender separately and directly. Instead, they affect the CEO's gender through the interaction between environments, such as moderating effect. Second, the gender culture in the macro-environment does not necessarily have a significant impact on the CEO's gender and the effective supervisions of government and other departments are required. For example, in models 4 and 6 , the gender culture has an insignificant impact on the moderating effect of the market environment, but it changed the influence symbol of the market environment in Model 4. As a type of soft restraint and informal system, a culture does not impose mandatory restraint on corporate behavior in relation to market-chasing interests. This also explains why Germany has passed a bill mandating that the proportion of female CEOs in large enterprises should not be less than 30\% (China News Network. Germany passed the law on the proportion of female CEOs in enterprises, stipulating that the proportion of female CEOs shall not be less than 30\%. [EB/OL]. http://www.chinanews.com/gj/2015/03-06/7109101.shtml, 2015-03-06/2018-08-20). Similarly, the Chinese government has also issued the Notice on Further Normalizing Recruitment Behavior to Promote Women's Employment, further elaborating specific manifestations of gender discrimination in employment and requiring enterprises not to restrict women's employment and refuse to hire women on the grounds of gender (Notice on Standardizing Recruitment Behavior and Promoting Women's Employment issued by the Network of the Central People's Government of the People's Republic of China, the Ministry of Human Resources and Social Security and other nine departments [EB/OL]. http://www.gov.cn/xinwen/2019-02/25/content_5368180.htm).

\subsection{Marginal Effect Analysis}

To visually obtain the impact of the micro-environment, meso-environment, and macro-environment on the CEO's gender, the marginal effect analysis was conducted in this paper, and the results thereof were reported in Table 8. Among them, the impacts of gender culture on the marginal effect under the moderation of the market environment are reported in models 8 and 12 .

\subsubsection{Micro-Environment}

In the micro-environment, the marginal effects of enterprise size, industry characteristics, female ownership, state-owned shareholding, and product market are significant.

In terms of basic company characteristics, the CEO's gender decreased by $0.0138 \%$ for every one unit added to the enterprise size. In terms of industry characteristics, the CEO's gender in the consumer goods industry increased by $0.0409 \%$ if compared with the non-consumer goods industry.

In terms of the stock equity characteristics, for every one unit added to the female ownership of a company, the CEO's gender increased by $0.156 \%$. For every one unit decrease in state-owned shareholding, the CEO's gender increased by $0.118 \%$. In terms of the operating characteristics of a company, for every one unit added to the product market of a company, the CEO's gender increased by $0.0301 \%$. 
Table 8. Analysis of marginal effects of environment on CEO gender.

\begin{tabular}{|c|c|c|c|c|c|c|}
\hline Variables & Model 7 & Model 8 & Model 9 & Model 10 & Model 11 & Model 12 \\
\hline Enterprise size & $\begin{array}{l}-0.0138^{* *} \\
(0.00552)\end{array}$ & & & & $\begin{array}{l}-0.0143^{* *} \\
(0.00570)\end{array}$ & $\begin{array}{l}-0.0142 * * \\
(0.00567)\end{array}$ \\
\hline Enterprise age & $\begin{array}{c}-0.00694 \\
(0.0121)\end{array}$ & & & & $\begin{array}{c}-0.00342 \\
(0.0118) \\
\end{array}$ & $\begin{array}{c}-0.00351 \\
(0.0118)\end{array}$ \\
\hline Company attributes & $\begin{array}{c}0.0180 \\
(0.0219)\end{array}$ & & & & $\begin{array}{c}0.0135 \\
(0.0237)\end{array}$ & $\begin{array}{c}0.0132 \\
(0.0237)\end{array}$ \\
\hline Industry characteristics & $\begin{array}{l}0.0424^{* * *} \\
(0.0136)\end{array}$ & & & & $\begin{array}{c}0.0409 * * * \\
(0.0140)\end{array}$ & $\begin{array}{c}0.0414^{* * *} \\
(0.0141)\end{array}$ \\
\hline Female ownership & $\begin{array}{l}0.154^{* * *} \\
(0.0246)\end{array}$ & & & & $\begin{array}{l}0.156^{* * *} \\
(0.0262)\end{array}$ & $\begin{array}{l}0.155^{* * *} \\
(0.0263)\end{array}$ \\
\hline Foreign shareholding & $\begin{array}{c}0.0436 \\
(0.0300)\end{array}$ & & & & $\begin{array}{c}0.0278 \\
(0.0340) \\
\end{array}$ & $\begin{array}{c}0.0271 \\
(0.0342) \\
\end{array}$ \\
\hline $\begin{array}{l}\text { State-owned } \\
\text { shareholding }\end{array}$ & $\begin{array}{l}-0.113^{*} \\
(0.0598)\end{array}$ & & & & $\begin{array}{l}-0.118^{*} \\
(0.0608)\end{array}$ & $\begin{array}{l}-0.116^{*} \\
(0.0612)\end{array}$ \\
\hline Product market & $\begin{array}{l}0.0325^{* *} \\
(0.0132)\end{array}$ & & & & $\begin{array}{c}0.0301 * * \\
(0.0125)\end{array}$ & $\begin{array}{l}0.0289 * * \\
(0.0124)\end{array}$ \\
\hline Financial risk & $\begin{array}{l}-0.0470^{*} \\
(0.0267)\end{array}$ & & & & $\begin{array}{l}-0.0446 \\
(0.0296)\end{array}$ & $\begin{array}{l}-0.0416 \\
(0.0301)\end{array}$ \\
\hline Competition order & & $\begin{array}{l}0.00225 \\
(0.0126)\end{array}$ & $\begin{array}{l}-0.00788 \\
(0.0125)\end{array}$ & & $\begin{array}{l}0.00183 \\
(0.0141)\end{array}$ & $\begin{array}{l}0.00119 \\
(0.0140)\end{array}$ \\
\hline Market environment & & $\begin{array}{l}0.0304^{* *} \\
(0.0126)\end{array}$ & $\begin{array}{l}1.132 * * * \\
(0.240)\end{array}$ & & $\begin{array}{c}-0.0498^{*} \\
(0.0278)\end{array}$ & $\begin{array}{l}0.177 \\
(0.344)\end{array}$ \\
\hline Economic level & & & & $\begin{array}{c}0.0193 \\
(0.0246)\end{array}$ & $\begin{array}{c}0.0101 \\
(0.0269)\end{array}$ & $\begin{array}{c}0.0212 \\
(0.0335)\end{array}$ \\
\hline Radiation effect & & & & $\begin{array}{l}-0.0956^{* * *} \\
(0.0307)\end{array}$ & $\begin{array}{l}-0.129^{* *} \\
(0.0504)\end{array}$ & $\begin{array}{l}-0.105^{*} \\
(0.0595)\end{array}$ \\
\hline City level & & & & $\begin{array}{l}0.0279 * * * \\
(0.00649)\end{array}$ & $\begin{array}{c}0.00927 \\
(0.00781)\end{array}$ & $\begin{array}{c}0.00693 \\
(0.00857)\end{array}$ \\
\hline Gender culture & & & $\begin{array}{c}0.0235 \\
(0.0719) \\
\end{array}$ & $\begin{array}{c}-0.0959 * \\
(0.0566)\end{array}$ & $\begin{array}{c}-0.178^{* *} \\
(0.0716)\end{array}$ & $\begin{array}{c}-0.138 \\
(0.0931)\end{array}$ \\
\hline $\begin{array}{l}\text { Market environment * } \\
\text { Gender culture }\end{array}$ & & & $\begin{array}{l}-0.534^{* * *} \\
(0.114)\end{array}$ & & & $\begin{array}{l}-0.106 \\
(0.160)\end{array}$ \\
\hline Sample size & 1534 & 2464 & 2464 & 2559 & 1465 & 1465 \\
\hline
\end{tabular}

\subsubsection{Meso-Environment}

In terms of meso-environment, the marginal effect of the market environment is significant, but the impacts vary in different models.

In Model 8, the market environment has a significant impact on the CEO's gender, and the company's probability of selecting a female CEO increased by $0.0304 \%$ for every one unit added to the market environment. In Model 9, under the moderating effect of gender culture, the CEO's gender increased by $1.132 \%$ for every one unit added to the market environment. In Model 11, the market environment has a negative impact on the CEO's gender, and the company's probability of selecting a female CEO decreased by $0.0498 \%$ for every one unit added to the market environment. In Model 12 , under the moderating effect of gender culture, the impact of the market environment on the CEO's gender changed from negative to positive.

\subsubsection{Macro Environment}

In the macro environment, the marginal effects of radiation effect and gender culture are significant. In terms of radiation effect, the CEO's gender decreased by $0.129 \%$ for every one unit reduced in the 
distance from company to central cities. In terms of gender culture, the CEO's gender increased by $0.178 \%$ for every one unit added to the gender culture.

\subsection{Handling of Endogenous Problems}

In terms of endogenous problems, this paper tries every possible method to minimize the impact of endogenous variables on research results. Firstly, the meso-environment and macro-environment belong to exogenous factors. Generally speaking, the behaviors of a company are unable to affect the development of the entire industry, and it is even less likely to directly affect the political level and economic and cultural level of this region. Thus, endogenous problems in the meso-environment and macro-environment are greatly weakened. However, in the micro-environment, there may be a two-way causal relationship between CEO genders and the micro-environment under which enterprises are located [44]. For example, along with corporate development, the construction of enterprise systems is becoming more and more perfect, which is in turn conducive to females becoming CEOs. There may be various other reasons such as the internal mutual supervision mechanism within the company [45], CEO power [46], enterprise size [22], etc. In addition, endogenous problems may also be caused by missing variables, measurement errors, and other reasons. Therefore, endogenous problems also need to be alleviated in this paper.

In this paper, the method of adding as many control variables as possible that affect both explanatory variables and dependent variables is adopted for the reasons as follows. (1) This method is an effective way to alleviate endogeneity, and it is adopted in international top-level journals. In this paper, the research results of Schijven and Hitt, [47] and Foss et al. [48] are used as reference, and the method of adding control variables is used to alleviate endogeneity. (2) In the aspect of variable design in this paper, in order to reflect the impact of the corporate micro-environment on CEO genders, it is not available or possible to choose a core variable, because no one variable can reflect the company's overall level. That is to say, a core variable can not reflect the overall picture of the micro-environment. Therefore, the selection of enterprise scale and corporate equity structure as core variables can not reflect the actual situation of the corporate micro-environment. In conclusion, this method is chosen to alleviate endogeneity in this paper.

The specific practice of using this method is to increase the control variables correlated to both dependent variables and independent variables. The endogeneity in this paper is caused by variables in the corporate micro-environment. For this reason, we have added more corporate micro-environments as the control variable. The variables and setting methods are specified as follows. (1) The degree of informationization (in questionnaire number $\mathrm{CNo} 8$, the question is: currently, what percentage of this establishment's workforce regularly use computers in their jobs?) considers there have been rapid developments in the degree of informationization in recent years. Thus, such a variable reflects the degree of corporate informationization, and this variable is set as the proportion of computers used in the work. The higher the proportion is, the higher the degree of corporate informationization will become. (2) Cooperative research and development (R\&D) (in questionnaire number $\mathrm{CNo5}$, the question is: in the last three years, did this establishment spend money on research and development activities contracted with other companies? The answer options are YES and No.) is set as a dummy variable that mainly reflects the cooperative $R \& D$ situation of enterprises. Cooperative $R \& D$ is assigned a 1; otherwise, 0. (3) Technology acquisition (in questionnaire number E6, the question is: does this establishment at present use technology licensed from a foreign-owned company, excluding office software?) is set as a virtual variable that is mainly reflected in the situation of corporate technology acquisition. The fact of technology acquisition is assigned a 1; otherwise, it is 0 . (4) International certification (in questionnaire B8, the question is: does this establishment have an internationally recognized quality certification? (INTERVIEWER: If there is need for clarification, some examples are: ISO 9000 or 14,000, or HACCP)) is set as a virtual variable, and enterprises are assigned a 1 if they have passed international certification; otherwise, they are assigned a 0 . 
In Table 9, the empirical results of the endogeneity test are reported. From the results, all of the models are significant as a whole. In terms of specific variables, except that the market environment in Model 14 is not significant, other variables are significant, and there are no significant changes in the market environments in Model 16 and Model 17. Therefore, we can think that the endogenous problems have been effectively alleviated.

Table 9. Empirical analysis of endogenous tests.

\begin{tabular}{|c|c|c|c|c|c|}
\hline & Model 13 & Model 14 & Model 15 & Model 16 & Model 17 \\
\hline Enterprise size & $\begin{array}{c}-0.162 * * \\
(-2.02)\end{array}$ & & & $\begin{array}{l}-0.156 \text { * } \\
(-1.76)\end{array}$ & $\begin{array}{l}-0.157 * \\
(-1.77)\end{array}$ \\
\hline Enterprise age & $\begin{array}{c}-0.0623 \\
(-0.33)\end{array}$ & & & $\begin{array}{c}-0.00792 \\
(-0.04)\end{array}$ & $\begin{array}{c}-0.00927 \\
(-0.05)\end{array}$ \\
\hline Company attributes & $\begin{array}{l}0.119 \\
(0.34)\end{array}$ & & & $\begin{array}{l}0.106 \\
(0.27)\end{array}$ & $\begin{array}{l}0.106 \\
(0.27)\end{array}$ \\
\hline Industry characteristics & $\begin{array}{c}0.600 \text { *** } \\
(2.91)\end{array}$ & & & $\begin{array}{c}0.614^{* * * *} \\
(2.78)\end{array}$ & $\begin{array}{c}0.619 * * * \\
(2.79)\end{array}$ \\
\hline Female ownership & $\begin{array}{c}2.285 \text { *** } \\
(6.35)\end{array}$ & & & $\begin{array}{c}2.322 \text { *** } \\
(6.05)\end{array}$ & $\begin{array}{c}2.315^{* * * *} \\
(6.00)\end{array}$ \\
\hline Foreign shareholding & $\begin{array}{l}0.644 \\
(1.40)\end{array}$ & & & $\begin{array}{l}0.568 \\
(1.04)\end{array}$ & $\begin{array}{l}0.558 \\
(1.01)\end{array}$ \\
\hline State-owned shareholding & $\begin{array}{c}-1.780 * * \\
(-2.09)\end{array}$ & & & $\begin{array}{c}-1.844 \text { ** } \\
(-2.08)\end{array}$ & $\begin{array}{c}-1.831 * * \\
(-2.06)\end{array}$ \\
\hline Product market & $\begin{array}{c}0.437 * * \\
(2.18)\end{array}$ & & & $\begin{array}{c}0.416 * * \\
(2.10)\end{array}$ & $\begin{array}{c}0.407 * * \\
(2.07)\end{array}$ \\
\hline Financial risk & $\begin{array}{l}-0.639 \\
(-1.52)\end{array}$ & & & $\begin{array}{l}-0.637 \\
(-1.31)\end{array}$ & $\begin{array}{l}-0.615 \\
(-1.25)\end{array}$ \\
\hline Competition order & & $\begin{array}{c}-0.0332 \\
(-0.16)\end{array}$ & & $\begin{array}{l}0.0140 \\
(0.06)\end{array}$ & $\begin{array}{c}0.00823 \\
(0.04)\end{array}$ \\
\hline Market environment & & $\begin{array}{l}0.227 \\
(1.14)\end{array}$ & & $\begin{array}{c}-0.862 * * \\
(-1.96)\end{array}$ & $\begin{array}{l}0.997 \\
(0.18)\end{array}$ \\
\hline Economic level & & & $\begin{array}{l}0.295 \\
(0.79)\end{array}$ & $\begin{array}{l}0.179 \\
(0.42)\end{array}$ & $\begin{array}{l}0.262 \\
(0.50)\end{array}$ \\
\hline Radiation effect & & & $\begin{array}{l}-0.935 * \\
(-1.91)\end{array}$ & $\begin{array}{c}-2.512 * * * \\
(-3.19)\end{array}$ & $\begin{array}{c}-2.292 * * \\
(-2.46)\end{array}$ \\
\hline City level & & & $\begin{array}{l}0.154 \\
(1.52)\end{array}$ & $\begin{array}{l}0.168 \\
(1.35)\end{array}$ & $\begin{array}{l}0.149 \\
(1.06)\end{array}$ \\
\hline Gender culture & & & $\begin{array}{c}-1.826 \text { ** } \\
(-2.15)\end{array}$ & $\begin{array}{c}-2.915^{* * *} \\
(-2.58)\end{array}$ & $\begin{array}{c}-2.588 * \\
(-1.84)\end{array}$ \\
\hline $\begin{array}{l}\text { Market environment* } \\
\text { Gender culture }\end{array}$ & & & & & $\begin{array}{l}-0.861 \\
(-0.34)\end{array}$ \\
\hline Informationization & $\begin{array}{c}1.086 * * \\
(2.36)\end{array}$ & $\begin{array}{c}1.194^{* * *} \\
(2.82)\end{array}$ & $\begin{array}{c}0.845^{* *} \\
(1.97) \\
\end{array}$ & $\begin{array}{l}0.710 \\
(1.44) \\
\end{array}$ & $\begin{array}{l}0.719 \\
(1.45) \\
\end{array}$ \\
\hline Cooperative R\&D & $\begin{array}{l}-0.0367 \\
(-0.11)\end{array}$ & $\begin{array}{l}-0.210 \\
(-0.67)\end{array}$ & $\begin{array}{l}-0.374 \\
(-1.20)\end{array}$ & $\begin{array}{l}-0.140 \\
(-0.38)\end{array}$ & $\begin{array}{l}-0.148 \\
(-0.39)\end{array}$ \\
\hline Technology acquisition & $\begin{array}{l}0.0641 \\
(0.25)\end{array}$ & $\begin{array}{l}0.130 \\
(0.56)\end{array}$ & $\begin{array}{c}0.0458 \\
(0.21) \\
\end{array}$ & $\begin{array}{l}-0.255 \\
(-0.93)\end{array}$ & $\begin{array}{l}-0.253 \\
(-0.92)\end{array}$ \\
\hline International certification & $\begin{array}{l}-0.302 \\
(-1.30)\end{array}$ & $\begin{array}{l}-0.379 * \\
(-1.72)\end{array}$ & $\begin{array}{c}-0.479 * * \\
(-2.29)\end{array}$ & $\begin{array}{l}-0.268 \\
(-1.06)\end{array}$ & $\begin{array}{l}-0.261 \\
(-1.02)\end{array}$ \\
\hline Constant term & $\begin{array}{c}-3.995 * * * \\
(-5.34)\end{array}$ & $\begin{array}{c}-2.679 * * * \\
(-10.17)\end{array}$ & $\begin{array}{l}-1.842 \\
(-0.38)\end{array}$ & $\begin{array}{l}0.855 \\
(0.15) \\
\end{array}$ & $\begin{array}{l}-0.809 \\
(-0.10)\end{array}$ \\
\hline $\mathrm{Chi}^{2}$ & 97.72 & $12.50 *$ & $33.56 * * *$ & $110.91^{* * *}$ & $111.62 * * *$ \\
\hline Pseudo $\mathrm{R}^{2}$ & 0.1359 & 0.0144 & 0.0359 & 0.1606 & 0.1608 \\
\hline Log-pseudolikelihood & -356.71718 & -399.76577 & -425.34368 & -325.83632 & -325.77685 \\
\hline Sample size & 1495 & 1497 & 1571 & 1435 & 1435 \\
\hline
\end{tabular}

Note: The values in parentheses are $t$ values; ${ }^{*}, * *$ and ${ }^{* * *}$ sub-tables represent significance at $10 \%, 5 \%$, and $1 \%$ levels. 


\subsection{Robustness Test}

Based on previous empirical results, the following methods are used to test robustness.

\subsubsection{Consideration of Replacing Empirical Methods}

In this paper, the regression model is replaced by the probit model. The empirical results are reported in Table 10, and the moderating effect of gender culture on market environment is reported in models 18 and 22. In terms of empirical results, the model as a whole is significant, and there is little difference with the benchmark regression results in Table 6 . Thus, the empirical results are robust.

Table 10. Main empirical results after replacing empirical methods.

\begin{tabular}{|c|c|c|c|c|c|}
\hline Variables & Model 18 & Model 19 & Model 20 & Model 21 & Model 22 \\
\hline Enterprise size & $\begin{array}{c}-0.109 * * * \\
(-2.59)\end{array}$ & & & $\begin{array}{c}-0.119^{* * *} \\
(-2.66)\end{array}$ & $\begin{array}{c}-0.119 * * * \\
(-2.65) \\
\end{array}$ \\
\hline Enterprise age & $\begin{array}{l}-0.0539 \\
(-0.58)\end{array}$ & & & $\begin{array}{l}-0.0229 \\
(-0.24)\end{array}$ & $\begin{array}{l}-0.0223 \\
(-0.24)\end{array}$ \\
\hline Company attributes & $\begin{array}{l}0.147 \\
(0.89) \\
\end{array}$ & & & $\begin{array}{l}0.127 \\
(0.70) \\
\end{array}$ & $\begin{array}{l}0.123 \\
(0.68) \\
\end{array}$ \\
\hline Industry characteristics & $\begin{array}{l}0.327^{* * *} \\
(3.16)\end{array}$ & & & $\begin{array}{l}0.341^{* * *} \\
(3.10)\end{array}$ & $\begin{array}{c}0.344^{* * *} \\
(3.12)\end{array}$ \\
\hline Female ownership & $\begin{array}{c}1.061^{* * * *} \\
(7.67)\end{array}$ & & & $\begin{array}{c}1.127^{* * *} \\
(7.35)\end{array}$ & $\begin{array}{c}1.121^{* * *} \\
(7.28)\end{array}$ \\
\hline Foreign shareholding & $\begin{array}{l}0.334 \\
(1.46) \\
\end{array}$ & & & $\begin{array}{l}0.234 \\
(0.89) \\
\end{array}$ & $\begin{array}{l}0.231 \\
(0.88) \\
\end{array}$ \\
\hline State-owned shareholding & $\begin{array}{l}-0.794 * * \\
(-2.06)\end{array}$ & & & $\begin{array}{l}-0.904 * * \\
(-2.21)\end{array}$ & $\begin{array}{l}-0.894^{* *} \\
(-2.18)\end{array}$ \\
\hline Product market & $\begin{array}{c}0.252 * * \\
(2.53)\end{array}$ & & & $\begin{array}{c}0.243^{* *} \\
(2.46)\end{array}$ & $\begin{array}{c}0.234^{* *} \\
(2.38) \\
\end{array}$ \\
\hline Financial risk & $\begin{array}{c}-0.420 * * \\
(-2.00)\end{array}$ & & & $\begin{array}{l}-0.387 \\
(-1.64) \\
\end{array}$ & $\begin{array}{l}-0.368 \\
(-1.54)\end{array}$ \\
\hline Competition order & & $\begin{array}{c}0.0140 \\
(0.20) \\
\end{array}$ & & $\begin{array}{c}0.0169 \\
(0.15) \\
\end{array}$ & $\begin{array}{l}0.0115 \\
(0.10) \\
\end{array}$ \\
\hline Market environment & & $\begin{array}{c}0.166^{* *} \\
(2.43)\end{array}$ & & $\begin{array}{c}-0.440 * * \\
(-2.08)\end{array}$ & $\begin{array}{l}1.125 \\
(0.42) \\
\end{array}$ \\
\hline Gender culture & & & $\begin{array}{l}-0.504 * \\
(-1.66)\end{array}$ & $\begin{array}{c}-1.601 * * * \\
(-2.87)\end{array}$ & $\begin{array}{l}-1.323^{*} \\
(-1.82)\end{array}$ \\
\hline Economic level & & & $\begin{array}{l}0.111 \\
(0.82)\end{array}$ & $\begin{array}{l}0.0746 \\
(0.35)\end{array}$ & $\begin{array}{l}0.146 \\
(0.57)\end{array}$ \\
\hline Radiation effect & & & $\begin{array}{c}-0.537^{* * *} \\
(-3.18)\end{array}$ & $\begin{array}{c}-1.117^{* * *} \\
(-2.93)\end{array}$ & $\begin{array}{c}-0.959^{* *} \\
(-2.13)\end{array}$ \\
\hline City level & & & $\begin{array}{c}0.157^{* * *} \\
(4.29)\end{array}$ & $\begin{array}{l}0.0747 \\
(1.21) \\
\end{array}$ & $\begin{array}{l}0.0592 \\
(0.89) \\
\end{array}$ \\
\hline Constant term & $\begin{array}{c}-1.838^{* * *} \\
(-5.10)\end{array}$ & $\begin{array}{l}-1.333 * * * \\
(-22.32)\end{array}$ & $\begin{array}{l}-1.636 \\
(-0.93)\end{array}$ & $\begin{array}{l}0.944 \\
(0.34)\end{array}$ & $\begin{array}{l}-0.479 \\
(-0.12)\end{array}$ \\
\hline $\begin{array}{l}\text { Market environment * } \\
\text { Gender culture }\end{array}$ & & & & & $\begin{array}{l}-0.728 \\
(-0.59) \\
\end{array}$ \\
\hline $\mathrm{Chi}^{2}$ & $93.02 * * *$ & $5.92 *$ & $50.23 * * *$ & $114.69^{* * *}$ & $114.38^{* * *}$ \\
\hline Pseudo $\mathrm{R}^{2}$ & 0.1286 & 0.0035 & 0.0298 & 0.1565 & 0.1569 \\
\hline Log-pseudolikelihood & -373.23996 & -836.05133 & -851.19876 & -337.8409 & -337.6714 \\
\hline Sample size & 1534 & 2464 & 2559 & 1465 & 1465 \\
\hline
\end{tabular}

Note: The values in parentheses are $t$ values; ${ }^{* * *}$, and ${ }^{* * *}$ sub-tables represent significance at $10 \%, 5 \%$, and $1 \%$ levels. 


\subsubsection{Considering the Impact of Biased Geographical Location of the Sample}

Due to data reasons, the samples in this paper are mainly concentrated in the eastern coastal areas of China. Thus, considering the impact of uneven sample distribution, variables in the eastern region are set in this paper; that is, the value assignment of samples from the eastern region is 1 and the value assignment of samples from non-eastern region is 0 . The empirical results are reported in Table 11. From the results, the samples in the eastern region are insignificant, so we can exclude the impact of sample concentration in the eastern region from the empirical results.

Table 11. Main empirical results after considering the geographical distribution of samples.

\begin{tabular}{|c|c|c|c|c|c|}
\hline Variables & Model 23 & Model 24 & Model 25 & Model 26 & Model 27 \\
\hline Enterprise size & $\begin{array}{c}-0.110 \text { *** } \\
(-2.61)\end{array}$ & & & $\begin{array}{c}-0.114 \text { ** } \\
(-2.54)\end{array}$ & $\begin{array}{c}-0.114 \text { ** } \\
(-2.54)\end{array}$ \\
\hline Enterprise age & $\begin{array}{c}-0.0537 \\
(-0.58)\end{array}$ & & & $\begin{array}{c}-0.0179 \\
(-0.19) \\
\end{array}$ & $\begin{array}{c}-0.0180 \\
(-0.19) \\
\end{array}$ \\
\hline Company attributes & $\begin{array}{l}0.153 \\
(0.93)\end{array}$ & & & $\begin{array}{l}0.117 \\
(0.65)\end{array}$ & $\begin{array}{l}0.117 \\
(0.65)\end{array}$ \\
\hline Industry characteristics & $\begin{array}{c}0.327 * * * \\
(3.15)\end{array}$ & & & $\begin{array}{c}0.338 * * * \\
(3.07)\end{array}$ & $\begin{array}{c}0.339 * * * \\
(3.06)\end{array}$ \\
\hline Female ownership & $\begin{array}{c}1.058^{* * *} \\
(7.63)\end{array}$ & & & $\begin{array}{c}1.124^{* * *} \\
(7.32)\end{array}$ & $\begin{array}{c}1.122 * * * \\
(7.29)\end{array}$ \\
\hline Foreign shareholding & $\begin{array}{l}0.344 \\
(1.50)\end{array}$ & & & $\begin{array}{l}0.237 \\
(0.90)\end{array}$ & $\begin{array}{l}0.236 \\
(0.90)\end{array}$ \\
\hline State-owned shareholding & $\begin{array}{c}-0.780 * * \\
(-2.01)\end{array}$ & & & $\begin{array}{c}-0.922 * * \\
(-2.25)\end{array}$ & $\begin{array}{c}-0.918^{* *} \\
(-2.23)\end{array}$ \\
\hline Product market & $\begin{array}{c}0.247^{* *} \\
(2.49)\end{array}$ & & & $\begin{array}{c}0.230 * * \\
(2.35)\end{array}$ & $\begin{array}{c}0.228 * * \\
(2.34)\end{array}$ \\
\hline Financial risk & $\begin{array}{c}-0.418^{* *} \\
(-2.00)\end{array}$ & & & $\begin{array}{l}-0.345 \\
(-1.45)\end{array}$ & $\begin{array}{l}-0.342 \\
(-1.43)\end{array}$ \\
\hline Competition order & & $\begin{array}{c}0.0107 \\
(0.16) \\
\end{array}$ & & $\begin{array}{c}0.00390 \\
(0.03)\end{array}$ & $\begin{array}{c}0.00313 \\
(0.03)\end{array}$ \\
\hline Market environment & & $\begin{array}{c}0.0946 \\
(1.15) \\
\end{array}$ & & $\begin{array}{c}-0.539 * * \\
(-2.29)\end{array}$ & $\begin{array}{c}-0.0798 \\
(-0.03)\end{array}$ \\
\hline Economic level & & & $\begin{array}{l}0.139 \\
(1.02)\end{array}$ & $\begin{array}{l}0.130 \\
(0.59) \\
\end{array}$ & $\begin{array}{l}0.147 \\
(0.57)\end{array}$ \\
\hline Radiation effect & & & $\begin{array}{l}-0.204 \\
(-0.76)\end{array}$ & $\begin{array}{c}-0.858^{* *} \\
(-1.99)\end{array}$ & $\begin{array}{c}-0.830 * \\
(-1.81)\end{array}$ \\
\hline City level & & & $\begin{array}{c}0.153^{* * *} \\
(4.20)\end{array}$ & $\begin{array}{c}0.0605 \\
(0.96) \\
\end{array}$ & $\begin{array}{c}0.0570 \\
(0.86) \\
\end{array}$ \\
\hline Gender culture & & & $\begin{array}{c}-0.672 \text { ** } \\
(-2.04)\end{array}$ & $\begin{array}{c}-1.989 * * * \\
(-2.91)\end{array}$ & $\begin{array}{c}-1.883 * \\
(-1.91)\end{array}$ \\
\hline Eastern region & $\begin{array}{l}0.110 \\
(0.86) \\
\end{array}$ & $\begin{array}{l}0.148 \\
(1.49) \\
\end{array}$ & $\begin{array}{l}0.216 \\
(1.52) \\
\end{array}$ & $\begin{array}{l}0.255 \\
(1.05) \\
\end{array}$ & $\begin{array}{l}0.239 \\
(0.88) \\
\end{array}$ \\
\hline $\begin{array}{l}\text { Market environment * } \\
\text { Gender culture }\end{array}$ & & & & & $\begin{array}{l}-0.211 \\
(-0.15)\end{array}$ \\
\hline Constant term & $\begin{array}{c}-1.915^{* * *} \\
(-5.06)\end{array}$ & $\begin{array}{c}-1.408^{* * *} \\
(-17.65)\end{array}$ & $\begin{array}{l}-1.832 \\
(-1.05)\end{array}$ & $\begin{array}{l}0.937 \\
(0.34) \\
\end{array}$ & $\begin{array}{l}0.525 \\
(0.13) \\
\end{array}$ \\
\hline $\mathrm{Chi}^{2}$ & $93.66^{* * *}$ & $7.96^{*}$ & $53.02 * * *$ & $115.15^{* * *}$ & $115.23^{* * *}$ \\
\hline Pseudo $\mathrm{R}^{2}$ & 0.1295 & 0.0048 & 0.0312 & 0.1580 & 0.1580 \\
\hline Log-pseudolikelihood & -372.86308 & -834.93147 & -849.92897 & -337.26453 & -337.25278 \\
\hline $\mathrm{N}$ & 1534 & 2464 & 2559 & 1465 & 1465 \\
\hline
\end{tabular}

Note: The values in parentheses are $t$ values; ${ }^{*},{ }^{* *}$, and ${ }^{* * *}$ sub-tables represent significance at $10 \%, 5 \%$, and $1 \%$ levels. 


\section{Discussion and Conclusions}

In recent years, along with the increase of female senior managers, factors influencing their employment have gradually become a focus of research. However, the existing literature has laid more emphasis on the number and proportion of female senior managers. Few studies have discussed the quality of employment. Therefore, a convincing explanation cannot be found in the present research. The key for explaining the phenomenon that women are shattering the glass ceiling and entering top management is the enterprise characteristics and environment. Thus, starting from the environment in which a company is involved, this paper combines the micro, meso, and macro levels and integrates them into a unified framework for analysis. By utilizing and matching the data of the World Bank Questionnaire Survey of Chinese Manufacturing Enterprises 2012, Chinese General Social Survey 2012, and relevant statistical yearbook data, this paper analyzes the influence of the corporate-level micro-environment, industry-level meso-environment, and regional-level macro-environment on the quality of employment of female senior managers and the influence mechanism. The main contribution of this paper is as follows. (1) It expands the theory of human resources and career acquisition from the perspective of the environment. (2) It gives attention to the influential factors of the quality of employment of female senior managers. (3) It provides a complete environment perspective that combines the micro-environment, meso-environment, and macro-environment. (4) It analyzes the mechanism of each environment's influence on the quality of employment of female senior managers. Fourth, this paper adopts Chinese samples to compensate for the existing inadequate literature in China, while providing valuable revelations for enterprise management and practice.

\subsection{Conclusions}

First, it outlines the profiles of companies with high CEO gender ratios and describes the general characteristics of such companies. In terms of the micro-environment, the enterprise size is small, with four to 17 employees. It is relatively new and has been established within the last six years. It is a subsidiary company and belongs to the consumer goods industry. It has female owners and has $80-90 \%$ of foreign shareholding and no state-owned shareholding. The product sales are mainly focused on the international market. Its financial risk is high, and the proportion of its self-owned funds is within $35-60 \%$. In terms of the meso-environment, the company's competitors are mainly unregistered enterprises, and the company is in a better market environment than the average. In terms of the macro-environment, the company is located in areas with good economic development levels, with the GDP per capita ranging between RMB 81,658-91,202. It is 135.6 to $174.5 \mathrm{~km}$ away from Beijing, Shanghai, Guangzhou, Chongqing, and other national central cities, which are located in municipalities directly under the central government, and in areas with cultures that display more gender equality.

Second, the micro-environment, meso-environment, and macro-environment may all influence the CEO's gender, yet the degree of influence varies. In terms of the micro-environment, enterprise size and state-owned shareholding have a significantly negative impact on female CEOs: the probability of female CEOs decreased by $0.0142 \%$ and $0.116 \%$ respectively for every one unit added to the enterprise size and state-owned shareholding. Product features, industry characteristics, and female ownership have a significantly positive impact on the CEO's gender. The probability of female CEOs in consumer goods companies and companies with female owners increased by $0.0414 \%$ and $0.155 \%$, if compared with non-consumer industries and companies without female owners, while the probability of female CEOs increased by $0.0289 \%$ for every one unit increased in the scope of product sales. In terms of the meso-environment, the market environment has a significantly negative impact on the quality of women's employment, and the probability of female CEOs decreased by $0.0498 \%$ for every one unit that it increased in the market environment. In terms of the macro-environment, the radiation effect and gender culture have a significant impact on the quality of women's employment. The probability of female CEOs increased by $0.129 \%$ for every one-unit increase in the distance between central cities. 
In terms of gender culture, the probability of female CEOs increased by $0.178 \%$ for every one unit added to the gender culture.

Third, this paper further analyzes the influence mechanism of the environment on the CEO's gender; that is, the positive moderation of the macro-environment on the influence of the meso-environment on the CEO's gender. As discovered in this paper, the impacts of the market environment on the CEO's gender vary in different models. As revealed by the research findings, the gender culture in the macro-environment has a positive moderating effect on the market environment in the meso-environment. The reason why the moderating effect is not significant may be that the current gender culture is unfair to women and inherent prejudices toward women are widespread.

\subsection{Theoretical Contribution}

Theoretically, the traditional career development theory and career development theory explain to a certain extent why women become senior executives, but can not explain why they can not become CEOs. The important reason is that they ignore the external environment and gender differences. When we incorporate gender into existing theories, we can clearly see that women's development faces many difficulties, and it is difficult to make a difference on their own. The Achilles' heel of traditional theories is that they only focus on men and ignore women, and thus cannot explain the differences in career development between men and women [49].

Therefore, human resource theory should recognize the importance of the environment and gender differences, attach great importance to gender stereotypes and gender discrimination in industry careers, and re-establish work ethics of gender equality in order to promote sustainable development.

\subsection{Implication and Suggestion}

First, the government needs to adopt a multi-pronged approach and take different measures at the micro, meso, and macro levels to provide a good environment for women's career development. The research in this essay finds that the company's micro-environment, industry meso-environment, and regional macro-environment will all affect the number of female CEOs. In addition, the macro-environment has a positive adjustment effect on the meso-environment. Therefore, in order to achieve gender balance and sustainable development, we need to constantly improve corporate governance mechanisms, optimize the market environment, establish an equal gender culture, and provide equal opportunities for women's development.

Second, an enterprise needs to establish an organizational environment based on gender cooperation. The modern organization is controlled by men, and the corporate culture is dominated by masculinity. Therefore, it is necessary to establish an organizational environment where partner protection and cooperation are the main content, and ethical care for women is stressed.

Third, from the perspective of women themselves, the essay provides a reference for women's career development. Women's career development often faces the "ceiling dilemma", so prudence is required while choosing an occupation. In this regard, the research findings of this paper have certain reference significance for women's employment. For example, cities with a culture that displays more gender equality, better economic levels, and higher levels may be selected. Regarding companies, it is advisable to choose those involved in the consumer goods industry, with female owners and a broader product market. At the same time, companies with smaller enterprise size, lower state-owned shareholding, higher financial risks, and closer distance to central cities are preferable.

\subsection{Research Deficiency}

In terms of research content, due to the limitations of the sample data, this paper failed to study the relationship between the environment and its interaction on the gender impact of CEOs. At the same time, the environment is constantly changing; this paper lacks the dynamic analysis of the environment. Therefore, in future studies, we can further study the interaction between environments and the impact of their dynamic changes on female CEOs. 
Author Contributions: Conceptualization, W.C.; Data curation, S.H.; Funding acquisition, W.C. and S.H.; Methodology, S.H. and W.C.; Project administration, W.C. and J.C.; Visualization, S.H.; Writing-original draft, S.H., W.C., and Y.F.; Writing-review and editing, S.H. and J.C.

Funding: This research was funded by The Philosophy and Social Sciences outstanding innovation team construction project of Jiangsu Province (No. 2015ZSTD006), The Development report of philosophy and social sciences of Ministry of education of China (No. 13JBG004), Postgraduate Research \& Practice Innovation Program of Jiangsu Province (No. KYCX19_1072).

Conflicts of Interest: The authors declare no conflicts of interest.

\section{References}

1. Hill, A.D.; Upadhyay, A.D.; Beekun, R.I. Female and Ethnically Diverse Executives Endure Inequity in the CEO Position or Do They Benefit from Their Minority Status? An Empirical Examination. Strateg. Manag. J. 2015, 36, 1115-1134. [CrossRef]

2. Navarro, A.; Gallo, A. The Female CEO in Developing Countries' Firms. Available SSRN 2014. [CrossRef]

3. Coxbill, A.L. Stock market reaction to a gender change in CEO. Diss. Theses Gradworks 2008. [CrossRef]

4. Grosvold, J.; Rayton, B.; Brammer, S. Women on Corporate Boards: A Comparative Institutional Analysis. Bus. Soc. 2016, 55, 1157-1196. [CrossRef]

5. De Beauvoir, S.; Parshley, H.M. The Second Sex; Vintage Books: New York, NY, USA, 2012.

6. Kirsch, A. The gender composition of corporate boards: A review and research agenda. Leadersh. Q. 2018, 29, 346-364. [CrossRef]

7. Ng, E.S.; Sears, G.J. The glass ceiling in context: The influence of CEO gender, recruitment practices and firm internationalisation on the representation of women in management. Hum. Resour. Manag. J. 2017, 27, 133-151. [CrossRef]

8. Huang, X.; Bond, M.; Ng, S. Handbook of Chinese Organizational Behavior: Integrating Theory, Research and Practice; Edward Elgar Publishing: Northampton, MA, USA, 2012.

9. Han, S.; Cui, W.; Chen, J.; Fu, Y. Female CEOs and Corporate Innovation Behaviors-Research on the Regulating Effect of Gender Culture. Sustainability 2019, 11, 682. [CrossRef]

10. Spence, J.T.; Helmreich, R.; Stapp, J. Ratings of self and peers on sex role attributes and their relation to self-esteem and conceptions of masculinity and femininity. J. Personal. Soc. Psychol. 1975, 32, $29-39$. [CrossRef]

11. Scott, W.J. Gender: A Useful Category of Historical Analysis. Am. Hist. Rev. 1986, 91, 1053-1075. [CrossRef]

12. Hambrick, D.C.; Mason, P.A. Upper Echelons: The Organization as a Reflection of Its Top Managers. Acad. Manag. Rev. 1984, 9, 193-206. [CrossRef]

13. Hadjimanolis, A. An investigation of innovation antecedents in small firms in the context of a small developing country. $R$ D Manag. 2010, 30, 235-246. [CrossRef]

14. Coles, J.L.; Li, Z.F. Managerial Attributes, Incentives, and Performance. 2018. Available online: https: //papers.ssrn.com/sol3/papers.cfm?abstract_id=1680484 (accessed on 27 July 2019).

15. Carter, D.A.; Simkins, B.J.; Simpson, W.G. Corporate governance, board diversity, and firm value. Financ. Rev. 2003, 38, 33-53. [CrossRef]

16. Francoeur, C.; Labelle, R.; Sinclair-Desgagné, B. Gender Diversity in Corporate Governance and Top Management. J. Bus. Ethics 2008, 81, 83-95. [CrossRef]

17. Pucheta-Martínez, M.C.; Bel-Oms, I.; Olcina-Sempere, G. Corporate governance, female directors and quality of financial information. Bus. Ethics Eur. Rev. 2016, 25, 363-385. [CrossRef]

18. De Beaufort, V.; Summers, L. Women on boards: Sharing a rigorous vision of the functioning of boards, demanding a new model of corporate governance. J. Res. Gend. Stud. 2014, 4, 101.

19. Child, J. Theorizing about organization cross-nationally. Adv. Int. Comp. Manag. 2000, 13, 27-76.

20. Johns, G. The Essential Impact of Context on Organizational Behavior. Acad. Manag. Rev. 2006, 31, 386-408. [CrossRef]

21. Cook, A.; Glass, C. Above the glass ceiling: When are women and racial/ethnic minorities promoted to CEO? Strateg. Manag. J. 2014, 35, 1080-1089. [CrossRef]

22. Frank, L.Z.; Chongyu, D. Measuring Firm Size in Empirical Corporate Finance. J. Bank. Financ. 2018, 86, 159-176. 
23. Gul, F.A.; Srinidhi, B.; Ng, A.C. Does board gender diversity improve the informativeness of stock prices? J. Account. Econ. 2011, 51, 314-338. [CrossRef]

24. Morikawa, M. What types of companies have female directors? Evidence from Japan. Jpn. World Econ. 2016, 37-38, 1-7. [CrossRef]

25. Brinkhuis, E.; Scholtens, B. Investor response to appointment of female CEOs and CFOs. Lead. Q. 2018, 29, 423-441. [CrossRef]

26. Bertrand, M.; Hallock, K.F. The Gender Gap in Top Corporate Jobs. Ind. Labor Relat. Rev. 2001, 55, 3-21. [CrossRef]

27. Adams, R.B.; Kirchmaier, T. Women on Boards in Finance and STEM Industries. Soc. Sci. Electron. Publ. 2016, 106, 81-277. [CrossRef]

28. Wolfers, J. Diagnosing Discrimination: Stock Returns and CEO Gender. J. Eur. Econ. Assoc. 2011, 4, 531-541. [CrossRef]

29. Wang, G.; Holmes, R.M.; Devine, R.A.; Bishoff, J. CEO gender differences in careers and the moderating role of country culture: A meta-analytic investigation. Organ. Behav. Hum. Decis. Process. 2018, 148, 30-53. [CrossRef]

30. Chizema, A.; Kamuriwo, D.S.; Shinozawa, Y. Women on corporate boards around the world: Triggers and barriers. Leadersh. Q. 2015, 26, 1051-1065. [CrossRef]

31. Grosvold, J.; Brammer, S.J. National Institutional Systems as Antecedents of Female Board Representation: An Empirical Study. Corp. Gov. Int. Rev. 2011, 19, 116-135. [CrossRef]

32. Aguilera, R.V.; Jackson, G. The Cross-National Diversity of Corporate Governance: Dimensions and Determinants. Acad. Manag. Rev. 2003, 28, 447-465. [CrossRef]

33. Terjesen, S.; Singh, V. Female Presence on Corporate Boards: A Multi-Country Study of Environmental Context. J. Bus. Ethics 2008, 83, 55-63. [CrossRef]

34. Wei, J.C.; Shuo, H.; Yu, F.; Wen, J.W.; Jia, L.Z. Research on the open innovation behaviors and influencing factors of Chinese manufacturing enterprises-Based on the world bank survey data in 2012. Sci. Technol. Prog. Policy 2018, 35, 76-81.

35. Zeng, P.; Wu, Q. The impact of female top management participation on Technological Innovation: An Empirical Study Based on GEM companies. Stud. Sci. Sci. 2012, 30, 773-781.

36. Core, J.; Guay, W. The use of equity grants to manage optimal equity incentive levels. J. Account. Econ. 1999, 28, 151-184. [CrossRef]

37. Giroud, X.; Mueller, H.M. Corporate governance, product market competition, and equity prices. J. Financ. 2011, 66, 563-600. [CrossRef]

38. Coles, J.L.; Li, Z.F.; Yan, A.W. Industry Tournament Incentives. Soc. Sci. Electron. Publ. 2012, 31, 1418-1459. [CrossRef]

39. Liu, F.; Yang, Z.; Yang, X. Institutional environment, tax incentives and enterprise innovation inputs. Manag. Rev. 2016, 2, 61-73.

40. Li, L.; Zhong, W.; Wang, Y. The development of Chinese Female Entrepreneurs: Current situation, problems and expectations-A Survey of 2505 female entrepreneurs. Manag. World 2017, 11, 50-64.

41. Wang, Q.; Zhou, Z. Female Executives and R\&D Investment: Empirical Evidence China. Manag. World 2015, $3,178-179$.

42. Hong, B.; Li, Z.; Minor, D. Corporate Governance and Executive Compensation for Corporate Social Responsibility. J. Bus. Ethics 2016, 136, 199-213. [CrossRef]

43. Ikram, A.; Li, Z.F.; Minor, D. CSR-Contingent Executive Compensation Contracts. Soc. Sci. Electron. Publ. 2017. [CrossRef]

44. Li, F. Endogeneity in CEO power: A survey and experiment. Invest. Anal. J. 2016, 45, 149-162. [CrossRef]

45. Li, Z. Mutual monitoring and corporate governance. J. Bank. Financ. 2014, 45, 255-269.

46. Li, F.; Li, T.; Minor, D. A Test of Agency Theory: CEO Power, Firm Value, and Corporate Social Responsibility. Int. J. Manag. Financ. 2016, 12, 611-628. [CrossRef]

47. Schijven, M.; Hitt, M.A. The vicarious wisdom of crowds: Toward a behavioral perspective on investor reactions to acquisition announcements. Strateg. Manag. J. 2012, 33, 1247-1268. [CrossRef] 
48. Foss, N.J.; Frederiksen, L.; Rullani, F. Problem-formulation and problem-solving in self-organized communities: How modes of communication shape project behaviors in the free open-source software community. Strateg. Manag. J. 2016, 37, 2589-2610. [CrossRef]

49. Tong, X. Introduction to the Gender Studies; Peking University Press: Beijing, China, 2018.

(c) (1)

(C) 2019 by the authors. Licensee MDPI, Basel, Switzerland. This article is an open access article distributed under the terms and conditions of the Creative Commons Attribution (CC BY) license (http://creativecommons.org/licenses/by/4.0/). 
Article

\title{
An Examination of Sustainable HRM Practices on Job Performance: An Application of Training as a Moderator
}

\author{
Faiza Manzoor ${ }^{1}$, Longbao Wei ${ }^{1, *}$, Tamás Bányai ${ }^{2}$, Mohammad Nurunnabi ${ }^{3,4, *}$ \\ and Qazi Abdul Subhan ${ }^{5}$ \\ 1 Department of Agricultural Economics and Management, Zhejiang University, Hangzhou 310029, China; \\ Faiza1885@yahoo.com or Faizamanzoor@zju.edu.cn \\ 2 Institute of Logistics, University of Miskolc, 3515 Miskolc, Hungary; alttamas@uni-miskolc.hu \\ 3 St Antony's College, University of Oxford, Oxford, 62 Woodstock Road, Oxford OX2 6JF, UK \\ 4 Department of Accounting, Prince Sultan University, P.O. Box 66833, Riyadh 11586, Saudi Arabia \\ 5 Bahria Business School, Bahria University, Islamabad, P.O. 44000, Pakistan; qazisubhan@bahria.edu.pk \\ * Correspondence: lbwei@zju.edu.cn (L.W.); mnurunnabi@psu.edu.sa (M.N.)
}

Received: 17 February 2019; Accepted: 11 April 2019; Published: 15 April 2019

\begin{abstract}
This study attempts to examine the role of sustainable Human Resource Management (HRM) practices on job performance and encompasses training as a moderator variable to further evaluate the association among HRM practices and employee's job performance.The study seeks to measure the effect of selection, participation, and employee empowerment on job performance in the publicly owned universities of Pakistan. The descriptive survey research design was utilized for this study. The target population was the entire teaching staff of two publicly owned universities (namely "The University of Agriculture Peshawar" and "Hazara University Mansehra" Pakistan). By using a convenient sampling technique, 130 sample participants were selected from the target population. The reliability scales were tallied by using Cronbach's Alpha. The findings of the study are gleaned by using regression to investigate the role of HRM practices in job performance and whether training moderated the association between HRM practices and employee performance. Through Statistical Package of Social Science (SPSS), Hayes process was used regarding the moderation effect of training between HRM practices and job performance. The main results of regression analysis validate that HRM practices, such as selection, participation, and employee empowerment, have a significant and positive effect on employee job performance. Specifically, the study suggests that training significantly moderates the effect of HRM practices on the performance of employees and that sustainability of HRM practices has a great impact on job performance. Based on the outcomes the study confirms that the proposed hypotheses are statistically significant. Furthermore, directions for future research are offered.
\end{abstract}

Keywords: selection; participation; employee empowerment; sustainability; job performance; training; sustainable HRM practices; public sector universities; Pakistan

\section{Introduction}

Human Resource Management (HRM) is the act of managerial activities and responsibilities concerned with developing and maintaining a competent employee [1]. HRM is concerned with the personnel in an organization and how they contribute to organizational efficiency and effectiveness. Senyucel [2] defined HRM as a "combination of people-cantered management practices that recognizes employees as assets and those that are geared to creating and maintaining a skillful and committed workforce for achieving organizational goals". The HRM function of an organization concentrates 
on the management level. It consists of practices that help the organization to effectively manage employees during the different phases of the employment, including pre-hire, staffing, and post-hire. HRM practices directly affect employee motivation, their behavior, and skill improvement to boost organizational performance [3].

The organizations use different HRM practices to achieve their appropriate goals. Accurate human resource management in an organization, such as a friendly environment, pay appreciation for performance, providing feedback to employees, a fair evaluation system for employees, an award ceremony, employee empowerment, extrinsic and intrinsic motivational rewards, recruitment and selection, training and involvement of employees, and performance evaluation, guarantee overall organizational performance.

HRM practices involve all management decision and actions. The role of practices starts with the hiring of people by an organization. Thus, appointing new personnel requires the achievement of HRM practices [4]. While employed, employees must to be included in the organization's structure through training and socialization. After this process, key elements of HRM are evaluated in the development of staff members and encourages them through compensation and reward systems [5]. Employee selection, training, assessment, communication, and compensating one's domestic workers could pose many difficulties and challenges for organizations [6]. It is very difficult to manage personnel in an efficient way. The personnel issue needs to be precisely confronted, otherwise it will harm the benefits of the organization [7].

HRM practices could be an obvious cure to motivate the personnel's expertise, attitude, and manner, which affect the performance of organizations as well as employees. A positive employee attitude can help them give maximum effort in the hopes of getting promoted in the organization [8]. Previous studies have demonstrated a direct and positive connection among HRM practices and job performance [6,9]. HRM practices also show a positive relationship with organizational performance [10]. With the HRM practices implementation, everyone can be self-assured that personnel will be fairly treated [11].

In addition, some comparable studies with the same concept have revealed a significant relationship of HRM practices and job performance [12-14]. Siddiqi et al. [12] have proposed a significant role of HR Practices in the academic staffs' performance. Further, he described that by training existing staff, the organization can obtain precise and accurate knowledge, and better direction to increase academic staff performance.

New public management is adapting traditional practices of HR in the public sector area of Pakistan, from permanent appointments to seniority and performance-based endorsement [15]. The effect of HRM practices on employee performance has been the subject of much attention. Previously, researchers have conducted research in many countries regarding HRM practices [16,17]. Sustainable HRM is an innovative concept, which is still in the pioneering stage and reflects attempts to link sustainability to HRM. The definition for sustainable HRM was recently presented by Ehnert et al. [18],

"... the adaption of HRM strategies and practices that enables the achievement of financial, social, and ecological goals, with an impact inside and outside of the organization and over a long-term time horizon, while controlling for unintended side effects and negative feedback".

Minor studies have investigated this concept in developing countries, such as Pakistan $[19,20]$. However, evaluation of the sustainable HRM practices on job performance across the university sector is nearly non-existent and very limited. Hence, the current study deliberately assesses this concept in Pakistan. The purpose of this study is to analyze the role of sustainable HRM practices in job performance in publicly owned universities of Khyber Pakhtunkhwa Province (KPK) in Pakistan. To the authors' knowledge there has never been a study carried out in regard to the correlation between sustainable HRM practices and employee job performance in the aforementioned province of Pakistan. Thus, the present study is based on an inventive idea whose purpose is to examine the hypothetical association of sustainable HRM practices and job performance. Furthermore, the present study argues the role of HRM practices and hypothesizes the effect of training on job performance. 
Additionally, the present study observes the moderating role of training among the association of HRM practices and job performance. In the current study, the HR practices that are considered are selection, participation, and employee empowerment, and a call for how these practices can play a role in employee job performance. The main reason for choosing these practices is that they connect sustainability to HRM practices. Sustainable HRM is one of the innovative concepts that some scholars and practitioners have researched $[16,21]$. As there is no previous study regarding sustainable HR practices (functions), in our study we choose sustainable HRM practices to evaluate employee performance. The purpose of the study is to increase the knowledge of sustainable HRM by revealing the practices, such as selection, training participation, and employee empowerment on employee performance. The present study has made an attempt to address the research questions that remain unsettled regarding HRM practices and how the organization can avoid failure by motivating employee interest. Employee interest in HRM practices is needed to evaluate the extent to which they are pursuing HR practices in accomplishing their career goals.

The current study examines the role of sustainable HRM practices on employee job performance and focuses on the moderating role of training between the association of HRM practices and job performance that exists in the mentioned universities. Here, the independent variables in HRM Practices are selection, participation, and employee empowerment. The dependent variable is job performance and training is the moderating variable.

The rest of the article consists of the subsequent sections. Second, relevant literature is reviewed and hypotheses are developed. In Section Three, research methods are presented. In Section Four, the results of the study are presented. Section Five includes discussion, conclusions, and recommendations. Furthermore, the limitations of the study and future research directions are discussed.

\section{Review of Literature and Hypotheses}

\subsection{Sustainable HRM Practices}

Sustainable HRM can be explained as "the adaptation of HRM practices and strategies that enable them to achieve the financial, ecological and social goals of the organization over a long term horizon, while controlling for negative feedback and unintended side effects" [22]. The Paradox theory creates links between sustainability and HRM by Enhert and Herry [23]. They recall this theory as "sustainability", as it is defined as reproduced resources and balance consumed, bringing about paradoxical choice situations and pressure for performance in sustainable HRM that need to be keenly dealt with and that can be a source for transformation and innovation". HR practices and job performance have been the subject matter of several research scholars. They have conducted research studies that have been preserved in their precious books and collections. Development and formulation of HR practices that can ensure a high level of employee performance result in increased attainment and achievement. High-quality management practices are a key driver of job performance [24]. The Action theory approach of performance provides various features that help to describe the directive method of learning and behavior. This approach not only includes the repertoire of training techniques but helps to illuminate the high order cognitive functioning that helps individuals regulate their learning and performance [25]. Paille et al. [26] argued that sustainable HRM contributes to improving green performance through staff members and organizational support, and has direct and indirect effects on the organization and the labor force. Wikhamn [16] explored the impact of sustainable HRM practices on customer satisfactionin Swedish hotels. The findings of his study indicated customer satisfaction is dependent on sustainable HR practices in the organization. He concluded in his study that sustainable HR practices impact customer satisfaction positively and these practices have a significant role in enhancing organizational performance.

Sustainable HRM highlights the importance of HR practices for organizational outcomes that go beyond financial performance [18]. Developing more sustainable practices is important to ensure a clean Earth in the future, healthy and happy employees, and many others emotive issues that 
some business leaders brush off. However, sustainability is good business. When employees of the organization truly care about mitigating waste and improving the efficiency of the business, it can pay off in dollars. Sustainability is something that every forward-thinking company should be at least considering when it comes to developing strategies for improvement and growth.

According to the Ehnert [27], maintains sustainable HRM entails not only attracting and retaining motivated and talented employees but also providing them with a healthy work environment and opportunities to develop.

It is important to define the characteristics of both sustainable HRM practices and sustainable HRM because they have different meanings. Sustainable HRM is highly concerned with context, for instance, the potential harm of HRM practices on employees. Researchers examined sustainable HRM based on the synthesis and simultaneous effects of high-performance work systems on organizational performance and employee harm and they have found that flexible high-performance work arrangements, such as tele-working and compressed working week, could have a negative effect on organizational performance. It is important to indicate particular HRM policies considered as part of a high-performance work arrangement and analyze their impacts on organizational profitability and employee wellbeing [28]. Another interesting study discusses the strategic potential of sustainability as a concept for HRM and examines the key paradoxes of sustainable HRM. The results of this study show that realizing efficient and effective, as well as sustainable, HRM systems may create paradoxical choice situations and tensions that need to be actively coped with [29]. De Prins et al., in 2015, defined the "ingredients of sustainable HRM" in terms of "Respect", "Openness", and "Continuity" (ROC), and they broaden the scope from a single career-perspective to a more integrated HRM and Corporate Social Responsibility (CSR) perspective. Based on these researches, we can say that sustainable human resource management is a promising domain for theory-building in HRM, focusing on both research and practice [30]. Literature supporting the role of HR in promoting, driving, or enabling sustainability in organizations abound. The central role of the HR function enables it to play a key role in promoting sustainability practices through broad, deep, internal and external relationships. Researchers tend to focus on strategic issues and sustainability. This study addresses that gap by presenting a framework of suggested sustainable HRM practices. The current study is paying special concentration and interest to three HR practices that manipulate job performance. They are selection, participation and employee empowerment. Also, training is used as a moderator. The views of the numerous research scholars about job performance are enumerated in the following sections.

\subsubsection{Selection and Job Performance}

The HR function should embrace sustainability, not only for organizational effectiveness and long-term economic benefits, but also for ethical reasons and for responsible leadership [31]. Selection is an essential practice of HR whenever it selects the right people with necessary characteristics, knowledge, and qualification in the right job to fit the organization's environment and culture [32]. It is accomplished by finding the right person for the particular job that fulfills the unfilled post of the organization [6]. Jepsen and Grob [33] demonstrated in their study that applying a sustainable selection process in the organization shows not only a commitment to the planet, people, and profits, but may serve as the competitive differentiator in the employee marketplace.

Johnson [34] examined the selection of qualified and top employees in the organizations. It is an effective way to achieve organizational goals. He suggested that the proper selection process is helpful in the increase of sales and output of the organization. Harris [35] highlighted that having a fair method of employee selection is very effective in achieving the organizational goal.

Kepha et al. [36] determined the recruitment and selection influence of the performance of the employees in Kenya research institutes. There is growing evidence that HRM practices plays a significant role in attaining high quality personnel. Specifically, selection has been singled out as a main practice of HRM that can have an influence on the level of employee performance in the organization. The findings of their study showed that the relationship between recruitment and 
selection and employee performance were highly significant $(p=0.000)$. Oaya et al. [37] investigated the recruitment and selection strategy on employee job performance. Their study revealed that the best methodof the recruitment and selection is to enable organizations to select a productive and creative workforce. Further studies described that fair selection on the basis of the capability of the candidates creates enthusiasm in the candidates and they perform better for the organization. On the basis of the above, it is clear that employee selection has an important role in performance. Thus, we hypothesized that:

Hypothesis 1 (H1). Sustainable selection process is positively related to Job performance.

\subsubsection{Participation and Job Performance}

Participation is a process by which all employees of an organization are involved in, and have authority and influence on, decisions related to development activities that will affect them. Some prior studies demonstrated that participation of employees is positively correlated to employee performance [38]. Bhatti et al. [39] revealed that employee participation and involvement in the workplace affect the employee's job performance. Paul [40] revealed employees who are close up to the work of the organization are skilled and the most competent to make suggestion regarding improvements and success of the organization. Therefore, employees of the organization should be authorized and allowed to increase their participation in the organization's decision making [41]. Wagner [42] explored the association among participation and the performance and satisfaction. Findings of his study revealed that participation can have a statistically significant effect on performance.

A sustainable work system and employee participation encourages and promotes business sustainability. On the basis of the above arguments, it is clear that employee participation plays a significant role in job performance. Therefore, we hypothesized that:

Hypothesis 2 (H2). Sustainable employee Participation has a positive correlation to Job performance.

\subsubsection{Employee Empowerment and Job Performance}

Empowerment means encouraging and motivating the employees to make decisions with higher level management of the organization. Employee empowerment is defined as providing the power and authority to employees to make decisions for the organization. There are some observed facts to maintain the use of employee involvement. Spreitzer and Mishra [43] stated a study of forty-three firms in the U.S. automotive industry. The Big Three (Ford, Chrysler, and General Motors) proved a positive association between employee involvement and productivity of labor. Empowerment is also an arrangement of power-granting, in which all the employees of the organization can make decisions themselves with independence, information, and responsibility [44,45].

Geralis and Terziovski [46] showed that practice of empowerment has a positive effect on output, service quality, and performance in Australian banks. Likewise, more empowered teams were found to be more proactive and productive and had job satisfaction; customer service level was higher, as was team commitment and organizational commitment, than those with lower levels of empowerment [47]. Chebat and Kollias [48] showed that empowerment affects the behavior of employees and their attitudinal nature (i.e., self-efficacy, role conflict, adaptability, organizational commitment, and job satisfaction). The outcomes of empowerment are well known, which enhance its perception. Personnel and other organizational aspects should be considered to achieve more insight into employees' perception of empowerment [49].

Bakri [50] demonstrated that employee empowerment has a significant influence on job performance. It has been found by many scholars around the world that job satisfaction of employees has a positive association with employee performance. They also expressed in the study that 
there is a significant relationship among empowerment and job satisfaction and job performance. Essentially, employee empowerment provides sustainable opportunities for employees in accordance with their aspirations and talents to acquire knowledge and skills and to apply them in a favorable work environment in order to achieve individual and organizational performance.Therefore, we posit that:

Hypothesis 3 (H3). Sustainable Employee Empowerment is positively related to Job performance.

\subsubsection{Training and Job Performance}

Training is defined as the giving of helpful and useful skills, ideas, and knowledge by teaching to be able to perform a practical job in a skilled way. Training is the continuous effort and attempt designed to improve the skill and performance of the employee [51]. Employees who are well-trained can easily share their skills and updated knowledge by using their creativity to improve the output of the organization [52]. Nassazi [53] assessed the effects of training on an employee's job performance in telecommunication companies in Uganda. A qualitative research approach was adopted using a questionnaire distributed to 120 respondents. The findings indicated that training has a positive effect on employee performance. The results of his study could prove useful to HR policy decision-makers, managers, and academic institutions, as well as government.

Githinji [54] explored the effects of training on employee performance among international civil servants in Somalia. He collected primary data from the 144 staff from the United Nations Support Office for the African Mission in Somalia. Findings of his study revealed that in general, training improves employee engagement and helps to improve the performance of the employees. Further training increases employee enthusiasm for work. In short, training and employee job performance have a significant and positive relationship.

Amos and Natamba [55] showed that job training has a positive and significant effect on employee job performance. Hanif [56] examined the effect of training on employee performance in the hotel industry of Lahore, Pakistan. His study found that job training improved employees'skills and enthusiasm for their work. In short, training is a learning process that increases knowledge and sharpens skills, enhancing employee performance. Like sustainability training, fostering workplace dialogue can also increase sustainability knowledge and skills in anorganization. Therefore, on the basis of aforementioned literature, it is plausible that training plays a significant role in job performance.Therefore, we posit that:

Hypothesis 4 (H4). Training is positively related to Job performance.

\subsubsection{Moderating Role of Training in HRM Practices and Job Performance}

Skinner's theory of reinforcement emphasizes the learning behavior of a person and suggests that the learner will repeat behavior that is attached with a positive outcome or result. This theory suggested that the training and development programs should be aligned with the organizational objectives and a positive outcome should be expected with such training programs [57]. Social learning theory is a theory of learning process and social behavior, which proposes that new behaviors can be acquired by observing and imitating others. It states that learning is a cognitive process that takes place in a social context and can occur purely through observation or direct instruction, even in the absence of motor reproduction or direct reinforcement [58]. Expectancy theory was originally presented by Victor Vroom; this theory can be used to influence employee behavior. Employees would be motivated to be involved in Human Resource Development activities if they expect that it will benefit them by enhancing their performance. Employee will feel encouraged to attend training if they expects that it will enhance their knowledge and if they knows that the outcome of these efforts will be rewarded [59]. These theories play vital roles in influencing employee behavior in the organization. 
The ultimate goal of Human resource development is to influence employee behavior (task performance and organizational citizenship behavior) to enhance both individual and organizational performance and to enable both to achieve their goals. Therefore, it can be concluded that all the aforementioned theories are very useful in influencing employee behavior. This ultimately would improve employee and organizational performance.

The above literature shows that HRM practices, such as selection, participation, and employee empowerment, have a positive and significant relationship with job performance [34,39,48]. Additionally, prior studies show that employee empowerment has a positive and significant moderating effect on the association of HRM practices and job performance [60], while employee participation has moderating effects on the relationship between high performance work systems and the perception of quality of care [61]. However, the moderation of training still needs to be explored. Hence, on the basis of this, we examined the moderating role of training on the relationship of sustainable HRM practices (i.e., selection, participation, employee empowerment) and job performance. Thus, we assume that:

Hypothesis 5a (H5a). Training has a moderate effect between the relationship of sustainable selection and job performance.

Hypothesis $\mathbf{5 b}(\mathbf{H} 5 \mathbf{b})$. Training has a moderate effect among the relationship of sustainable participation and job performance.

Hypothesis $5 \mathrm{c}(\mathrm{H} 5 \mathrm{c})$. Training has a moderate effect on the correlation between sustainable employee empowerment and job performance.

\section{Research Methods}

\subsection{Conceptual Framework}

The present study focused on exploring the association among sustainable HRM Practices and job performance with the insertion of training as a moderator variable in publicly owned universities of KPK, Pakistan. The conceptual model (Figure 1) of the study has been constructed on the basis of a literature review. 


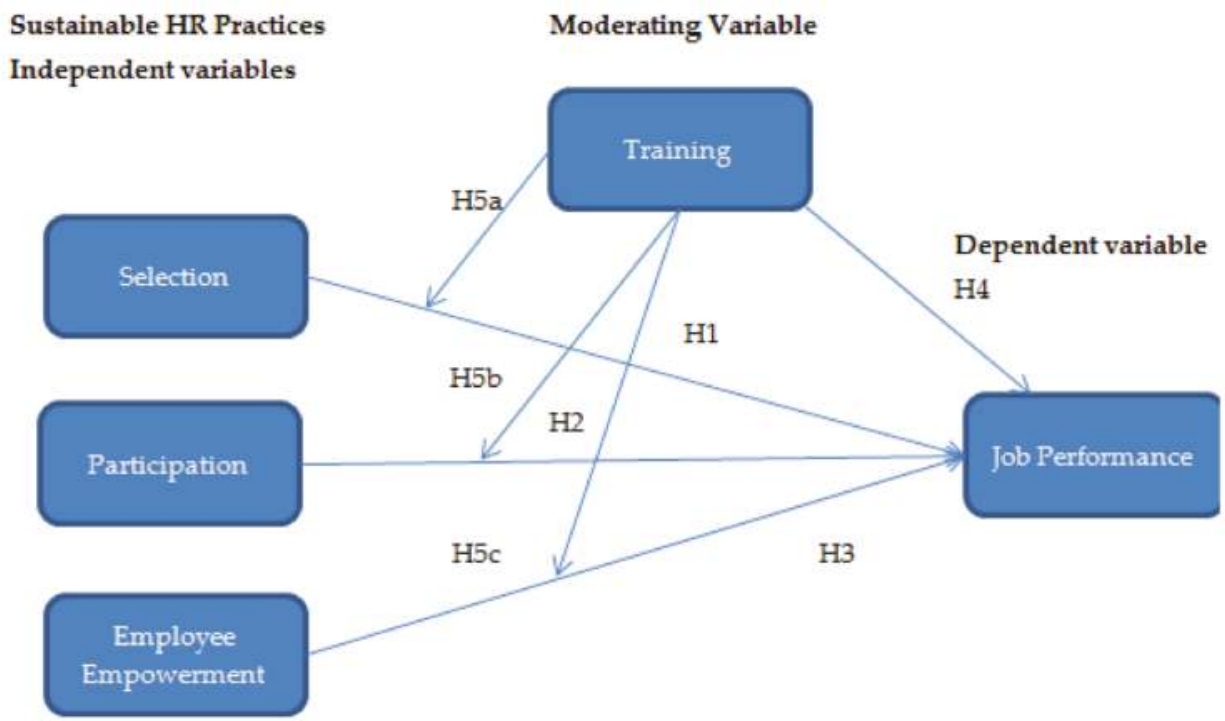

Figure 1. Conceptual model of the study and hypotheses.

Figure 1 showed that in our study, we have chosen three sustainable HRM practices, namely, sustainable selection, sustainable participation, and sustainable employee empowerment. A sustainable selection process can have a long-term impact on an organization's profitability, productivity, and employee happiness. Sustainable participation of employees means achieving living and working conditions that support people in engaging and remaining in work throughout an extended working life. Furthermore, employee empowerment means giving employees a certain degree of autonomy and responsibility for decision-making regarding their specific organizational tasks. Employee empowerment should be sustainable; this practice positively effects the organization's output. These practices can make the biggest impact on the individual and organizational performance.

The term sustainable HRM practices provides a dual relationship between sustainability and HRM practices. In other words, HRM practices improve sustainability, and as a result, sustainability contributes better to the longer-term performance of the firm. In the present research, sustainable HRM practices reflect those practices that contribute to enhancing sustainability, which results in improving long term performance of the firm.

The model tested in this study is "fair selection of employees promotes employee's job performance (H1)", and "selection relates positively to job performance". Participation, employee empowerment, and training also positively correlate to job performance ( $\mathrm{H} 2, \mathrm{H} 3$, and $\mathrm{H} 4$, respectively). In addition, training is the moderator between sustainable HRM practices (selection, participation, and employee empowerment) and job performance ( $\mathrm{H} 5 \mathrm{a}, \mathrm{H} 5 \mathrm{~b}$, and $\mathrm{H} 5 \mathrm{c})$. The conceptual framework and assumed hypotheses of the present study are given in Figure 1.

\subsection{Population, Sample, and Procedure}

The population considered for this study was two publicly owned universities, namely Hazara University situated in District Mansehra, and Agriculture University Peshawar (Peshawar Campus) from Pakistan. The number of faculty members of Hazara University and Agriculture University were reported as 360 and 293, respectively (Source: Registrar office). Data was gathered from the faculty members of the selected universities and hard copies of close-ended questionnaires were distributed individually from May to July, 2017. However, the total sample size of 130 was selected through the convenient sampling technique. The majority of the respondents (70: 53.4\%) were male 
and the remainder was female staff; almost $29 \%$ of them were between $36-40$ years old. The majority of the respondents (60: $45.5 \%$ ) had 5-years job experience. Furthermore, $60.3 \%$ of the respondents were lecturers and the remainder were assistant professors, associate professors, and full professors. Lastly, $52.7 \%$ of the respondents held a MS or MPhil qualification and $41.2 \%$ held doctorate degrees. Table 1 reported the demographic data of the respondents.

Table 1. Demographic data for respondents.

\begin{tabular}{|c|c|c|}
\hline Category & Frequency & Percentage \% \\
\hline \multicolumn{3}{|l|}{ Gender } \\
\hline Male & 70 & 53.4 \\
\hline Female & 60 & 45.8 \\
\hline \multicolumn{3}{|l|}{ Age } \\
\hline $25-30$ years & 26 & 19.8 \\
\hline $31-35$ & 51 & 38.9 \\
\hline $36-40$ & 38 & 29 \\
\hline 41-above & 15 & 11.5 \\
\hline \multicolumn{3}{|l|}{ Experience } \\
\hline $1-5$ years & 60 & 45.5 \\
\hline $6-10$ years & 54 & 41.2 \\
\hline $11-15$ years & 11 & 8.4 \\
\hline 16-above & 03 & 3.8 \\
\hline \multicolumn{3}{|l|}{ Designation } \\
\hline Lecturers & 79 & 60.3 \\
\hline Assistant Professor & 43 & 32.8 \\
\hline Associate Professor & 03 & 2.3 \\
\hline Professor & 05 & 3.8 \\
\hline \multicolumn{3}{|l|}{ Qualification } \\
\hline MS/MPhil & 69 & 52.7 \\
\hline Doctor & 54 & 41.2 \\
\hline Master & 07 & 5.3 \\
\hline Total & 130 & 100 \\
\hline
\end{tabular}

\subsection{Data Collection Instruments (Measures)}

To the best of author's knowledge, there is no validated scale for measuring sustainable HRM practices. Therefore, in the current study, the construction of instruments is based on traditional HRM practices. These may not cover the entire scope of sustainable HRM practices as proposed by scholars in the field but they do reveal practical examples that enable the organization to achieve its goals while reproducing its HR base. These instruments are elaborated below:

Selection (S): Selection is the process of collecting information about the job candidate in order to decide who should be hired for positions [62]. A three items questionnaire was used for assessment of selection, adopted from Wright et al. [63]. Items included "candidates for this job take formal tests before being hired". Items of the variables are presented in Appendix A.

Training (T): Training is an attempt to enhance employee skill, knowledge, and performance in the organization. In the education sector, providing training opportunities for academic staff is a more professional orientation towards their function as teachers. In this sector the aim of training focuses on boosting teaching skills. A five-items questionnaire for training was used for this study, which was initially developed by Ahmad [64]. The questionnaire for training included items such as, "I (teaching staff) receive training to perform task", and "I (teaching staff) receive training to execute multiple tasks", and so on. Items are presented in Appendix A. 
Participation (P): Participation is a process through which all the staff members of an organization are involved in every part of the activity and have power over decisions related to development activities of the organization. Participation was measured with the five-item scale adopted from Scott et al. [65]. Items for this variable were included "my seniors are receptive and listen to my suggestions and ideas, and I am free to decide how to do my job".

Employee Empowerment (EE): Employee empowerment is as "a transfer of power" from the employer to the employees [66]. The concept of empowerment increases employees' motivation at work in the organization through the allocation of authority to the lowest level employees in an organization. Employee empowerment was measured with a twelve-item scale developed by Spreitzer [43]. An example item is, "I (employee) can decide on my own how to go about doing my work". Appendix A presents all items of the variables.

Job Performance (JP): Performance is the process or action of accomplishing or carrying out an action, task, or function. It is the accomplishment of a given task. Job performance is an employee's output and results in terms of quantity and quality expected from every employee in the organization. Job performance assesses whether a person performs a job well. It also relates to the act of doing a job. It means reaching a goal or set of goals within a job, role, or organization [67]. Job performance was measured with a five-item scale. These were adopted from Janssen and Van [68] and used for assessment of employee job performance. Example items include, "employee (I) always completes the duties on time". These measures used a five-point Likert scale from 1 (strongly disagree) to 5 (strongly agree). Likert scaling is a bipolar and unipolar scaling method that measures a positive or negative response to a statement [69].

\subsection{Data Analysis}

Statistical Package for Social Sciences (SPSS) Version 25 (IBM: Chicago, USA) was used for data analysis. The major results of all variables in this study were established by Cronbach's alpha reliability test, descriptive and correlation tests, regression analysis, and Hayes process moderation.

\section{Results}

\subsection{Reliability Analysis}

A Cronbach's alpha reliability range above 70\% for each variable indicates that the collected data is reliable [70]. Hair et al. [71] recommended that given data would be considered reliable if the alpha value was greater than 60 percent [72]. In Table 2, the results of the Cronbach's alpha showed that inclusive data is observed within a given reliability range.

Table 2. Measures of various HRM practices.

\begin{tabular}{cccl}
\hline & No.of Items & Alpha Value & \multicolumn{1}{c}{ Comments } \\
\hline Selection & 03 & 0.60 & Reliability of 0.60 and 0.70 or \\
Training & 05 & 0.85 & more than 0.70 is the standard \\
Participation & 05 & 0.82 & criteria for demonstrating the \\
Employee Empowerment & 12 & 0.76 & internal consistency of new and \\
Job Performance & 05 & 0.60 & recognized scales [73] \\
\hline
\end{tabular}

\subsection{Descriptive Statistics and Correlation}

Mean, standard deviation, and correlation of the variables are stated in Table 3. Correlation analysis is used as a productive approach to test the relationship between the two variables, whether it is solid or weak [74]. Job performance is positively correlated with selection $(\mathrm{r}=0.299, p<0.01)$ and training $(r=0.242, p<0.01)$, and with participation and employment $(r=0.358, p<0.01)(r=0.384, p<0.01)$, respectively. These results support the main hypotheses of the study. 
Table 3. Mean standard deviation and correlation.

\begin{tabular}{ccccccc}
\hline Variables & Mean & Std. Dev. & $\mathbf{1}$ & $\mathbf{2}$ & $\mathbf{3}$ & $\mathbf{4}$ \\
\hline Job performance & 2.00 & 0.617 & 1 & & & \\
Selection & 1.20 & 0.825 & $0.299^{* *}$ & 1 & & \\
Training & 1.00 & 0.898 & $0.242^{* *}$ & 0.017 & 1 & \\
Participation & 1.00 & 0.733 & $0.358^{* *}$ & $0.285^{* *}$ & 0.051 & 1 \\
Employee Empowerment & 2.00 & 0.585 & $0.384^{* *}$ & 0.11 & 0.086 & $0.288^{* *}$ \\
\hline
\end{tabular}

Note: ${ }^{* *}$ Correlation is significant at the 0.01 level (2-tailed).

\subsection{Regression Analyses and Results Explanation}

For the present study, the multiple linear regression (SPSS Version 25) was used to test the main hypotheses.We used mean values of the variables for the analysis. Mean values provide consolidated measurement of the variable and all the dimensions of the variable into a single standardized value [75]. Table 4 results illustrate the effect that HRM practices have on employee job performance. Here, HR practices are the predictor variables and job performance is the predicted variable. For this study, three HRM practices, including selection, participation, and employee empowerment are used as predictor variables and training is used as a moderating variable.

Table 4. Regression analysis between HRM practices and job performance.

\begin{tabular}{cccccc}
\hline & \multicolumn{5}{c}{ Job Performance } \\
\cline { 2 - 6 } & B & T-Statistic & $p$-Value & F-Statistics & R-Square \\
\hline Selection & 0.224 & 3.547 & 0.001 & 12.579 & 0.089 \\
Participation & 0.302 & 4.342 & 0.000 & 18.85 & 0.128 \\
Employee Empowerment & 0.405 & 4.708 & 0.000 & 22.169 & 0.148 \\
Training & 0.167 & 2.827 & 0.005 & 7.992 & 0.059
\end{tabular}

Dependent variable: Job Performance. Independent variables: selection, participation, empowerment; $p<005$ is significant.

In Table 4, the main findings of the regression analysis indicate the relationship between HRM practices, such as selection, training, participation, and employee empowerment with the dependent variable "job performance". The findings of the regression analysis illustrate that selection and job performance have a significant and positive relationship with the results of (R-square $=0.089 ; \mathrm{F}=12.57$; $\beta=0.224 ; t$-value $=3.54$; and $p$-value $=0.001)$. Value of $\mathrm{R}^{2}$ shows 78 percent variation occurred in employee performance due to selection. Beta value has a positive sign, which shows that selection and employee performance have a positive relationship. The T-value is greater than 2 and $p$-value is less than 0.05 , which means variables have a positive and significant relationship. Hence, the results support Hypothesis 1. Also, Table 4 depicts the findings of participation and job performance $(\mathrm{R}$-square $=0.128$; $\mathrm{F}=18.85 ; \beta=0.302 ; \mathrm{T}=4.34 ; p$-value $=0.000)$. The $\mathrm{R}$-square value implies that a 12 percent change happens in the predicted variable due to a predictor variable. Furthermore, $p$-value is significant with the value of 0.000 , and the value of the T-ratio is greater than 2 , which means the explanatory variable participation and outcome variable job performance have a positive and significant relationship. Therefore, the results support Hypothesis 2.

Similarly, the regression analysis indicated the positive and significant effect of employee empowerment on job performance $(\mathrm{R}$-square $=0.148 ; \mathrm{F}=22.16 ; \beta=0.405 ; \mathrm{T}=4.70 ; p$-value $=0.000$ ). In the results, the Beta value reveals a positive sign, the $p$-value is less than 0.05 , and value of the T-ratio is greater than 2, which mean that these variables have a positive and significant relationship. The value of $\mathrm{R}^{2}$ shows 14 percent variation in the dependent variable because of employee empowerment. Therefore, outcomes fully support Hypothesis 3.

Furthermore, we regressed and found out the relationship of the moderator variable Training and job performance with the findings $\left(\mathrm{R}^{2}=0.05 ; \mathrm{F}=7.99 ; \beta=0.167 ; \mathrm{T}=2.82 ;\right.$ and $p$-value $\left.=0.005\right)$. The value of R-square implies 5 percent variation in the dependent variable due to the moderator 
variable (Training). The value of Beta is positive, and $p$-value is significant at the 0.005 , so the moderator variable Training and predicted variable job performance positively and significantly correlate to each other. Therefore, results are fully support Hypothesis 4 .

\subsection{Hayes Process Moderation Analysis}

We employed Hayes process (version 3) [76] through the computer software SPSS (version 25) to confirm the moderation hypotheses for the present study. To analyze the direct effect of selection, participation, and employee empowerment on job performance, we used regression analysis technique, as well as for moderation impact of Training we used Hayes process. In Table 5, Hayes process [76] moderation (Moderator1, Moderator2, and Moderator3) are discussed regarding moderation effect of Training between HRM practices and job performance. In Hypothesis $5 \mathrm{a}$, the present study predicted that Moderator1 (selection* training) has significant and positive effect on job performance. In Table 5, findings showed that $p=0.000$ and $\beta=0.58$, so these results support Hypothesis 5a. Moderator2 (participation*training) has a significant and positive effect on job performance, with the results showing $p=0.000$ and $\beta=0.66$. Therefore, these outcomes fully support Hypothesis $5 \mathrm{~b}$. Furthermore, Hypothesis $5 \mathrm{c}$ is acceptable because Moderator3 (employee empowerment*training) has a positive and significant influence on job performance. Findings showed that $p=0.000$ and $\beta=0.062$, so these are fully support Hypothesis $5 \mathrm{c}$.

Table 5. HRM Practices with inclusion of moderation and Job Performance (Hayes Process Moderation).

\begin{tabular}{cccccc}
\hline & \multicolumn{5}{c}{ Job Performance } \\
\cline { 2 - 6 } & $\mathbf{B}$ & T-Statistic & $p$-Value & F-Statistics & R-Square \\
\hline Moderator1 (Selection*Training) & 0.058 & 4.60 & 0.000 & 21.18 & 0.142 \\
Moderator2 (Participation*Training) & 0.066 & 4.96 & 0.000 & 24.65 & 0.162 \\
Moderator3 (Employee Empowerment*Training) & 0.062 & 4.79 & 0.000 & 23.01 & 0.152 \\
\hline
\end{tabular}

Calculation by using Hayes process (version 3).

\section{Discussion}

In the present study, we scrutinized the effect that sustainable HRM practices (selection, participation, employee empowerment) have on employee performance, as well as the moderating role of training in public sector universities of Pakistan. The current study explored an affirmative and positive association among sustainable HRM practices and job performance. Moreover, the study showed that training has a positive moderating role in examining the correlation between HRM practices (selection, participation, employee empowerment) and job performance. Furthermore, the practical implications are discussed.

The present study contributes to the literature on sustainable HRM and expands the knowledge by illustrating the interrelation among sustainable HRM practices and employee job performance. HRM practices have become a popular field of research for researchers and practitioners due to the significant effect on organizational performance and innovative performance [77,78]. The current study fills the mentioned gap by investigating the correlation between sustainable HRM practices (selection, participation, employee empowerment) and job performance in the context of publicly owned universities in Pakistan. We found a positive connection between sustainable HRM practices and job performance. In this study, outcomes demonstrated that the explanatory variable selection and the dependent variable job performance have a positive relationship. Our findings of selection and job performance are consistent with the past research results of Nadarajah et al. [6] and Mol et al. [79].

In the present study, we also derive a positive and significant effect of participation on job performance. These findings were in-line with the previous research results of Bhatti and Qureshi [39]. They developed their study in the banking sector of Pakistan. Employee empowerment also has a positive and significant effect on the job performance. The main outcomes of the explanatory variables employee empowerment and job performance are compatible with the previous study outcomes of Engstrom et al. [80] and Choi et al. [81]. They showed similar findings in their studies. 
Furthermore, training and job performance have a positive and significant association and the findings are consistent with the prior studies [82-84]. The outcomes of this study fully supported the hypotheses that there is positive relationship among HRM practices and employee job performance.

Many studies have been undertaken regarding the direct relationship between HRM practices and job performance, as well as organizational performance [77,85]. A research study for the moderating role of training between sustainable HRM practices and employee performance is still being explored. The current study scrutinized this gap and showed that sustainable HRM practices (selection, participation, employee empowerment) have a positive and significant influence on job performance with inclusion of training. Therefore, training positively moderates the relationship of HRM practices and job performance.

Likewise, the selection with inclusion of training has affirmative and positive effects on job performance. Also, participation with inclusion of training has significant and positive effects on job performance and employee empowerment. The inclusion of moderating variable training has affirmative and positive impacts on employee job performance. This suggests that proper implementation of sustainable HRM practices can improve employee job performance.

\section{Conclusions and Recommendation}

The most important and powerful factor in an organization is Human Resources (HR) or Human Assets. Recently, human resources have become one of most valuable resources or assets that cannot be denied in the public sector. Sustainable HRM is the only way forward for HR if it wants to stay relevant. The word sustainability means "longer" or "durable"; it means that what you do today has a positive effect on tomorrow. However, few organizations are capable of being completely bound to its potential. The purpose of the current study was to recognize the correlation between sustainable HRM practices, such as selection, participation, empowerment on job performance, and training as a moderator. This study was carried out in two publicly owned universities (Hazara University Mansehra and the Agriculture University Peshawar) from Pakistan. Findings and other relevant results of the study confirmed that HR Practices, such as selection, training, participation, and employee empowerment, have a significant and positive effect on job performance. It was also identified that training has a positive moderating role on job performance. HRM practices have a positive and significant effect on job performance in both types (whether or not training is incorporated as a moderator). This study shows that sustainable HRM practices accompany job performance by indicating the significant moderating role of training.

HR practices can play a significant and essential role in employee performance in any organization. The findings of the recent study suggest that universities (organizations) in the KPK can enhance their performance by implementing high-involvement HRM practices. Therefore, in order to improve employee performance, organizations should implement sustainable HRM practices to strengthen and boost their future performance. Our study contributes to the sustainable HRM research and systems [23] by presenting HRM practices as sustainable HRM practices in the education sector (university level). However, findings suggest that applying sustainable HR practices would lead to improved organizational and employee performance, as well as employee well-being. The current study makes a contribution to the understanding of sustainable HRM. The practical contribution of this study is the observation of sustainable HRM practices used in the university sector (organizations), and how to implement these practices to improve employee performance. Thus, it has stated that the implementation of sustainable HRM policies plays a central role in boosting employee performance. The present study showed that selection criteria must be clear for all employees to be fair and objective. Furthermore, an employee empowerment system should be launched within the organization; when the organization empowers personnel it will make them more confident and freer to do work in their own way, which is very essential to achieve organizational goals. An additional piece of the practical implications of the current study is that a well-designed training program should be designed for workers to improve their talent and ability to perform current jobs. 
It is recommended that the management of the organization revise its sustainable HRM practices by considering employee problems, identifying them and confronting the inequities they face. The acknowledgment method should be launched in order that an employee's effort can be properly acknowledged and rewarded. To achieve the required objectives, the organization should encourage the employee's effort through awards system and motivate them in different ways, rather than discouraging them based on poor performance or unfair conditions.

\section{Limitations and Future Research Directions}

It is extremely essential to highlight some limitations of this study. First, for the data collection, the cross-sectional study design was applied; in order to avoid the uncertainty of a casual relationship, future research should employ a longitudinal study design to the present study model. Secondly, the study's outcomes are only being generalized to the faculty members in publicly owned universities in Pakistan. It means the existing study is limited to one sector; therefore, it is suggested that to overcome the limitations of the present research, it should be increased to other institutions and organizations. Furthermore, the current study is carried out in the context of one developing country, Pakistan. Future studies should be performed by investigating the model in other less-developed nations to boost generalizability of the outcomes. Additionally, future researchers are encouraged to consider other HRM practices, such as reward systems, pay for performance, promotion, and fair evaluation systems, while focusing on employee job performance. Finally, future researchers should be required to identify the additional possible moderator and mediator inclusion of the variables in this process.

Author Contributions: F.M. and L.W. have equal contribution to writing the original draft. T.B. and M.N. reviewed and revised the paper. Q.A.S. contributed in data collection.

Funding: This research received no external funding.

Acknowledgments: I'd like to thank my benevolent Longbao Wei (Professor in the China Academy for Rural Development (CARD) Zhejiang University, Hangzhou, China) for his generous supervision and financial support. He always encouraged my research work and allowed me to grow as a research scholar. His important guidance, advice, and suggestions are priceless.

Conflicts of Interest: The author(s) report no potential conflicts of interest regarding the publication of this article.

\section{Appendix A (Questionnaires)}

\section{Selection}

1. Candidates undergo structured interviews (job-related questions, same questions asked of all candidates, and rating scales) before being hired.

2. Experienced and qualified workers have the opportunity to be promoted to positions of superior pay and/or responsibility within the department.

3. Candidates for this job take formal tests (paper and pencil or work sample) before being hired.

\section{Training}

1. Teaching staff (I) receive training in workplace to improve their skills on a regular basis.

2. The administration believes that continual training and promoting of employees' skills are important.

3. Teaching staff (I) receive training to execute multiple tasks.

4. Teaching staff (I) is cross trained so that they can perform other tasks if necessary.

5. Teaching staff (I) is encouraged to learn specific skills, rather than develop a broad skill base. 


\section{Participation}

1. Generally how much say or influence do you have on how you perform your work?

2. To what extent are you able to decide how to do your work?

3. Generally how much say or influence do you have on who does what on in your work group?

4. Generally how much say or influence do you have on decisions which affect your work?

5. My superiors are receptive and listen to my ideas and suggestions.

\section{Employee Empowerment}

1. The job I do is very meaningful for me.

2. My work activities are personally important to me?

3. The work I do is very important to me?

4. I am self-assured about my talent to perform my work?

5. I am confident about my abilities to execute my job activities?

6. I have the necessary skills for my job?

7. I have essential autonomy in determining how I perform my work?

8. I can make a decision on my own to perform my duties?

9. I have significant opportunity for independence in how I do my work?

10. My impact on what happens in my department is significant?

11. I have an immense deal of control over what happens in my department?

12. I have considerable influence over what happens in my department?

\section{Job Performance}

1. I always complete the duties specified in my job description.

2. I meet all the formal performance requirements of the job.

3. I fulfill all responsibilities required by my job.

4. I never neglect aspects of the job that I am obligated to perform.

5. I often fail to perform important duties.

\section{References}

1. Truss, C.; Mankin, D.; Kelliher, C. Strategic Human Resource Management; Oxford University Press: Oxford, UK, 2012.

2. Senyucel, Z. Managing the Human Resource in the 21st Century; BookBoon: London, UK, 2009.

3. Abdi, S.; Azizpour, M. Surveying the relationship between human resource strategies and employees work ethic in Iran's media. Arab. J. Bus. Manag. Rev. 2013, 2, 129. [CrossRef]

4. Iqbal, M.Z.; Arif, M.I.; Abbas, F. HRM practices in public and private universities of Pakistan: A comparative study. Int. Educ. Stud. 2011, 4, 215. [CrossRef]

5. Schuler, R.S.; MacMillan, I.C. Gaining competitive advantage through human resource management practices. Hum. Resour. Manag. 1984, 23, 241-255. [CrossRef]

6. Nadarajah, S.; Kadiresan, V.; Kumar, R.; Kamil, N.N.A.; Yusoff, Y.M. The relationship of HR practices and job performance of academicians towards career development in Malaysian private higher institutions. Procedia Soc. Behav. Sci. 2012, 57, 102-118. [CrossRef]

7. Harzing, A.-W.; Pinnington, A. International Human Resource Management; Sage: Newcastle upon Tyne, UK, 2010.

8. Ngima, W.M.; Kyongo, J. Contribution of motivational management to employee performance. Int. J. Humanit. Soc. Sci. 2013, 3, 219-239.

9. Snape, E.; Redman, T. HRM practices, organizational citizenship behaviour, and performance: A multi-level analysis. J. Manag. Stud. 2010, 47, 1219-1247. [CrossRef]

10. Paul, A.K.; Anantharaman, R.N. Impact of people management practices on organizational performance: Analysis of a causal model. Int. J. Hum. Resour. Manag. 2003, 14, 1246-1266. [CrossRef] 
11. Lambooij, M.; Sanders, K.; Koster, F.; Zwiers, M. Human Resource Practices and Organisational Performance: Can the HRM-performance linkage be explained by the cooperative behaviours of employees? Manag. Rev. 2006, 223-240. [CrossRef]

12. Siddiqi, M. The new public management and civil service reform in Pakistan: The case of recruitment and promotion practices. Unpublished. Master's Thesis, Governance and Development Management, University of Birmingham, Birmingham, UK, December 2005; pp. 2004-2005.

13. Gerhart, B.; Milkovich, G.T. Organizational differences in managerial compensation and financial performance. Acad. Manag. J. 1990, 33, 663-691.

14. Wolf, A.; Jenkins, A. Explaining greater test use for selection: The role of HR professionals in a world of expanding regulation. Hum. Resour. Manag. J. 2006, 16, 193-213. [CrossRef]

15. Zacher, H.; Chan, F.; Bakker, A.B.; Demerouti, E. Selection, optimization, and compensation strategies: Interactive effects on daily work engagement. J. Vocat. Behav. 2015, 87, 101-107. [CrossRef]

16. Wikhamn, W. Innovation, sustainable HRM and customer satisfaction. Int. J. Hosp. Manag. 2019, 76, 102-110. [CrossRef]

17. Chams, N.; García-Blandón, J. On the importance of sustainable human resource management for the adoption of sustainable development goals. Resour. Conserv. Recycl. 2019, 141, 109-122. [CrossRef]

18. Ehnert, I.; Parsa, S.; Roper, I.; Wagner, M.; Muller-Camen, M. Reporting on sustainability and HRM: A comparative study of sustainability reporting practices by the world's largest companies. Int. J. Hum. Resour. Manag. 2016, 27, 88-108. [CrossRef]

19. Chughtai, M.S. Hrm Practices and Employee's Performance: Moderating Role of Islamic Work Ethics and Mediating Role of Hr Outcomes in Judiciary of Punjab, Pakistan. Virtual University of Pakistan. 2017. Available online: https://www.researchgate.net/profile/Muhammad_Chughtai5/publication/327692837_ (accessed on 15 April 2019).

20. Shahzad, K.; Bashir, S.; Ramay, M.I. Impact of HR practices on perceived performance of university teachers in Pakistan. Int. Rev. Bus. Res. Pap. 2008, 4, 302-315.

21. Stankevičiūtè, Ž.; Savanevičienè, A. Designing Sustainable HRM: The Core Characteristics of Emerging Field. Sustainability 2018, 10, 4798. [CrossRef]

22. Kramar, R. Beyond strategic human resource management: is sustainable human resource management the next approach? Int. J. Hum. Resour. Manag. 2014, 25, 1069-1089. [CrossRef]

23. Ehnert, I.; Harry, W. Recent developments and future prospects on sustainable human resource management: Introduction to the special issue. Manag. Rev. 2012, 221-238. [CrossRef]

24. Rafiei, N.; Davari, F. The Role of Human Resources Management on Enhancing the Teaching Skills of Faculty Members. Mater. Socio Med. 2015, 27, 35. [CrossRef]

25. Frese, M.; Sonnentag, S. High Performance: An Action Theory Approach; Working Paper; University of Giessen and University of Konstanz: Konstanz, Germany, 2000.

26. Paillé, P.; Chen, Y.; Boiral, O.; Jin, J. The impact of human resource management on environmental performance: An employee-level study. J. Bus. Ethics 2014, 121, 451-466. [CrossRef]

27. Enhert, I. Sustainable Human Resource Management: A Conceptual and Exploratory Analysis from a Paradox Perspective; Physica-Verlag: Berlin, Germany, 2008.

28. Mariappanadar, S.; Kramar, R. Sustainable HRM: The synthesis effect of high performance work systems on organisational performance and employee harm. Asia Pac. J. Bus. Adm. 2014, 6, 206-224. [CrossRef]

29. Ehnert, I. Paradox as a Lens for Theorizing Sustainable HRM. In Sustainability and Human Resource Management; Springer: Berlin, Germany, 2014; pp. 247-271.

30. De Prins, P.; De Vos, A.; Van Beirendonck, L.; Segers, J. Sustainable HRM for Sustainable Careers: Introducing the 'Respect Openness Continuity (ROC) Model'. In Handbook of Research on Sustainable Careers; Edward Elgar Publishing: Northampton, MA, USA, 2015; pp. 319-334. [CrossRef]

31. Ketola, T. Responsible leadership. Corp. Soc. Responsib. Environ. Manag. 2010, 17, 123-124. [CrossRef]

32. Vlachos, I.P. High-performance workplace practices for Greek companies. EuroMed J. Bus. 2009, 4, 21-39. [CrossRef]

33. Jepsen, D.M.; Grob, S. Sustainability in recruitment and selection: building a framework of practices. J. Educ. Sustain. Dev. 2015, 9, 160-178. [CrossRef]

34. Johnson, E.K. The practice of human resource management in New Zealand: strategic and best practice? Asia Pac. J. Hum. Resour. 2000, 38, 69-83. [CrossRef] 
35. Harris, N.J.; Kilsha Toulson, P.; Livingston, E.M. New Zealand personnel consultants and the selection process. Asia Pac. J. Hum. Resour. 1996, 34, 71-87. [CrossRef]

36. Kepha, O.; Mukulu, E.; Waititu, G. The influence of recruitment and selection on the performance of employees in research institutes in Kenya. Int. J. Sci. Res. 2014, 3, 358.

37. Oaya, Z.C.T.; Ogbu, J.; Remilekun, G. Impact of Recruitment and Selection Strategy on Employees' Performance: A Study of Three Selected Manufacturing Companies in Nigeria. Int. J. Innov. Econ. Dev. 2017, 3, 32-42. [CrossRef]

38. Verma, A. Employee involvement in the workplace. Union Manag. Relat. Can. 1995, 3, 281-308.

39. Bhatti, K.K.; Qureshi, T.M. Impact of employee participation on job satisfaction, employee commitment and employee productivity. Int. Rev. Bus. Res. Pap. 2007, 3, 54-68.

40. Paul, J. Organizational Safety Strategies: Which Management Practices are Most Effective in Reducing Employee Injury Rates. Bus. J. Entrep. 2016, 2016.

41. Kane-Urrabazo, C. Management's role in shaping organizational culture. J. Nurs. Manag. 2006, 14, 188-194. [CrossRef] [PubMed]

42. Wagner, J.A., III. Participation's effects on performance and satisfaction: A reconsideration of research evidence. Acad. Manag. Rev. 1994, 19, 312-330. [CrossRef]

43. Spreitzer, G.M. Psychological empowerment in the workplace: Dimensions, measurement, and validation. Acad. Manag. J. 1995, 38, 1442-1465.

44. Rowley, C.; Quang, T.; Warner, M. To what extent can management practices be transferred between countries?: The case of human resource management in Vietnam. J. World Bus. 2007, 42, 113-127.

45. Elmuti, D.; Kathawala, Y. An overview of benchmarking process: A tool for continuous improvement and competitive advantage. Benchmarking Qual. Manag. Technol. 1997, 4, 229-243. [CrossRef]

46. Geralis, M.; Terziovski, M. A quantitative analysis of the relationship between empowerment practices and service quality outcomes. Total Qual. Manag. Bus. Excell. 2003, 14, 45-62. [CrossRef]

47. Kirkman, B.L.; Rosen, B. Beyond self-management: Antecedents and consequences of team empowerment. Acad. Manag. J. 1999, 42, 58-74.

48. Chebat, J.-C.; Kollias, P. The impact of empowerment on customer contact employees' roles in service organizations. J. Serv. Res. 2000, 3, 66-81. [CrossRef]

49. Amenumey, E.K.; Lockwood, A. Psychological climate and psychological empowerment: an exploration in a luxury UK hotel group. Tour. Hosp. Res. 2008, 8, 265-281. [CrossRef]

50. Bakari, H. Relationship Between Employee Empowerment and Performance of City Council of Nairobi; Unpublished MBA Project; School of Business, University of Nairobi: Nairobi, Kenya, 2008.

51. Mahony, D.; Trigg, M.; Griffin, R.; Pustay, M. International Business; Pearson: London, UK, 2001.

52. Cabrera, E.F.; Cabrera, A. Fostering knowledge sharing through people management practices. Int. J. Hum. Resour. Manag. 2005, 16, 720-735. [CrossRef]

53. Nassazi, A. Effects of Training on Employee Performance: Evidence from Uganda. 2013. Available online: http://urn.fi/URN:NBN:fi:amk-2013120419934 (accessed on 15 April 2019).

54. Githinji, A. Effects of Training on Employee Performance: A Case Study of United Nations Support Office for the African Union Mission in Somalia; United States International University-Africa: Nairobi, Kenyan, 2014.

55. Amos, K.J.; Natamba, B. The Impact of Training and Development on Job Performance in Ugandan Banking Sector. J. Innov. Sustain. 2015, 6, 65-71. [CrossRef]

56. Hanif, F. Impact of training on employee's development and performance in hotel industry of lahore, pakistan. J. Bus. Stud. Q. 2013, 4, 68.

57. Skinner, B.F. Contingencies of Reinforcement: A Theoretical Analysis; BF Skinner Foundation: Cambridge, MA, USA, 2014; Volume 3.

58. Ismail, A.I. Employee Learning Theories and Their Organizational Applications. Acad. J. Econ. Stud. 2017, 3, 96-104.

59. Yin, L.R.; Lien, N.; Werner, J.M. Learning in virtual groups: Identifying key aspects of a course management system affecting teamwork in an it training course. Inform. Technol. Learn. Perform. J. 2009, 25, 2.

60. Manzoor, F.; Sadozai, K.N.; Jan, D. Evaluating the role of human Resource management (HRM) practices on job performance: An application of employee empowerment as moderator. City Univ. Res. J. 2016, 6, 354-363. 
61. Bartram, T.; Stanton, P.; Casimir, G.; Leggat, S.G.; Bonias, D.; Cheng, C.; Bonias, D.; Cheng, C. Employee participation as a Moderator on the High Performance Work Systems and the Perception of Quality of Care Relationship in a Large Regional Australian Health Service; Australian and New Zealand Academy of Management: Gold Coast, QLD, Australia, 2009; pp. 1-15.

62. Chapman, D.S.; Webster, J. The use of technologies in the recruiting, screening, and selection processes for job candidates. Int.J. Sel. Assess. 2003, 11, 113-120. [CrossRef]

63. Wright, P.M.; Gardner, T.M.; Moynihan, L.M. The impact of HR practices on the performance of business units. Hum. Resour. Manag. J. 2003, 13, 21-36. [CrossRef]

64. Ahmad, S.; Schroeder, R.G. The impact of human resource management practices on operational performance: recognizing country and industry differences. J. Oper. Manag. 2003, 21, 19-43. [CrossRef]

65. Scott, D.; Bishop, J.W.; Chen, X. An examination of the relationship of employee involvement with job satisfaction, employee cooperation, and intention to quit in US invested enterprise in China. Int. J. Organ. Anal. 2003, 11, 3-19. [CrossRef]

66. Randolph, W.A. Navigating the journey to empowerment. Organ. Dyn. 1995, 23, 19-32. [CrossRef]

67. Campbell, J.P. Modeling the Performance Prediction Problem in Industrial and Organizational Psychology. In Handbook of Industrial and Organizational Psychology; Dunnette, M.D., Hough, L.M., Eds.; Consulting Psychologists Press: Palo Alto, CA, USA, 1990; pp. 687-732.

68. Janssen, O.; Van Yperen, N.W. Employees' goal orientations, the quality of leader-member exchange, and the outcomes of job performance and job satisfaction. Acad. Manag. J. 2004, 47, 368-384.

69. Allen, I.E.; Seaman, C.A. Likert scales and data analyses. Qual. Prog. 2007, 40, 64-65.

70. Holahan, C.K.; Sears, R.R.; Cronbach, L.J. The Gifted Group in Later Maturity; Stanford University Press: Palo Alto, CA, USA, 1995.

71. Hair, J., Jr.; Babin, B.; Money, A.; Samouel, P. Essentials of Business Research Methods; Johns Wiley \& Sons Inc.: Hoboken, NJ, USA, 2003.

72. Manzoor, F.; Wei, L.; Nurunnabi, M.; Subhan, Q.A.; Shah, S.I.A.; Fallatah, S. The Impact of Transformational Leadership on Job Performance and CSR as Mediator in SMEs. Sustainability 2019, 11, 436. [CrossRef]

73. Gounaris, S.P. Trust and commitment influences on customer retention: insights from business-to-business services. J. Bus. Res. 2005, 58, 126-140. [CrossRef]

74. Mukaka, M.M. A guide to appropriate use of correlation coefficient in medical research. Malawi Med. J. 2012, 24, 69-71.

75. Walpole, R.E.; Myers, R.H.; Myers, S.L.; Ye, K. Essentials of Probability and Statistics for Engineers and Scientists; Pearson: London, UK, 2014.

76. Hayes, A.F. Introduction to Mediation, Moderation, and Conditional Process Analysis: A Regression-Based Approach; The Guilford Press: New York, NY, USA, 2013.

77. Moideenkutty, U.; Al-Lamki, A.; Sree Rama Murthy, Y. HRM practices and organizational performance in Oman. Pers. Rev. 2011, 40, 239-251. [CrossRef]

78. Laursen, $\mathrm{K}$. The importance of sectoral differences in the application of complementary HRM practices for innovation performance. Int. J. Econ. Bus. 2002, 9, 139-156. [CrossRef]

79. Mol, S.T.; Born, M.P.; Willemsen, M.E.; Van Der Molen, H.T. Predicting expatriate job performance for selection purposes: A quantitative review. J. Cross Cult. Psychol. 2005, 36, 590-620. [CrossRef]

80. Engström, M.; Wadensten, B.; Häggström, E. Caregivers' job satisfaction and empowerment before and after an intervention focused on caregiver empowerment. J. Nurs. Manag. 2010, 18, 14-23. [CrossRef]

81. Choi, S.L.; Goh, C.F.; Adam, M.B.H.; Tan, O.K. Transformational leadership, empowerment, and job satisfaction: the mediating role of employee empowerment. Hum. Resour. Health 2016, 14, 73. [CrossRef]

82. Barzegar, N.; Farjad, S. A Study on the Impact of on the job training Courses on the Staff Performance (A Case Study). Procedia Soc. Behav. Sci. 2011, 29, 1942-1949. [CrossRef]

83. Bafaneli, S.; Setibi, G. The Impact of on-the-Job Training on Employee Performance: The Case of Riley's Hotel. J. Bus. Theory Pract. 2015, 3, 239. [CrossRef] 
84. Ndunguru, S. The Impact of on the Job Training on Employee's Performance: The case of Secondary School Teachers in SongeaMunicipalit; The Open University of Tanzania: Dar es Salaam, Tanzania, 2015.

85. Hassan, S. Impact of HRM practices on employee's performance. Int. J. Acad. Res. Account. Financ. Manag. Sci. 2016, 6, 15-22.

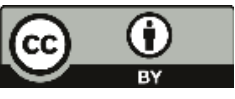

(C) 2019 by the authors. Licensee MDPI, Basel, Switzerland. This article is an open access article distributed under the terms and conditions of the Creative Commons Attribution (CC BY) license (http://creativecommons.org/licenses/by/4.0/). 

MDPI

St. Alban-Anlage 66

4052 Basel

Switzerland

Tel. +41616837734

Fax +41 613028918

www.mdpi.com

Sustainability Editorial Office

E-mail: sustainability@mdpi.com

www.mdpi.com/journal/sustainability

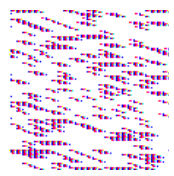



MDPI

St. Alban-Anlage 66

4052 Basel

Switzerland

Tel: +41 616837734

Fax: +41 613028918 